
A Sísifo

(dichoso) 
Condicionantes ecológicos de la distribución de anfibios en el $P_{\text {arque }} N_{\text {acional de }} D_{\text {oñana }}$

Carola Gómez Rodríguez

\author{
PhD Thesis
}

Salamanca, 2009 


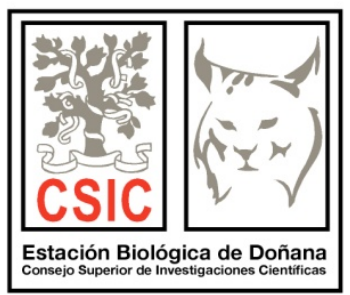

Estación Biológica de Doñana (CSIC)

Departamento de Ecología de Humedales

Universidad de Salamanca

Departamento de Biología Animal,

Parasitología, Ecología, Edafología y Química Agrícola B SALAMANCA

\title{
Condicionantes ecológicos de la distribución de anfibios en el Parque Nacional de Doñana
}

\author{
Memoria presentada por \\ Carola Gómez Rodríguez
}

para optar al Grado de Doctora en Ciencias en Ambientales

$\mathrm{V}^{\mathrm{o}} \mathrm{B}^{\mathrm{o}}$ de los directores:

Fdo. Dra. Carmen Díaz Paniagua

Estación Biológica de Doñana (CSIC)

$\mathrm{V}^{\circ} \mathrm{B}^{\circ}$ del tutor:
Fdo. Dr. Javier Bustamante Díaz

Estación Biológica de Doñana (CSIC)

Fdo. Dr. Miguel Lizana Avia (Universidad de Salamanca) 


\section{Contents}

INTRODUCTION........................................................ $\quad 3$

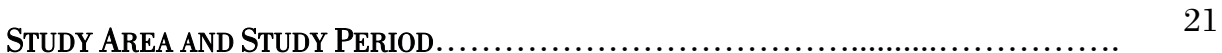

CHAPTER 1. DESCRIPTION OF THE BREEDING HABITAT

- Mediterranean temporary ponds as amphibian breeding habitats: The importance of preserving pond networks ...................................................... 47

Chapter 2. APPlication OF REMOte SENSING DATA FOR IDENTIFication, CHARACTERIZATION AND MONITORING OF AMPHIBIAN HABITATS

- Application of remote sensing to the cartography of small temporary ponds......... 65

- High-resolution remote-sensing data in amphibian studies: identification of breeding sites and contribution to habitat models............................................ 77

- Evidence of hydroperiod shortening in a preserved system of temporary ponds... $\quad 95$

Chapter 3. Temporal Variation of the amphibian Community in Doñana National PARK

- Inter-annual variability in amphibian assemblages: Implications for diversity assessment and conservation

- When should we survey amphibian communities? Application of detection probabilities to the design of monitoring programs 
Chapter 4. Spatial variation of the amphibian Community in Doñana National PARK: RELATIONSHIPS WITH HABITAT CHARACTERISTICS

- Relative importance of dynamic and static environmental variables as predictors of amphibian diversity patterns.

- What habitat requirements do amphibians have for breeding in Mediterranean temporary ponds?.......

DISCUSSION..

SUMMARY (RESUMEN EN ESPAÑOL, INCLUYE CONCLUSIONES).

LITERATURE CITED.

CoNCLUSIONS. 


\section{Introduction}

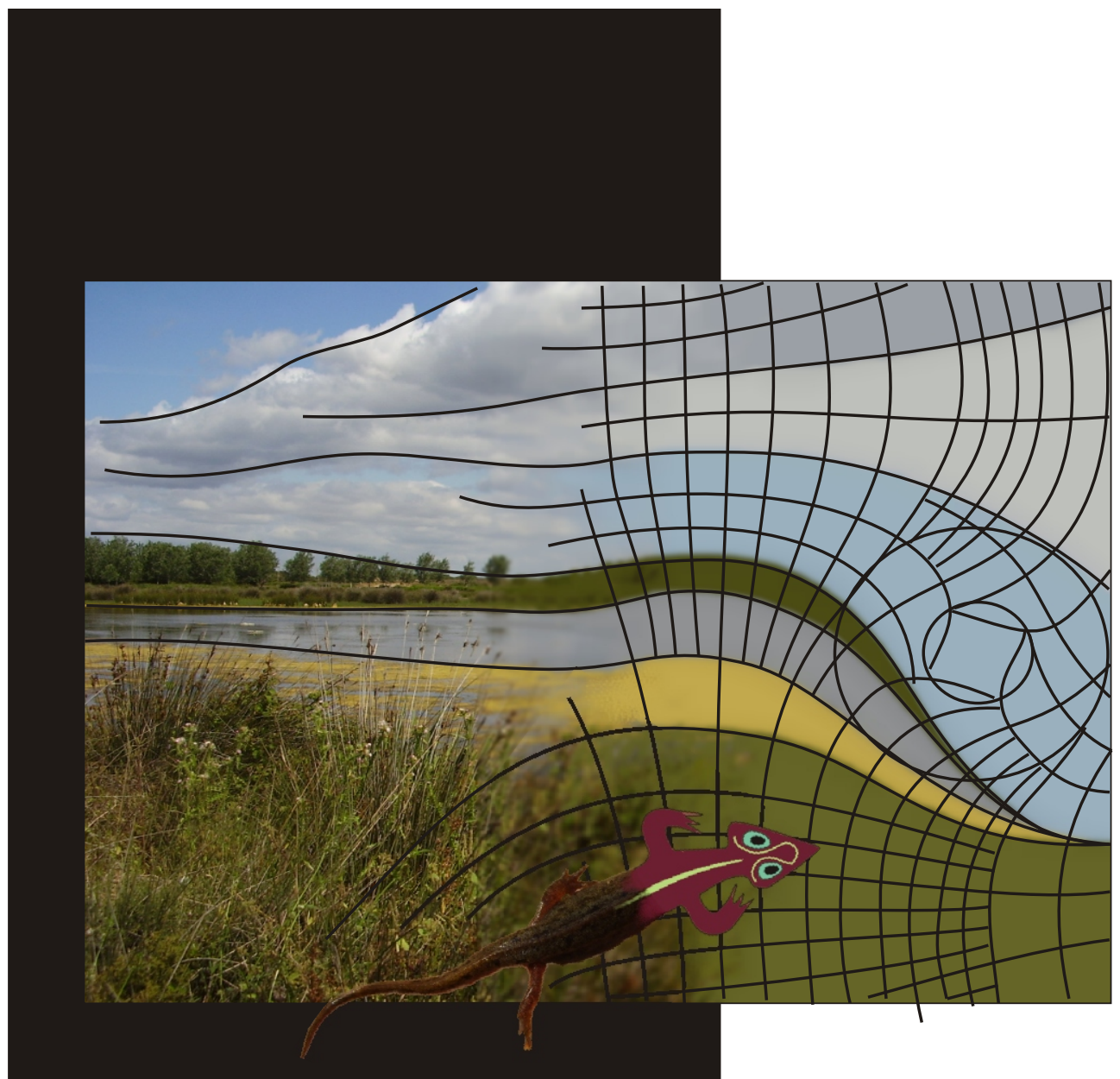




\section{The ecological determinants of amphibian distribution}

A central question in ecology is explaining the spatial variation of diversity (Gaston 2000). The spatial patterns in the distribution of species are limited, at least in part, by environmental factors and thereby provide information that allows the identification of forces that structure and maintain ecological diversity (Stiling 1999). This happens because each species has a unique set of requirements that must be provided by the habitat in order for the species to persist there. Similarly, the spatial distribution in the abundance of a species is also of interest. If environmental factors can limit where a species occur, they probably have a strong influence on population densities and thereby reflect the extent to which local sites satisfy the niche requirements of a species (Brown et al. 1995). For all these reasons, understanding the spatial distribution of species and its environmental drivers is highly relevant for conservation purposes. In the case of amphibians, conservation programs, focused on preserving suitable breeding sites, will highly benefit from studies providing tools to identify amphibian breeding habitats and, furthermore, evaluating the habitat requirements of pond-breeding species. Towards this latter aim, previous studies have quantified the relationship between pond characteristics and species richness (Beja and Alcazar 2003; Knutson et al. 2004; Werner et al. 2007), species occurrence (Beja and Alcazar 2003; Pearl et al. 2005; Van Buskirk 2005) or species relative abundance (Beja and Alcazar 2003; Van Buskirk 2005; Richter-Boix et al. 2007).

Most ecological models about amphibian habitat selection focus on four main aspects that have been identified as critical for amphibian ecology: i/ the abiotic characteristics of the breeding habitat, such as hydroperiod (Wellborn et al. 1996; Werner et al. 2007), pond area (Burne and Griffin 2005; Werner et al. 2007) or waterchemistry characteristics (Hecnar and M'Closkey 1996a; Knutson et al. 2004); ii/ the biotic interactions in the breeding habitat, such as competition or predation (Duellman and Trueb 1986); iii/ the characteristics of the aestivating habitat (i.e. landscape composition) (Gibbons 2003); and iv/ the structure of the metapopulationpatchy population (i.e. distance to nearest site, density of surrounding ponds...), which determines the dispersal or regular movements of individuals among ponds (Semlitsch and Bodie 1998; Semlitsch 
2002; Smith and Green 2005). Additionally, we may also consider other important habitat features not widely reflected in the literature such as pond morphometry, a characteristic that conditions the availability of different microhabitats which, in turn, each species may require in a selectively manner (Smith et al. 2003) or the amount of dense hygrophytic vegetation surrounding the pond, which increases pond shade, an important habitat attribute for amphibians in some studies (Sztatecsny et al. 2004; Burne and Griffin 2005).

\section{The amphibian community in Doñana National Park}

Eleven species of amphibians can be found in Doñana National Park: Alytes cisternasii Boscá, 1879, Bufo (Epidalea) calamita Laurenti, 1768, Bufo bufo (Linnaeus, 1758), Pelobates cultripes (Cuvier, 1829), Discoglossus galganoi Capula, Nascetti, Lanza, Bullini \& Crespo, 1985, Pelodytes ibericus Sánchez-Herráiz, Barbadillo, Machordom \& Sanchiz, 2000, Pelophylax (Rana) perezi (Seoane, 1885), Hyla meridionalis Boettger, 1874, Pleurodeles waltl Michahelles, 1830, Triturus pygmaeus (Wolterstorff, 1905) and Lissotriton boscai (Lataste, 1879).

Temporary ponds are the main breeding habitat of amphibians in the area. The only exception are $A$. cisternasii, a species that breeds in ephemeral streams in the north of the Park, and B. bufo, usually found in the permanent ponds (Díaz-Paniagua et al. 2005). Pelodytes ibericus may occasionally breed in temporary ponds although its main reproductive habitat in Doñana National Park are the marshes. The breeding season of amphibians may largely differ from year to year due to inter-annual variability in meteorological conditions (Díaz-Paniagua 1992). On an average year, the breeding activity of amphibians starts in autumn and ends in spring, although species may inhabit the pond as larvae until early summer or even for two years, in the case of $P$. perezi (Díaz-Paniagua et al. 2005). Amphibian adults aestivate during the summer season until the next rains start. In years of scarce rainfall, amphibians may delay breeding until winter or early spring and may even skip reproduction if environmental conditions are highly unfavourable (Díaz-Paniagua et al. 2005). The duration of larval development differs among species, from species that may complete metamorphosis in less than two months (i.e. B. calamita or D. galganoi), to species requiring more than three months, such as P. cultripes (Díaz-Paniagua 1988). Previous studies have reported a spatial and temporal segregation in the use of temporary ponds in the study area (Díaz-Paniagua 1982; Díaz-Paniagua 1988, 1990, 1992). This fact favours species coexistence as it reduces species interactions by using different ponds or the same pond at different times. Based on the observed temporal segregation, amphibian species may be classified as early breeders, which start the breeding season after the first rainfalls (i.e. $P$. cultripes, $P$. ibericus), intermediate breeders, which start the reproduction after the coldest period of time (i.e. B. calamita, H. meridionalis or T. pygmaeus), and late breeders, which start the breeding season in spring (i.e. $P$. perezi, the only late breeder in the area) (Díaz-Paniagua 1990, 1992; DíazPaniagua et al. 2005). Analogously to breeding strategies, which source temporal segregation, different habitat requirements source the spatial segregation in the study area, as reported in previous studies (DíazPaniagua 1982, 1983; Díaz-Paniagua 1990). For instance, B. bufo eggs are toxic and, in consequence, this species may breed in permanent ponds, where main 
predators also occur, for it is not subject to predation pressure. On the contrary, $B$. calamita usually breeds in highly ephemeral ponds, where predation pressure is almost inexistent. In general, the most remarkable spatial segregation is according to pond hydroperiod (Díaz-Paniagua 1990). So, B. calamita and D. galganoi usually breed in ephemeral pools; H. meridionalis, T. pygmaeus and $L$. boscai in ponds with intermediate hydroperiod and $P$. waltl, $P$. cultripes and $P$. perezi in temporary ponds of long duration. Pelophylax perezi also breeds in permanent ponds. For more details on the ecology of the amphibian community in Doñana National Park see Díaz-Paniagua et al. (2005).

Mediterranean

\section{temporary}

\section{ponds: The main breeding habitat of amphibians in Doñana National Park}

Mediterranean wetlands are among the most threatened ecosystems on the Earth (Blondel and Aronson 1999) and, in particular, Mediterranean temporary ponds are a priority habitat under the European Union Habitats Directive (European Commission 2007). Temporary ponds differ from permanent waters in the occurrence of a recurrent dry phase (Griffiths 1997). In the Mediterranean region, temporary ponds present a wide variability in filling onset and duration, depending on rainfall input and pattern (Zacharias et al. 2007). Due to their temporary nature and small size, these aquatic habitats are very vulnerable, being often inconspicuous and poorly known (Grillas et al. 2004). Because the study of temporary aquatic habitats is far less developed than the study of permanent waters, basic descriptions of temporary waters continue to be vital (Schwartz and Jenkins 2000).

In general, freshwater ponds highly contribute to regional diversity since they support more species, more unique species and more scarce species of macrophytes and macroinvertebrates than other water body types, i.e. streams or rivers (Williams et al. 2003). In particular, temporary ponds constitute the main breeding habitat of many amphibian (Díaz-Paniagua 1990; Griffiths 1997; Semlitsch 2003) and invertebrate species (Williams 1997; Boix et al. 2001; Williams 2006). Amphibian fauna associated to these habitats is tolerant to water loss (Griffiths 1997) and generally benefits from the absence of invertebrate top predators and fish (Semlitsch 2003). In the Mediterranean region, inter-annual variability in hydrological conditions is supposed to favour amphibian diversity in the medium-term (Jakob et al. 2003).

From an ecological perspective, freshwater ponds constitute an excellent system for exploring patterns of spatial variation in diversity, since they are arrayed along well defined environmental gradients (i.e. size, hydroperiod) with corresponding patterns in community composition (Werner et al. 2007). In addition, wetlands are unstable and dynamic per se (Fjeldsa and Lovett 1997) and thereby constitute an idoneous model system to assess the temporal dynamism of habitats and their associated species.

Doñana National Park is one of the most important wetlands in southern Europe. It preserves a large system of temporary ponds (Díaz-Paniagua et al. 2006), with a spatial configuration conferring robustness to interannual variability in hydrological conditions (Fortuna et al. 2006). These ponds are a critical habitat of many species of aquatic flora and fauna: macrophytes (García Murillo et al. 2006), invertebrates (Bigot and Marazanof 1966; Millán et al. 2005; 
Serrano and Fahd 2005), and amphibians (Díaz-Paniagua 1990; Díaz-Paniagua et al. 2005). Thereby, Doñana temporary ponds can provide a model system to assess temporary ponds characteristics, dynamics and associated fauna ecology. Most limnological studies of Doñana aquatic systems have traditionally focused to temporary waters with long hydroperiod (Montes et al. 1982; López et al. 1991; Serrano and Toja 1995; Muñoz Reinoso 1996) whereas ephemeral ponds have been only occasionally studied (García-Novo et al. 1991).

\section{Statistical tools for the assessment of amphibian habitat requirements}

Statistical regression methods for quantitative prediction of species distributions are useful for the understanding of species' environmental requirements (Guisan and Zimmermann 2000; Austin 2007; Graham et al. 2008). Regression models can be used to test whether there is a relationship between certain hypothesized environmental predictors and species richness, species occurrence or relative abundance. Although this type of statistical models does not imply causation, there should be a reasonable presumption that the environmental predictors are surrogates for causal processes based on ecological knowledge (Austin 2007). For that reason, it is of special relevance to strength the link between statistical models and ecological theory to improve the conclusions derived from them (Austin 2002; Guisan et al. 2006; Austin 2007).

To identify relevant habitat characteristics amidst all the environmental data available, we may follow two different strategies: "a priori thinking" or "a posteriori thinking". A priori thinking is based on the of different hypotheses of the relationship between environmental factors and species distribution, based on ecological knowledge, before analyzing the data. Data analysis is hence restricted only to the verification (or neglect) of those particular hypotheses, not taking into account the rest of the environmental data available. A posteriori thinking provides an interpretation of the observed patterns based on all the environmental data available, not having any prior expectations of the particular species-habitat responses. The problem with "a posterior thinking" is that it is unlikely to yield reliable knowledge because there will be multiple a posteriori hypothesis that provide reasonable explanations for any observed pattern (MacKenzie et al. 2006). For that reason, Burnham and Anderson (2002) emphasize the importance of a priori consideration of alternative hypotheses and the use of a posterior approaches only for early exploratory phases of initial investigation.

If we have several hypotheses, and hence, a corresponding number of regression models, we will have to use a statistical procedure to select the most realistic one. The Information Theoretic Approach (see Burnham and Anderson 2002) provides a tool to select the most plausible hypothesis from the ones conceived a priori (i.e. the most robust statistical model given the data). In contrast to null hypothesis significance testing, which selects one from two alternative statistical hypothesis (the null hypothesis or the alternative hypothesis), there is no concept of a "null" hypothesis or a statistical hypothesis within the Information Theoretic Approach (Burnham and Anderson 2002). The Information Theoretic Approach uses likelihood estimation to select a set of possible ecological models (hypotheses) for 
explaining reality. All those models partially fit the data and there is no need for one to be selected as clearly best. In other words, more than one ecological hypothesis may be plausible. Ideally, the best model should be simple, including a few number of parameters but still allowing valid inferences to be made about the system or process under study (Burnham and Anderson 2002). Burnham and Anderson (2002) emphasize that a model selected under an information theoretic approach is not the "true model" since we can only hope to identify a model that provides a good approximation to the data available. Notwithstanding, the best selected model may still be bad if the hypotheses formulated a priori did not contemplate the relevant aspects of ecosystem functioning. For that reason, it is also important to evaluate model performance since model reliability is critical for its utility in ecological studies or conservation management (Guisan and Zimmermann 2000; Guisan et al. 2006). The easiest way to evaluate model performance is to compare model predictions with independent, or semi-independent observations (Guisan and Zimmermann 2000; Guisan et al. 2006).

It should be noted that traditional regression models (i.e. regression, GLM, GAM) may provide information about ecological requirements of particular species or species richness. However, if we are interested in abiotic factors contributing to diversity, we should not limit to studies of species richness (Gardner et al. 2007). We should also contemplate that habitat characteristics may drive differences in species composition among pond assemblages (beta diversity) and hence, aim to identify such habitat factors. The relevance of differentiating variation in species richness from variation in community composition lies in the fact that two sites may have exactly the same number of species but completely different community compositions. In recent years, the interest in beta diversity has increased for its contribution to the understanding of spatial patterns in diversity (Baselga and Jiménez-Valverde 2007; Soininen et al. 2007; Arponen et al. 2008). The study of beta diversity relies on the assessment of differences in community composition, as computed from indexes of similarity or dissimilarity. Statistical methods focused to identify environmental factors that explain differences in community composition are: redundancy analysis (RDA), constrained correspondence analysis (CCA) or Constrained Analysis of Principal Coordinates (CAP), for example.

\section{New technologies: An} opportunity in the study of amphibian habitat require-

\section{ments}

The spatial distribution of freshwater habitats should be considered in conservation strategies since it determines the distribution and dynamics of amphibians (Semlitsch and Bodie 1998; Semlitsch 2003). However, this labour may be expensive and time consuming in large wetlands, where ponds are abundant or distributed over a large portion of territory. To easily assess the distribution of amphibian breeding habitats, researchers may take advantage of new technologies, such as remote sensing.

Remote sensing may provide data from broad spatial extents that would be prohibitively expensive if collected using field-based methods (Kerr and Ostrovsky 2003; Groom et al. 2006). In particular, remote sensing constitutes a useful tool for monitoring the extent of freshwater habitats (Revenga et al. 2005). Most previous 
remote-sensing studies of aquatic ecosystems have focused on the delineation of large water bodies (see Ozesmi and Bauer 2002 for a review), in particular in the Mediterranean region (Alphan and Yilmaz 2005; Castañeda et al. 2005; Papastergiadou et al. 2007). However, small ponds have been frequently disregarded because of spatial resolution constraints of satellite remote sensing. Similarly, the application of remote sensing to the delineation of seasonal flooded systems has been also scarce (Bryant 1999; Roshier and Rumbachs 2004; Lacaux et al. 2007), mainly because these fluctuating habitats are difficult to delimitate (Revenga et al. 2005).

Remote sensing data has scarcely been applied to amphibian research, with only some studies focusing on global (Carey et al. 2001; Middleton et al. 2001) and landscape scales (Scribner et al. 2001). The utility of remote sensing data to amphibian studies may be three-fold: i/ it could be used to assess the spatial distribution of breeding habitats, ii/ to understand the temporal dynamism of the ecosystem (i.e. discriminate natural fluctuations from negative trends in important habitat features for amphibians), or iii/ to predict species distributions. Regarding to the understanding of temporal dynamism, longterm studies recording temporal changes and tendencies in the number, distribution and extent of pond ecosystems are necessary. Its relevance relies on the worldwide threaten to pond ecosystem due to their drastic reduction in number (Oertli et al. 2005). Moreover, in amphibian conservation programs, remote sensing data may be also used to discriminate natural fluctuations from negative trends in important habitat characteristics such as hydroperiod (Wellborn et al. 1996; Brooks 2000; Snodgrass et al. 2000; Sanderson et al. 2005; Werner et al. 2007) or pond size (Laan and Verboom 1990; Spencer et al.
1999; Beja and Alcazar 2003; Werner et al. 2007). Finally, remote sensing imagery might enable the identification of habitat characteristics that condition the distribution of associated species (Kerr and Ostrovsky 2003; Turner et al. 2003; Gottschalk et al. 2005) and, in consequence, facilitate the identification of habitats holding rare, endangered or a large number of species.

The most common characterization of remote sensing images results from its spatial, temporal and spectral resolution. Spatial resolution refers to the size of the pixel that is recorded (i.e. how much of the earth's surface a single pixel covers). Temporal resolution is related to the repetitive coverage of the ground by the remote-sensing system (i.e. the frequency of image collection). Spectral resolution refers to the number of different frequency bands recorded in an image acquisition (i.e. high spectral resolution is achieved by narrow bandwidths which, collectively, are likely to provide a more accurate spectral signature for discrete objects than broad bandwidth).

High spatial resolution imagery might enable the accurate delineation of small ponds (Weiers et al. 2004; Lacaux et al. 2007), such as Mediterranean temporary ponds. However, high-spatial resolution imagery often lacks the temporal resolution necessary for an adequate monitoring of highly fluctuating ecosystems. Instead, we could use medium spatial resolution remote sensing images like Landsat MSS, TM and $\mathrm{ETM}+$, which have a 16 days repeat cycle and have been operational for more than 30 years. In fact, satellite data has proven a useful tool to reconstruct the temporal dynamics of large fluctuating wetlands over the past decades (Bryant and Rainey 2002; Roshier and Rumbachs 2004; Castañeda and Herrero 2005; Castañeda et al. 2005), but, to our knowledge, satellite data has been rarely used to assess temporal changes 
in small-sized wetlands (but see Beeri and Phillips 2007).

\section{The temporal variability in the} ecosystem: challenges for the study of amphibian habitat requirements

Stable ecosystems, defined as systems with no temporal variation, are more the exception than the rule (Ricklefs and Schluter 1993). In fact, it is widely accepted that both habitats and biological communities may vary over ecological time (Preston 1960; Collins and Glenn 1991; Fjeldsa and Lovett 1997; Innes 1998; Magurran 2007), which stresses the claim for a temporal perspective in ecological studies, especially in the analysis of biodiversity studies (Buckland et al. 2005; Magurran 2007). In fact, temporal variation in communities and habitats are not unrelated processes in an ecosystem, since temporal changes in community composition can be attributed to temporal changes in environmental characteristics (Houlahan et al. 2007). Considerations of temporal scale should not be restricted to ecological research but also should be also incorporated in conservation management (Hobbs 1998).

In particular, many amphibian communities are highly variable over time, with changes in the number or abundance of species from year to year (Pechmann et al. 1991; Hecnar and M'Closkey 1996b; Skelly et al. 1999; Trenham et al. 2003). Several studies have reported that temporal variation in amphibian assemblages results from inter-annual variability in meteorological/hydrological conditions (Jakob et al. 2003) or in local habitat attributes, both in breeding ponds (Skelly and Meir 1997) and in surrounding uplands (Skelly 2001).

From a practical standpoint, the temporal dynamism of species assemblages may become an error source in biodiversity assessments (i.e. spatial distribution of species) and those ecological interpretations derived from them. In amphibian assemblages with year-to-year changes, an annual survey would be insufficient to assess the spatial distribution of a species since individuals may use a pond but skip breeding in that pond in particular years. So, if we surveyed only in one of those years, we would not detect the species in the pond and thereby would record a "false" absence. For that reason, it is highly important to evaluate whether an amphibian community varies from year to year in order to identify the adequate temporal scale for amphibian inventories (i.e. annual surveys $v s$. surveys over several years).

Another difficulty in the study of dynamic ecosystems arises from environmental variability. Changes in habitat availability and quality over time may have pronounced effects on species-habitat relationships, thus complicating habitat evaluation studies (Mooij et al. 2007). Theoretically, in a stable system, spatial environmental variation largely explains the spatial variation in the incidence or abundance of a species (Stiling 1999). But, in an unstable system, the spatial variation of diversity will not be constant over time, since it will be responding both to spatially fixed environmental variation (not changing over time) and to environmental characteristics that change both over time and space. Under this scenario, one should assess the role of temporally fixed habitat characteristics and, independently, of fluctuating habitat characteristics in the spatial pattern of diversity, both in the short-term (annual diversity) and in the medium-long term (cumulative diversity). In 
theory, we expect that habitat characteristics that change over time should be important to explain annual diversity whereas habitat characteristics that do not change over time should be important to explain cumulative diversity. Based on the relevance of each type of habitat characteristics for the spatial distribution of diversity, we would be able to identify the adequate temporal scale for studies of diversity-habitat relationships. This is of special relevance for the design of future field-data sampling in diversity-habitat relationships because the spatiotemporal resolution of observations should match the level of ecological process under study to yield reliable insights (Reynolds-Hogland and Mitchell 2007).

In summary, it seems evident what Bissonette and Storch (2007) exposed in a recent monograph about temporal dimensions in ecology: "Animal response to spatial heterogeneity is complicated enough to understand; to include temporal heterogeneity explicitly in our thinking and research will not make the work of landscape ecologists any easier".

\section{The probability of detection} and absence reliability: a further challenge in the study of amphibian habitat requirements

Ecological data are almost invariability subject to error because of the size and complexity of ecological systems (McCarthy 2007). In any biological survey, a major source of error is the non-detection of a species in a unit where it is actually present (Yoccoz et al. 2001; Pollock et al. 2002; Pellet and Schmidt 2005). While species presence may be confirmed by detecting the species at a site, it is not usually possible to verify whether a species is absent (MacKenzie 2005a; MacKenzie et al. 2006). The non-detection of a species may result either from the species being genuinely absent or from the species being present at the site but undetected during the survey (MacKenzie 2005a; MacKenzie et al. 2006). Boulinier et al. (1998) define the detectability of a species "as the probability of detecting at least one individual of a given species in a particular sampling effort, given that individuals of the species are present in the area of interest during the sampling session". Species detectability is important because the imperfect detection of a species induces a component of variation in ecological studies that is strictly nuisance variation and does not usually correspond to any kind of phenomena of scientific or ecological relevance (Royle and Dorazio 2008).

The reliability of the data used to parameterize a distribution/habitat model is a critical issue for its utility and validity (Lobo 2008). The imperfect detection of species may lead to erroneous conclusions about species-environment relationships $(\mathrm{Gu}$ and Swihart 2004; Mazerolle et al. 2005; MacKenzie 2006; MacKenzie et al. 2006). Moreover, if habitat characteristics influence the detectabiliy of a species, we would be facing an additional bias in habitat suitability models (see $\mathrm{Gu}$ and Swihart 2004; Mazerolle et al. 2005). For example, if species detectability is a function of pond size, the lack of consideration of imperfect detection would potentially yield the spurious inference of a relationship between pond size and occupancy.

In the case of amphibians, imperfect detectability is expected to be a major source of error in species inventories. Many amphibians are secretive species and hence use to show low detectability (Mazerolle et 
al. 2007), being such detectability variable among species (i.e. Bailey et al. 2004; De Solla et al. 2006). Moreover, a given species may also differ in its detectability within a given breeding or among breeding seasons (De Solla et al. 2005; De Solla et al. 2006). Hence, detectability is not a species trait for amphibians (Mazerolle et al. 2007). For that reason, it is of special relevance to assess the actual detectability of a species in a particular region, also taking into account if it may change over time or, on the contrary, it is more likely that it remains constant over time. This type of results will improve the amphibian monitoring programs in a given region because they would constitute the basis for the identification of the period of time when amphibian surveys are more effective.

As mentioned above, we should also account for species detectability in habitat models in order to control for the reliability of absence data. The most robust approach would be to evaluate species-habitat relationships while explicitly accounting for the probability of detecting the species when present (MacKenzie et al. 2002; MacKenzie 2005b; MacKenzie et al. 2006). However, this approach requires from temporal replication at sampled sites, a condition that may not be feasible when monitoring a large area where, besides, the activity of species is restricted to a short period of time. A less expensive alternative would be the application of a double sampling design, which consists in the estimation of detection probabilities from the data collected at a short number of sites where repeated surveys are feasible and the application of such information to the sites surveyed only once (MacKenzie et al. 2006). Such an approach will inform us about species habitat requirements and, more importantly, these results would not be flawed by a potentially imperfect species inventory. 
In this thesis, I have analyzed the habitat requirements of amphibians in Doñana National Park while controlling for methodological constraints that may bias the observed relationships. In particular, I have accounted for the temporal dynamism of the system and for the reliability of absence data, a direct consequence of the imperfect detectability of species in the area. I have also incorporated the application of new methodologies (i.e. remote sensing data) to the study of amphibian habitats (spatial distribution and temporal dynamism) and to the building of distribution models. The structure of the thesis is as follows:

\section{Chapter 1. Description of the breeding habitat}

Here, I have described the main characteristics of amphibian breeding habitats, focusing both on its spatial and temporal variation (intra and inter-annual). I have also evaluated whether temporal dynamism in the system may yield different habitat model outputs depending on the year. In other words, I have assessed whether habitat models are year-specific in such a highly dynamic ecosystem. This point is of extremely relevance for this thesis, focused on the identification of habitat requirements of amphibians, because usefulness of habitat models for species conservation depends upon consistency across time and space

\section{Chapter 2. Application of remote sensing data for identification, characterization and monitoring of amphibian habitats}

In chapter 2, I have investigated the applicability of remote sensing data to build a map of amphibian breeding habitats and to evaluate the temporal variability in the distribution and extent of these habitats for a 23 -year period. I have also evaluated the contribution of remote-sensing data to amphibian distribution studies, both at community and species level. I used a high spatial and spectral resolution image (AHS) for the detailed habitat cartography and for amphibian distribution models. I used medium spatial resolution imagery (Landsat) to assess the temporal dynamism of the system of temporary ponds.

The pond cartography built in this chapter was critical both for Chapter 1 and Chapter 5 as it was used in the estimation of the characteristics related to pond connectivity.

\section{Chapter 3. Temporal variation of the amphibian community in Doñana Natinal Park}

In this chapter, I have evaluated the temporal variability in pond assemblages (inter-annual) as well as the temporal variability in species detectability (intra and inter-annual).

To evaluate inter-annual variability in amphibian pond assemblages (hereinafter "inter-annual turnover"), I have developed a comprehensive framework aiming to assess both changes at species and assemblage levels, and to discern variation in species richness (species loss) from changes in the identity or abundance of species (species replacement). The applied interest of this study is to evaluate the adequacy of single-year surveys in amphibian diversity inventories.

In the study of species detectability, I have evaluated whether detectability should be considered constant or variable over time within a breeding season and among seasons, as well as the relationship between species detectability and habitat variables. The applied interest of this study is to evaluate the adequacy of single-survey 
monitoring programs to represent the amphibian community and when they should be conducted.

Chapter 4. Spatial variation of the amphibian community in Doñana National Park: Relationships with habitat characteristics

Here, I have evaluated the role of abiotic habitat features in amphibian breeding habitat selection both at species and assemblage level.

At assemblage level, I have investigated the relationships between abiotic habitat characteristics and amphibian richness and beta diversity for a 4-year period. I have conducted the analyses both for the fauna detected in each sampling season (annual richness/diversity) and for the fauna detected along the entire study period (cumulative richness/diversity). In particular, in this study, I have focused on partialling out the effects of habitat characteristics that change over time from the effect of those characteristics that do not change over time.

At species level, I have focused on building presence/absence habitat models while accounting for the reliability of absence data. I have surveyed the study area for 4-year period and related habitat characteristics that do not change over time with the biotic data collected over the entire study period. 


\section{References}

Alphan H, Yilmaz KT 2005. Environ Manage 35, 607-619.

Arponen A et al. 2008. J Appl Ecol 45, 1436-1445.

Austin M 2007. Ecol Model 200, 1-19.

Austin MP 2002. Ecol Model 157, 101-118.

Bailey LL et al. 2004. Ecol Appl 14, 692702.

Baselga A, Jiménez-Valverde A 2007. Ecol Entomol 32, 312-318.

Beeri O, Phillips RL 2007. Global Change Biol 2007, 897-912.

Beja P, Alcazar R 2003. Biol Conserv 114, 317-326.

Bigot L, Marazanof F 1966. Ann Limnol 2, 491-502.

Bissonette JA, Storch I 2007. Temporal Dimensions of Landscape Ecology. Wildlife Responses to Variable Resources. Springer.

Blondel J, Aronson J 1999. Biology and Wildlife of the Mediterranean Region. Oxford University Press, Oxford, New York.

Boix D et al. 2001. Wetlands 21, 577-592.

Boulinier T et al. 1998. Ecology 79, 10181028.

Brooks RT 2000. Wetlands 20, 707-715.

Brown JH et al. 1995. Ecology 76, 20282043.

Bryant RG 1999. Earth Surf Proc Land 24, 283-302.

Bryant RG, Rainey MP 2002. Remote Sens Environ 82, 360-375.

Buckland ST et al. 2005. Philos Trans R Soc Lond B-Biol Sci 360, 243-254.

Burne MR, Griffin CR 2005. Wetlands Ecol Manag 13, 247-259.

Burnham KP, Anderson DR 2002. Model Selection and Multimodel Inference. A Practical Information-Theoretic Approach. Springer.

Carey C et al. 2001. Conserv Biol 15, 903913.
Castañeda C, Herrero J 2005. J Hydrol 310, 95-110.

Castañeda C et al. 2005. J Arid Environ 63, 497-516.

Collins SL, Glenn SM 1991. Ecology 72, 654-664.

De Solla SR et al. 2006. Biodivers Conserv $15,3481-3497$.

De Solla SR et al. 2005. Biol Conserv 121, 585-594.

Díaz-Paniagua C 1982. Bull Soc Herp Fr 22, 24-26.

Díaz-Paniagua C 1983. Doñana, Acta Vertebrata 10, 41-53.

Díaz-Paniagua C 1988. Amphibia-Reptilia 9, 15-26.

Díaz-Paniagua C 1990. Herpetol J 1, 447453.

Díaz-Paniagua C 1992. Ecography 15, 267272.

Díaz-Paniagua C et al. 2005. Los Anfibios de Doñana. Organismo Autónomo de Parques Nacionales. Ministerio de Medio Ambiente, Madrid.

Díaz-Paniagua C et al. 2006. Rev Esp Herpetol 20, 17-30.

Duellman WE, Trueb L 1986. Biology of Amphibians. McGraw-Hill Book Company

European Commission 2007. Interpretation Manual of European Union Habitats. Natura 2000, Nature and Biodiversity. European Commission.

Fjeldsa J, Lovett JC 1997. Biodivers Conserv 6, 315-323.

Fortuna M et al. 2006. $P$ Roy Soc Lond $B$ Bio 273, 1429-1434.

García-Novo F et al. 1991. III Simposium de Aguas de Andalucía, 165-176.

García Murillo PJ et al. 2006. Limnetica 5, 71-80.

Gardner TA et al. 2007. Biol Conserv 138, 166-179.

Gaston KJ 2000. Nature 405, 220-227. 
Gibbons JW 2003. Wetlands 23, 630-635.

Gottschalk TK et al. 2005. Int J Remote Sens 26, 2631-2656.

Graham CH et al. 2008. J Appl Ecol 45, 239-247.

Griffiths RA 1997. Aquat Conserv: Mar Freshw Ecosyst 7, 119-126.

Grillas P et al. 2004. Mediterranean Temporary Pools. Volume 1- Issues Relating to Conservation, Functioning and Management. Station Biologique de la Tour du Valat.

Groom G et al. 2006. Landscape Ecol 21, 391-408.

$\mathrm{Gu}$ WD, Swihart RK 2004. Biol Conserv 116, 195-203.

Guisan A et al. 2006. J Appl Ecol 43, 386392.

Guisan A, Zimmermann NE 2000. Ecol Model 135, 147-186.

Hecnar SJ, M’Closkey RT 1996a. Freshwater Biol 36, 7-15.

Hecnar SJ, M’Closkey RT 1996b. Ecology 77, 2091-2097.

Hobbs RJ 1998. Managing Ecological Systems and Processes. In: Peterson, D.L., et al. (Eds.), Ecological Scale. Theory and Applications. Columbia University Press, New York.

Houlahan JE et al. 2007. P Natl Acad Sci USA 104, 3273-3277.

Innes JL 1998. Measuring Environmental Change. In: Peterson, D.L., et al. (Eds.), Ecological Scale. Theory and Applications. Columbia University Press, New York.

Jakob C et al. 2003. Hydrobiologia 499, 5161.

Kerr JT, Ostrovsky M 2003. Trends Ecol Evol 18, 299-305.

Knutson MG et al. 2004. Ecol Appl 14, 669684.

Laan R, Verboom R 1990. Biol Conserv 54, 251-262.

Lacaux JP et al. 2007. Remote Sens Environ $106,66-74$.

Lobo JM 2008. Biodivers Inform 5, 14-19.
López T et al. 1991. Arch Hydrobiol 120, 357-378.

MacKenzie DI 2005a. Aust N Z J Stat 47, 65-74.

MacKenzie DI 2005b. J Wildl Manage 69, 849-860.

MacKenzie DI 2006. J Wildl Manage 70, 367-374.

MacKenzie DI et al. 2002. Ecology 83, 2248-2255.

MacKenzie DI et al. 2006. Occupancy Estimation and Modeling. Inferring Patterns and Dynamics of Species Occurrence. Elsevier.

Magurran AE 2007. Ecol Lett 10, 347-354.

Mazerolle MJ et al. 2007. J Herpetol 41, 672-689.

Mazerolle MJ et al. 2005. Ecol Appl 15, 824834.

McCarthy MA 2007. Bayesian Methods for Ecology. Cambridge University Press, Cambridge.

Middleton EM et al. 2001. Conserv Biol 15, 914-929.

Millán A et al. 2005. Boln Soc Entomol Aragonesa 37, 157-164.

Montes C et al. 1982. Studia Oecol 3, 129. 158.

Mooij WM et al. 2007. Exploring the temporal effects of seasonal water availability on the snail kite of Florida. In: Bissonette, J.A., et al. (Eds.), Temporal Dimensions of Landscape Ecology. Wildlife Responses to Variable Sources. Springer.

Muñoz Reinoso JC 1996. Limnetica 12, 5363.

Oertli B et al. 2005. Aquat Conserv: Mar Freshw Ecosyst 15, 535-540.

Ozesmi SL, Bauer ME 2002. Wetlands Ecol Manag 10, 381-402.

Papastergiadou E et al. 2007. Hydrobiologia $584,361-372$.

Pearl CA et al. 2005. Wetlands 25, 76-88.

Pechmann JHK et al. 1991. Science 253, 892-895. 
Pellet J, Schmidt BR 2005. Biol Conserv 123, 27-35.

Pollock KH et al. 2002. Environmetrics 13, 105-119.

Preston FW 1960. Ecology 41, 611-627.

Revenga $\mathrm{C}$ et al. 2005. Philos Trans $R$ Soc Lond B-Biol Sci 360, 397-413.

Reynolds-Hogland MJ, Mitchell MS 2007. Three axes of ecological studies: Matching process and time in landscape ecology. In: Bissonette, J.A., et al. (Eds.), Temporal Dimensions of Landscape Ecology. Wildlife Responses to Variable Sources. Springer.

Ricklefs RE, Schluter D (eds.)1993. Species Diversity in Ecological Communities: Historical and Geographical Perspectives. University of Chicago, Chicago.

Richter-Boix A et al. 2007. J Anim Ecol 76, 607-618.

Roshier DA, Rumbachs RM 2004. J Arid Environ 56, 249-263.

Royle JA, Dorazio RM 2008. Hierarchical Modeling and Inference in Ecology. Academic Press, Elsevier.

Sanderson RA et al. 2005. Ecography 28, 355-362.

Scribner KT et al. 2001. Biol Conserv 98, 201-210.

Schwartz SS, Jenkins DG 2000. Aquat Ecol 34, 3-8.

Semlitsch RD 2002. J Wildl Manage 64, 615-631.

Semlitsch RD (Ed.) 2003. Amphibian Conservation. Smithsonian Books, Washington and London.

Semlitsch RD, Bodie JR 1998. Conserv Biol $12,1129-1133$.

Serrano L, Fahd K 2005. Wetlands 25, 101111.

Serrano L, Toja J 1995. Arch Hydrobiol 133, 497-516.
Skelly DK 2001. Isr J Zool 47, 313-332.

Skelly DK, Meir E 1997. Conserv Biol 11, $531-538$.

Skelly DK et al. 1999. Ecology 80, 23262337.

Smith GR et al. 2003. J Freshwater Ecol 18, 491-496.

Smith MA, Green DM 2005. Ecography 28, 110-128.

Snodgrass JW et al. 2000. Conserv Biol 14, 414-419.

Soininen J et al. 2007. Ecology 88, 28302838.

Spencer M et al. 1999. Ecol Lett 2, 157-166.

Stiling P 1999. Ecology: Theories and Applications. Prentice Hall, New Jersey.

Sztatecsny M et al. 2004. Herpetol J 14, 8997.

Trenham PC et al. 2003. Ecol Appl 13, 1522-1532.

Turner W et al. 2003. Trends Ecol Evol 18, 306-314.

Van Buskirk J 2005. Ecology 86, 19361947.

Weiers S et al. 2004. Landscape Urban Plan 67, 43-65.

Wellborn GA et al. 1996. Annu Rev Ecol Evol $S$ 27, 337-363.

Werner EE et al. 2007. Oikos 116, 16971712.

Williams DD 1997. Aquat Conserv: Mar Freshw Ecosyst 7, 105-117.

Williams DD 2006. The Biology of Temporary Waters. Oxford University Press, Oxford, New York.

Williams P et al. 2003. Biol Conserv 115, 329-341.

Yoccoz NG et al. 2001. Trends Ecol Evol 16, 446-453.

Zacharias I et al. 2007. J Environ Biol 28, 1-9. 


\section{Study area and study period}

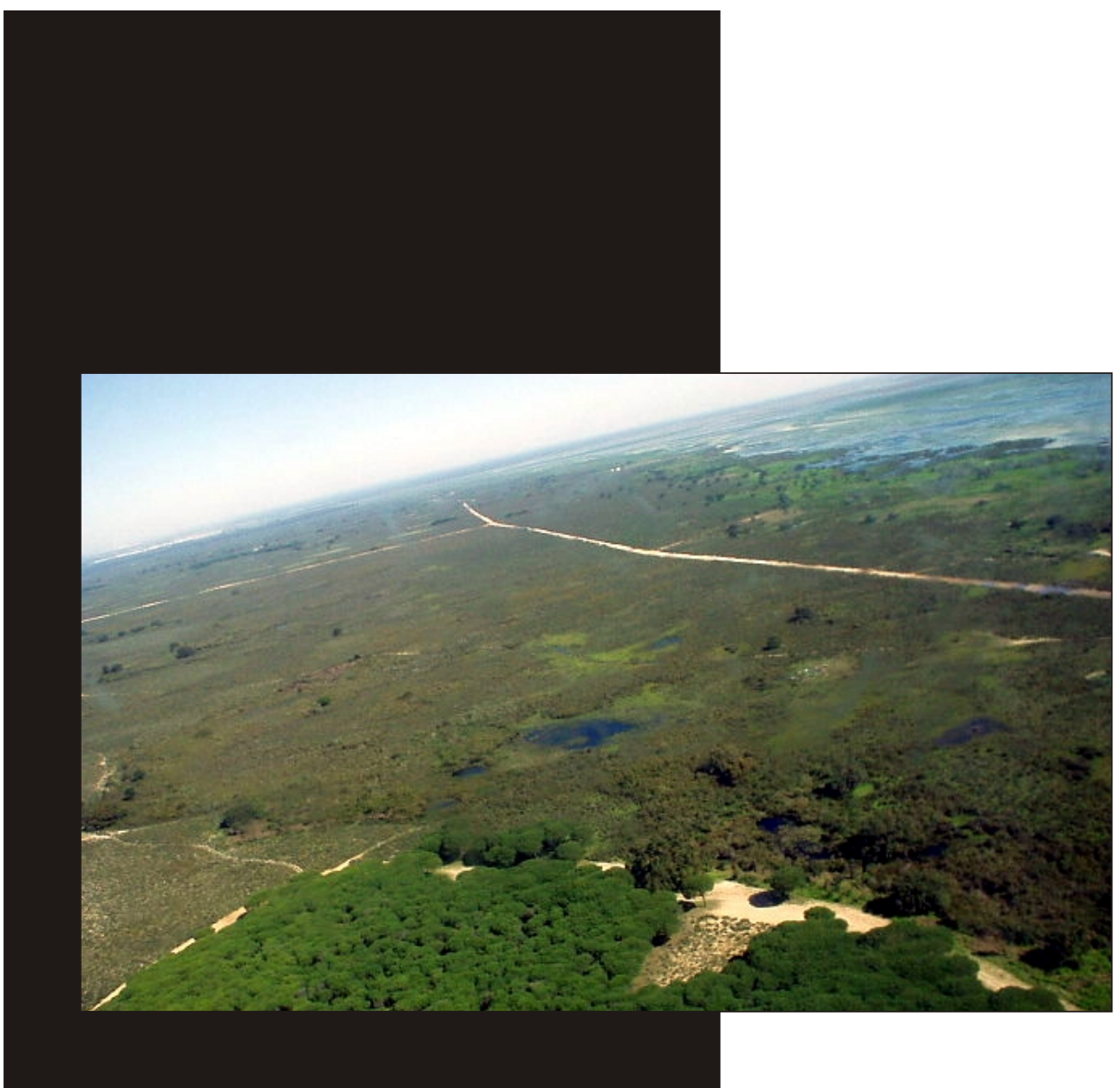




\section{Study Area}

\section{Location}

Doñana National Park is located in southwestern Spain (center coordinates: $37^{\circ} 00^{\prime} \mathrm{N}, 06^{\circ} 38^{\prime \prime} \mathrm{W}$ ), on the right bank of the mouth of the Guadalquivir river, astride the provinces of Huelva and Seville (Figure 1). The National Park, protected by the highest possible degree in Spain, is surrounded by a belt of land with a lower protection status (i.e. Pre-Park areas or Doñana Natural Park), that acts as a protecting buffer zone.

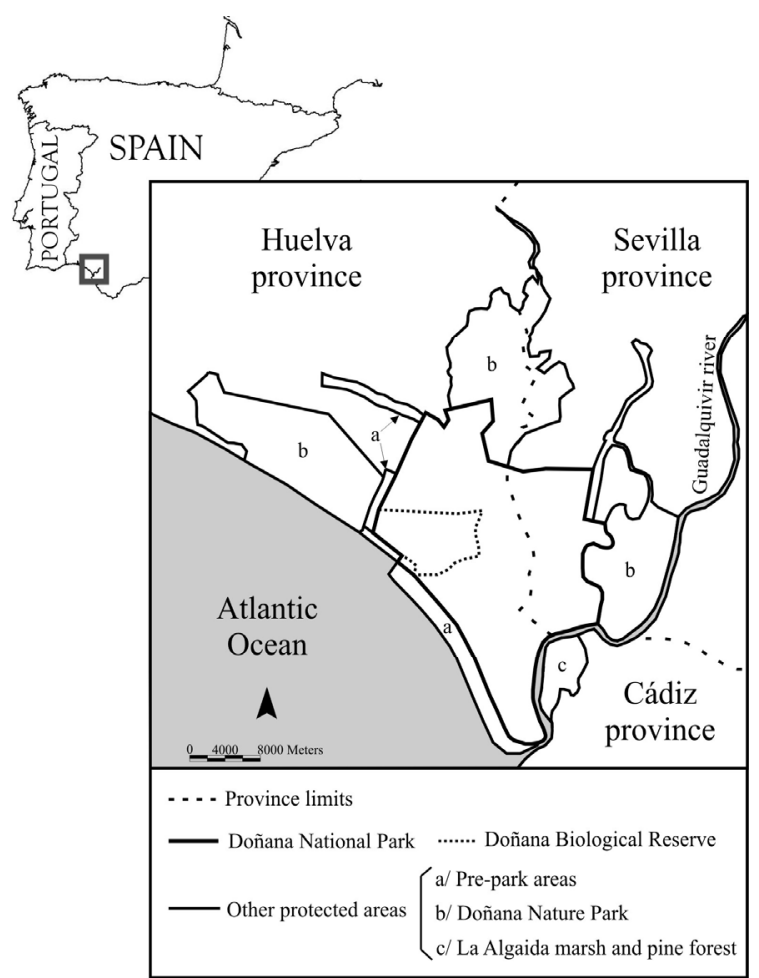

Figure 1. Location of Doñana National Park and surrounding protected areas. 
The total protected area extends over more than 121,000 ha, the National Park corresponding to 54,252 ha of the total (Table 1). Within the boundaries of the National Park, a territory designated as the Doñana Biological Reserve (6.794 ha) deserves special attention. This area constitutes the core of Doñana National Park. It is owned and managed by the Spanish National Research Council (Consejo Superior de Investigaciones Científicas, CSIC). In the present study, most of the intensive sampling effort was conducted within the Doñana Biological Reserve limits whereas extensive samplings where conducted across the National Park.

Doñana National Park is one of the largest and most important wetlands of Europe (Table 2), the largest RAMSAR wetland in
Spain (Table 3) and is amongst the largest National Parks in Spain (Table 4). Despite the vast area it comprises, its isolation from other protected areas may pose a serious threat to the long-term viability of some of its wildlife populations. Doñana region is surrounded by two natural barriers (i.e. the Guadalquivir river to the East and the Atlantic Ocean to the Southwest) and intensive agriculture fields (to the North and Northwest) that hamper the exchange of wildlife flora and fauna with adjoining protected areas outside Doñana region. Doñana National Park is located by the sea, presents a smooth topographic relief, and thereby it can be classified as a lowelevation natural reserve. The highest elevation ("La Loma del Chocolate") is at 47 metres a.m.s.l.

Table 1. Protected areas in the region of Doñana (source García Novo and Marín Cabrera 2006a).

\begin{tabular}{|llc|}
\hline Protected Nature Area & Figure & Extension (ha) \\
\hline Doñana National Park & National Park & 54251 \\
Doñana Natural Park & Nature Park & 53709 \\
Brazo del Este & Nature Area & 1336 \\
Enebrales de Punta Umbría & Nature Area & 162 \\
Estero de Domingo Rubio & Nature Area & 480 \\
Lagunas de Palos y las & Nature Area & 693 \\
Madres & Nature Area & 7185 \\
Marismas del Odiel & Nature Reserve & 480 \\
Isla de Enmedio & Nature Reserve & 597 \\
Marisma de El Burro & Concerted Nature Reserve & 7.43 \\
Cañada de los Pájaros & Concerted Nature Reserve & 617.71 \\
Dehesa de Abajo & Natural Monument & 11.85 \\
Acantilado del Asperillo & Natural Monument & 0.63 \\
Acebuches de El Rocío & Natural Monument & 0.2 \\
Pino Centenario del Parador & Protected Landscape & 2076.8 \\
de Mazagon & & \\
Guadimar Green Corridor & Puan & \\
\hline
\end{tabular}


Table 2. Largest Ramsar sites in Europe, sorted in descending order (source The Ramsar Convention on Wetlands: http://www.ramsar.org/index_list.htm).

\begin{tabular}{|llc|}
\hline Ramsar site & Location (Country) & Extension (ha) \\
\hline Volga Delta & Russian Federation & 800000 \\
Danube Delta & Romania & 647000 \\
Schleswig-Holstein Wadden Sea & Germany & 454988 \\
and adjacent areas & Russian Federation & 309000 \\
Veselovskoye Reservoir & Finland & 285990 \\
Lemmenjoki National Park & France & 255800 \\
Etangs de la Champagne humide & Netherlands & 249998 \\
Waddenzee (Wadden Sea) & Russian Federation & 226500 \\
Kama-Bakaldino mires & Russian Federation & 208000 \\
Kandalaksha Bay & Sweden & 188600 \\
Sjaunja & Ukranie & 165000 \\
Eastern Syvash & Russian Federation & 161542 \\
Oka \& Pra River Floodplains & Denmark & 150482 \\
Vadehavet (Wadden Sea) & United Kingdom & 143503 \\
Caithness \& Sutherland Peatlands & France & 140000 \\
La Brenne & Netherlands & 135000 \\
Waddeneilanden, & & 121620 \\
Noordzeekustzone, Breehaart & Germany & 112600 \\
Wattenmeer, Ostfriesisches & Russian Federation & \\
Wattenmeer \& Dollart MR & Spain & \\
Lake Manych-Gudilo & & \\
Doñana Ramsar Site & & \\
& & \\
\hline
\end{tabular}


Table 3. Largest Ramsar sites in Spain, sorted in descending order (source The Ramsar Convention on Wetlands: http://www.ramsar.org/index_list.htm).

\begin{tabular}{|llc|}
\hline Ramsar site & $\begin{array}{l}\text { Location (Autonomous } \\
\text { region) }\end{array}$ & Extension (ha) \\
\hline $\begin{array}{l}\text { Doñana Ramsar Site } \\
\text { Parque Nacional de }\end{array}$ & Andalucía & 111646 \\
$\begin{array}{l}\text { Aigüestortes i Estany de Sant } \\
\text { Maurici }\end{array}$ & Cataluña & 39979 \\
Albufera de Valencia & Comunidad Valenciana & 21000 \\
Mar Menor & Murcia & 14933 \\
Bahía de Cádiz & Andalucía & 10000 \\
Delta del Ebro & Cataluña & 7736 \\
Marismas del Odiel & Andalucía & 7185 \\
Marismas de Santoña & Cantabria & 6907 \\
Laguna de Gallocanta & Aragón & 6720 \\
Embalse de Orellana & Extremadura & 5500 \\
\hline
\end{tabular}

Table 4. Extension of National Parks in Spain (source Ministry of the Environment and Rural and Marine Affairs: http://reddeparquesnacionales.mma.es/parques/index.htm).

\begin{tabular}{|lc|}
\hline Park & Extension (ha) \\
\hline Archipiélago de Cabrera & $10021^{1}$ \\
Sierra Nevada & 86208 \\
Marítimo-Terrestre de las Islas Atlánticas de Galicia & $8480^{2}$ \\
Picos de Europa & 64660 \\
Doñana & 54252 \\
Cabañeros & 40856 \\
Teide & 18990 \\
Monfragüe & 18118 \\
Ordesa y Monte Perdido & 15608 \\
Aigüestortes i Estany de Sant Maurici & 14119 \\
Timanfaya & 5107 \\
Caldera de Taburiente & 4690 \\
Garajonay & 3986 \\
Tablas de Daimiel & 1928 \\
\hline
\end{tabular}




\section{A brief history}

The region of Doñana has garnered recognition as an outstanding wildlife refuge for centuries. At the early beginning (c. XIII), it was mainly considered as a hunting reserve and the king Alfonso X "The Wise" declared some territories "Royal Hunting Grounds" (Cazadero Real de la Corona) in 1262. So, the protection of the fauna was not an objective per se in its origins, although wildlife populations have indirectly benefited from this long-standing restriction to human intervention.

In their book, Fernández and Pradas (2000) document the history of Doñana. We will attempt to summarize it, focusing on the most relevant events (in our opinion) related to its conservation status nowadays. We will also include some notes from García Novo and Marín Cabrera (2006a) to provide a more comprehensive description of the history of Doñana (noted as such in the text). After the designation made by Alfonso X, Fernando II "The Catholic" created the "Royal Coto" (Coto Real) two centuries later, also known as "Royal Forest" (Bosque Real). From the XVIth to the XXth century, the land was owned by different Spanish aristocrats who used it as leisure/retirement property. Doñana remained as a private hunting reserve until 1636, when it was opened up to grazing livestock (García Novo and Marín Cabrera 2006a). The introduction of livestock cleared the woods and, as a consequence, the traditional woodland vegetation gave way to open grassland. In 1737, reforestation with pine tree (Pinus pinea L.) began in the stabilized sands, which led to the displacement of the juniper species (Juniperus oxycedrus L. subsp. macrocarpa (Sbith. \& Sm.) Ball and Juniperus phoenicea L. subsp. turbinata (Guss.) Nyman) by the planted pine trees (García Novo and Marín Cabrera 2006a). In the 20th century, the stabilized dunes were again reforested with faster growing forestry species (pine trees and eucalyptus [Eucalyptus camaldulensis Dehnh. and Eucalyptus globulus Labill.]) and the marshes were transformed into rice plantations (García Novo and Marín Cabrera 2006a).

The interest on the conservation of the biodiversity in Doñana does not emerge until the mid-XXth century. At this time, some national and international scientific expeditions were conducted in the region and the first research studies where published, evidencing the relevance of the wildlife fauna present in the area (Valverde 1958, 1960; Valverde 1967). At the same time, the area was under a major land-use transformation threat in the adjoining zones, where the wetland area was dramatically being reduced due to drainage and conversion into farmland. In response to these threats and the plea from the scientific community for protection measures, the Spanish government along with the World Wildlife Fund organization purchased a portion of the territory in 1963 with the aim of preserving it from environmental degradation. So, the first protected reserve was designated in the area, the Doñana Biological Reserve. A few years after, in 1969, the area under protection is enlarged with the creation of the Doñana National Park, adding up to a total extent of 37,425 ha. The designation of this territory as a National Park explicitly acknowledged its natural and cultural value and ensured its conservation through the application of specific management measures. In 1978, the Doñana Law (Ley de Doñana) was published and added more territories to the National Park, to a total of 50,720 ha. In the most recent years, more land has been incorporated to the National Park grounds until reaching the present surface of 54,252 hectares, with more than 73,000 additional hectares protected under different figures (i.e. Natural Park). 
Until July 2006, the central (Spanish Government) and regional authorities (Junta de Andalucía) were both involved in the management and conservation of this natural reserve. Since then, the regional authority is the only one responsible for its management.

\section{Conservation status and relevance for conservation}

Due to its outstanding importance for wildlife, it was given the highest degree of protection in Spain (National Park) in 1969. This natural reserve has also received international recognition as it has been granted the status of Biosphere Reserve by UNESCO in 1980, an Internationally Important Wetland Site under the Ramsar Convention in 1982, a Special Protection Area for Birds in 1988, and a Natural World Heritage Site in 1994. Despite being under such high protection status, it entered the Montreux Record of Ramsar sites that face threats to conservation in 1990.

A great variety of ecosystems and landscapes can be found within this area (i.e. pine woods, scrubland, cork oak forests, ponds, riverbank forests, marshes, sand dunes, coastal cliffs or beaches) that provide shelter for a large number of species. Most of the habitats preserved within the National Park have disappeared or suffered from an intensive degradation in other regions in the Iberian Peninsula (i.e. systems of temporary ponds of natural origin). So, we attribute its isolation from human activities for centuries (initially as an uninhabited royal hunting reserve and later as a national reserve) as one of the most crucial facts that has ensured the indirect preservation of non-emblematic ecosystems in this area. Nowadays, the access to the Park is restricted, a critical measure to increase its isolation from the surrounding threats. The edges of the Park are subject to pressure from the adjacent croplands, and water extraction from the underlying aquifer is drying some areas of the Park. Besides, a large tourist resort is located in its immediate surroundings, providing a high pressure from tourism and urban development.

Hundreds of bird species visit, breed, or permanently reside here, being the most emblematic one the imperial eagle (Aquila adalberti Brehm, 1861), a species under critical danger. It is also home to the last surviving populations of the world's most endangered cat species, the Iberian lynx (Lynx pardinus (Temminck, 1827)).The vertebrate fauna includes other species that are highly endangered in Spain, like the spur-thighed tortoise (Testudo graeca Linnaeus, 1758), red kite (Milvus milvus (Linnaeus, 1758)), ruddy shelduck (Tadorna ferruginea (Pallas, 1764)), osprey (Pandion haliaetus (Linnaeus, 1758)), slender-billed gull (Larus genei Brème, 1839,), spoonbill (Platalea leucorodia Linnaeus, 1758), crested coot (Fulica cristata Gmelin, 1789), marbled teal (Marmaronetta angustirostris (Menetries, 1832)), ferruginous duck (Aythya nyroca (Güldenstädt, 1770)) or white headed duck (Oxyura leucocephala (Scopoli, 1769)). This natural reserve is also of great importance for a large number of other vertebrates, as amphibians. The area has been designated as a location of "special interest for the conservation" of amphibians (Santos et al. 1996). Here, we may find all species from the southwest of the Iberian Peninsula except Salamandra salamandra (Linnaeus, 1758), a species that, in south Spain, is associated to high-altitude ecosystems. Some of the amphibian species in Doñana National Park are included in international, national and regional red lists (Table 5). 
Table 5. International, national and regional protection status of amphibian species in Doñana National Park.

\begin{tabular}{|c|c|c|c|}
\hline & $\begin{array}{l}\text { IUCN } \\
(2008)\end{array}$ & $\begin{array}{l}\text { Spanish Red List } \\
(2002)^{1}\end{array}$ & $\begin{array}{l}\text { Andalusian Red } \\
\text { List }(2001)^{2}\end{array}$ \\
\hline Alytes cisternasii & NT & NT & \\
\hline Bufo calamita & LC & $\mathrm{LC}$ & \\
\hline Bufo bufo & LC & LC & \\
\hline Pelobates cultripes & NT & NT & \\
\hline Discoglossus galganoi & LC & LC & \\
\hline Pelodytes ibericus & LC & DD & DD \\
\hline Pelophylax perezi & LC & $\mathrm{LC}$ & \\
\hline Hyla meridionalis & LC & NT & \\
\hline Pleurodeles waltl & NT & NT & \\
\hline Triturus pygmaeus & $\mathrm{LC}$ & VU & \\
\hline Lissotriton boscai & LC & LC & LC \\
\hline Vulnerable & & & \\
\hline Near threatened & & & \\
\hline Least concern & & & \\
\hline Data deficient & & & \\
\hline
\end{tabular}

${ }^{1}$ Spanish Red List: Pleguezuelos et al. (2002)

${ }^{2}$ Andalusian Red List: Junta de Andalucía (2001)

\section{Physical description}

\section{Geologic origin}

In the Quaternary, the Guadalquivir estuary covered the present area of Doñana. In fact, the current appearance of Doñana is no more than two thousand years old, as its terrain is sedimentary and recent, the result of the action of winds, tides and rivers (García Novo and Marín Cabrera 2006a). The large estuary was formed during the last sea level rise. Marine currents led to the progressive formation of an advancing coastal bar running NW-SE, which led to today's coastline. The estuary was then partially closed and created a vast saline lagoon (Ligurian Lake of Phoenician times and the Ligustinus Lake of the Roman
Empire). This lagoon has gradually been filled with alluvial sediments from the mainland, forming the base of the marshes. The sedimentary deposition has led to a progressive isolation from the sea. The present continental formation is composed of a sandy landscape, developed after the erosion of the coastal cliff, and a marshland with minimal tidal influence (García Novo and Marín Cabrera 2006a). Figure 2 represents a scheme of the geologic evolution of Doñana area. 


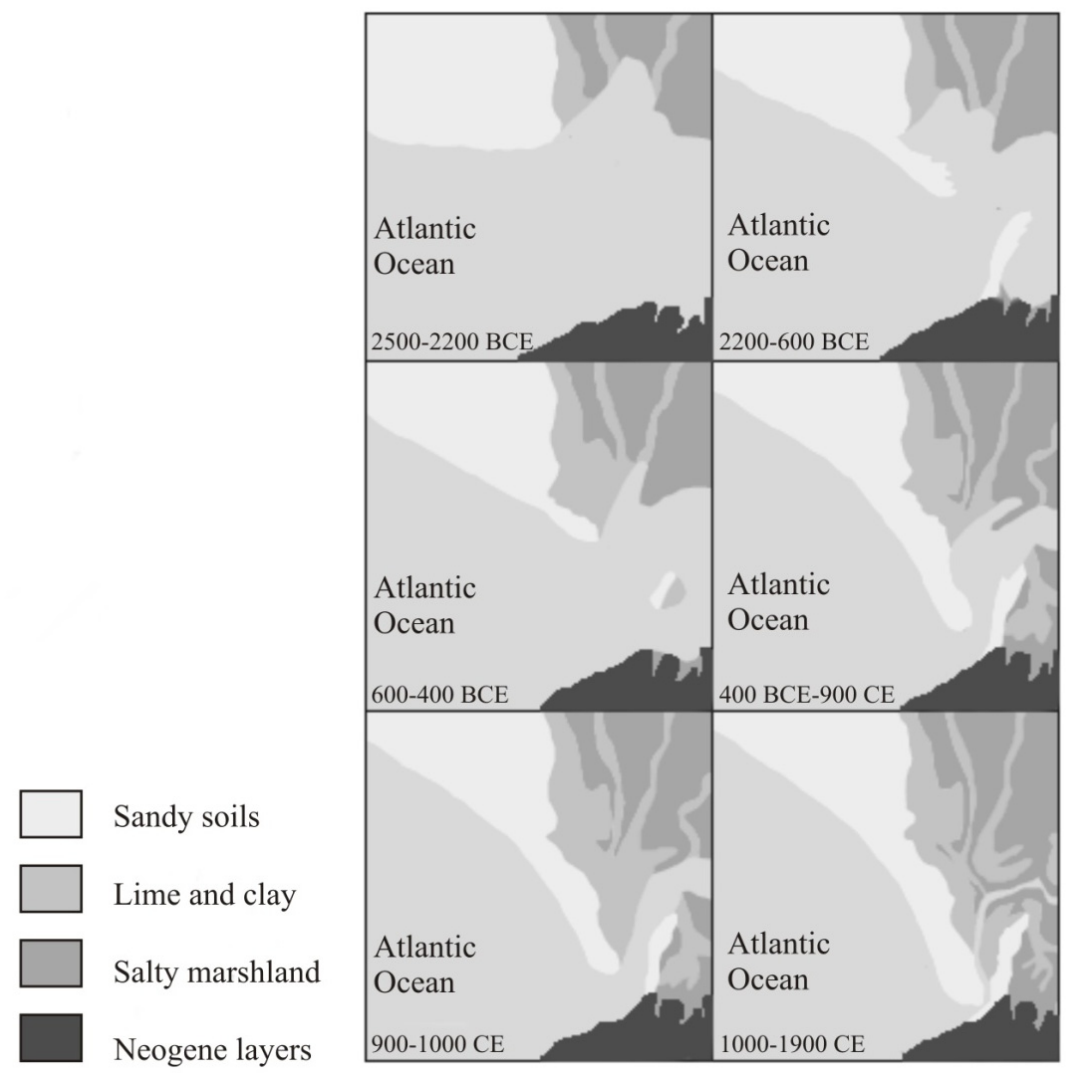

Figure 2. Scheme of the geologic evolution of Doñana National Park (modified from Junta de Andalucía 1998).

\section{Climate}

The area has a Mediterranean climate strongly moderated by the ocean. Summers are long, hot and dry while winters are wet and present mild temperatures. Annual mean temperature is $17^{\circ} \mathrm{C}$. In summer months, mean temperature is $25^{\circ} \mathrm{C}$, with maximum values over $35-40^{\circ} \mathrm{C}$ reached quite frequently. Temperatures during winter only occasionally reach $0^{\circ} \mathrm{C}$ or below. The coldest month is January, with a mean temperature of approx $10^{\circ} \mathrm{C}$ (see DíazPaniagua et al. 2005 for more information).

Rainfall input and pattern is highly variable and unpredictable among years.
Annual precipitation is $550 \mathrm{~mm}$ on average. However, in very wet years, the amount of rainfall may exceed $1000 \mathrm{~mm}$ while in very dry years the amount of rainfall may be below $300 \mathrm{~mm}$. In an average type year, the wettest period is autumn, when the area receives almost half of the annual rainfall. Winter and spring may also be rainy, with a rainfall input representing the $30 \%$ and $20 \%$ of the annual one, respectively. Summer months do not usually present a significant precipitation level. It should be stressed that this rainfall pattern represents a theoretic one, which may largely differ from the real one due to the large environmental variability the area is subject 
to. In accordance to this, rains may be scarce in autumn or even during the entire wet season (from autumn to spring) in dry years (see Díaz-Paniagua et al. 2005 for more information).

\section{Present-day geomorphology ecosystem zonation}

Numerous studies have described Doñana from an ecological perspective (Valverde 1958; Valverde 1967; Allier et al. 1974; García Novo et al. 1978; Amat et al. 1979; Castroviejo 1993; Montes et al. 1998; Ramos 2002) or a geomorphologic one (Siljeström et al. 1994; Rodríguez-Ramírez and Clemente 2002). These studies provided the basis for the simplified description and zonification we have used in this study.

Doñana National Park can be divided into three morphogenetic regions: littoral (shoreline), aeolian (sands) and estuarine (marsh) (Figure 3).

The shoreline (or coast) is situated in the southeast of the Park. The shore is $28 \mathrm{~km}$ long, washed by the Atlantic Ocean. Beaches are smooth and sandy and, at low tide, they may extend over a large surface due to their gentle slope.

The marshes are situated in the east, by the side of the Guadalquivir river. It is the largest morphogenetic region of the Park, covering more than half percent of its territory. In its origins, it was a coastal marshland with slow-moving canals within the Guadalquivir delta (Clemente et al. 1998). At present time, it functions as a continental/tidal marsh due to sediment deposition over the last millennia. The soil is composed of lime and clayey silt. Its inundation regime is intermittent, highly dependent on rainfall input and pattern. In wet years, it may flood in autumn and dry in late-spring or early-summer. Dominant vegetation is Scirpus maritimus L. and Scirpus lacustris L.. The marshes are carved up by a network of seasonal watercourses (locally called "caños"). We may also appreciate other small-scale local differences in relief: small elevations (locally called "vetas" or "paciles"), transition zones (low-lying areas filled with sedimentary deposits) and shallow pans (locally called "lucios"). The latter topographic elements are the ones that retain water for the longest time.

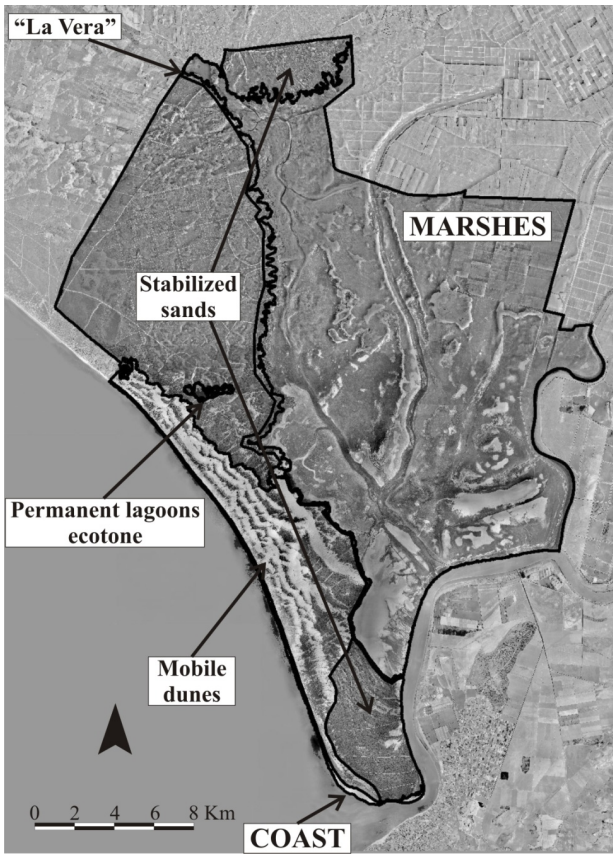

Figure 3. Morphogenetic regions in Doñana National Park. The figure shows the subregions in which the aeolian sands morphoregion can be subdivided: Mobile dunes, stabilized sands, permanent ponds ecotone and "La Vera" ecotone. 
The aeolian sands are located in the west part of the Park, covering almost half of its territory. This morphogenetic region can be subdivided into mobile dunes, stabilized sands and contact areas (ecotones). The mobile dunes form under the action of onshore winds, which blow this sand inland. The system of mobile dunes occupies a long narrow strip (3-5 km wide, $25 \mathrm{~km}$ long) and runs in four rows parallel to the shoreline. The dunes move 4-6 $\mathrm{m}$ a year, burying pine woods (P. pinea) and scrubland as they go. The top of the dunes constitutes the highest peaks in the area and are never subdued to flooding. Vegetation is scarce and adapted to xeric conditions. The most emblematic species are the large-fruited (J. oxycedrus subsp. macrocarpa) and the phoenicean juniper (J. phoenicea subsp. turbinata), both species adapted to the moving substrate. Waterbodies are almost non-existent in the dunes (excluding a few isolated man-made deep holes) whereas large ephemeral waterbodies of natural origin may develop in the interdune valleys, fed by dune perched aquifers. Dominant vegetation in the interdune valleys (locally called "corrales) is mediterranean scrub and pine forests $(P$. pinea).

The stabilized sands have a flat topography. The genesis of this region is based on the vegetation-driven stabilization of former mobile dunes. This sand sheet has been eroded by water drainage and wind deflation (Clemente et al. 1998). The watertable is very shallow $(<10$ meters below surface). So, small differences in elevation are determinant to water availability and this is the controlling factor for the composition of plant communities (Allier et al. 1974). The predominant vegetation is Mediterranean scrub. In the most arid zones, at higher altitudes, the dominant species are Halimium halimifolium (L.) Wilk. and Cistus spp.. This ecosystem is locally called "monte blanco". In the areas where the water table is accessible during summer, the dominant species are Calluna vulgaris (L.) Hull and Erica scoparia L. This ecosystem is locally called "monte negro". As tree species, we may find small patches of pine $(P$. pinea) and juniper forests $(J$. oxycedrus subsp. macrocarpa and $J$. phoenicea subsp. turbinata), as well as isolated cork oaks (Quercus suber L.). Juniper forests develop in the driest stabilized-sands zone, locally called "Las Naves", (Allier et al. 1974) which corresponds to the highest elevation (mean altitude of $30 \mathrm{~m}$ above sea level) and hence the maximum depth to the water-table.

The contact areas (or ecotones). We may differentiate two large ecotones within the stabilized sands: the marsh flooding limit, situated at the boundary between the stabilized sands and the marshes (locally called "La Vera"), and the contact area between the mobile dunes and the stabilized sands (permanent ponds ecotone). The characteristics of both ecotones depend to a great extent on the aquifer groundwater flow system (Suso and Llamas 1990).

"La Vera" corresponds to a narrow ecotone between the stabilized sands and the marshes. It extends from north to south, varying in width from 200 to $>1000 \mathrm{~m}$. Differences in permeability between the silt-clay marshes and the sands give its peculiarity to this ecosystem, for it enables the up-welling of groundwater flowing to the marshes at some points. This area maintains the humidity during the dry season. So, the vegetation is adapted to wet conditions, being numerous the extensive grasslands, hygrophyte vegetation and, in winter, dense ferns. Here, the old cork oaks (Q. suber L.) support a large mixed nesting colony of Ardea cinerea Linnaeus, 1758, Egretta garzetta Linnaeus, 1766, Nycticorax nycticorax Linnaeus, 1758, Ciconia ciconia (Linnaeus, 1758) and $P$. leucorodia. It is an outstanding ecosystem of the Park, 
deserving special conservation management due to its singularity and biotic diversity.

The permanent ponds ecotone is the contact area between the mobile dunes and the stabilized sands. Its low elevation is partially responsible for its density and variety of water-bodies, the largest in the National Park. This system of water-bodies includes many temporary ponds of natural origin and, most remarkably, the two permanent ponds of natural origin in the Park, locally called "Santa Olalla" and "La Dulce". While in the rest of the Park the hydrologic regime is mostly driven by rainfall input and water discharges from the regional aquifer, the water discharges from perched dune aquifers play a very important role in this ecotone as well (Clemente et al. 1998; Rodríguez-Ramírez and Clemente 2002).

In this study, we have adopted the ecosection zonation that Montes et al. (1998) proposed (Figure 4): they differentiated the ecotone marshes-aeolian sands and six units within the aeolian sands. The units are stabilized sands at low elevation, wet stabilized sands at higher elevation, dry stabilized sands at higher elevation, semi-stabilized dunes, mobile dunes and former beaches. Additionally, they also identified and mapped the humantransformed locations (i.e. houses).

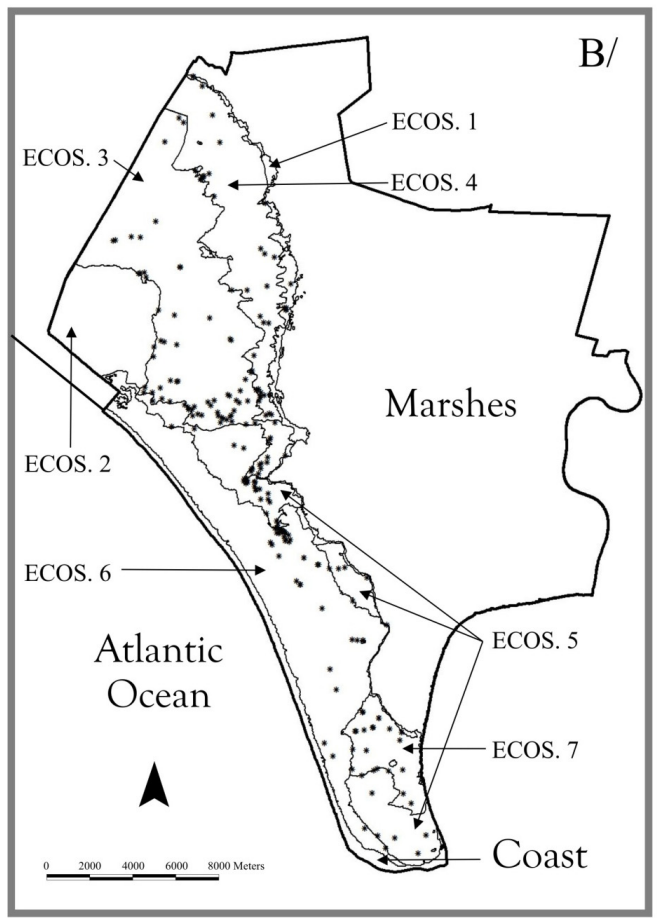

Figure 4. Ecosections of Doñana National Park, following Montes et al. (1998). The location of the ponds considered in this study is also shown. Note that an additional ecosection (terrestrial human-transformed areas) consists on isolated and small locations that are not visible in this graphical representation.

*Ecosection code: 1: Ecotone marshes-stabilized sands; 2: Dry stabilized sands at higher elevation; 3: Wet stabilized sands at higher elevation; 4: Stabilized sands at low elevation; 5: Semi-stabilized dunes; 6: Mobile dunes; 7: Former beaches. 
The aquatic systems in

\section{Doñana National Park}

\section{Doñana aquifer and groundwater system}

The hydrology of Doñana wetlands is directly dependent on groundwater. Doñana is located at the southern tip of the formerly aquifer system number 27 (according to the classification of the Spanish Institute of Geology and Mines [IGME]) and now Aquifer 05-51 + 04-14 (catalog of the Geological Survey of Spain) and, within this system, it forms part of the AlmonteMarismas sub-system (Manzano and Custodio 2006). The aquifer consists of a set of spatially and hydraulically interconnected units of different origin and ability for storing and transmitting water. The depth gradually increases from the north, where it is just a few metres deep, to over 220 metres in the South, under the marsh sediments (García Novo and Marín Cabrera 2006b). The water-table is a tight reproduction of the terrain topography except for the local relief of the sand dunes (Trick and Custodio 2004). On a regional scale, groundwater moves south and east, from the aeolian sands towards the marshes and the shore. The aquifer is free in the NW sector (aeolian sands) while it is confined under the marshes (E). On the aeolian sands, "the relatively thick sand deposits, occasionally inter-layered with finer sedimentary materials, form a relatively low permeability, unconfined upper aquifer directly overlying a heterogeneous lower aquifer which behaves hydraulically like a semiconfined one below the fine sands, whose role approaches that of an aquitard" (Trick and Custodio 2004). It should be noted that a recent conceptual model describes a more complex structure: a "Basal Unit", composed of sandy clay and fine grain sands, and two permeable units ("Superior Unit" and "Inferior Unit") separated by a clay layer that acts as an aquitard ("Intermediate Unit") (Lozano 2007). This vertical heterogeneity causes upward and downward vertical flows at different sites of the aquifer, some of them generating ground level low mineral-content fresh water discharges in "La Vera" (Manzano and Custodio 2006; García Novo and Marín Cabrera 2006b). In wet periods, when the water-table is high, natural discharge of the phreatic water also takes place at small wetlands (ponds and small topographic depressions) (Figure 5). This occurs because the water-table is generally shallow and it easily intersects the lowest topographical features of the terrain after several rainfall episodes (Manzano and Custodio 2006). In the dry season, the direct evaporation of phreatic water as well as the evapotranspiration from the vegetation draws the water-table down below ground level (Figure 5). On the mobile dune system, an additional type of groundwater flow takes place. Infiltrating rain feeds temporary local flows perched within the unsaturated zone of the terrain, above the regional water-table. On their way down to the water-table, these infiltrating waters may eventually find less permeable ground layers that facilitate their lateral displacement rather than vertical flow, thus discharging into the inter-dune valleys. Natural recharge occurs by filtration of rainwater falling on the sands, i.e. free part of the aquifer (Manzano and Custodio 2006). In sum, Suso and Llamas (1993) indentify the following types of aquifer discharge i/ groundwater flow to the ocean or to the rivers; ii/ seepage through the Marismas aquitard; iii/ evapotranspiration by bushes and trees; (d) evapotranspiration on the wet meadows of the ecotone and (e) evaporation in small lakes when the water table reaches the ground surface. 
xerophytic scrub

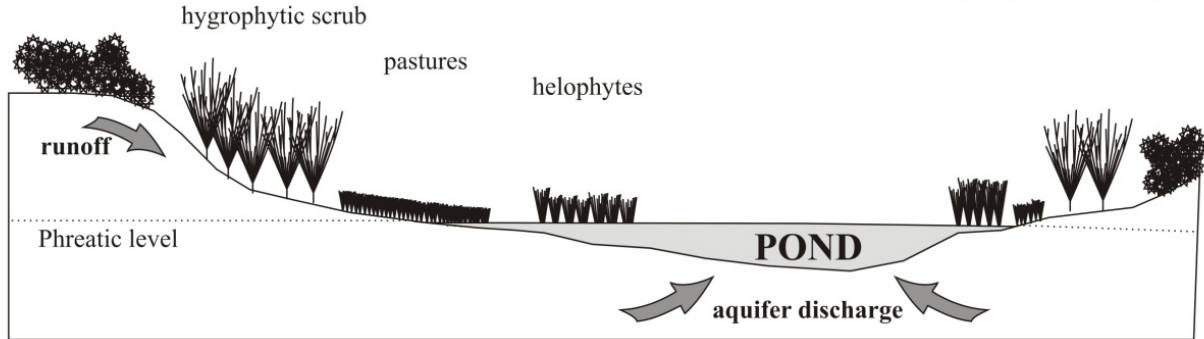

DRY PERIOD

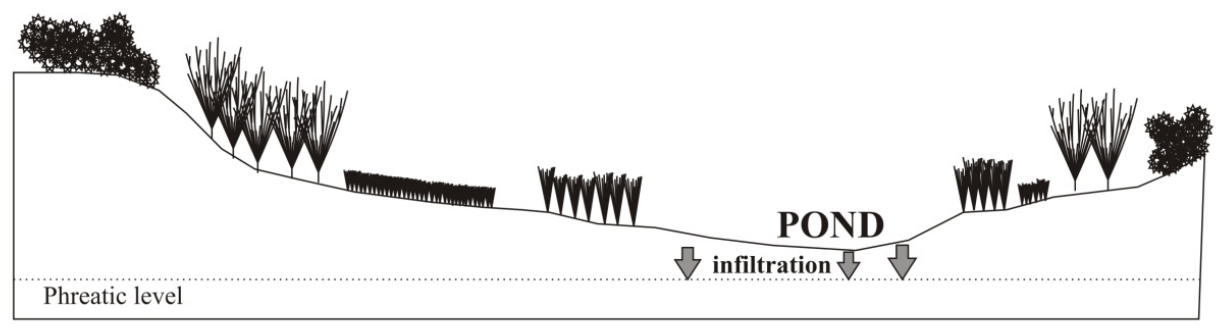

Figure 5. Sketch showing the hydrological behavior of temporary ponds (modified from Toja Santillana and Serrano Martín 2006).

The chemical background of the Doñana aquifers varies among zones of the aquifer (see Manzano and Custodio 2006 for details). In the unconfined areas, groundwater baseline is controlled by: rain water composition, equilibrium with silica, and dissolution of $\mathrm{CO}_{2}, \mathrm{Na} / \mathrm{K}$ feldspars and (locally) $\mathrm{CaCO}_{3}$ (Manzano et al. 2005). Groundwater baseline changes from the unconfined to the confined sector mostly by: mixing with old marine water, $\mathrm{Na} / \mathrm{Ca}-\mathrm{Mg}$ exchange, sulphate reduction and calcite dissolution/precipitation (Manzano et al. 2005). We may also notice large differences in concentration of several elements such as $\mathrm{N}, \mathrm{P}, \mathrm{Mg}, \mathrm{Ca}, \mathrm{Fe}, \mathrm{Cu}$ or Mn (García Novo and Marín Cabrera 2006b). Overexploitation of the aquifer is causing a progressive diminution in the phreatic level (Suso and Llamas 1990), a decrease in aquifer recharge rates for the same rainfall
(Trick and Custodio 2004) and a damage to ponds hydrology (Serrano and Zunzunegui 2008), such as a decrease in the frequency of appearance of temporary ponds (Custodio 2002).

According to their relations with the aquifer, we may classify waterbodies in Doñana as discharging or recharging waterbodies. However, this classification may not be a static one since the hydrology of the area is very dynamic, with recharge ponds turning temporarily into discharge ponds (Serrano et al. 2006), as a response to fluctuations in the depth of the water table. Besides, we may also find changes in the complex ground water feeding (Sacks et al. 1992). The main source of flooding (rainfall, semilocal (dune) aquifer or regional aquifer) is regarded as critical to pond characteristics (Serrano et al. 2006). 


\section{Description and classification}

Doñana National Park includes a great variety of aquatic systems, although the most well-known are the marshes. The water bodies that flood on the aeolian sands have received far less attention due to their small size. The only exceptions are the two large permanent ponds. Within the aeolian sands, we should discriminate water bodies of natural origin from those resulting from human intervention (locally called "zacallones"). We will briefly describe each water body type in the following lines:

The marshes (Figure 6-a) are the largest water bodies in the National Park, which extend over half of its territory when flooded. Due to their temporary nature, this area is largely reduced during summer, when surface water is limited to a few small depressions (locally called "lucios"). They are basically fed by direct rainfall on its floodplain and by several watersheds. The marshes usually flood in autumn although they may remain dry in years with scarce rainfall.

The permanent ponds, (Figure 6-b) locally called "Santa Olalla" and "La Dulce", are the largest freshwater water bodies of the Park. These ponds are considered permanent because they do not usually dry in summer. However, they sporadically dry after several years of severe drought (personal observation). In wet years, they may extend over more than 35 hectares (Chapter 1, in this study). They host native populations of eels (Anguilla anguilla (Linnaeus, 1758)) and "colmilleja" (Cobitis paludica (de Buen, 1930)), as well as introduced populations of common carps (Cyprinus carpio (Linnaeus, 1758)) and eastern mosquitofish (Gambusia holbrooki (Girard, 1859)). Along with these two large ponds, we may find several smaller permanent water bodies in the northeast of the Doñana Biological Reserve, where eastern mosquitofish populations have also established.

The temporary ponds. (Figure 6-c) Doñana National Park preserves a large system of temporary ponds of natural origin. Temporary ponds are located amid small depressions in the aeolian sands. They are usually water-filled during the wet season, from autumn to early winter, and dry during the dry season (late spring-early summer). In years with low rainfall, pond filling may be delayed until early spring or may not even occur. They constitute the main breeding habitat for amphibians in Doñana National Park. For that reason, its description deserves a separate mention in this study.

The "zacallones" (Figure 6-d) are humanmade water bodies. They consist of a small size $\left(20-30 \mathrm{~m}^{2}\right)$ deep hole and are used to water cattle or wild mammals during the dry season. So, they are permanent water bodies that do not dry during summer. Many of them are located within the basin of temporary ponds, in order to prolong their hydroperiod. During summer, the quality of the water dramatically decreases. They present low oxygen concentrations, high temperature and pronounced vegetation decomposition. In very dry years, these water bodies, along with the permanent ponds, are the only flooded areas of the National Park.

In the aeolian sands, we may also find a different type of water body: the "caños". These are temporary streams which flow towards the marshes during the wet season. In spring, they partially dry and transform into isolated ponds. The closer they are to the marshes, the larger their size and the higher the probability of harboring fish population since they hold water until summer and connect with the marshes during large floods. 

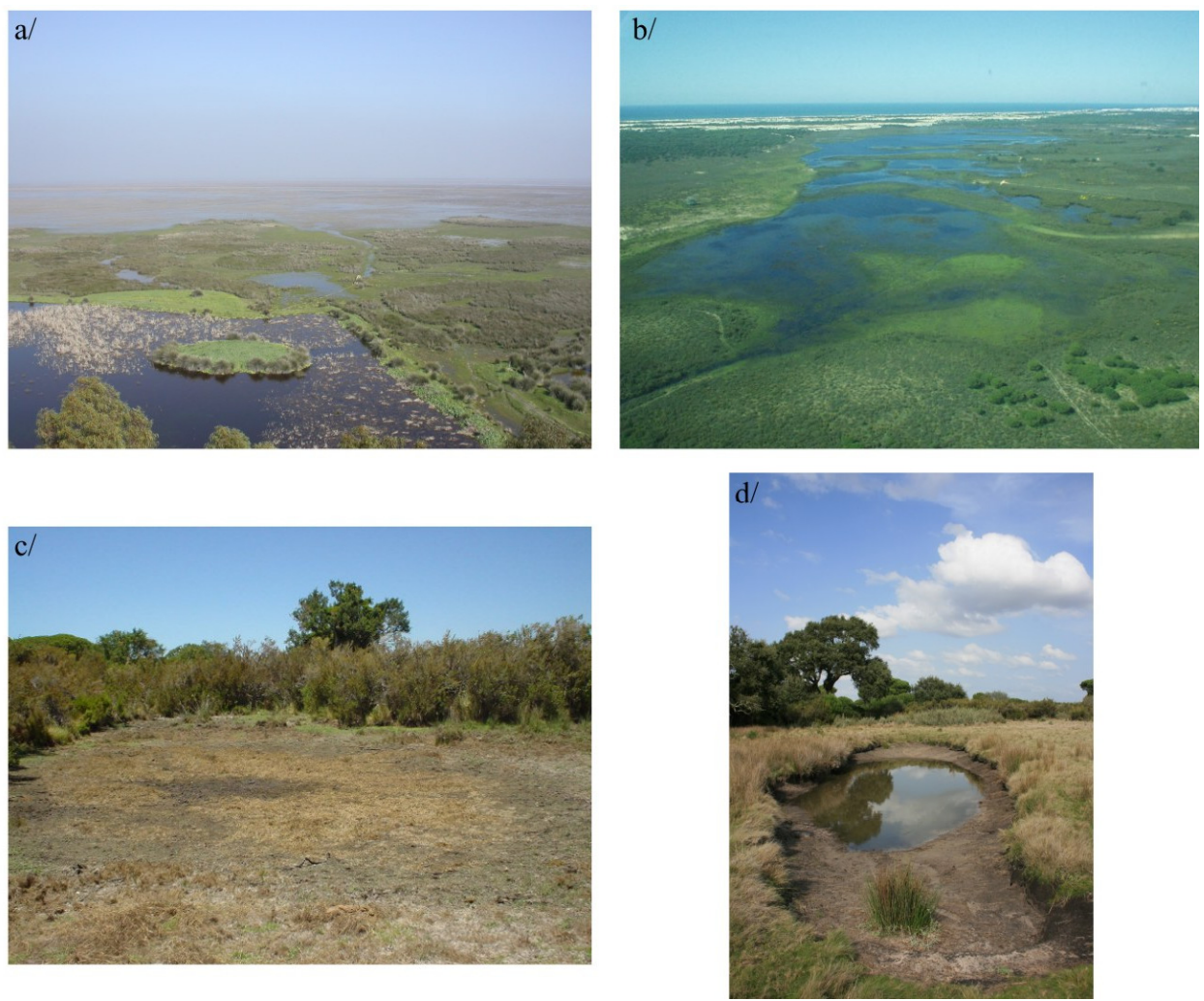

Figure 6. a/Marshes; b/ Permanent ponds; c/ Temporary pond in its dry phase; d/Zacallón in summer.

Finally, outside the National Park, we may find another type of water bodies, the ephemeral streams. They mouth to the marshes and are the main habitat for Alytes cisternasii Boscá, 1879.

\section{Mediterranean temporary ponds in Doñana National Park}

A large number of temporary ponds occur within Doñana National Park (DíazPaniagua et al. 2006). These ponds shelter many species of aquatic flora and fauna: macrophytes (García Murillo et al. 2006), invertebrates (Bigot and Marazanof 1966; Millán et al. 2005; Serrano and Fahd 2005), and amphibians (Díaz-Paniagua 1990; Díaz-Paniagua et al. 2005). Areas with such a high density and heterogeneity of natural ponds are not common in Europe, where the number of temporary ponds are probably a mere fraction of what they would had been in the past (Williams et al. 2001).

Doñana temporary ponds have a natural origin and correspond to the definition of isolated wetlands given by Leibowitz \& Nadeau (2003). They are fed by rainfall and a shallow water-table, having no direct connection with the sea except through airborne salt deposition (Sacks et al. 1992). During floods, ponds are occasionally interconnected during a very short time due to pond overflow and runoff (Serrano et al. 2006). Ponds are usually water-filled during the wet season, from autumn to early winter. However, in years with scarce rainfall, pond filling may be delayed until early spring or 
even may not occur. On an average year, most ponds dry out during spring or early summer. Thus, the length of water persistence (hydroperiod) is widely variable depending on rainfall (Serrano and Zunzunegui 2008). Vegetation in the ponds is mainly composed of meadow plants such as Mentha pullegium L., Illecebrum verticillatum L. or Hypericum elodes L. in the littoral, while aquatic macrophytes such as Juncus heterophyllus Dufour, Myriophyllum alterniflorum DC., Potamogeton pectinatus L. and Ranunculus peltatus Schrank are common species in deepest zones. The phytosociological alliances Isoetion, Nanocyperion flavescentis, Preslion cervinae, Eleochloion and Lythrion tribracteati, included in the European Union Habitats (European Commission 2007), develop in these ponds (Rivas-Martínez et al. 1980).

The preservation of such a large availability and variety of temporary ponds allows this National Park to be considered as a model system for the conservation of pond-breeding species.

Classification of temporary ponds according to the duration of flooding (hydroperiod)

With the aim of identifying different habitat types, we will broadly classify temporary ponds according to their hydroperiod for it is considered a major structuring factor in pond communities (Wellborn et al. 1996). Due to the wide intra and inter-annual variability in pond characteristics, the following classification is an oversimplification of the real-system but still useful for describing the wide variability of temporary pond types. It should be noted that a given pond may show different pond hydroperiods depending on the year. We will base the description of each type on the theoretical characteristics of an average rainfall year.
Ephemeral ponds (Figure 7-a). These ponds are shallow and small (diameter $\approx 2$ $-15 \mathrm{~m})$ and have a very short duration $(<3$ 4 months in a wet year). They are fed by rainfall inputs and usually are found on grasslands or amid the inter-dune valleys. As they depend on rainfall inputs, the formation of these water bodies is highly unpredictable as well as the drying out date. They usually lack a definable basin with marked depth gradient or helophyte vegetation. Prairie vegetation species subject to recurrent flooding develop in these water bodies (i.e. Illecebrum verticillatum L., Hypericum elodes L., Mentha pulegium L., Chaetopogon fasciculatus (Link) Hayek or Cynodon dactylon (L.) Pers., among others). From an ecological perspective, main predators are absent from these habitats and the possibility of an early desiccation poses the main risk for breeding success of associated species.

Intermediate temporary ponds (Figure 7b). These are the most abundant pond type in the National Park. In a wet year, they usually flood with autumn rainfall and last for 5-7 months. At an average inundation event, pond diameter may range from 15 to 30 meters. Aquatic macrophyte species develop in these ponds (i.e. Ranunculus peltatus Schrank subps. baudotii (Godron) Meikle, ex C.D.K. Cook, Myriophyllum alterniflorum DC, Callitriche truncata Guss., among others).

Temporary ponds of long duration (Figure 7-c). These ponds usually flood with autumn rains and last until early summer $(>8$ months). At a large inundation event, pond diameter may exceed 100 meters. They usually show a marked internal zonation with clearly differentiated microhabitats (i.e. deep zone with macrophyte species, helophyte zone, shallow zone...). 

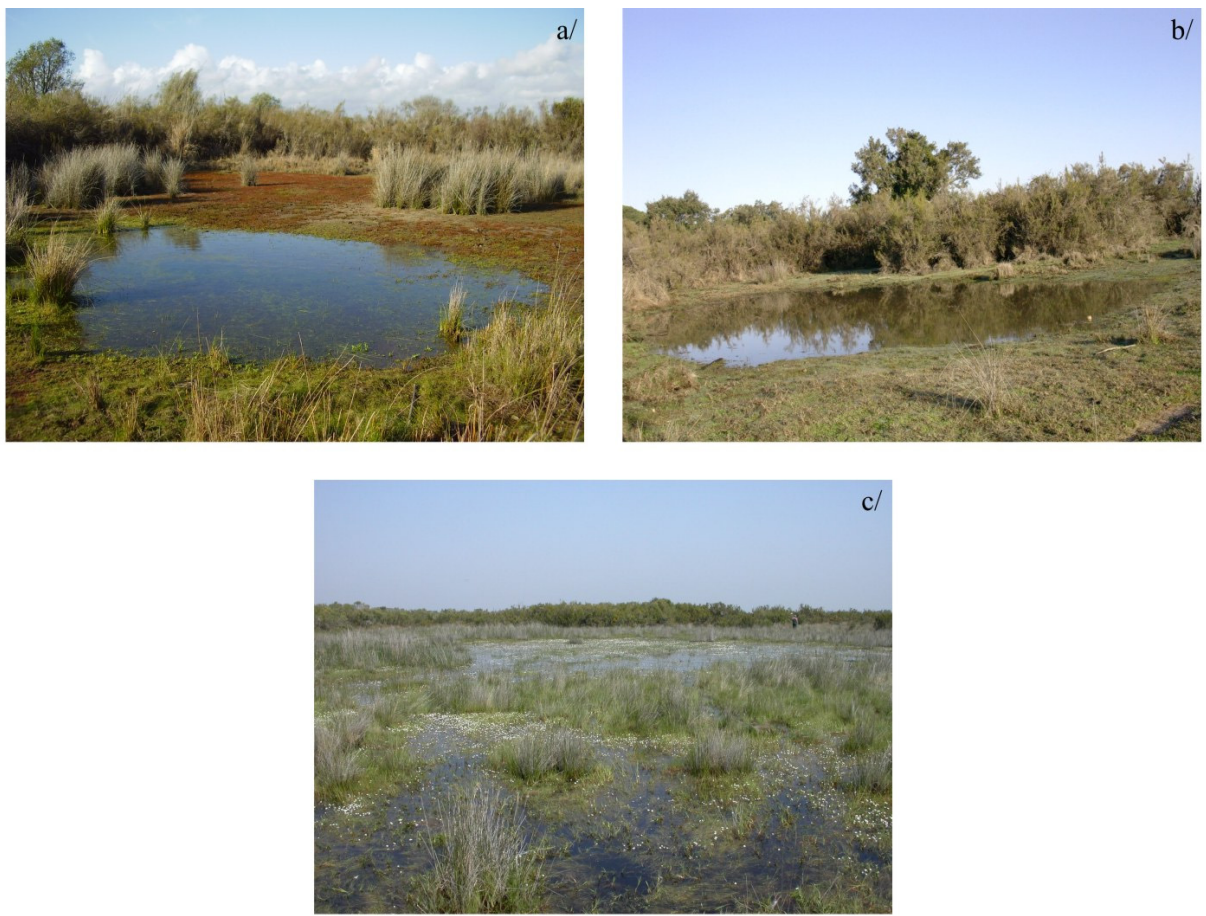

Figure 7. a/Ephemeral pond; b/ Intermediate temporary pond; c/ Temporary pond of long duration.

\section{Distribution of freshwater ponds in Doñana National Park}

Freshwater ponds are heterogeneously distributed across the aeolian system. We can differentiate different zones according to the density and typology of ponds.

Mobile dunes ecosystem. Ponds are almost absent in the dune fronts, except scarce and isolated "zacallones", while ephemeral temporary ponds are characteristic of interdune valleys.

Within the stabilized sands, we may differentiate (from South to North):

- "Marismillas" pine forest. Natural ponds are scarce here. In practice, the only water bodies are isolated "zacallones".

- "El Puntal". It is located in between the mobile dune system and Doñana Biological Reserve. Ephemeral and intermediate duration ponds are frequent in this area.
- Doñana Biological Reserve. The largest diversity and abundance of water bodies is in this area, as well as the driest spots within the stabilized sands ("Las Naves", in the West). The largest permanent water bodies ("Santa Olalla" and "La Dulce" ponds) are located here.

- "La Mogea" and "La Mata de los Domínguez". This area is located north to the Doñana Biological Reserve, in the west of the Park. It presents an endorheic hydrologic behavior. Temporary ponds cover the wide hydroperiod gradient of the area (from ephemeral pools to temporary ponds of long duration).

- "Manecorro" and Northeast of National Park. Water bodies are scarce in this area although many ephemeral ponds may flood after intense rainfall. The presence of streams and "caños" is remarkable. 


\section{$\mathbf{S}_{\text {tudy }} \mathbf{P}_{\text {eriod }}$}

The study period extended from autumn 2002 until summer 2006, although we have also included data from a 2-year previous survey (autumn 2000-summer 2002) in chapter 2 .

The pattern and amount of rainfall, measured from September to August varied among the years of study (Figure 8) and, consequently, the onset and duration of surface water in ponds. In 2002-03, autumn rainfall (from September to December) was abundant $(326.4 \mathrm{~mm})$ and ponds were filled in November. In 2003-2004, autumn rainfall was also abundant $(493.5 \mathrm{~mm})$ and ponds refilled in October-November 2003. In 2004-2005, a very dry year, temporary ponds did not flood. In 2005-06, autumn rainfall was scarce $(149.3 \mathrm{~mm})$ and ponds did not fill until late January 2006.

Monthly rainfall and mean temperature were also highly variable during the study period (Figure 9).

Rainfall and temperature data were obtained from a meteorological station located within the study area (Doñana Biological Reserve-CSIC).

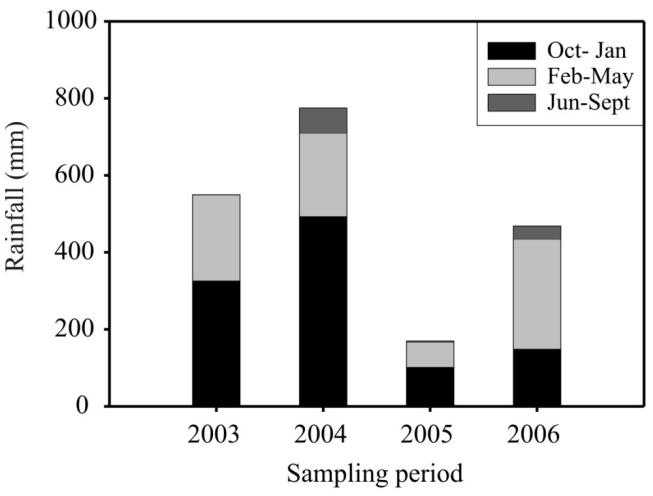

Figure 8. Rainfall input in hydrological years from 2002-2003 (2003 sampling period) to 2005-2006 (2006 sampling period). Three different periods were differentiated: October-January; FebruaryMay; June-September.

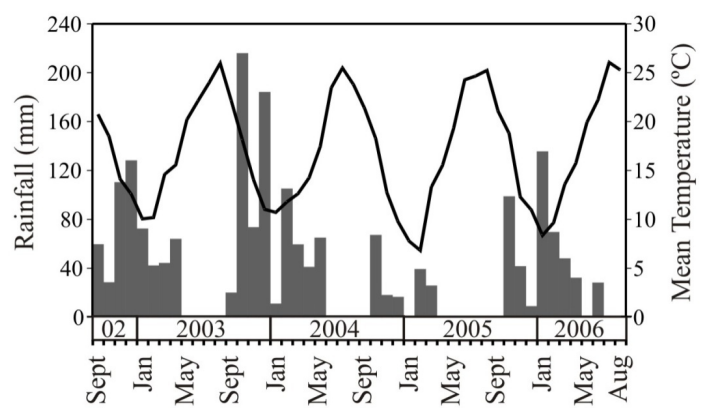

Figure 9. Monthly rainfall and mean temperature during the study period. 


\section{References}

Allier C et al. 1974. Mapa Ecológico de la Reserva Biológica de Doñana. División de Ciencias del CSIC, Estación Biológica de Doñana, Sevilla.

Amat JA et al. 1979. Parque Nacional de Doñana. Mapa ecológico. Ministerio de Agricultura, Instituto para la Conservación de la Naturaleza, Madrid.

Bigot L, Marazanof F 1966. Ann Limnol 2, 491-502.

Castroviejo J 1993. Memoria. Mapa del Parque Nacional de Doñana, escala 1/50.000. CSIC y Agencia de Medio Ambiente, Junta de Andalucía.

Clemente L et al. 1998. Los Suelos del Parque Nacional de Doñana. Organismo Autónomo de Parques Nacionales, Madrid.

Díaz-Paniagua C 1990. Herpetol J 1, 447453.

Díaz-Paniagua C et al. 2005. Los Anfibios de Doñana. Organismo Autónomo de Parques Nacionales. Ministerio de Medio Ambiente, Madrid.

Díaz-Paniagua C et al. 2006. Rev Esp Herpetol 20, 17-30.

European Commission 2007. Interpretation Manual of European Union Habitats. Natura 2000, Nature and Biodiversity. European Commission.

Fernández J, Pradas R, Madrid 2000. Historia de los Parques Nacionales Españoles. Doñana, Tablas de Daimiel, Cabrera y Cabañeros. Tomo IV. Organismo Autónomo de Parques Nacionales, Madrid.

García Murillo PJ et al. 2006. Limnetica 5, 71-80.

García Novo F et al. 1978. Doñana: Prospección e inventario de ecosistemas. Ministerio de Agricultura. ICONA. Monografía $\mathrm{n}^{\circ} 18$.

García Novo F, Marín Cabrera C 2006a. The Time of the Marshes. Lands marked by water and diversity. In: García Novo F,
Marín Cabrera C (Eds.), Doñana. Water and Biosphere. Doñana 2005 Project Confederación Hidrográfica del Guadalquivir (Guadalquivir Hydrologic Basin Authority), Spanish Ministry of the Environment, Madrid, pp. 77-94.

García Novo F, Marín Cabrera C 2006b. Water as the main player. In: García Novo F, Marín Cabrera C (Eds.), Doñana. Water and Biosphere. Doñana 2005 Project - Confederación Hidrográfica del Guadalquivir (Guadalquivir Hydrologic Basin Authority), Spanish Ministry of the Environment, Madrid, pp. 77-94.

Junta de Andalucía 1998. Datos Básicos Parque Nacional Doñana. Génesis y Morfología.

http://www.juntadeandalucia.es/medioa mbiente/site/web/

Junta de Andalucía 2001. Libro Rojo de los Vertebrados Amenazados de Andalucía. Consejería de Medio Ambiente, Junta de Andalucía.

Leibowitz SG, Nadeau T-L 2003. Wetlands $23,663-684$

Lozano E 2007. Las aguas subterráneas en los cotos de Doñana y su influencia en las lagunas (CD). Instituto Geológico y Minero de España.

Manzano M, Custodio E 2006. The Doñana aquifer and its relations with the natural environment. In: García Novo F, Marín Cabrera C (Eds.), Doñana. Water and Biosphere. Doñana 2005 Project Confederación Hidrográfica del Guadalquivir (Guadalquivir Hydrologic Basin Authority), Spanish Ministry of the Environment, Madrid, pp. 141-150.

Manzano M et al. 2005. El fondo hidroquímico natural del acuífero de Doñana (SO España). Congreso Ibérico de Geoquímica y IX Congreso de Geoquímica de España. Diputación Provincial de Soria. 
Millán A et al. 2005. Boln Soc Entomol Aragonesa 37, 157-164.

Montes C et al. 1998. Reconocimiento Biofísico de Espacios Naturales Protegidos. Doñana: Una Aproximación Ecosistémica. Junta de Andalucía. Consejería de Medio Ambiente.

Pleguezuelos JM et al. 2002. Atlas y Libro Rojo de los Anfibios y Reptiles de España. Dirección General de Conservación de la Naturaleza, Ministerio de Medio Ambiente, Madrid.

Ramos B 2002. Ecosistemas. In: García Canseco, V. (Ed.), Parque Nacional de Doñana. Canseco Editores SL, Talavera de la Reina, pp. 69-108.

Rivas-Martínez S et al. 1980. Lazaroa 2, 5189.

Rodríguez-Ramírez A, Clemente L 2002. Geomorfología. In: García Canseco, V. (Ed.), Parque Nacional de Doñana. Canseco Editores SL, Talavera de la Reina, pp. 19-42.

Sacks LA et al. 1992. J Hydrol 136, 123154.

Santos X et al. 1996. Inventario de las áreas importantes para los anfibios y reptiles de España. Colección Técnica. ICONA, Madrid.

Serrano L, Fahd K 2005. Wetlands 25, 101111.

Serrano L et al. 2006. Limnetica 25, 11-32.
Serrano L, Zunzunegui M 2008. Aquat Conserv: Mar Freshw Ecosyst 18, 261279.

Siljeström PA et al. 1994. J Arid Environ 26, 315-323.

Suso J, Llamas MR 1993. J Hydrol 141, 239-269.

Suso JM, Llamas M 1990. Estudios Geológicos 46, 317-345.

Toja Santillana T, Serrano Martín L 2006. The aquatic systems of Doñana. In: García Novo F, Marín Cabrera C (Eds.), Doñana. Water and Biosphere. Doñana 2005 Project - Confederación Hidrográfica del Guadalquivir (Guadalquivir Hydrologic Basin Authority), Spanish Ministry of the Environment, Madrid, pp. 213-220.

Trick T, Custodio E 2004. Hydrogeol J 12, 321-335.

Valverde JA 1958. British Birds 51, 1-23.

Valverde JA 1960. Archiv Inst Aclimatación Almería 9, 1-169.

Valverde JA 1967. Estructura de una comunidad mediterránea de vertebrados terrestres. Monografías de la Estación Biológica de Doñana (CSIC), Madrid.

Wellborn GA et al. 1996. Annu Rev Ecol Evol $S$ 27, 337-363.

Williams P et al. 2001. Freshw Forum 17, 715. 


\section{Chapter 1}

Description of the breeding habitat 


\section{Mediterranean temporary ponds as amphibian breeding}

\section{habitats: The importance of preserving pond networks}

We describe the spatial and temporal variation in the main characteristics of amphibian breeding habitats in Doñana National Park (south of Spain) during two hydrologic cycles with different rainfall amounts and timing (2002-03 and 2005-06). We also evaluate the relative importance of habitat characteristics for annual richness of amphibians and for the abundance of each species based on Akaike's Information Criterion (AIC). Our results evidenced large spatial variability in all pond characteristics and inter-annual differences in pond hydroperiod, depth and most water-chemistry characteristics. We recorded the presence of nine amphibian species. Eight of them attempted breeding in both years in spite of the marked inter-annual variability in many pond characteristics. Habitat models were speciesspecific and year-specific, as we found inter-annual differences in the pond characteristics relevant for species richness or for the relative abundance of particular species. All these results suggest that this large and diverse network of ponds provides different habitat opportunities each year, favouring the long-term persistence of the whole amphibian community. 


\section{Introduction}

Mediterranean wetlands are among the most threatened ecosystems on the Earth (Blondel and Aronson 1999) and, in particular, Mediterranean temporary ponds are a priority habitat under the European Union Habitats Directive (European Commission 2007). Temporary ponds differ from permanent waters in the occurrence of a recurrent dry phase (Griffiths 1997). In the Mediterranean region, temporary ponds present a wide variability in filling onset and duration, depending on rainfall input and pattern (Zacharias et al. 2007). Due to their temporary nature and small size, these aquatic habitats are very vulnerable, being often inconspicuous and poorly known (Grillas et al. 2004). Because the study of temporary aquatic habitats is far less developed than the study of permanent waters, basic descriptions of temporary waters continue to be vital (Schwartz and Jenkins 2000).

Temporary ponds are habitats of critical importance for many amphibian (DíazPaniagua 1990; Griffiths 1997; Semlitsch 2003) and invertebrate species (Williams 1997; Boix et al. 2001; Williams 2006). Amphibian fauna associated to these habitats is tolerant to water loss (Griffiths 1997) and generally benefits from the absence of invertebrate top predators and fish (Wellborn et al. 1996). In the
Mediterranean region, inter-annual variability in hydrological conditions is supposed to favour amphibian diversity in the medium-term (Jakob et al. 2003).

Amphibian conservation programs, focused on preserving suitable breeding sites, will highly benefit from studies evaluating the habitat requirements of Mediterranean pond-breeding species. Towards this aim, previous studies (not restricted to the Mediterranean region) have quantified the relationship between pond characteristics and species richness (Beja and Alcazar 2003; Knutson et al. 2004; Werner et al. 2007) species occurrence (Beja and Alcazar 2003; Pearl et al. 2005; Van Buskirk 2005) or species relative abundance (Beja and Alcazar 2003; Van Buskirk 2005; Richter-Boix et al. 2007) However, to our knowledge, no study has yet assessed whether inter-annual variability in hydrological conditions yields differences in habitat model outputs depending on the breeding season. Unpredictability and variability in climatic conditions, and hence hydrologic ones, are among the most prominent features of the Mediterranean climate (Blondel and Aronson 1999). In this study, we evaluated if habitat characteristics relevant for annual richness and annual relative abundance of amphibians differ between two breeding 
seasons with different rainfall input and timing. Schmidt and Pellet (2005) recommended the use of abundance rather than occurrence data in habitat models, since it provides more information about habitat suitability due to the fact that absence and presence are only a special case of abundance (abundance $=0$ and abundance $>0$, respectively). In fact, habitat variables identified as relevant in presence/absence approaches may not be the same as those identified in abundance approaches (Beja and Alcazar 2003; Van Buskirk 2005).

A large number of temporary ponds is protected within the boundaries of the Doñana National Park (Díaz-Paniagua et al. 2006). Doñana temporary ponds can provide a model system to assess temporary ponds characteristics, dynamics and associated fauna ecology. Most limnological studies of the Doñana aquatic systems have been traditionally focused on temporary waters with long hydroperiod (Montes et al. 1982; López et al. 1991; Serrano and Toja 1995; Muñoz Reinoso 1996) whereas ephemeral ponds have been only occasionally studied (García-Novo et al. 1991).

The aim of this study is to describe the spatial and temporal variation in the main characteristics of amphibian breeding habitats in Doñana National Park during two hydrologic cycles with different rainfall input and timing. We also investigate the relative importance of habitat characteristics in determining annual amphibian richness and species abundance in each hydrologic cycle and hence if habitat model outputs are year-specific. The assessment of inter-annual differences in model habitat outputs is relevant because usefulness of habitat models for species conservation depends upon consistency across time and space. Due to the homogeneity of soil and vegetation around these ponds, we have focus solely on: i/ major structuring factors of pond communities such as pond hydroperiod (Snodgrass et al. 2000; Beja and Alcazar 2003; Werner et al. 2007), pond area (Beja and Alcazar 2003; Burne and Griffin 2005; Werner et al. 2007) and pond depth (Laan and Verboom 1990; Joly et al. 2001); ii/ pond morphometry, because it conditions the availability of different microhabitats which, in turn, each species may require in a selectively manner (Smith et al. 2003); iii/ amount of dense hygrophytic vegetation surrounding the pond, which increases pond shade, an important habitat attribute for amphibians in some studies (Sztatecsny et al. 2004; Burne and Griffin 2005); iv/ water-chemistry characteristics relevant for amphibians (Hecnar and M'Closkey 1996; Houlahan and Findlay 2003; Knutson et al. 2004) such as those related to salinity, ionic composition, nutrient concentrations and primary production and $\mathrm{v} /$ the distribution pattern of surrounding aquatic habitats, as a measure of ecological connectivity in metapopulations/patchy populations (Marsh and Trenham 2001; Semlitsch 2002). We have discriminated complexes of ponds located within the dispersal range of most amphibian species $(<1000 \mathrm{~m})$ (Smith et al. 2003) from the ponds located nearby $(<200 \mathrm{~m})$. Individuals may frequently move among adjacent ponds, as Marsh et al. (1999) reported for tungara frogs, and hence encompass them as a single breeding site (Petranka et al. 2004). 


\section{Material and Methods}

\section{Study area}

The study was conducted in the Doñana Biological Reserve which covers 6794 ha within the Doñana National Park, in southwestern Spain (see Siljeström et al. 1994 for a geo-morphological description). Temporary ponds are mainly formed in shallow depressions amid stabilized sands. This area also includes man-made permanent water bodies and two large permanent ponds of natural origin that occasionally dry out after years of severe drought (López et al. 1991).

Doñana temporary ponds have a natural origin and correspond to the definition of isolated wetlands given by Leibowitz and Nadeau (2003). They are fed by rainfall and a shallow water-table, having no direct connection with the sea except through airborne salt deposition (Sacks et al. 1992). During floods, ponds are occasionally interconnected for very short periods due to pond overflow and runoff (Serrano et al. 2006). Ponds are usually water-filled during the wet season, from autumn to early winter. However, in years with low rainfall, pond filling may be delayed until early spring or even may not occur. Thus, the length of water persistence (hydroperiod) widely varies depending on rainfall (Serrano and Zunzunegui 2008). Vegetation in the ponds is mainly composed of meadow plants such as Mentha pullegium L., Illecebrum verticillatum L. or Hypericum elodes L. in the littoral, while aquatic macrophytes as Juncus heterophyllus Dufour, Myriophyllum alterniflorum DC., Potamogeton pectinatus L. and Ranunculus peltatus Schrank are common species in the deepest zones. The phytosociological alliances Isoetion, Nanocyperion flavescentis Preslion cervinae, Eleochloion and Lythrion tribracteati, included in the European Union Habitats

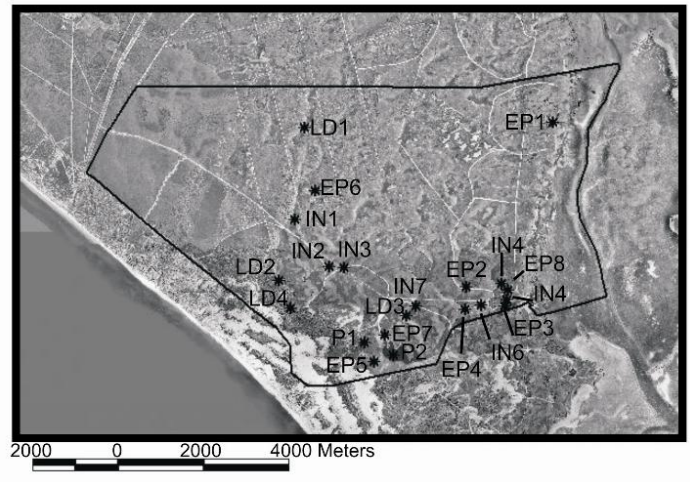

Figure 10. Ortophotography of the study area. Solid line represents Doñana Biological Reserve, where most of the study ponds are located. Pond nomenclature corresponds to hydroperiod categories in 2003 ( $\mathrm{P}=$ Permanent, LD = long-duration temporary pond [8-9 months], IN = intermediate temporary pond [6-7 months], EP = ephemeral [4-5 months]).

Directive (European Commission 2007), develop in these ponds (Rivas-Martínez et al. 1980).

For this study we chose 19 temporary ponds of natural origin (Figure 10), covering the wide hydroperiod gradient in the study area based on previous knowledge (DíazPaniagua, unpublished data). Hydroperiod is reported as one of the most critical features structuring assemblage composition in temporary ponds (Wellborn et al. 1996; Semlitsch 2003). Additionally, we also sampled the two permanent ponds of natural origin in the study area, to illustrate the idiosyncrasy of temporary ponds with respect to permanent ones under the same geologic, climatic and hydrologic conditions.

Rainfall data for each hydrologic cycle (September to August) were obtained from a meteorological station located within the study area (Doñana Biological ReserveCSIC). 


\section{Amphibian sampling}

A monthly survey was conducted during the breeding season of amphibians in two different sampling periods: from February to May 2003, and from March to May 2006. During the 2003 breeding season, one of the study ponds was only accessible in May.

We used dipnetting techniques (Heyer et al. 1994) to collect and identify amphibian larvae to species level in situ. We counted the larvae captured in each sampling unit (three consecutive sweeps on a stretch of approx. $1.5 \mathrm{~m}$ length) and then released them in the pond. The number of sampling units was adjusted proportionally to pond size. Larval sampling was complemented with visual surveys in and around the pond to detect eggs, larvae and metamorphic individuals. Visual surveys were conducted regularly, starting when ponds flooded (November 2002 and January 2006).

\section{Environmental characteristics}

We have classified the pond characteristics in two sets: i) those changing over time ("WATER" characteristics) such as hydroperiod, maximum water depth and water physico-chemistry, and ii) those which do not vary with time, such as site and potential connectivity characteristics ("POND/CONNECTIVITY"

characteristics).

In order to record WATER characteristics, each pond was visited monthly to assess the pattern of filling and desiccation in the 2003 and 2006 breeding seasons. Surface water (500-1500 ml) was sampled for physico-chemical characteristics on three different occasions (January 2003, May 2003 and March 2006, see Supplementary Material, Table 1-A for a detailed description). We could not sample one pond in May 2003 and two ponds in March 2006 since they were dry. We did not sample at the end of the ecological monitoring period of 2006 since only three temporary ponds and the two permanent ponds were flooded. Maximum water depth, electrical conductivity and $\mathrm{pH}$ were measured in situ. The concentration of main ions, planktonic chloropyll $a$, dissolved inorganic phosphate and nitrogen compounds were determined in the laboratory. We used the ratio of $\mathrm{Na}^{+}$ over $\mathrm{Mg}^{2+}\left(\mathrm{Na}^{+} / \mathrm{Mg}^{2+}\right)$ to distinguish aquifer recharge areas, i.e. water infiltrates to the aquifer, from groundwater discharge areas, i.e. the pond receives water from the aquifer (after García-Novo et al. 1991).

Pond morphometry and distribution pattern were considered POND/CONNECTIVITY characteristics. We calculated the geographic coordinates of each pond, measured the maximum pond area, the percentage of different microhabitats within each pond (i.e. helophyte vegetation in littoral zone, internal helophyte vegetation, rural paths adjacent to ponds which may be occasionally flooded, open water, deep areas and man-made deep holes within) and the percentage of pond shoreline immediately surrounded by dense hygrophyte vegetation, from $0.5 \mathrm{~m}$ pixel size ortophotos (acquisition date: 2001-2002; Junta de Andalucía 2003), later verified in the field (see Supplementary Material, Table 1-B for a detailed description). We determined pondslope in situ and pond altitude from topographic cartography. We calculated the distance to the nearest water body from a 5 $\mathrm{m}$ resolution pond map layer (GómezRodríguez, unpublished data). We also calculated the percentage of total flooded area and the number of ponds in two buffer areas (200 $\mathrm{m}$ and $1000 \mathrm{~m}$ radius) from the edge of each pond. We differentiated three categories of surrounding ponds according to their extent, which was expected to be related with hydroperiod in the study area. Thus, we aimed to discriminate ponds flooding in very wet years (all ponds, including those with smaller surface area) 
from those ponds that flood even during dry years (large ponds).

\section{Data analysis}

We evaluated temporal variation in WATER characteristics among sampling dates with Repeated Measures ANOVA and posthoc Tukey tests, using Statistica Software. We transformed WATER variables to fit normality. We evaluated relationships among environmental characteristics computing a Principal Components Analysis (PCA) with varimax rotation on WATER and POND/CONNECTIVITY characterristics. Only data from temporary ponds were included in the PCA. We excluded characteristics occurring in less than $10 \%$ of ponds (percentage of internal flooded path and percentage of man-made deep holes within). Missing values were substituted by mean value of the variable. We extracted six components since the scree-plot showed only a small increase in explained variation with the addition of further components.

For each species and breeding season, we evaluated PCA scores as explanatory variables of its relative abundance (catchper-unit-effort $=$ number of larvae collected per sampling unit). We followed a model selection approach based on Akaike's Information Criterion (AIC), as Mazerolle (2006) recommends for herpetological studies and previous authors have used to identify habitat characteristic conditioning the richness (Weyrauch and Grubb 2004; Van Buskirk 2005) and abundance of pondbreeding amphibians (Sztatecsny et al. 2004; Van Buskirk 2005; Richter-Boix et al. 2007). We fitted a multiple regression model (command "lm", R software) and searched for the best subset of explanatory variables. We cube-root transformed the relative abundance in order to achieve normality in model residuals. We evaluated all possible combinations of explanatory variables $(\mathrm{n}=58)$ and compared them according to their Second-Order AIC (AICc). We used the AICc rather than the AIC because it is recommended when the ratio between sample size and number of model parameters is less than 40 (Burnham and Anderson 2002). We selected the models with substantial empirical support given the data (modelAICc $-\operatorname{minAICc}<2$, following Burnham and Anderson 2002) and computed their adjusted $R^{2}$ to assess the variability in the data they accounted for. We also quantified the evidence for the importance of each explanatory variable from Akaike's model weights, as obtained from AICc values (see Burnham and Anderson 2002). Since we used Akaike's model weights to evaluate the relevance of each explanatory variable rather than selecting those in the model ranked as best (minimum AIC), we took into account the uncertainty that each model (possible combinations of explanatory variables) was the target best model.

A model selection approach was also conducted to evaluate PCA scores as explanatory variables of the number of species in a pond (species richness). Richness values were computed from larval sampling and visual surveys of eggs and metamorphs. We did not transform richness values. 


\section{Results}

\section{Hydrological conditions during the study period}

The pattern and amount of rainfall varied between $2003(549.5 \mathrm{~mm})$ and 2006 breeding season (468 mm). In 2002-03, autumn rainfall (from September to December) was abundant $(326.4 \mathrm{~mm})$ and ponds were filled in November. In 2005-06, autumn rainfall was scarce $(149.3 \mathrm{~mm})$ and ponds did not fill until late January 2006.

\section{General pond characteristics}

The low number of permanent ponds of natural origin (only two in the study area) precludes the statistical assessment of differences with temporary ponds. Notwithstanding, it should be noted that, for most habitat characteristics, the values recorded in permanent ponds were in the extremes of the range of variation for temporary ponds (see Supplementary Material, Tables 2 and 3).

Selected temporary ponds widely ranged in surface area $\left(237.5 \mathrm{~m}^{2}-5.25 \mathrm{ha}\right)$, but presented a similar pond-morphometry (Supplementary Material, Table 2). They had a pond basin with low internal slope, in which deeper zones and emergent vegetation areas occupied a small fraction of pond surface (mean value $<3 \%$ and $<8 \%$ respectively). On average, the number of surrounding water bodies was high (mean value $=6.9 \pm 3.3$ S.D. [200m-buffer]; mean value $=95.0 \pm 51.14$ S.D. $[1000 \mathrm{~m}$ buffer]) though the low percentage of surrounding flooded area evidenced the small size of these ponds (mean value $=$ $4.6 \% \pm 7.7$ S.D. [200m-buffer]; mean value $=6.5 \% \pm 6.5$ S.D. $[1000 \mathrm{~m}$-buffer $])$. This result agreed with the high reduction in pond number when increasing minimum size of surrounding ponds. Water electrical conductivity and $\mathrm{pH}$ ranged widely from 58 to $4180 \mu \mathrm{S} \mathrm{cm}^{-1}$ and 5.7 to 9.3 , respectively (Supplementary Material, Table 3). As expected, $\mathrm{Cl}^{-}$was the dominant anion and $\mathrm{Na}^{+}$the dominant cation in most ponds while the proportions of $\mathrm{Ca}^{2+}$ and $\mathrm{Mg}^{2+}$ were generally very similar. Nutrient concentrations were generally low: mean DIN concentration below $100 \mu \mathrm{M}$ in all sampling dates, and dissolved inorganic phosphate concentration $\leq 1 \mu \mathrm{M}$ on average.

As expected, most WATER characteristics exhibited a significant temporal variation (Table 6). Absolute values of hydroperiod differed widely and significantly $\left(\mathrm{F}_{1,18}=\right.$ 201.17, $\mathrm{p}<0.001$ ) due to the low duration of ponds in 2006. However, we obtained a similar ranking classification of ponds according to this characteristic since hydroperiod values in both seasons were significantly correlated (Spearman $\mathrm{r}=$ $0.739, \mathrm{p}<0.001)$. We found significant temporal variation, but different seasonal patterns, in the concentration of most major ions except $\mathrm{Ca}^{2+}$ and $\mathrm{K}^{+}$. In March 2006, about half of the ponds $(\mathrm{n}=9)$ showed $\mathrm{Na}^{+} / \mathrm{Mg}^{2+}$ ratio values higher than 4 , and hence should be considered as discharging ponds (following García-Novo et al. 1991), whereas only five reached these values in January and four in May 2003. The concentration of DIN did not differ among sampling dates though $\mathrm{NO}_{3}^{-}$and $\mathrm{NH}_{4}{ }^{+}$ concentrations changed through time. In January 2003, most ponds $(n=14)$ had low concentrations of chlorophyll-a $(<3 \mu \mathrm{g} / \mathrm{l})$ while concentrations were above this value in most ponds during the rest of samplings. 
Table 6. Results from the Repeated Measures ANOVA analysis of pond characteristics changing over time. F statistics, degrees of freedom (d.f.) and p-values are shown.

\begin{tabular}{|lccc|}
\cline { 2 - 4 } \multicolumn{1}{c|}{} & $\mathbf{F}$ & d.f. & $\mathbf{p}$ \\
\hline Hydroperiod $[\mathrm{months}]$ & 201.17 & 1,18 & $<0.001$ \\
Maximum water depth $[\mathrm{cm}]$ & 12.363 & 1,15 & 0.003 \\
$\mathbf{p H}$ & 26.575 & 1,14 & $<0.001$ \\
Conductivity and major ions & & & \\
Conductivity $[\mu \mathrm{S} / \mathrm{cm}]$ & 3.197 & 2,26 & 0.057 \\
Chloride $\left(\mathrm{Cl}^{-}\right)[\mathrm{mg} / \mathrm{l}]$ & 7.048 & 2,30 & 0.003 \\
Sulphate $\left(\mathrm{SO}_{4}{ }^{2-}\right)[\mathrm{mg} / \mathrm{l}]$ & 8.166 & 2,30 & 0.001 \\
Sodium $\left(\mathrm{Na}^{+}\right)[\mathrm{mg} / \mathrm{l}]$ & 4.126 & 2,30 & 0.026 \\
Potassium $\left(\mathrm{K}^{+}\right)[\mathrm{mg} / \mathrm{l}]$ & 1.076 & 2,30 & 0.354 \\
Magnesium $\left(\mathrm{Mg}^{2+}\right)[\mathrm{mg} / \mathrm{l}]$ & 9.476 & 2,30 & 0.001 \\
Calcium $\left(\mathrm{Ca}^{2+}\right)[\mathrm{mg} / \mathrm{l}]$ & 0.745 & 2,30 & 0.484 \\
Na ${ }^{+} / \mathrm{Mg}^{2+}$ & 7.439 & 2,30 & 0.002 \\
Nutrients & & & \\
Dissolved inorganic nitrogen $(\mathrm{DIN})[\mu \mathrm{M}]$ & 1.533 & 2,30 & 0.232 \\
Nitrate $\left(\mathrm{NO}_{3}{ }^{-}\right)[\mu \mathrm{M}]$ & 7.325 & 2,30 & 0.003 \\
Ammonium $\left(\mathrm{NH}{ }_{4}^{+}\right)[\mu \mathrm{M}]$ & 5.273 & 2,30 & 0.011 \\
Dissolved inorganic phosphate $[\mu \mathrm{M}]$ & 4.874 & 2,30 & 0.015 \\
Biological parameter & & & \\
Chlorophyll-a $[\mu \mathrm{g} / \mathrm{l}]$ & 8.215 & 2,30 & 0.001 \\
\hline
\end{tabular}

The extraction of six principal components explained $71.87 \%$ of the variance (Table 7 ). The low amount of variance explained with such a large number of components evidenced that few and weak correlations existed among variables. The first component (PCAl) showed that ion concentration increased in ponds at lower altitudes only in January 2003. Conductivity and ion concentrations were positively related to maximum surface area in March 2006 (PCA2) but to the percentage of flooded area in a $200 \mathrm{~m}$ buffer area in May
2003 (PCA5), thus evidencing low similarity in water ionic composition between sampling times. All variables accounting for the extent of surrounding aquatic habitats in a $1000 \mathrm{~m}$ buffer area (i.e. total flooded area) were interrelated (PCA3). We also observed a temporal alternation in the predominance of nitrogen compounds, with DIN and $\mathrm{NH}_{4}{ }^{+}$concentrations in March 2006 contributing to the fourth PCA component whereas DIN and $\mathrm{NO}_{3}^{-}$in January 2006 to the sixth component. 
Table 7. Variable loadings in Principal Components Analysis (PCA). Bold values represent values above abs(0.7).

\begin{tabular}{|c|c|c|c|c|c|c|}
\hline & PCAl & PCA2 & PCA3 & PCA4 & PCA5 & PCA6 \\
\hline Explained variance $(\%)$ & 23.21 & 14.46 & 10.72 & 9.43 & 8.41 & 5.64 \\
\hline \multicolumn{7}{|l|}{ Variables loadings } \\
\hline \multicolumn{7}{|l|}{ January 2003} \\
\hline Chloride $\left(\mathrm{Cl}^{-}\right)[\mathrm{mg} / \mathrm{l}]$ & 0.834 & -0.015 & 0.261 & 0.024 & 0.342 & -0.134 \\
\hline Sodium $\left(\mathrm{Na}^{+}\right)[\mathrm{mg} / \mathrm{l}]$ & 0.814 & 0.038 & 0.287 & 0.035 & 0.368 & -0.160 \\
\hline $\operatorname{Potassium}\left(\mathrm{K}^{+}\right)[\mathrm{mg} / \mathrm{l}]$ & 0.774 & 0.422 & 0.015 & -0.016 & 0.097 & 0.109 \\
\hline Magnesium $\left(\mathrm{Mg}^{2+}\right)[\mathrm{mg} / \mathrm{l}]$ & 0.815 & 0.245 & 0.080 & 0.002 & 0.155 & 0.397 \\
\hline Inorganic phospate [ug/l] & 0.356 & -0.062 & -0.196 & 0.702 & -0.009 & 0.073 \\
\hline $\begin{array}{l}\text { Dissolved inorganic nitrogen } \\
(\mathrm{DIN})[\mu \mathrm{M})\end{array}$ & 0.041 & 0.027 & -0.036 & 0.100 & 0.066 & 0.896 \\
\hline Nitrate $\left(\mathrm{NO}_{3}^{-}\right)[\mu \mathrm{M}]$ & -0.102 & 0.177 & 0.011 & 0.096 & 0.073 & 0.831 \\
\hline \multicolumn{7}{|l|}{ May 2003} \\
\hline Conductivity $[\mu \mathrm{S} / \mathrm{cm}]$ & 0.268 & 0.333 & 0.138 & 0.021 & 0.862 & 0.078 \\
\hline Chloride $\left(\mathrm{Cl}^{-}\right)[\mathrm{mg} / \mathrm{l}]$ & 0.278 & 0.260 & 0.215 & 0.040 & 0.854 & -0.074 \\
\hline Sodium $\left(\mathrm{Na}^{+}\right)[\mathrm{mg} / \mathrm{l}]$ & 0.308 & 0.258 & 0.204 & 0.045 & 0.860 & -0.051 \\
\hline $\operatorname{Potassium}\left(\mathrm{K}^{+}\right)[\mathrm{mg} / \mathrm{l}]$ & 0.302 & -0.007 & -0.137 & 0.072 & 0.778 & 0.089 \\
\hline Calcium $\left(\mathrm{Ca}^{2+}\right)[\mathrm{mg} / \mathrm{l}]$ & 0.247 & 0.466 & 0.026 & -0.046 & 0.733 & 0.295 \\
\hline \multicolumn{7}{|l|}{ March 2006} \\
\hline Conductivity $[\mu \mathrm{S} / \mathrm{cm}]$ & 0.230 & 0.847 & -0.024 & -0.074 & 0.245 & 0.292 \\
\hline Chloride $\left(\mathrm{Cl}^{-}\right)[\mathrm{mg} / \mathrm{l}]$ & 0.025 & 0.765 & 0.310 & 0.346 & 0.286 & -0.215 \\
\hline Sulphate $\left(\mathrm{SO}_{4}{ }^{2-}\right)[\mathrm{mg} / \mathrm{l}]$ & 0.116 & 0.945 & 0.037 & -0.092 & 0.041 & 0.013 \\
\hline Sodium $\left(\mathrm{Na}^{+}\right)[\mathrm{mg} / \mathrm{l}]$ & 0.058 & 0.763 & 0.352 & 0.323 & 0.283 & -0.181 \\
\hline $\operatorname{Potassium}\left(\mathrm{K}^{+}\right)[\mathrm{mg} / \mathrm{l}]$ & 0.000 & 0.892 & -0.127 & -0.088 & -0.074 & 0.148 \\
\hline Magnesium $\left(\mathrm{Mg}^{2+}\right)[\mathrm{mg} / \mathrm{l}]$ & 0.101 & 0.914 & 0.191 & 0.117 & 0.244 & -0.121 \\
\hline Calcium $\left(\mathrm{Ca}^{2+}\right)[\mathrm{mg} / \mathrm{l}]$ & 0.342 & 0.746 & -0.036 & -0.128 & 0.148 & 0.152 \\
\hline $\begin{array}{l}\text { Dissolved inorganic nitrogen } \\
(\mathrm{DIN})[\mu \mathrm{M})\end{array}$ & -0.007 & 0.054 & 0.249 & 0.906 & 0.144 & 0.043 \\
\hline Ammonium $\left(\mathrm{NH}_{4}^{+}\right)[\mu \mathrm{M}]$ & -0.094 & -0.001 & 0.005 & 0.840 & 0.004 & 0.015 \\
\hline Altitude $[\mathrm{m}]$ & -0.771 & -0.088 & -0.191 & -0.285 & -0.070 & 0.272 \\
\hline Maximum surface area $\left[\mathrm{m}^{2}\right]$ & 0.184 & 0.786 & -0.118 & -0.072 & 0.076 & 0.383 \\
\hline Total flooded area [\%] in $200 \mathrm{~m}$ & -0.291 & 0.020 & 0.368 & 0.042 & 0.748 & -0.150 \\
\hline Total number of ponds in $1000 \mathrm{~m}$ & 0.274 & 0.022 & 0.874 & 0.082 & 0.197 & 0.175 \\
\hline $\begin{array}{l}\text { Total number of ponds larger than } \\
150 \mathrm{~m}^{2} \text { in } 1000 \mathrm{~m}\end{array}$ & 0.310 & -0.047 & 0.906 & 0.008 & 0.105 & 0.017 \\
\hline $\begin{array}{l}\text { Total number of ponds larger than } \\
4000 \mathrm{~m}^{2} \text { in } 1000 \mathrm{~m}\end{array}$ & 0.267 & -0.022 & 0.818 & -0.196 & -0.004 & -0.292 \\
\hline Total flooded area $[\%]$ in $1000 \mathrm{~m}$ & -0.001 & 0.096 & 0.946 & 0.146 & 0.121 & -0.142 \\
\hline
\end{tabular}


Pond ordination based on the first and second PCA component did not discriminate independent pond groups but displayed a continuous gradient (Figure 11). Only one long-duration temporary pond (LD4) was clearly separated from the rest. Although gradients in pond ordination did not exactly match flooding duration during 2003, large duration ponds tended to appear at low values of PCAl, followed by intermediate-hydroperiod ponds and finally, by ephemeral ponds.

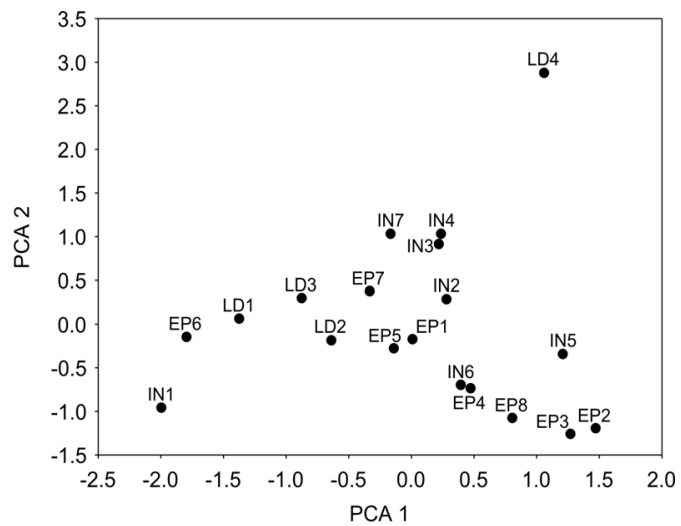

Figure 11. Pond ordination from PCA scores. Pond nomenclature corresponds to hydroperiod in 2003 $(\mathrm{LD}=$ long-duration temporary pond [8-9 months], IN = intermediate temporary pond [6-7 months], EP = ephemeral [4-5 months]).

\section{Temporary ponds as amphibian habitats}

Nine amphibian species were recorded during amphibian surveys. Bufo bufo (Linnaeus, 1758) occurred only in one of the permanent ponds in 2006. The rest of the species were recorded both in permanent and temporary ponds (Figure 12). Pelophylax perezi (Seoane, 1885) was never recorded in temporary ponds where flooding duration was below 4 months. In contrast to 2003, long-duration temporary ponds were not available for amphibian species to breed in 2006 because the longest hydroperiod of temporary ponds this year was 4 months.

We built habitat models for species detected as larvae in more than $25 \%$ of the ponds (Table 8). We obtained significant models for all the species except for Pelobates cultripes (Cuvier, 1829) in 2003 and Pleurodeles waltl Michahelles, 1830 in 2006. Despite being significant, most models explained a low percentage of variance in the data (adjusted $\mathrm{R}^{2}<0.5$ ). The most remarkable exception was Hyla meridionalis Boettger, 1874 in 2003 (Adj. $\mathrm{R}^{2}=0.853-0.864$ ).

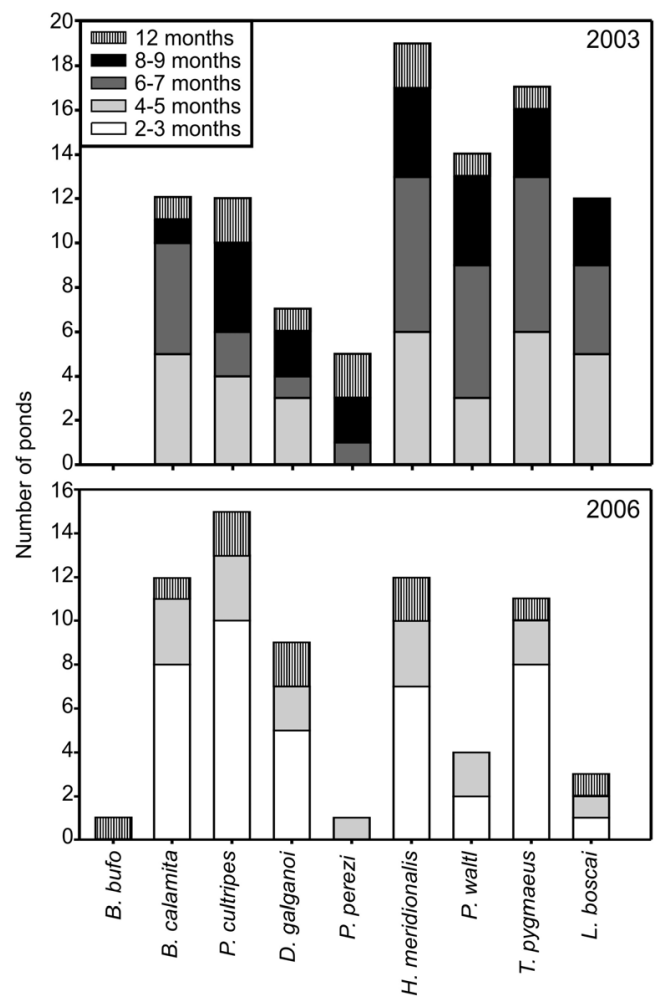

Figure 12. Number of ponds where amphibian species were recorded during the study period. Ponds are categorized according to their hydroperiod. 
Some species showed contrasting responses to habitat characteristics in the same breeding season. For instance, the relative abundance of $P$. cultripes and $H$. meridionalis in 2006 increased with altitude (PCAl) whereas the reverse was true for Bufo calamita Laurenti, 1768. In 2003, ion concentrations in May and percentage of flooded area in $200 \mathrm{~m}$ (PCA5) showed a positive relationship with the abundance of D. galganoi and negative with the abundance of $H$. meridionalis, Triturus pygmaeus (Wolterstorff, 1905) and Lissotriton boscai (Lataste, 1879). Similarly, pond area (PCA2) was positively related to the relative abundance of $P$. waltl and negatively with that of $T$. pygmaeus and $L$. boscai in 2003.

Even for the same species, the variables with highest relative importance differed between breeding seasons. The PCA component of ion concentrations in May and percentage of flooded area in 200m (PCA 5) was an important variable to explain the relative abundance of $D$. galganoi in 2003 , whereas the surrounding aquatic habitat in $1000 \mathrm{~m}$ (PCA3) and DIN concentration (PCA4) were important variables to explain its relative abundance in 2006 . The relative abundance of $H$. meridionalis in 2003 showed negative relationships with DIN concentration in January (PCA6), ion concentration in May (PCA5) and the amount of surrounding aquatic habitat in $1000 \mathrm{~m}$ (PCA3) whereas in 2006 the most important variable was the pond altitude (PCA1). In 2003, the relative abundance of T. pygmaeus decreased with maximum surface area (PCA2), ion concentrations in May and the percentage of flooded area in 200m (PCA5) whereas only the latter habitat characteristic was important in 2006.

Habitat models for species richness explained a similar percentage of variance both for 2003 and 2006. Species richness in
2003 decreased with an increase in the concentration of inorganic phosphate in January (PCA4), whereas species richness in 2006 increased with altitude (PCAl), maximum surface area and ion concentration (PCA2).

\section{Discussion}

The Doñana National Park encompasses a protected area that includes a large network of Mediterranean temporary ponds of natural origin, with more than 3000 water bodies flooded in very wet years (DíazPaniagua et al. 2006; Fortuna et al. 2006). Such high abundance of a well-preserved European priority habitat (European Commission 2007) deserves special attention as a reference system for pond conservation and management. Compared with other Mediterranean areas, the density of temporary ponds in Doñana National Park is higher (Denoël 2004; Richter-Boix et al. 2007), although lower than that Jakob et al. (2003) reported for man-made ponds in southern France, i.e. "ancient stone carriers that were exploited between Roman period and the end of 18th century". Regarding pond morphometry and waterchemistry, the characteristics of Doñana temporary ponds ranges within the values reported earlier for the Mediterranean region. For instance, pooling data from 2003 and 2006, conductivity ranged over the entire spectrum reported for Mediterranean temporary ponds (Zacharias et al. 2007). On average, temporary ponds in Doñana have smaller pond area and lower $\mathrm{pH}$ and conductivity than temporary ponds in southern France (Waterkeyn et al. 2008). However, Doñana ponds have larger pond area, although lower depth, than forested temporary ponds in central Italy (Mura and Brecciaroli 2003). 
Table 8. Number of models with substantial empirical support given the data and their range of adjusted $\mathrm{R}^{2}$ values. The sign of the relationship [(+): positive; (-): negative] and the relative importance of each explanatory variables is also shown. Bold values represent values above abs $(0.7)$.

\begin{tabular}{|c|c|c|c|c|c|c|c|c|c|}
\hline & & \multicolumn{2}{|c|}{ Models } & \multicolumn{6}{|c|}{ Relative importance of explanatory variables } \\
\hline & Year & $\mathbf{N}$ & $\begin{array}{l}\text { Adj. } R^{2} \\
\text { (min-max) }\end{array}$ & PCA_l & PCA_2 & PCA_3 & PCA_4 & PCA_5 & PCA_6 \\
\hline Richness & 2006 & 1 & $\begin{array}{l}0.508- \\
0.556^{* * *} \\
0.572 *\end{array}$ & $\begin{array}{c}(-) \\
0.249 \\
(-) \\
0.961\end{array}$ & $\begin{array}{c}(+) \\
0.214 \\
(+) \\
0.999\end{array}$ & $\begin{array}{c}(-) \\
0.498 \\
(-) \\
0.174\end{array}$ & $\begin{array}{c}(-) \\
0.999 \\
(-) \\
0.136\end{array}$ & $\begin{array}{c}(+) \\
0.160 \\
(+) \\
0.142\end{array}$ & $\begin{array}{c}(+) \\
0.170 \\
(+) \\
0.148\end{array}$ \\
\hline B. calamita & 2003 & No & model (only 1 & ase with & to null de & & & & \\
\hline & 2006 & 5 & $\begin{array}{l}0.385- \\
0.608 *\end{array}$ & $\begin{array}{c}(+) \\
0.723\end{array}$ & $\begin{array}{c}(-) \\
0.882\end{array}$ & $\begin{array}{c}(-) \\
0.110\end{array}$ & $\begin{array}{c}(-) \\
0.364\end{array}$ & $\begin{array}{c}(+) \\
0.606\end{array}$ & $\begin{array}{c}(-) \\
0.113\end{array}$ \\
\hline P. cultripes & 2003 & 4 & $\begin{array}{l}0.167- \\
0.274 \text { (n.s) }\end{array}$ & $\begin{array}{c}(-) \\
0.446\end{array}$ & $\begin{array}{c}(+) \\
0.365\end{array}$ & $\begin{array}{c}(+) \\
0.175\end{array}$ & $\begin{array}{c}(-) \\
0.169\end{array}$ & $\begin{array}{c}(+) \\
0.752\end{array}$ & $\begin{array}{c}(+) \\
0.170\end{array}$ \\
\hline & 2006 & 2 & $\begin{array}{l}0.367- \\
0.493 * *\end{array}$ & $\begin{array}{c}(-) \\
0.971\end{array}$ & $\begin{array}{c}(+) \\
0.617\end{array}$ & $\begin{array}{c}(+) \\
0.143\end{array}$ & $\begin{array}{c}(+) \\
0.129\end{array}$ & $\begin{array}{c}(+) \\
0.207\end{array}$ & $\begin{array}{c}(+) \\
0.132\end{array}$ \\
\hline D. galganoi & 2003 & 4 & $\begin{array}{l}0.278- \\
0.404 *\end{array}$ & $\begin{array}{c}(-) \\
0.314\end{array}$ & $\begin{array}{c}(-) \\
0.145\end{array}$ & $\begin{array}{c}(-) \\
0.201\end{array}$ & $\begin{array}{c}(+) \\
0.338\end{array}$ & $\begin{array}{c}(+) \\
0.940\end{array}$ & $\begin{array}{c}(-) \\
0.618\end{array}$ \\
\hline & 2006 & 3 & $\begin{array}{l}0.663- \\
0.682 * *\end{array}$ & $\begin{array}{c}(-) \\
0.121\end{array}$ & $\begin{array}{c}(+) \\
0.281\end{array}$ & $\begin{array}{c}(+) \\
0.990\end{array}$ & $\begin{array}{c}(+) \\
0.988\end{array}$ & $\begin{array}{c}(+) \\
0.269\end{array}$ & $\begin{array}{c}(-) \\
0.112\end{array}$ \\
\hline P. perezi & $\begin{array}{l}2003 \\
2006\end{array}$ & & $\begin{array}{l}\text { model (only } 3 \\
\text { model (only } 1\end{array}$ & $\begin{array}{l}\text { ases witl } \\
\text { ase with }\end{array}$ & $\begin{array}{l}\text { no null d } \\
\text { lo null de }\end{array}$ & $\begin{array}{l}\text { ta) } \\
\text { a) }\end{array}$ & & & \\
\hline $\begin{array}{l}\text { H. meri- } \\
\text { dionalis }\end{array}$ & 2003 & 2 & $\begin{array}{l}0.853- \\
0.864 * * *\end{array}$ & $\begin{array}{c}(-) \\
0.324\end{array}$ & $\begin{array}{c}(-) \\
0.157\end{array}$ & $\begin{array}{c}(-) \\
1.000\end{array}$ & $\begin{array}{c}(-) \\
0.199\end{array}$ & $\begin{array}{c}(-) \\
0.999\end{array}$ & $\begin{array}{c}(-) \\
1.000\end{array}$ \\
\hline & 2006 & 2 & $\begin{array}{l}0.467- \\
0.321 * *\end{array}$ & $\begin{array}{c}(-) \\
0.952\end{array}$ & $\begin{array}{c}(+) \\
0.648\end{array}$ & $\begin{array}{c}(-) \\
0.208\end{array}$ & $\begin{array}{c}(-) \\
0.136\end{array}$ & $\begin{array}{c}(+) \\
0.141\end{array}$ & $\begin{array}{c}(+) \\
0.164\end{array}$ \\
\hline P. waltl & 2003 & 3 & $\begin{array}{l}0.253- \\
0.451 *\end{array}$ & $\begin{array}{c}(-) \\
0.423\end{array}$ & $\begin{array}{c}(+) \\
0.713\end{array}$ & $\begin{array}{c}(-) \\
0.866\end{array}$ & $\begin{array}{c}(-) \\
0.198\end{array}$ & $\begin{array}{c}(-) \\
0.171\end{array}$ & $\begin{array}{c}(-) \\
0.189\end{array}$ \\
\hline & 2006 & 5 & $\begin{array}{l}0.204- \\
0.340 \text { (n.s.) }\end{array}$ & $\begin{array}{c}(-) \\
0.798\end{array}$ & $\begin{array}{c}(+) \\
0.249\end{array}$ & $\begin{array}{c}(-) \\
0.314\end{array}$ & $\begin{array}{c}(-) \\
0.224\end{array}$ & $\begin{array}{c}(+) \\
0.149\end{array}$ & $\begin{array}{c}(+) \\
0.418\end{array}$ \\
\hline T. pygmaeus & 2003 & 3 & $\begin{array}{l}0.456- \\
0.549 * *\end{array}$ & $\begin{array}{c}(-) \\
0.135\end{array}$ & $\begin{array}{c}(-) \\
0.740\end{array}$ & $\begin{array}{c}(-) \\
0.458\end{array}$ & $\begin{array}{c}(-) \\
0.383\end{array}$ & $\begin{array}{c}(-) \\
0.982\end{array}$ & $\begin{array}{c}(-) \\
0.158\end{array}$ \\
\hline & 2006 & 2 & $\begin{array}{l}0.321- \\
0.376 *\end{array}$ & $\begin{array}{c}(+) \\
0.151\end{array}$ & $\begin{array}{c}(+) \\
0.146\end{array}$ & $\begin{array}{c}(+) \\
0.143\end{array}$ & $\begin{array}{c}(-) \\
0.233\end{array}$ & $\begin{array}{c}(-) \\
0.915\end{array}$ & $\begin{array}{c}(-) \\
0.368\end{array}$ \\
\hline L. boscai & 2003 & 2 & $\begin{array}{l}0.355- \\
0.443 *\end{array}$ & $\begin{array}{c}(-) \\
0.156\end{array}$ & $\begin{array}{c}(-) \\
0.8411\end{array}$ & $\begin{array}{c}(-) \\
0.502\end{array}$ & $\begin{array}{c}(+) \\
0.177\end{array}$ & $\begin{array}{c}(-) \\
0.772\end{array}$ & $\begin{array}{c}(-) \\
0.148\end{array}$ \\
\hline & 2006 & & model (only & ases witl & no null & & & & \\
\hline
\end{tabular}

(n.s) No model with $\mathrm{p}<0.05$

* All models, $\mathrm{p}<0.05$

** All models, $\mathrm{p}<0.01$

*** All models, $\mathrm{p}<0.001$ 
On the contrary, pond surface area, depth and most water-chemistry characteristics for the Doñana ponds are similar to temporary ponds under agricultural intensification in southern Portugal (Beja and Alcazar 2003), except for the higher concentration of sulphate. Compared to a previous study in the same study area, dissolved inorganic phosphate concentrations were generally higher than those reported in these ponds during previous extensive flooding periods, while inorganic nitrogen concentrations remained within the same range (Espinar and Serrano in press). The application of a literature-based ratio $\left(\mathrm{Na}^{+} / \mathrm{Mg}^{2+}\right)$, developed for ponds in the same study area (García-Novo et al. 1991), yielded unexpected hydrologic regimes, such as a high number of temporary ponds receiving regional aquifer discharges in the drier year. Since this result seems unlikely, we think that the applicability of this ratio could be restricted to similar hydrologic conditions as those in which it was conceived (i.e. very large inundation events).

Our results show that this pond network presents a remarkable environmental variability in time and space and yet, they are a highly suitable breeding habitat for amphibians. As a case in point, hydroperiod in a given temporary pond widely changed between breeding seasons: a reduction in length of at least 4 months was recorded in 10 ponds between 2003 and 2006. Taking into account the large amount of PCA components required to explain a relative low percentage of variance, we can deduce that there is a remarkable independence of pond characteristics at different sampling dates. Such independence should warn us that a pond description made from a single survey may not be representative of the pond characteristics at a different sampling date. Besides, temporal variability in absolute values of water-chemistry characteristics suggests that pond descriptions based solely on measures of central tendency (i.e. mean) over time may bias results and those ecological interpretations derived from them. In fact, mean values are only meaningful when attributes fluctuate around a particular value, whereas water chemistry changes in temporary ponds are most likely produced by a combination of fluctuations and stochastic events.

The suitability of these temporary ponds for amphibian breeding probably relies upon the wide environmental gradient that they encompass as a whole. For instance, pooling data from both 2003 and 2006, conductivity ranged over the entire spectra reported for Mediterranean temporary ponds (Zacharias et al. 2007). We recorded the presence of eight out of eleven species, all of them common breeders in temporary ponds (Díaz-Paniagua 1990), in both study years. So, neither the delayed pond filling nor the reduction in pond hydroperiod during 2006 prevented the breeding attempt of any species in the study area. In fact, in our study period, we did not observe a strong segregation pattern according to hydroperiod, as reported in previous ones (Díaz-Paniagua 1990). Considering the data from both years altogether, all species attempted to breed in ponds along the entire hydroperiod gradient except $P$. perezi and $B$. bufo.

The large inter-annual variability in environmental conditions is also evidenced in habitat model outputs. Pond characteristics relevant for species richness or for the relative abundance of particular species differ between breeding seasons (2003 and 2006). So, in this highly dynamic system, the habitat model outputs appear to be year-specific. Piha et al. (2007) also reported year-specific habitat models for $R$. temporaria Linnaeus, 1758 in northern Europe when comparing a year under normal weather conditions with a year after 
a severe drought. From a temporal perspective, our results are analogous to the spatial differences found in studies reporting region-specific habitat models (Johansson et al. 2005; Richter-Boix et al. 2007). Inter-annual differences in the range of variation (minimum value - maximum value) of most water-related characteristics might explain the observed differences in model outputs. Theoretically, species responses to environmental factors should be bell-shaped along the entire gradient (Austin 2002). So, species responses may differ from year to year when the annual range of environmental variation is only a fraction of the entire gradient and can cover different gradient regions depending on the year. For example, we may infer a positive response when the observed environmental variation lies within the smallest values of the gradient's range and no response in the middle of the gradient, at the peak of the theoretical species-habitat curve.

Our results also agree with previous studies that have reported species-specific responses to habitat factors (Beja and Alcazar 2003; Weyrauch and Grubb 2004; Pearl et al. 2005; Van Buskirk 2005). In consequence, conservation programs should focus in habitat requirements at the species level, since important habitat factors maybe masked when considering solely species richness data (Hazell et al. 2001; Knutson et al. 2004). It should also be noted that the percentage of variance explained with habitat models is low, although similar to other studies (Babbitt et al. 2006; Piha et al. 2007). This could be explained by not having included important factors in the habitat models, such as landscape attributes (Gibbons 2003) and biotic interactions (Duellman and Trueb 1986; Semlitsch 2003), by demographic stochasticity (Green 2003) or by density-dependent regulation in amphibian communities (Semlitsch 2002).
A wide diversity of hydroperiods is required to maximize amphibian species diversity (Semlitsch 2003). Therefore, those areas with a high abundance and diversity of temporary ponds would favour conservation of different species within the amphibian community. Besides, due to the temporal variability of habitat characteristics, a network of ponds can be seen as a shifting mosaic of suitable habitats over time (as Urban 2004 described for a freshwater invertebrate community). In these systems, species persist because each is periodically favoured and exhibits boom years where large numbers of metamorphs are produced, rather than constant low-level reproductive success each year (Semlitsch 2002). Temporary ponds in Doñana National Park represent a good example of how the preservation of natural aquatic habitats with large inter-annual variability can result in sustaining a rich and abundant amphibian fauna. Areas with such a high density and heterogeneity of natural ponds are not common in Europe. In Europe, manmade ponds are the most frequent amphibian breeding habitat (Jakob et al. 2003; Denoël 2004), and the number of temporary ponds are probably a mere fraction of what they probably were in the past (Williams et al. 2001). For that reason, it is highly important to conduct specific programs aimed at the conservation of systems of temporary ponds of natural origin in Europe. And, in particular, to preserve its natural dynamism in order to ensure the long-term persistence of different breeding species.

Comments This section was done in collaboration with Carmen Díaz-Paniagua, Laura Serrano, Margarita Florencio and Alexandre Portheault. A version of this text is accepted for publication in Aquatic Ecology. 


\section{References}

Austin MP 2002. Ecol Model 157, 101-118.

Babbitt KJ et al. 2006. Can J Zool 84, 510519.

Beja P, Alcazar R 2003. Biol Conserv 114, 317-326.

Blondel J, Aronson J 1999. Biology and Wildlife of the Mediterranean Region. Oxford University Press, Oxford, New York.

Boix D et al. 2001. Wetlands 21, 577-592.

Burne MR, Griffin CR 2005. Wetlands Ecol Manag 13, 247-259.

Burnham KP, Anderson DR 2002. Model Selection and Multimodel Inference. A Practical Information-Theoretic Approach. Springer.

Denoël M 2004. Bull Soc Herp Fr 111-112 49-77.

Díaz-Paniagua C 1990. Herpetol J 1, 447453.

Díaz-Paniagua C et al. 2006. Rev Esp Herpetol 20, 17-30.

Duellman WE, Trueb L 1986. Biology of Amphibians. McGraw-Hill Book Company

Espinar JL, Serrano L. In press. Aquat Ecol. Online first.

European Commission 2007. Interpretation Manual of European Union Habitats. Natura 2000, Nature and Biodiversity. European Commission.

Fortuna M et al. 2006. $P$ Roy Soc Lond B Bio 273, 1429-1434.

García-Novo F et al. 1991. III Simposium de Aguas de Andalucía, 165-176.

Gibbons JW 2003. Wetlands 23, 630-635.

Green DM 2003. Biol Conserv 111, 331343.

Griffiths RA 1997. Aquat Conserv: Mar Freshw Ecosyst 7, 119-126.

Grillas $\mathrm{P}$ et al. 2004. Mediterranean Temporary Pools. Volume 1- Issues Relating to Conservation, Functioning and Management. Station Biologique de la Tour du Valat.
Hazell D et al. 2001. Biol Conserv 102, 155169.

Hecnar SJ, M’Closkey RT 1996. Freshwater Biol 36, 7-15.

Heyer WR et al. 1994. Measuring and Monitoring Biological Diversity. Standard Methods for Amphibians. Smithsonian Institution Press, Washington \& London.

Houlahan JE, Findlay CS 2003. Can J Fish Aquat Sci 60, 1078-1094.

Jakob C et al. 2003. Hydrobiologia 499, 5161.

Johansson M et al. 2005. Global Change Biol 11, 1664-1679.

Joly P et al. 2001. Conserv Biol 15, 239248.

Junta de Andalucía 2003. Ortofotografía Digital de Andalucía.

Knutson MG et al. 2004. Ecol Appl 14, 669684.

Laan R, Verboom R 1990. Biol Conserv 54, 251-262.

Leibowitz SG, Nadeau T-L 2003. Wetlands $23,663-684$

López T et al. 1991. Arch Hydrobiol 120, 357-378.

Marsh DM et al. 1999. J Anim Ecol 68, 804814.

Marsh DM, Trenham PC 2001. Conserv Biol $15,40-49$.

Mazerolle MJ 2006. Amphibia-Reptilia 27, 169-180.

Montes C et al. 1982. Studia Oecol 3, 159180.

Muñoz Reinoso JC 1996. Limnetica 12, 5363.

Mura G, Brecciaroli B 2003. Hydrobiologia 495, 93-102.

Pearl CA et al. 2005. Wetlands 25, 76-88.

Petranka JW et al. 2004. Ecol Appl 14, 1065-1078.

Piha H et al. 2007. Global Change Biol 13, 300-311. 
Richter-Boix A et al. 2007. J Anim Ecol 76, 607-618.

Rivas-Martínez S et al. 1980. Lazaroa 2, 5189.

Sacks LA et al. 1992. J Hydrol 136, 123154.

Schmidt BR, Pellet J 2005. J Wildl Manage 69, 884-893.

Schwartz SS, Jenkins DG 2000. Aquat Ecol 34, 3-8.

Semlitsch RD 2002. J Wildl Manage 64, 615-631.

Semlitsch RD (Ed.) 2003. Amphibian Conservation. Smithsonian Books, Washington and London.

Serrano L et al. 2006. Limnetica 25, 11-32.

Serrano L, Toja J 1995. Arch Hydrobiol 133, 497-516.

Serrano L, Zunzunegui M 2008. Aquat Conserv: Mar Freshw Ecosyst 18, 261279.

Siljeström PA et al. 1994. J Arid Environ 26, 315-323.

Smith GR et al. 2003. J Freshwater Ecol 18, 491-496.
Snodgrass JW et al. 2000. Conserv Biol 14, 414-419.

Sztatecsny M et al. 2004. Herpetol J 14, 8997.

Urban DL 2004. Ecology 85, 2971-2978.

Van Buskirk J 2005. Ecology 86, 19361947.

Waterkeyn A et al. 2008. Freshwater Biol $53,1808-1822$.

Wellborn GA et al. 1996. Annu Rev Ecol Evol $S$ 27, 337-363.

Werner EE et al. 2007. Oikos 116, 16971712.

Weyrauch SL, Grubb Jr TC. 2004. Biol Conserv 115, 443-450.

Williams DD 1997. Aquat Conserv: Mar Freshw Ecosyst 7, 105-117.

Williams DD 2006. The Biology of Temporary Waters. Oxford University Press, Oxford, New York.

Williams P et al. 2001. Freshw Forum 17, 715.

Zacharias I et al. 2007. J Environ Biol 28, 1-9. 


\section{Chapter 2}

Application of remote sensing data for identification, characterization and monitoring of amphibian habitats

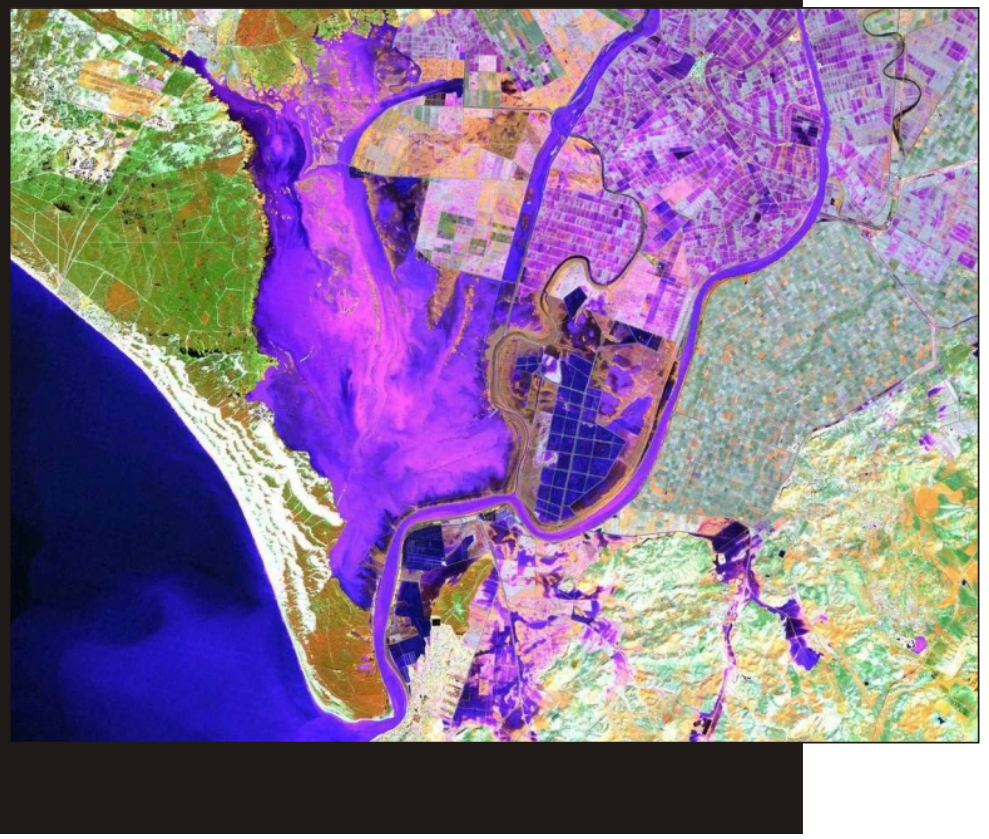




\section{Application of remote sensing to the cartography of small temporary ponds}

The spatial distribution of amphibian breeding habitats should be considered in conservation strategies. Therefore, the development and optimization of techniques to map them are necessary, especially in stochastic ecosystems like Mediterranean wetlands. We have applied remote sensing techniques on a high spectral and spatial resolution image to locate and delineate small temporary ponds in one of the most important wetlands in southern Europe, Doñana National Park. We used density slicing (Richards and Jia 1999) on a spectral band from the infrared part of spectra $(\lambda=1.004 \pm 0.030 \mu \mathrm{m}$ (centre \pm width)) followed by a supervised classification to delineate 3335 water bodies in the area, with an error rate of $15 \%$. The present cartography constitutes a snapshot of a highly fluctuating ecosystem that, following the technique described, can be easily updated to monitor intra and inter-annual variation in temporary ponds onset and duration. We show that remote sensing can be a useful tool for the monitoring of networks of temporary ponds. 


\section{Introduction}

The spatial distribution of freshwater habitats should be considered in conservation strategies since it determines the distribution and dynamics of associated species, such as amphibians (Semlitsch and Bodie 1998; Semlitsch 2003).

Current technologies, like remote sensing, constitute a useful tool for monitoring the extent of freshwater habitats (Revenga et al. 2005). Remote sensing has been broadly applied to map large wetlands (see Ozesmi and Bauer 2002 for a review) but its application on seasonal flooded systems has been scarce (Bryant 1999; Roshier and Rumbachs 2004; Lacaux et al. 2007), mainly because these fluctuating habitats are difficult to delimitate (Revenga et al. 2005). In addition, the identification and delimitation of small temporary water bodies, like Mediterranean ponds, encounters additional pitfalls caused by their small size, frequently below pixel size of most of the satellites images. Nevertheless, these problems can be solved with the use of high spatial resolution satellites or airborne sensors (Weiers et al. 2004; Lacaux et al. 2007), making plausible the application of remote sensing to map temporary ponds.

This approach will be useful for the monitoring of large areas, especially those lacking previous information, and fluctuating ecosystems, like Mediterranean temporary ponds. Comprehensive monitoring of fluctuating ecosystems is difficult because the number and size of ponds in an area shows intra and interannual variation. For this reason, the development of rapid and repeatable techniques to assess the spatio-temporal evolution of water bodies (see Lacaux et al. 2007 as an example) is necessary to partially overcome these difficulties.

With this study, we investigate the applicability of high spectral and spatial resolution remote sensing data to map a system of small temporary ponds. We have applied remote sensing techniques to discriminate water from land and, thus, obtained a detailed cartography of temporary ponds in Doñana National Park. We have also validated the resulting cartography with field data, to assess the goodness of the methodology applied. 


\section{Material and Methods}

\section{Study area}

Doñana National Park, located in southwestern Spain, in the estuary of the Guadalquivir River (see Siljeström et al. 1994 for a general description), is considered one of the largest (54252ha) and most important wetlands in southern Europe. Siljeström et al. (1994) differentiated three morphogenetic systems in the National Park: estuarine (marsh), littoral (shoreline) and aeolian (dunes) (Siljeström et al. 1994). Our study area is the aeolian system (27000ha approx.), mainly formed by stabilized dunes and, in a lesser extent, mobile dunes. Mediterranean scrub (Halimio halimifolii-Stauracanthetum genistoides and Erico scopariae-Ulicetum australis as defined by Rivas-Martínez et al. 1980) is the dominant vegetal cover on the stabilized sands except in the south of the Park, where a large pine forest (Pinus pinea L.) stands. Isolated and small pine forests and juniper (Juniperus phoenicea L.) forests are also sparsely spread in the National Park

On the aeolian sands numerous freshwater ponds usually flood during the rainy season (autumn) and constitute a large and robust network (Fortuna 2006). These water bodies vary widely in size, from rain puddles (several square metres) to large temporary ponds ( $>$ lha). Except for two shallow lakes, larger than 10ha, which dry out only sporadically (Serrano et al. 2006), most water bodies in this area are temporary ponds which dry out during summer. The duration of flooding varies widely among water bodies (Serrano et al. 2006).

\section{Remote sensing analyses}

Doñana National Park was overflown in a remote sensing campaign conducted by the
Remote Sensing Laboratory of the Instituto Nacional de Técnica Aerospacial (INTA) in a period of maximum flooding, April $27^{\text {th }}$, 2004. An airborne hyperspectral spectrometer (AHS, Sobrino et al. 2006) was used to obtain five cloud-free images, covering the National Park, with a spatial resolution of $5 \times 5 \mathrm{~m}$.

The Instituto Nacional de Técnica Aerospacial (INTA) radiometrically corrected the images, converting digital numbers (DNs) to absolute radiance values based on the instrument's calibration coefficients.

From the original images, we extracted the study area, the aeolian sands, and divided it into smaller images (20 images: $4500 \mathrm{x}$ $3000 \mathrm{~m}^{2}$ approx.) to simplify the georeferencing. We identified a mean number of 41 ground control points (GCPs) per subsetted image using aerial ortophotography with $0.5 \mathrm{~m}$ spatial resolution (Junta de Andalucía 2003). Then, we applied a second order polynomial transformation and nearest-neighbour resampling using ENVI 4.0.

The methodology applied to build the water bodies cartography consisted on: an exploratory analysis, a delineation of water bodies applying density slicing and an evaluation analysis to assess the goodness of fit of the cartography.

Exploratory analysis: Band and threshold value selection for density slicing (Richards and Jia 1999)

In one of the remote sensing images, we identified training areas of nine different land covers based on previous knowledge of the study area and on aerial ortophotography (Junta de Andalucía 2003). We considered three categories of flooded areas ("water"): deep water zones in permanent ponds, water in long duration temporary ponds, water in temporary ponds, and six terrestrial categories ("no-water"): 
dune, pine forest, Mediterranean shrub, reeds, path and path edge.

We computed the minimum and maximum radiance value for each land cover class in the visible and near infrared bands of the spectra $(21$ bands ranging from $0.445 \pm 0.027 \mu \mathrm{m}$ to $1.622 \pm 0.159 \mu \mathrm{m})$ and assessed the bands and radiance values for which "water" and "no water" spectral responses did not overlap. Then, we applied density slicing (Richards and Jia 1999) for each band and the corresponding threshold value, and visually determined its performance to delineate water bodies. We identified problems with commission errors, mainly due to misidentification of tree shades as water, and omission errors, mainly due to misidentified ephemeral ponds. We selected the band and threshold value that better discriminated "water" from "no water" classes for further analyses.

\section{Water bodies delineation}

Once we selected the spectral band and threshold value, we applied density slicing (Richards and Jia 1999) in each image and delineated water bodies.

In November 2004, we conducted a ground-truth campaign to validate the results. We visited 111 locations identified as water bodies. The existence of previous water had to be assessed from vegetation and basin type because ponds did not flood in the hydrological year 2004-2005. We used this information, previous knowledge and aerial photography (Junta de Andalucía 2003) to adjust the threshold value for each image to achieve the best discrimination between water and no-water classes. Differences among threshold values for each image were probably due to differences in radiance caused by the influence of the time of acquisition.

In January 2005 we conducted an additional ground-truth campaign to validate the initial cartography. It presented commission problems due to tree shades. Therefore, we conducted a supervised classification to specifically remove these errors using as training areas (water vs. shade) the groundtruth data collected from the November-2004 and January-2005 campaigns as well as data from visual inspection of aerial ortophotography (Junta de Andalucía 2003). We masked each image with the corresponding water bodies cartography and then conducted a Mahalanobis supervised classification (Lillesand and Kiefer 1994; Richards and Jia 1999) on the visible and near infrared bands of spectra (21 bands ranging from $0.445 \pm 0.027 \mu \mathrm{m}$ to $1.622 \pm 0.159 \mu \mathrm{m}$ ) to differentiate water from shade. Mahalobis supervised classification was applied with no distance threshold in order to classify all the pixels as water or shade. We masked out "shade pixels" from the cartography.

The resultant images were mosaicked to obtain a final cartography for the whole area. Water bodies sharing a vertex were considered to be the same water body.

Evaluation analysis: Assessment of cartography quality

We surveyed two areas of $1.5 \mathrm{~km} \times 1.5 \mathrm{~km}$ each in March-April 2006, to evaluate the performance of the final cartography of water bodies. We could not verify the cartography in 2005 because ponds did not flood that year. We visited each pond delineated in the cartography to assess if it was a correct identification or a commission error. We also located water bodies not identified in the cartography and considered them as potential omission errors. We estimated maximum surface area of omitted ponds from aerial ortophotography and verified it in the field (Junta de Andalucía 2003). 


\section{Results}

Initial discrimination between land cover classes was based on 11552 pixels, corresponding to the different categories considered (Table 9). Seven spectral bands, ranging from $0.862 \pm 0.028 \mu \mathrm{m}$ to $1.662 \pm 0.159 \mu \mathrm{m}$, showed no overlap in radiance response between "water" and "no water" classes (Figure 13). The "no water" category with the lowest minimum radiance value in those bands was "pine forest" (Figure 13). The best initial cartography was obtained applying density slicing in band number $20 \quad(\lambda=1.004 \pm 0.030 \mu \mathrm{m})$, since few problems due to tree shades or misidentification of ephemeral ponds occurred. This cartography identified 10489 elements as water bodies.

Supervised classifications to remove misidentification problems from the initial cartography were done based on 27095 pixels corresponding to water and 430 corresponding to tree shades.

The final cartography delineated 3335 ponds in the whole study area; with size ranging from $25 \mathrm{~m}^{2}$ to $45 \mathrm{ha}$ approximately (Appendix 1; see Figure 14 for detailed maps of two small areas). The most abundant ponds in the study area were the smallest in size (0.0025-0.01 has.) (Figure 15).

Evaluation results showed that we correctly detected $85 \%$ of the ponds present in the two $1.5 \times 1.5 \mathrm{~km}$ areas, and misidentified 17 elements out of 116 (15\%) as water bodies (Figure 14). Those polygons were small in size (mean size $=35 \mathrm{~m}^{2}$ ) (Table 10). Most commission problems were caused by confusion of tree shades as water. We could not access to two polygons identified as water in the cartography, so we could not determine their status. The final cartography failed to detect 13 ponds (mean size $=590 \mathrm{~m}^{2}$ ) that we visited in 2003 or 2004, all of them ephemeral ponds (omission errors).

Table 9. Land cover classes and number of pixels representing them used in the initial assessment of the wavelength (spectral band) and radiance threshold value that better discriminated between water and other land cover classes.

\begin{tabular}{|lc|}
\hline Land cover class & Number of pixels \\
\hline "Water" classes & 2962 \\
Deep waters & 379 \\
$\begin{array}{l}\text { Shallow waters in long duration temporary } \\
\text { ponds }\end{array}$ & 271 \\
Shallow waters in temporary ponds & \\
"No water" classes & 2644 \\
Dune & 1797 \\
Pine forest & 1062 \\
Mediterranean shrub & 217 \\
Reeds & 1180 \\
Path & 1040 \\
Path edge & \\
\hline
\end{tabular}


In these validation areas, Bravo and Montes (1993) had previously detected 11 water bodies; Montes et al. (1998) had identified 14 palustrine areas and the topographic map from Junta de Andalucía (Junta de Andalucía 2000) delineated 12 water bodies. Therefore, previous cartographies identified less than $15 \%$ percent of the water bodies detected in the present study (see Figure 14 and 16). These previous cartographies have missed small size water bodies (Figure 15). Bravo and Montes (1993) and Montes et al. (1998) identified larger flooded areas for similar number of ponds in the size category over 5 ha.

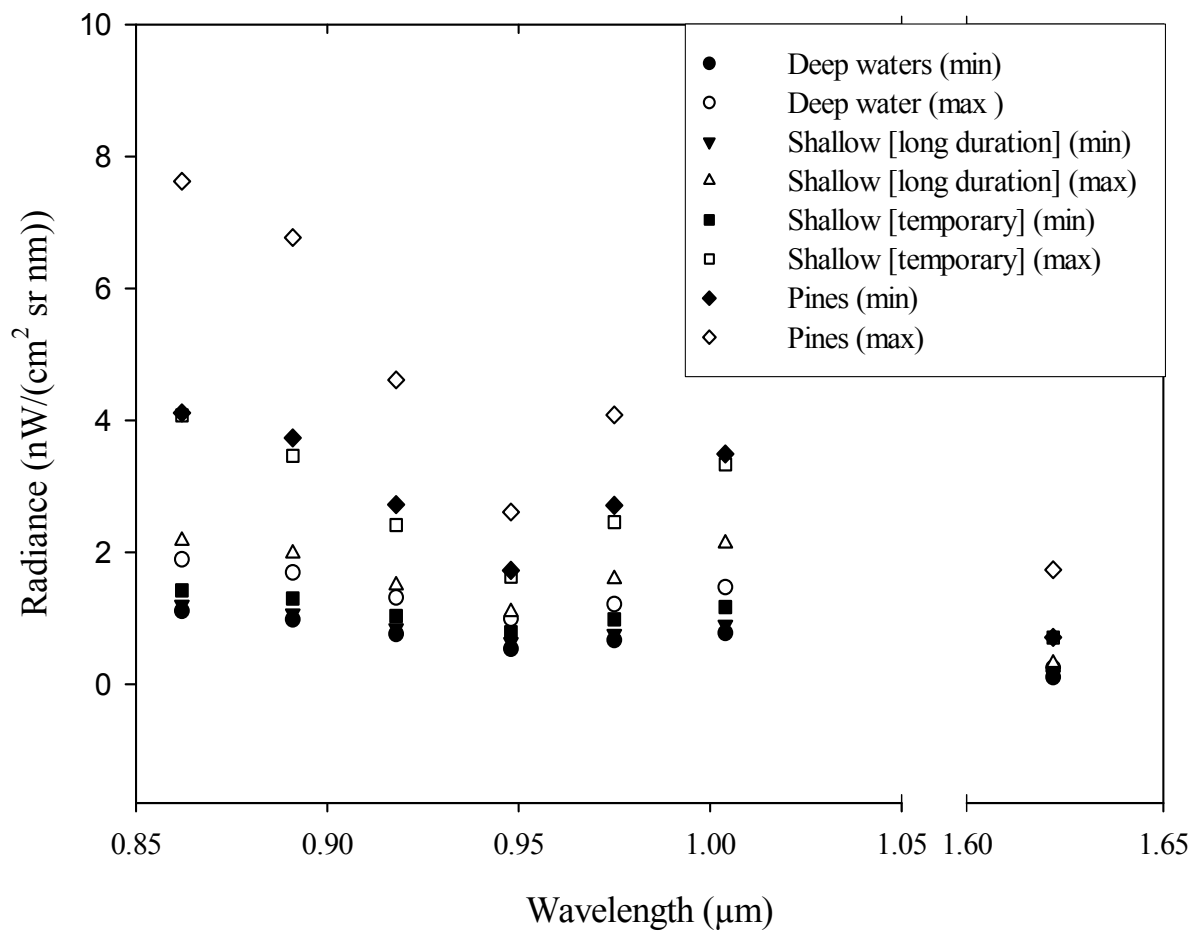

Figure 13. Minimum and maximum radiance value obtained for pixels of "water" land cover classes (deep waters, shallow waters in long temporary ponds, shallow waters in temporary ponds) and for the "no water" class that presented the lowest minimum value (pine forest). Only bands in which water was clearly discriminated from other land cover classes are represented (band number 15band number 21). 

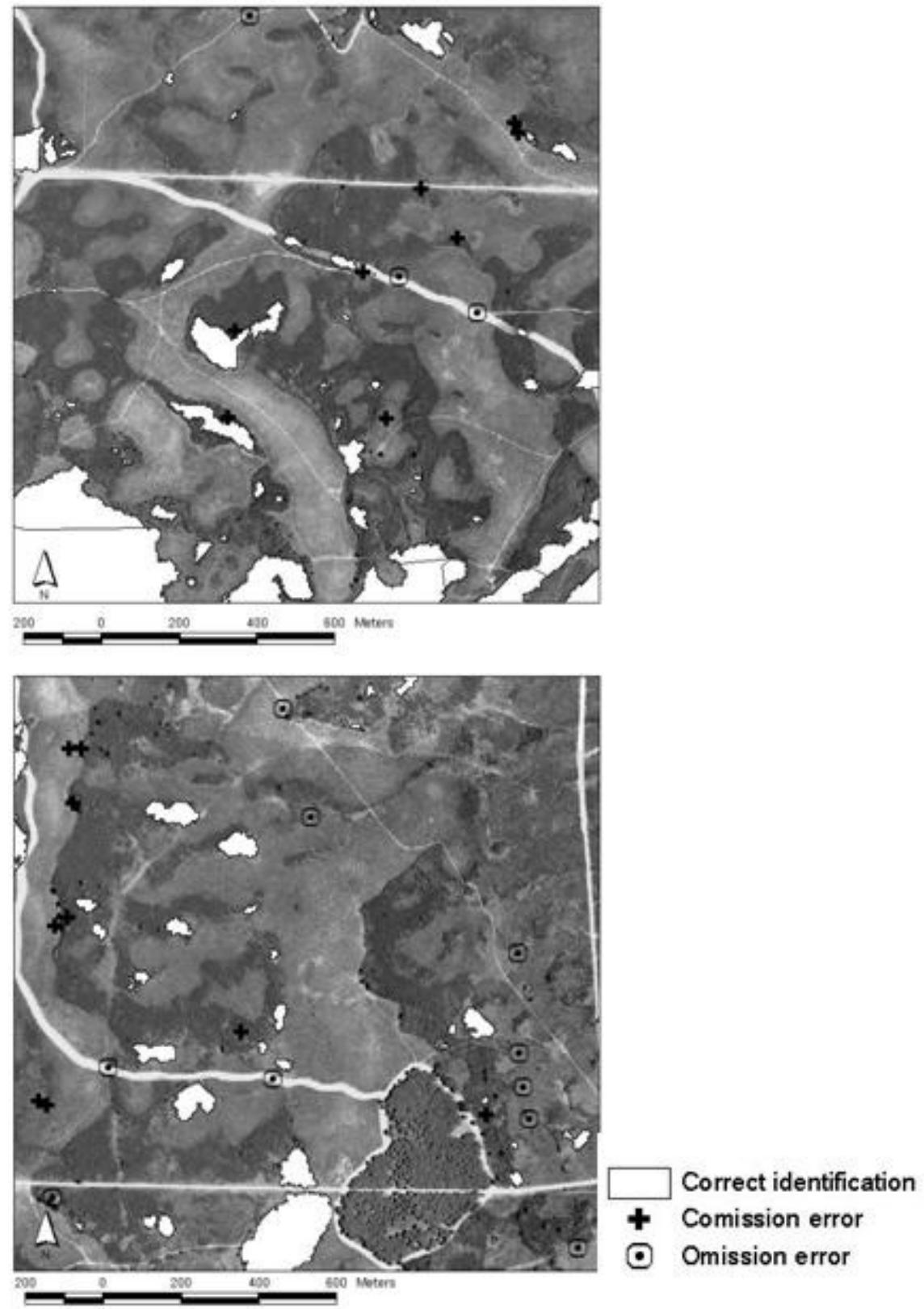

Figure 14. Cartography of water bodies in the two validation areas, represented on aerial ortophotography (Junta de Andalucía 2003). Omission and commission errors are specified. 


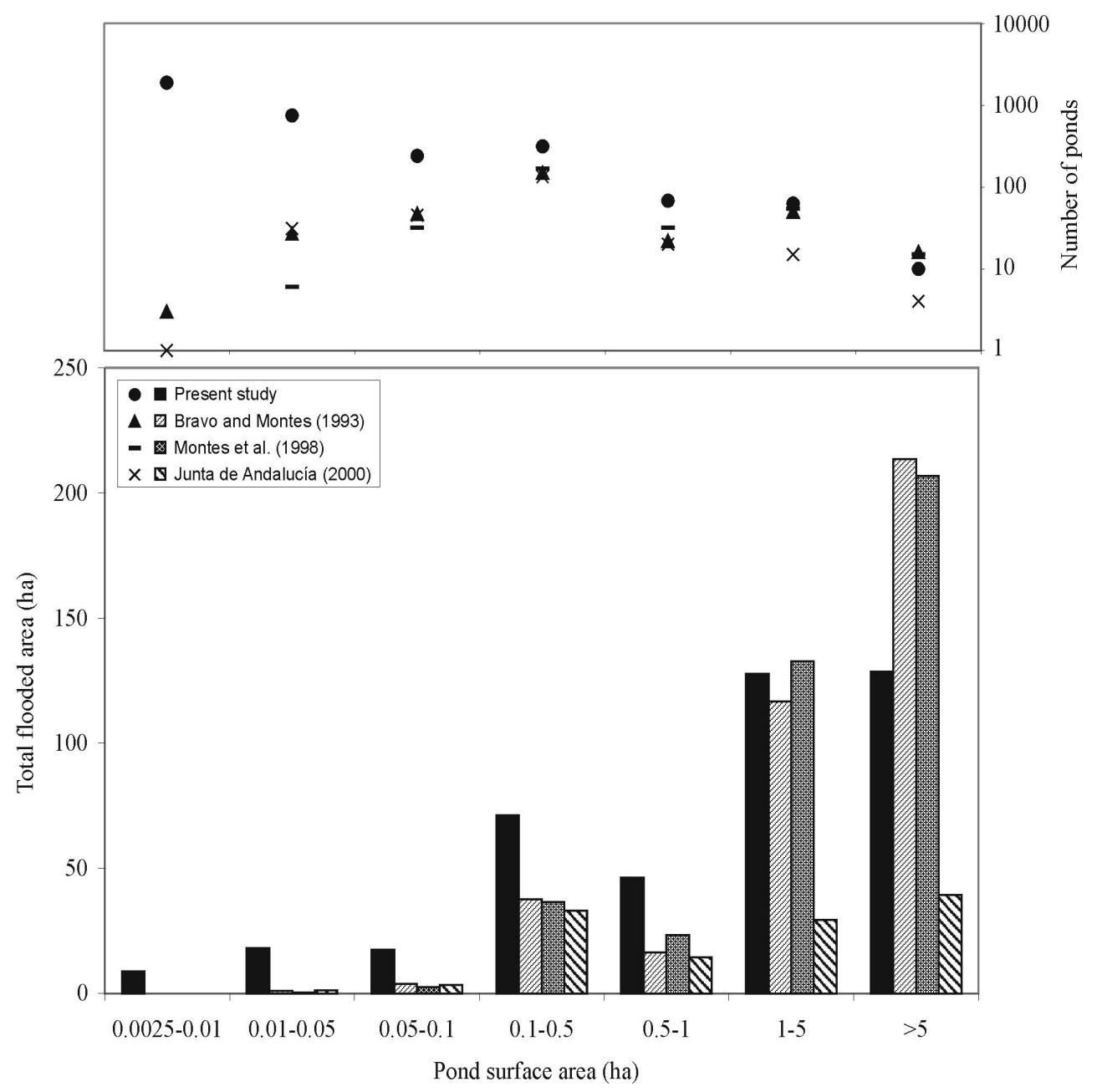

Figure 15. Number of water bodies and total flooded area detected in different cartographies of the study area (present study; Bravo and Montes 1993; Montes et al. 1998; Junta de Andalucía 2000) are specified for seven categories of water bodies according to their size. 

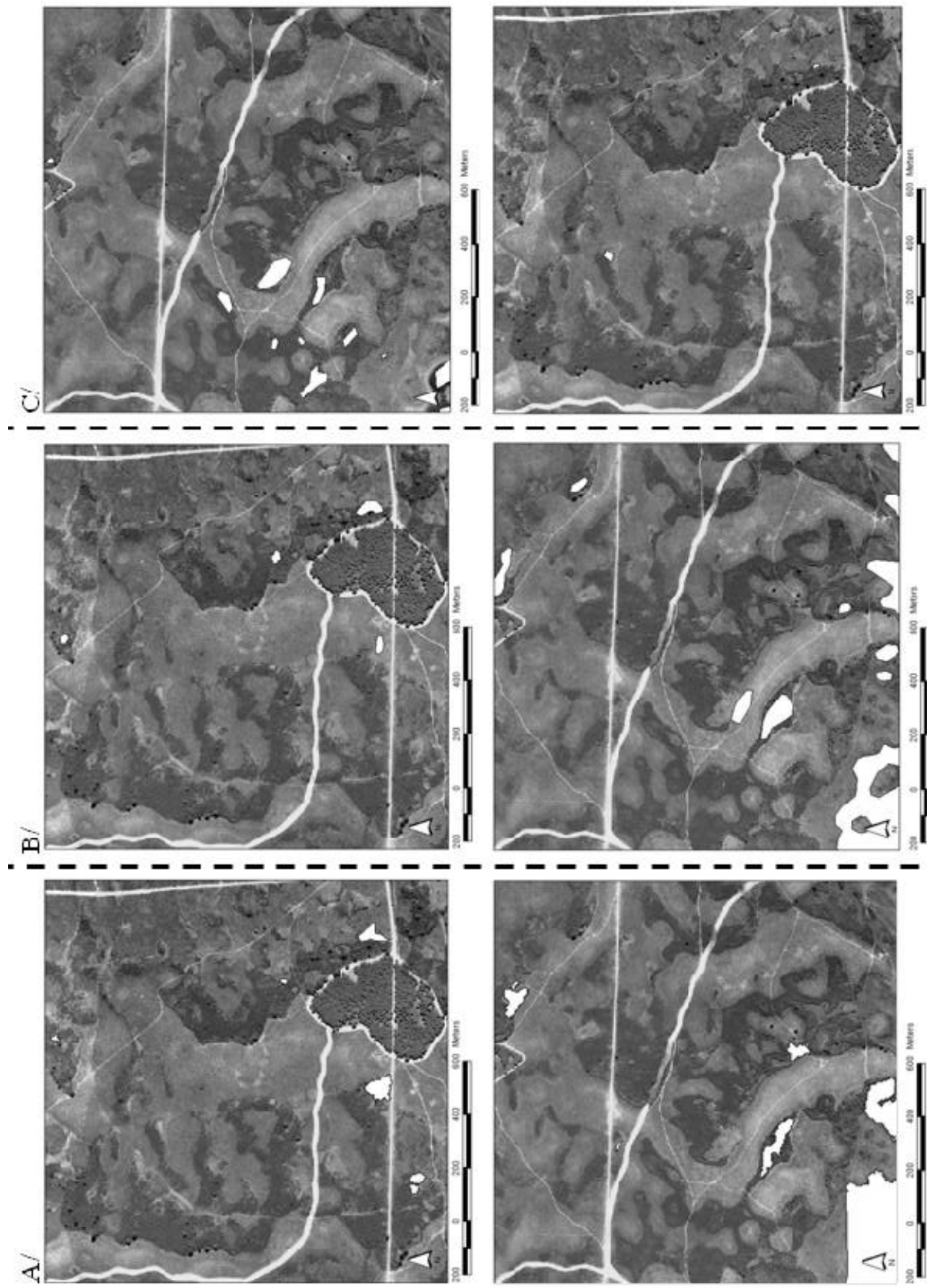

Figure 16. Water bodies detected in the two validation areas in the cartographies of $\mathrm{A} / \mathrm{Bravo}$ and Montes (1993); B/Montes et al. (1998); and C/topographic map from Junta de Andalucía (2000). Cartographies are represented on aerial ortophotography (Junta de Andalucía 2003). 
Table 10. Mapped water bodies in two areas $(1.5 \mathrm{~km} \times 1.5 \mathrm{~km}$, each) were visited in situ to assess the goodness of the cartography. Correct identifications and errors (commission and omission) are specified. The number of polygons and their size (mean, minimum and maximum value) were recorded for each category. Omission error size was estimated from aerial ortophotography. We could not access to two polygons and, therefore, determine their status.

\begin{tabular}{|lcccc|}
\cline { 2 - 5 } \multicolumn{1}{c|}{} & $\begin{array}{c}\text { Number of } \\
\text { water bodies }\end{array}$ & Mean size $\left(\mathrm{m}^{2}\right)$ & $\begin{array}{c}\text { Maximum size } \\
\left(\mathrm{m}^{2}\right)\end{array}$ & $\begin{array}{c}\text { Minimum size } \\
\left(\mathrm{m}^{2}\right)\end{array}$ \\
\hline $\begin{array}{l}\text { Correct } \\
\text { identifications } \\
\begin{array}{l}\text { Omission } \\
\text { errors }\end{array}\end{array}$ & 99 & 9633.03 & 454711.10 & 25 \\
$\begin{array}{l}\text { Commission } \\
\text { errors }\end{array}$ & 13 & 589.70 & 2114.79 & 188.84 \\
Not accesible & 17 & 35.29 & 50 & 25 \\
\hline
\end{tabular}

\section{Discussion}

We have used high spectral and high spatial resolution data to locate and to delineate temporary ponds in Doñana National Park. As recommended by Frazier and Page (2000) with Landsat data, we mapped water bodies applying density slicing in a band from the near-infrared part of the spectrum, based on land and water differences in absorption (Lillesand and Kiefer 1994). The high spectral resolution of the AHS imagery allowed us to apply this methodology (density slicing), much simpler than using decision-tree classifiers based on composite indexes of several bands as in similar studies (Lacaux et al. 2007). However, we encountered the same problem as (Lacaux et al. (2007), since the selection of the threshold value was not straightforward and comparable among the different images. In addition, we had to accomplish a posterior supervised classification to remove errors mainly caused by tree shades, removing $68 \%$ of the elements initially identified as water bodies. Therefore, the delineation of small and temporary water bodies involves an integrative process that should not be short-cut in a single band slicing procedure.

We identified 3335 water bodies in the aeolian system of Doñana National Park, in an area in which previous inventories (Bravo and Montes 1993; Montes et al. 1998; Junta de Andalucía 2000) had only identified 308, 307 or 250 water bodies respectively, less than $10 \%$ of the water bodies present at a time of maximum flooding. These previous cartographies (Bravo and Montes 1993; Montes et al. 1998; Junta de Andalucía 2000) have mainly used visual photointerpretation of ortophotography.

The application of aerial photography to map wetlands has produced both successful (Lathrop et al. 2005) and inadequate results (McCauley and Jenkins 2005). Nevertheless, it is likely that the failure in the identification of many water bodies in the study area was due to the moment of image acquisition (August -October), when most water bodies were dry, rather than to the weakness of the technique applied. 
Nevertheless, the detection of dry pools is difficult because there is no difference in the reflectance of the pool bottom from the surrounding (Lathrop et al. 2005) and they usually lack an identifiable basin. For this reason, we think that the high spatial resolution of current ortophotography (i.e: 1 $\mathrm{m}^{2}$ or $0.5 \mathrm{~m}^{2}$ ) would enable the building of more accurate water bodies cartographies if images were taken in a moment of maximum flooding and, especially on the infrared wavelength.

We recognize that the moment of image acquisition clearly determined the number of water bodies identified in the area since temporary ponds present high inter-annual variation, both in their presence, as they can be flooded or not, and their hydroperiod (water length duration). For this reason, we interpret our cartography as a representation of all potential water bodies in the area, because it was obtained in a moment of maximum flooding.

On the other hand, we do not expect important changes in the number of potential water bodies identified due to misidentification problems, because the number of commission errors was low and balanced to the number of omission errors. In fact, we can only presume omission problems to be true since we could not ground truth the data at the precise moment in which the images were taken and therefore it is possible, although unlikely, that those ponds were not flooded. Problems derived from commission errors could have been diminished by the removal of water bodies below two pixels size. This would lead to a conservative estimation of the number of ponds in the area, removing most of the commission errors as well as the smallest ponds.

Our technique is revealed as a good approach to map and monitor pond networks. This technique will highly ease and improve initial assessments of large wetlands or areas lacking previous data. In particular, amphibian conservation might benefit from its application in the identification of keystone habitats (Fortuna et al. 2006) or hotspots of breeding habitats (Díaz-Paniagua et al. 2006) and, in a wider sense, in connectivity studies (see Cushman 2006 for a review). Furthermore, it is adequate for monitoring unpredictable and fluctuant ecosystems, like Mediterranean temporary ponds, as it would enable the delimitation of real flooding and its annual and inter-annual fluctuation. In these ecosystems, the application of remote sensing to build different cartographies of a particular wetland, thus creating a "flooding dynamic map" that can easily be updated, will contribute to the understanding of the hydrology and dynamics of temporary ponds and highly improve management strategies of associated species.

Comments This section was done in collaboration with Javier Bustamante and Carmen Díaz-Paniagua. C. A. Pacheco (IGME) kindly gave us access to the AHS airborne image of the area; taken by the Remote Sensing Laboratory of Instituto Nacional Técnica Aerospacial (INTA). 


\section{References}

Bravo MA, Montes C 1993. Actas del Congreso Español de Limnología, Granada 31-43.

Bryant RG 1999. Earth Surf Proc Land 24, 283-302.

Cushman SA 2006. Biol Conserv 128, 231240.

Díaz-Paniagua C et al. 2006. Rev Esp Herpetol 20, 17-30.

Fortuna M et al. 2006. $P$ Roy Soc Lond $B$ Bio 273, 1429-1434.

Frazier PS, Page KJ 2000. Photogramm Eng Rem $S$ 66, 1461-1467.

Junta de Andalucía 2000. Mapa topográfico de Andalucía, 1:10000. Provincia de Huelva.

Junta de Andalucía 2003. Ortofotografía Digital de Andalucía.

Lacaux JP et al. 2007. Remote Sens Environ 106, 66-74.

Lathrop RG et al. 2005. J Environ Manage 76, 230-238.

Lillesand TM, Kiefer RW 1994. Remote Sensing and Image Interpretation. John Wiley \& Sons, Inc.

McCauley LA, Jenkins DG 2005. Ecol Appl 15, 1199-1208.

Montes C et al. 1998. Reconocimiento Biofísico de Espacios Naturales
Protegidos. Doñana: Una Aproximación Ecosistémica. Junta de Andalucía. Consejería de Medio Ambiente.

Ozesmi SL, Bauer ME 2002. Wetlands Ecol Manag 10, 381-402.

Revenga $\mathrm{C}$ et al. 2005. Philos Trans $R$ Soc Lond B-Biol Sci 360, 397-413.

Richards JA, Jia X 1999. Remote Sensing Digital Image Analysis. An Introduction. Springer.

Rivas-Martínez S et al. 1980. Lazaroa 2, 5189.

Roshier DA, Rumbachs RM 2004. J Arid Environ 56, 249-263.

Semlitsch RD (Ed.) 2003. Amphibian Conservation. Smithsonian Books, Washington and London.

Semlitsch RD, Bodie JR 1998. Conserv Biol $12,1129-1133$.

Serrano L et al. 2006. Limnetica 25, 11-32.

Siljeström PA et al. 1994. J Arid Environ 26, 315-323.

Sobrino JA et al. 2006. Remote Sens Environ $102,99-115$.

Weiers S et al. 2004. Landscape Urban Plan 67, 43-65. 


\title{
High-resolution remote-sensing data in amphibian
}

\section{studies: identification of breeding sites and contribution}

\author{
to habitat models
}

Remote sensing can provide an alternative to field data sampling in many species-habitat studies. However, its usefulness may depend on the species, habitat studied, spatial resolution and extent. We have used a high spatial and spectral remote sensing image to locate and delineate small amphibian breeding sites in a Mediterranean ecosystem (Doñana National Park). We have also evaluated its usefulness in detecting habitat heterogeneity (number and evenness of different radiometric zones) within ponds and its relation with amphibian species richness. Furthermore, Generalized Linear Models (GLMs) were used to evaluate the usefulness of high-resolution remotesensing data to model amphibian distribution at species level (presence/absence data), both when used alone or as a complement to field data. Amphibian species richness correlated positively with habitat heterogeneity when we discriminated a low number of potential different zones within ponds (four vs. nine). For most species, remotesensing data improved on amphibian distribution models built from field data but presented limited utility when used alone. In consequence, although remote-sensing data could be used for the preliminary identification of ponds supporting high species richness, we recommend initial assessment of its utility for indentifying speciesspecific breeding sites before conducting survey programs based on it. 


\section{Introduction}

Freshwater ponds support more species, more unique species and more scarce species than other water body types, i.e. streams or rivers (Williams et al. 2003). In particular, freshwater ponds with a recurrent dry phase, temporary ponds, constitute the main breeding habitat of many invertebrate (Williams 1997; Grillas et al. 2004; Williams 2006) and amphibian species (Díaz-Paniagua 1990; Griffiths 1997; Semlitsch 2003). Nevertheless, and despite its conservation value, pond ecosystems are threatened worldwide by their drastic diminution in number (Oertli et al. 2005). In order to protect such valuable and vulnerable ecosystems, Mediterranean temporary ponds are considered a priority habitat under the European Union Habitats Directive (European Commission 2007), deserving specific conservation programs. Conservation programs require from ecosystem monitoring, which is difficult in Mediterranean temporary ponds due to their unpredictability, temporal fluctuations and frequently small size. Besides, costefficiency precludes unlimited sample size. For this reason, ponds expected to support rare, endangered or a large number of species should be identified and prioritized in monitoring programs.

Remote sensing may provide data from broad spatial extents that would be prohibitively expensive if collected using field-based methods (Kerr and Ostrovsky 2003). Usefulness of remote-sensing data to predict species distributions constitutes an important research topic (Kerr and Ostrovsky 2003; Turner et al. 2003; Gottschalk et al. 2005). Previous studies have explored the contribution of remote sensing data, in comparison to climatic variables, to predictive species modeling at large scales (Venier et al. 2004; Zimmermann et al. 2007; Buermann et al. 2008). However, similar approaches have rarely been conducted for vertebrates at smaller scales. To be useful at landscape scale, remote sensing should at least be able to delineate potential habitats for the species of interest. The application of remote sensing to map potential habitats will provide a highly valuable tool for the management and conservation of species 
associated to spatially discrete habitat patches, such as pond-breeding amphibians. Despite remote sensing data is regarded as a useful tool for the delineation and monitoring of freshwater ecosystems (Revenga et al. 2005), it has scarcely been applied to amphibian research, with only some studies focusing on global (Carey et al. 2001; Middleton et al. 2001) and landscape scales (Scribner et al. 2001). Most previous remote-sensing studies of aquatic ecosystems have focused on the delineation of large water bodies (see Ozesmi and Bauer 2002), in particular in the Mediterranean region (Alphan and Yilmaz 2005; Castañeda et al. 2005; Papastergiadou et al. 2007). Small freshwater ponds, an important breeding habitat for amphibians, have been frequently disregarded because of spatial resolution constraints of satellite remote sensing. However, recent technology (i.e. airborne sensors) produces high-resolution spatial and spectral images, enabling the detection of small ponds (Weiers et al. 2004; Lacaux et al. 2007). From a biotic perspective, high-resolution images might also enable identification of habitat characteristics that condition the distribution of associated species (see Lacaux et al. 2007 as an example of the application of high spatial resolution satellite imagery to monitor mosquito habitat) and, in consequence, facilitate the identification of habitats holding rare, endangered or a large number of species. These theoretical potentialities of highresolution remote sensing data should be evaluated prior to the undertaking of survey, conservation or monitoring programs based on it. Doñana National Park, where a large number of temporary ponds are protected (Díaz-Paniagua et al. 2006), can provide a model system to assess the contribution of remote sensing to habitat models of amphibians breeding in small temporary ponds.

The existence of specific microhabitats within water bodies is especially important for some amphibian species (Díaz-Paniagua 1987; McAlpine and Dilworth 1989). Both depth and aquatic vegetation cover were previously observed to influence amphibian species-specific preferences for particular zones within ponds in Doñana National Park (Díaz-Paniagua 1987). Moreover, the great diversity of ponds in the area and, thus, differences in microhabitat presence and extension, result in differential usage of ponds as breeding habitats, with some species being restricted to a particular kind of water body (Díaz-Paniagua 1990). Observed spatial segregation due to abiotic characteristics of ponds, both at local (pond) and microhabitat scales, enables the differentiation of pond types and, furthermore, of zones within larger ponds favourable for particular species.

On the other hand, number, spatial structure and extent of microhabitats are factors determining habitat heterogeneity within a water body. Habitat heterogeneity positively correlates with species diversity since complex habitats usually provide more niches and diverse ways of exploiting the environmental resources (see Tews et al. 2004 for a review). Therefore, the assessment of habitat heterogeneity can be used to identify breeding habitats favouring amphibian diversity. 
In this study, we expected remote sensing to be useful to delineate different zones within ponds reflecting microhabitats differences. The underlying rationale is that, in the study area, pond microhabitat zonation can be established based on differences in aquatic vegetation distribution, related to differences in depth (Díaz-Paniagua 1987). On the other hand, hyperspectral remote-sensing data have been used to identify differences in vegetation (Hirano et al. 2003; Schmidt and Skidmore 2003) and depth (Marcus et al. 2003) and have also allowed delimitation of different zones within different water bodies (Marcus 2002; Marcus et al. 2003). So, we applied remote sensing data to identify different radiometric zones, i.e. zones with different radiometric reflectance, presumably caused by differences in depth and vegetation, within larger ponds. Radiometric zones were expected to be useful in predicting habitat availability and suitability for particular amphibian species as well as ponds supporting high amphibian richness in Doñana National Park.

With this study, we make an initial assessment of the contribution of remotesensing data to amphibian distribution studies, both at community and species level. We hypothesize that high-resolution remote sensing will identify amphibian breeding sites that have been missed in previous cartographies built by photointerpretation (Bravo and Montes 1993). We also hypothesize that remote sensing data will be a useful predictor in habitat models, as reported at larger scales (Venier et al. 2004; Zimmermann et al. 2007; Buermann et al. 2008), although best models will be those built from remote- sensing and field-data. In particular, in this study, we evaluate the potential of remotesensing to: i/ map a system of small temporary ponds; ii/ indentify different radiometric zones within the ponds, as a surrogate for habitat heterogeneity; iii/ explore the potential of radiometric zones for explaining species distribution and species richness; and iv/ explore the potential of radiometric zones for enhancing habitat distribution models based on fieldmeasured pond characteristics. This study is not designed to model amphibian habitat requirements, which will be analysed in further studies conducted in the entire National Park, including a larger number of amphibian breeding sites.

\section{Material and Methods}

Doñana National Park (see Siljeström et al. 1994 for a general description), located in south-western Spain (ure 1), is considered to be one of the largest (54 252 hectares) and most important wetlands in southern Europe. Our study area comprises approximately 7500 hectares of sandy soils in the National Park (Figure 17), where a large number of ponds are usually formed during the rainy season (Díaz-Paniagua et al. 2006; Serrano et al. 2006).

Freshwater ponds vary widely in size, from rain puddles (several square metres) to large temporary ponds ( $>1$ hectare). Most water bodies in this area are temporary ponds which dry out during summer. Only two shallow lakes, larger than 10 hectares, are permanent water bodies, although they have been reported to dry out sporadically. 
Temporary ponds are also subject to a wide range of flooding duration. Water table depth determines the onset and duration of inundation, with flooding occurring when water table rises above the topographical surface (Serrano et al. 2006). Water table depth also determines the presence of hygrophyte vegetation in the immediate surroundings of many ponds (dense vegetation mainly composed of Erica scoparia L., Erica ciliaris L., Calluna vulgaris (L.) Hull and Ulex minor Roth.). As a consequence, many pond basins are completely or partially enclosed by a fringe of hygrophyte vegetation that may be occasionally flooded. In addition, these water bodies differ in depth (Díaz-Paniagua 1990), vegetation (Rivas-Martínez et al. 1980; García Murillo et al. 2006) and water chemistry (Serrano and Toja 1995; Serrano et al. 2006).

For this study, we collected field data (pond characteristics and amphibian presence) in 63 ponds. Due to logistic limitations, we only selected 51 water bodies, not necessarily the same as those previously surveyed, to develop the classification of pixels into different radiometric zones using remote-sensing techniques. We applied this classification to all pixels within the 63 field-monitored ponds.

\section{Pond Characteristics}

In this study we considered the following characteristics of 63 ponds: hydroperiod

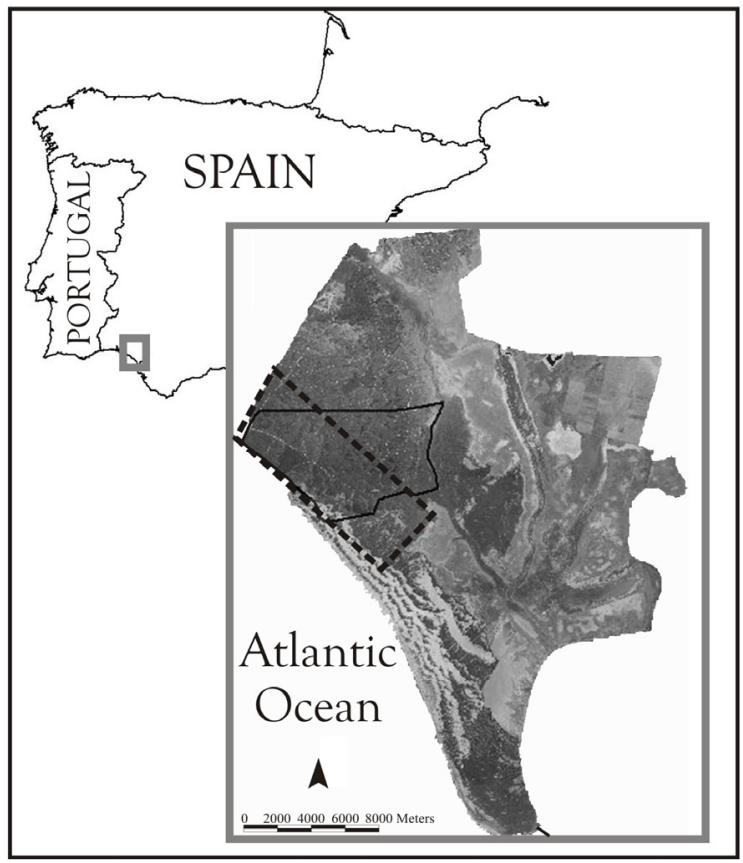

Figure 17. Location of Doñana National Park Park in southwestern Spain and orthophotography of the study area. Solid line represent the Doñana Biological Reserve, where most of the study ponds are located. Dot line represents the study area. 
(duration of flooding), water depth, percentage of surrounding vegetation, temporal surface connection to adjacent ponds and presence of deeper anthropogenic zones within (hereinafter referred to as zacallones, the local name), which prolong the hydroperiod and are used to water cattle or wild mammals during the dry season (Serrano et al. 2006). In addition, we also considered pond coordinates and size, both extracted from the water body cartography mapped with remote-sensing analyses (see below).

Hydroperiod was categorized in five groups according to data obtained in 2003: i/ ephemeral ponds (flooded 1-2 months), ii/ intermediate temporary ponds (3-6 months), iii/ long-duration temporary ponds (7-11 months), iv/ permanent water bodies (12 months) with natural origin (size $>10$ hectares) and v/ permanent water bodies (12 months) with anthropogenic origin, locally named isolated zacallones (size $20-30 \mathrm{~m}^{2}$ ). Although most ponds were regularly visited in various monitoring programs during that year, the exact date of desiccation could not be assessed for several water bodies. In those cases, hydroperiod category was inferred from control ponds $(n=21)$ that were visited on a weekly basis and represented the same pond typologies. Pond typologies were based on characteristics related with flooding duration such as aquatic vegetation associations (RivasMartínez et al. 1980), basin topography and past recordings of hydroperiod in those ponds in wet years (Díaz-Paniagua, unpublished data). Depth ranged from several centimetres in small puddles to more than $2.5 \mathrm{~m}$ in the largest ponds, and was grouped in three relatively broad categories: shallow $(40 \mathrm{~cm}$ approx. maximum depth), medium $(40-80 \mathrm{~cm}$ approx. maximum depth) and deep (> 80 cm approx. maximum depth). Proportion of pond shore surrounded by adjacent hygrophyte vegetation, estimated from aerial photography, led to five categories: i/ hygrophyte vegetation surrounding more than $75 \%$ of the pond; ii/ hygrophyte vegetation surrounding $25-50 \%$ of the pond; iii/ hygrophyte vegetation surrounding less than $25 \%$ of the pond; iv/ no hygrophyte vegetation, but trees in the immediate surroundings of the pond and v/ no hygrophyte vegetation nor trees in the immediate surroundings of the pond. We also distinguished between isolated ponds and ponds showing temporal surface connection to other water bodies, by visual inspection of the water body cartography (see below) and field verification. Temporal surface connection to a larger water body was determined if the pond was identified as part of a bigger mass of water. In those cases, limits between ponds had to be manually delineated, based on aerial orthophotography (Junta de Andalucía 2003). Presence or absence of zacallones within the pond was assessed during amphibian field survey. 


\section{Amphibian Sampling}

Although remote-sensing data were taken in 2004, amphibian data were collected during a four-year survey (2001-2004), to avoid overlooking the presence of any species due to inter-annual turnover in community composition (Skelly et al. 1999; Trenham et al. 2003). We assessed amphibian reproductive success in 63 ponds using dipnetting techniques to detect species larvae (Heyer et al. 1994). Depending on different monitoring programs, thirty one ponds were sampled repeatedly (2-18 surveys) while the rest were surveyed only once in the four years of the study (mean number of surveys $=4.37 \pm 1.35$ [S.D.]). Total number of species detected in a pond during the period 2001-2004, not accounting for the fact that there was a different sampling frequency, represented the cumulative species richness in the pond (hereinafter "species richness"). The correlation between species richness and the number of visits yielded a low value of shared variation (Spearman correlation, $r=$ $0.380, \mathrm{p}<0.05)$. This low correlation suggests that differences in sampling effort are not a relevant bias for richness values.

Amphibian sampling consisted on the capture of larvae using a dipnet along two perpendicular transects in each pond. We identified in situ the individuals captured in each sampling unit (three consecutive sweeps on a stretch of approx. $1.5 \mathrm{~m}$ length) and then released them in the pond. Sampling effort was proportional to pond size, except when not logistically achievable due to the large size of the water body (longduration and permanent water bodies), in which case we tried to sample all different pond microhabitats. Sampling units were distanced a minimum of five metres to avoid interferences between surveys.

\section{Remote-Sensing Analysis of High- Resolution Spectral and Spatial Data}

The study area was overflown during a remote-sensing campaign conducted by the Remote Sensing Laboratory of the Instituto Nacional de Técnica Aeroespacial (INTA) in a period of maximum inundation, April 2004. An airborne hyperspectral spectrometer (AHS, Sobrino et al. 2006) was used to obtain a cloud-free image with a spatial resolution of $5 \times 5 \mathrm{~m}$. We chose a remote-sensing image taken in a period of maximum flooding to map all potentially distinguishable radiometric zones, i.e. zones with different radiometric reflectance within ponds, presumably caused by differences in depth and vegetation. This cartography was considered a reference characterization of pond maximum heterogeneity and zonation. We radiometrically corrected the image, converting digital numbers (DNs) to absolute radiance values based on the instrument's calibration coefficients. We geo-referenced the image applying second order polynomial transformation and nearest-neighbour resampling. Afterwards, we applied remote-sensing techniques to delineate water bodies and to map different zones within (Figure 18). All analyses, except where otherwise noted, where conducted using ENVI 4.0.

We delineated water bodies by applying a density slicing (Richards and Jia 1999) in an infrared spectral band ( $\lambda$ center $=1.004$ $\mu \mathrm{m} ; \lambda$ width $=0.030 \mu \mathrm{m})$, based on land 
and water differences in absorption of radiation in the near-infrared part of the spectrum (Lillesand and Kiefer 1994). This technique consists on applying a threshold value that discriminates potential water bodies (pixel values below the threshold) from land (pixel values above the threshold), being the latter masked as zero values. We applied a supervised classification (Lillesand and Kiefer 1994; Richards and Jia 1999) to the resulting image (only potential water bodies), a procedure that clusters pixels into userdefined classes, in order to separate shaded areas from water, using field surveys and visual inspection of orthophotography (Junta de Andalucía 2003) as input data.

We mapped different radiometric zones within water bodies by applying a technique derived from the Modified cluster technique, first described by Fleming et al. (1975), to bands in the visible and infrared part of the spectrum (21 bands; $\lambda=0.453$ $1.622 \mu \mathrm{m})$. Our application of the Modified cluster technique basically consisted of initially applying an ISODATA unsupervised classification (Lillesand and Kiefer 1994; Richards and Jia 1999) to aggregate similar pixels into spectral classes in 51 water bodies. Since we conducted an independent ISODATA classification in each water body, we had to group similar spectral classes, identified in different ponds, using hierarchical agglomerative clustering (Statistica 6.0). Hierarchical agglomerative clustering groups spectral classes based on spectral values similarity, starting with individual classes until all classes are linked in different clusters. The number of groups is not known a priori and has to be determined from visual inspection of the results (dendrogram). Two different linkage-distance cut points were established based on dendrogram branches length (representing the degree of dissimilarity). The first linkage-distance cut point was set to differentiate the maximum number of major (largely dissimilar) types of spectral classes, yielding a classification of four classes (4-GROUP CLASSIFICATION). The second linkage-distance cut point was set to differentiate the maximum number of distinguishable groupings that had similar number of spectral classes (ten types of spectral classes). However, two of these latter types of spectral classes

However, two of these latter types of spectral classes presented low statistical differences in their response patterns, as evidenced by their low separability index (Jeffries-Matusita and Transformed Divergence [Richards and Jia 1999]), and had to be merged, to yield a classification of nine classes (9-GROUP CLASSIFICATION). For each classification, we performed a Maximum Likelihood Supervised Classification (Lillesand and Kiefer 1994; Richards and Jia 1999) on the 63 field-sampled ponds and applied Majority Analysis to smooth the final image through elimination of spurious pixels by means of changing their class identity to the dominant one in the adjacent pixels. This smoothing is necessary in order to preserve the integrity of polygons (i.e. we delineate homogeneous zones expected to correspond to different habitats). 
We produced two different maps; one distinguishing four different types of spectral classes (hereinafter radiometric zones) that may be present within water bodies (4-ZONE MAP) and the other distinguishing nine (9-ZONE MAP).

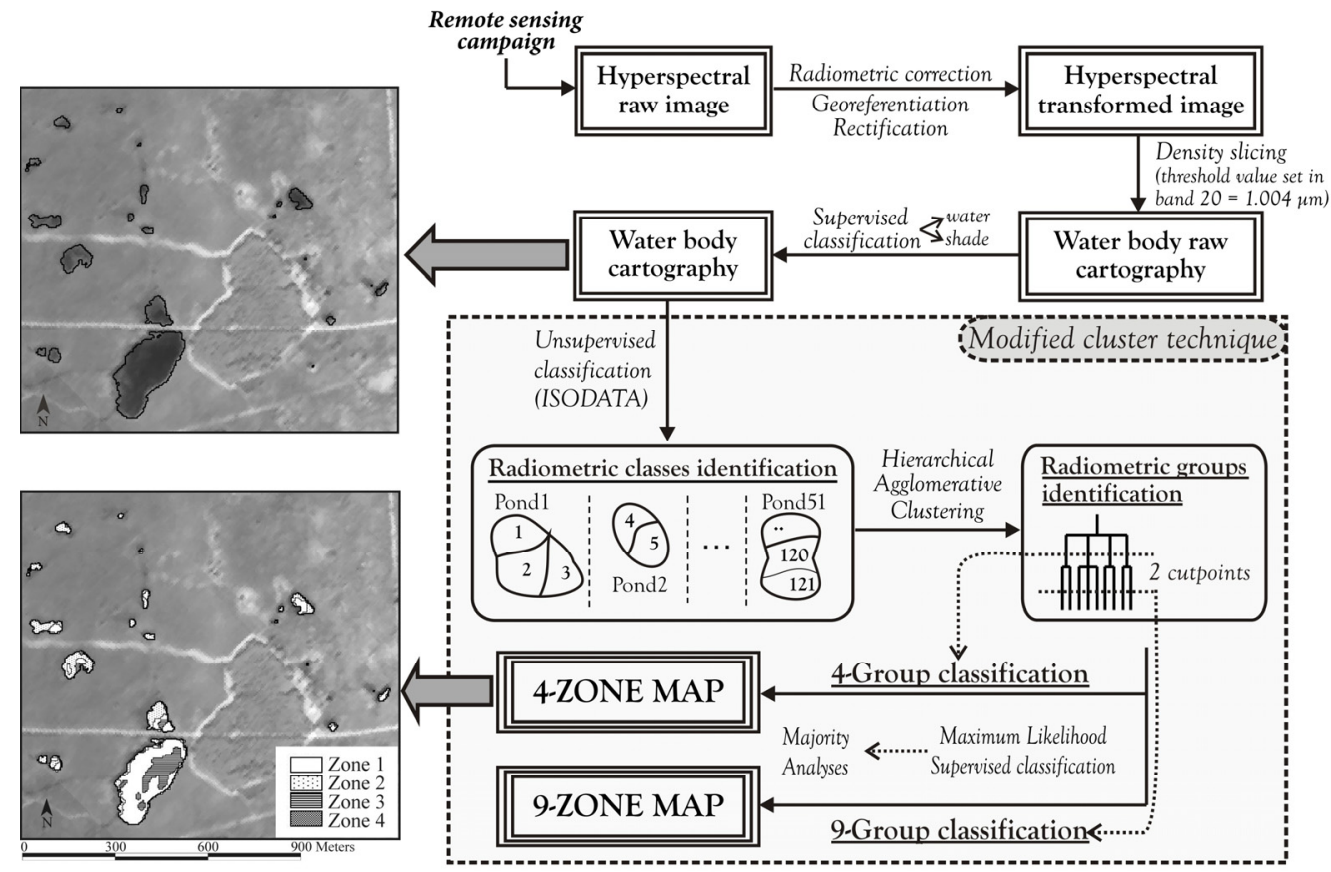

Figure 18. Scheme of the methodology applied. Remote sensing and classification analyses were conducted to obtain two cartographies representing different types of spectral classes (radiometric zones) within ponds. Cartographies differed in number of radiometric zones considered: nine (9ZONE MAP) or four (4-ZONE MAP). A subsample of the study area is used to illustrate the water body cartography and the 4-ZONE MAP cartography.

\section{Statistical Analyses}

We calculated the number and evenness of radiometric zones for each water body and each cartography (4-ZONE MAP and 9ZONE MAP). Evenness of radiometric zones constitutes an index of structural diversity, representing habitat heterogeneity (Tews et al. 2004), and was computed as the Shannon diversity index using vegan package (Oksanen et al. 2007) in $R$ ( $R$ Development Core Team 2006). Differences in zone number and evenness (habitat heterogeneity within pond) among depth and hydroperiod categories were tested with ANOVA analyses. We squared the Shannon index in the 9-ZONE MAP to achieve normality in model residuals. Relationship between species richness and number and evenness of radiometric zones was computed as Spearman correlation for each cartography.

We built Generalized Linear Models (GLMs) (McCullagh and Nelder 1989) to evaluate the predictive ability of radiometric zones for amphibian species occurrence. 
Models were not built for species present in less than $20 \%$ of ponds, due to their low prevalence. Additionally, we reduced potential biases caused by differences in species phenology in the area (DíazPaniagua 1988) by means of reducing each species dataset to the data recorded when the species was available to be detected in the field. Thus, for each species and sampling season, we considered only the surveys conducted between the dates of first and last detection of the species in any pond in the entire study area. We built GLMs using binomial errors and logit link. The response variable was a bound vector (number of presences/number of absences). Bound vectors weighted cases in proportion to the number of surveys conducted in the pond number of presences + number of absences). Model development and variable selection was based on Akaike's selection criterion (AIC), using an automatic forwardbackward stepwise procedure (step.glm, SPlus 2000).

The same analyses were applied to model species richness, using the number of species detected in a pond as response variable with gaussian errors and identity link. Each case was weighted by the number of surveys conducted in the pond.

We built five different models for each species and for species richness:

- One POND model. Characteristics of ponds assessed in field visits as well as pond area and latitude and longitude coordinates of the center of water body, to evaluate spatial dependence, were tested as potential predictors.
- Two RADIOMETRIC models. We built two models, one considered four radiometric zones (RM4), and the other considered nine (RM9) as potential predictors. Predictors consisted of the percentage of each radiometric zone in the pond as well as the number of different radiometric zones and surface area of the whole pond. All Pearson correlation coefficients calculated between predictors were lower than 0.75 , so all variables were tested as potential predictors.

- Two SEQUENTIAL models. Models built from pond variables were tested for improvement by including radiometric predictors: one model was built for four radiometric zones (SEQ4) and another for nine (SEQ9). We fixed the predictor variables from the final explanatory POND model as the initial and minimum model for each species. Then, we allowed the inclusion of radiometric variables: percentage of each radiometric zone and number of different radiometric zones.

Models were evaluated based on discrimination ability, with the same dataset used for model building. This will overestimate their accuracy but will not affect model comparisons (Seoane et al. 2004). Goodness-of-fit was assessed by calculating Spearman correlation coefficients, considered an effective accuracy measure for probabilistic models (Miller et al. 1991), between the number of presences/number of visits ratio and the predicted probability of occurrence. Model type differences were tested with a Repeated Measures ANOVA and post-hoc Tukey's pairwise comparisons of correlation coefficients. 


\section{Results}

We mapped a total of 1106 ponds, with a minimum pond size of $5 \times 5 \mathrm{~m}$. Remotesensing analyses showed that most ponds contained several radiometric zones, whose mean number was 2.57 ( \pm 0.78 S.D.) in 4ZONE MAPS and 4.08 ( \pm 1.60 S.D.) in 9ZONE MAPS. The number of radiometric zones registered varied significantly with depth (ANOVA, $\mathrm{F}_{2,60}=9.930, \mathrm{p}=0.002$ in 4-ZONE MAP and $\mathrm{F}_{2,60}=6.857, \mathrm{p}=0.002$ in 9-ZONE MAP), being higher in relatively deeper ponds (Table 11). The number of radiometric zones was not related to differences in hydroperiod (ANOVA, $\mathrm{F}_{4,58}=$ $1.232, \mathrm{p}=0.307$ in 4-ZONE MAP and $\mathrm{F}_{4,58}$ $=1.293, \mathrm{p}=0.283$ in 9-ZONE MAP) (Table 11). We also found significant differences, according to depth, in radiometric zone evenness, measured as an index of habitat heterogeneity (ANOVA, $\mathrm{F}_{2,60}=7.722, \mathrm{p}=0.001$ in 4-ZONE MAP and $\mathrm{F}_{2,60}=3.560, \mathrm{p}=0.035$ in $9-\mathrm{ZONE}$ MAP). Habitat heterogeneity increased with relative water depth (Table 11). No differences were found among hydroperiod categories (ANOVA, $\mathrm{F}_{4,58}=0.498, \mathrm{p}=$ 0.737 in 4-ZONE MAP and $F_{4,58}=0.077, p$ $=0.989$ in $9-\mathrm{ZONE}$ MAP).

Amphibian surveys revealed the presence of 10 species: Bufo bufo (Linnaeus, 1758), Bufo calamita Laurenti, 1768, Pelodytes ibericus Sánchez-Herráiz, Barbadillo, Machordom \& Sanchiz, 2000, Pelobates cultripes (Cuvier, 1829), Discoglossus galganoi Capula, Nascetti, Lanza, Bullini \& Crespo, 1985, Pelophylax perezi (Seoane, 1885), Hyla meridionalis Boettger, 1874, Pleurodeles waltl Michahelles, 1830, Triturus pygmaeus (Wolterstorff, 1905) and Lissotriton boscai (Lataste, 1879).

Table 11. Mean number and standard deviation (S.D.) of the number and evenness of radiometric zones per pond; specified for the whole study area (TOTAL) and also differentiating among ponds with different relative depth categories and different hydroperiod categories. Two cartographies of radiometric zones are considered, one differentiating four zones (4-ZONE MAP) and another nine (9-ZONE MAP).

\begin{tabular}{|lcccccccccc|}
\cline { 3 - 10 } & \multicolumn{1}{c}{} & \multicolumn{4}{c}{} & \multicolumn{3}{c}{ 4-ZONE MAP } & \multicolumn{3}{c|}{ 9-ZONE MAP } \\
\cline { 2 - 11 } & & \multicolumn{2}{c}{ Number } & \multicolumn{2}{c|}{ Evenness } & \multicolumn{2}{c|}{ Number } & Evenness \\
\cline { 2 - 11 } & N & Mean & S.D. & Mean & S.D. & Mean & S.D. & Mean & S.D. \\
\hline TOTAL & 63 & 2.57 & 0.78 & 0.702 & 0.266 & 4.08 & 1.60 & 0.987 & 0.416 \\
\hline Relative depth & & & & & & & & & \\
\hline Low depth & 26 & 2.19 & 0.75 & 0.565 & 0.304 & 3.46 & 1.48 & 0.842 & 0.468 \\
Medium depth & 29 & 2.69 & 0.66 & 0.776 & 0.191 & 4.21 & 1.45 & 1.049 & 0.346 \\
High depth & 8 & 3.38 & 0.52 & 0.880 & 0.148 & 5.63 & 1.51 & 1.232 & 0.333 \\
\hline Hydroperiod & & & & & & & & & \\
\hline Ephemeral & 7 & 2.86 & 0.90 & 0.745 & 0.282 & 4.29 & 1.89 & 1.001 & 0.489 \\
Intermediate & 36 & 2.44 & 0.73 & 0.671 & 0.263 & 3.92 & 1.50 & 0.983 & 0.424 \\
Long-duration & 16 & 2.63 & 0.81 & 0.751 & 0.295 & 4.06 & 1.61 & 0.985 & 0.398 \\
Permanent & 2 & 3.50 & 0.71 & 0.732 & 0.188 & 6.50 & 2.12 & 0.968 & 0.399 \\
Zacallon & 2 & 2.50 & 0.70 & 0.701 & 0.197 & 4.00 & 1.41 & 1.046 & 0.720 \\
\hline
\end{tabular}


Pond species richness correlated significantly with the number of radiometric zones (Spearman correlation, $\mathrm{r}=0.476, \mathrm{p}$ $<0.001)$ and habitat heterogeneity (Spearman correlation, $\mathrm{r}=0.400, \mathrm{p}=$ 0.001 ) in the case of four types of radiometric zones (4-ZONE MAP), but did not in the case of the 9-ZONE MAP (number of radiometric zones: Spearman correlation, $\mathrm{r}=0.249, \mathrm{p}=0.051$; habitat heterogeneity: Spearman correlation, $\mathrm{r}=$ $0.191, \mathrm{p}=0.136)$. Habitat use was modelled for seven species. Pelophylax perezi, $P$. ibericus and $B$. bufo, present in fewer than $20 \%$ of the ponds (twelve, five and five respectively), were excluded from the analysis due to their low prevalence.

Models of amphibian occurrence based on pond characteristics or exclusively on radiometric zones were not highly predictive
(Table 12). Models built only from radiometric variables as predictors (RADIOMETRIC models) produced results of a lower explanatory ability than models from pond characteristics did (POND models) (Figure 19, Table 13). Sequential models discriminated better than POND models (Figure 19), although significance was not high (Table 13). Post-hoc Tukey test did not differentiate sequential models built from radiometric predictors calculated from 4-ZONE MAP from sequential models built from radiometric predictors calculated from 9-ZONE MAP (SEQ4 and SEQ9), but did differentiate the latter from models only built from pond characteristics (Table 13). Thus, SEQUENTIAL models built from a cartography representing nine radiometric zones significantly improved on POND model discrimination.

Table 12. Discrimination ability of amphibian occurrence models, presented as Spearman's correlation coefficients between predicted probability of occurrence and percentage of presences (number of presences/number of surveys). Discrimination ability in cumulative species richness models is presented as Spearman's correlations coefficients between the observed number of species and the predicted number of amphibian species. Nomenclature corresponds to GLM model type: POND $=$ models built from field-assessed characteristics; RM $=$ RADIOMETRIC model $=$ models built from radiometric zones; SEQ = SEQUENTIAL models $=$ model built from field-assessed characteristics and radiometric zones; and maximum number of different radiometric zones considered (4vs. 9).

\begin{tabular}{|lccccc|}
\cline { 2 - 6 } \multicolumn{1}{c}{} & \multicolumn{5}{c|}{ Spearman's correlation coefficient } \\
\hline Response variable & POND & RM4 & RM9 & SEQ4 & SEQ9 \\
\hline $\begin{array}{l}\text { Species richness } \\
\text { Species } \\
\text { occurrence }\end{array}$ & 0.500 & 0.349 & 0.199 & 0.500 & 0.527 \\
$\quad$ B. calamita & 0.498 & 0.273 & 0.146 & 0.498 & 0.515 \\
P. cultripes & 0.543 & 0.388 & 0.261 & 0.543 & 0.644 \\
D. galganoi & 0.468 & 0.230 & 0.353 & 0.499 & 0.440 \\
H. meridionalis & 0.331 & 0.250 & 0.300 & 0.381 & 0.449 \\
P.waltl & 0.430 & 0.416 & 0.327 & 0.430 & 0.488 \\
T. pygmaeus & 0.294 & 0.215 & 0.360 & 0.391 & 0.339 \\
L. boscai & 0.383 & 0.205 & 0.060 & 0.443 & 0.451 \\
\hline
\end{tabular}


A similar pattern was observed when considering species richness as response variable (Table 12). SEQUENTIAL model discrimination of nine-radiometric-zone model (SEQ9) was superior to that of more simple models.

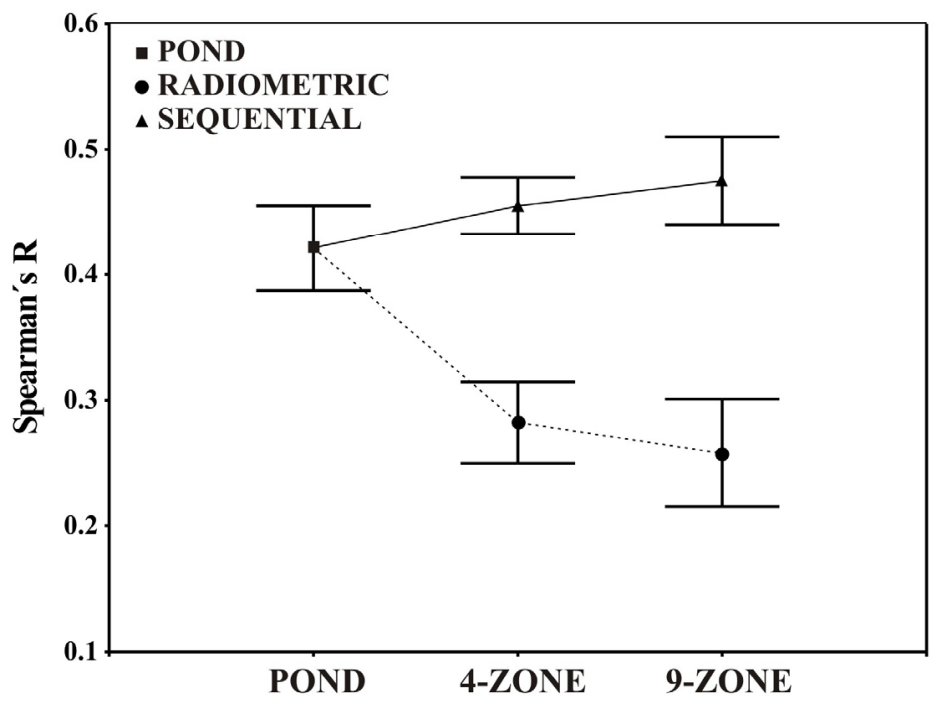

Figure 19. Mean and standard error of Spearman's correlation coefficients between the predicted probability of occurrence and percentage of presences (number of presences/number of surveys) of seven amphibian species. Three modelling approaches with different sets of predictor candidates were evaluated. Models built from radiometric zones (RADIOMETRIC) were compared with models built from pond characteristics (POND) and with models allowing the inclusion of potential radiometric predictors once explanatory variables of pond characteristics were fixed (SEQUENTIAL). Two cartographies, one representing nine radiometric zones (9-ZONE MAP) and another representing four (4-ZONE MAP), were considered as potential predictors in radiometric and sequential models.

Table 13. Results from the Repeated Measures ANOVA analysis comparing the discrimination ability of POND models with the one of RADIOMETRIC and SEQUENTIAL models. F statistics, degrees of freedom (d.f.) and p-values are shown. P-values of pairwise Posthoc Tukey comparisons are also shown.

\begin{tabular}{|lll|}
\cline { 2 - 3 } \multicolumn{1}{c|}{} & POND models & Posthoc Tukey \\
\hline RADIOMETRIC & $\mathrm{F}_{2,12}=6.743, \mathrm{p}=0.011$ & POND vs. RM4 $(\mathrm{p}=0.034)$ \\
models & & POND vs. RM9 $(\mathrm{p}=0.014)$ \\
& & RM4 vs. RM9 (n.s.) \\
SEQUENTIAL & $\mathrm{F}_{2,12}=4.180, \mathrm{p}=0.042$ & POND vs. SEQ4 (n.s) \\
models & & POND vs. SEQ9 (p $=0.036)$ \\
& & SEQ4 vs. SEQ9 (n.s) \\
\hline
\end{tabular}




\section{Discussion}

The spatial distribution of freshwater habitats should be considered in conservation strategies since it determines the distribution and dynamics of associated species, such as amphibians (Semlitsch and Bodie 1998; Semlitsch 2003). We have applied remote sensing techniques on a high spectral and high spatial resolution image to locate and to delineate temporary ponds in an area within the boundaries of Doñana National Park. As recommended by Frazier and Page (2000) with Landsat data, our methodology was mainly based on applying density slicing in a band from the near-infrared part of the spectrum, due to land and water differences in absorption (Lillesand and Kiefer 1994). We identified 1106 water bodies in an area in which a previous inventory has delineated 84 ponds, with a minimum pond basin of $100 \mathrm{~m}^{2}$, using visual photointerpretation of orthophotography (Bravo and Montes 1993). Due to the high spatial resolution of the AHS image, we detected ponds with a smaller size $\left(25 \mathrm{~m}^{2}\right)$. Since previous studies have reported a mean size of 0.53 ha for amphibian breeding sites in the study area (Gómez-Rodríguez et al. in press), we think that the spatial resolution of the AHS image was adequate for the detection of most amphibian breeding ponds. The most important advantage of using remote sensing data in wetland studies is that it can produce spatially explicit information of large areas that may not be realized by field sampling techniques (Shuman and Ambrose 2003). In our study area, the field-assessed mapping of such a large amount of temporary ponds would have been costprohibited.

Remote sensing also enables the detection of environmental parameters influencing species habitat selection or indirect predictors of their distribution (Turner et al.
2003). The successful prediction of species distribution with the use of land cover data depends on the characteristics of the species (Kerr and Ostrovsky 2003; Arntzen 2006), as some species' habitat requirements may not be identified by remote-sensing techniques. In the present study, the utility of remote-sensing data as an alternative tool to field data differed depending on the level of organization (community-level vs. species-level). At community level, it could be used to identify ponds with high species richness by means of identifying ponds presenting high habitat heterogeneity. However, at species level, remote sensing data presented limited utility as predictor of species distributions when used alone and hardly improved on amphibian distribution models built from field data. In consequence, high resolution remote sensing data does not provide robust data to identify potential breeding sites for particular species. Nevertheless, results of the present study, carried out in Mediterranean temporary ponds surrounded by sparse vegetation and with inter-annual variation in abiotic characteristics such as size, depth or hydroperiod, should only be extrapolated with caution to other types of water bodies or landscapes. This fact does not diminish the relevance of our results, since monitoring and conservation of Mediterranean temporary ponds is considered a priority (Zacharias et al. 2007).

Our results show that species richness is positively correlated to the number of radiometric zones and to habitat heterogeneity for pond zonation based on coarse identification of radiometric zones (4-ZONE MAP). However, an increase in the number of radiometric zones differentiated within ponds (9-ZONE MAP) yielded non-significant correlations with cumulative species richness. Therefore, amphibian species richness is related with zone numbers and habitat heterogeneity for 
general classes of microhabitats; but no further specialization is detected with more sensitivity in zone differentiation. So, this result suggests that a broad classification of microhabitats (that are assumed to reflect broad categories as, i.e., "Juncus spp.", "bare soil", "aquatic macrophytes") works better than a more detailed classification in which such microhabitats are subdivided (i.e. "shallower Juncus spp.", "deeper Juncus spp."). Using remote-sensing, there is no difference in the cost of conducting a 4-ZONE or 9-ZONE classification. However, a broad classification is easier and less-costly than a more detailed one if microhabitat zonation is done from field surveys. On the other hand, we tested for differences in the number of zones and habitat heterogeneity among hydroperiod and depth categories. We found significant differences among depth categories, indicating that radiometric zonation probably reflects pond depth zonation, because deeper ponds had a larger depth gradient, and thereby comprised a larger number of radiometric zones and radiometric zone evenness. On the contrary, we did not find differences in habitat heterogeneity nor in zone number among hydroperiod categories.

We also studied the relevance of radiometric zones in modelling the distribution of particular amphibian species. Our study shows that radiometric zones were not good predictors of amphibian occurrence per se and therefore could not be used for the preliminary identification of species-specific potential breeding sites of interest before field surveys. This result suggests that important habitat characteristics for particular species may not be identified by remote-sensing techniques. On the other hand, for most species, radiometric zones contributed, and were complementary, to general pond characteristics in predicting amphibian occurrence. Hence, at landscape scale, high-resolution remotely sensed variables are useful additional predictors for the spatial distribution of pond-breeding amphibian species. Analogous results have been reported at larger scales when assessing the contribution of satellite data to topo-climate variables for predictive modelling of trees (Zimmermann et al. 2007; Buermann et al. 2008), mammals (Buermann et al. 2008) or birds (Venier et al. 2004; Buermann et al. 2008). However, these studies show that remote sensing data were also useful predictors when used alone due to the fact that land cover patterns, obtained with satellite data, are highly correlated with bioclimatic gradients at large scales. Our result agrees with Saveraid et al. (2001), who states that habitat mapping with remote sensing should be complemented with landscape and habitat data collected in the field to predict species occurrences. Although an exhaustive habitat model would require a larger sample size, we think that our sample size was large enough for an initial assessment of the predictive ability of remote-sensing data in amphibian species modelling. Simultaneous field data collection was not possible in this study, so we did not relate radiometric categories to specific amphibian habitats, but rather assessed remote-sensing data predictive ability. Nevertheless, we think that our approach is of interest because remote-sensing campaigns performed with other aims (and thus lacking adequate ground-validation data of pond habitats) can provide radiometric information useful for amphibian distribution in similar temporary water systems. Potentially valuable information could be lost if such data were not examined for the purposes of this study.

Studies relating amphibian presence and abiotic characteristics might be biased by temporal dynamics of amphibian populations (Skelly et al. 1999; Trenham et al. 2003) or their habitats (Skelly 2001). In those cases, many studies reduced potential 
errors by considering cumulative fauna of several subsequent breeding seasons rather than annual fauna (Hecnar and $\mathrm{M}^{\prime}$ Closkey 1996; Houlahan and Findlay 2003) or by consideration of reference values of temporally variable characteristics (Hecnar and M'Closkey 1996; Houlahan and Findlay 2003). Our modelling approach is based on similar assumptions, since we related maximum potential heterogeneity and zonation with the maximum number of species recorded. Nevertheless, we think that an increase in temporal resolution (i.e. seasonal or annual) of the AHS imagery to represent habitat temporal dynamics might model cumulative fauna better than a "static" cartography does, for the latter represents a snapshot of a highly dynamic and stochastic system, as the pond network in Doñana National Park is (Fortuna et al. 2006). We also consider that the study of remote-sensing images from different years would facilitate the assessment of interannual variation in habitat extent and condition, which might be related to temporal variation in amphibian communities (Skelly et al. 1999; Trenham et al. 2003). This would be of special relevance in Mediterranean ecosystems, which are characterized by their unpredictability and fluctuations (Blondel and Aronson 1999).

Finally, our models could have been improved with the inclusion of additional explanatory variables that potentially influence amphibian habitat selection at different scales, like landscape characteristics (Burne and Griffin 2005; Van Buskirk 2005; Denoël and Lehmann 2006). Similarly, an increase in spatial resolution would enable the delineation of very small water bodies, such as rain puddles. This might have improved models of species reported to breed in highly ephemeral water bodies in the study area, such as B. calamita or D. galganoi (DíazPaniagua 1990).

We conclude that, although remote sensing provided a powerful tool in many species-habitat relationship studies (Gottschalk et al. 2005), it was not useful to pre-identify species-specific breeding habitat of interest. However, its application on the assessment of habitat heterogeneity could be used as a proxy to identify, previous to field surveys, ponds supporting high species richness, which should be preserved and monitored. The remote assessment of potential habitats of interest achieves special relevance in large areas with high density of water bodies, such as Doñana National Park (Díaz-Paniagua et al. 2006), where exhaustive survey and monitoring programs cannot be conducted and sampling effort has to be optimized. On the other hand, the inclusion of remotesensing data in medium-term conservation programs could provide valuable information to assess changes in habitat heterogeneity over time that might even be associated with habitat degradation. Finally, we also acknowledge the potential of high resolution remote sensing data for the assessment of the spatial distribution of breeding habitats, which is of special relevance for amphibian dynamics at regional scale, and should be considered in conservation strategies (Semlitsch and Bodie 1998).

Comments This section was done in collaboration with Javier Bustamante, Sampsa Koponen and Carmen DíazPaniagua. Most of the analyses were conducted during a short stay in the Spatial Technology Laboratory (University of Helsinki). This study has been published in the Herpetological Journal (GómezRodríguez et al. 2008. Herpetol J 18: 103113). 


\section{References}

Alphan H, Yilmaz KT 2005. Environ Manage 35, 607-619.

Arntzen JW 2006. Front Zool 3:8.

Blondel J, Aronson J 1999. Biology and Wildlife of the Mediterranean Region. Oxford University Press, Oxford, New York.

Bravo MA, Montes C 1993. Actas del Congreso Español de Limnología, Granada 31-43.

Buermann W et al. 2008. J Biogeogr 35, 1160-1176.

Burne MR, Griffin CR 2005. Wetlands Ecol Manag 13, 247-259.

Carey C et al. 2001. Conserv Biol 15, 903913.

Castañeda C et al. 2005. , J Arid Environ 63, 497-516.

Denoël M, Lehmann A 2006. Biol Conserv 130, 495-504.

Díaz-Paniagua C 1987. Herpetol J 1, 167169.

Díaz-Paniagua C 1988. Amphibia-Reptilia 9, $15-26$.

Díaz-Paniagua C 1990. Herpetol J 1, 447453.

Díaz-Paniagua C et al. 2006. Rev Esp Herpetol 20, 17-30.

European Commission 2007. Interpretation Manual of European Union Habitats. Natura 2000, Nature and Biodiversity. European Commission.

Fleming MD et al. 1975. 54-61.

Fortuna M et al. 2006. $P$ Roy Soc Lond B Bio 273, 1429-1434.

Frazier PS, Page KJ 2000. Photogramm Eng Rem $S$ 66, 1461-1467.

García Murillo PJ et al. 2006. Limnetica 5, 71-80

Gómez-Rodríguez $\mathrm{C}$ et al. In press. Aquat Ecol. Online first

Gottschalk TK et al. 2005. Int J Remote Sens 26, 2631-2656.

Griffiths RA 1997. Aquat Conserv: Mar Freshw Ecosyst 7, 119-126.
Grillas P et al. 2004. Mediterranean Temporary Pools. Volume 2- Species information sheets. Station Biologique de la Tour du Valat.

Hecnar SJ, M’Closkey RT 1996. Ecology 77, 2091-2097.

Heyer WR et al. 1994. Measuring and Monitoring Biological Diversity. Standard Methods for Amphibians. Smithsonian Institution Press, Washington \& London.

Hirano A et al. 2003. Wetlands 23, 436-448. Houlahan JE, Findlay CS 2003. Can J Fish Aquat Sci 60, 1078-1094.

Junta de Andalucía 2003. Ortofotografía Digital de Andalucía.

Kerr JT, Ostrovsky M 2003. Trends Ecol Evol 18, 299-305.

Lacaux JP et al. 2007. Remote Sens Environ $106,66-74$.

Lillesand TM, Kiefer RW 1994. Remote Sensing and Image Interpretation. John Wiley \& Sons, Inc.

Marcus WA 2002. J Geogr Syst 4, 113-126.

Marcus WA et al. 2003. Geomorph 55, 363380.

McAlpine DF, Dilworth TG 1989. Can J Zool 67, 2244-2252.

McCullagh P, Nelder JA 1989. Generalized Linear Models. Chapman and Hall, London.

Middleton EM et al. 2001. Conserv Biol 15, 914-929.

Miller ME et al. 1991. Stat Med 10, 12131226.

Oertli B et al. 2005. Aquat Conserv: Mar Freshw Ecosyst 15, 535-540.

Oksanen J et al. 2007.

Ozesmi SL, Bauer ME 2002. Wetlands Ecol Manag 10, 381-402.

Papastergiadou E et al. 2007. Hydrobiologia 584, 361-372.

R Development CoreTeam 2006. R: a language and environment for statistical computing. http://www.r-project.org. 
Revenga $\mathrm{C}$ et al. 2005. Philos Trans $R$ Soc Lond B-Biol Sci 360, 397-413.

Richards JA, Jia X 1999. Remote Sensing Digital Image Analysis. An Introduction. Springer.

Rivas-Martínez S et al. 1980. Lazaroa 2, 5189.

Saveraid EH et al. 2001. Landscape Ecol 16, 71-83.

Scribner KT et al. 2001. Biol Conserv 98, 201-210.

Schmidt KS, Skidmore AK 2003. Remote Sens Environ 85, 92-108.

Semlitsch RD (Ed.) 2003. Amphibian Conservation. Smithsonian Books, Washington and London.

Semlitsch RD, Bodie JR 1998. Conserv Biol $12,1129-1133$.

Seoane J et al. 2004. Ecol Model 171, 209222.

Serrano L et al. 2006. Limnetica 25, 11-32.

Serrano L, Toja J 1995. Arch Hydrobiol 133, 497-516.

Shuman CS, Ambrose RF 2003. Restor Ecol 11, 325-333.

Siljeström PA et al. 1994. J Arid Environ 26, 315-323.

Skelly DK 2001. Isr J Zool 47, 313-332.
Skelly DK et al. 1999. Ecology 80, 23262337.

Sobrino JA et al. 2006. Remote Sens Environ $102,99-115$.

Tews J et al. 2004. J Biogeogr 31, 79-92.

Trenham PC et al. 2003. Ecol Appl 13, 1522-1532.

Turner W et al. 2003. Trends Ecol Evol 18, 306-314.

Van Buskirk J 2005. Ecology 86, 19361947.

Venier LA et al. 2004. J Biogeogr 31, 315331.

Weiers S et al. 2004. Landscape Urban Plan 67, 43-65.

Williams DD 1997. Aquat Conserv: Mar Freshw Ecosyst 7, 105-117.

Williams DD 2006. The Biology of Temporary Waters. Oxford University Press, Oxford, New York.

Williams P et al. 2003. Biol Conserv 115, 329-341.

Zacharias I et al. 2007. J Environ Biol 28, 1-9.

Zimmermann NE et al. 2007. J Appl Ecol 44, 1057-1067. 


\section{Evidence of hydroperiod shortening in a preserved system of temporary ponds}

We used remote-sensing data (Landsat TM and ETM+ imagery) to evaluate the spatio-temporal variability in the flooding regime of a system of small temporary ponds for a 23years period. In particular, we tried to separate trends in pond deterioration (i.e. shortening of pond inundation) from natural random fluctuations. Although medium-resolution remote sensing data have rarely been applied to the reconstruction of the hydrological dynamics of small-sized wetlands, this study evidences its utility for the understanding of the hydrology of Mediterranean temporary ponds at a local scale. We show that the temporary ponds in Doñana National Park constitute a large and heterogeneous system with high intra and interannual variability, both critical attributes for the preservation of a rich associated fauna. We also evidence that the conservation value of this ecosystem is threatened by the observed tendency to shorter annual hydroperiods in recent years, probably associated to aquifer over-exploitation. The system of temporary ponds in Doñana National Park deserves special attention for the high density and heterogeneity of natural ponds, not common in Europe. For this reason, management decisions to avoid its destruction or degradation, such as the shortening of pond annual hydroperiods, are critical. 


\section{Introduction}

Conservation strategies should take into account the spatial distribution of habitats, since it conditions the distribution and dynamics of their associated species (Semlitsch and Bodie 1998; Semlitsch 2003; Briers and Biggs 2005; Sanderson et al. 2005). However, the spatial distribution of habitats that change over time (fluctuating habitats), such as temporary ponds, may not be constant. The occurrence and extent of temporary ponds may change from year-to-year and therefore alter the distribution pattern of habitats, conditioning the population dynamics of associated species. In consequence, conservation programs focused in such fluctuating ecosystems should incorporate the monitoring of temporal changes in their distribution and extent. Within this monitoring scheme, one of the most important assessments is the discrimination of natural random fluctuations from trends of habitat degradation or disappearance, which may threaten the population stability of their associated species.

Mediterranean temporary ponds present wide variability in filling onset and duration, depending on rainfall input and pattern (Zacharias et al. 2007). Thus, they represent a good example of complex ecosystems with a high temporal heterogeneity in their formation, extent or characteristics. Temporary ponds are the main breeding habitat of many aquatic invertebrate (Williams 1997; Grillas et al. 2004; Williams 2006) and amphibian species (Díaz-Paniagua 1990; Griffiths 1997; Semlitsch 2003). Due to its conservation value, temporary ponds are a priority habitat under the European Union Habitats Directive (European Commission 2007). However, pond ecosystems are threatened worldwide by their drastic reduction in number (Oertli et al. 2005). For this reason, long-term studies recording the temporal changes and tendencies in the number, distribution, extent and duration of flooding (hydroperiod) of pond ecosystems are necessary, although they have been scarce until now.

Remote sensing can be a valuable tool for the monitoring of freshwater ecosystems (Revenga et al. 2005). Satellite data has been broadly applied to map large permanent wetlands (see Ozesmi and Bauer 2002 for a review) and, occasionally, to reconstruct their temporal dynamics over 
the past decades (Bryant and Rainey 2002; Roshier and Rumbachs 2004; Castañeda and Herrero 2005; Castañeda et al. 2005; Díaz-Delgado et al. 2006). However, its application on seasonally flooded systems has been scarce (but see Verdin 1996; Roshier and Rumbachs 2004; Castañeda et al. 2005; Lacaux et al. 2007), and, in particular, in small-sized wetlands (but see Beeri and Phillips 2007) due to the difficulty of identifying landscape units below pixel size (i.e. De Roeck et al. 2008). Landsat imagery may provide adequate data for long-term reconstruction of wetland dynamics due to its temporal resolution (16 days repeat cycle) and temporal coverage (operational for more than 30 years). However, its spatial resolution $(30 \times 30 \mathrm{~m})$ may compromise the identification of small sized ponds. A retrospective pattern of the flooding regime of temporary ponds will provide a high quality data set to depict the effect of rainfall timing in the hydrologic regime of temporary ponds. The effect of rainfall in the area flooded, as extracted from remote sensing data, has been previously evaluated in medium-sized or large wetlands (i.e. Bryant and Rainey 2002; Castañeda and Herrero 2005), but such an approach has never been attempted for small temporary ponds.

The Doñana National Park is one of the most important wetlands in southern Europe. It preserves a large network of temporary ponds (Díaz-Paniagua et al. 2006), with a spatial configuration conferring robustness to inter-annual variability in flooding extent (Fortuna et al. 2006). These ponds are a critical habitat of many species of aquatic flora and fauna: macrophytes (García Murillo et al. 2006), invertebrates (Bigot and Marazanof 1966; Millán et al. 2005; Serrano and Fahd 2005), and amphibians (Díaz-Paniagua 1990; Díaz-Paniagua et al. 2005, 2006). The hydrology of Doñana temporary ponds is directly dependent on groundwater. They are fed by rainfall and a shallow watertable, which is close to the surface everywhere except beneath the dunes (Trick and Custodio 2004). The aquifer consists of two units: a relatively thick unconfined aquifer overlying a lower and more permeable aquifer (Trick and Custodio 2004). On a regional scale, groundwater moves South and East, from the aeolian sands towards the marshes and the sea coast. Serrano and Zunzunegui (2008), in a study conducted in six ponds, recently reported that some ponds may be under threat, since their hydrologic regime may have been damaged by aquifer water extraction by a nearby tourist resort (see also Serrano and Serrano 1996). Scientifically-based management of surface waters in Doñana National Park still requires from information on historical flooding patterns, both spatially and temporally, and their relationships with natural variability or anthropogenic modifications (Haberl et al. in press).

In this study we investigate the applicability of Landsat imagery to assess the spatio-temporal dynamism of a system of temporary ponds. We assess i/ the usefulness of Landsat imagery for the identification of flooding of small temporary ponds, many of them below pixel size; ii/ the intra-annual hydrologic regime of temporary ponds, mainly to depict the general pattern of flooding and drying out; iii/ the spatial variation in the hydrologic behaviour of ponds (i.e. differences in flooded area or duration of flooding) among ecosections within the National Park; iv/ the inter-annual changes in such hydrologic behaviour, mainly to discriminate natural random fluctuations from trends of habitat degradation; and $\mathrm{v} /$ the hydrologic response of temporary ponds to rainfall input and timing. 


\section{Material and Methods}

\section{Study area}

The study was conducted in the Doñana Biological Reserve (6794 ha), within the Doñana National Park (see Siljeström et al. 1994 for a geo-morphological description), in southwestern Spain. Two main ecosystems are differentiated within the Doñana Biological Reserve: the aeolian sands and the marshland. The object of the present study was the system of temporary ponds located on the aeolian sands. In this ecosystem, dominant vegetation is Mediterranean scrub (Halimio halimifoliiStauracanthetum genistoides and Erico scopariae-Ulicetum australis as defined by Rivas-Martínez et al. 1980) with small patches of pine (Pinus pinea L.) and juniper forests (Juniperus phoenicea L. subsp. turbinata (Guss.) Nyman). Based on previous descriptions of the study area (Montes et al. 1998; Díaz-Paniagua et al. 2006), we have differentiated seven ecosections within the aeolian sands, which show different pond density and different geomorphologic, stratigraphic and hydrodynamic characteristics (Figure 20).

A total of 883 temporary ponds and two permanent ponds have been identified in this area at a time of a large flooding event in April 2004 (Gómez-Rodríguez, unpublished data). A detailed description of these ponds can be found elsewhere (Gómez-Rodríguez et al. in press). The flooding regime of temporary ponds (dates of flooding and drying out) is highly variable among years depending on rainfall pattern and quantity. The wet season may extend from September to May and the dry season from June to August.

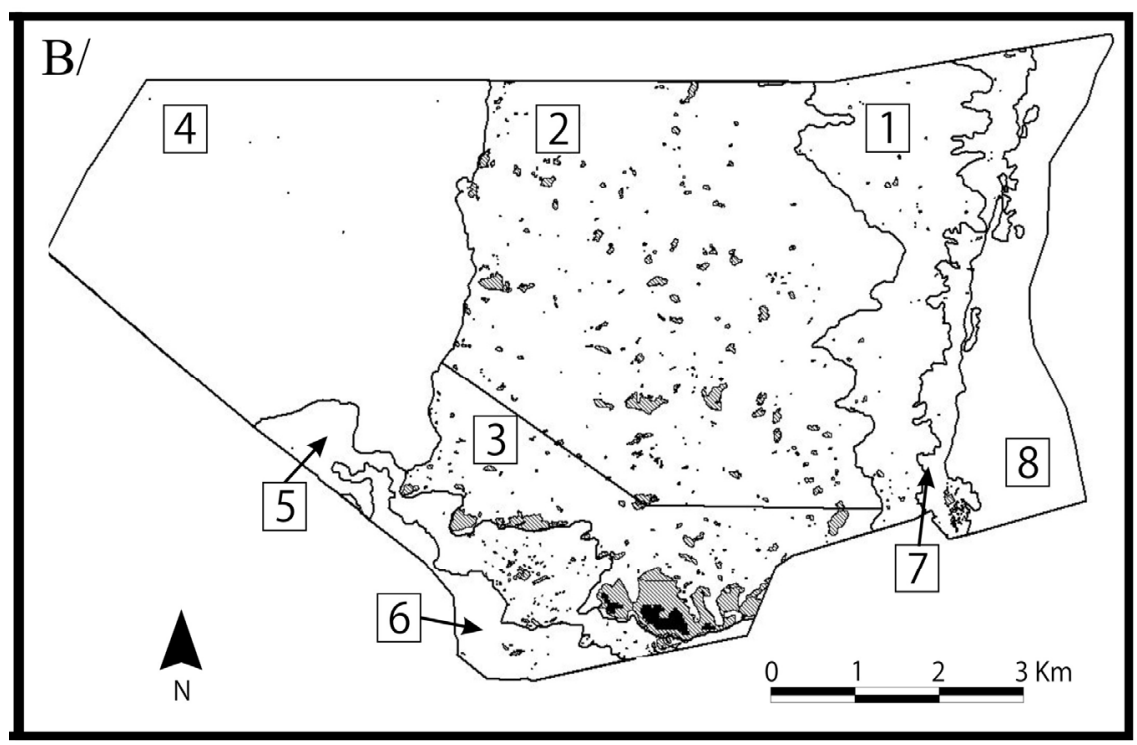

Figure 20. Pond map layer, in grey, and ecosections within Doñana Biological Reserve: 1. Low stabilized sands (exorheic zone)[LOW SANDS]; 2. Northern part of wet high stabilized sands (endorheic zone) [NORTHERN SANDS]; 3. Southern part of wet high stabilized sands (endorheic zone) [SOUTHERN SANDS]; 4. Dry high stabilized sands (arheic zone) [DRY SANDS]; 5. Semi-stabilized dunes [SEMI-STABILIZED DUNES]; 6. Mobile dunes [DUNES]; 7. Ecotone marshes- stabilized sands [ECOTONE]; 8. Marshes. Solid black area represents areas of permanent water and those areas were excluded from this study. 
In this study, we use hydrological years that follow the seasonal hydrological cycle, from September, $1^{\text {st }}$ to August, $31^{\text {st }}$. Mean annual rainfall, from 1984-1985 to 200607, is $585.0 \pm 230.8$ [S.D.] $\mathrm{mm}$, with minimum values of $169.8 \mathrm{~mm}$ recorded in 2004-05 and maximum values of 1027.8 $\mathrm{mm}$ recorded in 1995-96. Rainfall data were obtained from a meteorological station located at "El Palacio de Doñana" within the study area (Doñana Biological ReserveCSIC).

\section{Methods}

Pre-processing of time-series Landsat images

We used 174 cloud-free Landsat TM and Landsat ETM+ images (scene = path 202, row 34) taken between November 1984 and July 2007, from the GIS and Remote Sensing Lab of Doñana Biological Station (LAST-EBD). The number and dates of the images for each year differed because of cloud cover or acquisition failures. This set constitutes the largest remote sensing timeseries with comparable sensors for the area.

Pre-processing of Landsat data was carried out by the LAST-EBD. A total of 62 images, including those with ground-truth data, were co-registered with 80-100 control points (CGPs) to a Landsat ETM+ reference image acquired on July $18^{\text {th }} 2002$ (RMS $<1$ pixel). Due to time constraints, the rest of the images were pre-processed using a short-cut approach that consisted on using 9 GCPs to georreference the image (RMS $<1$ pixel). The resampling method was cubic convolution. Images were radiometrically corrected and transformed into reflectance values using Pons and Solé-Sugrañes (1994) method implemented in MIRAMON. Images were then normalized using a set of pseudoinvariant areas expected to have low seasonal changes in reflectance and covering all the range of reflectance values (see Aragonés et al. 2005; or Bustamante et al. in press for a detailed description of the image processsing procedure). In images georreferenced with 9 CGPs, radiometric correction and normalization was applied only to Band $5(\lambda=1.55-1.75 \mu \mathrm{m})$.

Ground-truth data: In situ delineation of flooded area

During 2005-06 and 2006-07, we systematically surveyed different portions of the study area in six different dates, coincident with an overpass of Landsat 5 or Landsat 7 satellite. On each field visit, we visited all the ponds in the portion of the area surveyed. The pond status (flooded $v s$. dry) was recorded and the limits of surface water, when present, registered with a differential Leica GS20 GPS receiver with an external antenna. GPS data were postprocessed with a reference station to achieve sub-meter locational accuracy. Field visit was guided with the help of a $5 \mathrm{~m}$ resolution pond map layer obtained at a time of a large flood event (see GómezRodríguez et al. 2008 for details on cartographic methods).

\section{Model development and validation}

We fitted a Generalized Linear Model (GLM) (McCullagh and Nelder 1989) to model to the response variable, fraction of a $30 \times 30 \mathrm{~m}$ pixel covered by water, using binomial errors and a logit link. The response variable was in the form of a bound vector (number of $3 \times 3 \mathrm{~m}$ flooded pixels/number of $3 \times 3 \mathrm{~m}$ dry pixels, within each $30-\mathrm{m}$ pixel). As completely dry pixels outnumbered flooded pixels, for each sampling date, we balanced the data by means of randomly selecting a sample of dry pixels equal in number to those partially or totally covered by water (balanced data set). We tested as potential predictors the pixel normalized reflectance in each spectral 
band (B) as well as the value obtained when correcting for its reflectance in the absence of water [Corrected band: $\mathrm{CB}=\left(\mathrm{B}-\mathrm{B}_{\mathrm{DRY}}\right)$ / $\left.B_{\text {DRY }}\right]$ (Table 14). Soil reflectance in the absence of water $\left(\mathrm{B}_{\mathrm{DRY}}\right)$ was extracted from a Landsat image taken in August 2006, when all temporary ponds were dry. Predictor selection was based on percentage of deviance reduction using a manual stepwise procedure.

Model validation was assessed by calculating the Spearman correlation coefficient between the observed fraction of water cover in a given pixel, and the ratio predicted by the model. So, we assume that, for any given pixel, its probability of flooding, as predicted from the GLM model, is a surrogate of the fraction of area covered by water. We used a cross-validation procedure to test the model. In each turn, we split the data set into a construction set (with data from five of the six sampling dates) and a validation set (data from the date that was left-out from model construction). We used the balanced data set for the construction and all the data available (unbalanced data set) for the validation set. The process was repeated until all dates were used as validation sets. We conducted four different model validations to evaluate (a) if the GLM model should be applied to all pixels in the area or only to pond pixels (potentially flooded pixels) and, additionally, (b) if the lowest values of model predictions should be considered as dry pixels. The rationale behind is that zero values (completely dry pixels) are not easily obtained from such GLM models and, thereby, we should expect low values of flooded area to be predicted for field-assessed dry pixels. To zerotransform the lowest values of model predictions, we selected a threshold value that misclassified as partially flooded less than $5 \%$ of groundtruth-assessed dry pixels. On the other hand, we considered a pixel as a potentially flooded pixel if it was included in the pond area, as extracted from the $5 \mathrm{~m}$ resolution pond map layer, or included in a buffer area of $30-\mathrm{m}$ from the edge of the pond.

We also evaluated the temporal differences in model performance by means of ANOVA analyses with posthoc Tukey test, considering the log-transformed model absolute residuals (observed fraction predicted fraction) as response variable and the date of image acquisition as grouping factor.

Historical reconstruction of water coverage in the study area (November 1984 - July 2007)

The final GLM model, fitted to data from all ground-truthing dates, was applied to the time-series of Landsat images to obtain a map of the fraction of water in each potentially flooded pixel on each date. We modified model predictions by applying the ZERO threshold value yielded by the validation procedure. Pixels in permanent ponds that contained water in August 2006 (136 pixels) were excluded from further pixel-based analyses, and analogously, those permanent ponds were removed from further pond-based analyses (i.e. average hydroperiod, pond annual hydroperiod or pond density).

Spatio-temporal variation in the distribution of water

We assessed the spatio-temporal differences in flooded area and duration of flooding (pond hydroperiod). We measured flooded area as the sum of the predicted fraction of water cover for all pixels. We measured pond hydroperiod as the ratio between the number of images in which it appeared to be flooded (at least one pixel of water) and the total number of images. We transformed ratio values to hydroperiod values measured in months. For each pond, we computed two 
different values of pond hydroperiod: average hydroperiod, to depict its hydrological behaviour over the entire study period and computed using all remotesensing images, and annual hydroperiod, computed for each particular year using the images collected then. We only computed pond annual hydroperiods in years with seven or more images and at least one image in each season (autumn, winter, spring, summer), thus resulting in hydroperiod data for twelve years.

- Differences in hydrologic behaviour among ecosections

We assessed the flooded area, pond density and pond size in each ecosection at the time of the largest flood event predicted for the study area (15 February 1990). We computed an ANOVA with post-hoc Tukey test to test for differences in average hydroperiod among ecosections. We squareroot transformed average hydroperiod values in order to achieve normality in model residuals.

- Seasonal hydrologic regime of temporary ponds

To summarize seasonal variation in flooded surface, we plotted the estimated flooded area for each image in an annual scatter graph. The date of acquisition (number of days from September the 1st) was plotted in the $\mathrm{X}$-axis and the total flooded surface in the $\mathrm{Y}$-axis.

- Inter-annual variation in hydrologic behaviour

We conducted a trend analysis of annual rainfall, maximum flooded area and pond annual hydroperiod during the entire study period. Analyses were computed both for the entire study area and for each ecosection. In the case of pond annual hydroperiod, we also computed a trend analysis for each pond in order to build a map representing such tendency.

- Relationship between flooded area and rainfall

We built a multiple linear regression model to assess the effect of rainfall timing in the predicted flooded area for each Landsat-acquisition date. We evaluated six rainfall-derived predictors: rainfall in the previous i/ 1 to 15 days, ii/ 16 to 30 days; iii/ 31 to 90 days; iv/ 91 to 180 days; v/ 181 to 365 days and vi/ 366 to 760 days. We square-root transformed the dependent variable (flooded area) to achieve normality in model residuals. We conducted an automatic forward stepwise procedure of variable selection. We searched for the standardized regression coefficients in order to compare the relative contribution of each independent variable in the prediction of flooded area.

We built eight different multiple linear regression models, one for each ecosection and one for the entire study area. In the model conducted for the entire study area, we searched for temporal differences in model performance with an ANOVA of the regression residuals with posthoc Tukey test. We conducted two ANOVAs, one testing the year in which the image was taken as grouping factor and the other testing the month. 


\section{Results}

\section{Model development and validation}

We monitored 64 different ponds during the ground-truthing campaigns in 2005-06 and 2006-07. Since each pond was visited at different sampling dates, we delineated a total of 164 pond perimeters.

The best model consisted in a single predictor (CB5) and significantly explained $47.09 \%$ of the deviance (Table 14). The inclusion of the second best predictor (CB4) contributed to a $9.1 \%$ increase in explained deviance. However, we did not include CB4 in the final model because its inclusion would yield a reduction of $64 \%$ in the available satellite images due to the fact that radiometric correction of band 4 was not available for 112 out of the 174 images. Model validation showed that the best model predictions were obtained when only potentially flooded pixels were considered and the ZERO threshold value was applied (Table 15). Threshold value of the predicted fraction of water coverage was set to 0.21 and this implied that ponds smaller than $189 \mathrm{~m}^{2}$ could not be identified. The mean size of ponds that were flooded but were classified as dry with the threshold value was $0.20 \pm 0.21 \quad$ [S.D] pixels, corresponding to $180 \pm 189 \mathrm{~m}^{2}$. Applying this threshold both to observed and predicted values of pixel flooding, we correctly classified $72 \%$ of the ponds visited during the ground-truth campaign (Table 16). The analysis of model residuals showed that there were differences in model adjustment among sampling dates (ANOVA $\left.\mathrm{F}_{5,2891}=191.93 ; \mathrm{p}<0.001\right)$. Significantly larger residuals were observed in data from 2006-07 (02-03-2007 and 18-03-2007), when ponds reached the largest observed extension during the field-sampling campaign.

Table 14. Parameters of the final GLM model used to predict the fraction of water cover in a 30x30m pixel from Landsat TM and ETM+ normalized reflectance. We tested as potential predictors the normalized reflectance of each spectral band (Band, B) and its value correcting for its reflectance in the absence of water (Corrected band, CB).

\begin{tabular}{|c|c|c|c|c|}
\hline \multicolumn{5}{|l|}{ Adjusted model parameters } \\
\hline \multicolumn{2}{|l|}{ Final model parametization } & $\mathrm{F}$ & d.f. & $\mathrm{p}$ \\
\hline \multicolumn{2}{|c|}{ Fraction of water cover $=-3.392-6.706 * \mathrm{CB} 5$} & 1215.70 & 1,1817 & 0.001 \\
\hline \multicolumn{5}{|c|}{ Manual step-wise predictor selection (Explained deviance [\%]) } \\
\hline & Band (B) & \multicolumn{3}{|c|}{ Corrected band (CB) } \\
\hline Band $1(\lambda=0.45-0.52 \mu \mathrm{m})$ & 8.81 & \multicolumn{3}{|c|}{15.23} \\
\hline Band $2(\lambda=0.52-0.60 \mu \mathrm{m})$ & 14.86 & \multicolumn{3}{|c|}{22.22} \\
\hline Band $3(\lambda=0.63-0.69 \mu \mathrm{m})$ & 19.24 & \multicolumn{3}{|c|}{32.00} \\
\hline Band $4(\lambda=0.76-0.90 \mu \mathrm{m})$ & 41.57 & \multicolumn{3}{|c|}{43.43} \\
\hline Band $5(\lambda=1.55-1.75 \mu \mathrm{m})$ & 36.49 & \multicolumn{3}{|c|}{47.09} \\
\hline Band $7(\lambda=2.08-2.35 \mu \mathrm{m})$ & 25.93 & \multicolumn{3}{|c|}{33.86} \\
\hline
\end{tabular}


Table 15. Model validation with Spearman correlation between the observed fraction of water cover in a given pixel and the ratio predicted by the model. The model was validated under four different circumstances: (1) Model predictions of all pixels; (2) Only pixels in potentially flooded areas could be flooded and those outside were assumed dry; (3) All pixels were considered but model predictions below 0.21 were considered as dry pixels and (4) Only pixels in potentially flooded areas with predictions equal and above 0.21 were flooded.

\begin{tabular}{|c|c|c|c|c|c|}
\hline \multicolumn{3}{|c|}{ Model validation circumstances } & \multirow[b]{2}{*}{$\mathbf{N}$} & \multirow[b]{2}{*}{ Spearman $\mathbf{r}$} & \multirow[b]{2}{*}{$\mathrm{p}$} \\
\hline & ictions & Pixels & & & \\
\hline 1 & Raw & All & 5778 & 0.367 & $<0.001$ \\
\hline 2 & Raw & Potentially flooded & 2897 & 0.457 & $<0.001$ \\
\hline 3 & Modified & All & 5778 & 0.502 & $<0.001$ \\
\hline 4 & Modified & Potentially flooded & 2897 & 0.562 & $<0.001$ \\
\hline
\end{tabular}

Table 16. Confusion matrix showing the correspondence between groundtruth-assessed ponds and the flooding status predicted with the GLM models after applying the ZERO-threshold value both for observed and predicted values of pixel flooding (flooded pixel: fraction of water cover $\geq 0.21)$.

\begin{tabular}{|l|l|c|c|c|}
\cline { 3 - 5 } \multicolumn{2}{c|}{} & \multicolumn{3}{c|}{ Observed ponds } \\
\cline { 2 - 5 } & Dry & Flooded & Total \\
\hline \multirow{3}{*}{ Predicted ponds } & Dry & 64 & 33 & 97 \\
\cline { 2 - 5 } & Flooded & 14 & 57 & 71 \\
\cline { 2 - 5 } & Total & 78 & 90 & 168 \\
\hline \multicolumn{3}{|l|}{} \\
\hline \multicolumn{2}{|l|}{ Correct classification } & $82 \%$ & $63 \%$ & $72 \%$ \\
\hline
\end{tabular}

\section{Historical reconstruction of water coverage in the study area}

Using Landsat imagery, we detected 864 out of 883 temporary ponds flooded at some time over the entire study period. The flooded area in any one date ranged between 0.81 ha, equivalent to nine pixels, [October 2005] and 246 ha [Feb 1990]. At the time of a maximum flood [Feb 1990], we detected 718 flooded ponds. Mean values of annual hydroperiod ranged from $3.7 \pm 2.9$ [S.D.] months in 1994-95 to $6.3 \pm 3.7$ [S.D.] months in 1988-89.

\section{Spatio-temporal variation in the distribution of water}

Differences in hydrologic behaviour among ecosections

The seven ecosections showed different flooded areas and pond densities (Figure 21 ), although similar distribution of pond sizes (Figure 22), at the time of the largest flood event predicted for the study area [Feb 1990]. The maximum flooded area occurred in the ecosections NORTHERN and SOUTHERN SANDS, whereas the maximum pond density occurred in the 
SEMI-STABILIZED DUNES. The minimum flooded area and pond density occurred in the DRY SANDS. Small ponds $\left(<1500 \mathrm{~m}^{2}\right)$ were the most frequent size class in all ecosections (Figure 22).

Ecosections also differed in the average hydroperiod over the entire study period $\left(\right.$ ANOVA $\left.\mathrm{F}_{6,916}=22.918, \mathrm{p}<0.001\right)$ (Figure 21). The highest average
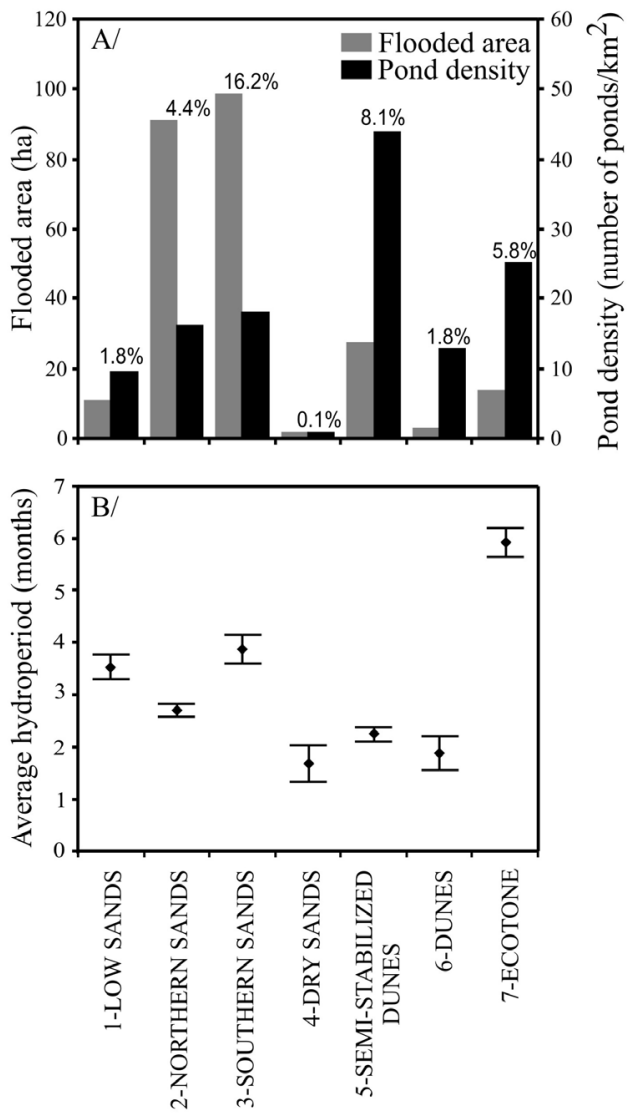

Figure 21. A/ Flooded area and pond density (number of ponds $/ \mathrm{km}^{2}$ ) predicted for each ecosection at the time of the largest flood event in the study area (15 February, 1990), as predicted from Landsat data. The percentage of flooded area for each ecosection is also shown. B/ Mean and standard error of average hydroperiod for each ecosection. hydroperiod was found in the ECOTONE ecosection, where water lasted twice as long as in other ecosections during the entire study period. Among the others, the average hydroperiod in the LOW SANDS and SOUTHERN SANDS was significantly longer than in the rest of the ecosections (Figures 21 and 23).
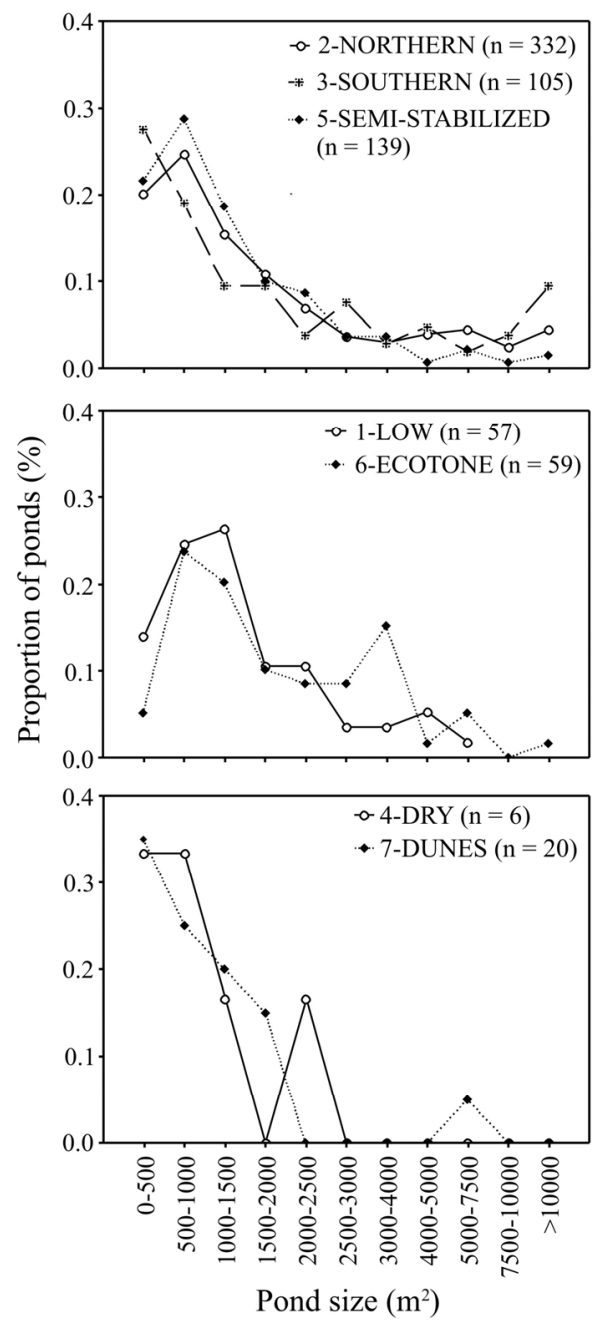

Figure 22. Distribution pattern of pond size in each ecosection at the largest flood event in the study area (15 February, 1990). 

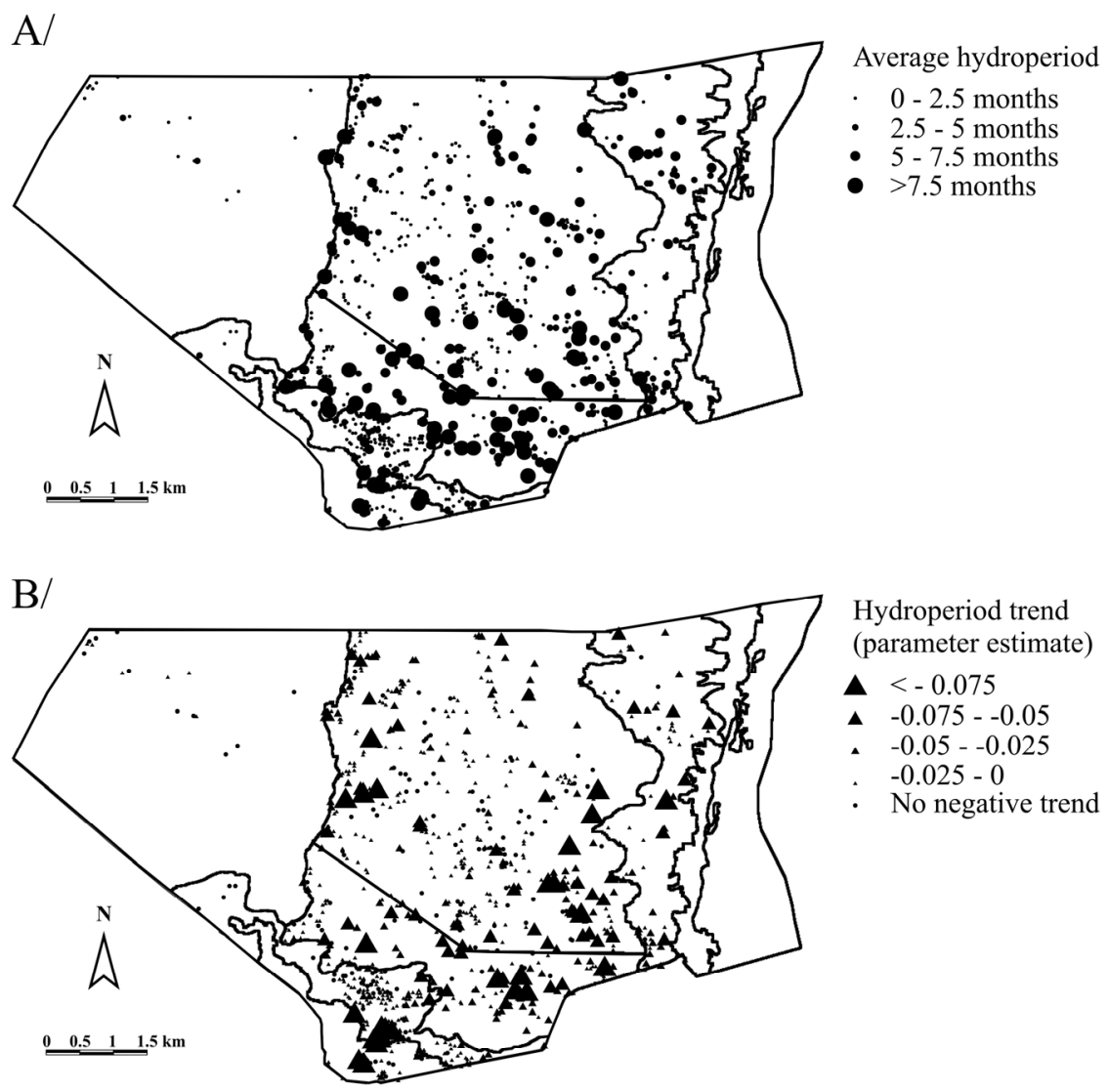

Figure 23. A/ Cartography of average hydroperiod (frequency of water occurrence) over the entire study period. B/ Cartography of the trend in annual hydroperiod for each pond over the entire study period.

\section{Seasonal hydrologic regime of temporary ponds.}

Flooded area presented a large intra-annual variability, mainly in years with annual rainfall higher than the long-term average (Figure 24). As a rule, flooded surface was low during the dry season (June-August) and continued low in September-November until the first autumn-winter rains (Figure 24). Values of flooded surface at the beginning of autumn were similar between wet and dry years; however, flooded surface in summer months was notably higher in wet years.

Flooded surface tended to increase from September to December and tended to decrease from April-May until August. We observed a notably increase in flooded surface, especially in wet years, at the end of autumn months (December). Similarly, we observed a marked decrease in flooded surface between April-May and June-July in rainy years while such decrease was more gradual in dry years. 


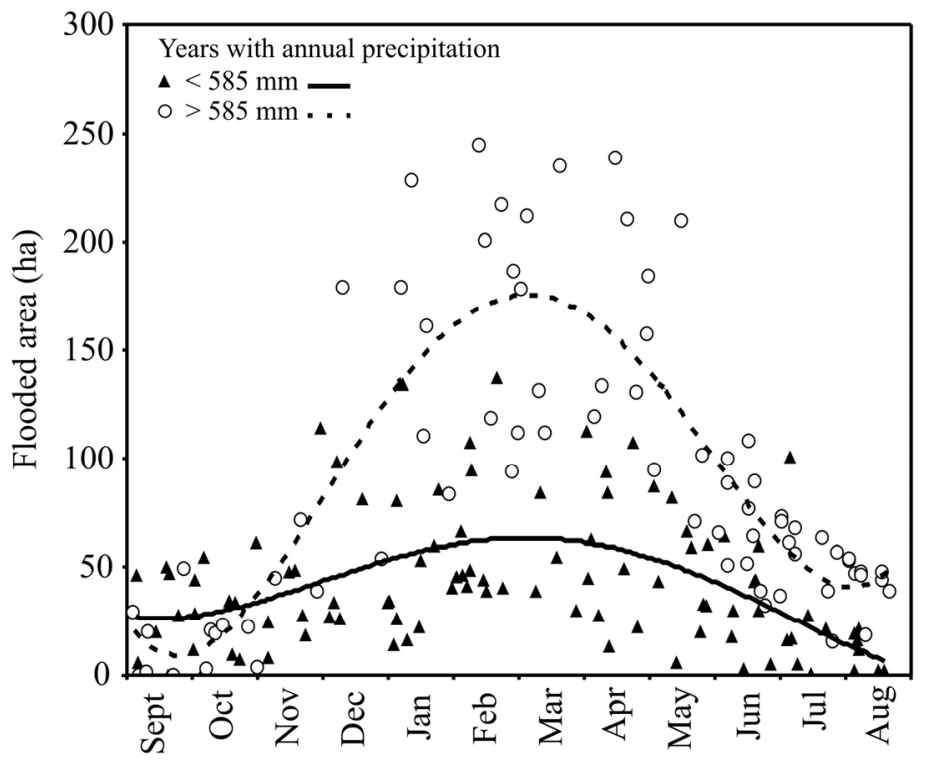

Figure 24. Synoptic characterization of intra-annual variation of flooded area as obtained from pooling pond model predictions from the entire time-series data (1984-2007).

Inter-annual variation in hydrologic behaviour

Maximum flooded surface and annual pond hydroperiod fluctuated on an inter-annual basis. We observed a significant temporal trend to shorter annual hydroperiod values for the entire study area $(y=6.00-0.10 x$; $\left.\mathrm{F}_{1,10}=11.632, \mathrm{p}=0.007\right)$ and for all ecosections except in the ECOTONE and in the LOW SANDS (Table 17). We did not observe trends in annual rainfall nor in maximum flooded surface for the entire study area (Figure 25). In contrast, we did observe a negative trend in maximum flooded surface in the drier ecosections: DUNES and DRY SANDS (Table 17).

\section{Relationship between flooded area and rainfall}

Focusing on the entire study area, rainfallderived variables explained the $80 \%$ of the variance in the percentage of flooded area (Table 18). The predicted flooded area in a given sampling date was significantly related to all the periods of accumulated rainfall we considered. In particular, rainfall fallen in the previous 31-180 days had the greatest contribution to model, evidencing that ground water has an important influence in the temporary ponds hydrologic regime. Model adjustment varied widely among ecosection. Those of the driest ecosections, DRY SANDS and DUNES, showed the lowest values of explained variance. Such models were the only ones that did not include all the periods of accumulated rainfall. The relevance of ground-waters was also evident in all ecosection models since rainfall in the previous 31-90 days showed the largest contribution to the model along with rainfall in the previous 91-180 days in the case of the SOUTHERN SANDS ecosection. 
Table 17. Trend analysis of flooded area and annual hydroperiod in each ecosection. Model parameterization, F statistics, degrees of freedom (d.f.) and significance (p) are shown.

\begin{tabular}{|c|c|c|c|c|}
\hline & & Model parameterization & $\mathbf{F}$ & p \\
\hline \multicolumn{5}{|c|}{ Flooded area (d.f. $=1,21)$} \\
\hline 1 & LOW SANDS & $y=5.57+0.03 x$ & 0.053 & 0.820 \\
\hline 2 & NORTHERN SANDS & $\mathrm{y}=36.23+0.07 \mathrm{x}$ & 0.006 & 0.940 \\
\hline 3 & SOUTHERN SANDS & $y=60.09+0.09 x$ & 0.010 & 0.921 \\
\hline 4 & DRY SANDS & $\mathrm{y}=1.34-0.04 \mathrm{x}$ & 4.254 & 0.052 \\
\hline 5 & $\begin{array}{l}\text { SEMI-STABILIZED } \\
\text { DUNES }\end{array}$ & $y=10.56-0.11 x$ & 0.157 & 0.696 \\
\hline 6 & DUNES & $\mathrm{y}=2.04-0.06 \mathrm{x}$ & 4.409 & 0.048 \\
\hline 7 & ECOTONE & $y=8.33+0.08 x$ & 0.418 & 0.524 \\
\hline \multicolumn{5}{|c|}{ Annual hydroperiod (d.f. $=1,10)$} \\
\hline 1 & LOW SANDS & $\mathrm{y}=5.87-0.12 \mathrm{x}$ & 3.483 & 0.091 \\
\hline 2 & NORTHERN SANDS & $\mathrm{y}=5.81-0.10 x$ & 12.728 & 0.005 \\
\hline 3 & SOUTHERN SANDS & $y=7.42-0.16 x$ & 11.273 & 0.007 \\
\hline 4 & DRY SANDS & $y=5.78-0.15 x$ & 6.761 & 0.026 \\
\hline 5 & $\begin{array}{l}\text { SEMI-STABILIZED } \\
\text { DUNES }\end{array}$ & $y=5.01-0.12 x$ & 16.765 & 0.002 \\
\hline 6 & DUNES & $\mathrm{y}=6.22-0.20 \mathrm{x}$ & 16.488 & 0.002 \\
\hline 7 & ECOTONE & $y=6.10+0.02 x$ & 0.268 & 0.616 \\
\hline
\end{tabular}

The performance of the rainfall-flood model for the entire study area differed among years (ANOVA $\mathrm{F}_{22,151}=2.709, \mathrm{p}<$ 0.001 ) and among months (ANOVA $\mathrm{F}_{11,162}$ $=2.946 ; \mathrm{p}=0.001)$. The rainfall-flood model predicted a smaller extension of flooded area than the one observed with Landsat data in December, which usually corresponds to the month of maximum flooding. The same inconsistency was observed for the most recent years (200107 ), mainly in 2003-04, a very wet year. On the contrary, Landsat data indicated a smaller extension of flooded area than the rainfall-flood model predicted for 2000-01, a year following a dry period (1998-2000) in which the rainfall was scarce in autumn and spring, being concentrated in the months of December and January. 

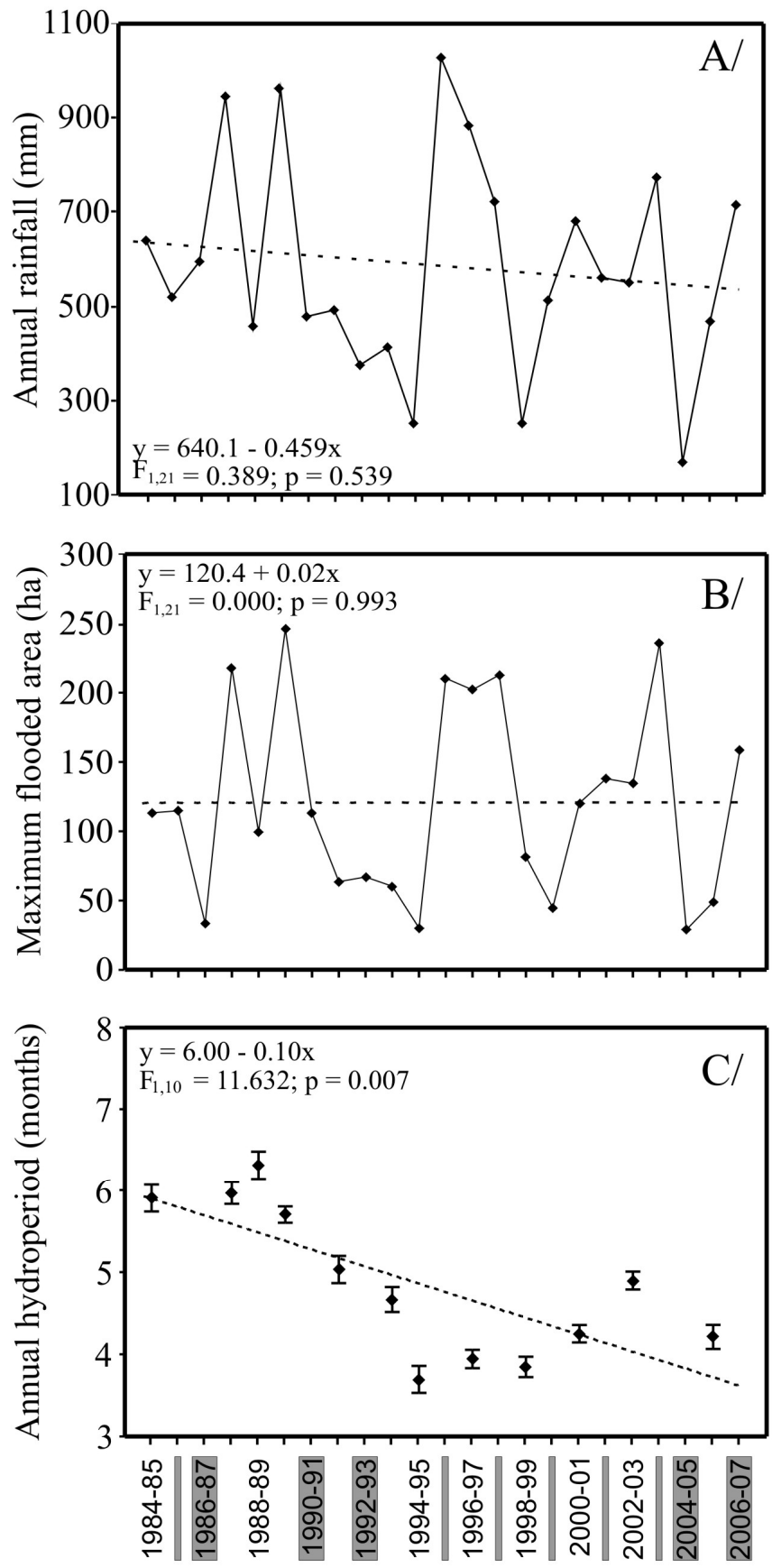

Figure 25. Inter-annual trends in A/ annual rainfall, B/ maximum flooded area and $\mathrm{C} /$ annual hydroperiod (mean and standard error) for the entire study area. Linear fit and adjusted equation is also shown. Years in grey indicate that no representative or enough images were available to compute annual hydroperiod that year. 
Table 18. Trend analysis of flooded area and annual hydroperiod in each ecosection. Model parameterization, $\mathrm{F}$ statistics, degrees of freedom (d.f.) and significance (p) are shown.

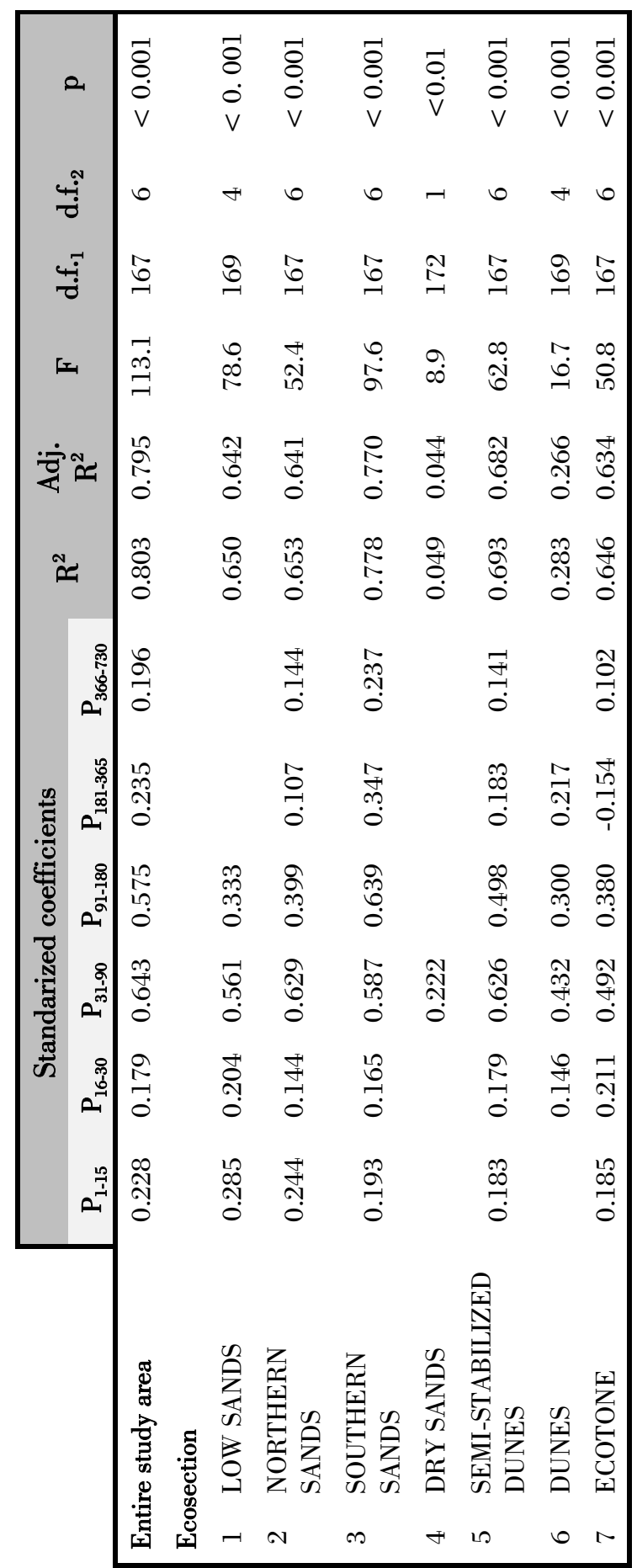




\section{$D_{\text {iscussion }}$}

\section{Application of remote sensing for the monitoring of temporary ponds}

Landsat imagery proved to be useful for reconstructing the retrospective spatiotemporal dynamics of a network of Mediterranean temporary ponds along a 23year period. With this basis, this study contributes to the understanding of the hydrology of these temporary ponds at a local scale. As a main advantage, the proposed methodology easily enabled mapping the status of small water bodies, many of them at sub-pixel size, with medium spatial resolution imagery (i.e. Landsat) and accurate knowledge on the spatial location of ponds. It constitutes an alternative to spectral unmixing techniques (i.e. linear mixture modelling, fuzzy-c means clustering), which map the fractional coverage of each land cover class in a pixel (i.e. pond cover, tree cover...) based on knowledge of their pure reflectance spectra (Settle and Drake 1993; Foody 2000; Lucas et al. 2002) or similar techniques which also requires spectral records of the cover types of interest (i.e. Beeri and Phillips 2007). It should be noted that we could have not applied unmixing techniques since we lacked "pure" land cover classes. The "temporary pond" cover class was expected to be "mixed" itself, as a combination of water, macrophyte and pond bottom reflectance, and to vary from pond-to-pond, according to changes in macrophyte cover and pond depth.

The main drawback of our methodology was the decrease in its performance at times of large flooding, when water levels overflowed pond basins and extended over areas that do not frequently flood. Those areas were included in this study through the use of a 30-m buffer around pond basins in order to control for potential positional errors. The decrease in model performance could be explained by the fact that the spectral response of these outside-basin pixels probably had a larger contribution of bottom reflectance than of water reflectance due to the low water depth. We should also be aware that the accuracy of model predictions is expected to get worse towards the beginning of the time-series data, due to changes in Landsat TM sensors, caused by their degradation over time, i.e. radiometric derive, (Liu et al. 2006), and changes in the vegetation cover in the pond basin and surroundings, as detected in particular ponds (Zunzunegui et al. 1998; Sousa Martín and García Murillo 2005; Serrano and Zunzunegui 2008).

\section{The system of Mediterranean temporary ponds in Doñana National Park}

Mediterranean temporary ponds in Doñana Biological Reserve may extend up to 200 ha in very wet years across the entire study area (6794 ha), thus conforming a large system of ponds of different sizes. Their contribution to the wetland system is remarkable in spite of the fact that they have been frequently overlooked in many previous studies, only focused to the marshes (e.g. Bustamante et al. in press), permanent ponds (e.g. López et al. 1991; Sacks et al. 1992) or large temporary ponds with long hydroperiod (e.g. Montes et al. 1982; Serrano and Toja 1995). This study, which is the first considering such a large period of time, reinforces the complex hydrology of the study area previously reported in more temporally restricted studies (García-Novo et al. 1991) and gives additional support to the ecosection zonation proposed (Montes et al. 1998). Ecosections presented differences in flooded area, pond density, average hydroperiod, pond annual hydroperiod and 
response to rainfall input. Such wide spatial variability evidenced that the system of temporary ponds in Doñana Biological Reserve is a widely heterogeneous system, being this characteristic an evidence of its importance for biodiversity conservation. Ecosystem heterogeneity favours the diversity of their associated species since it provides more niches and diverse ways of exploiting the environmental resources (see Tews et al. 2004 for a review). For example, a wide diversity of pond hydroperiods has been reported to benefit macroinvertebrate and amphibian communities at a landscape scale (Beja and Alcazar 2003; Jakob et al. 2003; Semlitsch 2003; Whiles and Goldowitz 2005).

The conservation importance of this temporary ponds system is enhanced by its temporal variability, since it increases habitat heterogeneity over time. Temporary ponds varied from year-to-year in their flooded area and hydroperiod, both habitat characteristics critical for pond-breeding species, such as amphibians or macroinvertebrates (Wellborn et al. 1996; Spencer et al. 1999; Brooks 2000; Beja and Alcazar 2003; Semlitsch 2003). The ecological relevance of such environmental fluctuation is that it provides opportunities for temporal niche partitioning: habitat conditions of a pond will favour different species in different years, depending on their niche requirements (Chesson and Huntly 1997). As an example, inter-annual differences in the timing of pond filling and desiccation may be critical for pondbreeding species depending on their phenology. In the case of amphibians, earlybreeding species (i.e. Pelobates cultripes or Pelodytes ibericus, following Díaz-Paniagua 1988) will be favoured in years with abundant autumn rainfall whereas, years with late pond filling and early desiccation will likely favour the reproduction success of species breeding in ephemeral ponds (i.e.
Bufo calamita or Discoglossus galganoi, after Díaz-Paniagua 1990).

It is of special relevance that we have detected a generalized inter-annual tendency to shorter annual hydroperiods, but not to lower annual flooded area or rainfall input. This fact suggests that annual hydroperiod shortening may have a cause independent of the natural flooding regime of ponds and it is probably related with ground-water dynamics. Notably, the ecotone was not affected, probably because ponds here receive deep aquifer water discharges (Suso and Llamas 1993) and hence are less sensitive to changes in watertable depth. A plausible driver of hydroperiod deterioration is the overexploitation of the aquifer, which is causing a progressive lowering of the phreatic level (Suso and Llamas 1990), a decrease in aquifer recharge rates for the same rainfall (Trick and Custodio 2004) and a damage to ponds hydrology (Serrano and Zunzunegui 2008), such as a decrease in the frequency of appearance of temporary ponds (Custodio 2002). Since pumping is concentrated in the more permeable layers of the lower aquifer, it is supposed to affect a large area through a small lowering of the water table (Trick and Custodio 2004). This would explain that a trend that had been already reported for some particular ponds (Serrano and Zunzunegui 2008), is general for the whole study area, as it was earlier predicted (Manzano and Custodio 2006) and this study evidences. From an ecological perspective, a progressively wetland desiccation is critical for amphibian communities, as revealed in the amphibian populations decline reported for Yellowstone National Park (McMenamin et al. 2008). In particular, in the study area, the reduction in pond annual hydroperiod may severely compromise the medium term population stability of pond-breeding species with an aquatic phase requiring a 
long period of time to complete metamorphosis, such as $P$. cultripes.

The flooded area was related both to immediate and previous rainfall inputs, including rainfall input in the previous year. Similar results have been reported in a different temporary pond system, such as the playa-lakes in the Monegros Dessert (Castañeda and Herrero 2005). This result adds to evidence of the relevance of groundwater influxes in the hydrological regime of the ponds in the area (Serrano et al. 2006). Temporary ponds in Doñana National Park are shallow depressional wetlands that flood when watertable raises above the topographical surface. So, the accumulation of rainfall water is necessary both to initially recharge the aquifer and then to fill the ponds. The amount of water required to completely recharge the aquifer depends on the aquifer level at the end of the previous year and thereby on the annual rainfall during the previous year. Serrano and Zunzunegui (2008) provided an analogous result, showing that the rainfall input in a given year was related to pond hydroperiod in the following one.

Doñana National Park is a large wetland, consisting on a temporary pond system and a large seasonal marsh. The conservation value for pond-breeding species lies on its heterogeneity across space and time (Gómez-Rodríguez et al. in press), since communities in wetland ecosystems require from spatial variability in order to be able to persist under high environmental variability (Shurin 2007). Areas with such a high density and heterogeneity of natural ponds are not common in Europe, where the number of temporary ponds are probably a mere fraction of what they would naturally had been in the past (Williams et al. 2001). For all these reasons, we think that the system of temporary ponds in Doñana deserves special attention and conservation measures focused to avoid its destruction or degradation. In particular, we should be concerned for the tendency to lower hydroperiods which may severely compromise their suitability as habitat for pond-breeding species.

Comments This section was done in collaboration with Javier Bustamante and Carmen Díaz-Paniagua. R. Díaz-Delgado and D. Aragonés provided helpful comments that contributed to improve the remotesensing analyses and the manuscript. 


\section{References}

Aragonés D et al. 2005. Tratamiento de una serie temporal larga de imagenes Landsat para la cartografia de la inundación histórica de las marismas de Doñana. In: Tierra., T.A.e.l.O.d.l. (Ed.), XI Congreso Nacional de Teledetección, 21-23 septiembre 2005., Puerto de la Cruz. Tenerife, pp. 407-410.

Beeri O, Phillips RL 2007. Global Change Biol 2007, 897-912.

Beja P, Alcazar R 2003. Biol Conserv 114, 317-326.

Bigot L, Marazanof F 1966. Ann. Limnol. 2, 491-502.

Briers RA, Biggs J 2005. Aquat Conserv: Mar Freshw Ecosyst 15, 549-557.

Brooks RT 2000. Wetlands 20, 707-715.

Bryant RG, Rainey MP 2002. Remote Sens Environ 82, 360-375.

Bustamante $\mathrm{J}$ et al. In press. J Environ Manage. Online first.

Castañeda C, Herrero J 2005. J Hydrol 310, 95-110.

Castañeda C et al. 2005. J Arid Environ 63, 497-516.

Chesson P, Huntly N 1997. Am Nat 150, 519-553.

De Roeck ER et al. 2008. Sensors 8, 35423556.

Díaz-Delgado R et al. 2006. Determining water body characteristics of Doñana shallow marshes through remote sensing. In: Society, G.a.R.S. (Ed.), Proceedings of the 2006 IEEE International Geoscience \& Remote Sensing Symposium \& 27th Canadian Symposium on Remote Sensing (IGARSS2006). Geoscience and Remote Sensing Society, Denver, Colorado, EE.UU, pp. 3662-3664.

Díaz-Paniagua C 1988. Amphibia-Reptilia 9, 15-26.

Díaz-Paniagua C 1990. Herpetol J 1, 447453.
Díaz-Paniagua C et al. 2005. Los Anfibios de Doñana. Organismo Autónomo de Parques Nacionales. Ministerio de Medio Ambiente, Madrid.

Díaz-Paniagua C et al. 2006. Rev Esp Herpetol 20, 17-30.

European Commission 2007. Interpretation Manual of European Union Habitats. Natura 2000, Nature and Biodiversity. European Commission.

Foody GM 2000. Remote Sens Environ 26, 469-478.

Fortuna M et al. 2006. $P$ Roy Soc Lond $B$ Bio 273, 1429-1434.

García-Novo F et al. 1991. III Simposium de Aguas de Andalucía, 165-176.

García Murillo PJ et al. 2006. Limnetica 5, 71-80.

Gómez-Rodríguez C et al. 2008. Herpetol J $18,103-113$.

Gómez-Rodríguez C et al. In press. Aquat Ecol. Online first.

Griffiths RA 1997. Aquat Conserv: Mar Freshw Ecosyst 7, 119-126.

Grillas P et al. 2004. Mediterranean Temporary Pools. Volume 2- Species information sheets. Station Biologique de la Tour du Valat.

Haberl $\mathrm{H}$ et al. In press. Ecol Econ Online first.

Jakob C et al. 2003. Hydrobiologia 499, 5161.

Lacaux JP et al. 2007. Remote Sens Environ 106, 66-74.

Liu Y et al. 2006. Int J Remote Sens 27, 3183-3201.

López T et al. 1991. Arch Hydrobiol 120, 357-378.

Lucas NS et al. 2002. Appl Geogr 22, 253270.

Manzano M, Custodio E 2006. The Doñana aquifer and its relations with the natural environment. In: García Novo F, Marín Cabrera C (Eds.), Doñana. Water and Biosphere. Doñana 2005 Project - 
Confederación Hidrográfica del Guadalquivir (Guadalquivir Hydrologic Basin Authority), Spanish Ministry of the Environment, Madrid, pp. 141-150.

McCullagh P, Nelder JA 1989. Generalized Linear Models. Chapman and Hall, London.

McMenamin SK et al. 2008. P Natl Acad Sci USA 105, 16988-16993.

Millán A et al. 2005. Boln. Soc. Entomol. Aragonesa 37, 157-164.

Montes C et al. 1982. Studia Oecol 3, 129158.

Montes C et al. 1998. Reconocimiento Biofísico de Espacios Naturales Protegidos. Doñana: Una Aproximación Ecosistémica. Junta de Andalucía. Consejería de Medio Ambiente.

Oertli B et al. 2005. Aquat Conserv: Mar Freshw Ecosyst 15, 535-540.

Ozesmi SL, Bauer ME 2002. Wetlands Ecol Manag 10, 381-402.

Pons X, Solé-Sugrañes L 1994. Remote Sens Environ 48, 191-204.

Revenga $C$ et al. 2005. Philos Trans R Soc Lond B-Biol Sci 360, 397-413.

Rivas-Martínez S et al. 1980. Lazaroa 2, 5189.

Roshier DA, Rumbachs RM 2004. J Arid Environ 56, 249-263.

Sacks LA et al. 1992. J Hydrol 136, 123154.

Sanderson RA et al. 2005. Ecography 28, 355-362.

Semlitsch RD (Ed.) 2003. Amphibian Conservation. Smithsonian Books, Washington and London.

Semlitsch RD, Bodie JR 1998. Conserv Biol 12, 1129-1133.

Serrano L, Fahd K 2005. Wetlands 25, 101111.

Serrano L et al. 2006. Limnetica 25, 11-32.
Serrano L, Serrano L 1996. J Environ Manage 46, 229-238.

Serrano L, Toja J 1995. Arch Hydrobiol 133, 497-516.

Serrano L, Zunzunegui M 2008. Aquat Conserv: Mar Freshw Ecosyst 18, 261279.

Settle JJ, Drake NA 1993. Int J Remote Sens 14.

Shurin JB 2007. Oikos 116, 957-965.

Siljeström PA et al. 1994. J Arid Environ 26, 315-323.

Sousa Martín A, García Murillo P 2005. Historia ecológica y evolución de las lagunas peridunares del Parque Nacional de Doñana. Organismo Autónomo de Parques Nacionales. Ministerio de Medio Ambiente.

Spencer M et al. 1999. Ecol Lett 2, 157-166. Suso J, Llamas MR 1993. J Hydrol 141, 239-269.

Suso JM, Llamas M 1990. Estudios Geológicos 46, 317-345.

Tews J et al. 2004. J Biogeogr 31, 79-92.

Trick T, Custodio E 2004. Hydrogeol J 12, 321-335.

Verdin JP 1996. Int J Remote Sens 17, 733748.

Wellborn GA et al. 1996. Annu Rev Ecol Evol $S$ 27, 337-363.

Whiles MR, Goldowitz BS 2005. Wetlands $25,462-472$

Williams DD 1997. Aquat Conserv: Mar Freshw Ecosyst 7, 105-117.

Williams DD 2006. The Biology of Temporary Waters. Oxford University Press, Oxford, New York.

Williams P et al. 2001. Freshw Forum 17, 715.

Zacharias I et al. 2007. J Environ Biol 28, 1-9.

Zunzunegui M et al. 1998. Appl Veg Sci 1, 151-160. 


\section{Chapter 3}

Temporal variation of the amphibian community in Doñana National Park

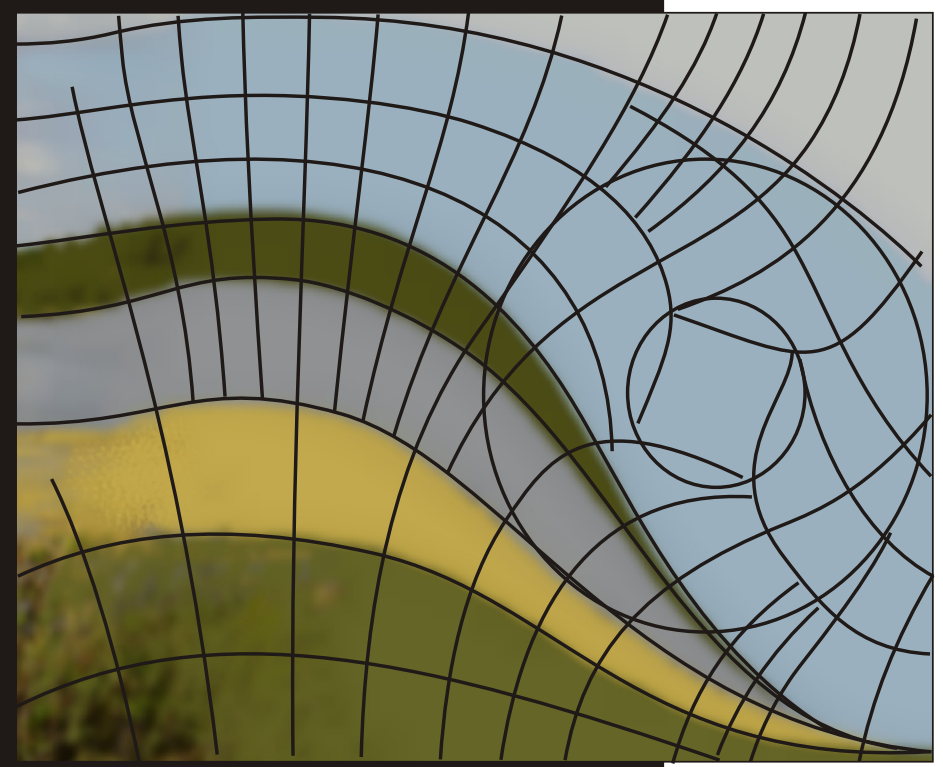




\section{Inter-annual variability in amphibian assemblages:}

\section{Implications for diversity assessment and conservation}

Diversity assessments and conservation management should take into account the dynamic nature of populations and communities, mainly when they are subject to highly variable and unpredictable environmental conditions. In this study, we evaluate the inter-annual variability in the assemblage composition (temporal turnover) of an amphibian community breeding in a highly dynamic habitat, a Mediterranean temporary pond system, during a 4-year period. We provide a comprehensive framework to evaluate temporal turnover from data of a differing nature (species richness, presence/absence and relative abundance) and, especially, to discern variation in richness (species loss) from changes in the identity or abundance of species (species replacement). Our results show that the pond amphibian assemblages in Doñana National Park exhibited high interannual variability during the study period, both in the number of species, species identity and their relative abundance. This result provides evidence for the inadequacy of surveys conducted only in one breeding season to characterize the species assemblage associated to a given pond. Besides, it suggests that a given pond offers different breeding opportunities over time, being suitable for different species depending on the year. This alternation will contribute to the middleterm preservation of all species in the assemblage. For that reason, it is highly relevant to preserve the natural dynamism and spatial variability of temporary pond systems, which will favour the conservation of populations through their intrinsic variability. 


\section{Introduction}

Stable ecosystems, defined as systems with no temporal variation, are more the exception than the rule (Ricklefs and Schluter 1993). In fact, it is widely accepted that both habitats and biological communities may vary over ecological time (Preston 1960; Collins and Glenn 1991; Fjeldsa and Lovett 1997; Innes 1998; Magurran 2007), which stresses the claim for a temporal perspective in ecological studies, especially in the analysis of biodiversity patterns (Buckland et al. 2005; Magurran 2007). For this reason, the dynamic nature of populations and communities has long been a subject of interest per se. For instance, ecologists have aimed to evaluate the temporal variation in diversity (Skelly et al. 1999; Werner et al. 2007; Azeria and Kolasa 2008), to disentangle natural population fluctuations from declining trends (Green 2003; Loman and Andersson 2007) or to evaluate causes of variation in assemblage composition, such as local habitat changes (Briers and Warren 2000; Biedermann 2004) or stochastic extinction-colonization events in a metapopulation scenario (Hels 2002; MacKenzie et al. 2003). Understanding the temporal variability in ecological systems is also crucial for successful management and conservation, which highly depends on the recognition of their dynamic nature (Hobbs 1998). From a practical standpoint, the temporal dynamism of species assemblages may become an error source in biodiversity assessments (i.e. spatial distribution of species) and those ecological interpretations derived from them. In order to avoid these flawed data in dynamic systems, it is necessary to evaluate whether species assemblages actually change over time.

Many amphibian communities are highly variable over time, with changes in the number or abundance of species from year to year (Pechmann et al. 1991; Hecnar and M'Closkey 1996; Skelly et al. 1999; Trenham et al. 2003; Werner et al. 2007). At a regional scale, these changes may be interpreted as intrinsic natural fluctuations in population size (Marsh 2001; Pellet et al. 2006) which may also undercover trends in population size (i.e. decline) (Green 2003; Collins and Halliday 2005). At pond scale, year-to-year changes in species occupancy have been frequently interpreted as extinction-colonization events (Skelly et al. 1999; Richter-Boix et al. 2007; Werner et al. 2007), which would yield a theoretical metapopulation structure (Hanski and Gilpin 1991; Hanski 1998). However, 
metapopulation structure may be more apparent than real (Marsh and Trenham 2001; Smith and Green 2005), mainly when connectivity among ponds is high and favours inter-pond movements of individuals (Smith and Green 2005; Petranka and Holbrook 2006). In this scenario we may find a patchy population structure, where a cluster of ponds (rather than a single one) constitutes a local population which may occupy different habitat patches over time (Petranka et al. 2004). Therefore, when metapopulation structure is lacking, temporal variation in pond assemblages may also respond to other processes rather than stochastic extinction/colonization events, i.e. skipped breeding or regular inter-pond movements of individuals (Marsh and Trenham 2001). The distinction is not trivial because after an extinction event, the species disappears from the pond and may not occupy it anymore, depending on its probability of recolonization. On the contrary, if individuals skip breeding or move to an adjacent pond, the species is still occupying the same breeding unit and hence the absence from that particular pond should be interpreted as a temporary event, probably in response to temporary changes in habitat suitability. Several studies have reported that temporal variation in amphibian assemblages results from inter-annual variability in meteorological/hydrological conditions (Jakob et al. 2003) or in local habitat attributes, both in breeding ponds (Skelly and Meir 1997) and in surrounding uplands (Skelly 2001). In general, high temporal turnover (i.e. temporal variation in assemblage composition) is expected in non-stable habitats (Moreno and Halffter 2001), such as Mediterranean temporary ponds.

From an applied point of view, methodological procedures appropriate for the detection and quantification of temporal turnover are necessary to avoid biases in biodiversity assessments. Temporal turnover can be assessed from data of a differing nature (i.e. presence/absence or their summary metrics, like species richness). Presence/absence is an information-poor but cheap source of data to infer community changes (Henry et al. 2008). Previous studies have considered the variation in the size of breeding populations (Pechmann et al. 1991), differences in species richness values (Hecnar and M'Closkey 1996; Werner et al. 2007) or dissimilarity in assemblage composition between consecutive years (Skelly et al. 1999; Werner et al. 2007). The first approach focuses on temporal variation at the species level, whereas the latter two summarize the variation of all species providing measures of turnover at the assemblage/community level. The variation in assemblage composition can be caused either by the gain or loss of some species or by the replacement of some species by others ("true" species turnover). Comparisons of species richness values are intended to reveal changes due to gains or losses of species. Thereby, they will prove misleading if the number of species does not change but the identity does, as it may occur if some species are replaced by others (Hecnar and M'Closkey 1996). Besides, differences in sampling effort may lead to potential biases in the assessment of temporal turnover due to the fact that the probability of detecting a species increases with the accumulation of sampling effort (Gotelli and Colwell 2001). To detect temporal turnover due to the replacement of species, we should address comparisons on the specific assemblage composition using dissimilarity indexes independent of richness values (Koleff et al. 2003; Baselga et al. 2007). Thereby, this approach will provide information complementary to richness comparisons. Moreover, we can also evaluate temporal turnover due to changes in species dominance patterns 
(common species $v s$. rare species) by using quantitative data (i.e. relative abundance), which is usually preferred in diversity assessments (Magurran 2004).

In this study, we evaluate temporal turnover at the assemblage level in a highly dynamic ecosystem, the amphibian community breeding in Mediterranean temporary ponds in Doñana National Park. We apply a comprehensive framework, including the three above-mentioned approaches, aiming to assess changes at species and assemblage levels, and to discern variation in richness (species loss) from changes in the identity or abundance of species (species replacement). The applied interest of this study is to evaluate the adequacy of single-year surveys in amphibian diversity studies in Mediterranean systems, even when the applied sampling effort proves enough to detect all species breeding that season.

\section{Material and Methods}

\section{Study area}

The study was conducted in an area of 6794 hectares within Doñana National Park, in southwestern Spain (see Siljeström et al. 1994 for a geo-morphological description). The dominant vegetation on this area is Mediterranean scrub (Halimio halimifoliiStauracanthetum genistoides and Erico scopariae-Ulicetum australis as defined by Rivas-Martínez et al. 1980) and isolated patches of pine (Pinus pinea L.) and juniper forests (Juniperus phoenicea L.).

On the sandy area of the Park, many temporary ponds flood during the rainy season. These ponds are fed by freshwater and have no direct connection to the sea. The duration of flooding (or hydroperiod) varies among ponds, from pools persisting one month to ponds persisting up to 10 months in very wet years. Annual hydroperiod is also widely variable, depending on rainfall. In years of scarce rainfall, most ponds may not flood, while hydroperiod is notably reduced in those that do flood. The area also includes two semipermanent ponds that occasionally dry out in years of severe drought.

For this study we included the two semipermanent ponds and 19 temporary ponds (Figure 26), covering the wide hydroperiod gradient in the study area (a detailed description of the temporary ponds can be found in Gómez-Rodríguez et al. in press). The pattern and amount of rainfall varied among the years of study (Figure 27) and consequently the onset and duration of surface water in ponds.

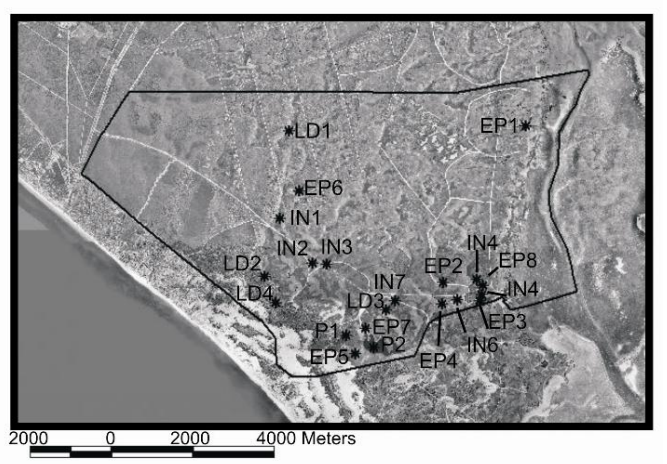

Figure 26. Ortophotography of the study area. Solid line represents Doñana Biological Reserve, where most of the study ponds are located. Pond nomenclature corresponds to hydroperiod categories in 2003 ( $\mathrm{P}=$ Permanent, LD = longduration temporary pond [8-9 months], IN = intermediate temporary pond [6-7 months], EP = ephemeral [4-5 months]). 


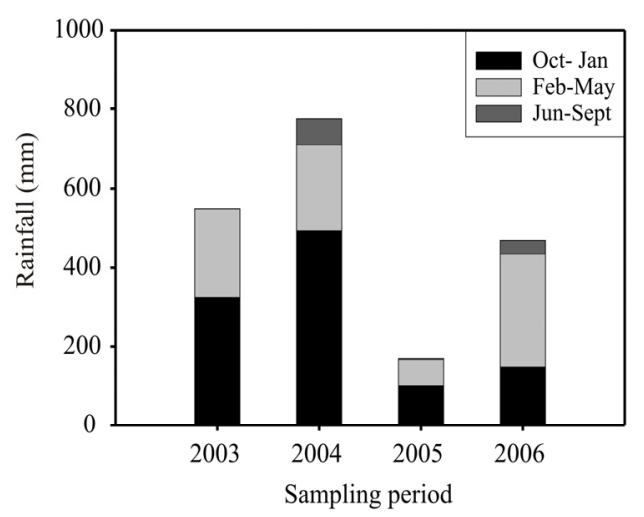

Figure 27. Rainfall input in hydrological years from 2003-season to 2006-season. Three different periods were differentiated: OctoberJanuary; February-May; June-September.

\section{Amphibian sampling}

An intensive monthly survey was conducted each year during the amphibian breeding season: February-May 2003, January-May 2004 and March-May 2006. Ponds did not flood in 2005-season and hence were not sampled. Nineteen ponds were sampled every month if flooded. Two ponds were not accessible in 2004-season and thus could not be sampled. In addition, in 2003season, one of those ponds was only accessible in May. In 2006-season, two ponds were flooded during less than one month and could not be sampled.

We used dipnetting techniques (Heyer et al. 1994) to collect and identify larvae to species level in situ (referred hereinafter as "larval sampling"). We counted the number of larvae captured in each sampling unit (three consecutive sweeps on a stretch of approx. $1.5 \mathrm{~m}$ length) and then released them in the pond. For most ponds, we set 12 sampling units as the standard sampling effort. Sampling units were separated a minimum of five metres to avoid interference between surveys. Small ponds were sampled in proportion to their size, so the number of sampling units could decrease to guarantee minimum separation (5 m). In large ponds we tried to sample all different microhabitats, increasing there the number of sampling units performed.

Larval sampling was complemented with visual surveys in and around the pond to detect eggs, larvae and metamorphic individuals. Visual surveys were conducted regularly, starting when ponds flooded (November 2002, November 2003 and January 2006).

\section{Data analysis}

Species level

We described inter-annual changes in the occupancy (proportion of occupied ponds) and overall relative abundance of species (see Table 19). For each species, overall relative abundance was measured as catchper-unit-effort (number of larvae collected per total number of sampling units) in the ponds it occupied, thus excluding the ponds where the species was not recorded, in order to achieve independence with occupancy metrics. Metrics were computed both for annual fauna (data collected in each breeding season) and cumulative fauna (data collected over the entire study period).

\section{Assemblage level}

We provide two different approaches to evaluate temporal turnover that depend on the type of data available: pond assemblage composition data (presence or relative abundance data) or their summary metrics (species richness).

- Richness-based approach: To evaluate year-to-year variation in the number of species detected in a pond (annual richness), we computed a Repeated Measures ANOVA with posthoc Tukey test. To evaluate temporal turnover, we followed 
the procedure Romanuk and Kolasa (2001) recommend. For each breeding season, we compared annual richness $\left(\mathrm{S}_{\mathrm{ann} \_2003} \mathrm{~S}_{\mathrm{ann} \_2004}\right.$ or $\mathrm{S}_{\text {an_ } 2006}$ ) with the total number of species detected in that pond over the entire study period, cumulative richness $\left(\mathrm{S}_{\text {cum }}\right)$. This approach outperforms annual comparisons, which might be biased from changes in species identity although not in species counts (Hecnar and M'Closkey 1996). We applied Repeated Measures ANOVA to each comparison and posterior Bonferroni correction to the level of significance.

This approach to detect temporal turnover does not account for differences in sampling effort and hence can be subject to potential biases due to the fact that the probability of detecting a species increases with the accumulation of sampling effort (Gotelli and Colwell 2001). For that reason, we complemented each analysis with an additional comparison between the value of annual richness for each pond and year and its respective rarefacted value, $S_{r}$, with a Repeated Measures ANOVA using Bonferroni correction. Rarefacted cumulative richness $\left(\mathrm{S}_{\mathrm{r}}\right)$ is an estimate value of $S_{\text {cum }}$ correcting for sampling effort and was assessed from sample-based rarefaction curves (Gotelli and Colwell 2001) computed from the complete dataset (2003-2006) with EstimateS 7.0 software (Colwell et al. 2004). Thus, for each sampling season, $\mathrm{S}_{\mathrm{r}}$ estimated the number of species that would have been detected in a given pond, with the sampling effort applied that season, in the absence of inter-annual turnover (i.e. all species collected during the entire study period were detectable that season). In this analysis, annual and rarefacted richness were computed from "larval sampling" data.

- Assemblage-composition-based approach: We applied traditional similarity measures, usually focused to the description of spatial variation in diversity, to evaluate changes in species composition of a given site over time (see Magurran 2004). Basically, in order to reject the hypothesis of inter-annual turnover, To determine the existence of inter-annual turnover in assemblage composition, we searched for the antagonist pattern: a high similarity in composition among the species assemblages of a given pond in different breeding seasons. That is to say, assemblages of the same pond in different breeding seasons should be highly similar, being grouped together and differentiated from assemblages of other ponds. We conducted two sets of analyses to calculate similarity in assemblage composition: one based on presenceabsence data and the other based on relative abundance of each species, measured as catch-per-unit-effort. For each data type (presence-absence $v s$. relative abundance), we computed a dissimilarity matrix considering as independent cases the assemblages of a given pond in different years. We used Simpson dissimilarity index for presence-absence data and MorisitaHorn dissimilarity index for relative abundance data because these indexes are not influenced by species richness gradients and sample size (Magurran 2004). So, both indices measure differences in species composition attributable only to true species turnover (i.e. some species are replaced by others) and not to species loss (i.e. some species disappear from the community or are not detected) (see Baselga et al. 2007).

To evaluate temporal turnover from similarity among species assemblages, we computed an analysis of similarities (ANOSIM) (Clarke 1993) (command anosim, package vegan, $\mathrm{R}$ statistical package) to each assemblage dissimilarity matrix using pond identity as grouping factor. ANOSIM evaluates whether there is a significant difference between groups of ponds, i.e. the assemblages detected in a given pond over time constitute an identifiable group. Thereby, in the absence 
of inter-annual turnover, ANOSIM statistic (R) would be significant and close to 1 , indicating that differences among years in assemblage composition in any particular pond were much lower than differences to other pond assemblages in any year. On the same basis, we assessed if particular species assemblages were favoured in particular years (year-specific effect) by applying an ANOSIM analysis with "year" as grouping factor. So, if ANOSIM statistic (R) was significant and close to 1 , it would show that assemblages of different ponds measured in the same breeding season were highly similar, being grouped together and differentiated from assemblages measured in other breeding seasons. To visually clarify the interpretation of ANOSIM tests, we conducted two unconstrained ordination of ponds, Non Metric Multidimensional Scaling (NMDS), one derived from each dissimilarity matrix (presence/absence vs. relative abundance). For each ordination, we represented two axes and marked the cases corresponding to each group (pond identity or year). In ordination plots, cases corresponding to the same pond would appear aggregated under low temporal turnover.

Table 19. Definition of biodiversity terms used throughout the text.

Terminology Definition

Species-level

Species occupancy Proportion of ponds in which the species was detected.

Depending on the period of time considered, we face annual occupancy (in an annual survey) or cumulative occupancy (over the entire study period).

Overall relative abundance For each species, the ratio between the number of detected (study area) larvae and the number of sampling units in a given period (i.e. annual survey [annual] or over the entire study period [cumulative]). Only the number of sampling units conducted in those occupied ponds is considered. The metric is computed from "larval sampling".

Relative abundance (pond) Idem for each pond.

Assemblage-level

Annual richness $\left(\mathrm{S}_{\mathrm{ann}}\right)$

Number of species detected in a given pond in a particular year

Cumulative richness $\left(\mathrm{S}_{\text {cum }}\right)$

Total number of species detected in a given pond over the entire study period.

Rarefacted cumulative richness $\left(\mathrm{S}_{\mathrm{r}}\right)$

Estimated number of species that would have been detected in a given pond with the sampling effort applied in a given season if all the species detected throughout the entire study period had been present that season (only for annual surveys).

Inter-annual/temporal Changes in the number, identity or relative abundance of species turnover of a defined pond assemblage from year to year. 


\section{Results}

\section{Species level}

Nine species were identified over the entire study period (Figure 28). All species but Bufo bufo (Linnaeus, 1758) were detected in every breeding season (always excluding 2005-season, when ponds did not flood and amphibian species did not breed in the study ponds). Amphibian species exhibited marked inter-annual variation in their occupancy and overall relative abundance (Figure 28). Over the entire study period, most species showed a large occupancy. However, the proportion of ponds a given species occupied every breeding season was moderate or low for all the species. For instance, Triturus pygmaeus (Wolterstorff, 1905), the species with a higher tendency of recurrent breeding in the same pond, was detected in only half of the ponds every breeding season. The two species with largest occupancy over the entire study period, T. pygmaeus and Hyla meridionalis Boettger, 1874 bred in more than $90 \%$ of ponds. These species also exhibited the largest annual occupancy in 2003 and 2004-season, although a notable decrease in 2006-season. The same decrease in the occupancy in 2006-season was found in the other two urodeles (Lissotriton boscai (Lataste, 1879) and Pleurodeles walt Michahelles, 1830). Pelobates cultripes (Cuvier, 1829) was also a common species, occurring in $86 \%$ of study ponds, but unlike the previous species its largest occupancy was observed in 2006-season. Bufo calamita Laurenti, 1768 and Discoglossus galganoi Capula, Nascetti, Lanza, Bullini \& Crespo, 1985 also occupied a larger proportion of ponds in 2006-season than in 2003 or 2004-season. The rarest species was $B$. bufo, which is not a common breeder in temporary ponds, and was only detected, as eggs, in a semipermanent pond in 2006. Pelophylax perezi (Seoane, 1885) was found in five ponds in 2003-season, not being collected in any other one in the rest of the seasons.

The pattern of overall relative abundance was largely different from year-to-year, both in the absolute values of catch-per-uniteffort and in the species ranks based on it (Figure 28). We could not measure the relative abundance of $B$. bufo since it was not detected in its larval-stage but only as eggs. The highest values of overall relative abundance were observed in 2006 for all species except $T$. pygmaeus and $P$. perezi, with highest relative abundance in 2003, and L. boscai, with highest relative abundance in 2004. Hyla meridionalis was one of the two most abundant species in every breeding season, while $T$. pygmaeus was also in 2003 and 2004-season and $B$. calamita in 2006-season. Thereby, the three species were the ones showing the highest values of overall cumulative abundance. The rest of the species, except $P$. cultripes, showed lower values of overall relative abundance in every season. 

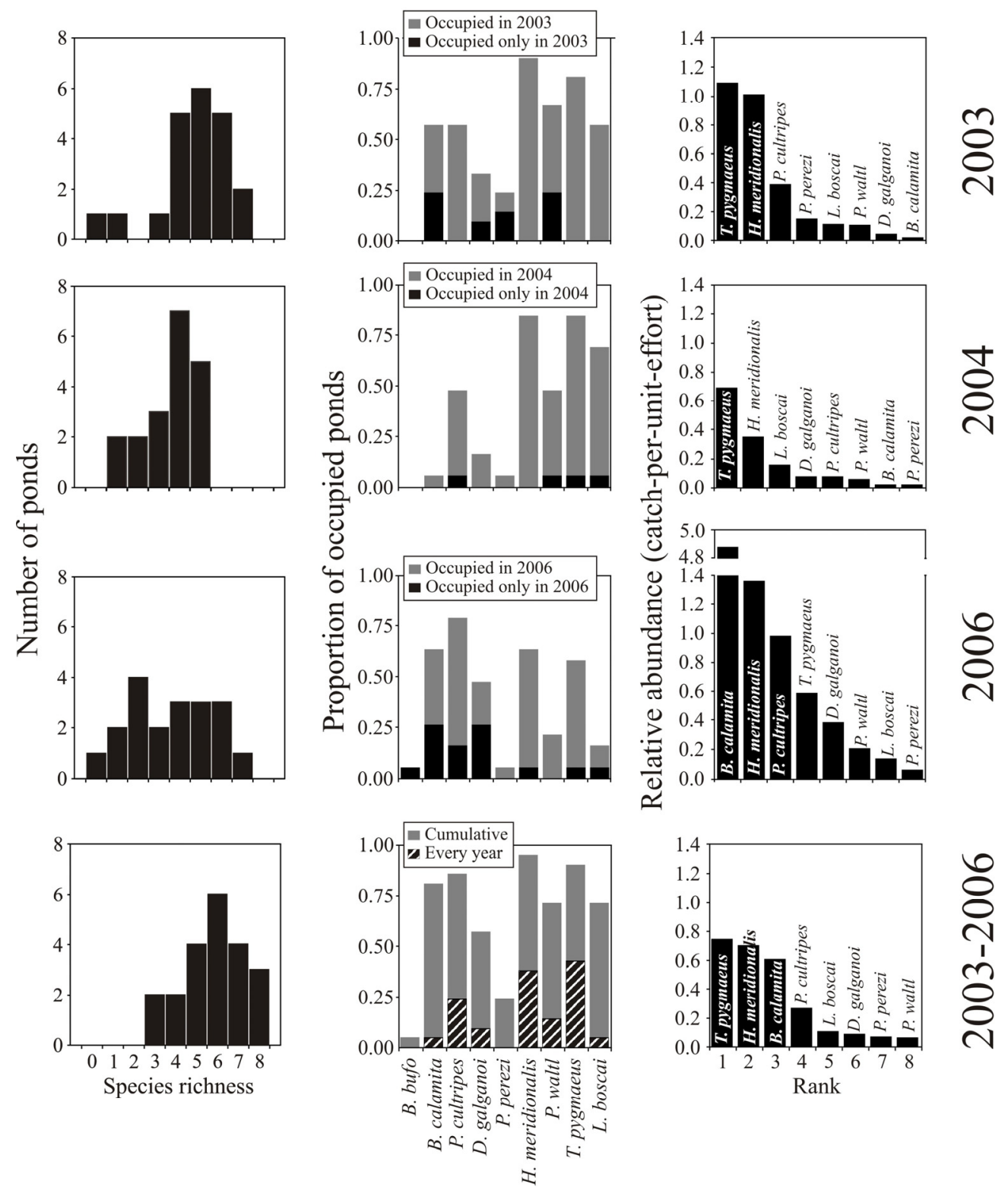

Figure 28. Species richness histograms, proportion of ponds each species occupied (occupancy) and their relative abundances in each breeding season and over the entire study period (cumulative data). In the proportion of occupied ponds, the percentage corresponding to the ponds in which the species was detected only in that particular year is highlighted for annual data. For cumulative data, the percentage of ponds that were used every year is also shown. 


\section{Assemblage level}

Inter-annual turnover in pond assemblage composition was evidenced in the richnessapproach. We observed inter-annual differences in species richness values $\left(\mathrm{F}_{2,32}\right.$ $=4.875 ; \mathrm{p}=0.014$ ) since annual richness in 2003 was significantly larger than in the rest of the seasons $(\mathrm{p}<0.050)$ while richness in 2004 and 2006-season did not significantly differ $(p=0.970)$. However, we could infer temporal turnover only when comparing annual values with cumulative ones. The number of species detected over the entire study period $\left(\mathrm{S}_{\text {cum }}\right)$ was larger than any annual richness (Table 20, Figure 28), indicating, for example, that some species absent in 2003-season were recorded in 2004-season or 2006-season. Accumulation of sampling effort during the entire sampling period did not explain differences between $S_{\text {cum }}$ and $S_{\text {ann_2003 }}$ neither between $S_{\text {cum }}$ and $S_{\text {ann_2004, because }} S_{r}$ was significantly higher than the annual values (Table 20). Thereby, we may discard a potential bias caused by differences in sampling effort; provided that the number of sampling units used to compute the cumulative values were much larger than the ones used to compute the annual values. On the contrary, $\mathrm{S}_{\mathrm{r}-2006}$ did not differ from $\mathrm{S}_{\text {ann_2006, suggesting that the smaller number }}$ of species detected in 2006-season, compared with cumulative richness, could be explained either by lower sampling effort or temporal turnover in amphibian pond assemblages.

Inter-annual turnover in pond assemblage composition was confirmed in the composition-based approach, both with presence-absence data (ANOSIM $\mathrm{R}=$ $0.133 ; p=0.024)$ and relative abundance data (ANOSIM $\mathrm{R}=0.146 ; \mathrm{p}=0.008$ ). Despite of being significant, the $\mathrm{R}$ statistic should be above 0.75 to be relevant (Clarke and Warwick 2001) and hence assume that ponds can be grouped based on the factor of interest (pond identity), which would imply high similarity in assemblage composition. In consequence, ANOSIM results evidence inter-annual temporal turnover in pond assemblage composition. In fact, the low value of ANOSIM $R$ shows that the assemblage composition in a given pond in a particular year was only slightly more similar to assemblage composition in the same pond in a different year than to any assemblage composition in a different pond (Figures 29-c and 29-d). Similarly, pond assemblage composition was not determined by a year-specific effect, as evidenced with the low values of ANOSIM $\mathrm{R}$ obtained for presence-absence data (ANOSIM $\mathrm{R}=$ $0.167 ; \mathrm{p}<0.001)$ or relative abundance data (ANOSIM $\mathrm{R}=0.161 ; \mathrm{p}<0.001)$.

Table 20. Results from the Repeated Measures ANOVA analyses comparing annual richness values $\left(S_{a n n}\right)$ with cumulative richness values $\left(S_{\text {cum }}\right)$ and annual richness values $\left(S_{\text {ann }}\right)$ with rarefacted richness values $\left(\mathrm{S}_{\mathrm{r}}\right)$. Analyses were computed for each breeding season. $\mathrm{F}$ statistics, degrees of freedom and p-values are shown.

\begin{tabular}{|ccc|}
\hline Year & Annual vs. Cumulative & Annual vs. Rarefacted \\
\hline 2003 & $\mathrm{~F}_{1,20}=26.667 ; \mathrm{p}<0.001$ & $\mathrm{~F}_{1,20}=7.806 ; \mathrm{p}=0.011$ \\
2004 & $\mathrm{~F}_{1,18}=53.581 ; \mathrm{p}<0.001$ & $\mathrm{~F}_{1,18}=31.412 ; \mathrm{p}<0.001$ \\
2006 & $\mathrm{~F}_{1,18}=33.996, \mathrm{p}<0.001$ & $\mathrm{~F}_{1,18}=0.030, \mathrm{p}=0.864$ \\
\hline
\end{tabular}


However, the graphical representation of the NMDS axes derived from dissimilarity matrices showed a tendency for some similarity among species assemblages of the

\section{Presence/absence}
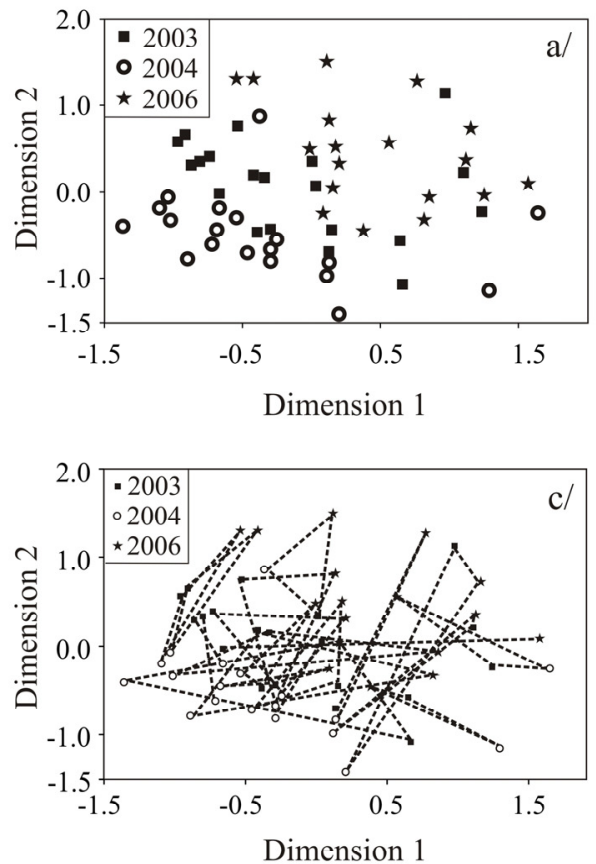

same breeding season, as they appeared aggregated although scattered among pond assemblages of different seasons (Figures 29-a and 29-b).

\section{Relative abundance}
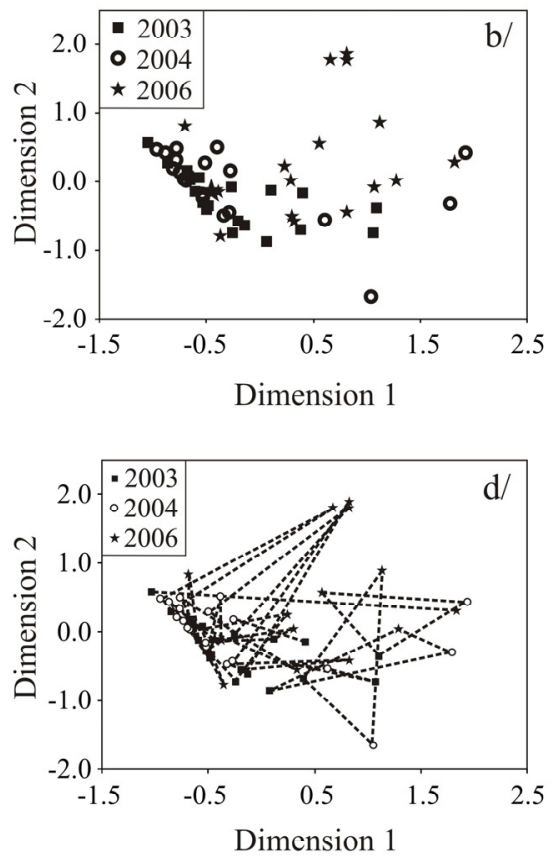

Figure 29. Ordination plot showing the dissimilarity in assemblage composition among ponds and years based on presence absence-data [NMDS stress $=0.252](\mathrm{a} / \mathrm{l} \text { and } \mathrm{c} /)^{2}$ and relative abundance data [NMDS stress $=0.159](\mathrm{b} /$ and $\mathrm{d} /$ ). Each case represents the species assemblage composition of a given pond in a particular year. $\mathrm{c} /$ is the same ordination as a/ but cases corresponding to the same pond have been joined with discontinuous lines to show the temporal turnover at pond scale (i.e. cases corresponding to the same pond would appear aggregated under low temporal turnover). The same applies to $\mathrm{b} /$ and $\mathrm{d} /$.

\section{Discussion}

The amphibian assemblages in Doñana National Park exhibited high inter-annual variability during the study period. The most dramatic change occurred in 2005season, when temporary ponds did not flood due to a severe drought and hence we did not detect amphibian species breeding. If we consider only "true" breeding seasons, when species did reproduce, temporal turnover at pond scale did not translate into large inter-annual faunal changes at regional scale, as evidenced in the fact that all species but $B$. bufo attempted breeding every breeding season. Therefore, temporal turnover patterns are scale-dependent and hence the scale of observation is critical when comparing results of different areas. 
For example, in studies conducted in different Mediterranean temporary pond systems, both Richter-Boix et al. (2006) and Jakob et al. (2003) found inter-annual changes in the species composition of the larval assemblage (pond scale). However, Jakob et al. (2003) reported inter-annual variability at the regional scale (i.e. some species disappeared from the study area in particular years) while Richter-Boix et al. (2006) found that all amphibian species regularly bred every year.

High temporal turnover is expected in non-stable habitats (Moreno and Halffter 2001), such as our study system, Mediterranean temporary ponds. Environmental fluctuations provide opportunities for temporal niche partitioning: habitat conditions of a pond will favour different species at different times, depending on their niche requirements (Chesson and Huntly 1997). From a practical perspective, inter-annual turnover at pond scale provides evidence for the inadequacy of surveys conducted only in one breeding season to characterize the species assemblage associated to a given pond. The relevance of the duration of surveys was already stressed by Skelly et al. (2003) in the context of decline studies when comparing present-day with historical data. He noticed that a 5-year resurvey would yield negligible changes in population whereas a shorter resurvey (1 or 2 years) would falsely suggest a population decline. In our study, we also noted that environmental fluctuations probably affected in a similar way all the pond assemblages. So, in any given year, the pond assemblages tended to be similar although not unequivocally differentiable from assemblages of different years. This result reinforces the relevance of yearspecific environmental conditions (i.e. hydrological or meteorological) in the species composition of the larval assemblage which Jakob et al. (2003) pointed out for a different Mediterrean temporary pond system.

Analyses at species level (proportion of occupied ponds and overall species abundance) were useful in indentifying which species showed the most remarkable inter-annual changes. However, they lacked statistical power and thereby had to be complemented with analyses focused on the assemblage-level, such as species richness comparisons or the assemblagecomposition-based approach. In general, we observed large fluctuations in species occupancy, probably due to differences in rainfall timing and quantity which conditioned the availability and characteristics of breeding sites. The breeding success of urodele species decreased in 2006-season, a year of scarce autumn rainfall, which agrees with previous studies reporting that Triturus species were negatively affected by delayed rainfall, both in the study area (Díaz-Paniagua 1998) and in a different Mediterranean temporary pond system (Jakob et al. 2003). Low occurrence and abundance of urodeles might have favoured higher occupancy and overall relative abundance of species such as $B$. calamita or D. galganoi, which would have faced lower predation pressure, as pointed out by Jakob et al. (2003) in a similar study. Besides, these species, which mostly breed in ephemeral unpredictable habitats (DíazPaniagua 1990), probably benefited from the reduction in hydroperiod in 2006season as well. Hydroperiod constraints would also explain the marked decrease in the proportion of ponds these two species occupied in an extremely wet year (2004season), when duration of flooding increased in ponds. This reduction in occupancy and overall relative abundance, also noticeable in most other species, could also be due to the formation of additional ponds in the surrounding area, which were not included in this study but may have 
provided alternative breeding sites for amphibian species.

Patterns of temporal turnover in amphibian communities have been previously documented in the literature (Trenham et al. 2003; Werner et al. 2007) and have been explained by various mechanisms, such as extinction/colonization processes, skipped breeding and movements among ponds (Werner et al. 2007). Although further research is required to understand the processes underlying inter-annual turnover in the study area, two of these mechanisms, movements among ponds and skipped breeding, seem more feasible. We think that the high connectivity in the system of temporary ponds (Fortuna et al. 2006) probably favoured movements of individuals from one pond to another. Inter-pond movements in response to changes in habitat suitability have been reported in amphibian populations which perceived a cluster of ponds, rather than a single one, as the same breeding unit (Petranka et al. 2004). On the other hand, the observed decrease in the occupancy of some species may support the hypothesis of individuals skipping breeding seasons in particular ponds, although not in the entire study area.

From a methodological perspective, we provide two alternative approaches to evaluate temporal turnover at the assemblage level depending on the type of data available. In the richness-based approach, we propose comparisons between annual and cumulative richness, as recommended by Romanuk and Kolasa (2001), complemented with comparisons between annual and rarefacted richness, to discard potential biases caused by simple accumulation of sampling effort (see Gotelli and Colwell 2001). As a case in point, in the present study, the absence of significant differences between annual richness in 2006-season and rarefacted richness for a equivalent sampling effort revealed us that, in 2006-season, differences between annual richness and cumulative richness were not unequivocally attributable to species turnover. On the other hand, the assemblage-composition-based approach evaluate temporal turnover from species presence-absence or relative abundance data. As a major advantage, it quantifies temporal turnover in an easy-to-compute single value for the entire study period and study area, which may enable comparisons with different areas or periods of time. A similar approach, also based on dissimilarity indices, was previously applied to quantify temporal turnover in an amphibian metacommunity (Werner et al. 2007). Although temporal turnover can be computed from any community dissimilarity index (i.e. Bray-Curtis, Jaccard), we recommend the use of indices that yield similarity values independent of richness variation, such as Morisita-Horn or Simpson. These indices will identify the replacement of species in the assemblage (substitution of some species by others) as inter-annual turnover but not the loss of species from the assemblage (reduction in species richness). Thereby, they provide complementary information to richnessbased approaches. Moreover, patterns of temporal turnover measured with abundance data also complement those obtained with presence-absence data. The identity of species breeding in a pond may not change from year-to-year while its abundance does. So, we can interpret that the breeding success of different species is favoured depending on the year, an alternation that will contribute to the middle-term preservation of all species in the assemblage.

This study contributes to the knowledge of the effects of temporal scale in biodiversity assessments. The observed inter-annual turnover in the area suggests that a given pond offers different breeding opportunities over time, being suitable for different 
species depending on its biotic and abiotic characteristics. In fact, sites supporting low annual richness are likely to have high species turnover and thus could be important to a larger number of species over a longer time span (White et al. 2006). So, from a conservation perspective, the relevance of these sites can only be assessed when taking into account the temporal dynamism of the pond assemblage. This temporal dynamism at pond scale creates a spatio-temporally dynamic system at landscape scale. Thus, in our study area, the network of ponds can be seen as a shifting mosaic of suitable habitats over time (as Urban 2004 described for a freshwater invertebrate community). The high abundance and diversity of temporary ponds (Díaz-Paniagua et al. 2006; GómezRodríguez et al. in press) would provide the spatial variability necessary for a community to persist under high environmental variability (Shurin 2007). So, the natural dynamism of the ecosystem in a highly preserved area seems the most important feature benefiting the conservation of biodiversity in the mediumterm. For that reason, it is highly relevant to preserve natural temporary pond networks that would favour the persistence of populations through their intrinsic variability. From an applied perspective, the major implication of this study is that amphibian monitoring should take temporal dynamics of amphibian communities into account (i.e. conducted during more than one breeding season to assess the complete diversity associated to a pond).

Comments This section was done in collaboration with Carmen Díaz-Paniagua, Javier Bustamante, Alexandre Portheault and Margarita Florencio. 


\section{References}

Azeria ET, Kolasa J 2008. Oikos 117, 10061019.

Baselga A et al. 2007. Biol Lett 3, 642-645.

Biedermann R 2004. Oikos 107, 645-653.

Briers RA, Warren PH 2000. Oecologia 123, 216-222.

Buckland ST et al. 2005. Philos Trans R Soc Lond B-Biol Sci 360, 243-254.

Clarke KR 1993. Aust J Ecol 18, 117-143.

Colwell RK et al. 2004. Ecology 85, 27172727.

Collins JP, Halliday T 2005. Philos Trans $R$ Soc Lond B-Biol Sci 360, 309-314.

Collins SL, Glenn SM 1991. Ecology 72, 654-664.

Chesson P, Huntly N 1997. Am Nat 150, 519-553.

Díaz-Paniagua C 1990. Herpetol J 1, 447453.

Díaz-Paniagua C 1998. Herpetol J 8, 93-98.

Díaz-Paniagua C et al. 2006. Rev Esp Herpetol 20, 17-30.

Fjeldsa J, Lovett JC 1997. Biodivers Conserv $6,315-323$.

Fortuna M et al. 2006. $P$ Roy Soc Lond B Bio 273, 1429-1434.

Gómez-Rodríguez $\mathrm{C}$ et al. In press. Aquat Ecol. Online first.

Gotelli NJ, Colwell RK 2001. Ecol Lett 4, 379-391.

Green DM 2003. Biol Conserv 111, 331343.

Hanski I 1998. Nature 396, 41-49.

Hanski I, Gilpin M 1991. Biol J Linn Soc 42, 3-16.

Hecnar SJ, M`Closkey RT 1996. Ecology 77, 2091-2097.

Hels T 2002. Ecography 25, 303-313.

Henry P-Y et al. 2008. Biodivers Conserv 17, 3357-3382.

Heyer WR et al. 1994. Measuring and Monitoring Biological Diversity. Standard Methods for Amphibians.
Smithsonian Institution Press, Washington \& London.

Hobbs RJ 1998. Managing Ecological Systems and Processes. In: Peterson, D.L., et al. (Eds.), Ecological Scale. Theory and Applications. Columbia University Press, New York.

Innes JL 1998. Measuring Environmental Change. In: Peterson, D.L., et al. (Eds.), Ecological Scale. Theory and Applications. Columbia University Press, New York.

Jakob C et al. 2003. Hydrobiologia 499, 5161.

Koleff P et al. 2003. J Anim Ecol 72, 367 382.

Loman J, Andersson G 2007. Biol Conserv 135, 46-56.

MacKenzie DI et al. 2003. Ecology 84, 2200-2207.

Magurran AE 2004. Measuring Biological Diversity. Blackwell Publishing.

Magurran AE 2007. Ecol Lett 10, 347-354.

Marsh DM 2001. Biol Conserv 101, 327335.

Marsh DM, Trenham PC 2001. Conserv Biol $15,40-49$.

Moreno CE, Halffter G 2001. Biodivers Conserv 10, 367-382.

Pechmann JHK et al. 1991. Science 253, 892-895.

Pellet J et al. 2006. Oecologia 149, 65-71.

Petranka JW, Holbrook CT 2006. Restor Ecol 14, 404-411.

Petranka JW et al. 2004. Ecol Appl 14, 1065-1078.

Preston FW 1960. Ecology 41, 611-627.

Ricklefs RE, Schluter D (eds.)1993. Species Diversity in Ecological Communities: Historical and Geographical Perspectives. University of Chicago, Chicago.

Richter-Boix A et al. 2006. AmphibiaReptilia 27, 549-559.

Richter-Boix A et al. 2007. J Anim Ecol 76, 607-618. 
Rivas-Martínez S et al. 1980. Lazaroa 2, 5189.

Romanuk TN, Kolasa J 2001. Ecoscience 8, 259-263.

Shurin JB 2007. Oikos 116, 957-965.

Siljeström PA et al. 1994. J Arid Environ 26, 315-323.

Skelly DK 2001. Isr J Zool 47, 313-332.

Skelly DK, Meir E 1997. Conserv Biol 11, $531-538$.

Skelly DK et al. 1999. Ecology 80, 23262337.
Skelly DK et al. 2003. Conserv Biol 17, 744751.

Smith MA, Green DM 2005. Ecography 28, 110-128.

Trenham PC et al. 2003. Ecol Appl 13, 1522-1532.

Urban DL 2004. Ecology 85, 2971-2978.

Werner EE et al. 2007. Oikos 116, 17131725.

White EP et al. 2006. Oikos 112, 185-195. 


\title{
When should we survey amphibian communities?
}

\section{Application of detection probabilities to the design of}

\author{
monitoring programs
}

Failure to detect a species in a spatial unit where it is present is a major source of error in any biological survey. In this study, we evaluate the intra and inter-annual variation in the detectability of amphibian species in order to allocate survey effort efficiently in a single-visit monitoring program and, thereby, minimize the possibility of false absences. We developed single-species occupancy models to estimate the occupancy and the probability of detection of species in each sampling visit during a four-year monitoring program in a system of Mediterranean temporary ponds. We evaluated alternative hypotheses to assess whether the probability of detecting a species was constant, changed among sampling visits, or in accordance to habitat characteristics. We followed an Information Theoretic Approach to model selection and multimodel inference of parameters. We could not find a "best month" to survey, common to all species and years, since the occupancy and probability of detection of amphibians were species-specific and changed among sampling visits within a breeding season and also among breeding seasons. So, we cannot a priori select the most adequate sampling date since we cannot predict with certainty when a species will occupy the largest number of ponds or when the probability of detection will be highest. This study evidences the variability and uncertainty in the efficacy of amphibian surveys in such a highly dynamic ecosystem and hence the importance of repeated sampling both for species occupancy and diversity assessments. 


\section{Introduction}

The main aim of monitoring programs is to assess the spatial and temporal trends of biological diversity (Yoccoz et al. 2001). Depending on the particular scope of a monitoring program, researchers may use different variables to characterize the status of a population. For instance, the fraction of sampling units in a landscape where a target species is present (occupancy) is frequently used as a surrogate for population size or species abundance (MacKenzie 2005b; MacKenzie 2005a). In any biological survey, a major source of error is the failure to detect a species in a spatial unit where it is actually present (Yoccoz et al. 2001; Pollock et al. 2002; Pellet and Schmidt 2005; Schmidt 2005). While species presence may be confirmed by detecting the species at a site, it is not usually possible to verify whether a species is absent (MacKenzie 2005b; MacKenzie et al. 2006). The non-detection of a species may result either from the species being genuinely absent or from the species being present at the site but undetected during the survey (MacKenzie 2005b; MacKenzie et al. 2006). Boulinier et al. (1998) define the detectability of a species "as the probability of detecting at least one individual of a given species in a particular sampling effort, given that individuals of the species are present in the area of interest during the sampling session".
Optimal survey design seeks the maximization of statistical power while minimizing financial costs (Field et al. 2005). To improve statistical power, we should avoid non-detection errors or, at least, reduce the probability that we may miss a species when present (i.e. increase the probability of detection). To do this, we may follow two alternatives: to statistically estimate occupancy while explicitly accounting for the imperfect detection of the species, or to efficiently allocate the survey effort as a way to minimize the possibility of a false absence. Theoretically, the most robust approach is the incorporation of detection probability into the estimates of population occupancy (MacKenzie 2005b; MacKenzie et al. 2006). However, it requires temporal replication at sampling sites (MacKenzie et al. 2002; MacKenzie et al. 2006) and hence it is an intensive and time-consuming labour. A less expensive alternative would be the application of information on detectability from other times or places to know a priori how to achieve a desired level of precision for a minimum survey effort. For instance, we may use data from detection probabilities to determine the minimum effort required to represent a population (De Solla et al. 2005; Pellet and Schmidt 2005) or to time the sampling visits in order to maximize the detection probability (MacKenzie and Royle 2005; De Solla et al. 2006). 
MacKenzie et al. (2006) provides a statistical methodology to estimate both the occupancy and detectability parameters simultaneously. Occupancy estimation models also enable the inclusion of habitat covariates that could influence the probability of occupancy or the probability of detection. Thereby, we may ascertain whether a particular habitat characteristic favours the presence of a species or it just facilitates its detection. Moreover, we may also evaluate if the probability of detecting a species changes among sampling visits or, on the contrary, it is more likely that it remains constant over time.

Occupancy estimation methods are not widely used by herpetologists and most studies rely on unadjusted count data (Schmidt 2003, 2004; Mazerolle et al. 2007). Many amphibians are secretive species and hence use to show low detectability (Mazerolle et al. 2007), being such detectability variable among species (i.e. Bailey et al. 2004; De Solla et al. 2006). Moreover, a given species may also differ in its detectability within a given breeding or among breeding seasons (De Solla et al. 2005; De Solla et al. 2006). Hence, detectability is not a species trait (Mazerolle et al. 2007). Moreover, the detectability of a species widely depends on the survey method used (Schmidt 2004; De Solla et al. 2005; MacKenzie et al. 2006). For that reason, we should extrapolate with caution literature data (i.e. probability values, influence of environmental factors...), as most previous studies are based on acoustic activity (MacKenzie et al. 2002; De Solla et al. 2005; De Solla et al. 2006) or observations on terrestrial salamanders (Bailey et al. 2004; Williams and Berkson 2004).

In this study, we assess the usefulness of occupancy-models to improve monitoring programs in a highly dynamic system, an amphibian community breeding in
Mediterranean temporary ponds. We address an explicit focus on detection probabilities in order to allocate survey effort efficiently. We are interested in evaluating the adequacy of single-visit monitoring programs to represent the community and when they should be conducted. So, we search for a sampling date when the probability of detecting all species is nearly perfect. For each species, we build occupancy models to assess if detectability should be considered constant or variable over time within a breeding season or among seasons as well as to evaluate its relationship with habitat variables. We question the efficacy of single-visit monitoring programs in this type of ecosystem, asking more particularly whether efficacy can be gained by framing the sampling visit within a particular period of time to increase species detectability.

\section{Material and Methods}

\section{Study area}

The study was conducted at the Doñana Biological Reserve, an area of 6794 hectares within Doñana National Park, in southwestern Spain (see Siljeström et al. 1994 for a geo-morphological description). The dominant vegetation on this area is Mediterranean scrub (Halimio halimifoliiStauracanthetum genistoides and Erico scopariae-Ulicetum australis as defined by Rivas-Martínez et al. 1980) and isolated patches of pine (Pinus pinea L.) and juniper forests (Juniperus phoenicea L.).

On the sandy area of the Park, many temporary ponds of natural origin flood during the rainy season. These temporary ponds are fed by freshwater and have no direct connection to the sea. Pond size is largely variable, from rain puddles (several square metres) to large temporary ponds (> 
1 hectare). The duration of flooding (or hydroperiod) varies among ponds, from pools persisting one month or less to ponds persisting up to 10 months in very wet years. Hydroperiod is widely variable among years. The area also includes two extensive permanent ponds of natural origin that occasionally dry out after years of severe drought.

For this study we chose the two permanent ponds and 19 temporary ponds covering the wide hydroperiod gradient in the study area (a detailed description of the temporary ponds can be found in Gómez-Rodríguez et al. in press).

\section{Field sampling}

We determined the maximum size of each pond delineating them on aerial orthophotos (Junta de Andalucía 2003) with ArcView GIS 3.2, and verifying the limits in the field. Every pond was visited monthly to assess if it was flooded or dry in the 2003 season and the 2006 season. In each season, pond hydroperiod is the number of months the pond was flooded. Since frequency of visits to ponds was much lower in the 2004 season, we assumed the same values of hydroperiod as in the previous season, based on field observations.

Amphibian monitoring consisted in an intensive sampling once a month during each breeding season: February - May 2003, January - May 2004 and March - May 2006. The monthly amount of rainfall varied among the years of study. Ponds did not flood in 2005 and therefore could not be sampled. Two ponds were not accessible in 2004 and thus could not be sampled. In addition, in 2003, one of those ponds was only accessible in May, and since no individuals were found, it was also excluded from the study. In 2006, two ponds were flooded during less than one month and could not be sampled.
We used dipnetting techniques (Heyer et al. 1994) to collect and to identify larvae to species level in situ (referred hereafter as "larval sampling"). We counted the number of larvae captured in each sampling unit (three consecutive sweeps on a stretch of approx. $1.5 \mathrm{~m}$ length) and then released them back. For most ponds, we set 12 sampling units as the standard sampling effort. Sampling units were separated a minimum of five metres to avoid interference between surveys. Small ponds were sampled in proportion to their size, so the number of sampling units could decrease to guarantee minimum separation (5 m). In large ponds we tried to sample all different microhabitats, increasing the number of sampling units performed as needed.

Larval sampling was complemented with visual surveys in and around the pond to detect eggs, larvae, and metamorphic individuals.

\section{Data analysis}

To depict each species phenology, we quantified its relative abundance and the number of ponds it was observed in (observed proportion of occupied ponds $[\mathrm{POP}])$ in each month. We also quantified the number of species detected across the entire study area (species richness) in each month. For each species, the monthly relative abundance was computed from the "larval sampling" data as the mean number of larvae collected per sampling unit, using only occupied ponds. We used Pearson correlation to determine the relationship between the monthly observed POP and the log-transformed monthly relative abundance.

To simultaneously estimate the single-visit probability of detection (p) and the proportion of occupied ponds (POP), we developed single-species occupancy models 
(MacKenzie et al. 2002; MacKenzie et al. 2006) with program PRESENCE (MacKenzie et al. 2002). PRESENCE uses standard maximum likelihood techniques to obtain estimates of model parameters ( $p$ and $\mathrm{POP})$ and requires at least two sampling events per breeding season in a set of ponds. The estimated POP differs from the observed POP when the organisms are imperfectly detected (they are not always detected when present at a site). Actually, single-species occupancy models estimate the probability that a site within a group of sites is occupied (probability of occupancy $[\Psi]$ ), which can be interpreted as the proportion of ponds occupied without penalty (MacKenzie et al. 2006). In this study, the estimated POP will be equal to the probability of occupancy. The singlevisit detection probability (p) of a species is the probability that it will be detected at a pond in one sampling visit, given that the species breeds in the pond. Both POP and $p$ may be constant across all ponds or to vary in accordance with habitat characteristics. POP is assumed not to vary during the sampling season ("closed occupancy status") whereas $p$ may be constant or visitspecific. However, in the study area, POP may change during the breeding season depending on each species' phenology (i.e. the pond is not occupied before the date of pond arrival, which may be delayed in the breeding season). So, in this study, the assumption of constant occupancy is a practical one that enables the assessment of differences in sampling efficacy for a given species (measured as its detection probability) depending on month of survey. In other words, we assume that if a species occupies a pond in a given breeding season, we should be able to detect it in any sampling visit that season. Hence, the probability of detection will be null, evidencing a very low sampling efficacy, if the species has not reached the pond (or already left it) when the survey is conducted.

For each species and breeding season, we developed the single-species occupancy models from the patterns of detection and non-detection over the multiple visits to the ponds (detection histories). We developed a set of six a priori candidate models, each representing an alternative hypothesis, to assess if the probability of occupancy was constant or varied in accordance with habitat characteristics known to be critical for amphibians, such as hydroperiod (Wellborn et al. 1996; Snodgrass et al. 2000; Werner et al. 2007) or pond size (Laan and Verboom 1990; Beja and Alcazar 2003; Werner et al. 2007) and to assess if the single-visit probability of detection was constant, visit-specific or varied in accordance with habitat characteristics such as hydroperiod or pond size (Table 2l). We examined the relationship between the probability of detection and both habitat characteristics because they account for the temporal and spatial dimension of ponds. So, we hypothesize that they may condition the probability of spatial and temporal coincidence between individuals and sampling visits (i.e. the longer the duration of a pond, the lower the probability that a given sampling visit is inevitably timed to the larval period of a species). All models included the intercept on both $\Psi$ and p. We did not construct a global model, including all parameters, since it would have included far more parameters than reasonable given our data (21 cases). Model covariates (hydroperiod and pond size) were standardized to $\mathrm{Z}$ scores (mean value $=0$; S.D. = 1). In some models, we could not reach algorithm convergence in the iterative search for the maximum likelihood and thereby had to discard the model output. To avoid problems with the standard error estimation in the visit-specific $p$ model $[\Psi(),. p($ month $)]$, we manually fixed the detection probability to be 0 or 1 in a given 
sampling visit if the species was not detected in any pond or detected in all the occupied ponds, respectively. Since there was not a global model, each model was checked for lack-of-fit using parametric bootstrapping (1000 samples) to determine whether the observed value of Pearson chisquare statistics was unusually large (see MacKenzie and Bailey 2004). The estimated $\hat{c}$ was close to $l$ in all models, evidencing no overdispersion.

We followed an Information Theoretic Approach, based on second-order Akaike's Information Criterion (AICc), to model selection and multimodel inference of parameters (see Burnham and Anderson 2002). So, estimates of the parameters of interest ( $p$ and $\Psi$ ) were based on the entire set of models rather than on the one selected as best. Model-averaged estimates have more precision and are less biased compared to the estimator from just the selected best model and are especially useful if no model is clearly best (Burnham and Anderson 2002). Our approach for model selection consisted on two steps: First, we ranked models according to their AICc values in order to obtain Akaike's model weights $(\omega)$, which quantify the uncertainty that each model is the target best model (see Burnham and Anderson 2002). We used the AICc rather than the AIC because it is recommended when the ratio between sample size and number of model parameters is less than 40 (Burnham and Anderson 2002). For each model, we also computed the averaged value of Akaike's weight for the entire study period, for each breeding season and for each species, in order to assess its "global" relevance. Second, we used model weights to compute the model-averaged estimates of parameters ( $p$ and $\Psi$ ) and their unconditional standard errors, which incorporate model selection uncertainty into

Table 21. Set of candidate models evaluated. $\Psi$ represents the probability of occupancy and $p$ represents the probability of detection. Covariates for each parameter are indicated within parentheses. Dots indicate constants.

\begin{tabular}{|c|c|}
\hline $\begin{array}{l}\text { Model } \\
\text { nomenclature }\end{array}$ & Hypothesis \\
\hline$\Psi(),. p()$. & $\begin{array}{l}\text { Probability of occupancy constant across ponds. } \\
\text { Probability of detection constant across ponds and visits. }\end{array}$ \\
\hline$\Psi(),. \mathrm{p}($ month $)$ & $\begin{array}{l}\text { Probability of occupancy constant across ponds. } \\
\text { Probability of detection constant across ponds but varies across visits. }\end{array}$ \\
\hline$\Psi($ area $), p()$. & $\begin{array}{l}\text { Probability of occupancy varies in accordance with pond size. } \\
\text { Probability of detection constant across ponds and visits. }\end{array}$ \\
\hline$\Psi$ (hydro), p(.) & $\begin{array}{l}\text { Probability of occupancy varies in accordance with pond hydroperiod. } \\
\text { Probability of detection constant across ponds and visits. }\end{array}$ \\
\hline$\Psi(),. \mathrm{p}($ area $)$ & $\begin{array}{l}\text { Probability of occupancy constant across ponds. } \\
\text { Probability of detection constant across visits but varies in accordance } \\
\text { with pond size. }\end{array}$ \\
\hline$\Psi(),. \mathrm{p}($ hydro $)$ & $\begin{array}{l}\text { Probability of occupancy constant across ponds. } \\
\text { Probability of detection constant across visits but varies in accordance } \\
\text { with pond hydroperiod. }\end{array}$ \\
\hline
\end{tabular}


estimates of precision (see Burnham and Anderson 2002). We could not compute a model-averaged probability of detection when the visit-specific p model was the one largely "best" supported by the data (lowest ranked model and with large Akaike's weigth), since it was the only model including those parameters. Models that did not fit the data and parameter values that did not converge were excluded from modelaveraging. We computed the annual probability of detection (annual $\mathrm{p}^{*}$ ), to assess the probability that the species was detected after the $\mathrm{k}$ times (sampling visits) the pond was surveyed that year, by applying the formula:

$$
p^{*}=\prod_{i=1}^{k}\left(1-p_{i}\right)
$$

\section{Results}

\section{Species phenology}

We detected the presence of eight amphibian species during the entire study period: Bufo calamita (Laurenti, 1768), Pelobates cultripes (Cuvier, 1829), Discoglossus galganoi Capula, Nascetti, Lanza, Bullini \& Crespo, 1985, Pelophylax perezi (Seoane, 1885), Hyla meridionalis Boettger, 1874, Pleurodeles waltl Michahelles, 1830, Triturus pygmaeus (Wolterstorff, 1905) and Lissotriton boscai (Lataste, 1879). All species attempted breeding in each breeding season. However, we did not detect all species in any single sampling visit (Figure 30). The observed number of species varied among sampling visits, being lowest (four species) in May 2006, whereas the largest number (seven species) was found at least in one sampling visit in each breeding season. Pelobates cultripes was the only species that was detected in all sampling visits. Bufo calamita was detected only in one sampling visit in 2003 and 2004; P. perezi in 2004 and 2006 and D. galganoi was observed in less than $50 \%$ of the sampling visits in 2004. The observations of B. calamita and D. galganoi occurred at the beginning of the breeding seasons whereas the observations of $P$. perezi occurred at the end of the breeding seasons. The rest of the species were detected, at least in one pond, in most of the sampling visits.

The maximum monthly observed POP did not equate the annual observed POP for most species and breeding seasons (Table 22). So, we could not identify all the occupied ponds if we surveyed only in one occasion. Besides, the monthly relative abundance and the number of ponds a species was observed to occupy in a given month (monthly observed POP) widely varied among sampling visits (Figure 30). The monthly relative abundance of a species correlated with its monthly observed POP (Pearson $\mathrm{r}=$ 0.654, $\mathrm{p}<0.001$ ), evidencing that the more abundant a species was in the ponds it bred in, the larger the number of ponds it was observed to occupy in the entire study area. 

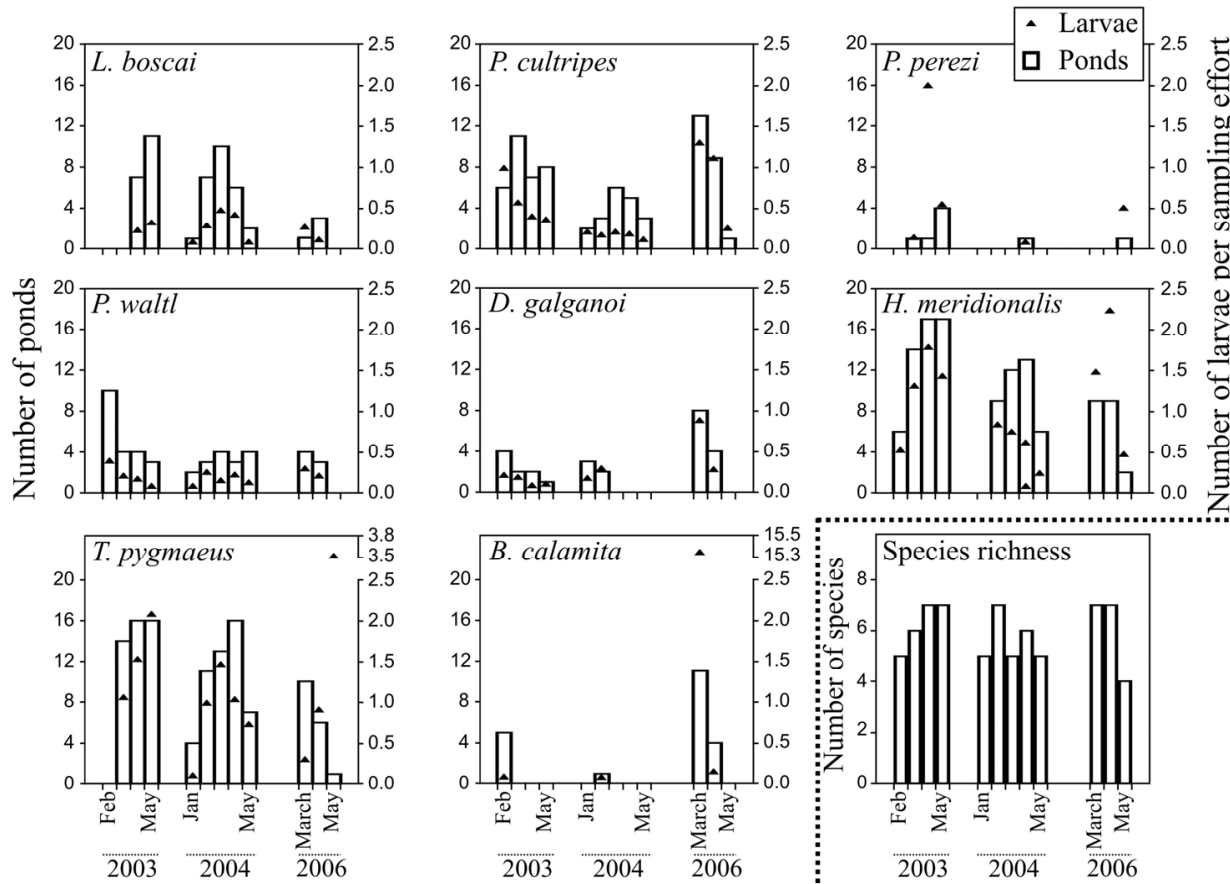

Figure 30. For each sampling visit, we show the number of ponds a species was observed to occupy (monthly observed POP), its monthly relative abundance (number of larvae per sampling effort) and the number of species detected in the entire study area (species richness).

Table 22. For each species and breeding season, the maximum monthly observed proportion of occupied ponds [POP], the annual observed occupancy and the model-averaged estimate of the proportion of occupied ponds (equivalent to the probability of occupancy), is shown. NA = Model parameters could not be estimated given the data.

Max. monthly POP

Annual POP

Observed Observed $\quad$ Estimated

2003

B. calamita

0.250

0.25

NA

P. cultripes

0.550

0.60

$0.743 \pm 0.261$

D. galganoi

0.200

0.35

$0.669 \pm 0.102^{4}$

P. perezi

0.200

0.25

NA

H. meridionalis

0.850

0.95

1.0001

P. waltl

0.500

0.70

$0.910 \pm 0.196^{1}$

T. pygmaeus

0.800

0.85

$0.850 \pm 0.080^{1}$

L. boscai

0.550

0.6

$0.689 \pm 0.135^{1}$

*Where not all models are used for model averaging $(n=6)$ superindices show the number of models used. 
Table 22. (cont.)

\begin{tabular}{|c|c|c|c|}
\hline & \multirow{2}{*}{$\frac{\text { Max. monthly POP }}{\text { Observed }}$} & \multicolumn{2}{|c|}{ Annual POP } \\
\hline & & Observed & Estimated \\
\hline \multicolumn{4}{|l|}{2004} \\
\hline B. calamita & 0.053 & 0.053 & NA \\
\hline P. cultripes & 0.316 & 0.474 & $0.527 \pm 0.134$ \\
\hline D. galganoi & 0.158 & 0.158 & $0.158 \pm 0.085$ \\
\hline$P$. perezi & 0.053 & 0.053 & NA \\
\hline H. meridionalis & 0.684 & 0.842 & $0.851 \pm 0.085^{1}$ \\
\hline P. waltl & 0.211 & 0.474 & $0.603 \pm 0.169^{5}$ \\
\hline T. pygmaeus & 0.842 & 0.842 & $0.898 \pm 0.101$ \\
\hline L. boscai & 0.526 & 0.684 & NA \\
\hline \multicolumn{4}{|l|}{2006} \\
\hline B. calamita & 0.579 & 0.632 & $0.774 \pm 0.179^{4}$ \\
\hline P. cultripes & 0.632 & 0.737 & $0.926 \pm 0.376^{5}$ \\
\hline D. galganoi & 0.421 & 0.474 & $0.764 \pm 0.352$ \\
\hline$P$. perezi & 0.053 & 0.053 & NA \\
\hline H. meridionalis & 0.474 & 0.632 & $0.983 \pm 0.410^{5}$ \\
\hline P.waltl & 0.211 & 0.211 & $0.218 \pm 0.100^{5}$ \\
\hline T. pygmaeus & 0.526 & 0.579 & $0.767 \pm 0.182$ \\
\hline L. boscai & 0.158 & 0.158 & $0.259 \pm 0.155^{5}$ \\
\hline
\end{tabular}

* Where not all models are used for model averaging $(n=6)$, superindices show the number of models used. 


\section{Single-species occupancy models}

We developed single-species occupancy models for all species and breeding seasons except for B. calamita in 2003 and 2004 and for P. perezi in 2004 and 2006, since they were detected only in one sampling visit and thus lacked the necessary repeated sampling (Table 23, see Supplementary Material Table 1-3 for details). For most of the species and breeding seasons, we computed model-averaged estimates of parameters from a set of candidate models with a summed weight of evidence above 0.750. We could not estimate model parameters (p and $\Psi$ ) of L. boscai in 2004 and of $P$. perezi in 2003 (see Table 3).

Taking into account the total Akaike's weight of each candidate model across all species and seasons, the visit-specific $p$ model $[\Psi(),. \mathrm{p}($ month $)]$ obtained the greatest support given the data (Figure 31). The second "best" model was the one considering the probability of detection constant across ponds and sampling visits, and the probability of occupancy to vary in accordance to pond size $[\Psi($ area $), p()$.$] . The$ same pattern was observed when we considered the total Akaike's weight of each candidate model across all species in a given sampling season. At species level, considering the total Akaike's weight across seasons, the visit-specific $\mathrm{p}$ model showed the highest support for all species except $P$. cultripes and $P$. perezi. For any given species, we observed differences in model ranking and model weights among breeding seasons, evidencing that there was not a "best supported hypothesis" valid for all the breeding seasons (see Supplementary Material Tables 1-3 for details). For example, we should consider the detection probability of $H$. meridionalis and $T$. pygmaeus to change among sampling visits in 2003, since the visit-specific $p$ model was clearly the best supported model $(\omega \geq$ 0.999), whereas the same hypothesis received low support in 2006 (H. meridionalis $\omega=0.077 ; T$. pygmaeus $\omega=$ 0.019 ) compared to the ones assuming $p$ to be constant across sampling visits.

Table 23. Sum of the Akaike's weights $(\omega)$ of the models used to compute the modelaveraged estimates of parameters ( $\mathrm{p}$ and $\Psi$ ) and their unconditional standard errors.

\begin{tabular}{|c|c|c|c|c|c|c|}
\hline & \multicolumn{2}{|c|}{ 2003-season } & \multicolumn{2}{|c|}{ 2004-season } & \multicolumn{2}{|c|}{ 2006-season } \\
\hline & $\Psi$ & $\mathrm{p}$ & $\Psi$ & p & $\Psi$ & p \\
\hline B. calamita & \multicolumn{2}{|c|}{$\mathrm{NM}$} & \multicolumn{2}{|c|}{$\mathrm{NM}$} & 0.964 & $0.886^{*}$ \\
\hline P. cultripes & 1 & 0.968 & 1 & 0.997 & 0.542 & 0.767 \\
\hline D. galganoi & 0.846 & 0.833 & 1 & $0.997 *$ & 0.948 & $0.618 *$ \\
\hline$P$. perezi & \multicolumn{2}{|c|}{ IS } & \multicolumn{2}{|c|}{ NM } & \multicolumn{2}{|c|}{ NM } \\
\hline H. meridionalis & 0.999 & $0.999 *$ & 0.999 & $0.999 *$ & 0.752 & 0.924 \\
\hline P. waltl & 0.082 & $0.082^{*}$ & 0.261 & 1 & 0.948 & $0.857^{*}$ \\
\hline T. pygmaeus & 1 & $1^{*}$ & 1 & $0.896^{*}$ & 1 & 0.981 \\
\hline L. boscai & 1 & $1 *$ & \multicolumn{2}{|c|}{$\mathrm{NF}$} & 0.988 & $0.901 *$ \\
\hline
\end{tabular}


The single-visit probability of detection was highly variable among species (Table 24 , Figure 32). In general, the single-visit detection probabilities were moderate for $P$. cultripes and T. pygmaeus (mean single-visit $\mathrm{p}$ between 0.50 and 0.75 ) and low for the rest of the species (mean single-visit $\mathrm{p}$ between 0.25 and 0.50). However, the probability of detection was highly variable among seasons and even among sampling visits within a given season, reaching high values at particular months (Figure 32). The single-visit probability of detection of all species was below 1 in all sampling visits except D. galganoi in January 2004, $P$. waltl in March 2006, L. boscai in April 2006 and T. pygmaeus in April and May 2003 and in April 2004. All species except $P$. cultripes showed a null single-visit probability of detection at least in one sampling visit. No single sampling visit showed the highest or the lowest probability of detection for all the species or most of them.

The probability that a given species was detected after the sampling effort conducted during the entire breeding season (annual $\left.\mathrm{p}^{*}\right)$ was high $(>0.75)$ for all the species except $D$. galganoi in 2003 (Table 24). The annual $p^{*}$ was very high $(\mathrm{p}>0.95)$, at least in one breeding season, for all species except B. calamita, which lacked data in two seasons: P. cultripes (2003 and 2006), D. galganoi (2004), H. meridionalis (2003, 2004, 2006), P. waltl (2006), T. pygmaeus (2003) and L. boscai (2003 and 2006). Due to such high annual probabilities of detection, the observed and estimated values of occupancy were similar for most species and breeding seasons except $D$. galganoi in 2003 (Table 22).

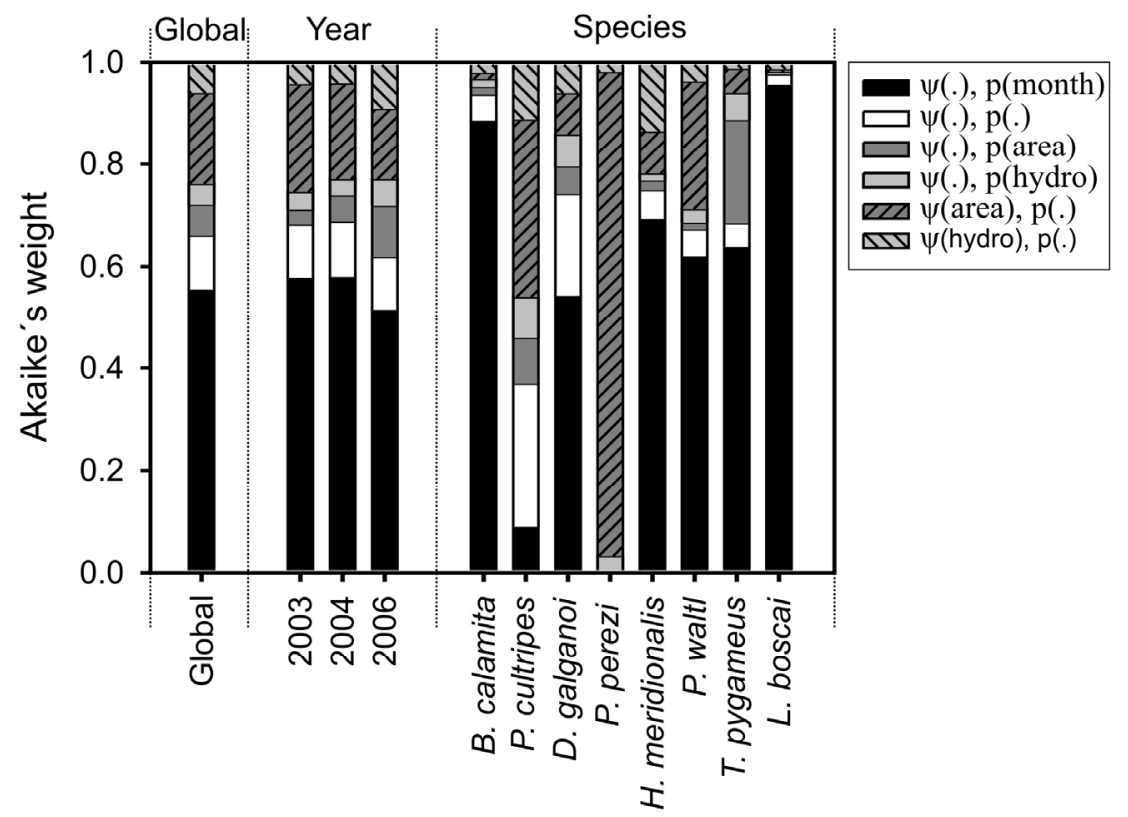

Figure 31. Averaged values of the Akaike's weight of each candidate model. Values have been averaged across all species and seasons (Global), across all species within a breeding season (Year) and across seasons for a given species (Species). 


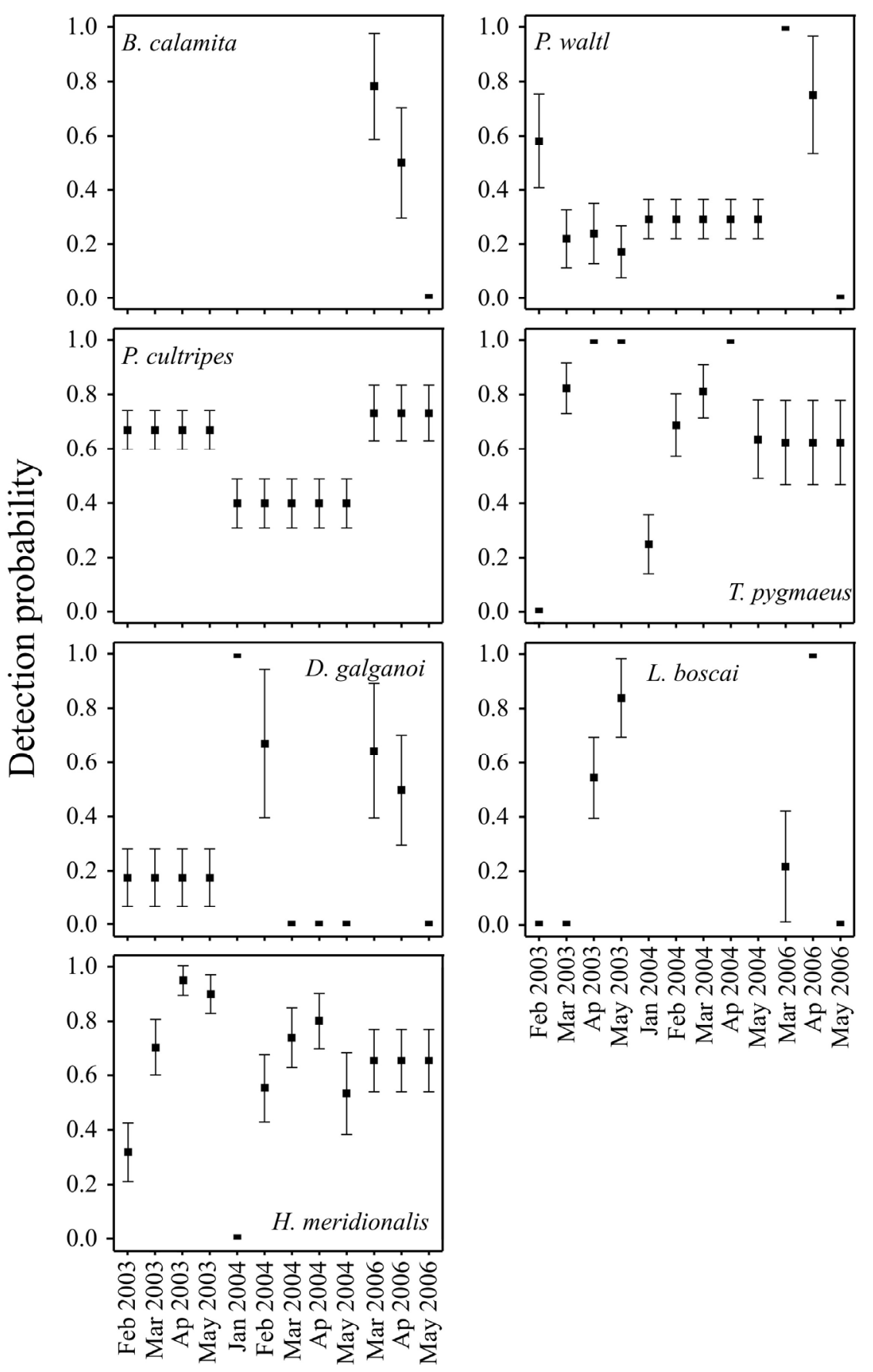

Figure 32. For each species, the temporal variation in the detection probability among sampling visits is shown. 
Table 24. Model-averaged estimates of the single-visit $(\mathrm{p})$ and annual $\left(\mathrm{p}^{*}\right)$ probabilities of detection for each species in each season. $\mathrm{NA}=$ Model parameters could not be estimated given the data.

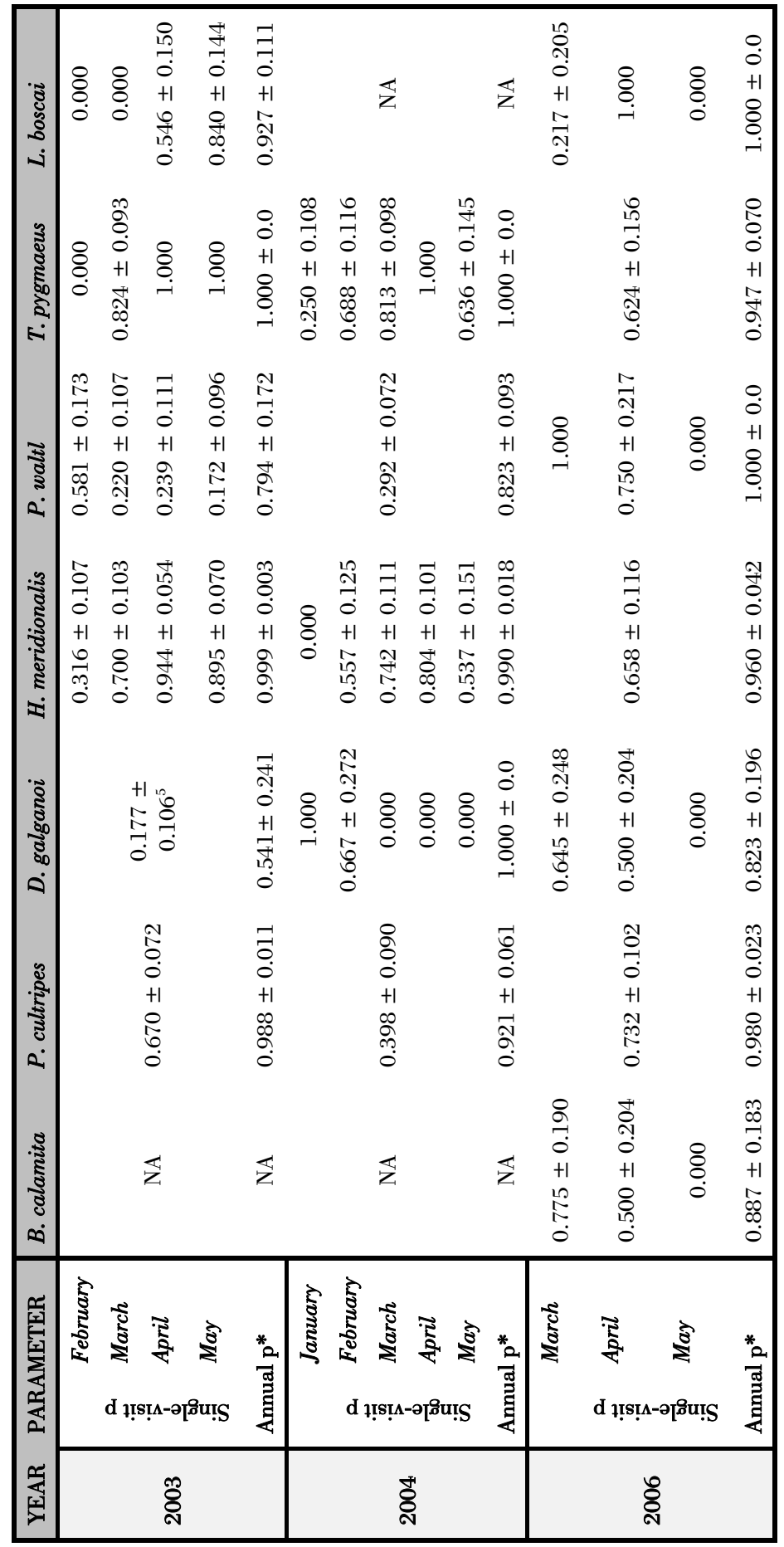




\section{$D_{\text {iscussion }}$}

\section{Heterogeneity of detection probability across time and species}

We evidenced the inadequacy of single-visit monitoring programs to represent an amphibian community breeding in Mediterranean temporary ponds. In these ecosystems, one cannot allocate the survey effort a priori in order to detect all species in a single sampling visit. We could not find a "best month" to survey, common to all species and years, since the occupancy and probability of detection of amphibians were species-specific and changed among sampling dates within a breeding season and also among breeding seasons. Although the probability of detection may vary at some time scale (Pollock et al. 2002; MacKenzie et al. 2006; Mazerolle et al. 2007), we expected a lower temporal variability, mainly between subsequent months, since we mostly used dipnetting surveys, a technique focused on the detection of larvae, which is the life-stage occurring in the breeding sites for longer periods (Heyer et al. 1994). We may discriminate two major causes reducing (or cancelling) the monthly probability of detection of a species in a pond where it breeds: i/ "methodological constraints", due to a low efficacy of the sampling survey to detect the species when it is actually present, and ii/ "phenological constraints", as a species can only be detected in the period between the dates of pond arrival and pond leaving. So, phenological constraints are mainly related to the reproductive strategy (i.e. long or short larval development) and timing of reproduction of a species. In this study, a non-null detection probability can be attributed to "methodological constraints" while a null value can be attributed to both "methodological" and/or "phenological" constraints. Non-null detection probabilities evidence that the species was present in some ponds and, hence, that those sampling visits were timed to the phenology of the species in the area. In that case, increasing the sampling effort (number of sampling units) conducted in each pond would probably have resulted in an increase of the monthly probability of detection. Nulldetection probabilities may evidence both an extremely low probability of detection (the species was in the ponds but we failed detect it) or inadequate timing of the sampling visit (being conducted outside the species breeding season) when it was not actually present at the breeding site. Identifying the causes of low detection probabilities (phenological or methodological) may help improving the sampling efficacy and reducing the proportion of false absences. Hereafter, we use the duality between phenological and methodological constraints as an operational framework to discuss our results.

Applying surveys at breeding sites, we observed inter-specific differences in the probability of detection, which is in concordance with results from previous studies based on acoustic surveys (De Solla et al. 2005; Pellet and Schmidt 2005; Schmidt 2005; De Solla et al. 2006; Gooch et al. 2006). For any given species, we also observed that the probability of detection varied within and between years. Both patterns have been reported in previous studies based on acoustic surveys (Schmidt 2005; Gooch et al. 2006). In our study, both phenological and methodological constraints may explain variation in detectability among species and years. Focusing on interspecific variation, phenological constraints can arise from the differences in reproductive strategies (see review in Wells 2007) and timing (Díaz-Paniagua 1992) among species, resulting in different temporal usages of the ponds and hence in some species being possibly absent in 
particular months. Methodological constraints can arise from inter-specific differences in conspicuousness (Heyer et al. 1994) and abundance, due to the fact that the more abundant a species the easier its detection (Royle and Nichols 2003; MacKenzie 2005b; MacKenzie et al. 2006; Royle 2006). Regarding temporal variation in the detectability of a species, phenological constraints can be related to the inter-annual variability in the pattern of breeding in response to variation in abiotic factors, such as the seasonal distribution of rainfall and date of pond flooding (Jakob et al. 2003; Wells 2007) and, within a breeding season, to the characteristics of the reproductive strategy of a species. For instance, sampling visits at the beginning of the breeding season were ineffective to detect the presence of $P$. perezi (a latebreeding species following Díaz-Paniagua et al. 2005) whereas the ones at the end of a very rainy season (2003 and 2004) were unsuccessful to detect the presence of earlybreeders with short larval development $(D$. galganoi and B. calamita following DíazPaniagua et al. 2005) and high susceptibility to predation (Portheault et al. 2007; Porthault in prep). Temporal variation in detection probabilities is also related to methodological constraints, caused by both biotic and abiotic factors. We can attribute the intra-annual differences in detectability to changes in biotic conditions, such as changes in the pond abundance of the species. On the other hand, the characteristics of the pond at the time of the survey may also have conditioned the detectability of a species. For instance, in 2006, when we observed a generalized increase in the probability of detection, the late pond flooding resulted in smaller pond sizes (personal observation) and hence improved the efficacy of surveys, since effectiveness of dipnetting techniques increases as the size of the pond decreases (Heyer et al. 1994). However, we could not evaluate this hypothesis since we have related detection probability to constant habitat covariates, which showed low relevance in habitat models. We lacked data on pond characteristics in the specific month of survey.

\section{Monitoring implications}

The efficacy of amphibian monitoring programs depends highly on the species, the breeding season, and the timing and frequency of sampling visits. In our community assessments, the efficacy of a single sampling visit was very low since not all species overlapped in time, i.e. we did not detect all species in any single sampling visit, and the single-visit probability of detection was moderate or low for many of them in most sampling visits. Thereby, to conduct community occupancy studies with a single visit, we would have required all species to coexist at a same time and to show an almost perfect probability of detection $(p \approx 1)$ in the date of sampling. Such conditions rarely occur in amphibian communities due to the fact that many species are difficult to detect in their natural environments and hence show low probabilities of detection (Mazerolle et al. 2007). Besides, even if amphibian species reached an almost perfect detection probability at some point during the breeding season, it would hardly be at the same time for all them. In that case, community assessments would be facing the potential bias due to temporal segregation of reproduction (Heyer 1976; Wiest 1982; Wells 2007), a strategy to reduce interspecific competition in larval communities (Lawler and Morin 1993; Wells 2007) which has been previously reported in the study area (Díaz-Paniagua 1988, 1992). We can hardly avoid such biological constraints which may cancel the probability of detection of a species in particular months. 
In species-level occupancy studies, a single-visit may be sufficient to evaluate the proportion of occupied ponds (POP) if it is timed when the probability of detection is close to 1 , and hence the monthly observed occupancy equates the annual observed occupancy. It should be noted that, under imperfect detection conditions $(p<1)$, surveying in the month of highest observed occupancy will under-estimate the species occupancy. Thereby, we do not recommend basing monitoring programs in similar dynamic ecosystems on a single-visit, since perfect probabilities of detection $(p \approx 1)$ are rarely observed and the best survey month (highest probability of detection or, at least, highest monthly POP) can differ among years and hence is hardly predictable from one year to the next. This means that, for most species in the study area, we should be able to predict the onset and the duration of the breeding season based on their reproductive strategy and rainfall input and pattern, but we cannot predict with certainty when a species will occupy the largest number of ponds or when the probability of detection will be highest.

\section{Conclusions}

Occupancy models constitute a powerful tool for assessing the efficacy and optimal timing of faunal monitoring programs. In this study, we showed that the efficacy of amphibian surveys in a Mediterranean pond-breeding community can vary considerably and yield large uncertainty in final occupancy estimates, a finding that could also apply to other taxonomic groups occurring in similar habitats. In such highly dynamic systems, designing a priori an efficient monitoring program is difficult without conducting an intensive survey (i.e. multi-visits survey). An insufficient or inappropriate sampling effort will likely only allow detecting the most frequent species, thus missing the ones that breed in a lower number of ponds and erroneously concluding that they are rarer than they actually are. Although knowledge of breeding phenologies is necessary for designing appropriate monitoring and inventory assessments in amphibians (Paton and Crouch 2002), we should not base the allocation of sampling effort only on the dates of pond arrival and pond leaving, since this approach may still result in false absences due to imperfect species detectability during the sampling period.

Comments This section was done in collaboration with Antoine Guisan, Javier Bustamante and Carmen Díaz-Paniagua. Ivan Gómez- Mestre provided helpful comments that contributed to improve the manuscript. Most of the analyses were conducted during a short stay in the Spatial Ecology Group (University of Lausanne, Switzerland) under the supervision of Dr. Guisan. 


\section{References}

Bailey LL et al. 2004. Ecol Appl 14, 692702.

Beja P, Alcazar R 2003. Biol Conserv 114, 317-326.

Boulinier T et al. 1998. Ecology 79, 10181028.

Burnham KP, Anderson DR 2002. Model Selection and Multimodel Inference. A Practical Information-Theoretic Approach. Springer.

De Solla SR et al. 2006. Biodivers Conserv 15, 3481-3497.

De Solla SR et al. 2005. Biol Conserv 121, 585-594.

Díaz-Paniagua C 1988. Amphibia-Reptilia 9, 15-26.

Díaz-Paniagua C 1992. Ecography 15, 267272.

Díaz-Paniagua C et al. 2005. Los Anfibios de Doñana. Organismo Autónomo de Parques Nacionales. Ministerio de Medio Ambiente, Madrid.

Field SA et al. 2005. J Wildl Manage 69, 473-482.

Gómez-Rodríguez C et al. In press. Aquat Ecol. Online first.

Gooch MM et al. 2006. Appl Herpetol 3, 129-142.

Heyer WR 1976. Studies in larval amphibian habitat partitioning. Smithsonian Institution Press, City of Washington.

Heyer WR et al. 1994. Measuring and Monitoring Biological Diversity. Standard Methods for Amphibians. Smithsonian Institution Press, Washington \& London.

Jakob C et al. 2003. Hydrobiologia 499, 5161.

Junta de Andalucía 2003. Ortofotografía Digital de Andalucía.

Laan R, Verboom R 1990. Biol Conserv 54, 251-262.

Lawler SP, Morin PJ 1993. Ecology 74, 174182.
MacKenzie DI 2005a. Aust $N Z$ J Stat 47, 65-74.

MacKenzie DI 2005b. J Wildl Manage 69, 849-860.

MacKenzie DI, Bailey LL 2004. J Agr Biol Envir St 9, 300-318.

MacKenzie DI et al. 2002. Ecology 83, 2248-2255.

MacKenzie DI et al. 2006. Occupancy Estimation and Modeling. Inferring Patterns and Dynamics of Species Occurrence. Elsevier.

MacKenzie DI, Royle JA 2005. J Appl Ecol $42,1105-1114$.

Mazerolle MJ et al. 2007. J Herpetol 41, 672-689.

Paton PWC, Crouch III WB 2002. Conserv Biol 16, 194-204.

Pellet J, Schmidt BR 2005. Biol Conserv 123, 27-35.

Pollock KH et al. 2002. Environmetrics 13, 105-119.

Porthault A In prep. La importancia de la depredación en el éxito reproductivo de la población de anfibios de Doñana. $\mathrm{PhD}$ Thesis, University of Sevilla, Sevilla.

Portheault A et al. 2007. Rev Ecol-Terre Vie 62, 315-322.

Rivas-Martínez S et al. 1980. Lazaroa 2, 5189.

Royle JA 2006. Biometrics 62, 97-102.

Royle JA, Nichols JD 2003. Ecology 84, 777-790.

Schmidt BR 2003. C R Biologies 326, 119124

Schmidt BR 2004. Herpetol J 14, 167-174

Schmidt BR 2005. Aquat Conserv: Mar Freshw Ecosyst 15, 681-692.

Siljeström PA et al. 1994. J Arid Environ 26, 315-323.

Snodgrass JW et al. 2000. Conserv Biol 14, 414-419.

Wellborn GA et al. 1996. Annu Rev Ecol Evol S 27, 337-363. 
Wells KD 2007. The Ecology and Behavior of Amphibians. The University of Chicago Press.

Werner EE et al. 2007. Oikos 116, 16971712.

Wiest JA 1982. Anuran succession at temporary ponds in a post oak-savanna region of Texas. In: Jr, N.J.S. (Ed.), Herpetological communities: a symposium of the Society for the Study of
Amphibians and Reptiles and the Herpetologists' League. U.S. Fish and Wildlife Service, Washington, D.C, p. 239.

Williams AK, Berkson J 2004. J Wildl Manage 68, 418-428.

Yoccoz NG et al. 2001. Trends Ecol Evol 16, 446-453. 


\section{Chapter 4}

Spatial variation of the amphibian community in Doñana National Park: relationships with habitat characteristics 


\section{Relative importance of dynamic and static environmental}

\section{variables as predictors of amphibian diversity patterns}

In this study we evaluate whether static approaches, i.e. including only habitat characteristics that do not change over time, are adequate to the assessment of diversity-habitat relationships. We have assessed the contribution of habitat characteristics that change over time compared to those that do not to the spatial pattern of diversity (variation in species richness and in assemblage composition). We have also provided an integral analysis to evaluate the role of hydroperiod in structuring amphibian assemblages at any diversity level: variation in species richness, variation in assemblage composition (i.e. nested pattern or species turnover) and variation in beta diversity. We have monitored 19 amphibian assemblages from 2003 to 2006 in highly fluctuating ecosystem, the temporary ponds in Doñana National Park. We required from both sets of habitat variables (temporally fixed and temporally variable) to develop a realistic understanding of amphibian diversity patterns, both when considering data collected in particular years or over several years. We found that environmental attributes irrelevant for pond species richness (alpha diversity) might be responsible for the variation in assemblage composition among ponds (beta diversity) assemblages and, hence, contribute to species diversity in the entire study area (gamma diversity). So, we evidence the need for an integral analysis of diversity in order not to disregard any relevant habitat factors. The relevance of hydroperiod was not constant across time, being negligible in the wet year while, in the dry one, we observed a strong nested pattern along hydroperiod gradient as well as small differences in species predominance among assemblages. So, our results evidence two conservation priorities in the study area: the preservation of ponds along the wide hydroperiod range and, secondarily, a particular concern for the preservation of those with long duration, since they will provide breeding habitat for most species in unfavourable years. 


\section{Introduction}

A central question in ecology is explaining the spatial variation of diversity (Gaston 2000). In a stable system, spatial environmental variation largely explains the spatial variation in the incidence or abundance of species and thereby in the assembly of species in space (Stiling 1999). However, stable systems are more the exception than the rule since both communities and habitats may change over time (Ricklefs and Schluter 1993). In fact, temporal variation in communities and habitats are not unrelated processes in an ecosystem and, in many scenarios, temporal changes in community composition can be attributed to temporal changes in environmental characteristics (Houlahan et al. 2007). So, the spatial variation of diversity will not be constant over time in temporally variable ecosystems since it will be responding both to spatially fixed environmental variation (not changing over time) and to environmental characteristics that change both over time and space. If we disentangled the role of fixed and fluctuating environmental characteristics in the spatial pattern of diversity, we would ascertain whether static approaches to the assessment of diversity-habitat relationships are adequate. From a practical standpoint, the main advantages of static approaches are the low data collection costs, since they do not require from simultaneous field sampling of habitat characteristics and, instead, may be mostly based on cartographic environmental data.

Implicit theory assumes that environmental variables determine, at least in part, species distributions across space and, thereby, promote the existence of different species assemblages (spatial diversity) along environmental gradients. Most studies on diversity-habitat relationships focus on the analysis of richness gradients, which are just a particular case of diversity patterns. Following Legendre et al. (2005) and Tuomisto and Ruokolainen (2006), the distribution of communities along environmental and spatial gradients can be evaluated at three different levels: (1) community composition; (2) variation in community composition (beta diversity), both in species composition or species abundances and (3) variation in the variation in community composition (variation in beta diversity). The relevance of differentiating variation in species richness from variation in community composition lies in the fact that two sites 
may have exactly the same number of species but completely different community compositions. In recent years, the interest in beta diversity has increased for its contribution to the understanding of spatial patterns in diversity (Baselga and JiménezValverde 2007; Soininen et al. 2007; Arponen et al. 2008). A particular concern in many diversity studies has been to differentiate the effects of spatial and environmental variation, both in richness gradients (Lobo et al. 2001; Baselga 2008) or beta diversity (Borcard et al. 1992; Parris 2004; Baselga 2008), mainly to discriminate the role of dispersion/migration processes and species ecological requirements. However, the assessment of the relative contribution of habitat characteristics that change over time, in relation to those that do not remains untested. Partitioning the effect of temporally fixed and temporally variable habitat characteristics is relevant because it will help to clarify whether environmental variability should be explicitly accounted for in diversity-habitat models. In this sense, it seems reasonable to expect that habitat characteristics changing over time (i.e. water physico-chemical characteristics) would influence diversity patterns at specific sampling dates whereas habitat characteristics that do not change over time (i.e. geographical position) would mostly influence diversity patterns in the medium or long term. In our study, which uses an amphibian community breeding in Mediterranean temporay ponds as model system, the rationale behind is that pondbreeding communities are, in part, structured on an annual basis by species responses to current hydrological conditions (Church 2008). With this study, we will follow the aforementioned approach in order to contribute to the understanding of the adequate time frame (annual or medium term) for diversity-habitat studies given the nature of environmental data available (temporally fixed or temporally variable). Moreover, the integrated assessment of variation in species richness and in assemblage composition will ensure that important environmental factor are not disregarded since we will be considering diversity-habitat relationships at every diversity level they might manifest.

In this study, we have assessed the relationships between environmental characteristics and variation in amphibian species richness and assemblage composition at a landscape scale, taking into account the temporal dynamics of the community and their breeding habitats. To account for environmental temporal variability, we have evaluated the unique contribution of habitat characteristics that change with time and the unique contribution of those that do not in explaining the spatial variation in amphibian assemblages. To control for temporal variability in amphibian assemblages, we have conducted diversity assessments over several years as well as in particular years with different rainfall amounts and timing and, thereby, representing opposite hydric scenarios (see Gómez-Rodríguez et al. in press). The study was conducted in a highly fluctuating Mediterranean ecosystem, the temporary ponds in Doñana National Park, southwest Spain. Freshwater ponds constitute an excellent system for exploring patterns of spatial variation in diversity, since they are arrayed along well defined environmental gradients (i.e. size, hydroperiod) with corresponding patterns in community composition (Werner et al. 2007). In addition, wetlands are unstable and dynamic per se (Fjeldsa and Lovett 1997) and thereby constitute an idoneous model system to integrate the spatiotemporal dynamism of habitats with the spatial distribution of diversity. In the study area, previous studies have evidenced interannual variation both in temporary pond 
characteristics (Gómez-Rodríguez et al. in press), in amphibian assemblages (GómezRodríguez et al., Chapter 3 this thesis) and in species-habitat relationships (GómezRodríguez et al. in press). Moreover, a previous study has evidenced speciesspecific responses to habitat factors and, thereby, that important habitat factors for amphibians may be masked when considering solely species richness data (Gómez-Rodríguez et al. in press). This fact reinforces the need for analyses of assemblage composition, which account for the identity of the species rather than just the total number, as richness analyses do.

To summarize environmental variability, we have focused on habitat variables relevant for amphibian habitat selection based on available ecological information: i/ major structuring factors of pond communities such as pond hydroperiod (Snodgrass et al. 2000b; Beja and Alcazar 2003; Werner et al. 2007), pond area (Beja and Alcazar 2003; Burne and Griffin 2005; Werner et al. 2007) and pond depth (Laan and Verboom 1990; Joly et al. 2001); ii/ pond morphometry, because it conditions the availability of different microhabitats which, in turn, each species may require in a selectively manner (Smith et al. 2003); iii/ amount of dense hygrophytic vegetation surrounding the pond, which increases pond shade, an important habitat attribute for amphibians in some studies (Sztatecsny et al. 2004; Burne and Griffin 2005); iv/ water-chemistry characteristics relevant for amphibians (Hecnar and M'Closkey 1996; Houlahan and Findlay 2003; Knutson et al. 2004) such as those related to salinity, ionic composition, nutrient concentrations and primary production $\mathrm{v} /$ the characteristics of the terrestrial habitat since they provide refugee for amphibian species during the dry season (mostly adjacent habitat) and also constitute the matrix that interconnect ponds (Gibbons 2003) and vi) the distribution pattern of surrounding aquatic habitats, as a measure of ecological connectivity in metapopulations/patchy populations (Marsh and Trenham 2001; Semlitsch 2002). We have discriminated complexes of ponds located within the dispersal range of most amphibian species $(<1000 m)$ (Smith and Green 2005) from those ponds located nearby $(<200 \mathrm{~m})$. Individuals may frequently move among adjacent ponds, as Marsh et al. (1999) reported for tungara frogs, and hence encompass them as a single breeding site (Petranka et al. 2004).

In addition to these global analyses, we have also conducted a specific set of analyses to evaluate the unique contribution of pond hydroperiod in structuring amphibian assemblages in the study area. Hydroperiod is regarded as a major force structuring pond communities (Wellborn et al. 1996). So, we aimed to evaluate whether it explained species richness gradients or/and whether it was responsible for variation in assemblage composition among ponds (beta diversity pattern). Moreover, we have discriminated among different types of beta diversity patterns it might be related to, such as a nested pattern or a species turnover pattern, which, in fact, are opposing patterns (Leibold and Mikkelson 2002). A species turnover pattern reflects the tendency for species to replace each other (Leibold and Mikkelson 2002) while a nested patterns evidences that species composition of species-poor assemblages is a nested subset of species-rich assemblages (see Patterson and Atmar 1986; Ulrich et al. 2009). Similarly, we have also evaluated if differences in hydroperiod could explain the variation in beta diversity observed in the study area. Thus, with this approach, we have assessed to what extent we could use hydroperiod categories to discriminate ponds with different amphibian assemblages. 


\section{Material and Methods}

\section{Study area}

The study was conducted in an area of 6794 hectares within Doñana National Park, in southwestern Spain (see Siljeström et al. 1994 for a geo-morphological description). The dominant vegetation on this area is Mediterranean scrub (Halimio halimifoliiStauracanthetum genistoides and Erico scopariae-Ulicetum australis as defined by Rivas-Martínez et al. 1980) and isolated patches of pine (Pinus pinea L.) and juniper forests (Juniperus phoenicea L.).

On the sandy area of the Park, many temporary ponds of natural origin flood during the rainy season. These temporary ponds are fed by freshwater and have no direct connection to the sea. Pond size is largely variable, from rain puddles (several square metres) to large temporary ponds (> 1 hectare). The duration of flooding (or hydroperiod) varies among ponds, from pools persisting one month or less to ponds persisting up to 10 months in very wet years. Hydroperiod is widely variable among years. The area also includes two extensive permanent ponds of natural origin that occasionally dry out after years of severe drought. Anthropogenic permanent water bodies (locally named zacallones) are also sparsely distributed through the study area, consisting in deep and small $\left(<10 \mathrm{~m}^{2}\right)$ holes made to water cattle during summer. Many of them are located within basins of temporary ponds. A detailed description of Doñana freshwater ponds and its temporal variation can be found in Gómez-Rodríguez et al. (in press).

We chose 19 temporary ponds of differing hydroperiods. The duration of these ponds (pond hydroperiod) shows large inter-annual variation depending on rainfall input and pattern (Gómez-Rodríguez et al. in press).

\section{Amphibian sampling}

From 2003 to 2006, an intensive monthly survey was conducted during each sampling season: February - May 2003, January May 2004 and March - May 2006. Ponds did not flood in 2005 and, therefore could not be sampled. Nineteen ponds were sampled every month. Two ponds were not accessible in 2004 and thus could not be sampled. In addition, in 2003, one of those ponds was only accessible in May. In 2006, two ponds were flooded during less than one month and could not be sampled.

We used dipnetting techniques (Heyer et al. 1994) to collect and identify larvae to species level in situ (referred hereinafter as "larval sampling"). We counted the number of larvae captured in each sampling unit (three consecutive sweeps on a stretch of approx. $1.5 \mathrm{~m}$ length) and then released them in the pond. For most ponds, we set 12 sampling units as the standard sampling effort. Sampling units were separated a minimum of five metres to avoid interference between surveys. Small ponds were sampled in proportion to their size, so the number of sampling units could decrease to guarantee minimum separation (5 m). In large ponds we tried to sample all different microhabitats, increasing there the number of sampling units performed.

Larval sampling was complemented with visual surveys in and around the pond to detect eggs, larvae and metamorphic individuals. Visual surveys were conducted regularly, starting when ponds filled (November 2002, November 2003 and January 2006). 


\section{Environmental and spatial variables}

In this paper, we considered two sets of variables: i/ those changing over time (WATER) such as hydroperiod and water physico-chemistry and ii/ site/landscape variables (POND/LANDSCAPE), which do not vary with time.

\section{Water-related characteristics (WATER)}

Every pond was visited monthly to assess the months of filling and desiccation in 2003 and 2006. Annual rainfall was 549.5 $\mathrm{mm}$ in 2003, with abundant autumn input (326.4 mm); while it was $468 \mathrm{~mm}$ in 2006 , a year of scarce autumn rainfall (149.3mm). Water physico-chemistry was sampled on three different occasions (January 2003, May 2003, March 2006). We measured: electrical conductivity, $\mathrm{pH}$, chloride $\left(\mathrm{Cl}^{-}\right)$, sulphate $\left(\mathrm{SO}_{4}{ }^{2-}\right)$, sodium $\left(\mathrm{Na}^{+}\right)$, potasium $\left(\mathrm{K}^{+}\right)$, magnesium $\left(\mathrm{Mg}^{2+}\right)$, calcium $\left(\mathrm{Ca}^{2+}\right)$, photosynthetic pigments (CHL-A), dissolved inorganic phosphate (i-P) and dissolved inorganic nitrogen (DIN) and the ratio between $\mathrm{Na}^{+}$and $\mathrm{Mg}^{2+}\left(\mathrm{Na}^{+} / \mathrm{Mg}^{2+}\right)$. We did not sample for water-related characteristics in 2004. A detailed description of sampling methodology, parameter values and temporal variability are provided in GómezRodríguez et al. (in press).

\section{Site and landscape characteristics (POND/LANDSCAPE)}

We calculated pond geographic coordinates, pond altitude, maximum pond area, pond slope, percentage of pond shoreline immediately surrounded by dense hygrophyte vegetation, percentage of different microhabitats within each pond (i.e. helophyte vegetation in littoral zone, internal helophyte vegetation, rural paths adjacent to ponds which may be occasionally flooded, open water, deep areas and man-made deep holes within).
Regarding to surrounding aquatic habitat that may be potentially flooded, we measured the distance to the nearest water body and the percentage of flooded area and the number of ponds in two buffer areas (200 $\mathrm{m}$ and $1000 \mathrm{~m}$ radius) from the edge of each pond. A detailed description of sampling methodology and values of these characteristics are provided in GómezRodríguez et al. (in press). In addition, we also measured the distance to key features (sea, marshland, road) and percentage of surrounding terrestrial habitat (dune, dune valley, rural path, xerophytic scrub, hygrophytic scrub, pine forest, palustrine area, human-transformed area, marshes and ecotone between the marshes and the aeolian sands) in the aforementioned buffer areas from ortophotos (Junta de Andalucía 2003) using ArcView GIS 3.2.

\section{Data analysis}

Firstly, we described the spatial variation in amphibian diversity. This first step is intended to demonstrate that biotic differences exist among ponds previous to the assessment of whether those differences are related to environmental gradients. Since differences in the number of species detected in a pond (species richness) are provided elsewhere (G-R, turnover), we only described variation in assemblage composition (beta diversity) in this study. We computed an unconstrained ordination of ponds, Non Metric Multidimensional Scaling (NMDS) (Legendre and Legendre 1998) (command metaMDS, package vegan, $\mathrm{R}$ statistical package), using Morisita-Horn dissimilarity index (Magurran 2004) and the relative abundance of each species over the entire study period, measured as catch-perunit-effort (number of larvae collected per sampling unit). We used Morisita-Horn dissimilarity index because it is not influenced by species richness gradients and sample size (Magurran 2004). To detect 
assemblage variation due to the replacement of species, we should address comparisons on the specific assemblage composition using dissimilarity indexes independent of richness values (Koleff et al. 2003; Baselga et al. 2007). Schmidt and Pellet (2005) recommend the use of abundance rather than presence/absence data since it provides more information due to the fact that absence and presence are only a special case of abundance (abundance $=0$ and abundance $>0$, respectively). We set the number of dimensions in the ordination (NMDS) to two to reduce stress to values lower than $10 \%$. We identified which species significantly influenced the ordination with the envfit command (package vegan, $\mathrm{R}$ statistical package). Significance was tested with 1000 permutations.

Secondly, we explored the relationships between environmental variation and amphibian diversity patterns. We summarized environmental variation with Principal Components Analyses (PCAs) with varimax rotation. Since we aimed to disentangle the effect of POND/LANDSCAPE and WATER variables as well as to evaluate relationships on the short-term (annual data) and on medium term (data from the entire study period), we computed four PCAs: on POND/LANDSCAPE variables, on all WATER variables, on WATER variables measured in 2003 and on WATER variables measured in 2006. Missing values were substituted by mean value of the variable in order to not reduce the data set. In each analysis, we retained PCA components that contributed to an increase in explained variation higher than $10 \%$.

We evaluated PCA components as explanatory variables of richness gradients and, independently, of variation in assemblage composition. For each dependent variable (species richness or assemblage composition), we fitted two statistical models for each sampling period considered: the entire study period (200306), 2003 season and 2006 season. One model tested as potential predictors POND/LANDSCAPE PCA components and the other WATER PCA components (extracted from all variables, from variables measured in 2003 or from variables measured in 2006, depending on the sampling period of the response variable).Variables were selected, based on significant contribution to the model, using a manual step-forward procedure to ascertain the minimal subset of variables. For each sampling period, we built a global model, including all the predictors selected in both final statistical models, in order to partition the variance explained by each data set (POND/LANDSCAPE vs. WATER). Variation partitioning is a way of estimating how much of the variation of the response variable can be attributed exclusively to one set of factors, once the effect of the other set has been taken into account (Legendre and Legendre 1998). So, we quantified the absolute and relative contribution of each data set to explain the patterns of amphibian diversity.

The type of statistical models differed between analyses of richness gradients and of variation in assemblage composition, given the different nature of the data. For richness gradients, we conducted multiple regression models (command "lm", R software) using as response variable the number of species recorded in a pond. Richness values were computed from larval sampling and visual surveys of eggs and metamorphs. To explain variation in assemblage composition, we conducted a Constrained Analysis of Principal Coordinates (CAP) (Oksanen et al. 2007) with command capscale (package vegan, $R$ statistical package) and preserving MorisitaHorn dissimilarity and relative abundance data. We added a constant to the non- 
diagonal dissimilarities to correct for negative eigenvalues (see Legendre and Anderson 1999). Compared with traditional canonical analyses, such as redundancy analysis (RDA) or constrained correspondence analysis (CCA), CAP has the advantage of accommodating any dissimilarity measure through the use of principal coordinates analysis (PCoA) as an intermediate step, while also taking into account the correlation structure among variables in the response data (Arponen et al. 2008). We used a variant of the method ("partial CAP") in the assessment of the relative contribution of each data set. Significance of each data set was tested using permutations of residuals under the reduced model (Legendre and Legendre 1998).

Thirdly, we conducted a specific set of analysis to evaluate the role of hydroperiod in structuring amphibian assemblages by means of analyzing its relationship with each different type of diversity patterns (i.e. richness gradients, variation in assemblage composition or variation in beta diversity). We conducted a Pearson correlation to assess the relationship between hydroperiod and species richness. We conducted three different analyses to evaluate the role of hydroperiod in explaining variation in assemblage composition as we examined three potential beta diversity patterns: i/ a nested pattern along hydroperiod gradient, by means of a Spearman correlation between hydroperiod value and the nested rank of ponds. So, we had to previously build the nested matrix, evaluate nestedness with the Nestedness Temperature Calculator (command nestedtemp, package vegan, $\mathrm{R}$ statistical package) and assess the nonrdanomness of results by comparing it with 999 simulated null models with command oecosimu (package vegan, $\mathrm{R}$ statistical package); ii/ species replacement among ponds, by means of a CAP analysis testing hydroperiod as the unique predictor and computing Simpson dissimilarity on a presence-absence data matrix. We selected Simpson dissimilarity index because it is not influenced by species richness gradients and sample size (Magurran 2004); and iii/ replacement in species abundance among ponds, by means of a CAP analysis testing hydroperiod as the unique predictor and computing Morisita-Horn dissimilarity on a relative abundance data matrix. Finally, we assessed whether hydroperiod categories (see below) explained variation in beta diversity (i.e. analysis of beta diversity in the sense of Tuomisto and Ruokolainen 2006) and hence whether hydroperiod categories could be used to identify ponds with different amphibian assemblages. We conducted two different analyses of similarities (ANOSIM) (Clarke 1993) (anosim command, vegan package, $\mathrm{R}$ statistical package) with hydroperiod category as grouping factor. One analysis evaluated variation in assemblage composition from presence/absence data using Simpson dissimilarity index and the other evaluated variation in assemblage composition from relative abundance data Morisita-Horn dissimilarity index. Hydroperiod categories in 2003 were: ephemeral (4-5 months), intermediate temporary ponds (6-7 months) and longduration temporary ponds (8-9 months). Given the low hydroperiod gradient in 2006, hydroperiod categories corresponded to hydroperiod raw values.

All hydroperiod analyses were conducted both for annual and cumulative values of species richness and assemblage composition. We related biotic data collected over the entire study period both to hydroperiod values measured in 2003 and in 2006. 


\section{Results}

Spatial variation in assemblage composition among ponds (beta diversity)

We detected eight species and all of them attempted reproduction in every year: Bufo calamita Laurenti, 1768, Pelobates cultripes (Cuvier, 1829), Discoglossus galganoi Capula, Nascetti, Lanza, Bullini \& Crespo, 1985, Pelophylax perezi (Seoane, 1885), Hyla meridionalis Boettger, 1874, Pleurodeles waltl Michahelles, 1830, Triturus pygmaeus (Wolterstorff, 1905) and Lissotriton boscai (Lataste, 1879). We did not observe a marked segregation among ponds based on their assemblage composition (Figure 33-A). Only three pond assemblages, those with a high abundance of B. calamita, clearly differed from the rest. In detail, the ordination of ponds accounted for $90.13 \%$ of the variation in pond assemblage composition. On the first axis, representing $76.74 \%$ of the variation in pond assemblage composition, two major groups of ponds were distinguishable. A small group of ponds $(\mathrm{n}=6)$ with a high relative abundance of $B$. calamita or $D$. galganoi [GROUP 1-A \& GROUP 1-B], and a larger group of ponds, where $H$. meridionalis and T. pygmaeus predominated [GROUP 2]. The inclusion of the second dimension, accounting for $13.38 \%$ of variability, displayed a gradient in the largest group [GROUP 2] and differentiated two subgroups in the smallest one, ponds dominated by the abundance of $B$. calamita [GROUP 1-A] from those dominated by the abundance of D. galganoi [GROUP 1-B]. In the largest group, the gradient seemed to depict a succession from ponds assemblages with a high abundance of species breeding in ponds with a larger duration (i.e. $P$. cultripes following Díaz-Paniagua 1990) to ponds assemblages with a high abundance of species breeding in intermediate duration ponds (i.e. T. pygmaeus or H. meridionalis following Díaz-Paniagua 1990).
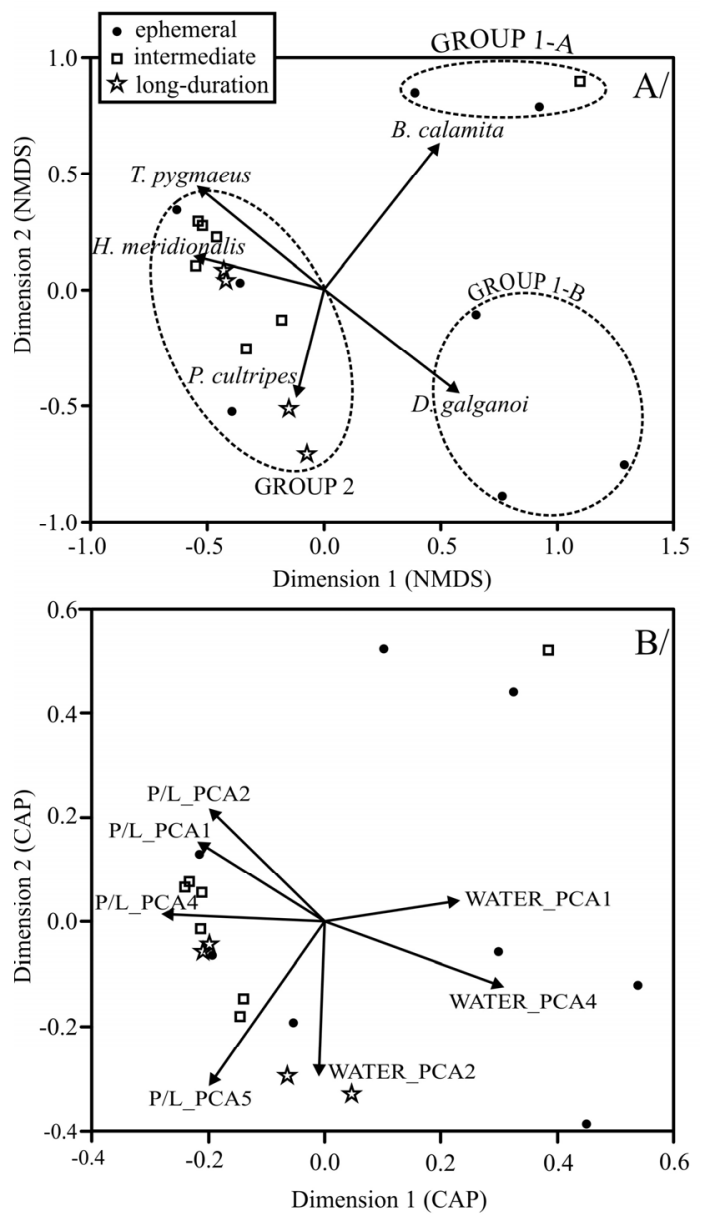

Figure 33. Scaling of temporary ponds according to their faunal composition, measured as relative abundance, considering the three years of study. Pond hydroperiod (ephemeral, intermediate and long-duration) is indicated with different symbols. A/ NMDs ordination of ponds. Species vectors with significant squared correlation $(p<0.05)$ with the resulting ordination were added to the ordination plot. B/ Constrained ordination of ponds (CAP analysis) showing PCA components that significantly explained differences in assemblage composition among ponds. 
Relationship between environmental variation and richness gradients

In species richness analyses, we did not find a global model including variables from both data sets (WATER and POND/LANDSCAPE) in any sampling period and hence we did not conduct analyses of variation partitioning (Table 25). At least one WATER PCA component significantly explained species richness in the entire study period and in 2006 but none was selected in 2003 season. On the contrary, a POND/LANDSCAPE PCA component significantly explained species richness in 2003 but no component was selected in regression models for data collected in 2006 or over the entire study period. All models explained a lowmoderate percentage of variance $\left(\mathrm{R}^{2}<\right.$ $0.33)$.

\section{Relationship between environmental variation and variation in assemblage composition}

Both WATER and POND/LANDSCAPE variable sets significantly explained variation in assemblage composition computed for the entire study period (Table 26). The global model explained $58.4 \%$ of total variation (Figure 34). When pooling together both predictor sets to compute partial CAPs, the POND/LANDSCAPE set alone significantly explained $24.4 \%$ of variance (Figure 34 and Table 26). The unique contribution of the WATER set was non-significant and resulted in $14.1 \%$ of total variation explained. Figure 33-B shows that WATER variables mostly explained differences in species composition among pond assemblages dominated by $D$. galganoi while POND/LANDSCAPE variables were related to differences in assemblage composition in GROUP 2 (assemblages dominated by $P$. cultripes, $H$. meridionalis or T. pygmaeus).

We obtained different results in the analyses for annual data. The percentage of explained variation was lower than in the analysis for the entire study period $(33.1 \%$ in 2003 and $40.3 \%$ in 2006) (Figure 34). WATER and POND/LANDSCAPE variable sets significantly explained variation in assemblage composition when tested independently (CAP analyses) (Table 26). However, the unique contribution (partial CAP analyses) of both sets was significant in 2006 while, in 2003, only WATER variables showed a significant unique contribution. Notably, the fraction of explained variation shared by both sets of variables was very low in $2006(0.04 \%)$ (Figure 34).

Table 25. Explained variance $\left(\mathrm{R}^{2}\right)$ and significance $(\mathrm{p})$ obtained in multiple regressions analyses for species richness in 2003, in 2006 and in the entire study period. Predictor set (WATER vs. POND/LANDSCAPE) and number of predictors included in the final model are shown. NS $=$ No potential predictor contributed significantly to explain species richness.

\begin{tabular}{|llccc|}
\hline Sampling period & Variable set & Predictors & $\mathbf{R}^{2}$ & $\mathbf{p}$ \\
\hline $2003-2006$ & WATER & 1 & 0.292 & 0.017 \\
& POND/LANDSCAPE & \multicolumn{3}{c}{ NS } \\
2003 & WATER & & NS & \\
\multirow{2}{*}{2006} & POND/LANDSCAPE & 1 & 0.328 & 0.013 \\
& WATER & 1 & 0.279 & 0.043 \\
& POND/LANDSCAPE & & NS & \\
\hline
\end{tabular}


Table 26. Pseudo-F and significance (p) obtained for each set of variables (WATER vs. POND/LANDSCAPE variables) in explaining variation in assemblage composition with Constrained Analysis of Principal Coordinates (CAP) for 2003, 2006 and the entire study period. Significance of unique contribution for each set of variables was tested with Partial CAP. Number of axes is shown.

\begin{tabular}{|llccc|}
\cline { 3 - 4 } \multicolumn{1}{l}{} & & \multicolumn{1}{c|}{ CAP } & Partial CAP \\
\hline Sampling period & Variable set & Axes & Pseudo-F $(\mathrm{p})$ & Pseudo-F $(\mathrm{p})$ \\
\hline \multirow{2}{*}{$2003-2006$} & WATER & 3 & $2.567(\mathrm{p}<0.01)$ & $1.249(\mathrm{p}=0.18)$ \\
& POND/LANDSCAPE & 4 & $2.769(\mathrm{p}<0.01)$ & $1.614(\mathrm{p}=0.03)$ \\
2003 & 1 & $5.638(\mathrm{p}<0.01)$ & $3.990(\mathrm{p}<0.01)$ \\
& WATER & 1 & $2.881(\mathrm{p}=0.02)$ & $1.570(\mathrm{p}=0.12)$ \\
& POND/LANDSCAPE & 1 & $2.601(\mathrm{p}<0.01)$ & $2.375(\mathrm{p}=0.01)$ \\
& WATER & 2 & & \\
& POND/LANDSCAPE & 1 & $4.597(\mathrm{p}<0.01)$ & $3.872(\mathrm{p}<0.01)$ \\
\hline
\end{tabular}

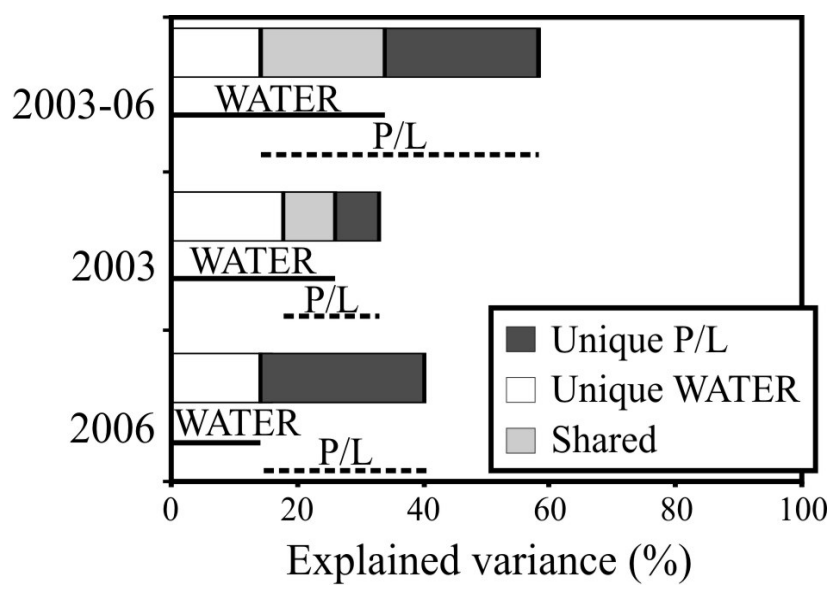

Figure 34. Percentage of variation explained by Partial CAP analyses, identifying the total [lines] and unique contribution [bars] of each subset (WATER variables vs. POND/LANDSCAPE $[\mathrm{P} / \mathrm{L}]$ variables) and the fraction of shared variation explained by both subsets [bars]. Independent analyses were conducted on pond assemblage composition in 2003-season; 2006-season and in the entire study period (2003-2006). 
The role of pond hydroperiod in amphibian diversity patterns

The relevance of hydroperiod to explain diversity patterns differed between the years of study. In 2006, it significantly explained species richness gradients, assemblage nestedness (Figure 35) and species replacement among assemblages when measured with relative abundance data (Table 27).

On the contrary, we did not find any significant relationship between hydroperiod and amphibian diversity patterns in 2003 (Table 27). Hydroperiod significantly correlated with species richness when considering data from the entire study period. Hydroperiod values in 2003 also explained variation in assemblage composition measured during the entire study period. In particular, hydroperiod explained species replacement among ponds when measured with relative abundance data and showed a marginally significant relationship when it was measured with presence/absence data. In general, the percentage of explained variance was low in all beta diversity analyses (explained variance $\leq 20 \%$ ) except in the nestedness analysis for 2006 (explained variance $=70 \%$ ). The percentage of variance explained in species richness analyses was higher (explained variance $\geq 48 \%$ ).

It should be noted that we obtained a low, but significant, ANOSIM $\mathrm{R}$ value when analyzing beta diversity in 2006 from relative abundance data. This result shows that the assemblage composition of ponds with the same hydroperiod were slightly similar although we could not discriminate pond groups given the low value of the statistic. The ANOSIM R statistic should be above 0.75 to be relevant and hence assume that ponds can be grouped based on the factor of interest (Clarke and Warwick 2001).
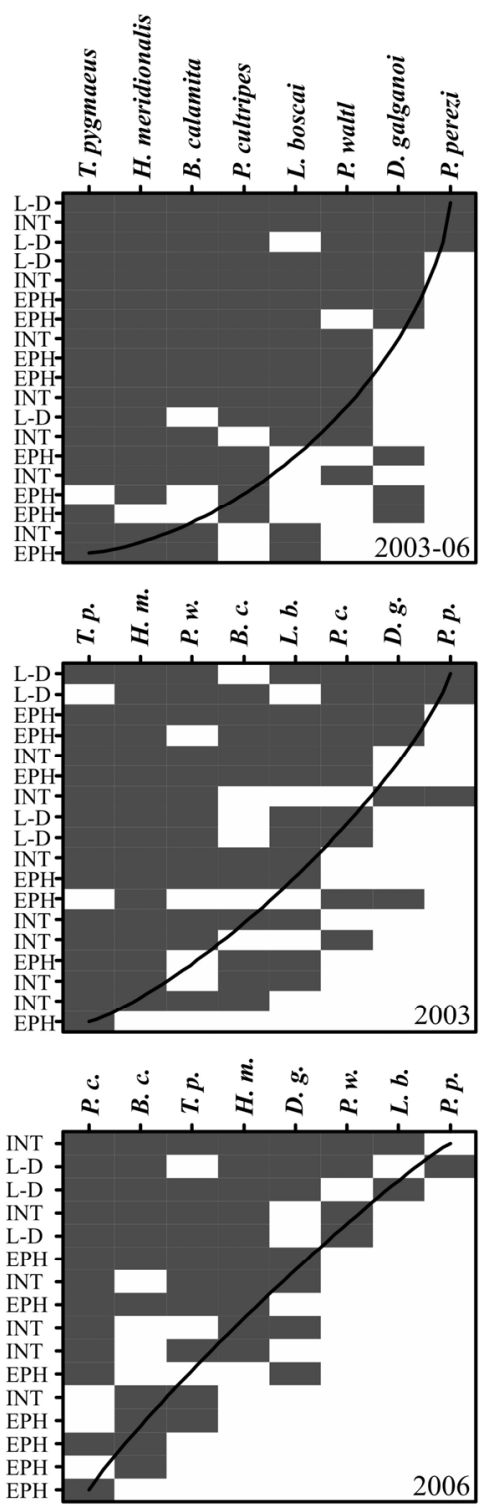

Figure 35. Nested matrix of amphibian presence/absence in the entire study period (2003-06), in 2003 and in 2006. Pond nomenclature corresponds to hydroperiod categories. L-D = long-duration temporary pond [8-9 months in 2003, 4 months in 2006], INT $=$ intermediate temporary pond [6-7 months in 2003, 3 months in 2006], EPH = ephemeral [4-5 months in 2003, 2 months in 2006]). Hydroperiod nomenclature from 2003 is applied to the matrix for the entire study period (2003-06).subset. 
Table 27. Relationships between hydroperiod and amphibian diversity patterns, both measured each year (2003 biotic data and 2006 biotic data) and over the entire study period (2003-06 biotic data). For diversity data measured over the entire study period, relationships with hydroperiod values measured in 2003 and in 2006 are shown (year indicated in brackets).

\begin{tabular}{|c|c|c|}
\hline & Data & 2003-06 biotic data \\
\hline \multicolumn{3}{|c|}{ Explaining alpha diversity } \\
\hline \multirow[t]{2}{*}{ Richness gradients } & Species richness & Pearson $r=0.482 ; p=0.037[2003]$ \\
\hline & & Pearson $r=0.486 ; p=0.048[2006]$ \\
\hline \multicolumn{3}{|c|}{ Explaining beta diversity } \\
\hline \multirow[t]{3}{*}{ Nestedness } & Presence/Absence & $\mathrm{T}=14.597 ; \mathrm{p}=0.503$ \\
\hline & & Spearman $r=0.452 ; p=0.052[2003]$ \\
\hline & & Spearman $\mathrm{r}=0.409 ; \mathrm{p}=0.082[2006]$ \\
\hline \multirow[t]{8}{*}{ Species replacement } & Presence/Absence & Explained variance $=10.75 \%[2003]$ \\
\hline & & Pseudo- $F=2.047 ; p=0.08[2003]$ \\
\hline & & Explained variance $=7.02 \%[2006]$ \\
\hline & & Pseudo- $F=1.283 ; p=0.25[2006]$ \\
\hline & Relative abundance & Explained variance $=14.12 \%[2003]$ \\
\hline & & Pseudo- F $=2.797 ; \mathrm{p}<0.01$ [2003] \\
\hline & & Explained variance $=7.84 \%[2006]$ \\
\hline & & Pseudo- F $=1.448 ; p=0.13[2006]$ \\
\hline \multicolumn{3}{|c|}{ Analyzing beta diversity } \\
\hline \multirow{4}{*}{$\begin{array}{l}\text { Similar assemblage } \\
\text { composition }\end{array}$} & Presence/Absence & ANOSIM $\mathrm{R}=0.043 ; \mathrm{p}=0.294[2003]$ \\
\hline & & ANOSIM $\mathrm{R}=-0.041 ; \mathrm{p}=0.63[2006]$ \\
\hline & Relative abundance & ANOSIM R $=-0.008 ; p=0.47[2003]$ \\
\hline & & ANOSIM R $=0.000 ; p=0.47[2006]$ \\
\hline
\end{tabular}


Table 27. (cont.)

\begin{tabular}{|c|c|c|c|}
\hline & Data & 2003 biotic data & 2006 biotic data \\
\hline \multicolumn{4}{|c|}{ Explaining alpha diversity } \\
\hline $\begin{array}{l}\text { Richness } \\
\text { gradients }\end{array}$ & Richn & Pearson $r=0.382 ; p=0.107$ & Pearson $r=0.680 ; p=0.003$ \\
\hline \multicolumn{4}{|c|}{ Explaining beta diversity } \\
\hline \multirow{3}{*}{$\begin{array}{l}\text { Species } \\
\text { replacement }\end{array}$} & $\mathrm{P} / \mathrm{A}$ & $\begin{array}{l}\mathrm{T}=27.467 ; \mathrm{p}=0.043 \\
\text { Spearman } \mathrm{r}=0.234 ; \mathrm{p}=0.350\end{array}$ & $\begin{array}{l}\mathrm{T}=11.483 ; \mathrm{p}=0.005 \\
\text { Spearman } \mathrm{r}=0.705 ; \mathrm{p}=0.002\end{array}$ \\
\hline & $\mathrm{P} / \mathrm{A}$ & $\begin{array}{l}\text { Explained variance }=6.51 \% \\
\text { Pseudo- } \mathrm{F}=1.115 ; \mathrm{p}=0.21\end{array}$ & $\begin{array}{l}\text { Explained variance }=4.70 \% \\
\text { Pseudo- } F=0.690 ; p=0.96\end{array}$ \\
\hline & Abund & $\begin{array}{l}\text { Variance explained }=4.32 \% \\
\text { Pseudo- } \mathrm{F}=0.723 ; \mathrm{p}=0.56\end{array}$ & $\begin{array}{l}\text { Variance explained }=20.04 \% \\
\text { Pseudo- } \mathrm{F}=3.259 ; \mathrm{p}<0.01\end{array}$ \\
\hline \multicolumn{4}{|c|}{ Analyzing beta diversity } \\
\hline $\begin{array}{l}\text { Similar } \\
\text { assemblage } \\
\text { composition }\end{array}$ & $\begin{array}{l}\mathrm{P} / \mathrm{A} \\
\text { Abund }\end{array}$ & $\begin{array}{l}\text { ANOSIM R }=0.106 ; p=0.11 \\
\text { ANOSIM } R=-0.027 ; p=0.55\end{array}$ & $\begin{array}{l}\text { ANOSIM R }=-0.065 ; \mathrm{p}=0.757 \\
\text { ANOSIM R }=0.202 ; \mathrm{p}=0.047\end{array}$ \\
\hline
\end{tabular}

\section{Discussion}

\section{Relationships between hydroperiod and amphibian diversity}

We observed inter-annual differences in the relationship between hydroperiod and pond diversity patterns, which would be in accordance to inter-annual differences previously reported in species-habitat relationships in the study area (GómezRodríguez et al. in press). Hydroperiod was not an important factor explaining amphibian diversity in 2003, when pond hydroperiod was long (4-9 months). On the contrary, in 2006, when pond hydroperiod was short ( $\leq 4$ months), hydroperiod gradient explained the richness gradient and, mostly, the nested pattern in species occurrence. Besides, it also partly explained variation in assemblage composition when measured with relative abundance data. Taken altogether (richness, nested and beta diversity patterns), these results evidenced a gain of species along hydroperiod gradient but also small differences in species predominance among assemblages. We attribute the lack of relevance of hydroperiod in 2003 to the fact that the most ephemeral ponds that year lasted even longer than the period required for successful metamorphosis of those species with longest larval development (i.e. $P$. cultripes following Díaz-Paniagua et al. 2005). So, amphibian species did not face strong desiccation stress that year and, therefore, one of the main ecological traits structuring amphibian assemblages along hydroperiod gradient (tolerance to desiccation risk) was not critical. Additionally, inter-annual differences in the role of hydroperiod might be related not only to habitat suitability but also to habitat availability. Given the strong intra-annual segregation in larval communities in the 
study area (Díaz-Paniagua 1988), the duration of a pond (hydroperid) will also condition the number of species that may potentially breed in it, independently of their ecological requirements. So, highly ephemeral pools (i.e. 1-2 months) may not be coincident in time with the reproduction of all species while ponds with hydroperiod values above a given threshold (for example, 4 or 5 months) would be available habitats for all species.

Focusing on amphibian assemblages on the medium term, pond hydroperiod related with species richness and explained some variation in assemblage composition, both in species incidence and relative abundance data. Although, the percentage of explained beta diversity was low, it was similar to the one obtained by Snodgrass et al. (2000a), who identified hydroperiod as a major force causing spatial turnover. The observed lack of nestedness would agree with the high inter-annual turnover reported for the study area, where a given pond is suitable for different species depending on the year (Gómez-Rodríguez et al., Chapter 3 this thesis). Focusing on variation in beta diversity, the ANOSIM analysis proved that hydroperiod categories could not satisfactorily identify different species assemblages. This result was relatively surprising since a preliminary analysis of pond ordination would suggest the opposite because the pattern of species dominance resembled spatial segregation of species according to pond hydroperiod previously described in the area (Díaz-Paniagua 1990): two isolated groups of ponds dominated by species associated to ephemeral ponds (B. calamita and $D$. galganoi, after Díaz-Paniagua 1990), and a gradual spatial turnover in pond assemblage composition, from pond assemblages dominated by species breeding mainly in intermediate temporary ponds, i.e. $T$. pygmaeus (after Díaz-Paniagua 1990) to species breeding mainly in permanent or extensive water bodies, i.e. P. cultripes (after Díaz-Paniagua 1990). In consequence, we attribute lack of significance in analyses of beta diversity to the fact that we faced gradual, instead of discrete variation, both in hydroperiod and faunal composition.

This study constitutes an important step towards the understanding of hydroperiod role in amphibian diversity patterns. We evidence that pond hydroperiod may be related to different diversity patterns, being even some of them antagonist (nested pattern $v s$. species replacement), depending on the temporal time frame considered. Several studies have already addressed the role of hydroperiod in some of these patterns: i.e. species richness (Beja and Alcazar 2003; Babbitt 2005; Werner et al. 2007), nestedness (Baber et al. 2004; Werner et al. 2007) or beta diversity (Snodgrass et al. 2000a). However, this study is the first one that provides an integral analysis of the role of hydroperiod at any diversity level: variation in species richness, variation in assemblage composition and variation in beta diversity and also taken into account different types of variation in assemblage composition (beta diversity patterns), i.e. nested pattern, turnover in species occurrence or turnover in species abundance. The overall conclusion is that pond hydroperiod may be a major driver of pond-breeding assemblages only in years when the duration of ponds is short and strong nested pattern occur along hydroperiod gradient. On the contrary, the role of hydroperiod is negligible in wet years, when desiccation risk is not a major stress and the pond is available for a long time, enabling the potential breeding of many species. It should be noted that we found inter-annual stability in nestedness patterns, like Azeria and Kolasa (2008) found in an aquatic invertebrate community in a similar dynamic system, but we found different 
results in the associated hydroperiod gradient analyses. So, in wet years (i.e. 2003), we should hypothesize alternative mechanism leading to the observed nested pattern in amphibian assemblages. Taking into account that habitat heterogeneity is related with species richness in the study area (Gómez-Rodríguez et al. 2008), a plausible driver would be habitat nestedness, which one of the main mechanisms leading biotic nestedess in the literature (Ulrich et al. 2009).

Our results evidence two conservation priorities in the study area: the preservation of ponds along the wide hydroperiod range and, secondarily, a particular concern for the preservation of those with long duration, since they will provide breeding habitat for most species in unfavourable years. Beja and Alcazar (2003) gave a similar recommendation in a different temporary ponds system. In general, it is widely acknowledged that a wide spatial variability in pond hydroperiods is required to maximize amphibian species diversity for it will provide habitat for different species (Semlitsch 2003). The particularity in the study area is that it also increases the overall abundance of species in the study area, which results from variability in species predominance along hydroperiod gradient.

\section{Relationship between environmental/ spatial variables and amphibian diversity}

We found inter-annual differences in the relevance of dynamic and static predictors to explain both variation in species richness and in assemblage composition. WATER variables had a significant unique contribution to explain variation in assemblage composition in both years but they only explained richness gradients in 2006 , the drier year. This result is partially in agreement with our expectations, since we hypothesized that temporally variable characteristics would be important drivers of annual diversity. However, we did not expect that POND/LANDSCAPE variables would be the only significant predictor of species richness in 2003. A plausible explanation might be that, in 2003, a hydrologically favourable year, there were not major environmental stresses precluding species breeding attempt in the study area. This fact would have favoured that most individuals in the surroundings of a pond attempted breeding independently of the particular characteristics that year. The presence of those individuals in the surroundings would be related to more stable characteristics of the habitat (such as terrestrial cover) since it would highly depend on the probability of adult survival on the medium term. Once species attempted breeding, the particular hydric conditions, summarized in dynamic attributes (WATER), would be responsible for variation in species predominance among pond assemblages, as evidenced in beta diversity results. Focusing on amphibian assemblages on the medium term, the most remarkable result was the relevance of WATER variables to explain amphibian richness while POND/LANDSCAPE variables did not. Thereby, we should contemplate that amphibian diversity in the medium term is also associated with environmental variability in time. In consequence, speciesdiversity analyses should incorporate variables summarizing the temporally variable characteristics of ponds even when studying diversity over several years.

A remarkable conclusion is that, despite hydrology and water chemistry of ponds are supposed to be governed by landscape features (Batzer et al. 2004), we required from both sets of variables to develop a realistic understanding of amphibian diversity patterns in the study area, both 
when considering data collected in particular years or over several years. It should be clarified that we used dynamic predictors that intend to summarize the hydrologic conditions in two years with largely different hydrologic conditions. We avoided examining relationships between temporally variable characteristics measured at a particular point in time (i.e. May 2003) and diversity over the entire study period since those would probably be spurious results, lacking ecological meaning. In that case, we would have related a given invariant pond assemblage composition to a predictor that may show different and independent values depending on the sampling moment (see GómezRodríguez et al. in press) and, thereby, the inferred relationship would depend on the date of habitat sampling. In other words, we have taken into account the temporal scale of variation both in habitat and biotic data, in order to avoid spurious conclusions due to asynchrony between hypothesized causes (environmental characteristics) and observed consequence (diversity).

Finally, our study also evidence that environmental attributes irrelevant for pond species richness (alpha diversity) might be responsible for the variation in assemblage composition among ponds (beta diversity) and, hence, contribute to species diversity in the entire study area (gamma diversity). It should be also noted that environmental variation explained a larger proportion of variance in variation in assemblage composition than in richness gradients, thus providing more robust explanations. These results reinforce the idea that beta diversity is a key concept for understanding the functioning of ecosystems, for conservation of biodiversity and for ecosystem management (Legendre et al. 2005). Previous authors have also argued the necessity of complementing species richness and community turnover assessments in conservation prioritization (Arponen et al. 2008) or in analysis of macroecological patterns (Gañan et al. 2008). We argue that such complementarity is also necessary in ecological studies relating species diversity to habitat attributes at small scales, which should include the various spatial scales at which relationships between diversity and habitat characteristics may become manifest. We should not be content with multi-scale measurements of habitat attributes, as many authors suggest (Hazell et al. 2001; Van Buskirk 2005), but should also include a multi-scale perspective of diversity in order to avoid disregarding environmental variables as irrelevant when they are contributing to the increase of species diversity in the entire study area.

Comments This section was done in collaboration with Carmen Díaz-Paniagua, Javier Bustamante, Laura Serrano and Alexandre Portheault. 


\section{References}

Arponen A et al. 2008. J Appl Ecol 45, 1436-1445.

Azeria ET, Kolasa J 2008. Oikos 117, 10061019.

Babbitt KJ 2005. Wetlands Ecol Manag 13, 269-279.

Baber MJ et al. 2004. Oikos 107, 16-27.

Baselga A 2008. Ecography 31, 263-271.

Baselga A, Jiménez-Valverde A 2007. Ecol Entomol 32, 312-318.

Baselga A et al. 2007. Biol Lett 3, 642-645.

Batzer DP et al. 2004. J N Am Benthol Soc 23, 50-68.

Beja P, Alcazar R 2003. Biol Conserv 114, 317-326.

Borcard D et al. 1992. Ecology 73, 10451055.

Burne MR, Griffin CR 2005. Wetlands Ecol Manag 13, 247-259.

Clarke KR 1993. Aust J Ecol 18, 117-143.

Clarke KR, Warwick RM 2001. Change in Marine Communities: An Approach to Statistical Analysis and Interpretation. Primer-E, Plymouth, UK.

Church DR 2008. Copeia, 115-125.

Díaz-Paniagua C 1988. Amphibia-Reptilia 9, $15-26$.

Díaz-Paniagua C 1990. Herpetol J 1, 447453.

Díaz-Paniagua C et al. 2005. Los Anfibios de Doñana. Organismo Autónomo de Parques Nacionales. Ministerio de Medio Ambiente, Madrid.

Fjeldsa J, Lovett JC 1997. Biodivers Conserv 6, 315-323.

Gañan I et al. 2008. Environ Entomol 37, 1488-1497.

Gaston KJ 2000. Nature 405, 220-227.

Gibbons JW 2003. Wetlands 23, 630-635.

Gómez-Rodríguez C et al. 2008. Herpetol J 18, 103-113.

Gómez-Rodríguez $\mathrm{C}$ et al. Chapter 3 this thesis.

Gómez-Rodríguez $\mathrm{C}$ et al. In press. Aquat Ecol. Online first.
Hazell D et al. 2001. Biol Conserv 102, 155169.

Hecnar SJ, M'Closkey RT 1996. Freshwater Biol 36, 7-15.

Heyer WR et al. 1994. Measuring and Monitoring Biological Diversity. Standard Methods for Amphibians. Smithsonian Institution Press, Washington \& London.

Houlahan JE et al. 2007. P Natl Acad Sci USA 104, 3273-3277.

Houlahan JE, Findlay CS 2003. Can J Fish Aquat Sci 60, 1078-1094.

Joly P et al. 2001. Conserv Biol 15, 239248.

Junta de Andalucía 2003. Ortofotografía Digital de Andalucía.

Knutson MG et al. 2004. Ecol Appl 14, 669684.

Koleff P et al. 2003. J Anim Ecol 72, 367 382.

Laan R, Verboom R 1990. Biol Conserv 54, 251-262.

Legendre P, Anderson MJ 1999. Ecol Monogr 69, 1-24.

Legendre P et al. 2005. Ecol Monogr 75, 435-450.

Legendre P, Legendre L 1998. Numerical Ecology. Elsevier Science.

Leibold MA, Mikkelson GM 2002. Oikos 97, 237-250.

Lobo JM et al. 2001. Biol J Linn Soc 73, 233-253.

Magurran AE 2004. Measuring Biological Diversity. Blackwell Publishing.

Marsh DM et al. 1999. J Anim Ecol 68, 804814.

Marsh DM, Trenham PC 2001. Conserv Biol $15,40-49$.

Oksanen J et al. 2007.

Parris KM 2004. Ecography 27, 392-400.

Patterson BD, Atmar W 1986. Biol J Linn Soc 28, 65-82.

Petranka JW et al. 2004. Ecol Appl 14, 1065-1078. 
Ricklefs RE, Schluter D (eds.)1993. Species Diversity in Ecological Communities: Historical and Geographical Perspectives. University of Chicago, Chicago

Rivas-Martínez S et al. 1980. Lazaroa 2, 5189.

Schmidt BR, Pellet J 2005. J Wildl Manage 69, 884-893.

Semlitsch RD 2002. J Wildl Manage 64, 615-631.

Semlitsch RD (Ed.) 2003. Amphibian Conservation. Smithsonian Books, Washington and London.

Siljeström PA et al. 1994. J Arid Environ 26, 315-323.

Smith GR et al. 2003. J Freshwater Ecol 18, 491-496.

Smith MA, Green DM 2005. Ecography 28, 110-128.
Snodgrass JW et al. 2000a. Ecol Appl 10, 1219-1229.

Snodgrass JW et al. 2000b. Conserv Biol 14, 414-419.

Soininen J et al. 2007. Ecology 88, 28302838.

Stiling P 1999. Ecology: Theories and Applications. Prentice Hall, New Jersey.

Sztatecsny M et al. 2004. Herpetol J 14, 8997.

Tuomisto H, Ruokolainen K 2006. Ecology 87, 2697-2708.

Ulrich W et al. 2009. Oikos 118, 3-17.

Van Buskirk J 2005. Ecology 86, 19361947.

Wellborn GA et al. 1996. Annu Rev Ecol Evol $S$ 27, 337-363.

Werner EE et al. 2007. Oikos 116, 16971712. 


\section{What habitat requirements do amphibians have for}

\section{breeding in Mediterranean temporary ponds?}

The imperfect detection of species may lead to erroneous conclusions about species-environment relationships. We applied a double-sampling approach to evaluate three main competing hypothesis of the role of abiotic habitat features in amphibian habitat selection while explicitly accounting for the reliability of absence data. Hypothesis related to breeding habitat characteristics, aestivating habitat characteristics and the structure of the patchy population. The study was conducted in Donana National Park for a 4-year period. We developed habitat models for six pond-breeding amphibian species using GLMs with a binomial link under an Information Theoretic Approach based on AIC and computed model-averaged estimation of parameters. Absence reliability was estimated from species detectability in each particular pond. The large variability in absence reliability warned us that, for any given species, we should not assume all the non-detections as if they were real absences and neither that the reliability of all non-detection records is the same. The occurrence of Hyla meridionalis and Triturus pygmaeus did not relate specifically to any available habitat characteristics but to a particular ecosection within the Park. Characteristics of the breeding habitat (area and hydroperiod) were of high importance for the occurrence of Pelobates cultripes and Pleurodeles waltl. Terrestrial characteristics were the most important predictors of the occurrence of Discoglossus galganoi and Lissotriton boscai, along with the structure of the patchy population for the latter species. In summary, we did not a find a best supported hypothesis valid for all species, which stresses the importance of multi-scale approaches involving multiple environmental predictors since both the characteristics of the pond and the landscape (terrestrial and surrounding aquatic habitat) were important for different species. 


\section{Introduction}

Distribution models attempt to quantify species-environment relationships, a central issue in ecology. The utility of distribution models may be both to search for causal relationships of the present distribution of a species or/and to forecast species distribution across time or space. To be useful, distribution models should underlie an ecological hypothesis (Austin 2002) and the selected environmental variables should have a direct biological relationship with the organism (Vaughan and Ormerod 2003). The reliability of the data used to parameterize a model is also critical for its utility and validity (Lobo 2008). The recorded presence of an organism is usually the only reliable information on its distribution. While species presence is confirmed by detecting the species at a site, it is usually not possible to confirm if absences are true or the species was present but not detected during the survey (MacKenzie 2005; MacKenzie et al. 2006).

The imperfect detection of species may lead to erroneous conclusions about species-environment relationships $(\mathrm{Gu}$ and Swihart 2004; Mazerolle et al. 2005;
MacKenzie 2006). The best modelling approach is to evaluate species-habitat relationship while explicitly accounting for the probability of detecting the species when present (MacKenzie 2005; MacKenzie et al. 2006). The main drawback of this statistical framework is that it requires from temporal replication at all sampled sites, a condition that may not be always feasible. In that case, we may conduct a double sampling design, which consists in the estimation of detection probabilities from the data collected at sites where repeated surveys were conducted and the application of such information to the sites surveyed only once (MacKenzie et al. 2006). Following this approach, we would integrate information from species detectability at a site, as a surrogate for the reliability of the absence record, into traditional presenceabsence models. This surrogacy relies in the following premise: the higher the probability of having detected the species when present at a site, the higher the reliability of the absence recorded and the higher its relevance for the model parameterization. 
The amphibian community in Doñana National Park can provide a model system to quantify the habitat requirements of amphibian species breeding in highly dynamic ecosystems. The information obtained will contribute to improvement of amphibian conservation programs focused on preserving suitable breeding sites. Towards this aim, previous studies have quantified the relationships between habitat characteristics and amphibian richness, species occurrence or species relative abundance in Mediterranean temporary ponds (Díaz-Paniagua 1982; Beja and Alcazar 2003; Richter-Boix et al. 2007). However, to our knowledge, no study has explicitly accounted for the reliability of absence data in this type of ecosystem. We may find two different causes of low absence reliability in biological data of amphibian distributions in Mediterranean temporary ponds: inter-annual turnover in assemblage composition and low species detectability. Previous studies have reported that amphibian assemblages in Mediterranean temporary ponds change from year-to-year (Jakob et al. 2003; Richter-Boix et al. 2006), also in the study area (GómezRodríguez et al., Chapter 3 this thesis). So, an annual survey is expected to yield "false absences" since we would require data from several breeding seasons to characterize the species assemblage associated to a given pond. On the other hand, amphibians are inconspicuous species and hence use to show low detectability (Mazerolle et al. 2007). In the study area, a previous study evidenced that the probability of detecting a species with a single-visit was low, speciesspecific and variable over time (GómezRodríguez et al., Chapter 3 this thesis). In consequence, non-detection data does not necessarily corresponds to real absence data and hence its reliability should be assessed based on the history of survey of the site (dates of sampling visits) and explicitly incorporated into distribution models.
Most ecological models about amphibian habitat selection focus on four main aspects that have been identified as critical for amphibian ecology: the abiotic characteristics of the breeding habitat, such as hydroperiod (Wellborn et al. 1996; Werner et al. 2007) or pond area (Burne and Griffin 2005; Werner et al. 2007); the biotic interactions in the breeding habitat, such as competition or predation (Duellman and Trueb 1986); the characteristics of the aestivating habitat (i.e. landscape composition) (Gibbons 2003); and the structure of the metapopulation/patchy population (i.e. distance to nearest site, density of surrounding ponds...), which determines the dispersal or regular movements of individuals among ponds (Semlitsch and Bodie 1998; Smith and Green 2005). A patchy population structure, defined as a population where individuals move frequently among habitat patches and may reproduce in several patches during their lifetime (Harrison 1991; Ovaskainen and Hanski 2004), may be expected in areas where connectivity among ponds is high and favours inter-pond movements of individuals (Smith and Green 2005; Petranka and Holbrook 2006). So, a cluster of ponds (rather than a single one) constitutes a local population which may occupy different habitat patches over time (see Petranka et al. 2004). Under this scenario, the distribution of breeding sites in the immediate surroundings of a pond may be critical to explain the occurrence of a species.

In this study, we apply a double-sampling approach to evaluate competing hypothesis of the role of abiotic habitat features in amphibian habitat selection while accounting for the reliability of absence data. For each pond where a species was not detected, we use the single-visit probability of detection computed in a previous study (Gómez-Rodríguez et al., Chapter 3 this thesis) to estimate the reliability of that 
absence, taking into account the pond history of survey (number and date of sampling visits). The tested hypotheses are framed within three of the aforementioned ecological models: the relationship between the occurrence of a species and the characteristics of their breeding habitat, the ones of their aestivating habitat and the structure of the patchy population. Given that the connectivity among ponds is very high in the study area (Fortuna et al. 2006; Gómez-Rodríguez et al. in press), we think that movements of individuals among nearby ponds are likely and hence that a patchy population structure is plausible instead of a metapopulation structure, where the migration among discrete populations is infrequent. Notwithstanding, it should be noted that this assumption is a practical one since we would require additional data on dispersion or genetic structure to reject (or accept) the hypothesis of isolation among ponds.

\section{Material and $M_{\text {ethods }}$}

\section{Study area}

The study was conducted in Doñana National Park (see Siljeström et al. 1994 for a geo-morphological description), in southwestern Spain (Figure 36). Doñana National Park is considered to be one of the largest (54 252 hectares) and most important wetlands in southern Europe. Three morphogenetic regions are differentiated within the Doñana National Park: the coast (current beaches), the aeolian sands and the marshland; being the former a very small portion of the Park. Our study was conducted on the aeolian sands, where moving dunes and stabilized sands occur. The dominant vegetation on the aeolian stabilized sands is Mediterranean scrub (Halimio halimifolii-Stauracanthetum genistoides and Erico scopariae-Ulicetum australis as defined by Rivas-Martínez et al. 1980) and isolated patches of pine (Pinus pinea L.) and juniper forests (Juniperus phoenicea L.). Within this morphogenetic region, Montes et al. (1998) differentiated eight ecosections based on differences in their geomorphologic, stratigraphic and hydrodynamic characteristics (Figure 36).

On the aeolian sands, there are numerous temporary ponds of natural origin that flood during the rainy season. The area also includes two extensive permanent ponds of natural origin that occasionally dry out after years of severe drought. Man-made permanent water bodies (locally named zacallones) are also sparsely distributed through the study area, consisting in deep and small $\left(<10 \mathrm{~m}^{2}\right)$ holes made for cattle drinking during summer. Pond size is largely variable, from rain puddles (several square metres) to large temporary ponds $(>$ 1 hectare). The annual duration of flooding (or hydroperiod) varies among ponds, from pools persisting one month to ponds persisting up to 10 months in very wet years. Hydroperiod is also widely variable among years. Many pond basins are completely or partially enclosed by a fringe of hygrophyte vegetation (dense vegetation mainly composed of Erica scoparia L., Erica ciliaris L., Calluna vulgaris (L.) Hull and Ulex minor Roth.) that may be occasionally flooded. A detailed description of Doñana temporary ponds can be found in GómezRodríguez et al. (in press). 
A/

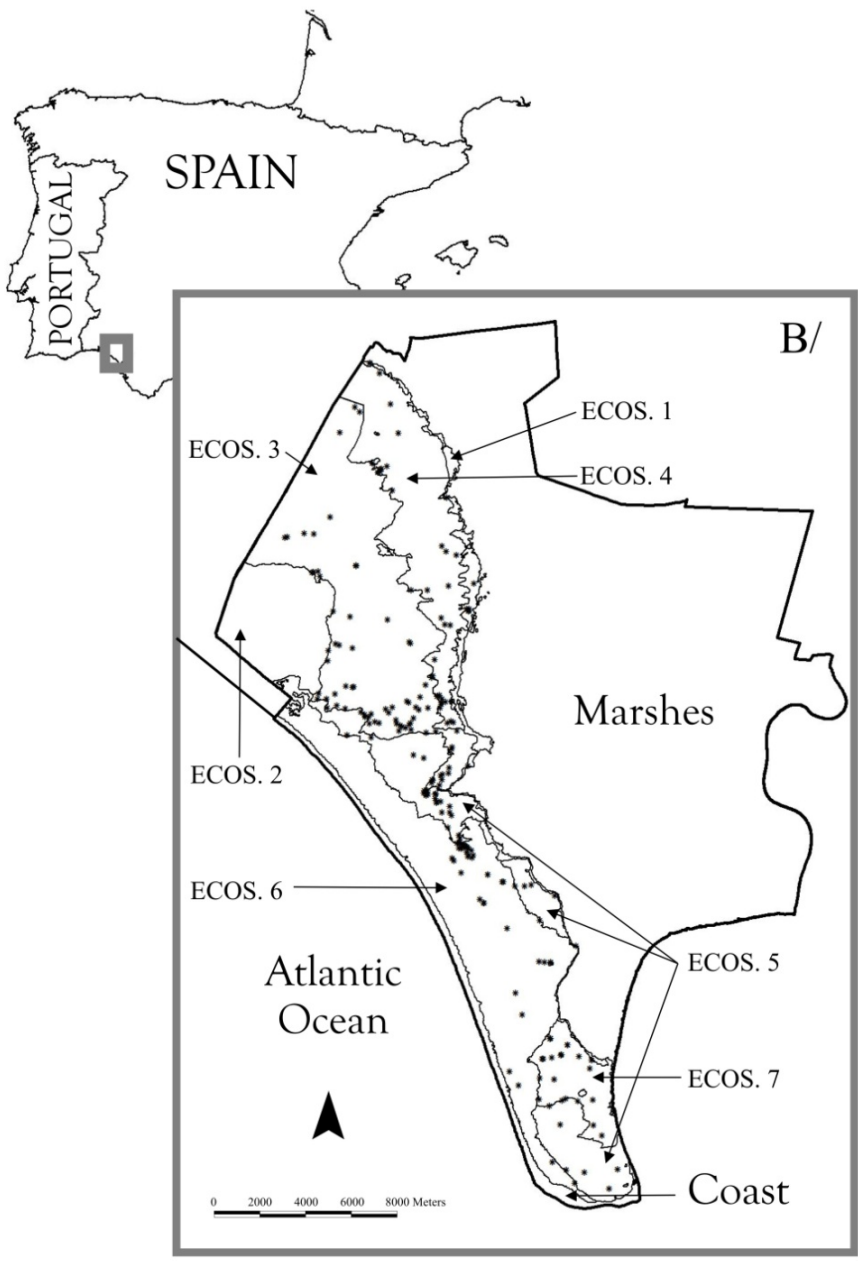

Figure 36. A/ Location of Doñana National Park in southwestern Spain. B/ Location of the study ponds. The map also shows the different ecosections within the aeolian sands in Doñana National Park. [Ecosection code is detailed in the Study Area section) 


\section{Amphibian sampling}

For this study, we sampled 221 amphibian breeding sites (169 natural ponds and 52 man-made zacallones), located in seven different ecosections (Figure 36). Amphibian data were collected during the amphibian breeding season in a four-year survey (from 2002-03 to 2005-06) (Table 28), although ponds did not flood in 200405 and therefore could not be sampled. Due to the large number of ponds, we could not monitor all the ponds every year. 140 ponds were visited only in one year whereas 16 ponds were visited every year (Table 28). In 2006, a year with scarce autumn rainfall, we visited all the ponds monitored in the previous years and surveyed the flooded ones $(\mathrm{n}=129)$. The number of visits to a given pond ranged from 1 to 12 (mean = $2.01 \pm 2.42$ S.D).
We used dipnetting techniques (Heyer et al. 1994) to sample the amphibian larvae. We identified in situ the individuals captured in each sampling unit (three consecutive sweeps on a stretch of approx. $1.5 \mathrm{~m}$ length) and then released them back. Sampling effort was proportional to pond size, except when not logistically achievable due to the large size of the water body, in which case we tried to sample all different pond microhabitats. Larval sampling was complemented with visual surveys in and around the pond to detect eggs, larvae and metamorphic individuals. Since this study analyzes the habitat requirements for amphibian breeding, we only included data from breeding attempts, not just the occurrence of a species. So, we did not include the contingent detection of adults or calling activity because the sampling protocol was not optimized for its detection, which improves with nightly surveys (Heyer et al. 1994).

Table 28. Number of ponds surveyed during each breeding season and mean number of sampling visits (total number of ponds surveyed over the entire study period $=221$ ). The number of ponds is detailed as: number of ponds visited only in that season, in all seasons, or in two of the three seasons.

\begin{tabular}{|c|c|c|c|}
\hline & 2003 & 2004 & 2006 \\
\hline & (Feb-May) & (Jan-Jun) & (Mar-May) \\
\hline Total number of ponds surveyed & 94 & 95 & 129 \\
\hline Number of visits per pond (mean \pm s.d.) & $1.5 \pm 1.1$ & $1.7 \pm 1.4$ & $1.1 \pm 0.4$ \\
\hline \multicolumn{4}{|l|}{ Number of ponds surveyed } \\
\hline Only that season & 29 & 61 & 50 \\
\hline Every season & & 16 & \\
\hline In 2003 and 2004 & \multicolumn{2}{|c|}{2} & \\
\hline In 2004 and 2006 & & \multicolumn{2}{|c|}{32} \\
\hline In 2003 and 2006 & 47 & & 47 \\
\hline
\end{tabular}




\section{Underlying hypotheses for predictor selection}

For this study, we selected a set of habitat variables in order to test competing hypothesis of amphibian habitat selection based on available ecological information. The habitat variables can be classified as (see Table 29):

Ecosection type: We recorded the ecosection in which the pond was located, as extracted from the ecosystem cartography in Montes et al. (1998). This parameter is an indirect predictor, with no biological relevance for a species, which informs us whether habitat selection is conditioned by local attributes related to ecosystem type (i.e. dry zones, ecotones...) that may have not been contemplated in the rest of the hypotheses.

Breeding habitat. We recorded two major structuring drivers of amphibian communities: pond hydroperiod (Wellborn et al. 1996) and pond size (Werner et al. 2007). Amphibian species are supposed to be sorted along the hydroperiod gradient according to whether they are able to metamorphose in short-duration ponds or tolerant to the presence of major predators in ponds of longer duration (Wellborn et al. 1996). Hydroperiod has been identified as an important factor explaining amphibian richness (Beja and Alcazar 2003; Burne and Griffin 2005) and the occurrence of particular pond-breeding species (Weyrauch and Grubb 2004; Otto et al. 2007; Richter-Boix et al. 2007). The relationship between species occurrence and pond size is two-fold. First, metacommunity theory predicts that the probability of occurrence increases with pond size because it assumes a functional relationship between the area of a patch and its extinction probability (Hanski 1998). Second, patch area and habitat heterogeneity are highly interconnected (Rosenzweig 1995), and the latter positively correlates with species diversity since complex habitats usually provide more niches and diverse ways of exploiting the environmental resources (Tews et al. 2004). Pond size has been reported as an important factor explaining amphibian richness (Beja and Alcazar 2003; Burne and Griffin 2005) and the occurrence of particular species (Beja and Alcazar 2003; Babbitt et al. 2006; Piha et al. 2007).

Pond size was extracted from a $5 \mathrm{~m}$ resolution pond map layer obtained at a large flooding event (see Gómez-Rodríguez et al. 2008 for details on the methodology used). We have considered both the linear and quadratic response of pond size to investigate the possibility of curvilinear relationships, as previously observed Werner et al. (2007) and analogously to the unimodal responses to hydroperiod in species richness gradients (Snodgrass et al. 2000; Werner et al. 2007) or species occurrence (Beja and Alcazar 2003; Otto et al. 2007). Hydroperiod was categorized in four wide groups. A ranked ordination of ponds hydroperiod is similar both in wet and dry years although the actual duration of ponds may largely differ (GómezRodríguez et al. in press). Since most ponds were visited only once, hydroperiod categories were based on characteristics related with flooding duration such as aquatic vegetation associations described in (Rivas-Martínez et al. 1980), basin topography and past recordings of hydroperiod in those ponds (Díaz-Paniagua, unpublished data). 
Aestivating habitat: Amphibians have a complex life cycle and pond breeding species require both terrestrial and aquatic habitats. So, terrestrial habitats should be considered in habitat models since they provide refugee for amphibian species during the dry season and also constitute the matrix that interconnect ponds (Gibbons 2003). In this study, we have differentiated three habitat types according to a gradient of moist-arid environment. Aridity may be a barrier to amphibian pond movements and also a source for hydric stress during amphibian aestivation. Aestivation is the period of inactivity and metabolic reduction in response to lack of water or high temperatures that may compromise individual survivals due to dehydration (Pinder et al. 1992). We used the ecosystem cartography of Doñana National Park (Montes et al. 1998) to assess the percentage of dune habitat, forest habitat and scrub habitat in a $200 \mathrm{~m}$ buffer area from the edge of the pond. Rittenhouse and Semlitsch (2007) studied the distribution of amphibians in the terrestrial habitat and reported that $75 \%$ of individuals occur within $205 \mathrm{~m}$ from the wetland edge.

Patchy population structure: These are variables regarding to pond accessibility from nearby water bodies. The pond spatial arrangement is critical in the spatial dynamics of amphibian populations and metapopulations (Marsh and Trenham 2001). In areas where the connectivity among ponds is high and favours inter-pond movements of individuals, we may find a patchy population structure (Smith and Green 2005; Petranka and Holbrook 2006). In this scenario, habitat suitability depends both on pond accessibility and pond connectivity to nearby ponds. Marsh et al. (1999) reported that tungara frogs routinely move between ponds located at distances less than $200 \mathrm{~m}$.

As a measure of pond accessibility, we classified in three categories the proportion of pond shore surrounded by adjacent hygrophyte vegetation (Table 29) using aerial photography (Junta de Andalucía 2003). As a measure of pond connectivity, we measured the edge-to-edge distance to the nearest pond, using the $5 \mathrm{~m}$ resolution pond map layer (Gómez-Rodríguez, unpublished data), and to the marshes with ArcView GIS 3.2. We also counted the number of nearby water bodies (excluding the marshes) surrounding each study pond in a $200 \mathrm{~m}$ buffer area from the edge of the pond. To account for inter-annual variability in pond connectivity due to meteorological conditions, we categorized surrounding ponds according to their extension, which was related to the hydroperiod of temporary ponds (excluding zacallones) in the study area $\left(\right.$ ANOVA $\left.\mathrm{F}_{2,93}=12.280, \mathrm{p}<0.001\right)$. So, we used pond size to discriminate ponds flooding in very wet years (all ponds, including those with shorter surface area) from those ponds that flood even during dry years (pond size larger than $4000 \mathrm{~m}^{2}$ ). 
Table 29. Set of candidate models evaluated within each hypothesis. The variable and its form continuous/ categorical/ordered categorical) is specified.

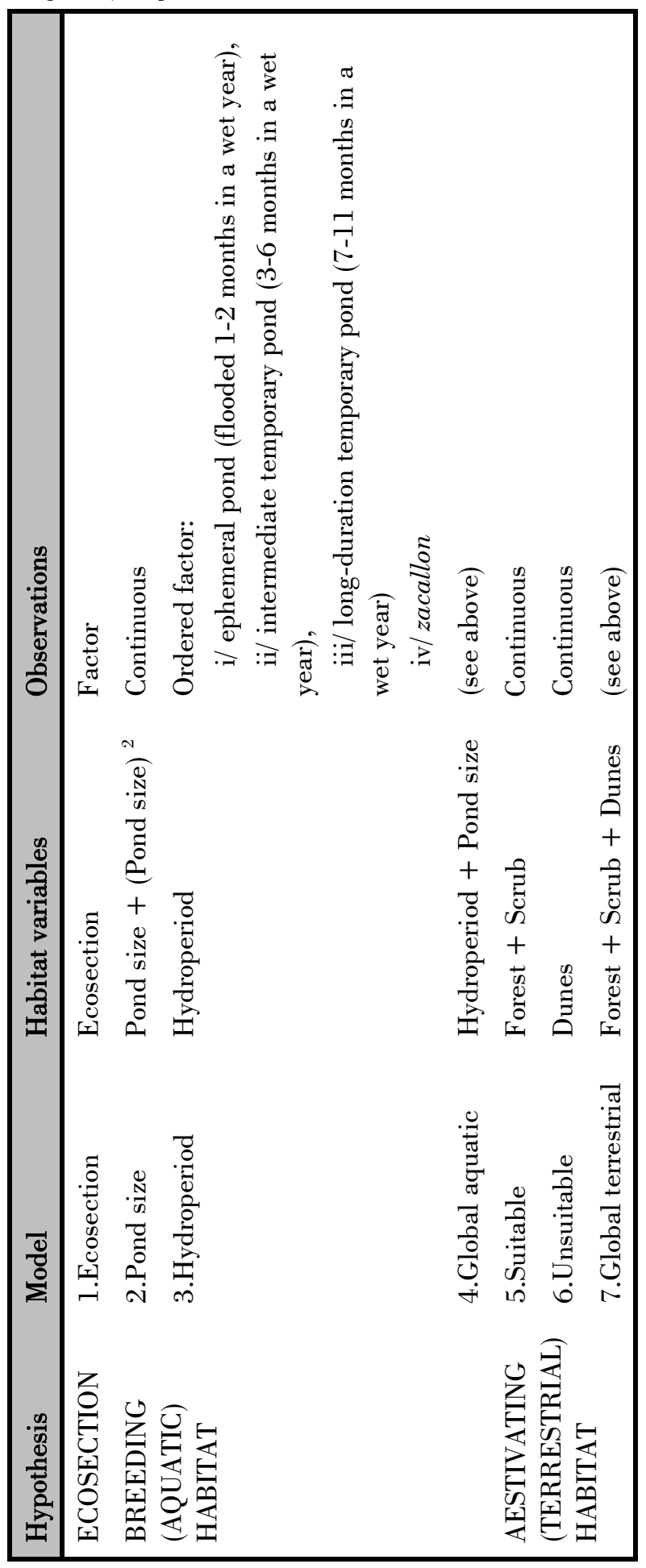


Table 29. (cont.)

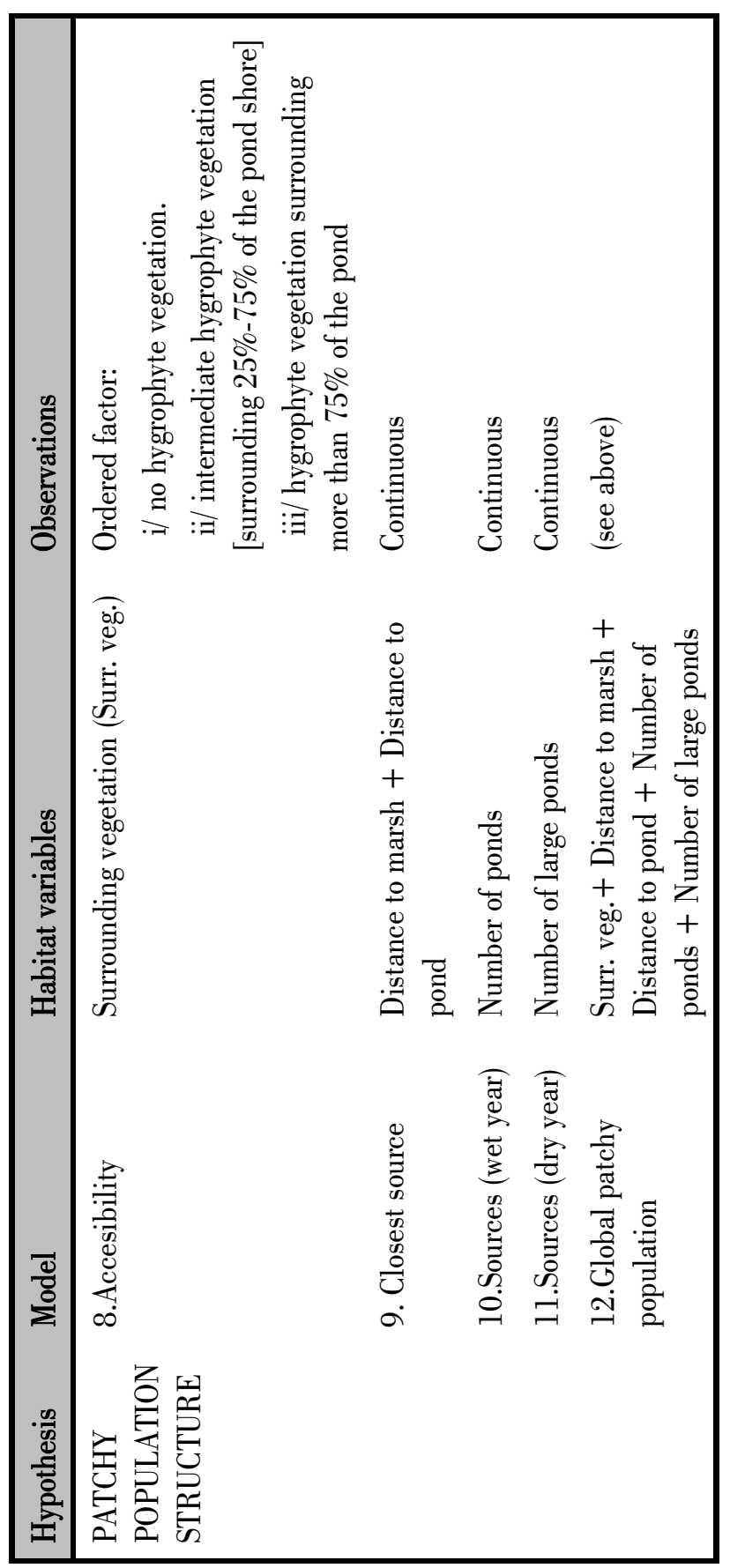




\section{Statistical analyses}

Since spatial autocorrelation may pose a serious bias in spatial analyses (Dormann 2007), we checked for the presence of spatial autocorrelation in biological data (species presence/absence) before conducting the species habitat models, as Dormann et al. (2007) recommend. Spatial autocorrelation occurs when the values of the variable (i.e. presence/absence) sampled at nearby locations are not independent of each other. This phenomenon may bias parameter estimates from habitat models and falsely mask the relative importance of environmental variables. For each species, we evaluated the spatial autocorrelation with Moran's I statistics and Monte-Carlo permutation tests, using 1000 simulated values (command "moran.mc", R library "spdep"). We computed the autocorrelation on cases with high reliability, defined as those with a high probability of having detected the species, when present, after all the sampling visits to the pond $\left(\mathrm{p}^{*}\right)$, see below. We set $\mathrm{p}^{*}$ $\geq 0.80$ for most species, $\mathrm{p}^{*} \geq 0.50$ for Lissotriton boscai (Lataste, 1879), to identify cases with high reliability. We set the maximum distance to identify spatial autocorrelation in $6000 \mathrm{~m}$, to ensure that all the ponds with reliable data had at least one pond within the distance range. As we found very low values of spatial autocorrelation in species presence/absence data, we did not need to incorporate spatial autocorrelation in the modelling process and hence conducted non spatial statistical modelling methods (i.e. GLMs).

For each species, we developed a set of twelve $a$ priori candidate models (Table 29), to assess which variables explained best its probability of breeding attempt in a given pond during the study period. Models were classified under four main hypotheses, depending on the type of habitat characteristics included: i/ Local conditions (ecosection); ii/ characteristic of the breeding (aquatic) habitat; iii/ characteristics of the aestivating (terrestrial) habitat and iv/ landscape characteristics that may determine the structure of the patchy population (Table 29). Within each hypothesis, we developed simple models, to test the relevance of specific habitat characteristics, and a general one, including all parameters, in order to compare the alternative main hypotheses. A previous exploration with Generalized Additive Models (GAMs)(Hastie and Tibshirani 1990) evidenced that species-habitat relationships were not apparently curvilinear, except the relationship with pond size for some species. So, we considered that the theoretical shapes of the responses, based on aforementioned ecological knowledge, were adequate and hence we did not include any additional one (i.e. quadratic). We did not construct a global model, including all parameters in any hypothesis, since it would have included far more parameters than reasonable given our data. We neither consider all possible combinations of variables, as this approach typically inflates the number of models beyond the number that can be reliably analyzed (Burnham and Anderson 2002).

We built candidate models using Generalized Linear Models (GLM) (McCullagh and Nelder 1989) with binomial errors and a logit link (command "glm", R software). The response variable was the presence/absence (breeding evidence $v s$. no breeding evidence) of the species in a given pond during the entire study period. We explicitly accounted for the reliability of the data by means of weighting each case by its reliability. Since presences were completely reliable, the weight for presence cases was 1. If we did not detect the species, we assumed as absence reliability the probability of having detected the species given the timing of survey in each particular 
case (i.e. taking into account the dates in which the pond was surveyed). To estimate absence reliability, we used detectability values reported in a previous study (GómezRodríguez et al., Chapter 3 section 2 this thesis). In this preceding study, we developed single-species occupancy models (MacKenzie et al. 2002; MacKenzie et al. 2006) with program PRESENCE (MacKenzie et al. 2002) and within an Information Theoretic Approach (see Burnham and Anderson 2002) to calculate the single-visit probability of detection for each species and month of survey (February - May 2003, January - May 2004 and March - May 2006). In the present study, we used the single-visit probability of detection in each sampling visit to compute the probability of detecting a species after $k$ visits $\left(\mathrm{p}^{*}\right)$ conducted in each particular pond by applying the formula:

$$
p^{*}=\prod_{i=1}^{k}\left(1-p_{i}\right)
$$

being $\mathrm{p}_{\mathrm{i..k}}$ the probability of detection in a given sampling visit. The probability of detection after $\mathrm{k}$ visits ( $\mathrm{p}^{*}$ ) was null in 73 ponds for Discoglossus galganoi Capula, Nascetti, Lanza, Bullini \& Crespo, 1985, in four ponds for Pleurodeles walt Michahelles, 1830 and in 124 ponds for $L$. boscai. These cases were excluded from habitat models. We could not estimate the probability of detection neither build habitat models for Bufo calamita Laurenti, 1768 and Pelophylax perezi (Seoane, 1885), since we lacked on single-visit probability of detection for most sampling visits (see Gómez-Rodríguez et al., Chapter 3 section 2 this thesis).

To identify the best model within the set of candidate models, we followed a model selection approach based on Akaike's Information Criterion (AIC), as Mazerolle
(2006) recommends for herpetological studies. We also conducted a multimodel inference of parameters (see Burnham and Anderson 2002) so that estimates of model parameters were based on the entire set of models rather than on the one selected as best. Model-averaged estimates have more precision and are less biased compared to the estimator from just the selected best model and are especially useful if no model is clearly best (Burnham and Anderson 2002). Our approach for model selection and multimodel inference consisted on two steps: First, we ranked models according to their AIC values in order to obtain Akaike's model weights $(\omega)$, which range between 0 (low model importance) and 1 (high model importance) and quantify the uncertainty that each model is the target best model (see Burnham and Anderson 2002). Second, we computed the relative importance of each parameter by summing the Akaike weights across all the models in the set where the variable occurs (Burnham and Anderson 2002). We considered importance weights above 0.30 to be relevant. For each parameter, we also computed its modelaveraged estimate and its unconditional standard error, which incorporate model selection uncertainty into estimates of precision (Burnham and Anderson 2002).

Models were evaluated based on AUC (command "somers2", R library "Hmisc"), the percentage of explained deviance $\left(D^{2}\right)$ and the adjusted $\mathrm{D}^{2}$, which takes into account the number of parameters in the model. We computed the AUC only from cases with high reliability $\left(\mathrm{p}^{*} \geq 0.80\right)$. In the case of $L$. boscai, all data with positive $\mathrm{p}^{*}$ values were considered, since only two ponds showed $\mathrm{p}^{*} \geq 0.80$ (note that $\mathrm{p}^{*}$ was always higher than 0.5 in all positive cases). We assessed the standard error of each evaluation statistic using a parametric bootstrap (1000 samples) in which the species prevalence in each sample was kept constant and equal to the one in the real 
data set. Bootstrap techniques are recommended to assess the stability of a model when the data set is too small to be split into separate data sets for model building and evaluation (Guisan and Zimmermann 2000), as in this study. Besides, since the aim of this study is to provide a model that faithfully represents the statistically important aspects of the data set, using the same data set for model calibration and evaluation is adequate (Maurer 2002).

\section{Results}

We detected eight species in the study area: B. calamita, Pelobates cultripes (Cuvier, 1829), D. galganoi, P. perezi, Hyla meridionalis Boettger, 1874, P. waltl, Triturus pygmaeus (Wolterstorff, 1905) and L. boscai. Triturus pygmaeus and $H$. meridionalis were the species that bred in a larger proportion of ponds (55\% and $46 \%$, respectively), whereas $D$. galganoi was only detected in $13 \%$ of the ponds (Figure 37).

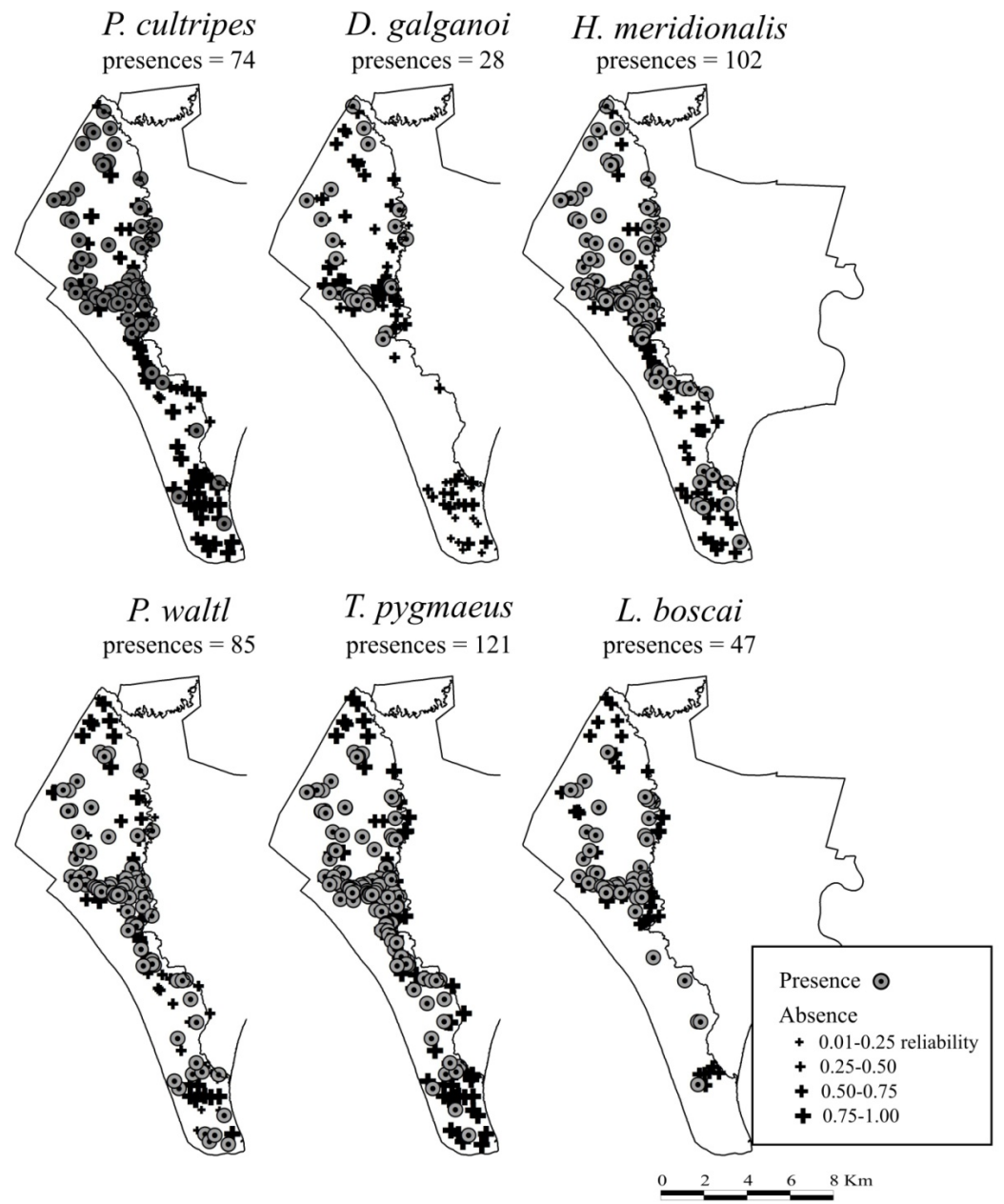

Figure 37. Presence/absence data of each species in the study area. Absences are weighted according to reliability of the data, as obtained from the probability of detection after all the sampling visits conducted in that pond. Absences with null reliability are not shown. 
In any given pond, the reliability of absence data widely differed among species. Triturus pygmaeus and $H$. meridionalis showed the highest mean probability of detection in ponds where we did not detect the species, thereby evidencing high levels of reliability in their absence data (Figure 38). On the contrary, D. galganoi and $L$. boscai were the species with less reliable absence data, being absence reliability even null in 73 ponds and in 124 ponds, respectively.

The effect of spatial autocorrelation was very low in the data set (Table 30). Despite all species but $D$. galganoi showed significant values of Moran's I, the value of the statistics was low, close to 0 in most cases, evidencing a very low spatial autocorrelation in the data set. The data with a higher spatial autocorrelation corresponded to $P$. cultripes occurrence (Moran's I $=0.380, \mathrm{p}<0.001$ ).
Table 30. Results of spatial autocorrelation in biological data, measured as Moran's I statistics with p-values computed through Monte-Carlo permutation tests.

\begin{tabular}{|lcc|}
\hline & Moran's I & p-value \\
\hline P. cultripes & 0.380 & $<0.001$ \\
D. galganoi & 0.021 & 0.126 \\
H. meridionalis & 0.171 & $<0.001$ \\
P. waltl & 0.084 & $<0.001$ \\
T. pygmaeus & 0.181 & $<0.001$ \\
L. boscai & 0.110 & $<0.001$ \\
\hline
\end{tabular}

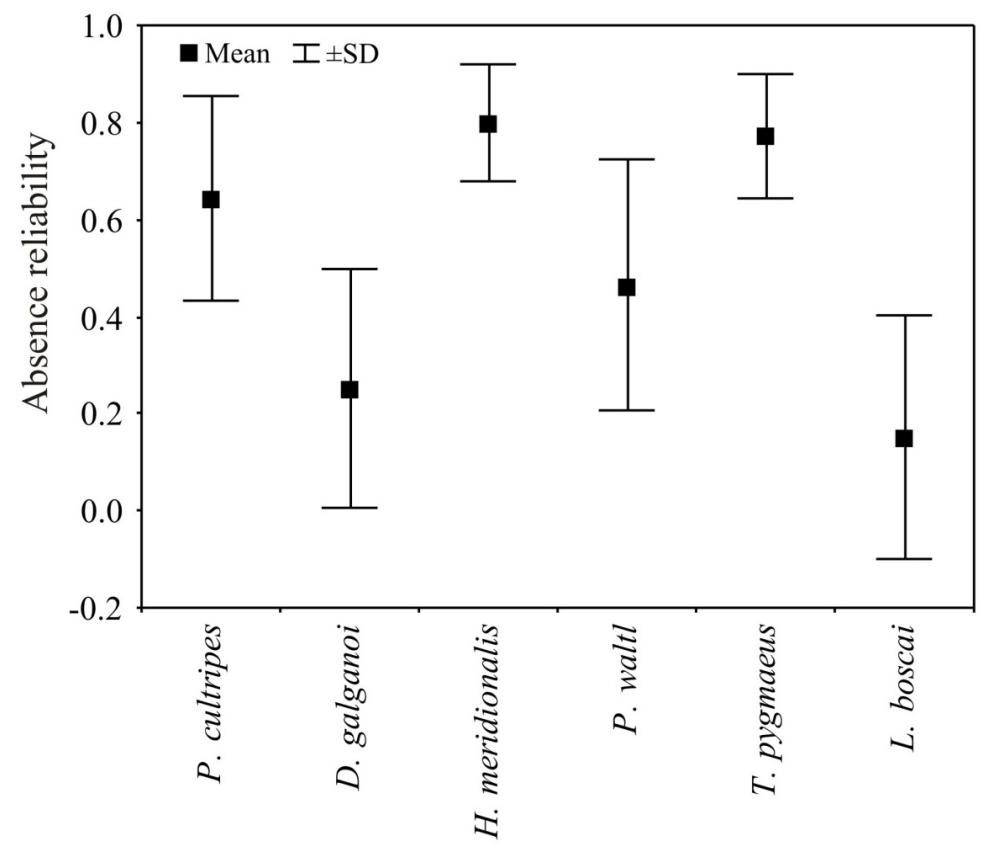

Figure 38. Mean value and standard deviation of absence reliability in the ponds where the non-detection of the species was recorded. Absence reliability represents the probability of having detected the species, given presence, after the sampling visits conducted during the entire study period. 
We developed habitat models for six out of the eight amphibian species (Appendix). We observed differences in model ranking and model weights among species, evidencing that there was not a "best supported hypothesis" valid for all of them. Only $P$. cultripes and $H$. meridionalis showed a model clearly ranked as best (Akaike $\omega>0.98$ ), whereas the rest of the species showed similar support for competing models, although those models were within the same main hypothesis except in the case of $L$. boscai. The models that obtained a higher mean support were the "ecosection", the "global aquatic" and the "global terrestrial", whereas the ones with lower mean support were the ones regarding to the "patchy population hypothesis", except the one including all parameters (Figure 39).

The ecosection models obtained a great support in species breeding in a large proportion of ponds (H. meridionalis and $T$. pygmaeus) (Appendix). The $48 \%$ of the presences of $T$. pygmaeus (total presences $=$ $121)$ and the $61 \%$ of the presences of $H$. meridionalis (total presences $=102$ ) were observed in the ecosection 3 ("Wet stabilized sands at higher elevation") whereas only 10 and 6 absences with high reliability were recorded, respectively (Figure 40). This was the ecosection with a higher ratio between presences and absences for both species.

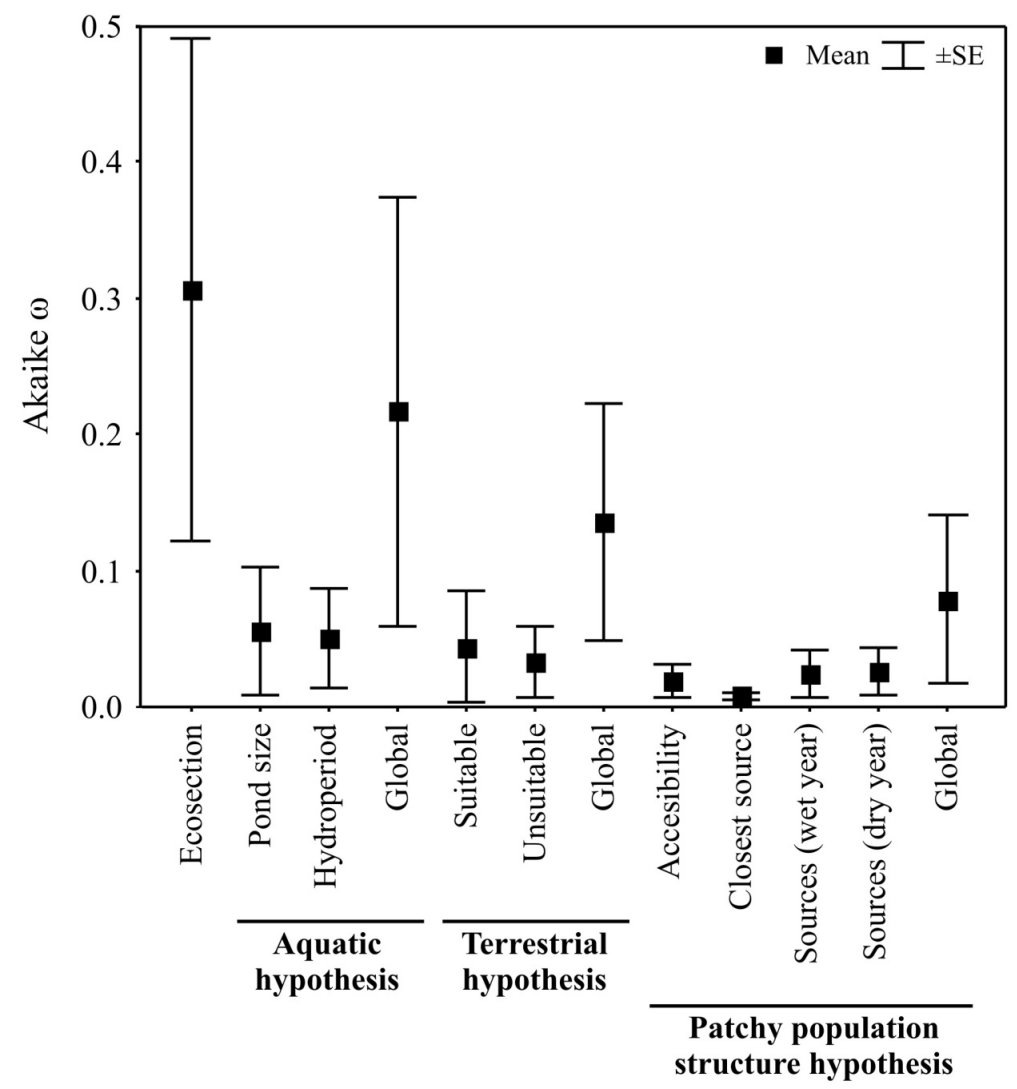

Figure 39. Mean value and standard error of the Akaike weight of each model across all species. 
Models within the "aquatic habitat hypothesis" obtained a great support in species with long larval development $(P$. walt and $P$. cultripes) (Appendix). The probability of occurrence of $P$. cultripes and $P$. waltl increased with pond size (Table 31). Intermediate values of hydroperiod favoured the presence of $P$. waltl, whereas the longer the hydroperiod, the lower the probability of occurrence of $P$. cultripes. Such negative tendency was caused by the fact that we detected $P$. cultripes only in six zacallones, the water bodies with longer hydroperiod (Figure 40).
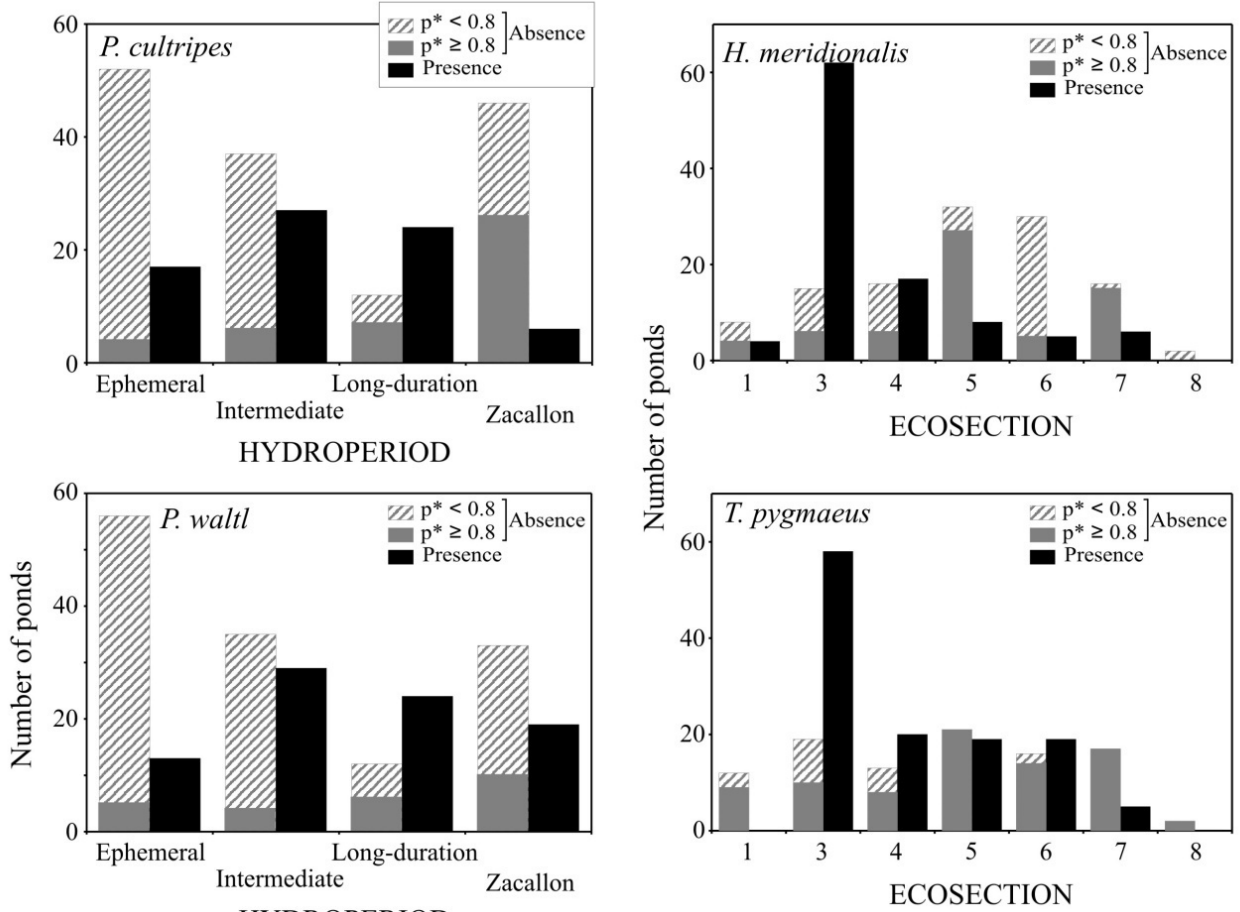

HYDROPERIOD

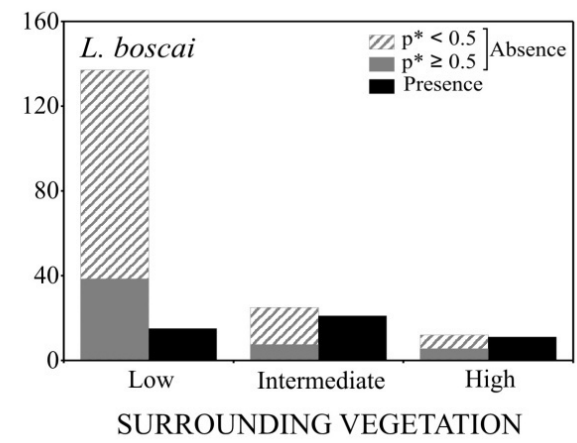

Figure 40. Number of observed presences and absences in each category of habitat factors with high relative importance. Data is shown both for all absences and for absences with high reliability $\left(\mathrm{p}^{*} \geq\right.$ $0.8)$. 
Table 31. Relative importance and model-averaged estimates of parameters obtained for habitat selection models of anuran species. The unconditional standard error of each parameter (S.E.) is also shown.

\begin{tabular}{|c|c|c|c|c|}
\hline & \multicolumn{2}{|r|}{ P. cultripes } & \multicolumn{2}{|c|}{ D. galganoi } \\
\hline & $\begin{array}{l}\text { Relat. } \\
\text { import. }\end{array}$ & $\begin{array}{l}\text { Av. parameter } \\
\quad( \pm \text { S.E. })\end{array}$ & $\begin{array}{l}\text { Relat. } \\
\text { import. }\end{array}$ & $\begin{array}{l}\text { Av. parameter } \\
( \pm \text { S.E. })\end{array}$ \\
\hline (Intercept) & & $-0.661 \pm 0.232$ & & $-0.283 \pm 0.767$ \\
\hline Ecosection & & & & \\
\hline (code 3) & & $-0.269 \pm 1.519$ & & $0.220 \pm 5.759$ \\
\hline (code 4) & & $-0.619 \pm 1.542$ & & $0.116 \pm 5.768$ \\
\hline (code 5) & 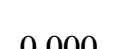 & $-3.157 \pm 5.746$ & 0014 & $-1.014 \pm 10.282$ \\
\hline (code 6) & 0.000 & $-2.454 \pm 4.080$ & 0.014 & $-16.700 \pm 5.617$ \\
\hline (code 7) & & $-2.866 \pm 5.621$ & & $-16.691 \pm 5.620$ \\
\hline (code 8) & & $0.120 \pm 11.652$ & & NA \\
\hline Pond size & & & & \\
\hline Linear & 0.995 & $1.05 * 10^{-4} \pm 9.2 * 10^{-5}$ & & $6.35 * 10^{-5} \pm 5.4 * 10^{-5}$ \\
\hline Quadratic & 0.995 & $-1.06 * 10^{-9} \pm 0.001$ & 0.064 & $-4.59 * 10^{-10} \pm 0.026$ \\
\hline Hydroperiod & & & & \\
\hline (eph.-inter.) & & $-0.806 \pm 0.610$ & & $-0.330 \pm 1.330$ \\
\hline $\begin{array}{l}\text { (inter.- } \\
\text { long) }\end{array}$ & 0.994 & $-1.231 \pm 0.510$ & 0.059 & $0.111 \pm 1.508$ \\
\hline (long-zac.) & & $-0.518 \pm 0.004$ & & $-1.092 \pm 0.839$ \\
\hline Forest & 0.000 & $-2.441 \pm 0.919$ & 0.575 & $-2.669 \pm 1.483$ \\
\hline Scrub & 0.000 & $0.862 \pm 0.449$ & 0.575 & $-1.016 \pm 0.758$ \\
\hline Dunes & 0.000 & $-1.454 \pm 1.085$ & 0.486 & $2.700 \pm 11.237$ \\
\hline $\begin{array}{l}\text { Surrounding } \\
\text { vegetation }\end{array}$ & & & & \\
\hline (low-inter.) & & $0.034 \pm 0.471$ & & $0.430 \pm 0.705$ \\
\hline $\begin{array}{l}\text { (inter.- } \\
\text { high) }\end{array}$ & 0.000 & $-0.648 \pm 0.342$ & 0.024 & $-0.322 \pm 0.492$ \\
\hline $\begin{array}{l}\text { Distance to } \\
\text { marsh }\end{array}$ & 0.000 & $1.48 * 10^{-4} \pm 0.011$ & 0.018 & $9.63 * 10^{-5} \pm 0.049$ \\
\hline $\begin{array}{l}\text { Distance to } \\
\text { pond }\end{array}$ & 0.000 & $-0.002 \pm 0.014$ & 0.018 & $-0.002 \pm 0.074$ \\
\hline $\mathrm{N}$ ponds & 0.000 & $0.081 \pm 0.036$ & 0.048 & $0.067 \pm 0.050$ \\
\hline $\mathrm{N}$ large ponds & 0.000 & $0.220 \pm 0.199$ & 0.067 & $0.289 \pm 0.211$ \\
\hline
\end{tabular}


Table 31. (cont.)

\begin{tabular}{|c|c|c|c|c|}
\hline & \multicolumn{2}{|r|}{ H. meridionalis } & \multicolumn{2}{|r|}{ P.waltl } \\
\hline & $\begin{array}{l}\text { Relat. } \\
\text { import. }\end{array}$ & $\begin{array}{l}\text { Av. parameter } \\
\text { (士 S.E.) }\end{array}$ & $\begin{array}{l}\text { Relat. } \\
\text { import. }\end{array}$ & $\begin{array}{l}\text { Av. parameter } \\
\text { (士 S.E.) }\end{array}$ \\
\hline (Intercept) & 0.000 & $-0.501 \pm 2.603$ & & $0.182 \pm 0.164$ \\
\hline \multicolumn{5}{|l|}{ Ecosection } \\
\hline (code 3) & & $2.183 \pm 2.623$ & & $0.680 \pm 1.873$ \\
\hline (code 4) & & $0.817 \pm 2.636$ & & $-0.490 \pm 1.906$ \\
\hline (code 5) & 7000 & $-0.683 \pm 2.649$ & רח & $-0.147 \pm 1.904$ \\
\hline (code 6) & 1.000 & $-0.993 \pm 3.071$ & 0.002 & $0.043 \pm 1.937$ \\
\hline (code 7$)$ & & $-0.381 \pm 2.798$ & & $-0.280 \pm 2.014$ \\
\hline (code 8) & & $-14.962 \pm 2.403$ & & $1.095 \pm 10.503$ \\
\hline \multicolumn{5}{|l|}{ Pond size } \\
\hline Linear & $000 \Omega$ & $7.73 * 10^{-5} \pm 9.2 * 10^{-5}$ & 0400 & $4.04 * 10^{-5} \pm 6.4 * 10^{-5}$ \\
\hline Quadratic & 0.000 & $-8.33 * 10^{-10} \pm 0.009$ & 0.400 & $1.02 * 10^{-10} \pm 0.040$ \\
\hline \multicolumn{5}{|l|}{ Hydroperiod } \\
\hline (eph.-inter.) & & $0.277 \pm 0.314$ & & $0.563 \pm 0.335$ \\
\hline $\begin{array}{l}\text { (inter.- } \\
\text { long) }\end{array}$ & 0.000 & $-1.317 \pm 0.375$ & 0.431 & $-1.072 \pm 0.358$ \\
\hline (long-zac.) & & $-0.107 \pm 0.057$ & & $-0.110 \pm 0.229$ \\
\hline Forest & 0.000 & $-0.848 \pm 0.654$ & 0.019 & $-0.602 \pm 0.669$ \\
\hline Scrub & 0.000 & $1.784 \pm 0.425$ & 0.019 & $0.044 \pm 0.433$ \\
\hline Dunes & 0.000 & $-0.254 \pm 0.814$ & 0.040 & $-0.146 \pm 0.692$ \\
\hline \multicolumn{5}{|l|}{$\begin{array}{l}\text { Surrounding } \\
\text { vegetation }\end{array}$} \\
\hline (low-inter.) & & $1.382 \pm 0.762$ & & $0.149 \pm 0.355$ \\
\hline $\begin{array}{l}\text { (inter.- } \\
\text { high) }\end{array}$ & 0.000 & $-0.748 \pm 0.423$ & 0.007 & $-0.489 \pm 0.326$ \\
\hline $\begin{array}{l}\text { Distance to } \\
\text { marsh }\end{array}$ & 0.000 & $1.04 * 10^{-4} \pm 0.774$ & 0.019 & $2.48 * 10^{-4} \pm 0.010$ \\
\hline $\begin{array}{l}\text { Distance to } \\
\text { pond }\end{array}$ & 0.000 & $-1.89 * 10^{-4} \pm 1.214$ & 0.019 & $1.67 * 10^{-4} \pm 0.011$ \\
\hline $\mathrm{N}$ ponds & 0.000 & $-0.006 \pm 1.2 * 10^{-4}$ & 0.104 & $0.056 \pm 0.034$ \\
\hline $\mathrm{N}$ large ponds & 0.000 & $0.521 \pm 0.001$ & 0.094 & $0.359 \pm 0.174$ \\
\hline
\end{tabular}


Table 31. (cont.)

\begin{tabular}{|c|c|c|c|c|}
\hline & \multicolumn{2}{|r|}{ T.pygmaeus } & \multicolumn{2}{|r|}{ L. boscai } \\
\hline & $\begin{array}{l}\text { Relat. } \\
\text { import. }\end{array}$ & $\begin{array}{l}\text { Av. parameter } \\
\quad( \pm \text { S.E. })\end{array}$ & $\begin{array}{l}\text { Relat. } \\
\text { import. }\end{array}$ & $\begin{array}{l}\text { Av. parameter } \\
\quad( \pm \text { S.E. })\end{array}$ \\
\hline (Intercept) & & $13.276 \pm 6.506$ & & $-1.799 \pm 2.347$ \\
\hline Ecosection & & & & \\
\hline (code 3) & & $18.847 \pm 0.560$ & & $18.223 \pm 0.828$ \\
\hline (code 4) & & $18.117 \pm 0.632$ & & $18.109 \pm 0.900$ \\
\hline (code 5) & 0762 & $17.448 \pm 0.567$ & 0050 & $18.500 \pm 9.795$ \\
\hline (code 6) & 0.602 & $17.914 \pm 0.592$ & $0.0 \supset 8$ & $34.967 \pm 1.244$ \\
\hline (code 7) & & $16.348 \pm 1.437$ & & $15.704 \pm 7.768$ \\
\hline (code 8) & & $0.039 \pm 0.017$ & & NA \\
\hline Pond size & & & & \\
\hline Linear & 0.091 & $6.45^{*} 10^{-5} \pm 7.2 * 10^{-5}$ & 0.000 & $-6.61 * 10^{-5} \pm 1.5 * 10^{-}$ \\
\hline Quadratic & & $-6.84 * 10^{-10} \pm 0.017$ & & $0.137 \pm 0.064$ \\
\hline Hydroperiod & & & & \\
\hline (eph.-inter.) & & $0.019 \pm 0.308$ & & $-0.943 \pm 1.266$ \\
\hline $\begin{array}{l}\text { (inter.- } \\
\text { long) }\end{array}$ & 0.121 & $-1.386 \pm 0.348$ & 0.000 & $0.022 \pm 2.568$ \\
\hline (long-zac.) & & $0.634 \pm 0.098$ & & $-0.167 \pm 1.632$ \\
\hline Forest & 0.000 & $-0.126 \pm 0.600$ & 0.483 & $-2.245 \pm 3.933$ \\
\hline Scrub & 0.000 & $1.469 \pm 0.444$ & 0.483 & $2.488 \pm 1.399$ \\
\hline Dunes & 0.000 & $0.796 \pm 0.755$ & 0.483 & $10.151 \pm 19.736$ \\
\hline $\begin{array}{l}\text { Surrounding } \\
\text { vegetation }\end{array}$ & & & & \\
\hline (low-inter.) & & $0.859 \pm 0.330$ & & $0.224 \pm 0.671$ \\
\hline $\begin{array}{l}\text { (inter.- } \\
\text { high) }\end{array}$ & 0.108 & $-0.692 \pm 0.122$ & 0.455 & $-0.115 \pm 0.347$ \\
\hline $\begin{array}{l}\text { Distance to } \\
\text { marsh }\end{array}$ & 0.105 & $3.72 * 10^{-4} \pm 0.575$ & 0.380 & $0.043 \pm 1.080$ \\
\hline $\begin{array}{l}\text { Distance to } \\
\text { pond }\end{array}$ & 0.105 & $-0.002 \pm 0.773$ & 0.380 & $-0.081 \pm 1.282$ \\
\hline $\mathrm{N}$ ponds & 0.096 & $-0.004 \pm 1.3 * 10^{-4}$ & 0.376 & $-0.834 \pm 0.000$ \\
\hline $\mathrm{N}$ large ponds & 0.096 & $0.252 \pm 0.001$ & 0.376 & $1.234 \pm 0.005$ \\
\hline
\end{tabular}


Models related with the "terrestrial habitat hypothesis" obtained the greatest support in the case of D. galganoi (Appendix). The global model of the "patchy population hypothesis" and the global model of the "terrestrial habitat hypothesis" obtained a similar high support in the case of $L$. boscai (Appendix). The presence of D. galganoi was negatively associated with percentage of forest and scrub habitat in the surroundings, whereas it showed a positive relationship with the percentage of dune habitat (Table 31). A similar pattern was observed for $L$. boscai, except for the fact that the percentage of scrub was positively associated with species presence. The presence of $L$. boscai was also positively associated with the number of ponds persisting in dry years and with the distance to the marshes; but negatively associated with the number of ponds persisting in wet years and with the distance to the ponds. Intermediate values of surrounding vegetation favoured the presence of $L$. boscai (Figure 40).

Models ranked as best showed a useful value of $\mathrm{AUC}(>0.80)$ in the case of anurans and lower values for urodele species (Appendix). In general, the low values of $\mathrm{D}^{2}$ and Adj. $\mathrm{D}^{2}(<0.25$ in all the models and species) evidenced that the models explained a low proportion of the variability in the data.

\section{Discussion}

This study evidences a wide variability in the reliability of absence data when the number of surveys or its timing (months of sampling visits) is not the same for all ponds. So, for any given species, we should not assume all the non-detections as valid absences but, instead, we should question its reliability. We neither should assume that the reliability of all non-detection records is the same. Although absence uncertainty may pose a serious problem in any distribution model (Lobo 2008), it should be especially taken into account when the detectability of a species is low and changes over time. In particular, when the simultaneous survey of all locations is not feasible, temporal variation in detectability will source large differences in reliability among absence records, as in the present study. Under this scenario, temporal replication of sampling visits is critical in order to improve the reliability of absence records as we would increase the detection probability of a species (replication within a season) and minimize false absences due to temporal turnover in community composition (replication among seasons). Skelly et al. (2003) previously stressed the relevance of temporal replication among breeding seasons to detect all species of a population. Accounting for absence reliability is of special relevance in distribution models of scarce or rare species, which use to show low detectability (Gómez-Rodríguez et al., Chapter 3 section 2 this thesis). In this study, species with large occupancy (i.e. T. pygmaeus and $H$. meridionalis, following Díaz-Paniagua et al. 2006) or of long larval period of time (i.e. Pelobates cultripes) showed more reliable absence data than less common species (i.e. L. boscai or D. galganoi, following DíazPaniagua et al. 2006).

For most species, the habitat model ranked as "best" evidenced low explanatory ability although they provide "a reasonable discrimination ability appropriate for many uses" based on its predictive ability (following Pearce and Ferrier 2000). Low explanatory ability is expected in binomial models where probability values ranging from 0 to 1 (predictive values) are compared to a dichotomic variable that just takes value 1 (observed presence) or value 0 (observed absence). Notwithstanding, we could have probably increased model 
performance if we had included additional predictors that may condition the probability of occupancy of a species, such as biotic interactions (Duellman and Trueb 1986), or modelled larval density rather than species occurrence (see Van Buskirk 2005). We should also contemplate that species occupancy, measured as "evidence of breeding attempt", may be an inadequate indicator of habitat suitability in amphibian distribution models. Models of habitat selection usually assume that suitable habitats will be occupied and unsuitable habitats will be unoccupied but the reality may not be so (Pulliam 1996). In the study area, we may expect the absence of a species from suitable habitats due to environmental stochasticity, a characteristic of Mediterranean ecosystems (Blondel and Aronson 1999), or because the large number of breeding sites (Díaz-Paniagua et al. 2006; Gómez-Rodríguez et al. 2008) might result in an unsaturated ecosystem. Unsuitable habitats may be occupied when a species does not actually choose the best available site (Pulliam 1996). In fact, lack of habitat selection is expected in many pond-breeding amphibians which, as typical r-strategists, do not select specific habitats for breeding and, instead, reproduce in a wide number of different ponds in order to increase the probability of reproductive success. So, assuming that habitat selection of a species may be deficient, amphibian distribution models might improve if we monitor developmental stages indicative of breeding success (i.e. metamorphic individuals) to assess habitat suitability.

In this study, we observed a very low spatial autocorrelation in the distribution of species and, for that reason, we built distribution models on the basis that the probability of a species occurring in a pond was determined purely by its environmental characteristics. However, it should be noted that we did not sample all ponds and hence our study lacked data to asseverate that assemblage composition was not just a function of distance to an inhabited habitat patch, as spatial autocorrelation theory states (see Legendre 1993). So, spatial autocorrelation may still be a plausible major driver of biogeographical patterns in the study area and we should be aware that the design of this study is not adequate to confirm (or reject) that biological hypothesis. In this study, we only aimed to control for the statistical bias that spatial autocorrelation may pose.

The ecological interpretation of the results presented in this study should be taken with caution given the low variance explained, although it can be useful to partially understand the idiosyncrasy of the system. We did not a find a best supported hypothesis valid for all the species. So, our results agree with previous studies that have reported species-specific responses to habitat factors (Beja and Alcazar 2003; Weyrauch and Grubb 2004; Pearl et al. 2005; Van Buskirk 2005). This result stresses the importance of multi-scale approaches for modelling amphibian distributions since both the characteristics of the pond and the landscape (terrestrial and surrounding aquatic habitat) were important for different species. We attribute the low support for the hypothesis of patchy population to an over-simplistic characterization of pond connectivity, for it does not correspond to the specific years of study, and to lack on information about the actual occupancy of surrounding ponds or their suitability as habitat for particular species. With this respect, Denoël and Lehmann (2006) state that the quality of surrounding breeding patches is more important than just the number of available ponds in determining the abundance of Triturus helveticus (Razoumowsky, 1789) in a particular pond. In the study area, assessing the assemblage composition of all surroundings ponds or the real connectivity each year rather than the potential one 
would have been highly costly and, thereby, we could not provide this information for habitat models.

Hyla meridionalis and T. pygmaeus showed a high support for the ecosection hypothesis since they occurred in almost every pond in the "wet stabilized sands at higher elevation", evidencing so that the habitat conditions in that ecosection were highly favourable independently of the characteristics of each particular pond. The occurrence of these species might be associated to the large availability of water bodies in this ecosection, the one with the largest percentage of flooded surface within Doñana Biological Reserve (GómezRodríguez et al. Chapter 2 section 3 this thesis). Pleurodeles waltl and P. cultripes showed a high support for the aquatic hypothesis. Previous studies reported that these species require ponds with long hydroperiod for breeding success (DíazPaniagua et al. 2005) while we observed a different response. We attribute this unexpected result to the large uncertainty in the absence data recorded in ephemeral ponds, which led to the "practical" dismissal of most observed absences in those ponds. So, the larger proportion of presences over reliable absences in those ponds may be a direct consequence of the large uncertainty of absence data rather than an ecological process. Terrestrial characteristics were the most important predictors of the occurrence of $D$. galganoi and $L$. boscai although the shape of the response was contrary to expected in the case of forest cover and, for L. boscai, also in the case of dune cover. This result suggests that the role of terrestrial habitat for these species may not be related to terrestrial usage by adults (i.e. movements between ponds or terrestrial residence), as previous authors proposed (see Gibbons 2003), but may be an indirect predictor of the hydrological dynamics of this particular area. For instance, the ecosection between dunes and stabilized sands shows the largest density and variability of temporary ponds in the study area (Díaz-Paniagua et al. 2006) and thereby dune cover in the surroundings may be interpreted as a surrogate for habitat availability. Lissotriton boscai, a species reported to breed in ponds of intermediate hydroperiod in the area (Díaz-Paniagua et al. 2005), also showed high support for the patchy population hypothesis. The habitat requirements of this species could be interpreted in accordance to Denoël and Lehmann (2006), who reported that, for a different Triturus species (T. helveticus), the quality of surrounding breeding habitats was of more importance than just the number of available ponds. So, the occurrence of this species would be related to the formation of ponds of intermediate/long hydroperiod in the surroundings but not to the formation of ephemeral ones that only flood in wet years. Besides, intermediate values of surrounding aquatic vegetation favoured the occurrence of $L$. boscai, probably because they enable pond access while offering a refugee for adults during their terrestrial stage. Notwithstanding we should also take into account that surrounding vegetation also gives shade to the pond and, in a different area, the highest abundance of Triturus spp. embryos occurred in ponds with intermediate values of shade (Sztatecsny et al. 2004).

As a conclusion, distribution models of amphibians in Mediterranean temporary ponds should account for the reliability of absence data since it might be low for many cases, in particular for rare or scarce species. Notwithstanding, we should not expect high performance of distribution models in these stochastically and dynamically changing environments. Distribution models are static in nature (Guisan and Zimmermann 2000) and hence prediction errors are inevitable if there is temporal variability in the habitat 
relationships (Fielding 2002), as happens in the study system (Gómez-Rodríguez et al. in press). In particular, in Doñana National Park, the high values of occupancy for most species, the low species detectability (Gómez-Rodríguez et al., Chapter 3 section 2 this thesis) and high temporal turnover (Gómez-Rodríguez et al, Chapter 3 section 1 this thesis) suggest the possibility that habitat segregation may not be a major driver when considering the species assemblage over a moderate-long time frame. So, it could be possible that all species occur in all the temporary ponds over a moderate time frame. This would be favoured by the dynamically nature of the environment and the spatial robustness of the system of temporary ponds, which makes that a pond might be good for several different species over time and be also accessible to individuals.

Comments This section was done in collaboration with Antoine Guisan, Javier Bustamante and Carmen Díaz-Paniagua. Most of the analyses were conducted during a short stay in the Spatial Ecology Group (University of Lausanne, Switzerland) under the supervision of Dr. Guisan. 


\section{References}

Austin MP 2002. Ecol Model 157, 101-118.

Babbitt KJ et al. 2006. Can J Zool 84, 510519.

Beja P, Alcazar R 2003. Biol Conserv 114, 317-326.

Blondel J, Aronson J 1999. Biology and Wildlife of the Mediterranean Region. Oxford University Press, Oxford, New York.

Burne MR, Griffin CR 2005. Wetlands Ecol Manag 13, 247-259.

Burnham KP, Anderson DR 2002. Model Selection and Multimodel Inference. A Practical Information-Theoretic Approach. Springer.

Denoël M, Lehmann A 2006. Biol Conserv 130, 495-504.

Díaz-Paniagua C 1982. Bull Soc Herp Fr 22, 24-26.

Díaz-Paniagua C et al. 2005. Los Anfibios de Doñana. Organismo Autónomo de Parques Nacionales. Ministerio de Medio Ambiente, Madrid.

Díaz-Paniagua C et al. 2006. Rev Esp Herpetol 20, 17-30.

Dormann CF 2007. Global Ecol Biogeogr $16,129-138$.

Dormann CF et al. 2007. Ecography 30, 609-628.

Duellman WE, Trueb L 1986. Biology of Amphibians. McGraw-Hill Book Company

Fielding AH 2002. What are the appropriate characteristics of an accuracy measure? In: Scott, M., et al. (Eds.), Predicting Plant and Animal Occurrences: Issues of Accuracy and Scale. Island Press.

Fortuna M et al. 2006. $P$ Roy Soc Lond $B$ Bio 273, 1429-1434.

Gibbons JW 2003. Wetlands 23, 630-635.

Gómez-Rodríguez C et al. 2008. Herpetol J 18, 103-113.

Gómez-Rodríguez C et al. In press. Aquat Ecol. Online first.
$\mathrm{Gu}$ WD, Swihart RK 2004. Biol Conserv 116, 195-203.

Guisan A, Zimmermann NE 2000. Ecol Model 135, 147-186.

Hanski I 1998. Nature 396, 41-49.

Harrison S 1991. Biol J Linn Soc 42, 73-88.

Hastie TJ, Tibshirani RJ 1990. Generalized Additive Models. Chapman and Hall.

Heyer WR et al. 1994. Measuring and Monitoring Biological Diversity. Standard Methods for Amphibians. Smithsonian Institution Press, Washington \& London.

Jakob C et al. 2003. Hydrobiologia 499, 5161.

Junta de Andalucía 2003. Ortofotografía Digital de Andalucía.

Legendre P 1993. Ecology 74, 1659-1673.

Lobo JM 2008. Biodivers Inform 5, 14-19.

MacKenzie DI 2005. J Wildl Manage 69, 849-860.

MacKenzie DI 2006. J Wildl Manage 70, 367-374.

MacKenzie DI et al. 2002. Ecology 83, 2248-2255.

MacKenzie DI et al. 2006. Occupancy Estimation and Modeling. Inferring Patterns and Dynamics of Species Occurrence. Elsevier.

Marsh DM et al. 1999. J Anim Ecol 68, 804814.

Marsh DM, Trenham PC 2001. Conserv Biol $15,40-49$.

Maurer BA 2002. Predicting Distribution and Abundance. Thinking Within and Between Scales. In: Scott, J.M., et al. (Eds.), Predicting Species Occurrences. Issues of Accuracy and Scale. Island Press, Covello, CA.

Mazerolle MJ 2006. Amphibia-Reptilia 27, 169-180.

Mazerolle MJ et al. 2007. J Herpetol 41, 672-689.

Mazerolle MJ et al. 2005. Ecol Appl 15, 824834. 
McCullagh P, Nelder JA 1989. Generalized Linear Models. Chapman and Hall, London.

Montes C et al. 1998. Reconocimiento Biofísico de Espacios Naturales Protegidos. Doñana: Una Aproximación Ecosistémica. Junta de Andalucía. Consejería de Medio Ambiente.

Otto CRV et al. 2007. Wetlands 27, 261269.

Ovaskainen O, Hanski I 2004. Am Nat 164, 364-377.

Pearce J, Ferrier S 2000. Ecol Model 133, 225-245.

Pearl CA et al. 2005. Wetlands 25, 76-88.

Petranka JW, Holbrook CT 2006. Restor Ecol 14, 404-411.

Petranka JW et al. 2004. Ecol Appl 14, 1065-1078.

Piha H et al. 2007. Global Change Biol 13, 300-311.

Pinder AW et al. 1992. Estivation and Hibernation. In: Feder, M.E., et al. (Eds.), Environmental Physiology of the Amphibians. University of Chicago Press, Chicago and London.

Pulliam HR 1996. Sources and Sinks: Empirical Evidence and Population Consequences. In: Rhodes, O.E., et al. (Eds.), Population Dynamics in Ecological Space and Time. University of Chicago Press, pp. 45-74.

Richter-Boix A et al. 2006. AmphibiaReptilia 27, 549-559.
Richter-Boix A et al. 2007. J Anim Ecol 76, 607-618.

Rittenhouse TAG, Semlitsch RD 2007. Wetlands 27, 153-161.

Rivas-Martínez S et al. 1980. Lazaroa 2, 5189.

Rosenzweig ML 1995. Species Diversity in Space and Time. Cambridge University Press.

Semlitsch RD, Bodie JR 1998. Conserv Biol 12, 1129-1133.

Siljeström PA et al. 1994. J Arid Environ 26, 315-323.

Skelly DK et al. 2003. Conserv Biol 17, 744751.

Smith MA, Green DM 2005. Ecography 28, 110-128.

Snodgrass JW et al. 2000. Conserv Biol 14, 414-419.

Sztatecsny M et al. 2004. Herpetol J 14, 8997.

Tews J et al. 2004. J. Biogeogr. 31, 79-92.

Van Buskirk J 2005. Ecology 86, 19361947.

Vaughan IP, Ormerod SJ 2003. J Appl Ecol 17, 1601-1611.

Wellborn GA et al. 1996. Annu Rev Ecol Evol $S$ 27, 337-363.

Werner EE et al. 2007. Oikos 116, 16971712.

Weyrauch SL, Grubb Jr TC. 2004. Biol Conserv 115, 443-450. 
Appendix. Model selection and model evaluation results for each species. $\mathrm{k}$ is the number of parameters. $\mathrm{AIC}$ is the difference between the model with the lowest AIC and the given model. Akaike $\omega$ is the model Akaike's weight. $D^{2}$ and Adj. $D^{2}$ are the explained deviance and adjusted explained deviance, respectively. The number of cases used in model construction (n) as well as number of valid cases used to compute the AUC are specified.

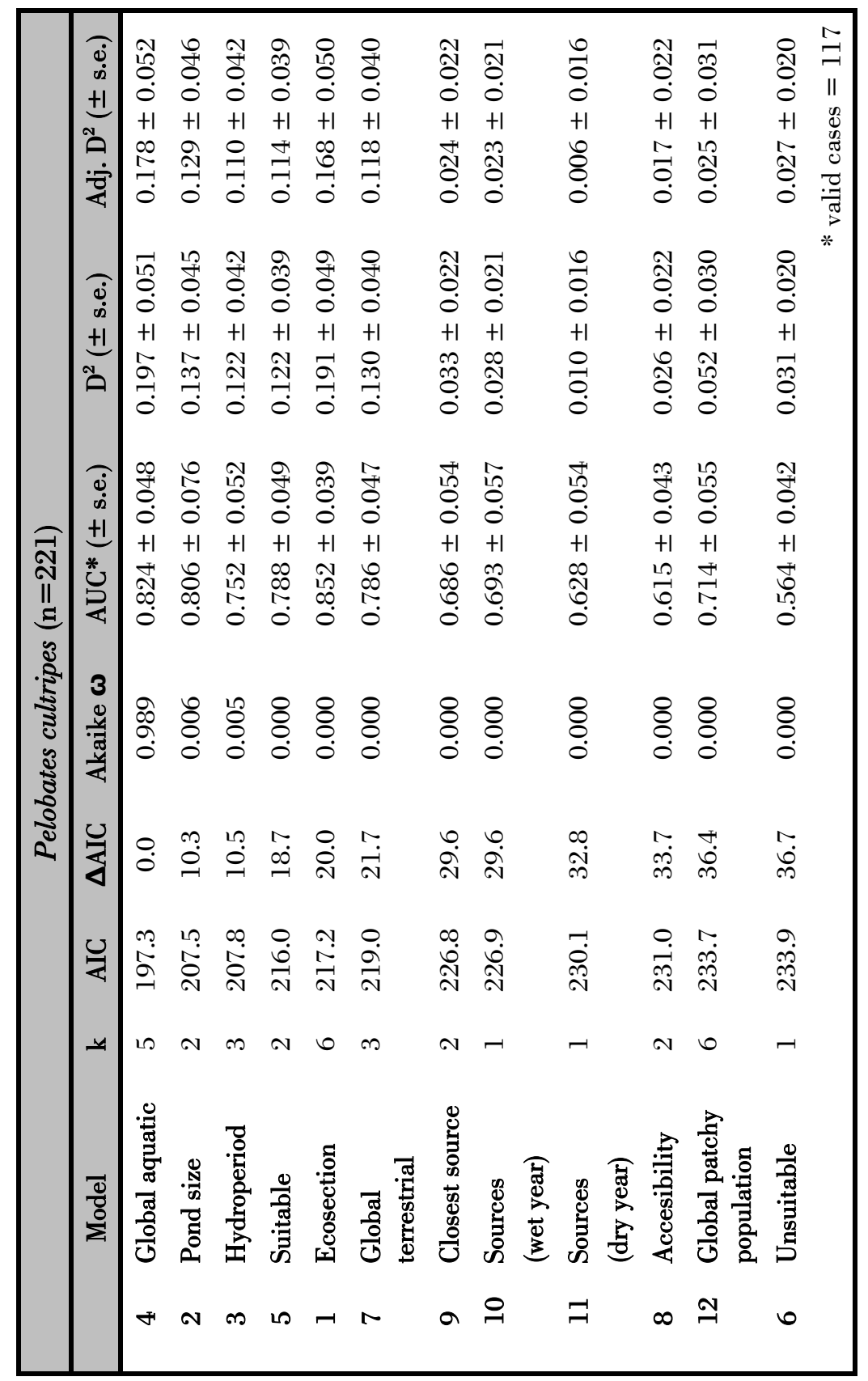


Appendix. (cont.)

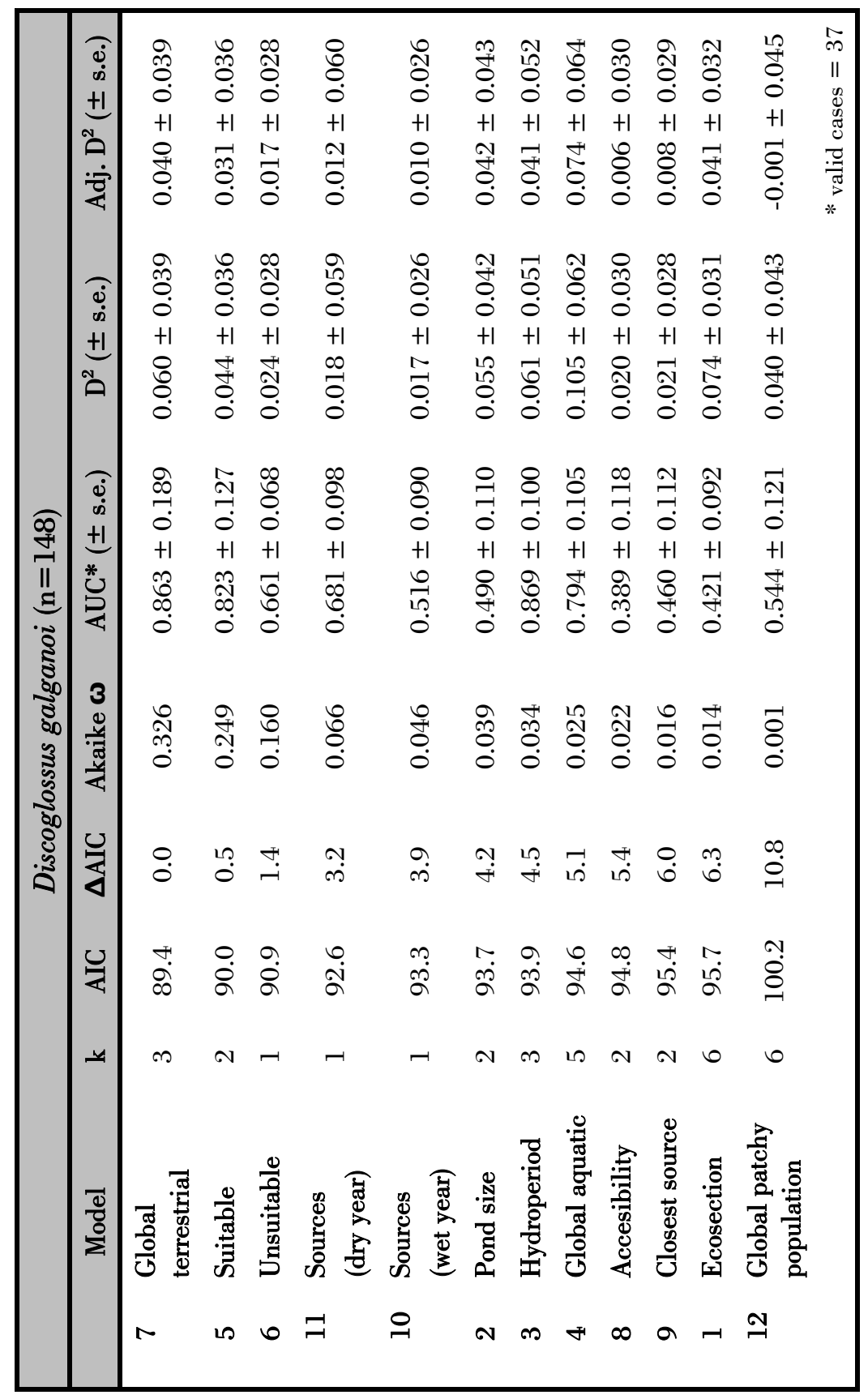


Appendix. (cont.)

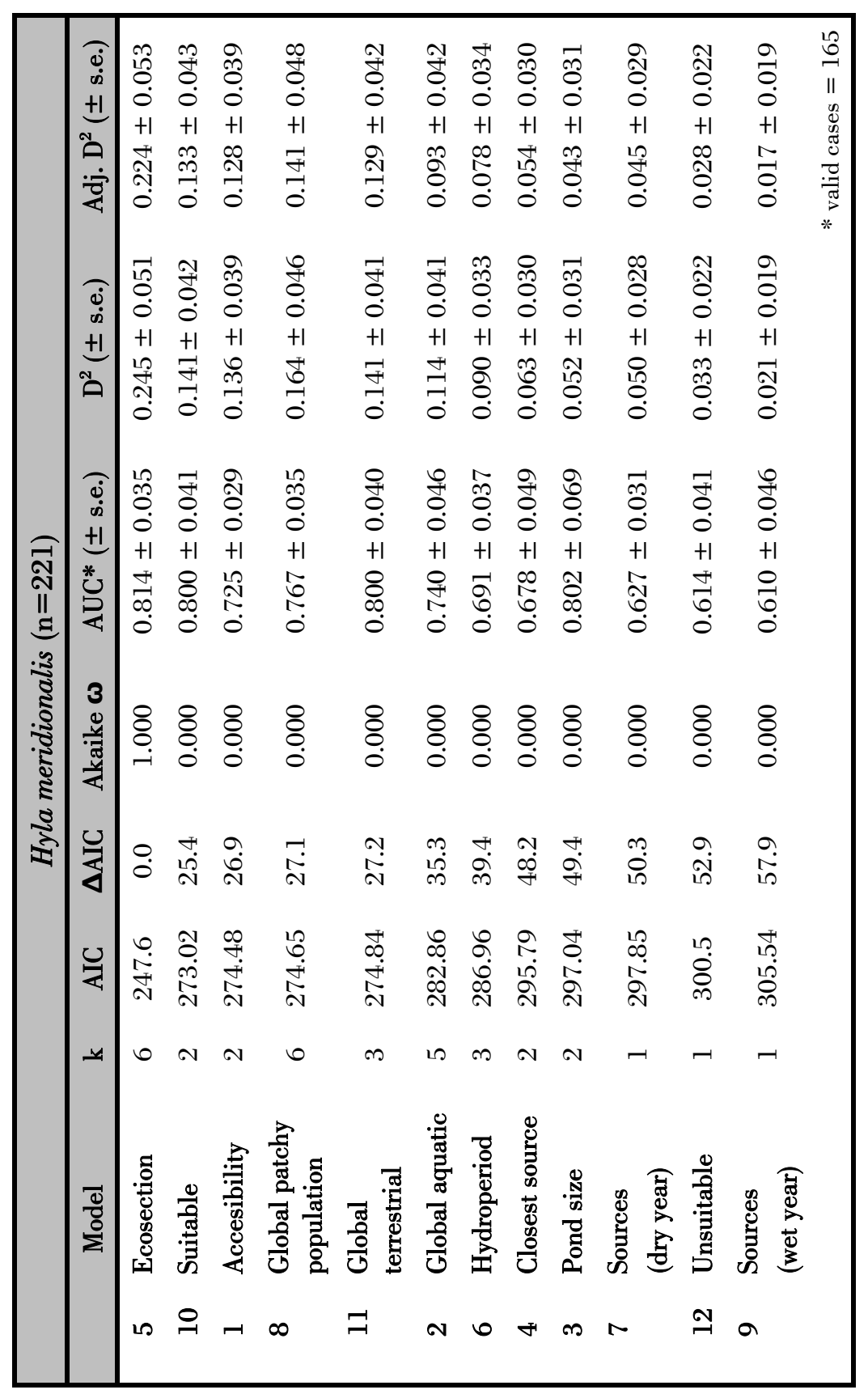


Appendix. (cont.)

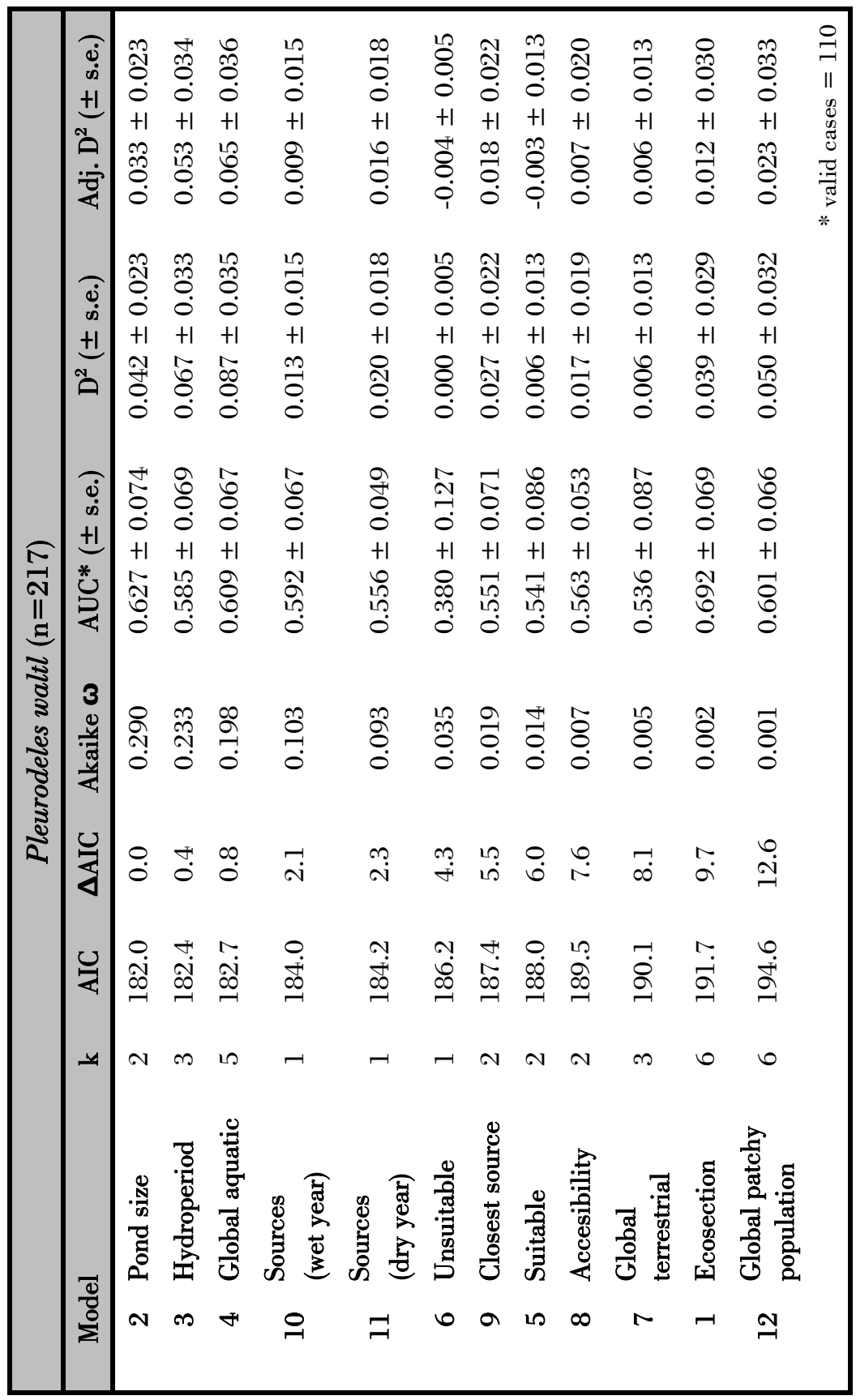


Appendix. (cont.)

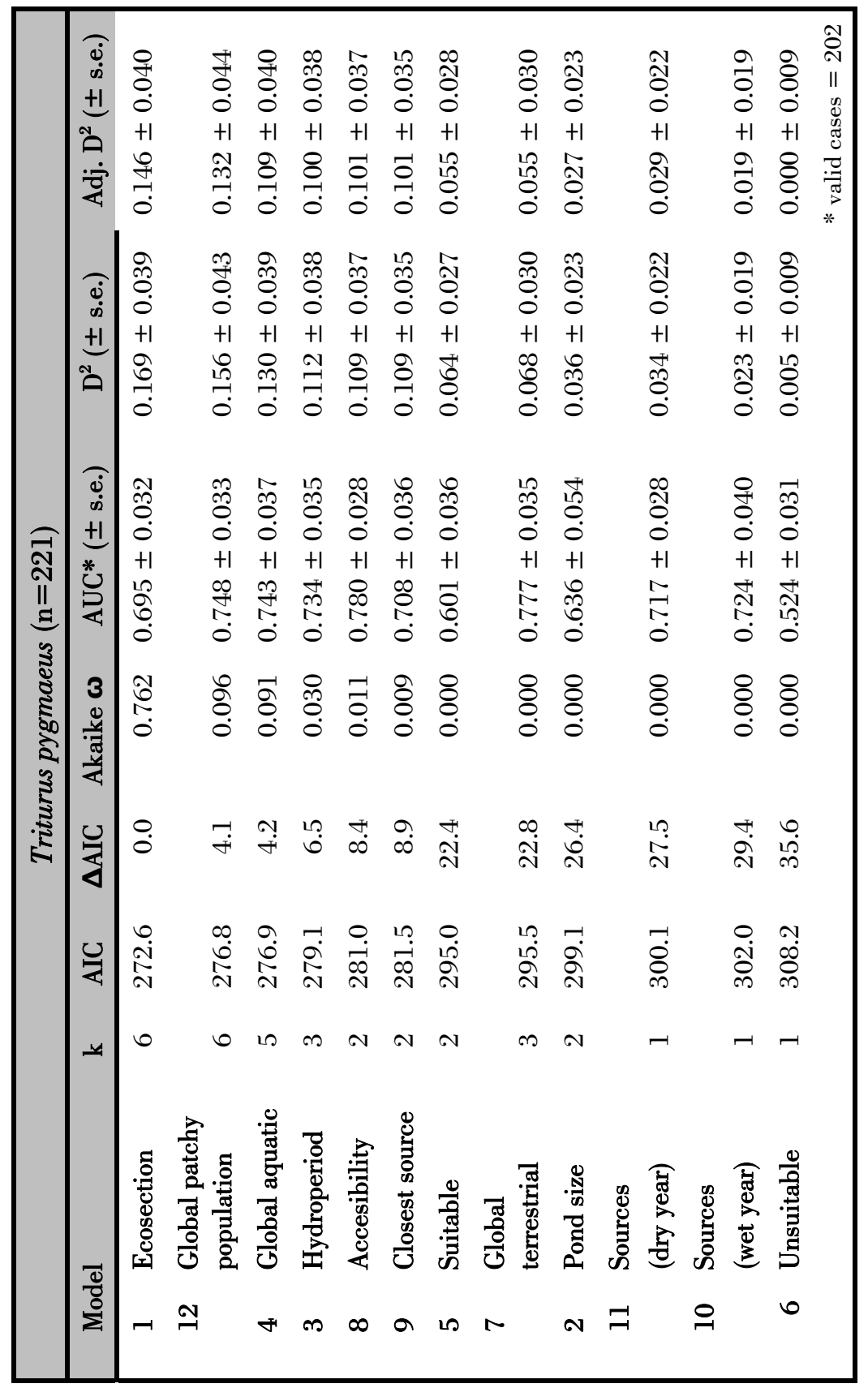


Appendix. (cont.)

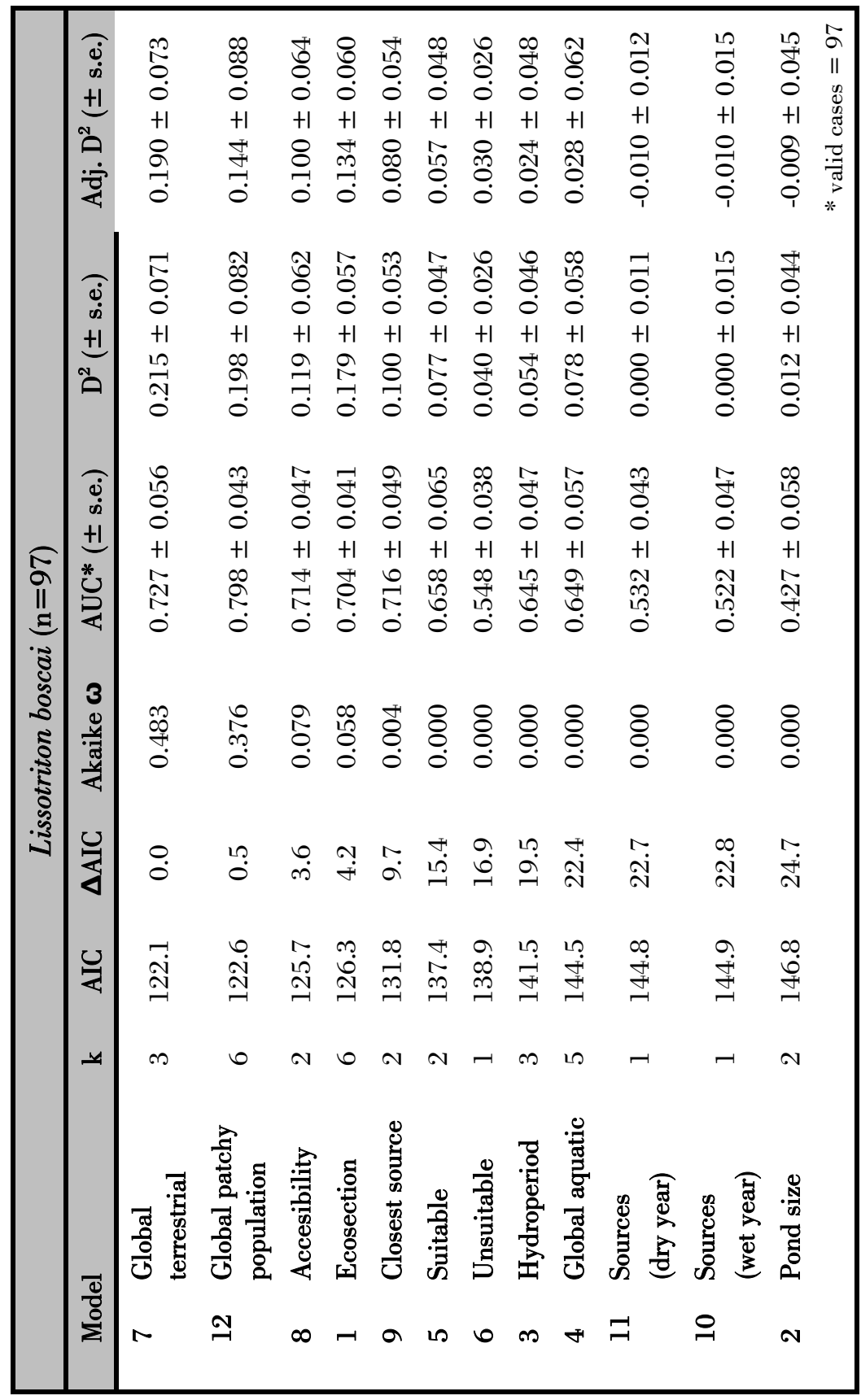



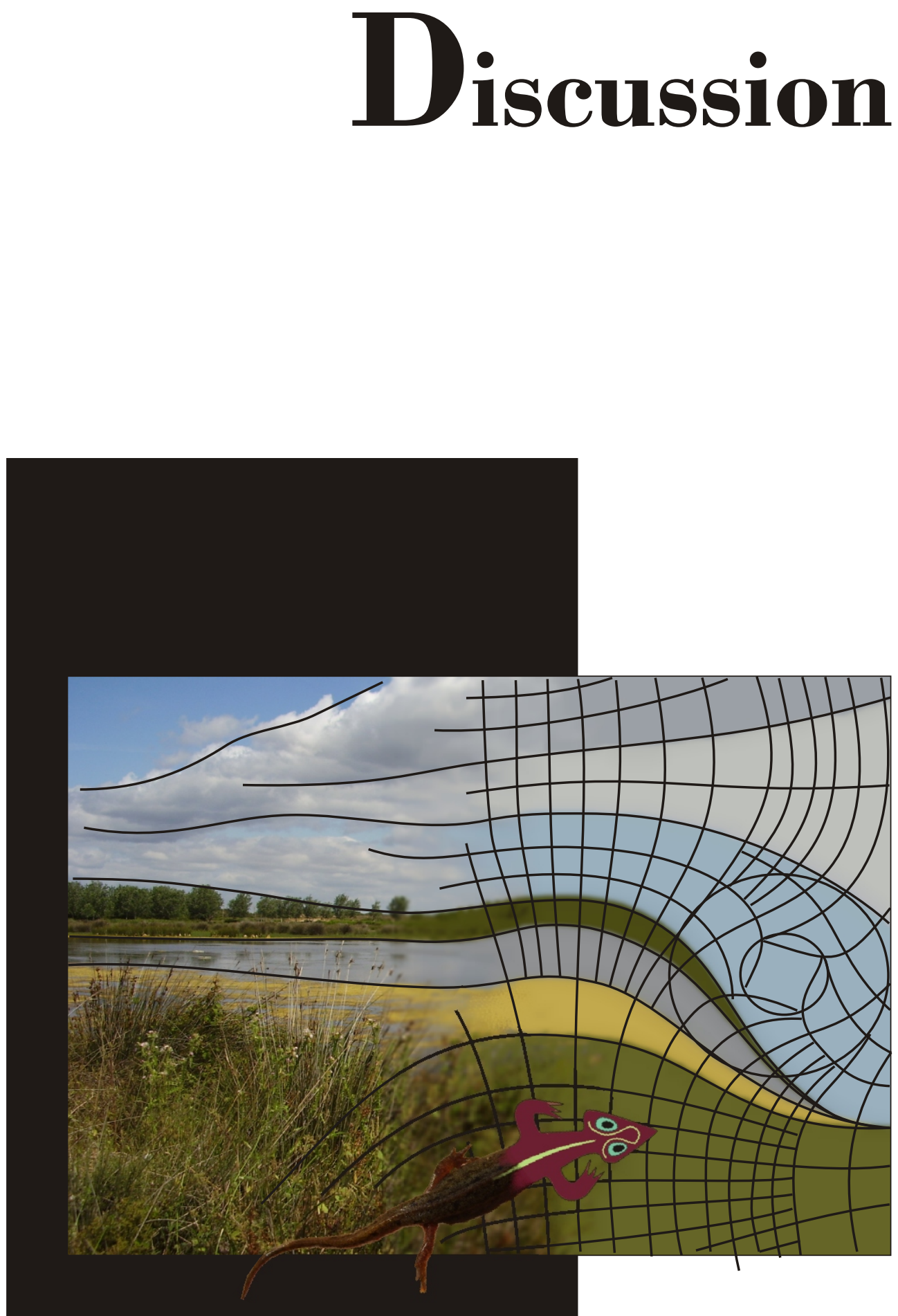


\section{Application of new techno- logies to the assessment of amphibian breeding habitats}

As an initial step in the study of amphibian habitats in Doñana National Park, I required accurate data about its location and extent. Therefore, I developed two different methodologies in order to map amphibian breeding habitats using new technologies (remote-sensing imagery). I had little previous information available because remote sensing has been broadly applied to map large wetlands (see Ozesmi and Bauer 2002 for a review) but its application on seasonal flooded systems has been scarce (Bryant 1999; Roshier and Rumbachs 2004; Lacaux et al. 2007). An additional difficulty I met was the small size of the studied ponds, many of them below pixel size of most available remote sensing data, mainly satellite imagery.

I assessed the spatial distribution, extent and temporal variability of temporary ponds using both a high-resolution image (AHS) and medium resolution imagery (Landsat data). The AHS image provided a high spatial resolution cartography (pixel size $=$ $5 \times 5 \mathrm{~m}$ ) of temporary ponds at a time of a large flooding event (April 2004) in Doñana National Park. I used Landsat data to reconstruct the retrospective spatiotemporal dynamics of the system of temporary ponds in Doñana Biological Reserve along a 23-year period.

High-resolution remote-sensing data (AHS image). I mapped 3335 water bodies in the aeolian system of Doñana National Park. In this area, previous inventories (Bravo and Montes 1993; Montes et al. 1998; Junta de Andalucía 2000) had indentified a far small number of ponds: 308, 307 or 250, respectively. The field-assessed mapping of such a large amount of temporary ponds would have been highly time consuming. I also evaluated the utility of high-resolution remote-sensing data as an alternative tool to field data in studies of species-environment relationships. The obtained results evidenced that, at assemblage level, high resolution remote sensing data could be used to identify ponds with high species richness by means of identifying ponds with high habitat heterogeneity. However, at species level, it presented limited utility as predictor of species distributions when used alone and hardly improved on the amphibian distribution models built from field data. So I can conclude that, in the study area, high resolution remote sensing data does not provide robust data to identify potential breeding sites for particular species. 
Medium-resolution remote-sensing data (Landsat imagery). I used the pond cartography obtained with the AHS image as the basis for the study of the temporal dynamics of the system of temporary ponds with Landsat data. I limited the spatial coverage of this study to the Doñana Biological Reserve, where I had identified 883 temporary ponds with the AHS image. Using Landsat imagery, I detected a smaller number of ponds (864 ponds) although many of them were smaller than the imagery pixel size $(30$ x $30 \mathrm{~m})$. Temporal resolution (16-day repeat cycle) and temporal coverage (23-years) of Landsat imagery allowed me to build "a map of the flooding dynamics" that revealed the large fluctuations in the size and duration of these ponds as well as the hydrological trends in the study area. This study evidences the complex hydrology of the study area previously reported in more temporally restricted studies (García-Novo et al. 1991), the large contribution of groundwater influxes to the hydrological regime of the these ponds (Serrano et al. 2006) and also gives additional support to the ecosection zonation that Montes et al. (1998) proposed. It is of special relevance that I observed a significant inter-annual tendency to shorter hydroperiods in most ecosections whereas I only detected a tendency to smaller flooded surface in the drier ecosections. A plausible driver of hydroperiod reduction is the overexploitation of the aquifer, which is causing a progressive lowering of the phreatic level (Suso and Llamas 1990), a decrease in aquifer recharge rates for the same rainfall (Trick and Custodio 2004) and a damage to ponds hydrology (Serrano and Zunzunegui 2008), such as a decrease in the frequency of appearance of temporary ponds (Custodio 2002). Since pumping is concentrated in the more permeable layers of the lower aquifer, it is supposed to affect a large area through a small lowering of the water table (Trick and Custodio 2004). This would explain that a trend that had been already reported for some particular ponds (Serrano and Zunzunegui 2008), is general for the whole study area, as it was earlier predicted (Manzano and Custodio 2006) and this study evidences. From an ecological perspective, a progressively wetland desiccation is critical for amphibian communities, as revealed in the amphibian populations decline reported for Yellowstone National Park (McMenamin et al. 2008). In particular, in the study area, the reduction of pond annual hydroperiod may severely compromise the medium term population stability of pond-breeder species with an aquatic phase requiring a long period of time to complete metamorphosis, such as Pelobates cultripes (Cuvier, 1829).

The most important advantage of using remote sensing data in wetland studies is that it can produce spatially explicit information of large areas that may not be accomplished by field sampling techniques (Shuman and Ambrose 2003). Therefore, the remote sensing assessment of potential habitats of interest achieves special relevance in large areas with high density of water bodies, such as Doñana National Park (Díaz-Paniagua et al. 2006), where exhaustive survey and monitoring programs cannot be conducted and sampling effort has to be optimized. In addition, information on the temporal dynamics, provided by Landsat imagery, is extremely valuable in this highly unpredictable and fluctuating ecosystem. It contributes to the understanding of its flooding dynamics and it will highly improve the management strategies of its associated species. 


\section{Ecosystem variability and uncertainty}

As evidenced with remote sensing data, the system of temporary ponds may consist on more than 3000 water bodies in wet years, thus providing a large number of available breeding sites for amphibians. In addition to the abundance of potential habitats, another important characteristic of this ecosystem is its remarkable environmental variability across space. Thereby, the suitability of these ponds for amphibian breeding probably relies upon the wide environmental gradient that they encompass as a whole. As a case in point, I evidenced that some habitat characteristics (i.e conductivity) vary over the entire range reported for Mediterranean temporary ponds (Zacharias et al. 2007). Ecosystem heterogeneity favours the diversity of associated species as it provides more niches and environmental resources to be exploited (see Tews et al. 2004 for a review).

The ecological relevance of this temporary ponds system is enhanced by its temporal variability, since it increases habitat heterogeneity over time. Unpredictability and variability, two of the main characteristics of Mediterranean ecosystems (Blondel and Aronson 1999), are also key attributes of the temporal dynamics of this system. I observed large inter-annual variation in meteorological conditions and, consequently, in hydrological behaviour and pond characteristics (i.e. water-chemistry parameters). Rainfall input and pattern was determinant for the formation and duration of ponds and hence was crucial for the existence of amphibian breeding habitats. For instance, low rainfall input hampered the flooding of temporary ponds in 20042005 while delayed rainfall input in 20052006, a year of scarce autumn rainfall, resulted in a large reduction of pond hydroperiod. Even if flooded, habitat suitability for amphibian breeding probably varied from year-to-year since I observed large inter-annual differences in habitat characteristics critical for pond-breeder species, such as flooded surface and pond hydroperiod (Wellborn et al. 1996; Spencer et al. 1999; Brooks 2000; Beja and Alcazar 2003; Semlitsch 2003) during a 23-year period. Other pond characteristic ssupposed to be relevant for annual diversity of amphibians (i.e. water-chemistry) also showed differences between years with different rainfall pattern (2002-2003 and 2005-2006) as well as intra-annual variation (in 2002-2003).

During the study period, not only pond characteristics showed temporal variation, but also the amphibian assemblages did. Amphibian assemblages exhibited high inter-annual variability in the number of species, species occurrence and relative abundance. The most drastic change was observed in 2004-2005, when temporary ponds did not flood and hence I did not detect amphibian species breeding. However, if I consider only "true" breeding seasons, when species did reproduce, temporal turnover at pond scale did not translate into large inter-annual faunal changes at regional scale, as evidenced in the fact that all species except Bufo bufo (Linnaeus, 1758) attempted breeding every reproductive season. So, neither the delay in pond filling nor the reduction in pond hydroperiod during 2005-06 prevented the breeding attempt of any recorded species in the study area. This result is in accordance with the stability expected in such a robust pond network, in which the ponds spatial arrangement allows individuals to find a suitable pond within their movement range even in unfavourable years, when many ponds do not flood (Fortuna et al. 2006). Although relevant, this result is not surprising since patterns of temporal turnover in amphibian communities have 
been previously documented in the literature (Trenham et al. 2003; Werner et al. 2007b) and, in particular, high temporal turnover is expected in non-stable habitats (Moreno and Halffter 2001), such as the study system.

The large inter-annual variability in environmental conditions and assemblage composition was also evidenced in habitat model outputs. Pond characteristics relevant for species richness or for the relative abundance of particular species were different between breeding seasons (2003 and 2006). So, in this highly dynamic system, the habitat model outputs are yearspecific. Piha et al. (2007) reported a similar result for Rana temporaria Linnaeus, 1758 in northern Europe when comparing years with different meteorological conditions. I attribute the observed variability in model outputs to the inter-annual differences in the range of variation (minimum value - maximum value) of most water-related characteristics. Theoretically, species responses to environmental factors should be bell-shaped (normally distributed) along the entire gradient (Austin 2002). So, species responses may differ from year to year when the annual range of environmental variation is only a fraction of the entire gradient and can cover different gradient regions depending on the year. For example, we may infer a positive response when the observed environmental variation lays within the smallest values of the gradient range and no response in the middle of the gradient, at the peak of the theoretical species-habitat curve. These year-specific responses were also evidenced in diversityhabitat relationships, when evaluating the role of temporally fixed and temporally variable habitat characteristics in explaining diversity patterns. Habitat variables that changed over time (i.e. hydroperiod or water-chemistry) had a significant unique contribution to explaining variation in assemblage composition in both 2003 and 2006, but they only explained richness gradients in 2006, the drier year. This result is partially in agreement with my expectations, since I hypothesized that temporally variable characteristics would be important drivers of annual diversity. However, I did not expect that habitat characteristics that do not change over time (i.e. pond location or terrestrial habitat) would be the only significant predictor of species richness in 2003. A plausible explanation might be that, in 2003, a hydrologically favourable year, there were not major environmental stresses precluding species breeding attempt in the study area. This fact would have favoured that most individuals in the surroundings of a pond attempted breeding independently of the particular characteristics of that year. The presence of those individuals in the surroundings would be related to more stable characteristics of the habitat (such as terrestrial cover) since it would highly depend on the probability of adult survival on the medium term. A remarkable conclusion is that, despite the fact that hydrology and water chemistry of ponds are supposed to be governed by landscape features (Batzer et al. 2004), we require both sets of variables to develop a realistic understanding of amphibian diversity patterns in the study area, both when considering data collected in particular years or over several years.

This large temporal variability, of both abiotic and biotic factors, makes any ecological assessment difficult. We may discriminate four major difficulties: i/ when shall we survey for habitat characteristics? ii/ which is the adequate temporal scale (annual vs. medium-term) for biotic inventories and habitat modelling? iii/ which is the adequate sampling effort to obtain a representative biotic sample and when should we survey? iv/ which is the best response variable for species-level 
biotic assessments (i.e. relative abundance or presence/absence data)?

When shall we survey for habitat characteristics? There was a remarkable independence of pond characteristics at different sampling dates. Such result should warn us that a pond description made from a single survey may not be representative of the pond characteristics at a different sampling date. Besides, temporal variability in absolute values of water-chemistry characteristics suggests that pond descriptions based solely on measures of central tendency (i.e. mean) over time may bias results and those ecological interpretations derived from them. In fact, mean values are only meaningful when attributes fluctuate around a particular value, whereas in temporary ponds, most water chemical characteristics decrease or increase with time, being also subjected to radical changes due to stochastic events (i.e. rainfall refilling). For all these reasons, it is necessary to conduct repeated sampling in order to describe both the characteristics of a pond at a single sampling date and its temporal variability.

Which is the adequate temporal scale (annual vs. medium-term) for biotic inventories and habitat modelling? Since amphibian assemblages changed from yearto-year, I required data from several breeding seasons to characterize the species assemblage associated to a given pond. Under temporal turnover in amphibian assemblage composition, as observed in this study, the absence of a species from a particular pond in a given year should be interpreted as a potential temporary event. With this basis, the medium-term would be the logical temporal scale for specieshabitat models aiming at conservation targets on this temporal scale. The alternative temporal scale, models of annual occurrence/diversity, presents two inconveniences. Firstly, models built from annual data are not transferable from yearto-year and hence are of limited utility to assess species ecological requirements. Secondly, dynamic characteristics vary within a season and values of the same variable measured in different dates within a given season do not correlate. So, we may obtain different model outputs depending on the date in which environmental characteristics are measured, not knowing $a$ priori which ones are more realistic. In that case, a partial solution would be to summarize all habitat characteristics that change with time in a few predictors by means of Principal Components Analysis, for example.

Which is the adequate sampling effort to obtain a representative biotic sample and when should we survey? In this study, I provide evidence of the temporal variability and uncertainty in the efficacy of amphibian surveys in a Mediterranean pond-breeding community, a finding that could be also applicable to different taxa occurring in similar habitats. As mentioned above, interannual turnover at pond scale is responsible for the inadequacy of surveys conducted only in one breeding season to characterize the species assemblage associated to a given pond. Therefore, we require temporal replication of surveys on different breeding seasons. In community-level studies, we should also conduct repeated surveys within a season since the efficiency of a single survey to detect all species breeding in a pond is very low. I observed that not all species overlapped in time, i.e. I did not detect all species in any single sampling occasion, and the single-visit probability of detection was moderate or low for many of them in most sampling occasions. In species-level occupancy studies, a single- 
survey would be enough if it is timed when the probability of detecting a species (when present) is perfect. However, in this ecosystem, the best month to survey differs among years and hence is not predictable from one year to the next. So, we should still conduct repeated surveys within a season for species-level studies since we cannot predict with certainty when the probability of detecting a species will be maximum in order to allocate the survey effort. It should be noted that the convenience of repeated surveys is not only because it increases the chance of sampling in the month with highest detectability, but also because temporal replication increases per se the probability of detecting a species during the breeding season due to the fact that the sampling effort is being increased (Gotelli and Colwell 2001; MacKenzie et al. 2002; De Solla et al. 2005). So, if temporal replication of surveys within a breeding season is high, we may provide accurate representation of the community from field data. In sum, in this study, I evidence a wide variability in the probability of detection among species and across time, which leads to a wide variability in the reliability of absence data in biotic assessments, depending on the number and timing of surveys. So, for any given species, we should not assume all the non-detections as valid absences but, instead, we should question its reliability. Moreover, we should neither assume that the reliability of nondetection records is the same.

Which is the best response variable for species-level biotic assessments (relative abundance vs. presence/absence data)? In this study, I have built habitat models using both relative abundance data (measured as "catch-per-unit-effort") and presence/ absence data. Schmidt and Pellet (2005) recommend the use of abundance rather than occurrence data in habitat models, since it provides more information about habitat suitability due to the fact that absence and presence are only a special case of abundance (abundance $=0$ and abundance $>0$, respectively). However, we should be aware that the estimation of relative abundance data may also depend on the timing of surveys in this highly variable ecosystem. For instance, given a constant number of larvae in a pond, the number of larvae collected per sampling effort is expected to be higher when the surface extent of the pond is very small (all the larvae are located in a small area and hence are more easily catchable) than when the pond extends over a large surface. So, given the same number of larvae, the relative abundance is dependent, at least in part, on the extent of the pond for it may favour (or not) its detectability and catchability. With this fact in mind, in this study I am assuming that the temporal variation in relative abundance is comparable among ponds.

On the other hand, I have used breeding attempts as occurrence data for habitat requirement models. So, I am implicitly assuming that a species always choose suitable habitats for breeding. This assumption, however, could not be certain if habitat selection is deficient. Unsuitable habitats may be occupied when a species does not actually choose the best available site (i.e. they are opportunistic and breed in most available/accessible ponds not taking into account the likelihood of breeding success) or when it chooses based on incomplete information (Pulliam 1996). In fact, lack of habitat selection is expected in many pond-breeding amphibians which, as typical r-strategists, do not select specific habitats for breeding and, instead, reproduce over a wide number of different ponds in order to increase the probability of reproductive success. Regarding to habitat selection based on incomplete/inadequate information, we should take into account 
that, in amphibians breeding in highly dynamic ecosystems, such as Mediterranean temporary ponds, breeding philopatry may be a bad indicator of habitat suitability since pond characteristics change from year-to-year. For that reason, I think that "breeding site selection" might not equate to "breeding success" and hence it could be an imperfect indicator of habitat suitability. An alternative would be to monitor developmental stages indicative of breeding success (i.e. metamorphics) to assess habitat suitability. The main disadvantage of this response variable is that the detection probability of metamorphics is expected to be even lower as they inhabit the pond for a short period of time. So, the "sampling window" for metamorphic surveys would be shorter, a fact that would reduce the number of ponds that could be sampled in a biotic assessment.

\section{Diversity assessments and habitat requirements of amphibian species in Doñana National Park}

\section{Assemblage-level}

In this dissertation, I show that studies relating species diversity to habitat attributes should include the various spatial scales at which relationships between diversity and habitat characteristics may become manifest. So, diversity assessment should complement conclusions based on alpha diversity (i.e. species richness) with analyses to explain beta diversity (i.e. variation in assemblage composition among ponds). For instance, I found physicochemical variables to be scarcely relevant to explain richness gradients in particular years, whereas they were relevant to explain variation in assemblage composition. In other words, attributes irrelevant for pond species richness (alpha diversity) might be responsible for the variation in assemblage composition among ponds (beta diversity) and, hence, contribute to species diversity in the entire study area (gamma diversity). This result reinforces the idea that beta diversity is a key concept for understanding the functioning of ecosystems, for conservation of biodiversity and for ecosystem management (Legendre et al. 2005).

Hydroperiod, a major structuring force of pond-breeders assemblages (Wellborn et al. 1996), deserves a separate mention. To provide a comprehensive understanding of pond hydroperiod relevance at assemblage level, I will also refer to its role at specieslevel. Hydroperiod did not appear as a critical habitat factor for the occurrence of particular species. Considering the data from both 2003 and 2006 altogether, all species attempted to breed in ponds along the entire hydroperiod gradient except Pelophylax perezi (Seoane, 1885) and $B$. bufo. So, my results did not evidence a strong segregation pattern in species occurrence according to hydroperiod, as previous studies have reported for the study area (Díaz-Paniagua 1990). At assemblage level, I observed inter-annual differences in the relationship between hydroperiod and pond diversity patterns, which would be in accordance to inter-annual differences in species-habitat relationships. Hydroperiod was not an important factor explaining amphibian diversity in 2003, when pond hydroperiod was long (4-9 months). On the contrary, in 2006, when pond hydroperiod was short ( $\leq 4$ months), hydroperiod gradient explained the richness gradient and, mostly, the nested pattern in species occurrence. Besides, it also partly explained variation in assemblage composition when measured with relative abundance data. Taken altogether, these results evidenced a gain of species along hydroperiod gradient but also small differences in species 
predominance among assemblages. I attribute lack of relevance of hydroperiod in 2003 to the fact that the most ephemeral ponds lasted that year even longer than the period required for successful metamorphosis of species with long larval development (i.e. P. cultripes following Díaz-Paniagua et al. 2005). So, amphibian species did not face strong desiccation stress that year and, thereby, one of the main ecological traits structuring amphibian assemblages along hydroperiod gradient (tolerance to desiccation risk) was not critical. Additionally, inter-annual differences in the role of hydroperiod might be related not only to habitat suitability but also to habitat availability. Given the strong intra-annual segregation in larval communities in the study area (DíazPaniagua 1988), the duration of a pond will also condition the number of species that may potentially breed in it, independently of their ecological requirements. So, highly ephemeral pools (i.e. 1-2 months) may not be coincident in time with the reproduction of all species while ponds with hydroperiod values above a given threshold (for example, 4 or 5 months) would be available habitats for all species.

Several studies have already addressed the role of hydroperiod in some of these patterns: i.e. species richness (Beja and Alcazar 2003; Babbitt 2005; Werner et al. 2007a), nestedness (Baber et al. 2004; Werner et al. 2007a) or beta diversity (Snodgrass et al. 2000). However, this study is the first one that provides an integral analysis of the role of hydroperiod at any diversity level: variation in species richness, variation in assemblage composition and variation in beta diversity and that also takes into account different types of variation in assemblage composition (beta diversity patterns), i.e. nested pattern, turnover in species occurrence or turnover in species abundance. The overall conclusion is that pond hydroperiod may be a major driver of pond-breeding assemblages only in years when the duration of ponds is short and strong nested pattern occurs along a hydroperiod gradient. On the contrary, the role of hydroperiod is negligible in wet years, when desiccation risk is not a major stress and the pond is available for a longer time, enabling the potential breeding of many species.

\section{Species-level}

In the study of habitat requirements at species-level, I did not find a best supported hypothesis valid for all the species, both when analysing relative abundance or occurrence data. So, these results are in accordance with previous studies that have reported species-specific responses to habitat factors in different areas (Beja and Alcazar 2003; Weyrauch and Grubb 2004; Pearl et al. 2005; Van Buskirk 2005). In consequence, conservation programs should focus in habitat requirements at the species level, since important habitat factors may be masked when considering solely species richness data (Hazell et al. 2001; Knutson et al. 2004).

In general, both the characteristics of ponds and landscape (terrestrial and aquatic habitat) are important for different amphibian species. Species with a large occupancy, such as Hyla meridionalis Boettger, 1874 and Triturus pygmaeus (Wolterstorff, 1905), do not show preference for any specific habitat characteristic but for a specific ecosection in the study area (the "wet stabilized sands at higher elevation"), as they occurred in almost every pond there. Habitat characteristics in regards to the aquatic habitat (pond hydroperiod and size) are important predictors of the occurrence of species that require ponds with long duration for breeding success such as 
Pleurodeles waltl Michahelles, 1830 and $P$. cultripes (following Díaz-Paniagua et al. 2005). Terrestrial characteristics are the most important predictors of the occurrence of Discoglossus galganoi Capula, Nascetti, Lanza, Bullini \& Crespo, 1985 and Lissotriton boscai (Lataste, 1879). As I observed non-expected responses to particular terrestrial covers (i.e. forest or dune cover), I think that the role of terrestrial habitat for these species may not be related to terrestrial use by adults (i.e. movements between ponds or terrestrial residence), as previous authors proposed (see Gibbons 2003), but may be an indirect predictor of the hydrological dynamics of this particular area. Lissotriton boscai, a species reported to breed in ponds of intermediate hydroperiod in the area (DíazPaniagua et al. 2005), also shows high support for the patchy population hypothesis. The occurrence of this species is probably related to the formation of suitable breeding habitats in the surrounding, as Denoël and Lehmann (2006) reported for other Triturus species. So, the presence of ponds of intermediate/long hydroperiod in the surroundings would benefit the species occurrence in a particular pond, but not to the formation of ephemeral ones that only flood in wet years. Besides, intermediate values of surrounding aquatic vegetation favours the occurrence of $L$. boscai, probably because they enable pond access while offering a refugee for adults during their terrestrial stage. I could not build habitat models for Bufo calamita Laurenti, 1768 nor $P$. perezi due to the low prevalence of these species in the data sets.

At this point I would like to stress that we should not expect a high performance of distribution models in these stochastically and dynamically changing environments due to the fact that habitat/distribution models are static in nature (Guisan and Zimmermann 2000). In particular, in
Doñana National Park, the high values of occupancy for most species, the low species detectability and the high temporal turnover suggest the possibility that habitat segregation may not be a major driver when considering the species assemblage over a moderate-long time frame. So, it could be possible that all species occur in all the temporary ponds over a moderate time frame. This would be favoured by the dynamic nature of the environment and the spatial robustness of the system of temporary ponds, which may allow a pond to be good for several different species over time and also be accessible to individuals.

\section{Implications for conservation of amphibian species and their breeding habitats in Doñana National Park}

The Doñana National Park protects an area that includes one of the largest networks of Mediterranean temporary ponds of natural origin in Europe. Areas with such a high density and heterogeneity of natural ponds are not common in Europe, where manmade ponds are the most frequent pondbreeding species habitats (Jakob et al. 2003; Denoël 2004), and the number of temporary ponds are probably a mere fraction of what they were in the past (Williams et al. 2001). So, temporary ponds in Doñana National Park represent a good example of how the preservation of natural aquatic habitats with large inter-annual variability results in a rich and abundant amphibian fauna. Such high abundance and variability of a well-preserved European priority habitat (European Commission 2007) deserves special attention as a reference system for pond conservation and management. 
Preserving the wide pond variability in the area, and not only a particular pond or the total number of ponds, should be a priority because, as mentioned above, ecosystem heterogeneity favours the diversity of associated species (Tews et al. 2004). In the particular case of amphibians, a wide diversity of pond hydroperiods, as observed in Doñana, has been reported to benefit amphibian communities at a landscape scale (Beja and Alcazar 2003; Semlitsch 2003).

Another critical conservation aspect is to preserve the natural dynamism of the system. The observed inter-annual turnover in assemblage composition suggests that a given pond offers different breeding opportunities from year-to-year, being suitable for different species depending on its biotic and abiotic characteristics. Thus, in the study area, the system of temporary ponds can be seen as a shifting mosaic of suitable habitats over time (as Urban 2004 described for a freshwater invertebrate community). Although not obvious, it should be highlighted the relevance of the high abundance and diversity of temporary ponds (Díaz-Paniagua et al. 2006; GómezRodríguez et al. 2008; Gómez-Rodríguez et al. in press) in the temporal dynamics of the system, since it will provide the spatial variability necessary for a community to persist under high environmental variability (Shurin 2007). In sum, this pond system would be favouring the persistence of populations through its intrinsic variability. Species would persist because each one is periodically favoured and exhibits boom years in which large numbers of metamorphics are produced, rather than constant low-level reproductive success every year (Semlitsch 2002). 


\section{References}

Austin MP 2002. Ecol Model 157, 101-118.

Babbitt KJ 2005. Wetlands Ecol Manag 13, 269-279.

Baber MJ et al. 2004. Oikos 107, 16-27.

Batzer DP et al. 2004. J N Am Benthol Soc 23, 50-68.

Beja P, Alcazar R 2003. Biol Conserv 114, 317-326.

Blondel J, Aronson J 1999. Biology and Wildlife of the Mediterranean Region. Oxford University Press, Oxford, New York.

Bravo MA, Montes C 1993. Actas del Congreso Español de Limnología, Granada 31-43.

Brooks RT 2000. Wetlands 20, 707-715.

Bryant RG 1999. Earth Surf Proc Land 24, 283-302.

De Solla SR et al. 2005. Biol Conserv 121, 585-594.

Denoël M 2004. Bull Soc Herp Fr 111-112 49-77.

Denoël M, Lehmann A 2006. Biol Conserv 130, 495-504.

Díaz-Paniagua C 1988. Amphibia-Reptilia 9, 15-26.

Díaz-Paniagua C et al. 2005. Los Anfibios de Doñana. Organismo Autónomo de Parques Nacionales. Ministerio de Medio Ambiente, Madrid.

Díaz-Paniagua C et al. 2006. Rev Esp Herpetol 20, 17-30.

European Commission 2007. Interpretation Manual of European Union Habitats. Natura 2000, Nature and Biodiversity. European Commission.

Fortuna M et al. 2006. $P$ Roy Soc Lond B Bio 273, 1429-1434.

García-Novo F et al. 1991. III Simposium de Aguas de Andalucía, 165-176.

Gibbons JW 2003. Wetlands 23, 630-635.

Gómez-Rodríguez C et al. 2008. Herpetol J $18,103-113$.

Gómez-Rodríguez $\mathrm{C}$ et al. In press. Aquat Ecol. Online first.
Gotelli NJ, Colwell RK 2001. Ecol Lett 4, 379-391.

Guisan A, Zimmermann NE 2000. Ecol Model 135, 147-186.

Hazell D et al. 2001. Biol Conserv 102, 155169.

Jakob C et al. 2003. Hydrobiologia 499, 5161.

Junta de Andalucia 2000. Mapa topográfico de Andalucía, 1:10000. Provincia de Huelva.

Knutson MG et al. 2004. Ecol Appl 14, 669684.

Lacaux JP et al. 2007. Remote Sens Environ 106, 66-74.

Legendre P et al. 2005. Ecol Monogr 75, 435-450.

MacKenzie DI et al. 2002. Ecology 83, 2248-2255.

Manzano M, Custodio E 2006. The Doñana aquifer and its relations with the natural environment. In: García Novo F, Marín Cabrera (Eds.), Doñana. Water and Biosphere. Doñana 2005 Project Confederación Hidrográfica del Guadalquivir (Guadalquivir Hydrologic Basin Authority), Spanish Ministry of the Environment, Madrid, pp. 141-150.

McMenamin SK et al. 2008. P Natl Acad Sci USA 105, 16988-16993.

Montes C et al. 1998. Reconocimiento Biofísico de Espacios Naturales Protegidos. Doñana: Una Aproximación Ecosistémica. Junta de Andalucía. Consejería de Medio Ambiente.

Moreno CE, Halffter G 2001. Biodivers Conserv 10, 367-382.

Ozesmi SL, Bauer ME 2002. Wetlands Ecol Manag 10, 381-402.

Pearl CA et al. 2005. Wetlands 25, 76-88.

Piha H et al. 2007. Global Change Biol 13, 300-311.

Pulliam HR 1996. Sources and Sinks: Empirical Evidence and Population Consequences. In: Rhodes, O.E., et al. 
(Eds.), Population Dynamics in Ecological Space and Time. University of Chicago Press, pp. 45-74.

Roshier DA, Rumbachs RM 2004. J Arid Environ 56, 249-263.

Schmidt BR, Pellet J 2005. J Wildl Manage 69, 884-893.

Semlitsch RD 2002. J Wildl Manage 64, 615-631.

Semlitsch RD (Ed.) 2003. Amphibian Conservation. Smithsonian Books, Washington and London.

Serrano L et al. 2006. Limnetica 25, 11-32.

Serrano L, Zunzunegui M 2008. Aquat Conserv: Mar Freshw Ecosyst 18, 261279.

Shuman CS, Ambrose RF 2003. Restor Ecol 11, 325-333.

Shurin JB 2007. Oikos 116, 957-965.

Snodgrass JW et al. 2000. Ecol Appl 10, 1219-1229.

Spencer M et al. 1999. Ecol Lett 2, 157-166.
Suso JM, Llamas M 1990. Estudios Geológicos 46, 317-345.

Tews J et al. 2004. J Biogeogr 31, 79-92.

Trenham PC et al. 2003. Ecol Appl 13, 1522-1532.

Trick T, Custodio E 2004. Hydrogeol J 12, 321-335.

Van Buskirk J 2005. Ecology 86, 19361947.

Wellborn GA et al. 1996. Annu Rev Ecol Evol $S$ 27, 337-363.

Werner EE et al. 2007a. Oikos 116, 16971712.

Werner EE et al. 2007b. Oikos 116, 17131725.

Weyrauch SL, Grubb Jr TC. 2004. Biol Conserv 115, 443-450.

Williams P et al. 2001. Freshw Forum 17, 715.

Zacharias I et al. 2007. J Environ Biol 28, 1-9. 


\section{Resumen}

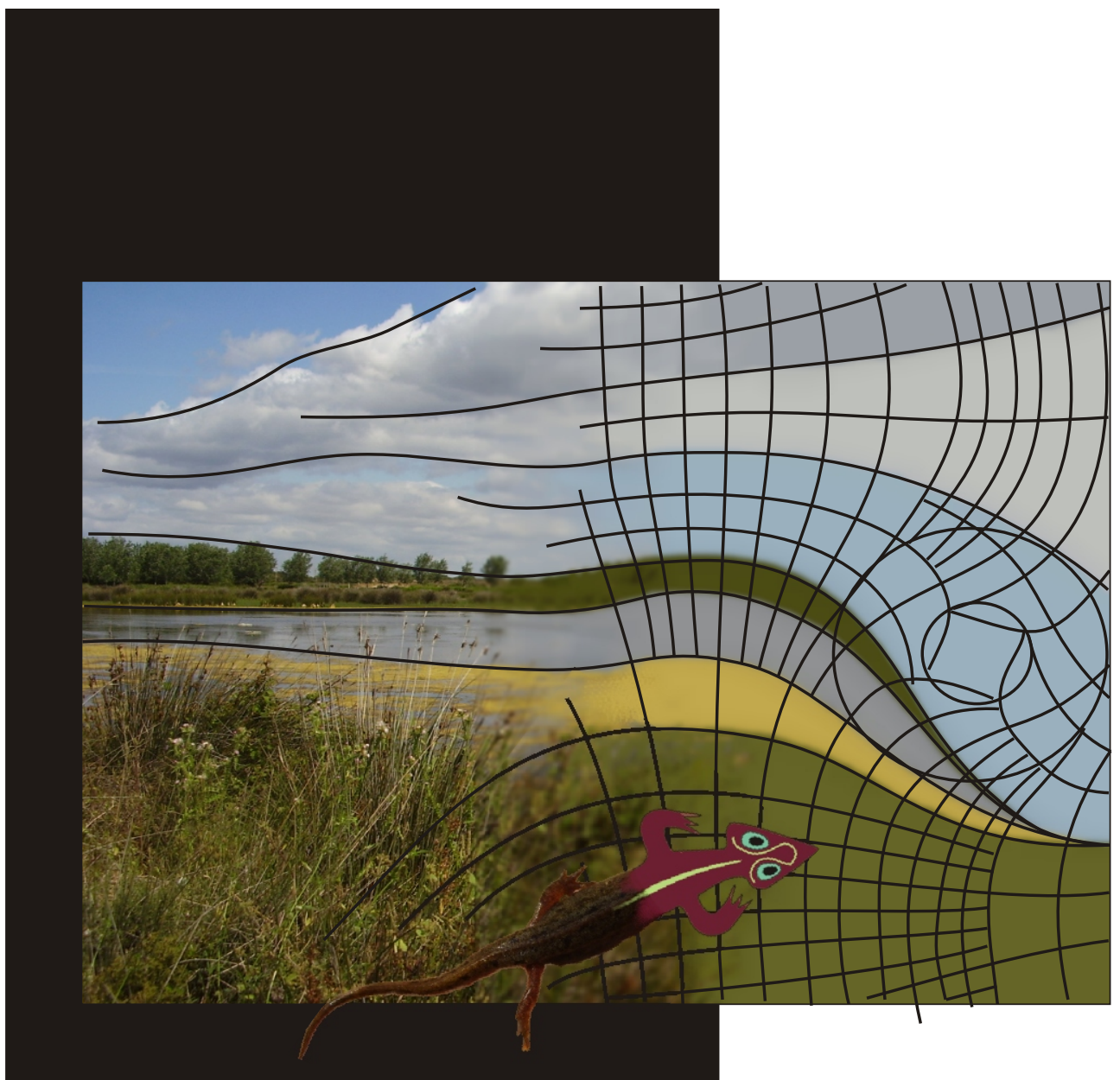




\section{Introducción}

\section{Los condicionantes ecológicos} de la distribución de los anfibios en las charcas temporales de Doñana

Un tema central en ecología es el estudio de la variación espacial de la diversidad (Gaston 2000). El conocimiento de los factores ambientales que determinan la distribución actual de las especies permitirá que los programas de conservación de las mismas sean elaborados a partir de sólidas bases científicas. En concreto, la calidad de los programas de conservación de anfibios se verá reforzada si se realizan estudios encaminados a la identificación de sus hábitats reproductivos favorables $\mathrm{y}$, sobre todo, a la identificación de los requerimientos ecológicos de las especies. Este ha sido uno de los principales objetivos de estudios previos que han cuantificados las relaciones entre las características del hábitat, charcas temporales en este caso, y el número de especies (Beja y Alcazar 2003, Weyrauch y Grubb 2004, Werner y col. 2007), la presencia de especies concretas (Beja y Alcazar 2003, Pearl y col. 2005, Van Buskirk 2005) o su abundancia relativa (Beja y Alcazar 2003, Van Buskirk 2005, Richter-Boix y col. 2007). Los cuerpos de agua temporales de reducido tamaño (charcas temporales) son uno de los principales hábitats reproductivos de un gran número de especies de anfibios, sobre todo en las regiones templadas.

La mayoría de los estudios de selección de hábitat de anfibios, principalmente los realizados en charcas temporales, se han centrado en cuatro tipos de variables ambientales por su relevancia en la ecología de las poblaciones de anfibios: i/ las características abióticas del hábitat reproductivo, como la extensión del hábitat (Burne y Griffin 2005, Werner y col. 2007), las características físico-químicas del agua (Hecnar y M’Closkey 1996, Knutson y col. 2004) o la duración de la inundación, también denominada hidroperiodo, (Wellborn y col. 1996, Werner y col. 2007); ii/ las interacciones bióticas en el hábitat reproductivo, como la competencia o la depredación (Duellman y Trueb 1986); iii/ las características del medio estival (Gibbons 2003), como puede ser la presencia de cubiertas vegetales concretas en el hábitat terrestre; y iv/ la estructura de la metapoblación o de la población fragmentada (patchy population), medidas, por ejemplo, como la distancia a la masa de agua más próximo o la densidad de cuerpos de agua en los alrededores, ya que estos que condicionarán la dispersión o los movimientos regulares de individuos entre charcas (Semlitsch y Bodie 1998, Smith y Green 2005). Aunque estas son las hipótesis más comunes en la literatura científica, existen otras características de los cuerpos de agua temporales que podrían desempeñar un papel importante en la 
selección del hábitat realizada por los individuos. Este es el caso de la morfometría del cuerpo de agua, ya que determina la abundancia y variabilidad de microhábitats dentro de él, un factor clave para las especies que lo habitan, ya que cada una utilizará de forma selectiva los diferentes tipos de microhábitat disponibles (Smith y col. 2003). Otra características que podría ser crítica para que una charca sea seleccionada o no como hábitat reproductivo es la estructura de la vegetación que rodea el cuerpo de agua (vegetación de orla). La vegetación de orla proporciona sombra al cuerpo de agua, un aspecto que podría ser clave ya que la insolación de la charca ha sido identificada como un factor importante para algunas especies de anfibios (Sztatecsny y col. 2004, Burne y Griffin 2005).

El Parque Nacional de Doñana es uno de los humedales más importantes del sur de Europa, siendo la marisma el cuerpo de agua más conocido. Sin embargo, la marisma no es el único medio acuático importante para la conservación de la fauna acuática. En el Parque Nacional de Doñana también se encuentra un vasto sistema de charcas temporales (Díaz-Paniagua y col. 2006) cuya configuración espacial le confiere estabilidad frente a la variación interanual en las condiciones hidrológicas (Fortuna y col. 2006). Estas charcas son hábitat de numerosas especies de flora y fauna: macrófitos (García Murillo y col. 2006), invertebrados (Bigot y Marazanof 1966, Millán y col. 2005, Serrano y Fahd 2005) y anfibios (Díaz-Paniagua 1990, Díaz-Paniagua y col. 2005, Díaz-Paniagua y col. 2006). Las once especies de anfibios que se reproducen en Doñana son: Alytes cisternasii Boscá, 1879, Bufo (Epidalea) calamita Laurenti, 1768, Bufo bufo (Linnaeus, 1758), Pelobates cultripes (Cuvier, 1829), Discoglossus galganoi Capula, Nascetti, Lanza, Bullini \& Crespo, 1985, Pelodytes ibericus Sánchez-Herráiz,
Barbadillo, Machordom \& Sanchiz, 2000, Rana (Pelophylax) perezi Seoane, 1885, Hyla meridionalis Boettger, 1874, Pleurodeles waltl Michahelles, 1830, Triturus pygmaeus (Wolterstorff, 1905) y Lissotriton boscai (Lataste, 1879).

Los humedales mediterráneos se encuentran entre los más amenazados del mundo (Blondel y Aronson 1999) y, en concreto, las charcas temporales mediterráneas son un hábitat prioritario recogido en la Directiva Hábitat de la Unión Europea (European Commission 2007). La principal diferencia entre las charcas temporales y las charcas/lagunas permanentes es que las primeras presentan una fase seca recurrente (Griffiths 1997) mientras que las segundas están siempre inundadas. En la región mediterránea, el aporte de lluvia determina el momento de llenado de las charcas y el periodo de inundación de las mismas (Zacharias y col. 2007). En general, el conocimiento actual sobre las charcas temporales es muy limitado ya que estos medios suelen pasar desapercibidos al tener un tamaño pequeño, generalmente, y una fase seca (Grillas y col. 2004). Por ello, descripciones básicas de los medios acuáticos temporales siguen siendo vitales (Schwartz y Jenkins 2000).

\section{La teledetección: Utilidad en el estudio de los requerimientos ecológicos de los anfibios}

Los programa de conservación de anfibios deben basarse en un conocimiento preciso de la distribución de los hábitats reproductivos, ya que esta determina la distribución y dinámica de las poblaciones (Semlitsch y Bodie 1998, Semlitsch 2003). Sin embargo, el coste económico de realizar cartografías de masas de agua puede ser 
excesivamente alto si se realizada aplicando las técnicas tradicionales (p.ej. muestreo de campo o fotointerpretación). Las limitaciones económicas y de tiempo son especialmente serias en áreas donde el número de cuerpos de agua es elevado o están repartidas por una amplia extensión de territorio. Una alternativa a estas técnicas tradicionales sería la aplicación de técnicas de teledetección para la cartografía de los hábitats reproductivos de los anfibios.

Las imágenes obtenidas mediante teledetección pueden aportar información sobre amplias extensiones de terreno que sería prácticamente imposible conseguir por métodos tradicionales de muestreo de campo (Kerr y Ostrovsky 2003). La utilidad de la teledetección en el seguimiento y monitorización de los ecosistemas acuáticos es incuestionable (Revenga y col. 2005). Sin embargo, la mayoría de los estudios de teledetección se han centrado en la delimitación de masas de agua de gran tamaño, (ver la revisión realizada por Ozesmi y Bauer 2002), sobre todo en la región mediterránea (Alphan y Yilmaz 2005, Castañeda y Herrero 2005, Papastergiadou y col. 2007). La utilidad de la teledetección en la delimitación de cuerpos de agua pequeños es prácticamente desconocida, sobre todo por la dificultad que entraña identificar elementos del paisaje de tamaño inferior a la resolución espacial de la mayoría de las imágenes fácilmente disponibles. De forma similar, la aplicación de la teledetección para la delimitación de los sistemas acuáticos temporales también ha sido escasa (Bryant 1999, Roshier y Rumbachs 2004, Lacaux y col. 2007), principalmente porque es complicado establecer el perímetro de sistemas acuáticos que fluctúan ampliamente en su extensión.

Finalmente, hay que destacar que la aplicación de la teledetección en estudios relacionados con los anfibios ha sido muy limitada, estando restringida a escasas aplicaciones a escala global (Carey y col. 2001, Middleton y col. 2001) y de paisaje (Scribner y col. 2001). En resumen, la utilidad de la teledetección para el estudio de los anfibios puede ser: i) para determinar la distribución espacial de los hábitats reproductivos; ii) para comprender la dinámica temporal de los hábitats reproductivos; o iii/ para predecir la distribución de determinadas especies.

\section{La variación temporal del sistema: un reto en el estudio de los requerimientos ecológicos de los anfibios}

Los sistemas estables, definidos como aquellos que no muestran variación con el tiempo, son una excepción en ecología (Ricklefs y Schluter 1993). En realidad, tanto los hábitats como las comunidades de especies suelen variar con el tiempo (Preston 1960, Collins y Glenn 1991, Fjeldsa y Lovett 1997, Innes 1998). Por ello, es recomendable que los estudios ecológicos no se centren únicamente en el análisis de patrones espaciales sino que, por el contrario, incorporen una perspectiva temporal, especialmente en los análisis de diversidad (Buckland y col. 2005, Magurran 2007). Esto es también importante en los estudios que relacionan los patrones de distribución de las especies con las características del hábitat (modelos de selección de hábitat), ya que gran parte de los cambios temporales que experimenta una comunidad de especies pueden ser atribuidos a cambios temporales en las características ambientales (Houlahan y col. 2007). 


\section{La probabilidad de detección} y la fiabilidad de las ausencias: un reto añadido en el estudio
de los requerimientos
ecológicos de los anfibios

Una fuente de error importante en cualquier inventario biológico es la posibilidad de no detectar la especie en una unidad de hábitat en la que sí está presente (Yoccoz y col. 2001, Pollock y col. 2002, Pellet y Schmidt 2005). Mientras que la presencia de una especie se confirma al ser detectada, generalmente no es posible verificar si una especie está ausente de una localidad (MacKenzie 2005, MacKenzie y col. 2006). Las "no detecciones" registradas en un inventario biológico pueden estar causadas tanto por la ausencia real de la especie como por el hecho de que la especie estuviera presente pero no fuera detectada durante el muestreo. Boulinier y col. (1998) definen la detectabilidad de una especie como "la probabilidad de detectar al menos un individuo durante un esfuerzo de muestreo determinado, siempre y cuando individuos de esa especie ocupen el área de interés durante la temporada de muestreo".

Los sesgos en los inventarios biológicos causados por la baja detectabilidad de las especies constituyen también una fuente de error en el estudio de sus requerimientos ecológicos. La fiabilidad de los datos con los que construyen los modelos estadísticos de distribución de las especies es crítica para determinar la utilidad y la validez de las inferencias realizadas a partir de los modelos (Lobo 2008). En el caso de los anfibios, la baja detectabilidad de muchas especies es una fuente de error frecuente en cualquier inventario poblacional (Mazerolle y col. 2007). Cada especie de anfibio presenta una detectabilidad propia (Bailey y col. 2004, De Solla y col. 2006) que, además, es diferente entre regiones y puede ser variable en el tiempo, tanto dentro de una misma temporada reproductora como entre temporadas diferentes (De Solla y col. 2005, De Solla y col. 2006). Por esa razón, es importante evaluar la detectabilidad de una especie en la región específica en la que se va a realizar el estudio de sus requerimientos de hábitat. 


\section{Contenido específico de la tesis}

En esta tesis se analizan los requerimientos de hábitat de las especies de anfibios en el Parque Nacional de Doñana, prestando una atención especial a los aspectos metodológicos que pueden sesgar los resultados inferidos. En particular, se ha tenido en cuenta la dinámica temporal del sistema y la fiabilidad de las ausencias, una consecuencia directa de la detectabilidad imperfecta de la especies en el área. También se ha evaluado la utilidad de la teledetección en el estudio de la variación espacial y temporal de los hábitats reproductivos los de anfibios y en la elaboración de modelos estadísticos de distribución de las especies.

La estructura de la tesis es la siguiente:

\section{Capítulo 1. Descripción de los hábitats reproductivos}

Se describen las características principales de los hábitats reproductivos de los anfibios resaltando su variación espacial y temporal (dentro de un mismo año y entre años con condiciones hidrológicas diferentes). También se evalúa el efecto de la dinámica temporal del sistema en la construcción de los modelos estadísticos de selección de hábitat. Es decir, se evalúa si los modelos de hábitat elaborados para una misma especie varían entre años. La importancia de este estudio radica en el hecho de que la utilidad de este tipo de análisis para la conservación de una especie depende de su consistencia en el espacio y el tiempo.

\section{Capítulo 2. Aplicación de la teledetección} para la identificación, caracterización y seguimiento de los hábitats de anfibios

Se aplican técnicas de teledetección para la elaboración de una cartografía de los hábitats reproductivos de los anfibios y para evaluar la variación temporal de su distribución, extensión y duración durante un periodo de 23 años. También se ha evaluado la utilidad de los datos obtenidos mediante teledetección en los modelos estadísticos de distribución de las especies de anfibios. En concreto, se ha utilizado una imagen con una alta resolución espacial y espectral (imagen AHS) para realizar una cartografía detallada del hábitat y su utilidad en los modelos de distribución. Por otro lado, se ha utilizado una serie de imágenes con una resolución espacial intermedia (imágenes Landsat) para el estudio de la dinámica temporal del sistema de charcas temporales.

La cartografía realizada en este capítulo se ha utilizado también en los capítulos 1 y 5. Con ella se ha caracterizado la conexión (connectivity) de cada cuerpo de agua en el área de estudio.

Capítulo 3. Variación temporal en la comunidad de anfibios del Parque Nacional de Doñana

Se ha evaluado tanto la variación temporal de las agrupaciones de especies (species assemblages) de las charcas temporales (variación entre temporadas) como en la detectabilidad de las especies (variación dentro de una misma temporada y entre temporadas).

En el estudio de la variación interanual en las agrupaciones de anfibios (inter-annual turnover), se ha desarrollado un marco metodológico que permite evaluar diferentes aspectos de la variación en la agrupación, como son los cambios en el número de especies (pérdida o ganancia de especies), en la identidad de esas especies o en su abundancia. De esta forma, se proporciona una base científica que permite determinar si los inventarios faunísticos realizados en una única temporada reproductora son representativos de la composición faunística de una charca temporal a medio plazo. 
Por otro lado, se ha evaluado si la detectabilidad de cada especie es constante o, por el contrario, varía en el tiempo. De forma adicional, se ha contemplado la posibilidad de que exista una relación entre la detectabilidad y variables del hábitat, como el área de la charca o el hidroperiodo. Este estudio permite concluir si se puede caracterizar la composición faunística de una charca temporal con una única visita y, sobre todo, qué fechas serían las más favorables para realizar muestreos representativos.

Capítulo 4. Variación espacial en la comunidad de anfibios del Parque Nacional de Doñana: Relaciones con las características del hábitat

En este capítulo se evalúa la relación entre las variables ambientales y la selección del hábitat reproductivo de los anfibios, tanto a nivel de especie como de agrupación.

Respecto al nivel de agrupación, se ha investigado la relación entre las características abióticas del medio y los gradientes de riqueza y la variación en composición faunística entre agrupaciones de especies. Para ello, se han utilizado los datos recogidos durante un muestreo intensivo de la comunidad de anfibios, realizado mensualmente durante cuatro años, y sus correspondientes variables ambientales. Se han realizado análisis independientes para evaluar las relaciones existentes en cada temporada de muestreo (fauna anual) así como las que se manifiestan al considerar los datos recogidos durante varios años (fauna acumulada). En concreto, se ha evaluado cual es la contribución única de las características ambientales que cambian con el tiempo respecto a las que no cambian a la hora de explicar los patrones espaciales de diversidad.

En relación al nivel de especie, se han elaborado modelos estadísticos de selección de hábitat basados en datos de presencia/ausencia de la especie en el medio acuático. El aspecto más innovador de este capítulo es que se tiene en cuenta de forma explícita la fiabilidad de cada ausencia en la construcción del modelo. Los datos utilizados corresponden al muestreo intensivo, anteriormente mencionado, y a un muestreo extensivo adicional, así como a las variables de hábitat extraídas a partir de cartografía, principalmente. 


\section{Área de $_{\text {studio y }} \mathbf{M}_{\text {aterial y }} \mathbf{M}_{\text {étodos }}$}

El área de estudio es el Parque Nacional de Doñana (ver Siljeström y col. 1994 para una descripción geomorfológica detallada), en el suroeste de la Península Ibérica (Figura 1). En concreto, se ha estudiado la comunidad de anfibios que se reproduce en las charcas temporales que se forman en el manto eólico. En determinados capítulos, también se han incorporado datos de las dos lagunas permanentes (Santa Olalla y la Dulce) que existen en el Parque.

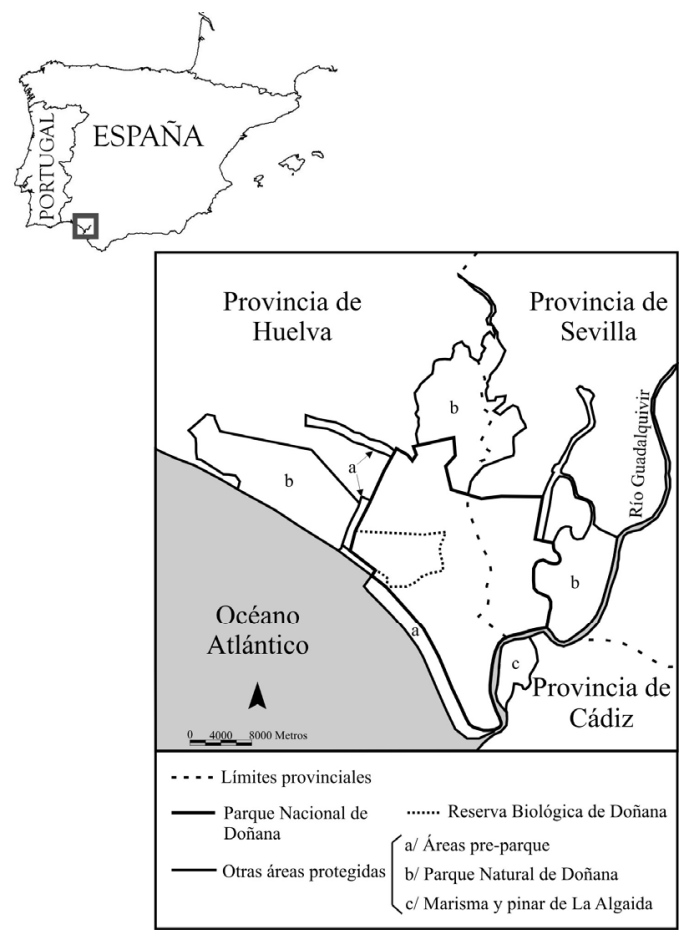

Figura 1. Localización del Parque Nacional de Doñana y las áreas adyacentes protegidas. 
Las charcas temporales de Doñana son de origen natural y se pueden clasificar dentro de la definición de "humedales aislados" proporcionada por Leibowitz y Nadeau (2003). Se alimentan de lluvia y de una capa freática somera, y no tienen conexión directa con el mar excepto por deposición aérea (Sacks et al. 1992). En momentos puntuales de gran inundación, las charcas pueden interconectarse por acción de la escorrentía superficial y/o el desbordamiento de la cubeta (Serrano y col. 2006). Aunque el sistema presenta una gran variación interanual, que impide hacer afirmaciones rotundas sobre el funcionamiento hídrico del mismo, se podría generalizar que las charcas suelen formarse durante la época húmeda, entre el otoño y el invierno. Sin embargo, en años en los que la precipitación es escasa, el llenado de las charcas se puede retrasar hasta la primavera o incluso no llegar a producirse. Este hecho hace que la duración de la inundación (hidroperiodo) varíe mucho entre años dependiendo de la precipitación (Serrano y Zunzunegui 2008). La vegetación de las charcas está principalmente compuesta por especies como la Mentha pullegium L., el Illecebrum verticillatum L. o el Hypericum elodes L. en la orilla, mientras que los macrófitos acuáticos, como Juncus heterophyllus Dufour, Myriophyllum alterniflorum DC., Potamogeton pectinatus L. y Ranunculus peltatus Schrank son especies comunes en las zonas más profundas. Las asociaciones fitosociológicas Isoetion, Nanocyperion flavescentis, Preslion cervinae, Eleochloion y Lythrion tribracteati, todas ellas incluidas en la Directiva Hábitat de la Unión Europea (European Commission 2007), se desarrollan en estas charcas.

\section{Datos bióticos y abióticos}

\section{Comunidad de anfibios}

Los muestreos de anfibios se realizaron en las temporadas 2002-03 (equivalente a 2003 en el texto), 2003-04 $(\approx 2004)$, y 2005-06 $(\approx 2006)$. La precipitación varió mucho de una temporada a otra (Figura 2). En el año 2004-05, la precipitación fue tan escasa que las charcas temporales no llegaron formarse $\mathrm{y}$, por tanto, no hubo reproducción de anfibios en el área de estudio. Para caracterizar la comunidad de anfibios se realizó una estrategia de muestreo doble (double-sampling scheme). Es decir, se realizó un muestreo intensivo en un número reducido de charcas (19 charcas temporales y las dos lagunas permanentes) y un muestreo extensivo en un número mayor de ellas (202). De esta forma, se muestrearon un total de 223 hábitats reproductivos de anfibios para elaborar este estudio.

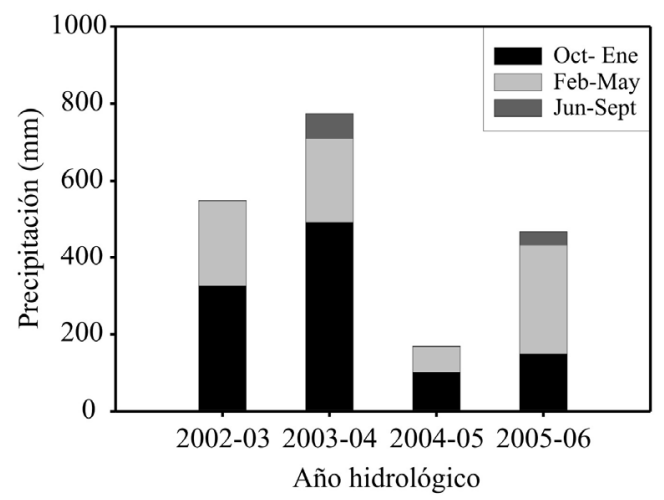

Figura 2. Aporte de precipitación durante el periodo de estudio. 
El muestreo intensivo se realizó mediante visitas mensuales a las charcas durante la época reproductiva de los anfibios para detectar huevos, larvas o metamórficos. El principal método de muestreo fue el mangueo (dipnetting), que se complementó con observaciones visuales (visual surveys) de huevos, larvas y adultos. Los individuos capturados en cada unidad de esfuerzo (mangueo) fueron identificados y contabilizados in situ y posteriormente liberados en la charca. Con la información obtenida en los mangueos se calcularon las abundancias relativas de cada especie, medidas como el número de larvas capturado por unidad de esfuerzo (catchper-unit-effort).

El muestreo extensivo consistió en una única visita anual a un mayor número de charcas ( $\mathrm{n}=94-129$, dependiendo del año). Ninguna charca fue muestreada cada año. El principal método de muestreo fue el mangueo complementado con observaciones visuales de huevos, larvas y adultos. Los individuos capturados en cada muestreo fueron identificados in situ y posteriormente liberados en la charca. Esta información nos permitió establecer la presencia o la ausencia de cada especie en la charca muestreada.

\section{Variables ambientales}

El diseño de muestreo de las variables ambientales es análogo al realizado para las variables bióticas. Se realizó un muestreo de campo detallado de las variables ambientales y su variación temporal en las charcas seleccionadas para el muestreo biótico intensivo. Las variables ambientales del muestreo extensivo se extrajeron principalmente de cartografía previa (Montes y col. 1998), ortofotografía digital (Junta de Andalucía 2003) y la cartografía de cuerpos de agua elaborada en el segundo capítulo. También se incluyeron datos recopilados in situ (p.ej. hidroperiodo).

Las variables ambientales del muestreo intensivo se pueden clasificar en dos tipos. En primer lugar, las que varían con el tiempo y fueron muestreadas en tres fechas diferentes (enero 2003, mayo 2003 y marzo 2006): hidroperiodo (dato anual), profundidad máxima, $\mathrm{pH}$, conductividad, concentración iónica, clorofila-a, fosfato inorgánico disuelto y compuestos nitrogenados. En segundo lugar, las características que no varían con el tiempo: altitud, coordenadas geográficas, distancia a elementos paisajísticos importantes (marisma, costa y carretera), área máxima de la charca, pendiente interna, porcentaje de vegetación de orla, microhábitats (p.ej. vegetación helofítica en la orilla, vegetación helofítica dentro de la cubeta principal, caminos rurales que cruzan el área inundable de la charca, aguas abiertas, aguas profundas y excavaciones realizadas por el hombre). También se midieron las cubiertas terrestres y los cuerpos de agua en los alrededores de cada charca en dos áreas de $200 \mathrm{~m}$ y $1000 \mathrm{~m}$ de radio, medidos a partir del borde de la charca.

Las variables ambientales correspondientes al muestreo extensivo de anfibios se clasifican en: ecosección, área máxima, hidroperiodo en un año húmedo, vegetación de orla, hábitats terrestres y hábitats acuáticos en un área de $200 \mathrm{~m}$ de radio. 


\section{Resultados y $\mathbf{D}_{\text {iscusión }}$}

\section{Aplicación \\ de \\ nuevas \\ tecnologías para el estudio de los hábitats reproductivos de los anfibios}

Como paso previo al estudio de los hábitats de anfibios en el Parque Nacional de Doñana, necesitaba información precisa sobre su localización y extensión. Por ello, en esta tesis he desarrollado dos métodos alternativos que permiten cartografiar los hábitats reproductivos de los anfibios mediante el uso de la teledetección. La principal dificultad que encontré fue la poca información previa, ya que la teledetección ha sido ampliamente utilizada en la cartografía de humedales permanentes de extenso tamaño (ver la revisión realizada por Ozesmi y Bauer 2002) pero su aplicación en sistemas de inundación temporal ha sido escasa (Bryant 1999, Roshier y Rumbachs 2004, Lacaux y col. 2007) y prácticamente nula si son de tamaño tan pequeño como el de las charcas temporales de Doñana.

En esta tesis he descrito la distribución espacial, el tamaño y la variación temporal de las charcas temporales usando una imagen con una alta resolución espacial y espectral (AHS) y una serie de imágenes con una resolución espacial intermedia (imágenes Landsat). A partir de la imagen AHS pude elaborar una cartografía de las charcas temporales con una alta resolución espacial (tamaño del pixel $=5 \times 5$ metros). Esta cartografía representa la localización y extensión de las charcas temporales en un momento de gran inundación en el Parque Nacional de Doñana (Abril 2004). A partir de las imágenes de Landsat, he realizado un estudio retrospectivo de la dinámica espacio-temporal del sistema de charcas temporales en la Reserva Biológica de Doñana durante un periodo de 23 años.

Imagen de alta resolución espacial y espectral (AHS). He cartografiado 3335 cuerpos de agua en el sistema eólico del Parque nacional de Doñana. En este área, inventarios previos (Bravo y Montes 1993, Montes y col. 1998, Junta de Andalucía 2000) habían identificado un número menor de cuerpos de agua: 308, 307 y 205, respectivamente. La elaboración de una cartografía similar a partir de datos de campo conllevaría un alto coste en personal y tiempo. Por otro lado, también he evaluado la utilidad de los datos de teledetección como alternativa a los datos de campo en modelos de distribución de especies de anfibios. Los resultados obtenidos evidencian que, a nivel de agrupación, los datos de teledetección 
permiten identificar charcas ocupadas por un gran número de especies, ya que son las que presentan mayor heterogeneidad de microhábitats (Correlaciones de Spearman entre la riqueza de especies y el número de microhábitats, $\mathrm{r}=0.476, \mathrm{p}<0.001$, y la heterogeneidad de microhábitats, $\mathrm{r}=$ $0.400, \mathrm{p}=0.001)$, una característica fácilmente medible mediante teledetección. Sin embargo, a nivel de especie, los datos obtenidos mediante teledetección fueron de escasa utilidad como predictores de la distribución de las especies y apenas mejoraron los modelos de distribución de anfibios elaborados a partir de datos de campo exclusivamente (Tabla 1). Por lo tanto, se puede concluir que los datos de teledetección con una alta resolución espacial (p.ej. AHS) no proporcionan información fiable que permita identificar hábitats reproductivos de especies concretas.
Imágenes de satélite con resolución espacial intermedia (imágenes Landsat). He utilizado la cartografía elaborada a partir de la imagen AHS como base del estudio de la dinámica temporal del sistema a partir de imágenes Landsat. En este caso, he acotado el área de estudio a la Reserva Biológica de Doñana, donde previamente había identificado 883 charcas temporales con la imagen de alta resolución espacial. Usando imágenes Landsat, he detectado un número de cuerpos de agua ligeramente menor (864). Gracias a la cobertura (23 años) y resolución temporal (una imagen cada 16 días) de las imágenes Landsat, he podido construir una cartografía dinámica de la inundación en el área de estudio. Esta cartografía revela las grandes fluctuaciones en el tamaño y la duración de estas charcas al igual que las tendencias hidrológicas del sistema. De esta forma, este estudio pone en evidencia la compleja hidrología de las charcas temporales, un hecho que ya había sido destacada en estudios más restringidos

Tabla 1. Se muestra la correlación de Spearman entre la probabilidad de ocupación predicha por el modelo y el porcentaje de presencias observado en la charca a lo largo de diferentes muestreos.

\begin{tabular}{|llllll|}
\cline { 2 - 6 } & \multicolumn{5}{c}{ Coeficiente de correlación de Spearman } \\
\cline { 2 - 6 } & POND & RM4 & RM9 & SEQ4 & SEQ9 \\
\hline Bufo calamita & 0.498 & 0.273 & 0.146 & 0.498 & 0.515 \\
Pelobates cultripes & 0.543 & 0.388 & 0.261 & 0.543 & 0.644 \\
Discoglossus galganoi & 0.468 & 0.230 & 0.353 & 0.499 & 0.440 \\
Hyla meridionalis & 0.331 & 0.250 & 0.300 & 0.381 & 0.449 \\
Pleurodeles waltl & 0.430 & 0.416 & 0.327 & 0.430 & 0.488 \\
Triturus pygmaeus & 0.294 & 0.215 & 0.360 & 0.391 & 0.339 \\
Lissotriton boscai & 0.383 & 0.205 & 0.060 & 0.443 & 0.451 \\
\hline
\end{tabular}

POND = modelos elaborados sólo con variables medidas en el campo;

$\mathrm{RM}=$ modelos elaborados sólo con variables de teledetección;

$\mathrm{SEQ}=$ modelos elaborados con variables de campo y de teledetección.

Se muestra también el número de microhábitas potenciales considerado (4 vs. 9). 
temporalmente (García-Novo y col. 1991), la importancia de los aportes subterráneos en su régimen hidrológico (Serrano y col. 2006) y también constituye un soporte adicional a la zonificación ecosistémica que Montes et al. (1998) propuso para la Reserva Biológica de Doñana. Cabe destacar la tendencia negativa que se ha observado en el hidroperiodo de las charcas cuando el mismo patrón no se manifiesta en la precipitación o el área total inundada (Figura 3). Esta misma tendencia en el hidroperiodo había sido demostrada para algunas charcas concretas (Serrano y Zunzunegui 2008) y, por ello, la importancia de este estudio radica en el hecho de que muestra que es un patrón general para todo el área. La reducción en la duración de las charcas puede comprometer la estabilidad poblacional de especies que necesitan un periodo prolongado de tiempo para completar la metamorfosis, como es el caso de $P$. cultripes.

La teledetección proporciona información espacial de áreas extensas que difícilmente se podría conseguir mediante muestreos de campos, lo que la convierte en una herramienta muy útil para el seguimiento de los humedales (Shuman y Ambrose 2003). En particular, puede ser extremadamente útil en regiones amplias o con alta densidad de cuerpos de agua, como sería el caso del Parque Nacional de Doñana. Además, la información de la dinámica temporal, proporcionada por las imágenes Landsat, permite realizar un seguimiento que, de otra forma, sería complicado en un sistema tan impredecible y fluctuante. Por tanto la teledetección permite delimitar los hábitats reproductivos de los anfibios, identificar los que albergan un gran número de especies y facilita la comprensión de la dinámica de inundación del sistema, lo que permitirá mejorar la gestión de las poblaciones asociadas a este tipo de medios.
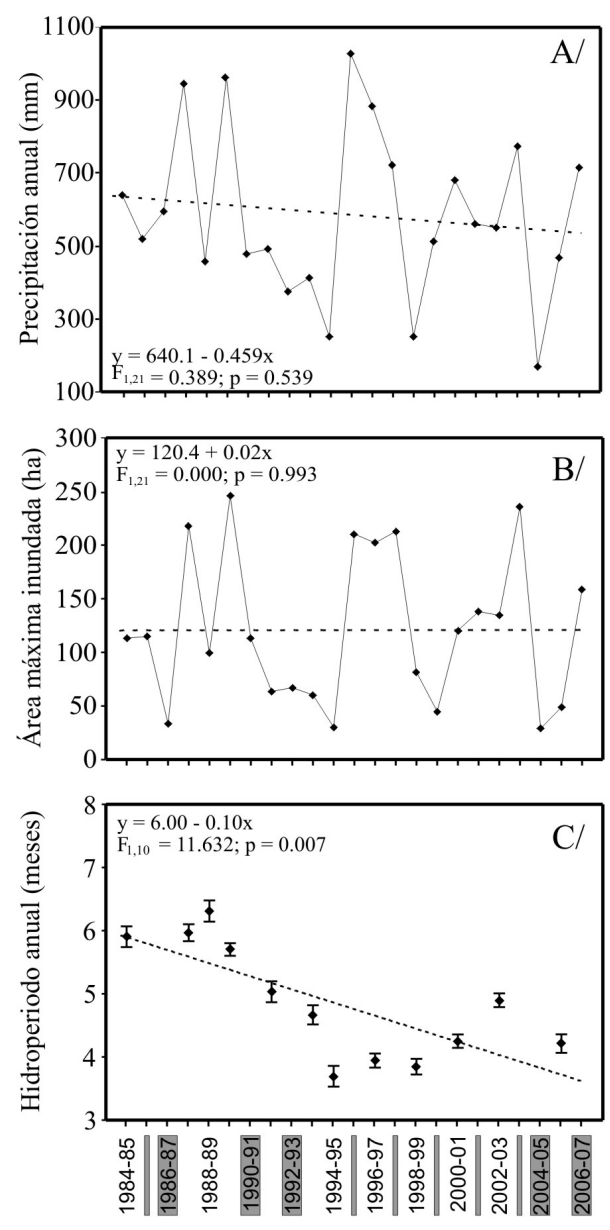

Figura 3. Tendencias interanuales en A/ precipitación anual, B/ área máxima inundada y C/ hidroperiodo anual (media y error estándar). Se muestra también el ajuste lineal del análisis de tendencia (trend analysis). Los años en gris carecen de imágenes suficientes para calcular el hidroperiodo anual. 


\section{V ariabilidad e incertidumbre en el ecosistema}

Como se muestra en el apartado anterior, el sistema de charcas temporales de Doñana está formado por más de 3000 cuerpos de agua, lo que proporciona un amplio número de lugares de reproducción para los anfibios. Sin embargo, la abundancia de cuerpos de agua temporales no es el único elemento clave para la conservación de la fauna, hay que destacar también la gran variabilidad espacial. Las charcas temporales de Doñana pueden ser muy diferentes entre ellas, lo que proporciona un amplio gradiente ambiental en algunas características claves para la reproducción de especies asociadas (p.ej. el hidroperiodo o el área inundada). Por tanto, la idoneidad de estas charcas para la reproducción de anfibios probablemente reside en el amplio gradiente ambiental que cubren en su conjunto. Esta tesis muestra que algunas características de las charcas temporales (p.ej. conductividad) cubren el rango total de valores registrados en charcas temporales mediterráneas. $\mathrm{La}$ heterogeneidad del ecosistema favorece la diversidad de las especies asociadas ya que proporciona más nichos y más recursos ambientales que pueden ser explotados (ver la revisión elaborada por Tews y col. 2004).

La variabilidad temporal del sistema aumenta su relevancia ecológica ya que incrementa la heterogeneidad del hábitat en una escala temporal. La impredecibilidad y la variación temporal, dos de las principales características de los ecosistemas mediterráneos (Blondel y Aronson 1999), son por tanto claves para este sistema de charcas temporales. Este estudio muestra la gran variación interanual en las condiciones meteorológicas y, en consecuencia, en el comportamiento hidrológico y las características de las charcas. El aporte de precipitación y su distribución a lo largo del año determinan cuándo se llenarán las charcas y cuánto tiempo durará la inundación. Por tanto, la lluvia es responsable de que se formen (o no) hábitats reproductivos de los anfibios en un año concreto. Por ejemplo, la escasa precipitación impidió la formación de las charcas en 2004-05, mientras que, en 2005-06, la escasa lluvia otoñal fue responsable de la corta duración de las charcas ese año. Aunque el hecho de que se formen o no las charcas constituye la mayor variación interanual observada, esta tesis también muestra que las características de las charcas pueden variar entre años y, por tanto, las condiciones ambientales que ofrecen como hábitat para los anfibios. Cabe destacar la gran variación interanual en las características del hábitat críticas para la reproducción de los anfibios, como es el área inundada o el hidroperiodo (Wellborn y col. 1996, Spencer y col. 1999, Brooks 2000, Beja y Alcazar 2003, Semlitsch 2003), durante el periodo de 23 años considerado en los análisis de teledetección (Figura 3). Asimismo, otras características de los cuerpos de agua, como es la composición físico-química del agua, también varían dentro de un mismo año y al comparar un año con un patrón de lluvias regular, 2002-03, con un año con escasa lluvia otoñal, 2005-06 (Tabla 2). 
Tabla 2. Variación temporal de al composición fisico-química del agua y el hidroperiodo. Se muestran los resultados de los ANOVAs de Medidas Repetidas (Estadístico de la F, grados de libertad [g.l.] y significación $[\mathrm{p}])$.

\begin{tabular}{|c|c|c|c|}
\hline & $\mathbf{F}$ & g.l. & p \\
\hline Hidroperiodo [meses] & 201.17 & 1,18 & $<0.001$ \\
\hline Máxima profundidad [cm] & 12.363 & 1,15 & 0.003 \\
\hline $\mathrm{pH}$ & 26.575 & 1,14 & $<0.001$ \\
\hline \multicolumn{4}{|l|}{ Conductividad y composición iónica } \\
\hline Conductividad $[\mu \mathrm{S} / \mathrm{cm}]$ & 3.197 & 2,26 & 0.057 \\
\hline Cloruro $\left(\mathrm{Cl}^{-}\right)[\mathrm{mg} / \mathrm{l}]$ & 7.048 & 2,30 & 0.003 \\
\hline Sulfato $\left(\mathrm{SO}_{4}{ }^{2-}\right)[\mathrm{mg} / \mathrm{l}]$ & 8.166 & 2,30 & 0.001 \\
\hline Sodio $\left(\mathrm{Na}^{+}\right)[\mathrm{mg} / \mathrm{l}]$ & 4.126 & 2,30 & 0.026 \\
\hline Potasio $\left(\mathrm{K}^{+}\right)[\mathrm{mg} / \mathrm{l}]$ & 1.076 & 2,30 & 0.354 \\
\hline Magnesio $\left(\mathrm{Mg}^{2+}\right)[\mathrm{mg} / \mathrm{l}]$ & 9.476 & 2,30 & 0.001 \\
\hline Calcio $\left(\mathrm{Ca}^{2+}\right)[\mathrm{mg} / \mathrm{l}]$ & 0.745 & 2,30 & 0.484 \\
\hline $\mathrm{Na}^{+} / \mathrm{Mg}^{2+}$ & 7.439 & 2,30 & 0.002 \\
\hline \multicolumn{4}{|l|}{ Nutrientes } \\
\hline Compuestos nitrogenados $[\mu \mathrm{M}]$ & 1.533 & 2,30 & 0.232 \\
\hline Nitrato $\left(\mathrm{NO}_{3}^{-}\right)[\mu \mathrm{M}]$ & 7.325 & 2,30 & 0.003 \\
\hline Amonio $\left(\mathrm{NH}_{4}^{+}\right)[\mu \mathrm{M}]$ & 5.273 & 2,30 & 0.011 \\
\hline Fosfato inorgánico disuelto $[\mu \mathrm{M}]$ & 4.874 & 2,30 & 0.015 \\
\hline \multicolumn{4}{|l|}{ Parámetro biológico } \\
\hline Clorofila-a $[\mu \mathrm{g} / \mathrm{l}]$ & 8.215 & 2,30 & 0.001 \\
\hline
\end{tabular}


No sólo las características de las charcas mostraron variación temporal durante el periodo de estudio, también lo hicieron las agrupaciones de anfibios. Estos variaron en el número de especies, en su composición específica y en la abundancia de las especies que los componían (Figuras 4 y 5 ).
El cambio más drástico ocurrió en 2004-05, cuando las charcas temporales no llegaron a formarse $\mathrm{y}$, por tanto, las especies de anfibios no tuvieron la oportunidad de reproducirse. Sin embargo, si consideramos exclusivamente "temporadas reproductoras reales", cuando las especies sí se
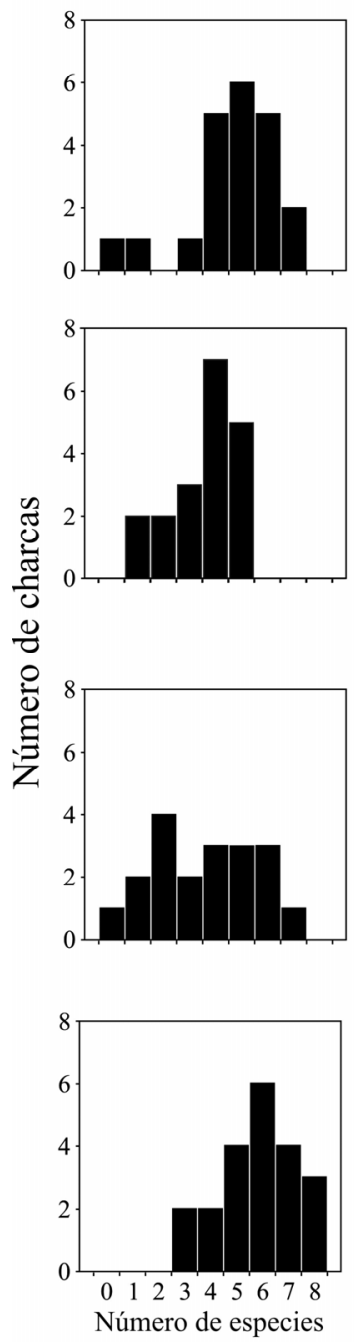
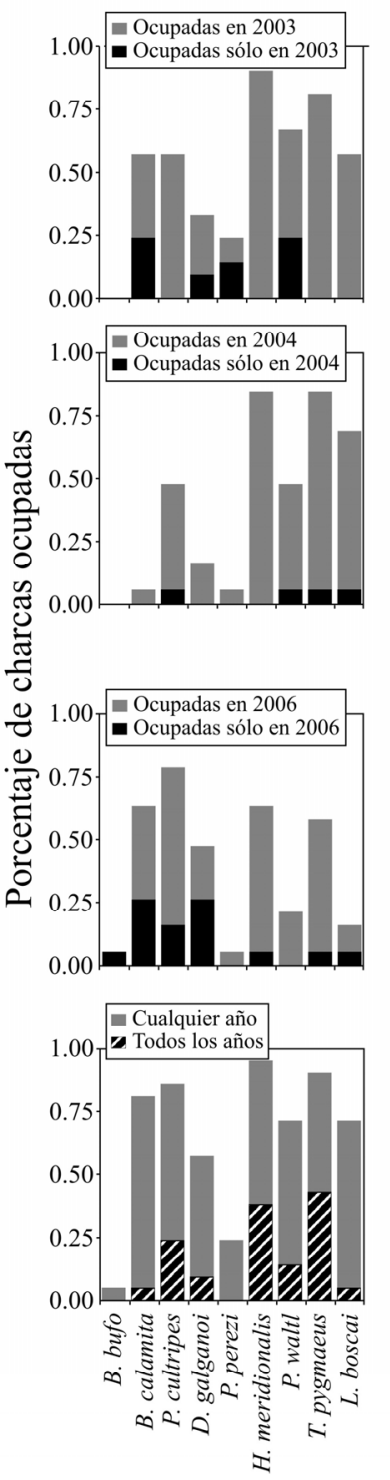

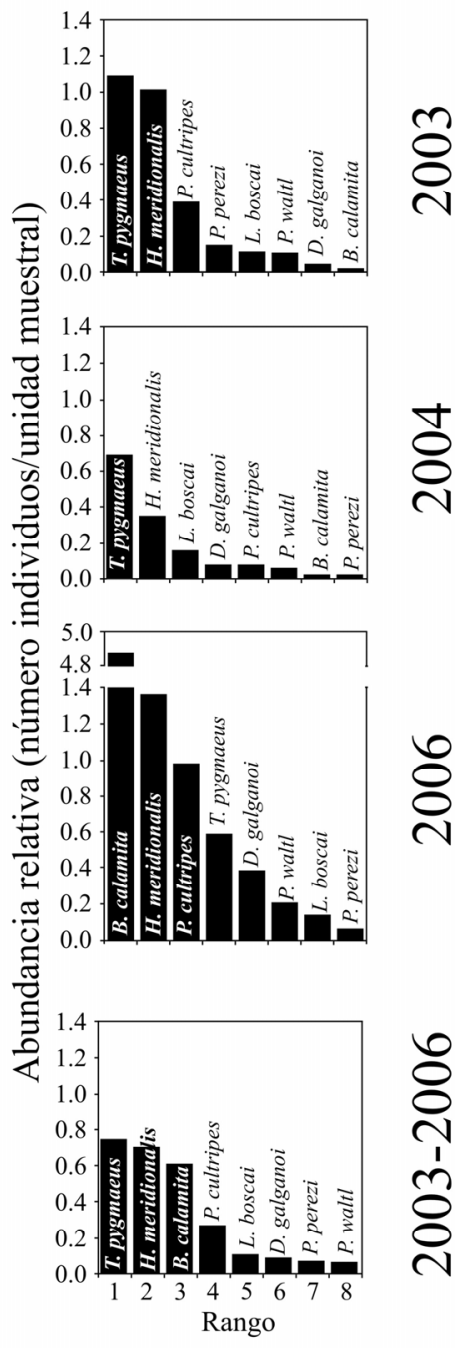

$\wp_{N}$

Figura 4. Histogramas de la riqueza de especies, porcentaje de charcas ocupadas por cada especie y abundancia relativa en cada temporada reproductora y a lo largo de todo el periodo de estudio. 
reprodujeron, la amplia variación interanual de las agrupaciones no se vio reflejada a escala regional, como muestra el hecho de que todas las especies excepto B.bufo intentaron reproducirse en todas y cada una de las temporadas reproductoras. Por tanto, cabe resaltar que, ni el retraso en la formación de las charcas ni la reducción del hidroperiodo en 2005-06, un año teóricamente desfavorable, impidieron que todas las especies intentaran reproducirse en el área de estudio. Este resultado es acorde con la estabilidad que se espera en un sistema de charcas con una estructura espacial tan robusta, en el cual la

\section{Presencia/ausencia}

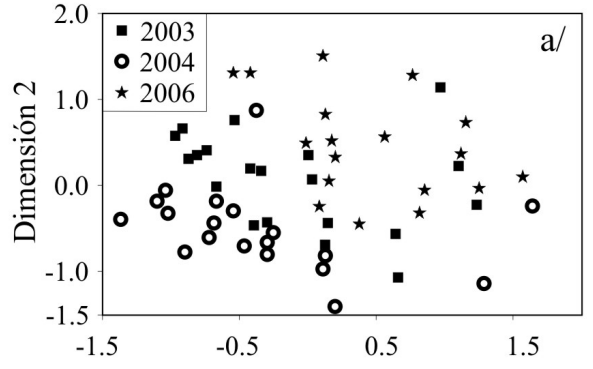

Dimensión 1

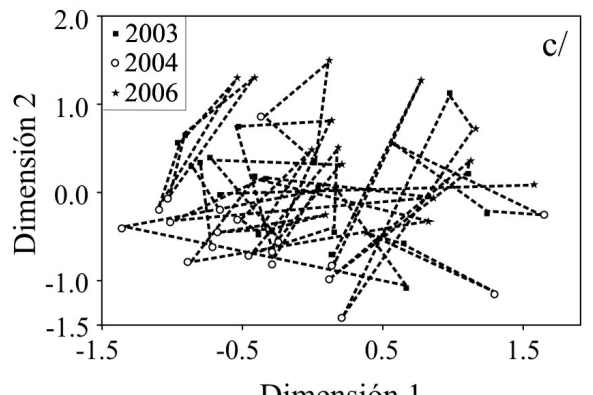

Dimensión 1 disposición espacial de la charcas permite que cualquier individuo pueda acceder a una charca, dentro de su rango de dispersión, incluso en año desfavorables en los que muchas charcas no se inundan (Fortuna y col. 2006). La amplia variación interanual de los agrupaciones de anfibios no es sorprendente, ya que ha sido previamente descritos en la literatura científica (Trenham y col. 2003, Werner y col. 2007) y, además, altas tasas de variación temporal son características de hábitats no estables (Moreno y Halffter 2001), como las charcas temporales del sistema de estudio.
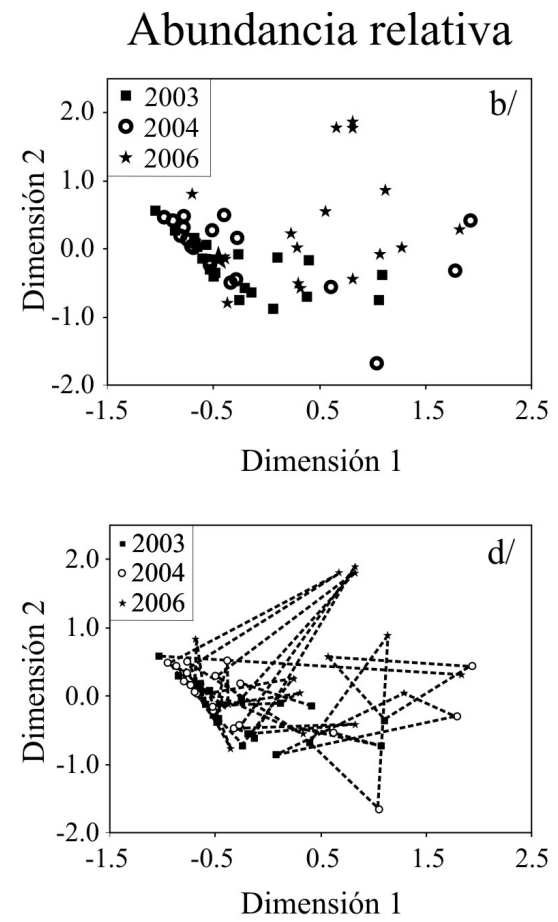

Figura 5. Gráficos de ordenación que muestran la similitud en la composición de las agrupaciones entre charcas y años basados en datos de presencia/ausencia (a/ y c/) y en datos de abundancia relativa (b/ y d/). Cada caso representa la composición de la agrupación en un año determinado. $\mathrm{c} /$ representa la misma ordenación que a/ pero los casos que corresponden a la misma charca han sido unidos mediante una línea discontinua para mostrar la variación de cada charca. Lo mismo se aplica a b/ y d/. 
La gran variación interanual de las condiciones ambientales y la composición de las agrupaciones repercute en los resultados obtenidos en los modelos de selección de hábitat (Tabla 3). Las características de la charca importantes para explicar las diferencias en riqueza o la presencia/ausencia de especies concretas varían entre temporadas reproductoras (2003-03 y 2005-06). Es decir, en este sistema tan dinámico, los modelos de selección de hábitat son específicos para cada año. Piha y col. (2007) publicaron un resultado similar para Rana temporaria en el norte Europa al comparar años con diferentes condiciones meteorológicas. En este estudio, la inconsistencia en los modelos de selección de hábitat se atribuye a las diferencias interanuales en el rango de variación (valor mínimo - valor máximo) del hidroperiodo y la mayor parte de las variables físico-químicas. Teóricamente, la respuesta de una especie a un gradiente ambiental debe tener una forma gausiana (distribución normal) a lo largo de todo el gradiente (Austin 2002). De esta forma, la respuesta de una especie a un determinado gradiente ambiental puede variar entre años si el rango anual de variación ambiental es sólo una fracción de todo el gradiente y, además, puede cubrir diferentes regiones del gradiente dependiendo del año. Por ejemplo, inferiremos una respuesta positiva cuando la variación ambiental observada se localice en los valores más bajos del gradiente potencial de la variable. Por el contrario, inferiremos una ausencia de respuesta si se localiza en la mitad del gradiente, en el pico de la curva teórica de la relación especie-hábitat.

Las relaciones entre la diversidad de anfibios y las condiciones ambientales también son específicas de cada año. Las variables ambientales que cambian con el tiempo (p.ej. el hidroperiodo o la composición físico-química del agua) explicaron los gradientes de riqueza en el año 2005-06 pero no en el 2002-03. No obstante, tuvieron un papel significativo a la hora de explicar la variación en la composición de la agrupación en ambos años. Este resultado concuerda parcialmente con los resultados esperados para el sistema, ya que era esperable que las características del hábitat que cambian con el tiempo fueran importantes promotores de la diversidad anual. Sin embargo, un resultado inesperado fue que las variables que no cambian con el tiempo (p.ej. la localización de la charca o las características del hábitat terrestre) fueran las únicas que explicaron la riqueza anual en 2003. Una explicación plausible de este resultado sería que, en 2003, un año hidrológicamente favorable, los valores ambientales no supusieron un fuerte estrés ambiental y, por tanto, la mayoría de las especies intentaron reproducirse en todas las charcas que estaban a su alcance. De esta forma, prácticamente todos los individuos que estivaban en los alrededores de una charca habrían acudido a la misma durante el periodo reproductor del año 2002-03. La presencia de esos individuos en los alrededores de la charca estaría relacionada con características más estables del hábitat (como son las cubiertas terrestres), ya que estas condicionan la probabilidad de supervivencia a medio plazo de los individuos durante su fase adulta. Una conclusión importante es que, a pesar de que la hidrología y la composición físico-química del agua están teóricamente interrelacionadas con las características paisajísticas (Batzer y col. 2004), ambos tipos de variables deben ser incluidos en los estudios de diversidad de anfibios. 
Tabla 3. Modelos de hábitat con alto soporte empírico construidos a partir de la riqueza de especies y su abundancia relativa anual. Se muestra el número de modelos con alto soporte y su rango de valores $\mathrm{R}^{2}$ ajustados. Para cada variable se muestra el signo de la relación [(+): positiva; (-): negativa] y su importancia relativa. Los valores de importancia relativa superiores a 0.7 están resaltados en negrita.

\begin{tabular}{|c|c|c|c|c|c|c|c|c|c|}
\hline & & \multicolumn{8}{|c|}{$\begin{array}{l}\text { Modelos con soporte Importancia relativa de los predictores ambientales } \\
\text { empírico relevante }\end{array}$} \\
\hline & ก̃̃o & $\mathbf{N}$ & $\mathrm{R}^{2}$ aj. (min-max) & PCA_1 & PCA_2 & $\overline{\text { PCA_3 }}$ & PCA_4 & PCA_5 & PCA_6 \\
\hline Riqueza & 2003 & 2 & $\begin{array}{l}0.508-0.55 \\
0.572 *\end{array}$ & $\begin{array}{c}(-) \\
0.249 \\
(-) \\
0.961\end{array}$ & $\begin{array}{c}(+) \\
0.214 \\
(+) \\
0.999\end{array}$ & $\begin{array}{c}(-) \\
0.498 \\
(-) \\
0.174\end{array}$ & $\begin{array}{c}(-) \\
0.999 \\
(-) \\
0.136\end{array}$ & $\begin{array}{c}(+) \\
0.160 \\
(+) \\
0.142\end{array}$ & $\begin{array}{c}(+) \\
0.170 \\
(+) \\
0.148\end{array}$ \\
\hline B. calamita & 2003 & & agún modelo (solo u & in caso co & n datos 1 & o nulos) & & & \\
\hline & 2006 & 5 & $0.385-0.608 *$ & $\begin{array}{c}(+) \\
0.723\end{array}$ & $\begin{array}{c}(-) \\
0.882\end{array}$ & $\begin{array}{c}(-) \\
0.110\end{array}$ & $\begin{array}{c}(-) \\
0.364\end{array}$ & $\begin{array}{c}(+) \\
0.606\end{array}$ & $\begin{array}{c}(-) \\
0.113\end{array}$ \\
\hline P. cultripes & 2003 & 4 & $\begin{array}{l}0.167-0.274 \text { (n.s) } \\
0.367-0.493 * *\end{array}$ & $\begin{array}{c}(-) \\
0.446 \\
(-) \\
0.971\end{array}$ & $\begin{array}{c}(+) \\
0.365 \\
(+) \\
0.617\end{array}$ & $\begin{array}{c}(+) \\
0.175 \\
(+) \\
0.143\end{array}$ & $\begin{array}{c}(-) \\
0.169 \\
(+) \\
0.129\end{array}$ & $\begin{array}{c}(+) \\
0.752 \\
(+) \\
0.207\end{array}$ & $\begin{array}{c}(+) \\
0.170 \\
(+) \\
0.132\end{array}$ \\
\hline D. galganoi & 2003 & 4 & $0.278-0.404 *$ & $\begin{array}{c}(-) \\
0.314 \\
(-) \\
0.121\end{array}$ & $\begin{array}{c}(-) \\
0.145 \\
(+) \\
0.281\end{array}$ & $\begin{array}{c}(-) \\
0.201 \\
(+) \\
0.990\end{array}$ & $\begin{array}{c}(+) \\
0.338 \\
(+) \\
0.988\end{array}$ & $\begin{array}{c}(+) \\
0.940 \\
(+) \\
0.269\end{array}$ & $\begin{array}{c}(-) \\
0.618 \\
(-) \\
0.112\end{array}$ \\
\hline P. perezi & $\begin{array}{l}2003 \\
2006\end{array}$ & & $\begin{array}{l}\text { agún modelo (solo tı } \\
\text { agún modelo (solo u }\end{array}$ & $\begin{array}{l}\text { res casos } \\
\text { in caso co }\end{array}$ & on dato & no nulos & & & \\
\hline$H$. & 2003 & 2 & $0.853-0.864 * * *$ & $(-)$ & $(-)$ & $(-)$ & $(-)$ & $(-)$ & $(-)$ \\
\hline neridionalis & 2006 & 2 & $0.467-0.321 * *$ & $\begin{array}{l}0.324 \\
(-) \\
0.952\end{array}$ & $\begin{array}{l}0.157 \\
(+) \\
0.648\end{array}$ & $\begin{array}{l}1.000 \\
(-) \\
0.208\end{array}$ & $\begin{array}{l}0.199 \\
(-) \\
0.136\end{array}$ & $\begin{array}{l}0.999 \\
(+) \\
0.141\end{array}$ & $\begin{array}{l}1.000 \\
(+) \\
0.164\end{array}$ \\
\hline P. waltl & 2003 & 3 & $0.253-0.451 *$ & $\begin{array}{l}(-) \\
0.423 \\
(-) \\
0.798\end{array}$ & $\begin{array}{l}(+) \\
0.713 \\
(+) \\
0.249\end{array}$ & $\begin{array}{l}(-) \\
0.866 \\
(-) \\
0.314\end{array}$ & $\begin{array}{l}(-) \\
0.198 \\
(-) \\
0.224\end{array}$ & $\begin{array}{l}(-) \\
0.171 \\
(+) \\
0.149\end{array}$ & $\begin{array}{l}(-) \\
0.189 \\
(+) \\
0.418\end{array}$ \\
\hline T.pygmaeus & 2003 & 3 & $0.456-0.549 * *$ & $\begin{array}{l}(-) \\
0.135 \\
(+) \\
0.151\end{array}$ & $\begin{array}{l}(-) \\
0.740 \\
(+) \\
0.146\end{array}$ & $\begin{array}{l}(-) \\
0.458 \\
(+) \\
0.143\end{array}$ & $\begin{array}{l}(-) \\
0.383 \\
(-) \\
0.233\end{array}$ & $\begin{array}{l}(-) \\
0.982 \\
(-) \\
0.915\end{array}$ & $\begin{array}{l}(-) \\
0.158 \\
(-) \\
0.368\end{array}$ \\
\hline L. boscai & 2003 & 2 & $0.355-0.443 *$ & $\begin{array}{l}(-) \\
0.156\end{array}$ & $\begin{array}{l}(-) \\
0.841\end{array}$ & $\begin{array}{l}(-) \\
0.502\end{array}$ & $\begin{array}{l}(+) \\
0.177\end{array}$ & $\begin{array}{l}(-) \\
0.772\end{array}$ & $\begin{array}{l}(-) \\
0.148\end{array}$ \\
\hline
\end{tabular}

(n.s) Ningún modelo con $\mathrm{p}<0.05$

* Todos los modelos con $\mathrm{p}<0.05$

** Todos los modelos con $\mathrm{p}<0.01$

*** Todos los modelos con $\mathrm{p}<0.001$ 
Esta gran variabilidad temporal, tanto biótica como abiótica, dificulta cualquier estudio ecológico que se lleve a cambo en el sistema. En concreto, en este estudio se ha prestado atención a cuatro cuestiones relevantes, con la intención de minimizar las fuentes de sesgo o error: i/ ¿cuándo se deben muestrear las características del hábitat que varían con el tiempo? ii/ ¿cuál es la escala temporal adecuada (anual o medio plazo) para realizar los inventarios bióticos y estudiar los requerimientos de hábitat de las especies? iii/ ¿cuál es el esfuerzo de muestreo adecuado para caracterizar la comunidad de anfibios y cuándo se deben realizar los muestreos? iv/ ¿cuál es la variable respuesta más adecuada en los modelos de requerimientos de hábitat de las especies, la abundancia relativa o la presencia/ausencia de la especie?

¿Cuándo debemos muestrear las características del hábitat que varían con el tiempo?

Existe una marcada independencia entre los valores de una misma característica ambiental medidos en diferentes fechas. Este resultado evidencia que la descripción de una charca basada en datos de un único muestreo puede no ser representativa de las características de la charca en otras fechas diferentes. Además, la marcada variación temporal de los valores absolutos de las variables físico-químicas sugiere que las medidas de tendencia central (p.ej. media aritmética) a lo largo del tiempo pueden ser inadecuadas para describir una charca temporal. De hecho, los valores promedio sólo tienen sentido cuando las características ambientales fluctúan en torno a un valor determinado. Sin embargo, en el caso de las charcas temporales, el valor de la mayoría de las variables físicoquímicas aumenta o disminuye con el tiempo, estando también sujeto a cambios radicales por eventos estocásticos (p.ej. rellenado por lluvia). Por todas estas razones, es necesario realizar un muestreo repetido de las variables ambientales que cambian con el tiempo para poder describir tanto las características de una charca como su variación temporal.

¿Cuál es la escala temporal adecuada para realizar los inventarios bióticos y estudiar los requerimientos de hábitat de las especies de anfibios: estudios anuales o a medio plazo?

Teniendo en cuenta que las agrupaciones de anfibios varían de año en año, se necesitan datos recogidos a lo largo de varias temporadas reproductivas para poder caracterizar la agrupación de anfibios asociado a una charca concreta. Cuando la variabilidad interanual es elevada, como en el área de estudio, la ausencia de una especie de una charca en un año determinado se debe interpretar como un evento que podría ser temporal. Por ello, el medio plazo sería la escala temporal lógica para realizar los estudios de selección de hábitat cuyo objetivo sea la conservación a medio-largo plazo de la comunidad. La escala temporal alternativa, los estudios anuales, presenta dos inconvenientes principales. En primer lugar, los modelos construidos con datos anuales no son transferibles de año en año y por tanto, su utilidad es limitada para identificar los requerimientos ecológicos de las especies o el efecto de las variables ambientales en los patrones de diversidad. En segundo lugar, las características dinámicas del hábitat varían a lo largo de una misma temporada y, además, los valores de una misma variable medidos en diferentes fechas no están relacionados. Por ello, podemos inferir diferentes relaciones ecológicas dependiendo de la fecha en la que se midieron las variables ambientales $y$, además, no podríamos establecer a priori cuales son más realistas. En ese caso, una solución parcial sería resumir todas las 
características ambientales, incluyendo los valores medidos en diversas fechas, en un número reducido de variables por medio de un Análisis de Componentes Principales, por ejemplo.

¿Cuál es el esfuerzo de muestreo adecuado para caracterizar la comunidad de anfibios y cuándo se deben realizar los muestreos?

Este estudio demuestra la variabilidad e incertidumbre en la eficacia de los muestreos de anfibios realizados en charcas temporales. Este resultado no está restringido sólo a las comunidades de anfibios, sino que puede ser extrapolado a otros taxones que se reproducen en este tipo de medios. Como se ha mencionado anteriormente, la gran variación interanual de las agrupaciones de las charcas es la causa principal de la ineficacia de los muestreos realizados exclusivamente en una única temporada reproductora. Por tanto, es recomendable realizar muestreos en diferentes temporadas. En estudios a nivel de comunidad, se deberían realizar además varios muestreos a lo largo de una misma temporada, ya que la eficacia de un único muestreo para detectar todas las especies es muy baja. Esto ha sido evidente en los muestreos realizados a lo largo de esta tesis, ya que no fue posible detectar todas las especies en ningún muestreo (Figura 6) y, además, la detectabilidad de las mismas en un único muestreo fue baja o moderada en la mayoría de los casos (Figura 7).
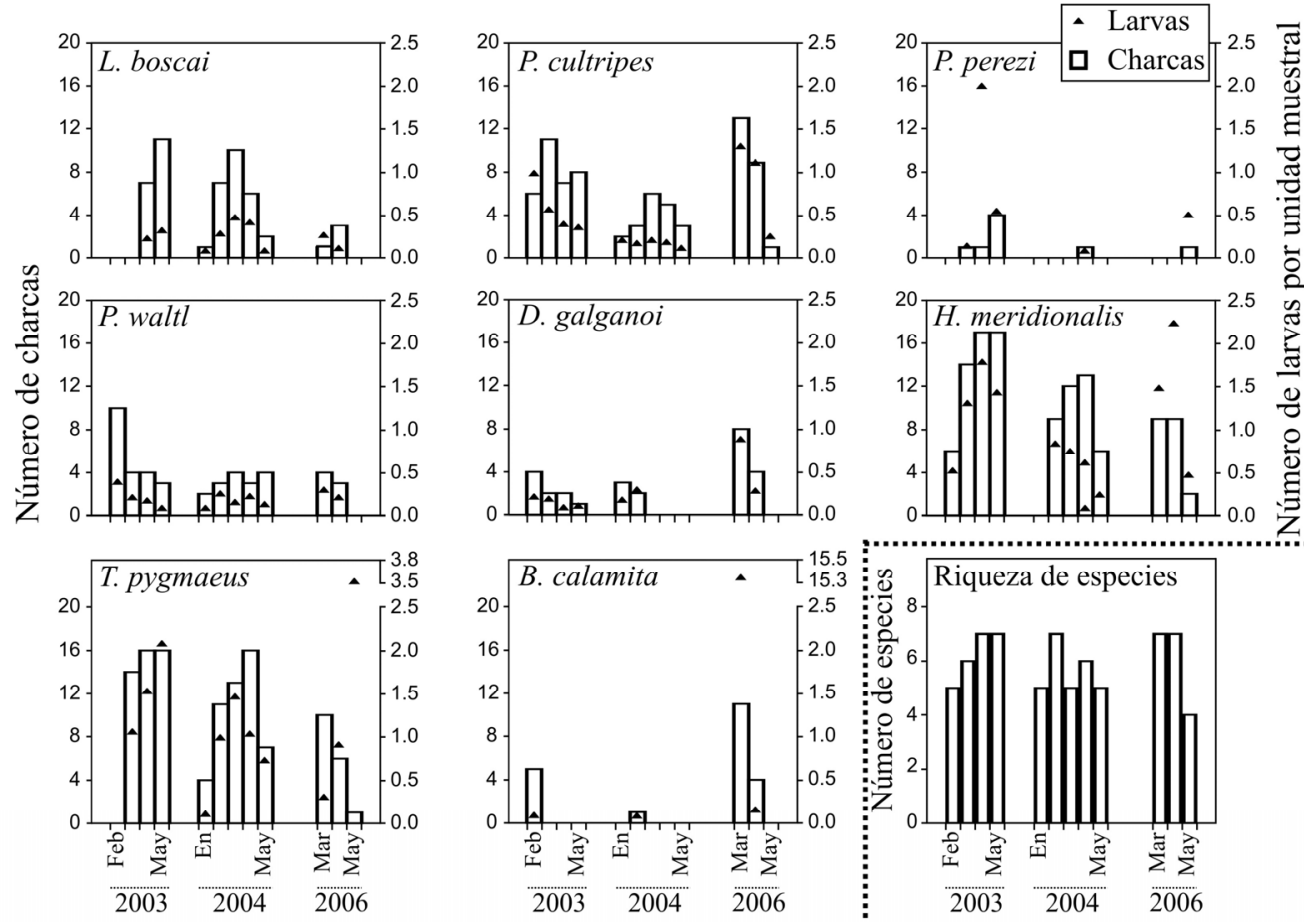

Figura 6. Abundancia relativa y número de charcas ocupadas por cada especie en cada mes de muestreo. También se muestra el número de especies detectadas en el área de estudio. 


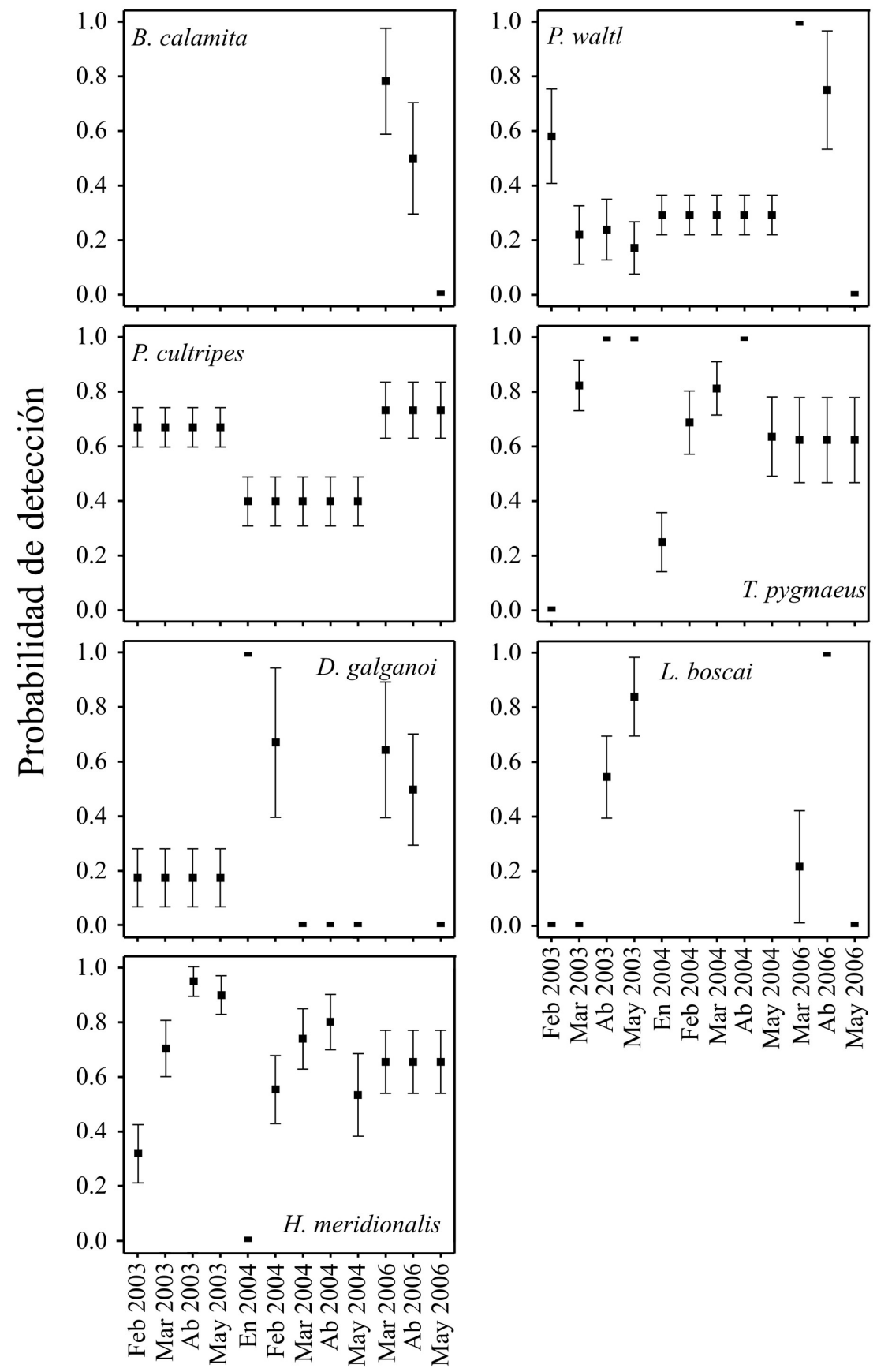

Figura 7. Probabilidad de detección mensual realizando un único muestreo. 
Si el estudio se centra en la distribución de una única especie, un único muestreo sería suficiente si se realizara justo en el momento en el que la probabilidad de detectar la especie (cuando estuviera presente) fuera prácticamente perfecta $(\approx$ $100 \%$ ). No obstante, es prácticamente imposible diseñar un muestreo con este objetivo, ya que el mejor mes de muestreo varió entre años $\mathrm{y}$, además, no era predecible de un año a otro (Figura 7). Por lo tanto, la repetición de los muestreos a lo largo de una misma temporada también es altamente recomendable en los estudios de distribución de una única especie. En resumen, esta tesis muestra la amplia variación de la detectabilidad de una especie a lo largo del tiempo y las diferencias en detectabilidad entre especies. Este resultado genera una amplia variabilidad en la fiabilidad de las ausencias en los inventarios bióticos (Figura 8). En términos generales, la fiabilidad de una ausencia depende de la especie muestreada, del número de muestreos y la fecha en la que fueron realizados. La principal implicación de este resultado es que no se deben considerar "ausencias reales" todos los registros de no-detecciones y, ni siquiera, asumir que la fiabilidad de todos los registros en los que no se detecta la especie es la misma.

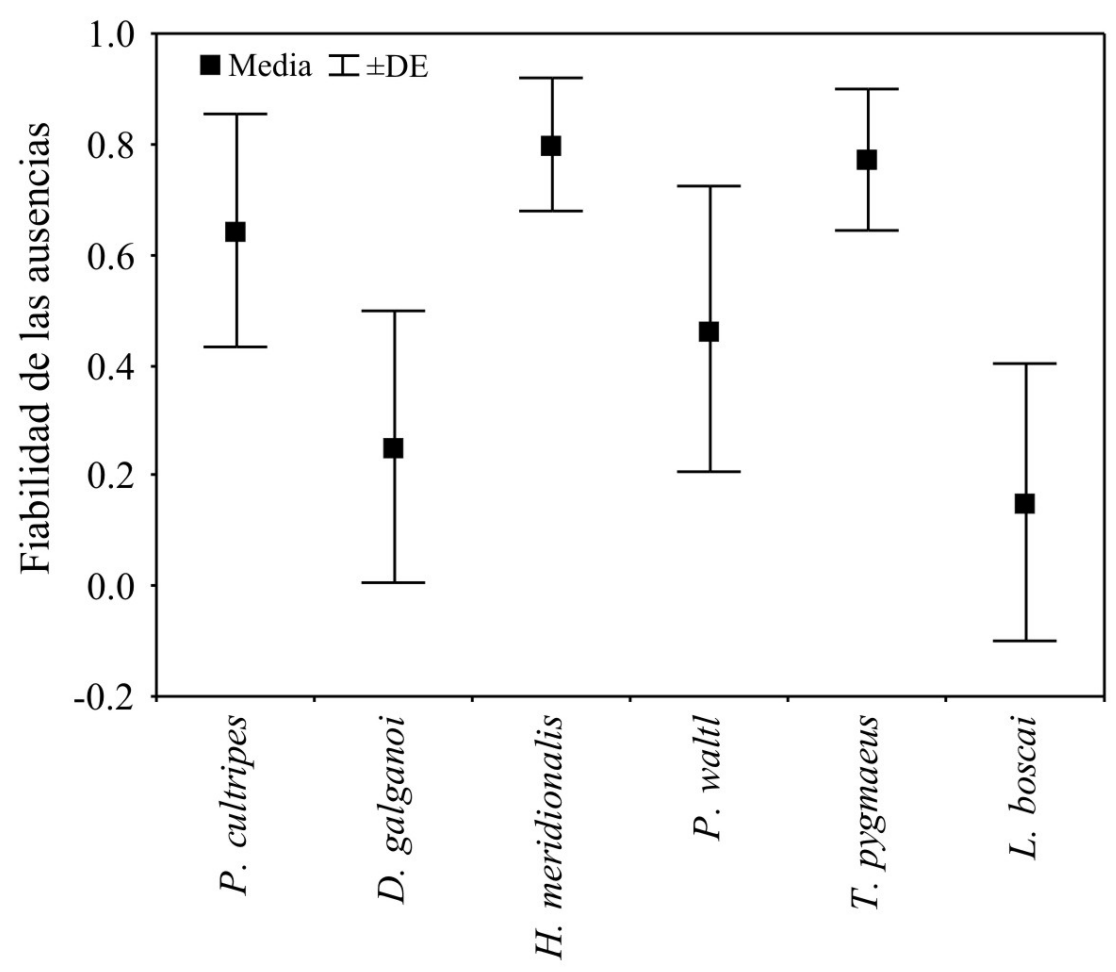

Figura 8. Valor medio y desviación estándar de la fiabilidad de las ausencias obtenida a partir del muestreo intensivo y extensivo. 
¿Cuál es la variable respuesta más adecuada en los modelos de requerimientos de hábitat de las especies, la abundancia relativa o la presencia/ausencia de la especie?

En esta tesis se han realizado modelos de selección de hábitat usando dos tipos de variable respuesta: la abundancia relativa de las especies (calculada como "número de individuos capturados por unidad de esfuerzo") y su presencia o ausencia. Schmidt y Pellet (2005) recomiendan el uso de la abundancia en vez de la presencia/ausencia en los modelos de hábitat, ya que proporciona más información acerca de la idoneidad del hábitat dado que la ausencia y la presencia son sólo dos casos particulares de abundancia (abundancia $=0$ y abundancia $>0$, respectivamente). Sin embargo, dada la gran variabilidad temporal existente en los sistemas de charcas temporales, hay que tener en cuenta que las estimaciones de la abundancia relativa pueden depender del momento en el que se realizan los muestreos. Por ejemplo, si tenemos un número constante de larvas en una charca, la proporción de ellas que capturaremos en un único muestreo será probablemente mayor cuando la superficie inundada de la charca sea reducida (todas las larvas se encuentran en un área pequeña y, por tanto, es más fácil capturarlas) que cuando la charca se extiende sobre una amplia superficie. Por tanto, para un número idéntico de individuos en la charca, la abundancia relativa estimada dependerá, al menos en parte, de la extensión de la charca, ya que esta favorecerá (o no) su detección y captura.

Por otro lado, las presencia de una especie ha sido equiparada a la "evidencia de reproducción" (breeding attempt) en la charca. De esta forma, se está asumiendo de forma implícita que una especie siempre selecciona un hábitat favorable para reproducirse. Esta asunción, sin embargo, puede ser falsa si las especies no son capaces de seleccionar los mejores hábitats para su reproducción. En ese caso, los hábitats no favorables pueden estar ocupados si la especie no realiza ningún tipo de selección (p.ej. la especie posee una estrategia de reproducción oportunista y se reproduce en todas la charcas disponibles/accesibles sin tener en cuenta la probabilidad de éxito reproductor que le proporcionan) o si lo selecciona basándose en información incompleta (p.ej. las condiciones ambientales son favorables cuando el individuo realiza la ovoposición, pero se vuelven desfavorables con el tiempo, durante el desarrollo larvario) (la teoría ecológica subyacente está detallada en Pulliam 1996). De hecho, como la mayoría de las especies de anfibios que se reproducen en charcas temporales son estrategas de la r, no sería sorprendente que los individuos no seleccionaran hábitats específicos para su reproducción y, por el contrario, se reprodujeran en un amplio número de cuerpos de agua, independientemente de sus características, para aumentar la probabilidad de éxito reproductivo. Por otro lado, también es factible que exista selección de hábitat pero que se realice en base a información incompleta o inadecuada. La filopatría, que consiste en volver al lugar en el que se nació para reproducirse, es uno de los principales mecanismos de selección de hábitat en los anfibios. Sin embargo, la filopatría puede ser un mal indicador de la idoneidad del hábitat en los ecosistemas de charcas temporales, ya que las características del hábitat varían de año en año. Por esa razón, es posible que la "selección de hábitat reproductivo" no sea equivalente a "éxito reproductivo" en este tipo de sistema y que, por tanto, sea un indicador imperfecto de la idoneidad del hábitat. Una alternativa sería muestrear estadíos de desarrollo directamente asociados con el éxito reproductor (p.ej. 
individuos metamórficos) para determinar la idoneidad del hábitat. El principal inconveniente de esta variable respuesta es que la detectabilidad de individuos en estadío metamórfico es probablemente más baja que cuando se encuentran en estadío larvario, principalmente porque ocupan la charca durante un periodo de tiempo más reducido. De esta forma, sería necesario concentrar los muestreos en un breve periodo de tiempo, lo que limitaría el número de cuerpos de agua que se podrían visitar y, por tanto, el tamaño muestral del estudio.

\section{Estudios de diversidad y los} requerimientos de hábitat de las especies de anfibios en el Parque Nacional de Doñana

\section{Nivel de agrupación}

Esta tesis demuestra que las relaciones entre las características ambientales y la diversidad de especies deben evaluarse a distintas escalas espaciales para que se contemplen todos los patrones de diversidad que pueden existir en el área. De esta forma, los estudios de diversidad deben complementar las conclusiones basadas en diversidad alfa (riqueza de especies) con análisis que expliquen la diversidad beta (variación en la composición entre agrupaciones). Por ejemplo, este estudio muestra que las variables físico-químicas del agua pueden ser poco importantes para explicar los gradientes de riqueza pero tener un papel destacado en la variación de la composición de las agrupaciones. Este resultado implica que las características irrelevantes para la riqueza de especies en charcas concretas (diversidad alfa) pueden ser responsables de las diferencias en la composición de las agrupaciones (diversidad beta) $\mathrm{y}$, por tanto, estarían contribuyendo a un incremento en la diversidad de especies en todo el área de estudio (diversidad gamma). Este resultado refuerza la idea de que la diversidad beta es un concepto clave para comprender el funcionamiento de los ecosistemas, para optimizar su manejo y para la conservación de la biodiversidad (Legendre y col. 2005).

El hidroperiodo, una de los factores ambientales que determina en mayor grado la composición de las agrupaciones de especies en los cuerpos de agua (Wellborn y col. 1996), merece una mención aparte. Para proporcionar una visión integral de la importancia del hidroperiodo en esta comunidad de anfibios, detallaremos también los resultados obtenidos a nivel de especie, no sólo a nivel de agrupación. Cuando se analizó la presencia de las especies en las charcas, el hidroperiodo no se mostró como un factor ambiental determinante de la ocupación. Si tenemos en cuenta los datos tanto del 2003 como el 2006, todas las especies intentaron reproducirse en charcas a lo largo de todo el gradiente de hidroperiodo excepto $P$. perezi y B. bufo (Fig. 9).

$\mathrm{Si}$ se examina la relación entre el hidroperiodo y los patrones de diversidad, se observan diferencias interanuales en el papel del hidroperiodo, las cuales estarían en consonancia con las variaciones interanuales en los modelos de selección de hábitat a nivel de especie y de agrupación. El hidroperiodo no se mostró como una variable ambiental importante en el año 2003, cuando el hidroperiodo de las charcas fue largo (4-9 meses). Por el contrario, en el año 2006, cuando la duración de las charcas fue corta ( $\leq 4$ meses), el gradiente de hidroperiodo explicó el gradiente de riqueza y, principalmente, el patrón de anidamiento en la presencia/ausencia de las especies (Tabla 4). Además, el hidroperiodo también era parcialmente responsable de la variación en la composición de la 
agrupación medida en función de la abundancia relativa de las especies. Teniendo todo esto en cuenta, estos resultados muestran un incremento en el número de especies a lo largo del gradiente de hidroperiodo, principalmente producido por la inclusión de nuevas especies en la agrupación (Fig. 10). Asimismo, también existirían pequeñas diferencias en el predominio de las especies entre agrupaciones en función del hidroperiodo de la charca. La escasa relevancia del hidroperiodo en 2003 se atribuye a la larga duración de las charcas de menor hidroperiodo ese año, que fue superior al periodo de tiempo que requieren las especies con largo desarrollo larvario para completar la metamorfosis (p.ej. P. cultripes según Díaz-Paniagua y col. 2005). De esta forma, las especies de anfibios no estuvieron sometidas a un fuerte estrés por desecación y, por ello, uno de los principales rasgos ecológicos responsable de la estructura de las agrupaciones en función del gradiente de hidroperiodo (la tolerancia al estrés por desecación) no fue crítico ese año. De forma adicional, la variación interanual en el papel del hidroperiodo podría estar relacionada no sólo con la idoneidad del hábitat, sino también con su disponibilidad. Teniendo en cuenta la fuerte segregación temporal en las comunidades larvarias de esta área dentro de una misma temporada reproductiva (Díaz-Paniagua 1988), la duración de una charca condicionará el número de especies que pueden reproducirse en ella, independientemente de los requerimientos ecológicos que tengan. Es decir, las charcas muy efímeras (p.ej. 1-2 mees) pueden no coincidir en el tiempo con la reproducción de todas las especies mientras que las charcas con valores de hidroperiodo superiores a un umbral determinado (p.ej. 4-5 meses) serían hábitats reproductivos que estarían disponibles para todas las especies.

Varios autores han analizado previamente el papel del hidroperiodo en los patrones de diversidad de anfibios: p.ej. riqueza de especies (Beja y Alcazar 2003, Babbitt 2005, Werner y col. 2007), anidamiento (Baber y col. 2004, Werner y col. 2007) o diversidad beta (Snodgrass y col. 2000). Sin embargo, este estudio es el primero que proporciona un análisis integral de la importancia del hidroperiodo en todos los niveles de diversidad: variación en la riqueza de especies, variación en la composición de la agrupación y variación en la diversidad beta. Además, también tiene en cuenta diferentes tipos de patrones de variación en la composición de la agrupación (patrones de diversidad beta), p.ej. patrones anidados, remplazo en la presencia/ausencia de especies o remplazo en la abundancia de las especies. La conclusión principal es que el hidroperiodo de la charca puede determinar los patrones de diversidad en años hídricamente desfavorables, cuando la duración de las charcas es baja y se produce un fuerte anidamiento a lo largo del gradiente de hidroperiodo. Por el contrario, el papel del hidroperiodo es despreciable en años húmedos, cuando el riesgo de desecación no es una fuente principal de estrés ambiental y la charca está disponible durante un periodo prolongado de tiempo, lo que permite que sea accesible para la reproducción de la práctica totalidad de las especies. 


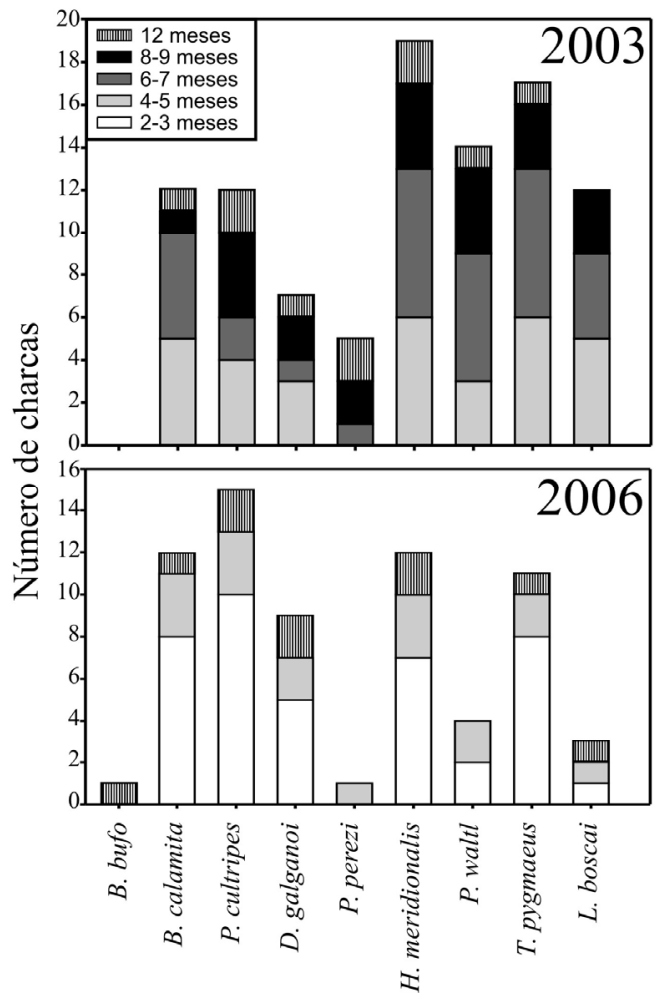

Figura 9. Número de charcas ocupadas por cada especie de anfibios en 2003 y 2006. Las charcas están categorizadas en función de su hidroperiodo.
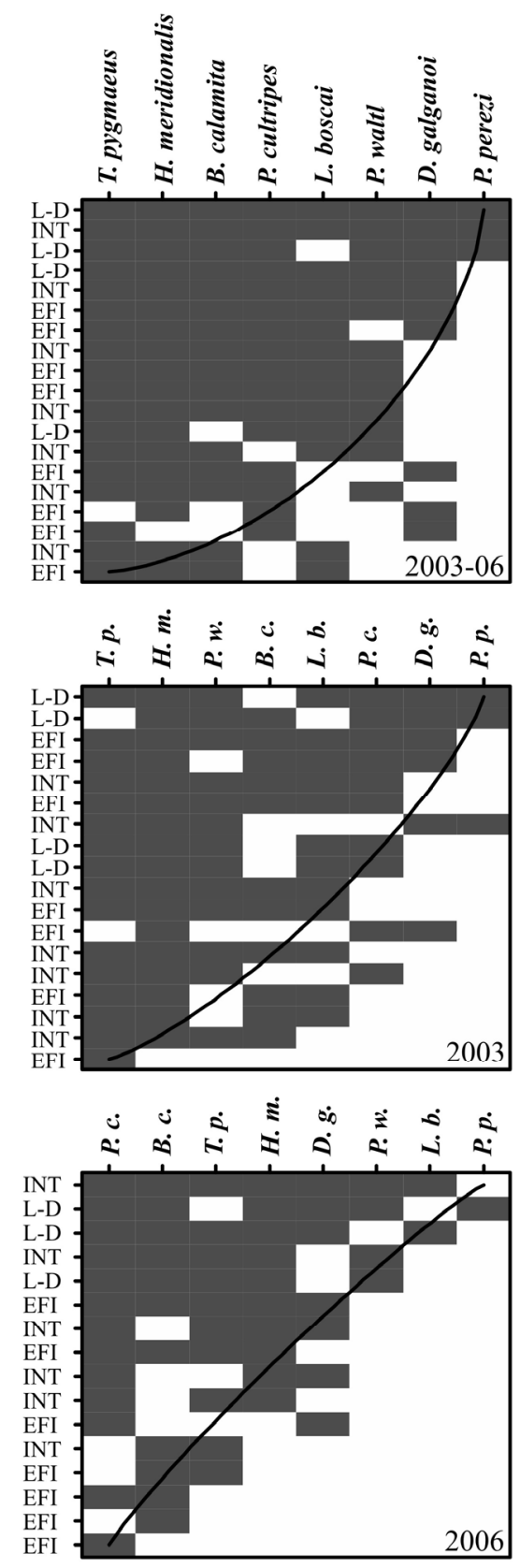

Figura 10. Matrices anidadas de la presencia/ausencia de las especies en el periodo de estudio (2003-06), en 2003 y en 2006. L-D = larga duración [8-9 meses en 2003, 4 meses en 2006], INT $=$ hidroperiodo intermedio [6-7 meses en 2003, 3 meses en 2006], EFI = efímeras [4-5 meses en 2003, 2 meses en 2006]). La nomenclatura de la matriz para todo el periodo de estudio corresponde al hidroperiodo en 2003. 
Tabla 4. Relaciones entre el hidroperiodo y los patrones de diversidad de anfibios medidos a lo largo de todo el periodo de estudio (2003-06) o en cada año (2003 y 2006). Para la diversidad medida a lo largo de todo el periodo de estudio, se muestra la relación tanto con los valores del hidroperiodo en 2003 y como con los de 2006.

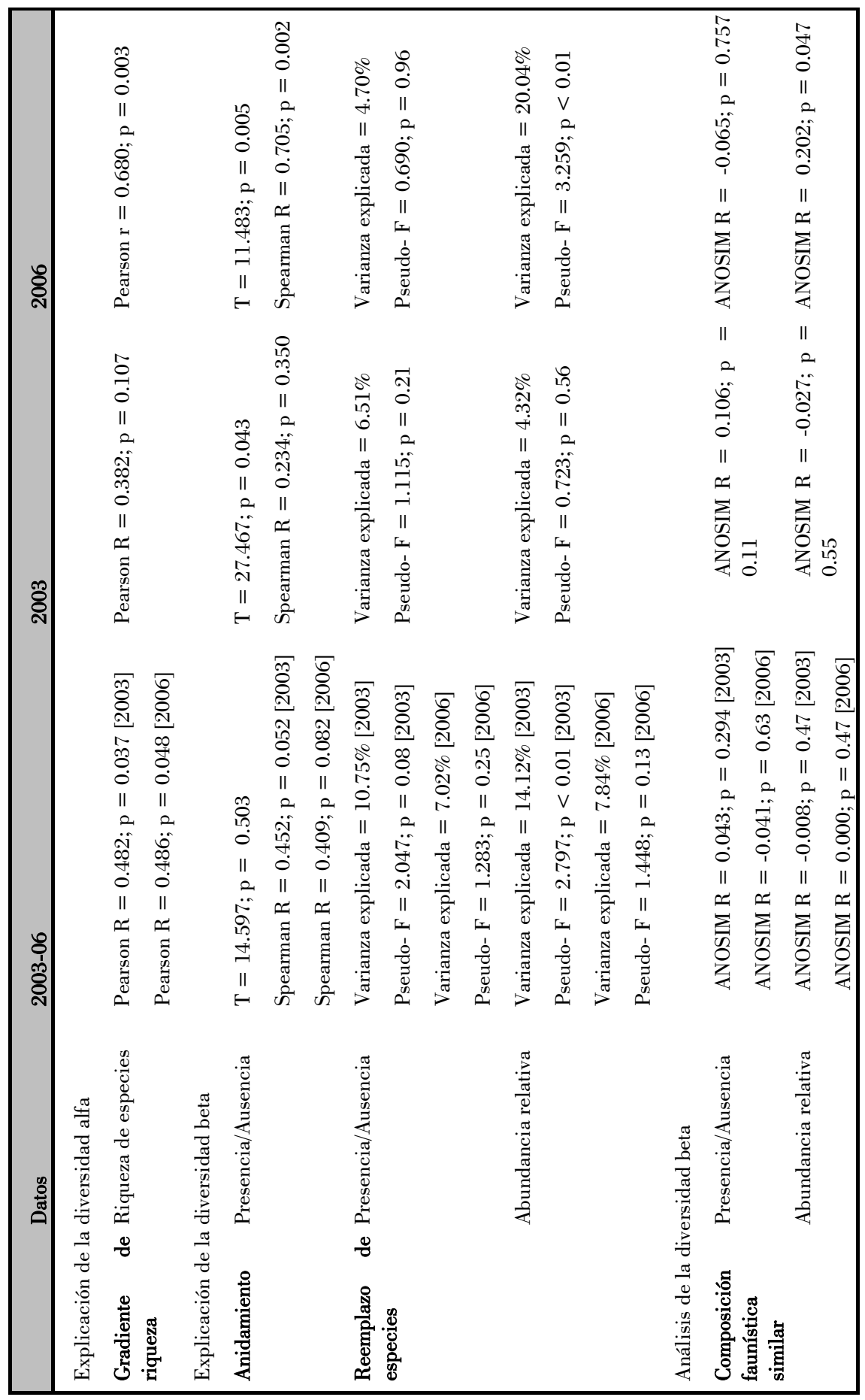




\section{Nivel de especie}

En los estudios de selección de hábitat a nivel de especie, tanto los elaborados con presencias/ausencias o con abundancias relativas, los datos recogidos no respaldaron ninguna hipótesis ecológica que fuera común para todas las especies (Tablas 3,5 y Apéndice). Estos resultados concuerdan con estudios previos realizados en otras regiones que mostraron que cada especie de anfibio tiene una respuesta específica a las diferentes características del hábitat (Beja y Alcazar 2003, Weyrauch y Grubb 2004, Pearl y col. 2005, Van Buskirk 2005). En consecuencia, los programas de conservación de anfibios deben centrarse en los requerimientos de hábitat a nivel de especie, ya que características del hábitat importantes pueden ser enmascaradas al considerar simplemente datos de riqueza de especies.

En general, tanto las características de las charcas como las del entorno (hábitat terrestre y hábitat acuático) son importantes para los anfibios (Anexo 1). En particular, los modelos de selección de hábitat realizados a partir de la presencia/ausencia de las especies en todo el Parque Nacional muestran que las especies frecuentes en el área, como son $H$. meridionalis y $T$. pygmaeus, no estaban relacionadas con ninguna característica concreta del hábitat. Estas especies mostraron una preferencia clara por una ecosección específica dentro del parque (las arenas húmedas estabilizadas), ya que fueron detectadas en prácticamente todas las charcas de esa ecosección, independientemente de sus características ambientales. Las características del hábitat acuático (hidroperiodo y tamaño de la charca) fueron importantes para las especies que requieren charcas de larga duración para completar con éxito la metamorfosis, como son $P$. waltl y $P$. cultripes (según Díaz-Paniagua y col. 2005). Las características del hábitat terrestre fueron los predictores más importantes de la ocupación de D. galganoi y L. boscai. Cabe destacar que las respuestas observadas para algunas cubiertas terrestres particulares (p. ej. bosque o dunas) fueron diferentes a las esperadas. Esto sugiere que el papel del hábitat terrestre para estas especies podría no estar excesivamente relacionado con los requerimientos ecológicos de los individuos durante su fase terrestre (p. ej. movimientos entre charcas o residencia durante la fase terrestre) y que, por el contrario, las cubiertas terrestres fueran indicadores indirectos de la dinámica hidrológica del área. En el caso de L. boscai, una especie asociada a charcas de duración intermedia en el área (según Díaz-Paniagua y col. 2005), otra hipótesis ecológica, la relacionada con la estructura de la población fragmentada, también recibió un fuerte soporte empírico. Teniendo en cuenta la importancia relativa de cada variable ambiental recogida en esta hipótesis (Tabla $6)$, se deduce que la presencia de esta especie está probablemente relacionada con la formación de hábitats acuáticos adecuados en los alrededores, dando así lugar a un patrón similar al publicado por Denoël y Lehmann (2006) para otra especie de tritón. La probabilidad de que esta especie ocupe una charca aumentaría con la existencia en los alrededores de cuerpos de agua de duración intermedia-larga, su hábitat teóricamente idóneo. Sin embargo, no se vería beneficiada por la existencia de charcas efímeras, que sólo se forman en años muy húmedos. Por otro lado, los valores intermedios de vegetación de orla también favorecerían la presencia de $L$. boscai, probablemente porque favorecen el acceso a la charca a la vez que proporcionan un refugio para los adultos durante su fase terrestre. En este estudio no se han realizado modelos de selección de hábitat para $B$. calamita y $P$. perezi debido a 
la baja prevalencia de la especie en nuestros datos.

Es importante aclarar que no se deben esperar resultados robustos en los modelos de selección de hábitat realizados en sistemas estocásticos y variables en el tiempo, como son las charcas temporales, ya que este tipo de modelos estadísticos son teóricamente estáticos (Guisan y Zimmermann 2000). En particular, en el Parque Nacional de Doñana, los altos valores de ocupación que hemos observado para la mayoría de las especies, la baja detectabilidad y la elevada variabilidad temporal de las agrupaciones de especies sugieren que podría no existir segregación espacial de las especies a medio-largo plazo. De esta forma, cabe la posibilidad de que todas las especies utilicen todas las charcas temporales a lo largo del un periodo de tiempo no excesivamente largo. Esta hipótesis estaría respaldada por la naturaleza dinámica del ambiente, que hace que una charca puede ser útil para diferentes especies lo largo del tiempo, y a la configuración espacial del sistema de charcas temporales, que facilita que las charcas puedan ser accesibles a todas las especies. 
Table 5. Importancia relativa de las variables ambientales evaluadas en los modelos de presencia/ausencia de las especies de anfibios. Se muestra el valor promedio del parámetro (model averaged estímate from Akaike's weigths) y su error estándar incondicional.

\begin{tabular}{|c|c|c|c|c|}
\hline & \multicolumn{2}{|r|}{ P. cultripes } & \multicolumn{2}{|r|}{ D. galganoi } \\
\hline & $\begin{array}{c}\text { Imp. } \\
\text { relativa }\end{array}$ & $\begin{array}{l}\text { Parámetro prom. } \\
\text { ( } \pm \text { S.E. })\end{array}$ & $\begin{array}{l}\text { Relat. } \\
\text { import. }\end{array}$ & $\begin{array}{l}\text { Parámetro prom. } \\
\text { ( } \pm \text { S.E. })\end{array}$ \\
\hline (Intercepto) & & $-0.661 \pm 0.232$ & & $-0.283 \pm 0.767$ \\
\hline \multicolumn{5}{|l|}{ Ecosección } \\
\hline (código 3) & \multirow{6}{*}{0.000} & $-0.269 \pm 1.519$ & \multirow{6}{*}{0.014} & $0.220 \pm 5.759$ \\
\hline (código 4) & & $-0.619 \pm 1.542$ & & $0.116 \pm 5.768$ \\
\hline (código 5) & & $-3.157 \pm 5.746$ & & $-1.014 \pm 10.282$ \\
\hline (código 6) & & $-2.454 \pm 4.080$ & & $-16.700 \pm 5.617$ \\
\hline (código 7) & & $-2.866 \pm 5.621$ & & $-16.691 \pm 5.620$ \\
\hline (código 8) & & $0.120 \pm 11.652$ & & NA \\
\hline \multicolumn{5}{|l|}{ Tamaño charca } \\
\hline $\begin{array}{l}\text { Lineal } \\
\text { Cuadrática }\end{array}$ & 0.995 & $\begin{array}{l}1.05 * 10^{-4} \pm 9.2 * 10^{-5} \\
-1.06 * 10^{-9} \pm 0.001\end{array}$ & 0.064 & $\begin{array}{l}6.35^{*} 10^{-5} \pm 5.4 * 10^{-5} \\
-4.59^{*} 10^{-10} \pm 0.026\end{array}$ \\
\hline \multicolumn{5}{|l|}{ Hidroperiodo } \\
\hline (efi.-inter.) & & $-0.806 \pm 0.610$ & & $-0.330 \pm 1.330$ \\
\hline (inter.-larg.) & 0.994 & $-1.231 \pm 0.510$ & 0.059 & $0.111 \pm 1.508$ \\
\hline (larg.-zac.) & & $-0.518 \pm 0.004$ & & $-1.092 \pm 0.839$ \\
\hline Bosque & 0.000 & $-2.441 \pm 0.919$ & 0.575 & $-2.669 \pm 1.483$ \\
\hline Matorral & 0.000 & $0.862 \pm 0.449$ & 0.575 & $-1.016 \pm 0.758$ \\
\hline Dunas & 0.000 & $-1.454 \pm 1.085$ & 0.486 & $2.700 \pm 11.237$ \\
\hline \multicolumn{5}{|c|}{ Vegetación de orla } \\
\hline (baja-inter.) & & $0.034 \pm 0.471$ & 0024 & $0.430 \pm 0.705$ \\
\hline (inter-alta) & 0.000 & $-0.648 \pm 0.342$ & 0.024 & $-0.322 \pm 0.492$ \\
\hline $\begin{array}{l}\text { Distancia a } \\
\text { marisma }\end{array}$ & 0.000 & $1.48 * 10^{-4} \pm 0.011$ & 0.018 & $9.63 * 10^{-5} \pm 0.049$ \\
\hline $\begin{array}{l}\text { Distancia a } \\
\text { charca }\end{array}$ & 0.000 & $-0.002 \pm 0.014$ & 0.018 & $-0.002 \pm 0.074$ \\
\hline Número charcas & 0.000 & $0.081 \pm 0.036$ & 0.048 & $0.067 \pm 0.050$ \\
\hline $\begin{array}{l}\text { Número charcas } \\
\text { grande }\end{array}$ & 0.000 & $0.220 \pm 0.199$ & 0.067 & $0.289 \pm 0.211$ \\
\hline
\end{tabular}


Tabla 5. (cont.)

\begin{tabular}{|c|c|c|c|c|}
\hline & \multicolumn{2}{|c|}{ H. meridionalis } & \multicolumn{2}{|r|}{ P.waltl } \\
\hline & $\begin{array}{c}\text { Imp. } \\
\text { relativa }\end{array}$ & $\begin{array}{l}\text { Parámetro prom. } \\
\qquad( \pm \text { S.E. })\end{array}$ & $\begin{array}{l}\text { Relat. } \\
\text { import. }\end{array}$ & $\begin{array}{l}\text { Parámetro prom. } \\
\qquad( \pm \text { S.E. })\end{array}$ \\
\hline (Intercepto) & 0.000 & $-0.501 \pm 2.603$ & & $0.182 \pm 0.164$ \\
\hline \multicolumn{5}{|l|}{ Ecosección } \\
\hline (código 3) & \multirow{6}{*}{1.000} & $2.183 \pm 2.623$ & \multirow{6}{*}{0.002} & $0.680 \pm 1.873$ \\
\hline (código e 4) & & $0.817 \pm 2.636$ & & $-0.490 \pm 1.906$ \\
\hline (código 5) & & $-0.683 \pm 2.649$ & & $-0.147 \pm 1.904$ \\
\hline (código 6) & & $-0.993 \pm 3.071$ & & $0.043 \pm 1.937$ \\
\hline (código 7) & & $-0.381 \pm 2.798$ & & $-0.280 \pm 2.014$ \\
\hline (código 8) & & $-14.962 \pm 2.403$ & & $1.095 \pm 10.503$ \\
\hline \multicolumn{5}{|l|}{ Tamaño charca } \\
\hline Lineal & \multirow{2}{*}{0.000} & $7.73 * 10^{-5} \pm 9.2 * 10^{-5}$ & \multirow{2}{*}{0.488} & $4.04 * 10^{-5} \pm 6.4 * 10^{-5}$ \\
\hline Cuadrática & & $-8.33 * 10^{-10} \pm 0.009$ & & $1.02 * 10^{-10} \pm 0.040$ \\
\hline \multicolumn{5}{|l|}{ Hidroperiodo } \\
\hline (efi.-inter.) & \multirow{3}{*}{0.000} & $0.277 \pm 0.314$ & \multirow{3}{*}{0.431} & $0.563 \pm 0.335$ \\
\hline (inter.-larg.) & & $-1.317 \pm 0.375$ & & $-1.072 \pm 0.358$ \\
\hline (larg.-zac.) & & $-0.107 \pm 0.057$ & & $-0.110 \pm 0.229$ \\
\hline Bosque & 0.000 & $-0.848 \pm 0.654$ & 0.019 & $-0.602 \pm 0.669$ \\
\hline Matorral & 0.000 & $1.784 \pm 0.425$ & 0.019 & $0.044 \pm 0.433$ \\
\hline Dunas & 0.000 & $-0.254 \pm 0.814$ & 0.040 & $-0.146 \pm 0.692$ \\
\hline \multicolumn{5}{|c|}{ Vegetación de orla } \\
\hline (baja-inter.) & \multirow{2}{*}{0.000} & $1.382 \pm 0.762$ & \multirow{2}{*}{0.007} & $0.149 \pm 0.355$ \\
\hline (inter.-alta) & & $-0.748 \pm 0.423$ & & $-0.489 \pm 0.326$ \\
\hline $\begin{array}{l}\text { Distancia a } \\
\text { marisma }\end{array}$ & 0.000 & $1.04 * 10^{-4} \pm 0.774$ & 0.019 & $2.48 * 10^{-4} \pm 0.010$ \\
\hline $\begin{array}{l}\text { Distancia a } \\
\text { charca }\end{array}$ & 0.000 & $-1.89 * 10^{-4} \pm 1.214$ & 0.019 & $1.67 * 10^{-4} \pm 0.011$ \\
\hline Número charcas & 0.000 & $-0.006 \pm 1.2 * 10^{-4}$ & 0.104 & $0.056 \pm 0.034$ \\
\hline $\begin{array}{l}\text { Número charcas } \\
\text { grandes }\end{array}$ & 0.000 & $0.521 \pm 0.001$ & 0.094 & $0.359 \pm 0.174$ \\
\hline
\end{tabular}


Tabla 5. (cont.)

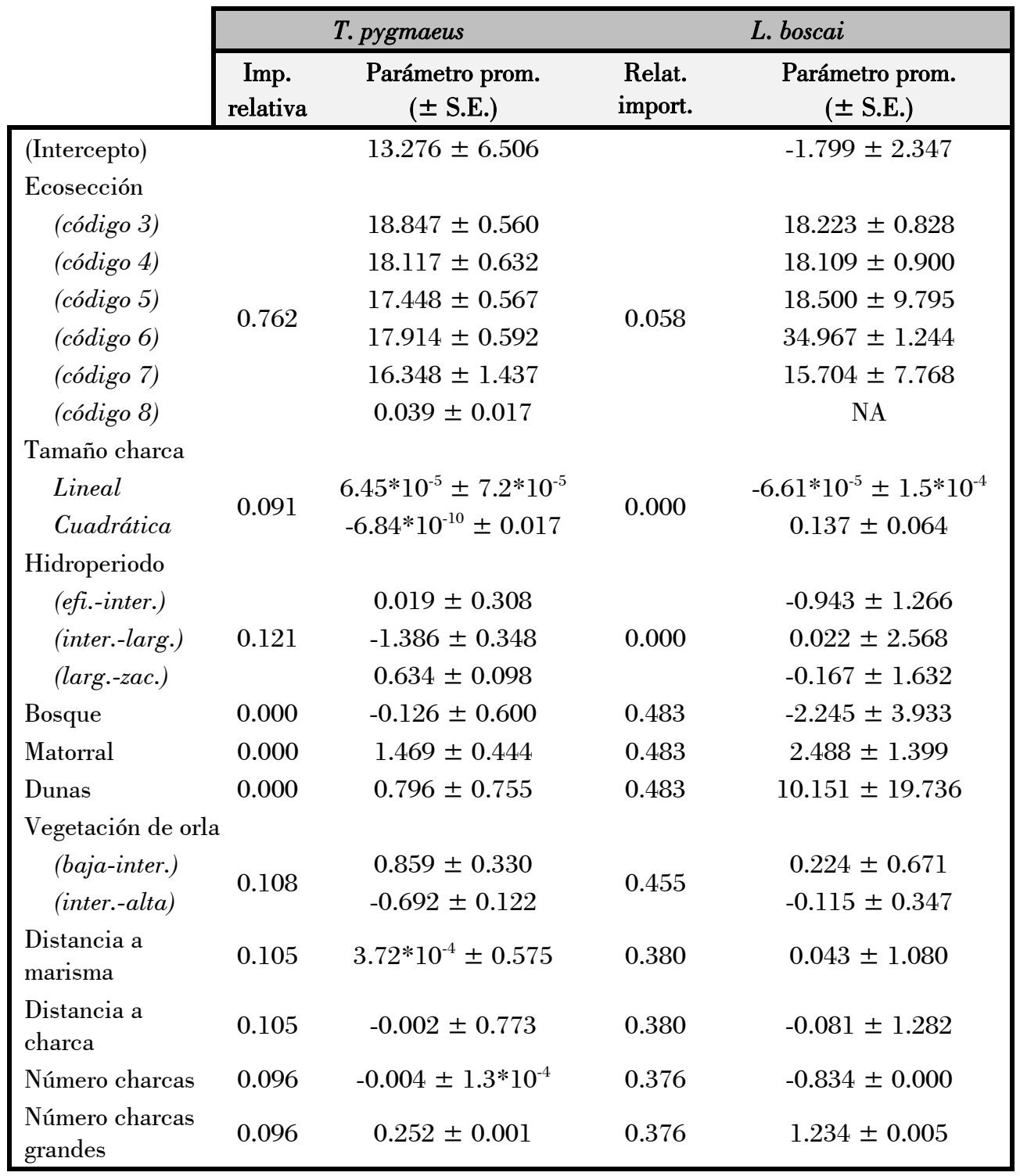




\section{Implicaciones}

para la conservación de las especies de anfibios y sus hábitats reproductivos en el Parque Nacional de Doñana

El Parque Nacional de Doñana protege uno de los sistemas de charcas temporales de origen natural más extensos de Europa. Áreas con tal densidad y heterogeneidad de charcas de origen natural no son frecuentes en Europa, donde los principales hábitats de anfibios son cuerpos de agua temporales intervenidos por el hombre (Jakob y col. 2003, Denoël 2004) y el número actual de charcas temporales es una pequeña fracción del que hubo en el pasado (Williams y col. 2001). Por todo ello, las charcas temporales del Parque Nacional de Doñana constituyen un ejemplo de cómo la conservación de sistemas acuáticos naturales con una alta variabilidad interanual favorece la persistencia de una fauna de anfibios rica y abundante. Tal abundancia y variabilidad de un hábitat prioritario en Europa (European Commission 2007) merece una atención especial como sistema de referencia para la conservación y manejo de este tipo de ecosistemas. El objetivo principal de los programas de conservación en el Parque Nacional de Doñana deberá ser el mantenimiento de la amplia variabilidad de cuerpos de agua existente, evitando por tanto conservar un único tipo de charca concreto o el número total de charcas. Preservar la variabilidad ambiental es clave para la conservación del sistema ya que la heterogeneidad de hábitats favorece la diversidad de las especies asociadas (Tews y col. 2004). En el caso particular de los anfibios, numerosos autores han afirmado que una amplia diversidad de hidroperiodos, como la que se ha visto en Doñana, beneficia a las comunidades de anfibios a escala de paisaje (Beja y Alcazar 2003, Semlitsch 2003).

Otro aspecto crítico de la conservación del sistema es la preservación de su dinámica natural. La variación interanual en la composición de las agrupaciones sugiere que una charca determinada es el hábitat adecuado de diferentes especies dependiendo del año. Es necesario destacar que la variabilidad espacial anteriormente mencionada es esencial en este sistema desde un punto de visa dinámico, para poder garantizar que la comunidad de anfibios pueda persistir ante tan marcada variabilidad temporal. Las poblaciones de anfibios en el área son abundantes porque cada especie es periódicamente favorecida. Es decir, existen temporadas reproductoras muy propicias en las que el número de individuos de una especie que completan la metamorfosis con éxito es muy elevado, en vez de un nivel bajo de éxito reproductivo que se mantiene relativamente constante todos los años. 


\section{Conclusiones}

1. El sistema de charcas temporales del Parque Nacional de Doñana presenta una variabilidad espacial y temporal importante, por lo que constituye un ecosistema heterogéneo en el espacio y en el tiempo que favorece la diversidad de especies al proporcionar un gran número de nichos para la fauna asociada.

2. Los datos obtenidos mediante teledetección de alta resolución espectral y espacial son útiles para la delimitación de las charcas temporales en el Parque Nacional de Doñana. Además, dichas técnicas permiten la identificación de las charcas que albergan un número mayor de especies, aunque no sirven para identificar los lugares de reproducción de especies concretas.

3. Las imágenes de teledetección de resolución espacial media son útiles para estudiar la dinámica de inundación de charcas pequeñas y altamente fluctuantes. En particular, estas imágenes se pueden utilizar para discernir entre fluctuaciones naturales y tendencias negativas en características del hábitat importantes para las especies asociadas. En el Parque Nacional de Doñana, se ha identificado una tendencia que puede resultar crítica para la conservación de las especies de anfibios: el hidroperiodo de las charcas tiende a ser más corto en años recientes.

4. Las agrupaciones de anfibios del Parque Nacional de Doñana varían interanualmente, tanto en la presencia como en la abundancia de las especies. Sin embargo, a escala regional (área de estudio en su conjunto), no se observó una marcada variación interanual durante el periodo de estudio, ya que prácticamente todas las especies se reprodujeron todos los años, excepto en los extremadamente secos, cuando las charcas no se inundaron, como 20042005.

5. El reemplazo interanual de especies en las charcas pone de manifiesto que los muestreos efectuados durante una única temporada reproductora no son adecuados para identificar la agrupación de especies asociada a una determinada charca.

6. La probabilidad de detección en un único muestreo es específica de cada especie, muestra valores bajos para la mayor parte de ellas, y varía entre muestreos y temporadas reproductoras. Para una especie concreta, el "mes óptimo"para muestrear no es predecible de año en año, hecho que evidencia la variabilidad e incertidumbre asociada a la eficiencia de los muestreos. Por tanto, los estudios de ocupación del hábitat deberían basarse en muestreos reiterados en lugar de muestreos únicos. 
7. En los estudios sobre los requerimientos de hábitat de los anfibios, no se debe asumir que todas las no-detecciones son ausencias reales, ni otorgar la misma fiabilidad a todos los registros de no-detección. Esto adquiere especial relevancia cuando no es posible muestrear simultáneamente todas las localidades y, principalmente, cuando el número y fecha de los muestreos varía entre casos (charcas), pudiendo además ser bajo para muchos casos, como en este estudio.

8. Se requieren características del hábitat invariables en el tiempo y con variabilidad temporal para comprender los patrones de diversidad de los anfibios en el área de estudio, tanto teniendo en cuenta datos obtenidos en años concretos como datos correspondientes a varios años.

9. Las características ambientales que no muestran relación con los gradientes de riqueza pueden ser responsables de la variación en composición entre charcas (diversidad beta). Por tanto, es esencial adoptar una perspectiva que abarque múltiples escalas para evitar menospreciar variables ambientales que contribuyen al incremento de la diversidad de especies.

10. El hidroperiodo puede ser un factor determinante de la composición de las agrupaciones de anfibios en los años en los que la duración de las charcas es corta, y se observa un fuerte patrón de anidamiento a lo largo del gradiente de hidroperiodo. Por el contrario, el efecto del hidroperiodo es despreciable en años húmedos, cuando el riesgo de desecación no constituye un estrés ambiental importante y las charcas están inundadas durante un largo periodo de tiempo, permitiendo, potencialmente, la reproducción de la mayoría de las especies. Esto explicaría que, a nivel de especie, no se haya observado un patrón claro de segregación en función del hidroperiodo, ya que, durante el periodo de estudio, todas las especies excepto Pelophylax perezi y Bufo bufo intentaron reproducirse en charcas que abarcaban todo el gradiente de hidroperiodo.

11. Los modelos de selección de hábitat, tanto los elaborados a partir de la presencia de especies como de su abundancia relativa, son específicos para cada especie. Por tanto, los programas de conservación de anfibios deberían orientarse hacia los requerimientos de hábitat específicos de cada especie, ya que si se considerasen sólo los datos de riqueza de especies, algunas características importantes del hábitat podrían pasar inadvertidas. 
12. Los resultados de los modelos de selección de hábitat cambian entre años, tanto los construidos a partir de datos anuales de riqueza como los específicos de la abundancia de las especies. Esta inconsistencia de los modelos en el tiempo compromete la utilidad para la conservación de los estudios anuales sobre anfibios en Doñana, ya que no se pueden identificar con certeza los requerimientos de hábitat de las especies ni de las agrupaciones en base a estudio anuales.

13. La presencia de Hyla meridionalis y Triturus pygmaeus no se relacionó con ninguna característica del hábitat en particular, sino con una ecosección concreta del Parque. Las características del hábitat reproductivo (área e hidroperiodo) tuvieron una gran importancia para explicar la presencia de Pelobates cultripes y Pleurodeles waltl. Las características del hábitat terrestre fueron las variables más importantes para explicar la presencia de Discoglossus galganoi y Lissotriton boscai. La probabilidad de presencia de $L$. boscai también estuvo relacionada con la estructura espacial de la población fragmentada.

14. El dinamismo natural del ecosistema parece ser la característica más importante para la conservación de la biodiversidad a medio plazo. En este sistema, una charca concreta ofrece diferentes oportunidades de reproducción a lo largo del tiempo, resultando favorable para diferentes especies dependiendo de sus características bióticas y abióticas. Además, la gran abundancia y diversidad de charcas temporales proporciona, teóricamente, la variabilidad espacial necesaria para la persistencia de una comunidad sujeta a una variabilidad ambiental tan elevada. 
Apéndice. Resultados de la selección de modelos realizada mediante un procedimiento "information-theoretic" basado en el criterio de información de Akaike (AIC). También se muestran los resultados de la evaluación del modelo con datos reales.. k es el número de parámetros en el modelo (excluyendo el intercepto). $\triangle \mathrm{AIC}$ es la diferencia de AIC entre el modelo considerado y el modelo con menor AIC. Akaike $\omega$ es el peso Akaike del modelo. $\mathrm{D}^{2}$ and $\mathrm{Adj} . \mathrm{D}^{2}$ son la devianza y la devianza ajustada, respectivamente. Se especifica también el número de casos usado en la construcción del modelo (n) y el número de casos válidos usado en el cálculo del AUC. [s.e. = error estándar]

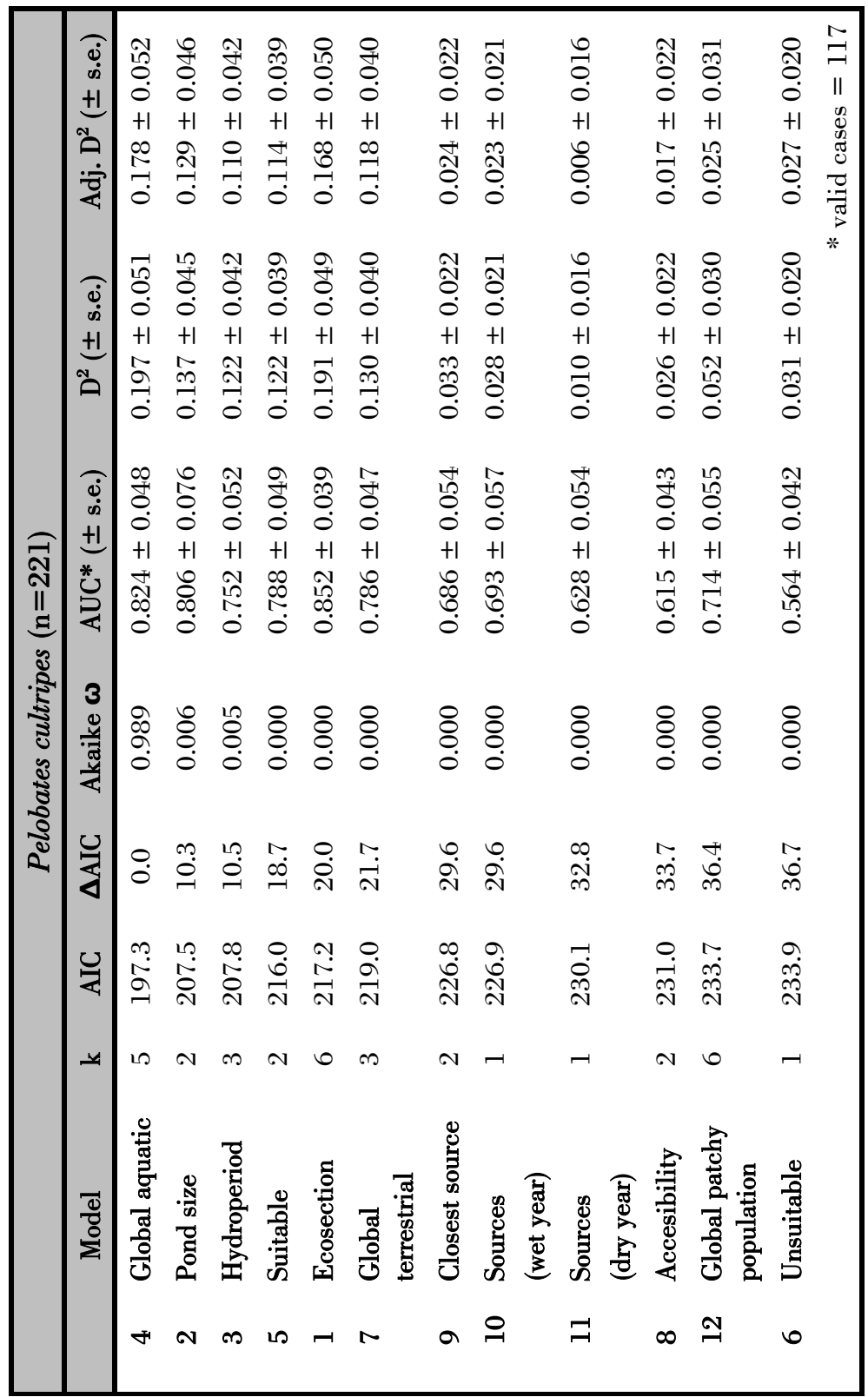


Apéndice. (cont.)

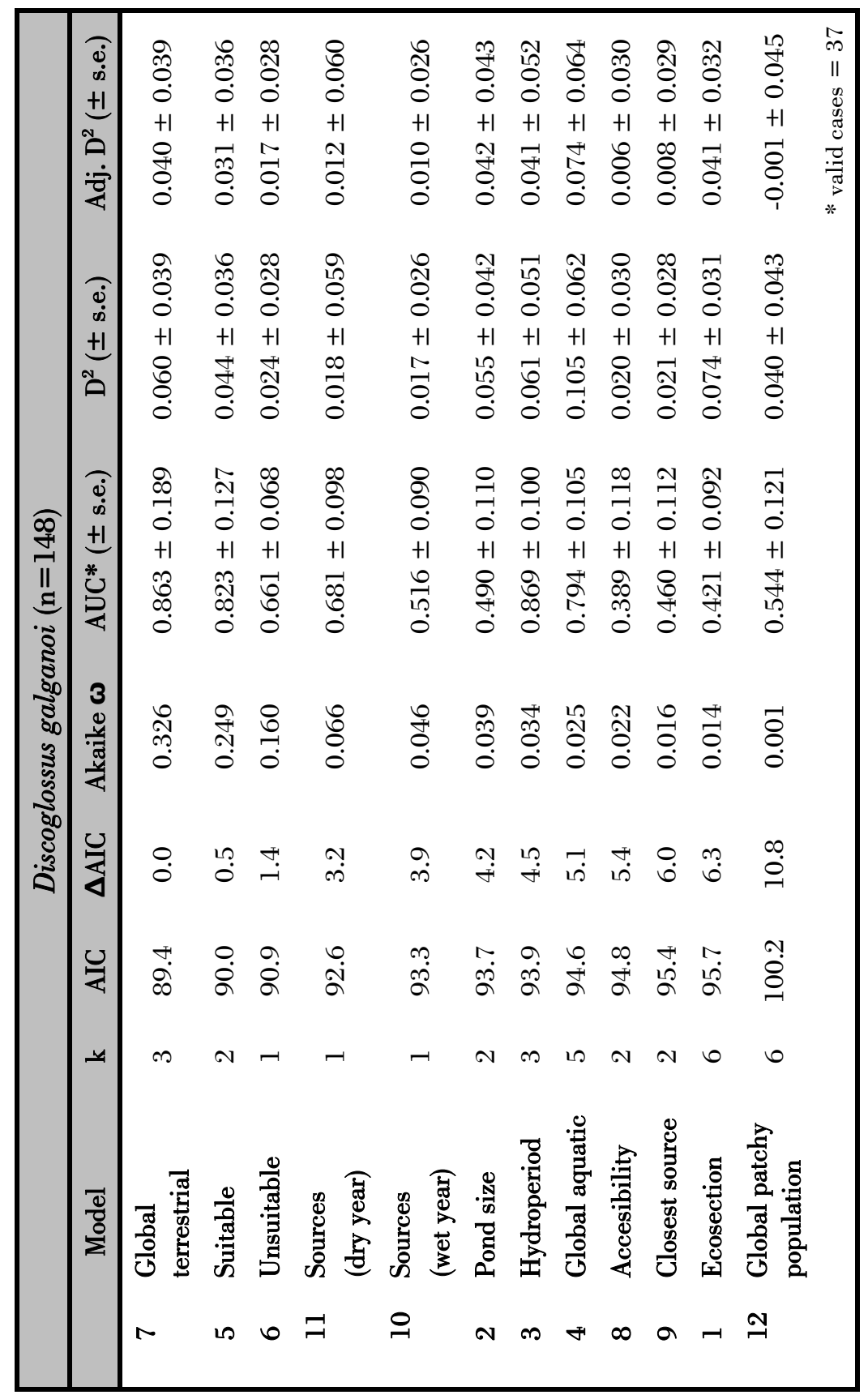


Apéndice. (cont.)

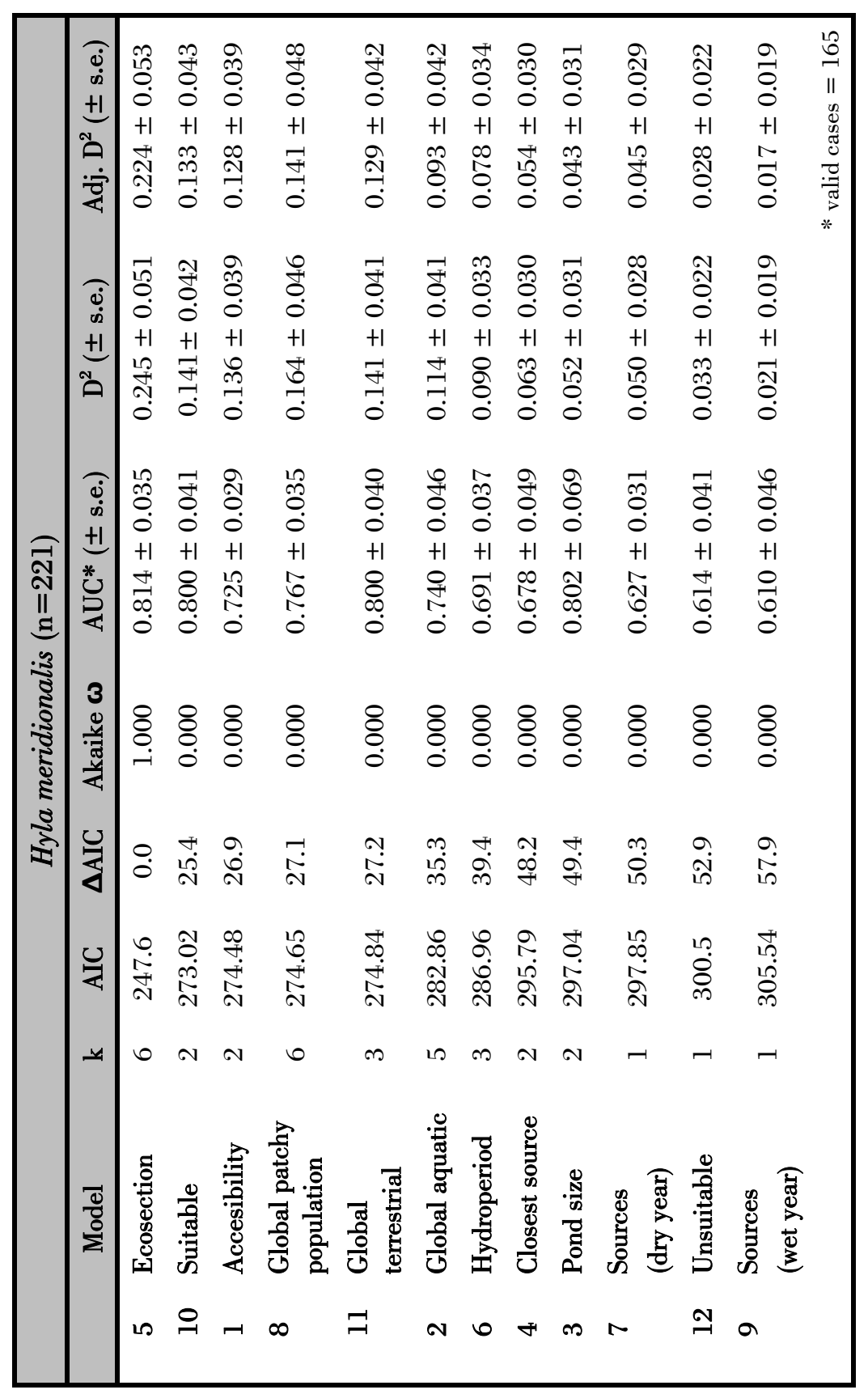


Apéndice. (cont.)

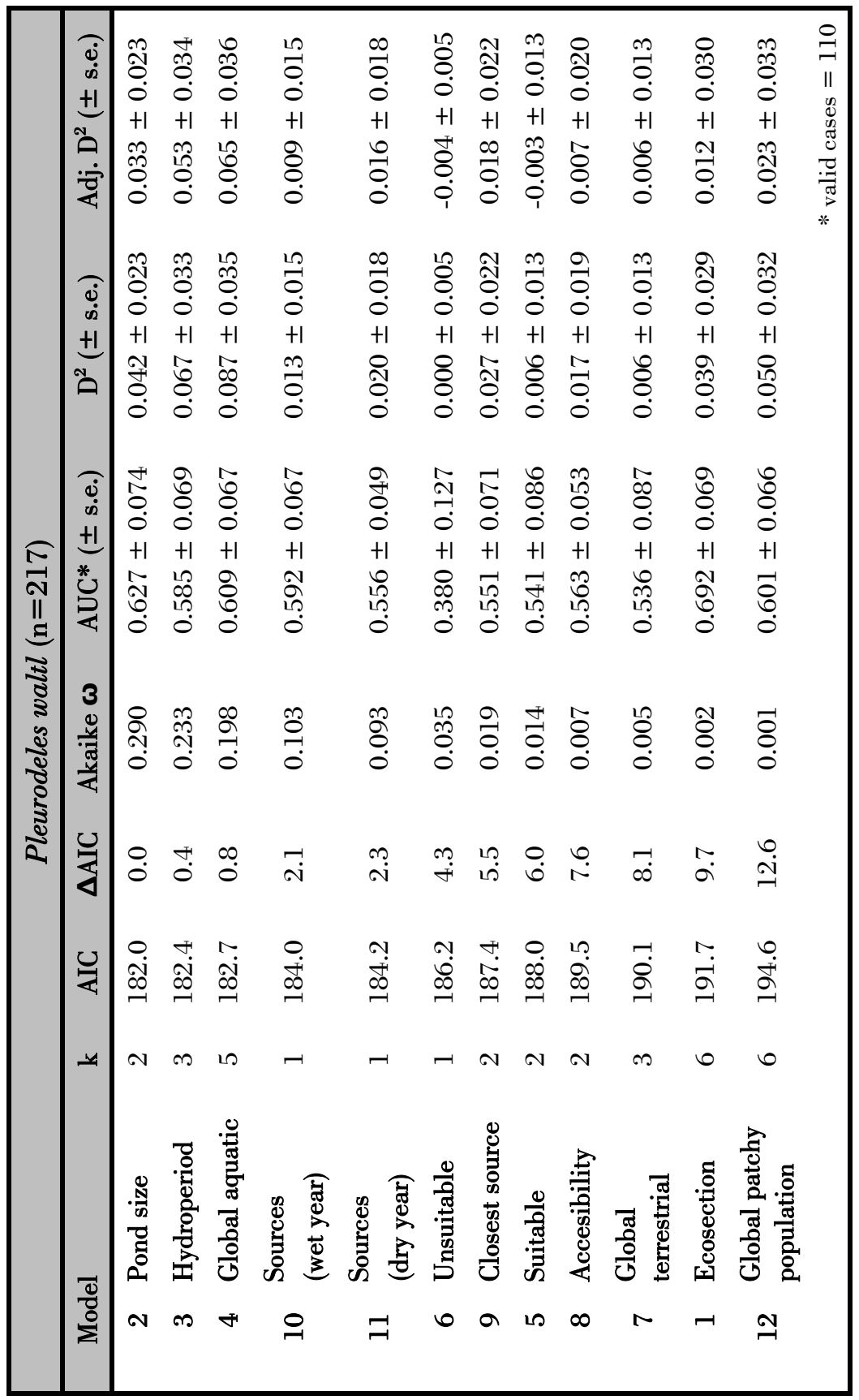


Apéndice. (cont.)

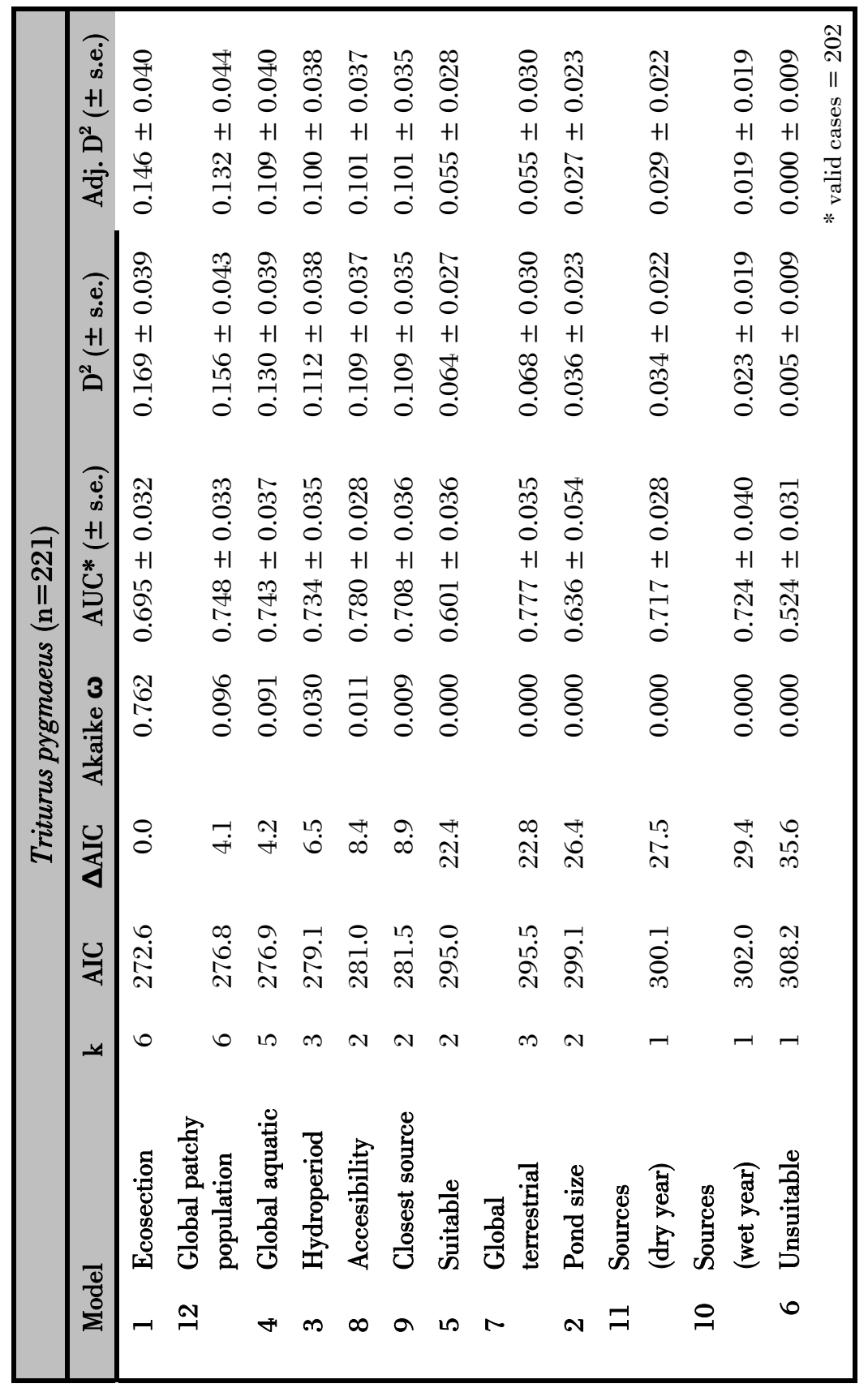


Apéndice.(cont.)

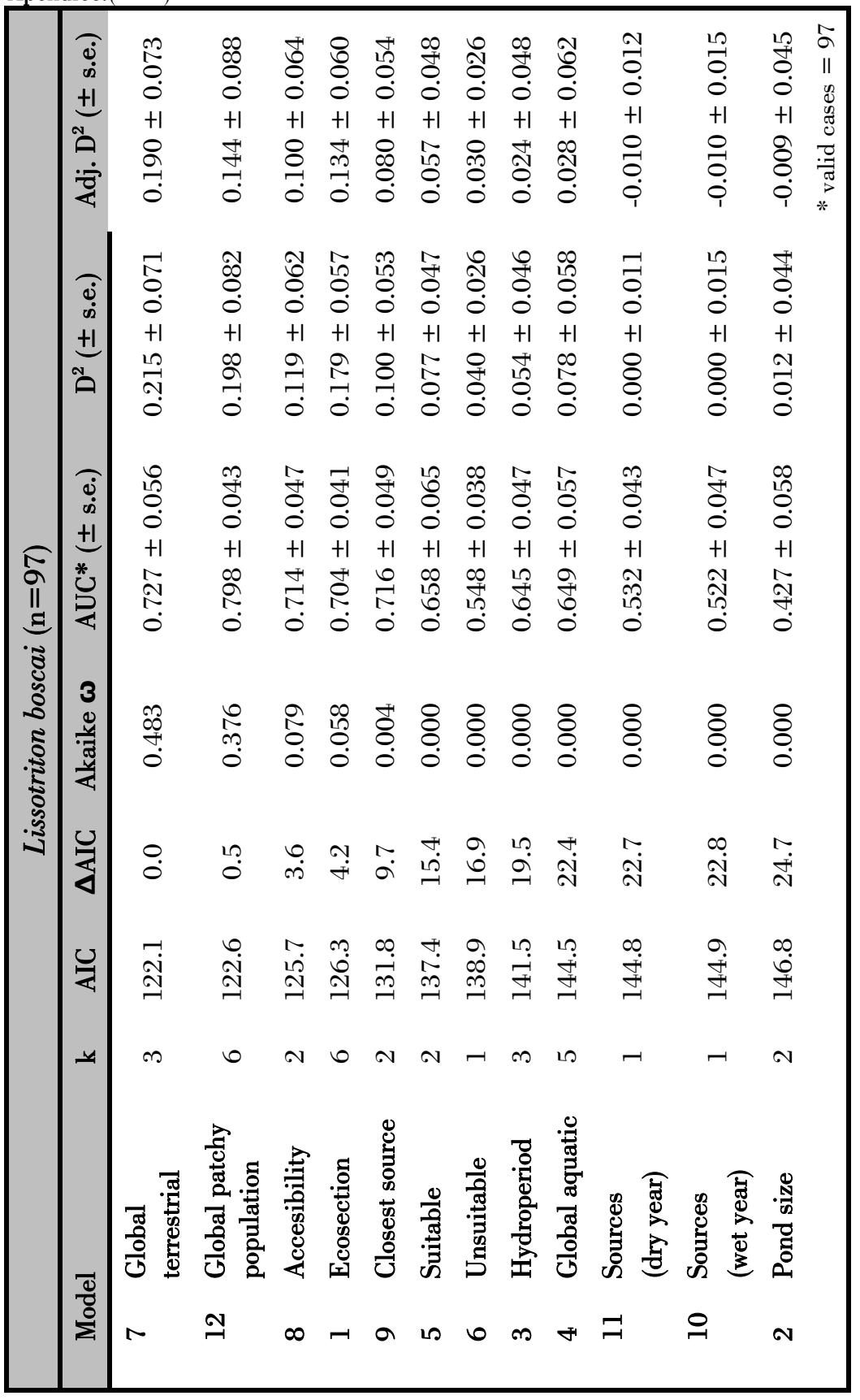

Nomeclatura. 1. Ecosección; 2. Tamaño de la charca; 3. Hidroperiodo; 4. Acúatico globlal; 5. Hábitat terrestre favorable; 6 . Hábitat terrestre desfavorable; 7. Terrestre global; 8. Accesibilidad; 9. Cuerpo de agua más cercano; 10. Número de cuerpos de agua de gran tamaño; 11. Número de cuerpos de agua totales; 12. "Población fragmentada"global. 


\section{Titerature cited}

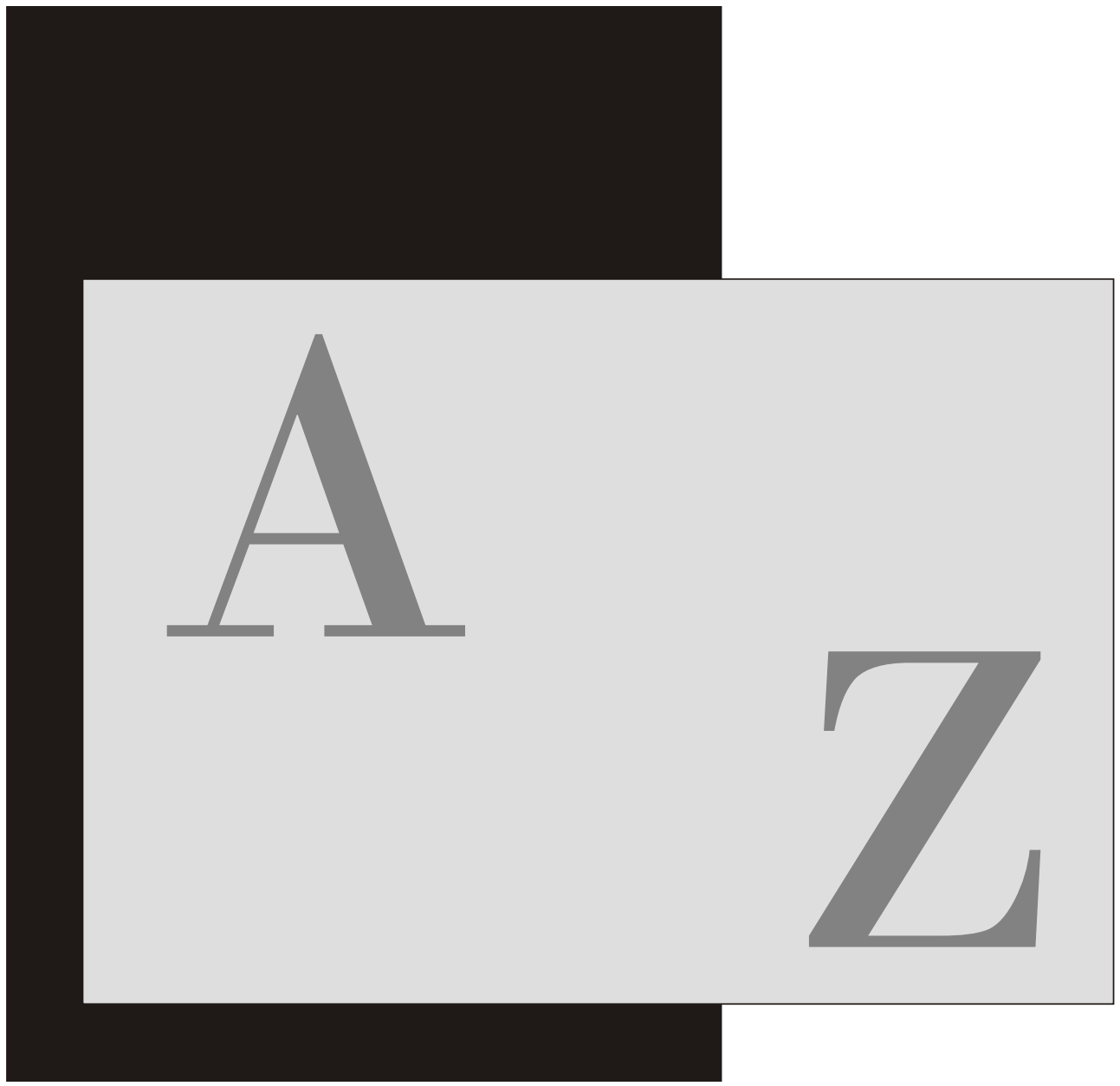


Alphan H and Yilmaz KT 2005. Monitoring environmental changes in the Mediterranean coastal landscape: The case of Cukurova, Turkey. Environmental Management 35, 607-619.

Allier C, González-Bernáldez F and Ramírez-Díaz L 1974. Mapa Ecológico de la Reserva Biológica de Doñana. División de Ciencias del CSIC, Estación Biológica de Doñana. .

Amat JA, Montes C, Ramírez L and Torres A 1979. Parque Nacional de Doñana. Mapa ecológico. Ministerio de Agricultura, Instituto para la Conservación de la Naturaleza.

Aragonés D, Díaz-Delgado R and Bustamante J 2005. Tratamiento de una serie temporal larga de imágenes Landsat para la cartografía de la inundación histórica de las marismas de Doñana. XI Congreso Nacional de Teledetección, 21-23 septiembre 2005., Puerto de la Cruz. Tenerife, 407-410.

Arntzen JW 2006. From descriptive to predictive distribution models: a working example with Iberian amphibians and reptiles. Frontiers in Zoology 3:8.

Arponen A, Moilanen A and Ferrier S 2008. A successful community-level strategy for conservation prioritization. Journal of Applied Ecology 45, 1436-1445.

Austin MP 2002. Spatial prediction of species distribution: an interface between ecological theory and statistical modelling. Ecological Modelling 157, 101-118.

Austin M 2007. Species distribution models and ecological theory: A critical assessment and some possible new approaches. Ecological Modelling 200, 1-19.

Azeria ET and Kolasa J 2008. Nestedness, niche metrics and temporal dynamics of a metacommunity in a dynamic natural model system. Oikos 117, 1006-1019.

Babbitt KJ 2005. The relative importance of wetland size and hydroperiod for amphibians in southern New Hampshire, USA. Wetlands Ecology and Management 13, 269-279.

Babbitt KJ, Baber MJ and Brandt LA 2006. The effect of woodland proximity and wetland characteristics on larval anuran assemblages in an agricultural landscape. Canadian Journal of Zoology 84, 510-519.

Baber MJ, Fleishman E, Babbitt KJ and Tarr TL 2004. The relationship between wetland hydroperiod and nestedness patterns in assemblages of larval amphibians and predatory macroinvertebrates. Oikos 107, 16-27. 
Bailey LL, Simons TR and Pollock KH 2004. Estimating site occupancy and species detection probability parameters for terrestrial salamanders. Ecological Applications 14, 692-702.

Baselga A and Jiménez-Valverde A 2007. Environmental and geographical determinants of beta diversity of leaf beetles (Coleoptera: Chrysomelidae) in the Iberian Peninsula. Ecological Entomology 32, 312-318.

Baselga A, Jiménez-Valverde A and Niccolini G 2007. A multiple-site similarity measure independent of richness. Biology Letters 3, 642-645.

Baselga A 2008. Determinants of species richness, endemism and turnover in European longhorn beetles. Ecography 31, 263-271.

Batzer DP, Palik BJ and Buech R 2004. Relationships between environmental characteristics and macroinvertebrate communities in seasonal woodland ponds of Minnesota. Journal of the North American Benthological Society 23, 50-68.

Beeri $\mathrm{O}$ and Phillips RL 2007. Tracking palustrine water seasonal and annual variability in agricultural wetland landscapes using Landsat from 1997 to 2005. Global Change Biology 2007, 897-912.

Beja P and Alcazar R 2003. Conservation of Mediterranean temporary ponds under agricultural intensification: an evaluation using amphibians. Biological Conservation 114, 317-326.

Beja P and Alcazar R 2003. Conservation of Mediterranean temporary ponds under agricultural intensification: an evaluation using amphibians. Biological Conservation 114, 317-326.

Biedermann R 2004. Modelling the spatial dynamics and persistence of the leaf beetle Gonioctena olivacea in dynamic habitats. Oikos 107, 645-653.

Bigot L and Marazanof F 1966. Notes sur l'écologie des Coléoptères aquatiques des Marismas du Guadalquivir et premier inventaire des Coléoptères et Lépidoptères du Coto Doñana (Andalucía). Annales de Limnologie 2, 491-502.

Bissonette JA and Storch I 2007. Temporal Dimensions of Landscape Ecology. Wildlife Responses to Variable Resources. Springer.

Blondel J and Aronson J 1999. Biology and Wildlife of the Mediterranean Region. Oxford University Press.

Boix D, Sala J and Moreno-Amich R 2001. The faunal composition of Espolla pond (NE Iberian peninsula): the neglected biodiversity of temporary waters. Wetlands 21, 577-592.

Borcard D, Legendre P and Drapeau P 1992. Partialling out the spatial component of ecological variation. Ecology 73, 1045-1055.

Boulinier T, Nichols JD, Sauer JR, Hines JE and Pollock KH 1998. Estimating species richness: The importance of heterogeneity in species detectability. Ecology 79, 1018-1028. 
Bravo MA and Montes C 1993. Inventario de las formaciones palustres del manto eólico del Parque Nacional de Doñana (SW España). Actas del Congreso Español de Limnología, Granada, 31-43.

Briers RA and Warren PH 2000. Population turnover and habitat dynamics in Notonecta (Hemiptera: Notonectidae) metapopulations. Oecologia 123, 216222.

Briers RA and Biggs J 2005. Spatial patterns in pond invertebrate communities: separating environmental and distance effects. Aquatic Conservation: Marine and Freshwater Ecosystems 15, 549-557.

Brooks RT 2000. Annual and seasonal variation and the effects of hydroperiod on benthic macroinvertebrates of seasonal forest ("vernal") ponds in central Massachusetts, USA. Wetlands 20, 707-715.

Brown JH, Mehlman DW and Stevens GC 1995. Spatial variation in abundance. Ecology 76, 2028-2043.

Bryant RG 1999. Application of AVHRR to monitoring a climatically sensitive playa. Case study: Chott el Djerid, southern Tunisia. Earth Surface Processes and Landforms 24, 283-302.

Bryant RG and Rainey MP 2002. Investigation of flood inundation on playas within the Zone of Chotts, using a time-series of AVHRR. Remote Sensing of Environment 82, 360-375.

Buckland ST, Magurran AE, Green RE and Fewster RM 2005. Monitoring change in biodiversity through composite indices. Philosophical Transactions of the Royal Society B-Biological Sciences 360, 243-254.

Buermann W, Saatchi S, Smith TB, Zutta BR, Chaves JA, Milá B and Graham CH 2008. Predicting species distributions across the Amazonian and Andean regions using remote sensing data. Journal of Biogeography 35, 1160-1176.

Burne MR and Griffin CR 2005. Habitat associations of pool-breeding amphibians in eastern Massachusetts, USA. Wetlands Ecology and Management 13, 247259.

Burnham KP and Anderson DR 2002. Model Selection and Multimodel Inference. A Practical Information-Theoretic Approach. $2^{\text {nd }}$ ed. Springer.

Bustamante J, Pacios F, Díaz-Delgado R and Aragonés D. In press. Predictive models of turbidity and water depth in the Donana marshes using Landsat TM and ETM+ images. Journal of Environmental Managament.

Carey C et al. 2001. Amphibian declines and environmental change: Use of remotesensing data to identify environmental correlates. Conservation Biology 15, 903913.

Castañeda C and Herrero J 2005. The water regime of the Monegros playa-lakes as established from ground and satellite data. Journal of Hydrology 310, 95-110. 
Castañeda C, Herrero J and Casterad MA 2005. Landsat monitoring of playa-lakes in the Spanish Monegros desert. Journal of Arid Environments 63, 497-516.

Castroviejo J 1993. Memoria. Mapa del Parque Nacional de Doñana, escala 1/50.000. CSIC y Agencia de Medio Ambiente, Junta de Andalucía

Clarke KR 1993. Nonparametric multivariate analyses of changes in community structure. Australian Journal of Ecology 18, 117-143.

Clarke KR and Warwick RM 2001. Change in Marine Communities: An Approach to Statistical Analysis and Interpretation. $2^{\text {nd }}$ ed. Primer-E.

Clemente L, García LV and Siljeström P 1998. Los Suelos del Parque Nacional de Doñana. Organismo Autónomo de Parques Nacionales.

Colwell RK, Mao CX and Chang J 2004. Interpolating, extrapolating, and comparing incidence-based species accumulation curves. Ecology 85, 27172727.

Collins SL and Glenn SM 1991. Importance of spatial and temporal dynamics in species regional abundance and distribution. Ecology 72, 654-664.

Collins JP and Halliday T 2005. Forecasting changes in amphibian biodiversity: aiming at a moving target. Philosophical Transactions of the Royal Society BBiological Sciences 360, 309-314.

Cushman SA 2006. Effects of habitat loss and fragmentation on amphibians: A review and prospectus. Biological Conservation 128, 231-240.

Chesson P and Huntly N 1997. The roles of harsh and fluctuating conditions in the dynamics of ecological communities. American Naturalist 150, 519-553.

Church DR 2008. Role of current versus historical hydrology in amphibian species turnover within local pond communities. Copeia, 115-125.

De Roeck ER, Verhoest NEC, Miya MH, Lievens H, Batelaan O, Thomas A and Brendonck L 2008. Remote sensing and wetland ecology: a South African case study. Sensors 8, 3542-3556.

De Solla SR, Shirose LJ, Fernie KJ, Barrett GC, Brousseau CS and Bishop CA 2005. Effect of sampling effort and species detectability on volunteer based anuran monitoring programs. Biological Conservation 121, 585-594.

De Solla SR, Fernie KJ, Barrett GC and Bishop CA 2006. Population trends and calling phenology of anuran populations surveyed in Ontario estimated using acoustic surveys. Biodiversity and Conservation 15, 3481-3497.

Denoël M 2004. Répartition, habitat et conservation des amphibiens du Pays de Herve (Belgique). Bulletin de la Société Herpétologique de France 111-112 4977.

Denoël M and Lehmann A 2006. Multi-scale effect of landscape processes and habitat quality on newt abundance: Implications for conservation. Biological Conservation 130, 495-504. 
Díaz-Delgado R, Bustamante J, Aragonés D and Pacios F 2006. Determining water body characteristics of Doñana shallow marshes through remote sensing. Proceedings of the 2006 IEEE International Geoscience \& Remote Sensing Symposium \& 27th Canadian Symposium on Remote Sensing (IGARSS2006), Denver, Colorado, EE.UU, Geoscience and Remote Sensing Society, 36623664 .

Díaaz-Paniagua C 1982. Facteurs associés a la reproduction des amphibiens de Donana. Détermination de l'habitat. Bulletin de la Société Herpétologique de France 22, 24-26.

Díaz-Paniagua C 1983. Influencia de las características del medio acuático sobre las poblaciones de larvas de anfibios en la Reserva Biológica de Doñana (Huelva, España). Doñana, Acta Vertebrata 10, 41-53.

Díaz-Paniagua C 1987. Tadpole distribution in relation to vegetal heterogeneity in temporary ponds. Herpetological Journal 1, 167-169.

Díaz-Paniagua C 1988. Temporal segregation in larval amphibian communities in temporary ponds at a locality in SW Spain. Amphibia-Reptilia 9, 15-26.

Díaz-Paniagua C 1990. Temporary ponds as breeding sites of amphibians at a locality in southwestern Spain. Herpetological Journal 1, 447-453.

Díaz-Paniagua C 1992. Variability in timing of larval season in an amphibian community in SW Spain. Ecography 15, 267-272.

Díaz-Paniagua C 1998. Reproductive dynamics of a population of small marbled newts (Triturus marmoratus pygmaeus) in South-western Spain. Herpetological Journal 8, 93-98.

Díaz-Paniagua C, Gómez-Rodríguez C, Portheault A and de Vries W 2005. Los Anfibios de Doñana. Organismo Autónomo de Parques Nacionales. Ministerio de Medio Ambiente, 181 pp.

Díaz-Paniagua C, Gómez-Rodríguez C, Portheault A and de Vries W 2006. Distribución de los anfibios del Parque Nacional de Doñana en función de la abundancia y densidad de los hábitats de reproducción. Revista Española de Herpetología 20, 17-30.

Dormann CF 2007. Effects of incorporating spatial autocorrelation into the analysis of species distribution data. Global Ecology and Biogeography 16, 129-138.

Dormann CF et al. 2007. Methods to account for spatial autocorrelation in the analysis of species distributional data: a review. Ecography 30, 609-628.

Duellman WE and Trueb L 1986. Biology of Amphibians. McGraw-Hill Book Company

Espinar JL and Serrano L. In press. A quantitative hydrogeomorphic approach to the classification of temporary wetlands in the Donana National Park (SW Spain). Aquatic Ecology, Online first. 
European Commission 2007. Interpretation Manual of European Union Habitats. Natura 2000, Nature and Biodiversity. European Commission.

Fernández J and Pradas R, Madrid 2000. Historia de los Parques Nacionales Españoles. Doñana, Tablas de Daimiel, Cabrera y Cabañeros. Tomo IV. Organismo Autónomo de Parques Nacionales.

Field SA, Tyre AJ and Possingham HP 2005. Optimizing allocation of monitoring effort under economic and observational constraints. Journal of Wildlife Management 69, 473-482.

Fielding AH 2002. What are the appropriate characteristics of an accuracy measure? Predicting Plant and Animal Occurrences: Issues of Accuracy and Scale, Scott M, Heglund PJ, Morrison M, Haufler JB, Raphael MG, Wall WB and Samson F, Eds., Island Press.

Fjeldsa J and Lovett JC 1997. Biodiversity and environmental stability. Biodiversity and Conservation 6, 315-323.

Fleming MD, Berkebile JS and Hoffer RM 1975. Computer-aided analysis of LANDSAT-1 MSS data: A comparison of three approaches, including a "Modified clustering" approach. LARS Information Note 072475, 54-61.

Foody GM 2000. Estimation of sub-pixel land cover composition in the presence of untrained classes. Computers \& Geosciences 26, 469-478.

Fortuna M, Gómez-Rodríguez C and Bascompte J 2006. Spatial network structure and amphibian persistence in stochastic environments. Proceedings of the Royal Society B: Biological Sciences 273, 1429-1434.

Frazier PS and Page KJ 2000. Water body detection and delineation with Landsat TM data. Photogrammetric Engineering and Remote Sensing 66, 1461-1467.

Gañan I, Baselga A and Novoa F 2008. Diversity patterns in Iberian Calathus (Coleoptera, Carabidae: Harpalinae) species turnover shows a story overlooked by species richness. Environmental Entomology 37, 1488-1497.

García Murillo PJ, Fernández Zamudio R, Cirujano S and Sousa Martín A 2006. Aquatic macrophytes in Doñana protected area (SW Spain): An overview. Limnetica 5, 71-80.

García Novo F et al. 1978. Doñana: Prospección e inventario de ecosistemas. Ministerio de Agricultura. ICONA. Monografía no 18.

García-Novo F et al. 1991. Tipificación de los ecosistemas acuáticos sobre sustrato arenoso del Parque Nacional de Doñana. III Simposium de Aguas de Andalucía, $165-176$.

García Novo F, Marín Cabrera C 2006a. The Time of the Marshes. Lands marked by water and diversity. In: García Novo F, Marín Cabrera C (Eds.), Doñana. Water and Biosphere. Doñana 2005 Project - Confederación Hidrográfica del Guadalquivir (Guadalquivir Hydrologic Basin Authority), Spanish Ministry of the Environment, Madrid, pp. 77-94. 
García Novo F, Marín Cabrera C 2006b. Water as the main player. In: García Novo F, Marín Cabrera C (Eds.), Doñana. Water and Biosphere. Doñana 2005 Project - Confederación Hidrográfica del Guadalquivir (Guadalquivir Hydrologic Basin Authority), Spanish Ministry of the Environment, Madrid, pp. 77-94.

Gardner TA, Barlowa J and Peres CA 2007. Paradox, presumption and pitfalls in conservation biology: The importance of habitat change for amphibians and reptiles Biological Conservation 138, 166-179.

Gaston KJ 2000. Global patterns in biodiversity. Nature 405, 220-227.

Gibbons JW 2003. Terrestrial habitat: A vital component for herpetofauna of isolated wetlands. Wetlands 23, 630-635.

Gómez-Rodríguez C, Bustamante J, Koponen S and Díaz-Paniagua C 2008. Highresolution remote-sensing data in amphibian studies: identification of breeding sites and contribution to habitat models. Herpetological Journal 18, 103-113.

Gómez-Rodríguez C, Díaz-Paniagua C, Serrano L, Florencio M and Portheault A. In press. Mediterranean temporary ponds as amphibian breeding habitats: The importance of preserving pond networks. Aquatic ecology, Online first.

Gooch MM, Heupel AM, Price SJ and Dorcas ME 2006. The effects of survey protocol on detection probabilities and site occupancy estimates of summer breeding anurans Applied Herpetology 3, 129-142.

Gotelli NJ and Colwell RK 2001. Quantifying biodiversity: procedures and pitfalls in the measurement and comparison of species richness. Ecology Letters 4, 379391.

Gottschalk TK, Huettmann F and Ehlers M 2005. Thirty years of analysing and modelling avian habitat relationships using satellite imagery data: a review. International Journal of Remote Sensing 26, 2631-2656.

Graham CH, Elith J, Hijmans RJ, Guisan A, Peterson AT, Loiselle BA and Gro NPSW 2008. The influence of spatial errors in species occurrence data used in distribution models. Journal of Applied Ecology 45, 239-247.

Green DM 2003. The ecology of extinction: population fluctuation and decline in amphibians. Biological Conservation 111, 331-343.

Griffiths RA 1997. Temporary ponds as amphibian habitats. Aquatic Conservation: Marine and Freshwater Ecosystems 7, 119-126.

Grillas P, Gauthier P, Yavercovski N and Perennou C 2004a. Mediterranean Temporary Pools. Volume 1- Issues Relating to Conservation, Functioning and Management. Station Biologique de la Tour du Valat.

Grillas P, Gauthier P, Yavercovski N and Perennou C 2004b. Mediterranean Temporary Pools. Volume 2- Species information sheets. tation Biologique de la Tour du Valat. 
Groom G, Mucher CA, Ihse M and Wrbka T 2006. Remote sensing in landscape ecology: experiences and perspectives in a European context. Landscape Ecology 21, 391-408.

Gu WD and Swihart RK 2004. Absent or undetected? Effects of non-detection of species occurrence on wildlife-habitat models. Biological Conservation 116, 195-203.

Guisan A and Zimmermann NE 2000. Predictive habitat distribution models in ecology. Ecological Modelling 135, 147-186.

Guisan A, Lehmann A, Ferrier S, Austin M, Overton JMC, Aspinall R and Hastie T 2006. Making better biogeographical predictions of species' distributions. Journal of Applied Ecology 43, 386-392.

Haberl $\mathrm{H}$ et al In press. Towards an integrated model of socioeconomic biodiversity drivers, pressures and impacts. A feasibility study based on three European long-term socio-ecological research platforms. Ecological Economics. Online first.

Hanski I and Gilpin M 1991. Metapopulation dynamics - Brief-history and conceptual domain. Biological Journal of the Linnean Society 42, 3-16.

Hanski I 1998. Metapopulation dynamics. Nature 396, 41-49.

Harrison S 1991. Local extinction in a metapopulation context: an empirical evaluation. Biological Journal of the Linnean Society 42, 73-88.

Hastie TJ and Tibshirani RJ 1990. Generalized Additive Models. Chapman and Hall.

Hazell D, Cunnningham R, Lindenmayer D, Mackey B and Osborne W 2001. Use of farm dams as frog habitat in an Australian agricultural landscape: factors affecting species richness and distribution. Biological Conservation 102, 155169.

Hecnar SJ and M'Closkey RT 1996. Amphibian species richness and distribution in relation to pond water chemistry in south-western Ontario, Canada. Freshwater Biology 36, 7-15.

Hecnar SJ and M'Closkey RT 1996. Regional dynamics and the status of amphibians. Ecology 77, 2091-2097.

Hels T 2002. Population dynamics in a Danish metapopulation of spadefoot toads Pelobates fuscus. Ecography 25, 303-313.

Henry P-Y et al. 2008. Integrating ongoing biodiversity monitoring: potential benefits and methods. Biodiversity and Conservation 17, 3357-3382.

Heyer WR 1976. Studies in larval amphibian habitat partitioning. Smithsonian Institution Press.

Heyer WR, Donnelly MA, McDiarmid RW, Hayek L-AC and Foster MS 1994. Measuring and Monitoring Biological Diversity. Standard Methods for Amphibians. Smithsonian Institution Press, 364 pp. 
Hirano A, Madden M and Welch R 2003. Hyperspectral image data for mapping wetland vegetation. Wetlands 23, 436-448.

Hobbs RJ 1998. Managing Ecological Systems and Processes. Ecological Scale. Theory and Applications, Peterson DL and Parker T, Eds., Columbia University Press.

Houlahan JE and Findlay CS 2003. The effects of adjacent land use on wetland amphibian species richness and community composition. Canadian Journal of Fisheries and Aquatic Sciences 60, 1078-1094.

Houlahan JE et al. 2007. Compensatory dynamics are rare in natural ecological communities. Proceedings of the National Academy of Sciences of the United States of America 104, 3273-3277.

Innes JL 1998. Measuring Environmental Change. Ecological Scale. Theory and Applications, Peterson DL and Parker T, Eds., Columbia University Press.

Jakob C, Poizat G, Veith M, Seitz A and Crivelli AJ 2003. Breeding phenology and larval distribution of amphibians in a Mediterranean pond network with unpredictable hydrology. Hydrobiologia 499, 51-61.

Johansson M, Primmer CR, Sahlsten J and Merilä J 2005. The influence of landscape structure on occurrence, abundance and genetic diversity of the common frog, Rana temporaria. Global Change Biology 11, 1664-1679.

Joly P, Miaud C, Lehmann A and Grolet O 2001. Habitat matrix effects on pond occupancy in newts. Conservation Biology 15, 239-248.

Junta de Andalucía (1998) Datos Básicos Parque Nacional Doñana. Génesis y Morfología Web information.

Junta de Andalucía 2000. Mapa topográfico de Andalucía, 1:10000. Provincia de Huelva.

Junta de Andalucía 2001. Libro Rojo de los Vertebrados Amenazados de Andalucía. Consejería de Medio Ambiente, Junta de Andalucía.

Junta de Andalucía 2003. Ortofotografía Digital de Andalucía.

Kerr JT and Ostrovsky M 2003. From space to species: ecological applications for remote sensing. Trends in Ecology \& Evolution 18, 299-305.

Knutson MG, Richardson WB, Reineke DM, Gray BR, Parmelee JR and Weick SE 2004. Agricultural ponds support amphibian populations. Ecological Applications 14, 669-684.

Koleff P, Gaston KJ and Lennon JJ 2003. Measuring beta diversity for presenceabsence data. Journal of Animal Ecology 72, 367 - 382.

Laan R and Verboom R 1990. Effects of pool size and isolation on amphibian communities. Biological Conservation 54, 251-262. 
Lacaux JP, Tourre YM, Vignolles C, Ndione JA and Lafaye M 2007. Classification of ponds from high-spatial resolution remote sensing: Application to Rift valley fever epidemics in Senegal. Remote Sensing of Environment 106, 66-74.

Lathrop RG, Montesano P, Tesauro J and Zarate B 2005. Statewide mapping and assessment of vernal pools: A New Jersey case study. Journal of Environmental Management 76, 230-238.

Lawler SP and Morin PJ 1993. Temporal overlap, competition, and priority effects in larval anurans. Ecology 74, 174-182.

Legendre P 1993. Spatial autocorrelation - Trouble or new paradigm. Ecology 74, 1659-1673.

Legendre P and Legendre L 1998. Numerical Ecology. $2^{\text {nd }}$ ed. Elsevier Science.

Legendre P and Anderson MJ 1999. Distance-based redundancy analysis: Testing multispecies responses in multifactorial ecological experiments. Ecological Monographs 69, 1-24.

Legendre P, Borcard D and Peres-Neto PR 2005. Analyzing beta diversity: Partitioning the spatial variation of community composition data. Ecological Monographs 75, 435-450.

Leibold MA and Mikkelson GM 2002. Coherence, species turnover, and boundary clumping: elements of meta-community structure. Oikos 97, 237-250.

Leibowitz SG and Nadeau T-L 2003. Isolated wetlands. State-of-the-science and future directions. Wetlands 23, 663-684

Lillesand TM and Kiefer RW 1994. Remote Sensing and Image Interpretation. $3^{\text {rd }}$ ed. John Wiley \& Sons, Inc., 750 pp.

Liu Y, Hiyama T, Kimura R and Yamaguchi Y 2006. Temporal influences on Landsat-5 Thematic Mapper image in visible band. International Journal of Remote Sensing 27, 3183-3201.

Lobo JM 2008. More complex distribution models or more representative data? Biodiversity Informatics 5, 14-19.

Lobo JM, Castro I and Moreno JC 2001. Spatial and environmental determinants of vascular plant species richness distribution in the Iberian Peninsula and Balearic Islands. Biological Journal of the Linnean Society 73, 233-253.

Loman J and Andersson G 2007. Monitoring brown frogs Rana arvalis and Rana temporaria in 120 south Swedish ponds 1989-2005. Mixed trends in different habitats. Biological Conservation 135, 46-56.

López T, Toja J and Gabellone N 1991. Limnological comparison of two peridunar ponds in the Doñana National Park (Spain). Archiv für Hydrobiologie 120, 357378.

Lozano E 2007: Las aguas subterráneas en los cotos de Doñana y su influencia en las lagunas (CD). Instituto Geológico y Minero de España. 
Lucas NS, Shanmugamb S and Barnsley M 2002. Sub-pixel habitat mapping of a costal dune ecosystem. Applied Geography 22, 253-270.

MacKenzie DI, Nichols JD, Lachman GB, Droege S, Royle JA and Langtimm CA 2002. Estimating site occupancy rates when detection probabilities are less than one. Ecology 83, 2248-2255.

MacKenzie DI, Nichols JD, Hines JE, Knutson MG and Franklin AB 2003. Estimating site occupancy, colonization, and local extinction when a species is detected imperfectly. Ecology 84, 2200-2207.

MacKenzie DI and Bailey LL 2004. Assessing the fit of site-occupancy models. Journal of Agricultural Biological and Environmental Statistics 9, 300-318.

MacKenzie DI 2005. Was it there? Dealing with imperfect detection for species presence/absence data. Australian \& New Zealand Journal of Statistics 47, 6574 .

MacKenzie DI 2005. What are the issues with presence-absence data for wildlife managers? Journal of Wildlife Management 69, 849-860.

MacKenzie DI and Royle JA 2005. Designing occupancy studies: general advice and allocating survey effort. Journal of Applied Ecology 42, 1105-1114.

MacKenzie DI 2006. Modeling the probability of resource use: The effect of, and dealing with, detecting a species imperfectly. Journal of Wildlife Management $70,367-374$.

MacKenzie DI, Nicholson JD, Royle JA, Pollock KH, Bailey LL and Hines JE 2006. Occupancy Estimation and Modeling. Inferring Patterns and Dynamics of Species Occurrence. Elsevier.

Magurran AE 2004. Measuring Biological Diversity. Blackwell Publishing, 256 pp.

Magurran AE 2007. Species abundance distributions over time. Ecology Letters 10, $347-354$.

Manzano M, Custodio E and Colomines M, 2005: El fondo hidroquímico natural del acuífero de Doñana (SO España). Congreso Ibérico de Geoquímica y IX Congreso de Geoquímica de España., Diputación Provincial de Soria.

Manzano M and Custodio E 2006. The Doñana aquifer and its relations with the natural environment. Doñana. Water and Biosphere, García Novo F and Marín Cabrera C, Eds., Doñana 2005 Project - Confederación Hidrográfica del Guadalquivir (Guadalquivir Hydrologic Basin Authority), Spanish Ministry of the Environment, 141-150.

Marcus WA 2002. Mapping of stream microhabitats with high spatial resolution hyperspectral imagery. Journal of Geographical Systems 4, 113-126.

Marcus WA, Legleiter CJ, Aspinall RJ, Boardman JW and Crabtree RL 2003. High spatial resolution hyperspectral mapping of in-stream habitats, depths, and woody debris in mountain streams. Geomorphology 55, 363-380. 
Marsh DM 2001. Fluctuations in amphibian populations: a meta-analysis. Biological Conservation 101, 327-335.

Marsh DM and Trenham PC 2001. Metapopulation dynamics and amphibian conservation. Conservation Biology 15, 40-49.

Marsh DM, Fegraus EH and Harrison S 1999. Effects of breeding pond isolation on the spatial and temporal dynamics of pond use by the tungara frog, Physalaemus pustulosus. Journal of Animal Ecology 68, 804-814.

Maurer BA 2002. Predicting Distribution and Abundance. Thinking Within and Between Scales. Predicting Species Occurrences. Issues of Accuracy and Scale, Scott JM, Heglund PJ, Morrison ML, Haufler JB, Raphael MG, Wall WA and Samson FB, Eds., Island Press.

Mazerolle MJ, Desrochers A and Rochefort L 2005. Landscape characteristics influence pond occupancy by frogs after accounting for detectability. Ecological Applications 15, 824-834.

Mazerolle MJ 2006. Improving data analysis in herpetology: using Akaike's Information Criterion (AIC) to assess the strength of biological hypotheses. Amphibia-Reptilia 27, 169-180.

Mazerolle MJ, Bailey LL, Kendall WL, Royle JA, Converse SJ and Nichols JD 2007. Making great leaps forward: Accounting for detectability in herpetological field studies. Journal of Herpetology 41, 672-689.

McAlpine DF and Dilworth TG 1989. Microhabitat and prey size among three species of Rana (Anura: Ranidae) sympatric in eastern Canada. Canadian Journal of Zoology 67, 2244-2252.

McCarthy MA 2007. Bayesian Methods for Ecology. Cambridge University Press, 296 pp.

McCauley LA and Jenkins DG 2005. GIS- based estimates of former and current depressional wetlands in an agricultural landscape. Ecological Applications 15, 1199-1208.

McCullagh P and Nelder JA 1989. Generalized Linear Models. $2^{\text {nd }}$ ed. Chapman and Hall, $\mathrm{xx}+512 \mathrm{pp}$.

McMenamin SK, Hadly EA and Wright CK 2008. Climatic change and wetland desiccation cause amphibian decline in Yellowstone National Park. Proceedings of the National Academy of Sciences of the United States of America 105, 1698816993.

Middleton EM, Herman JR, Celarier EA, Wilkinson JW, Carey C and Rusin RJ 2001. Evaluating ultraviolet radiation exposure with satellite data at sites of amphibian declines in Central and South America. Conservation Biology 15, 914-929.

Millán A, Hernando C, Aguilera P, Castro A and Ribera I 2005. Los coleópteros acuáticos y semiacuáticos de Doñana: reconocimiento de su biodiversidad y 
prioridades de conservación. Boletín de la Sociedad Entomológica Aragonesa $37,157-164$.

Miller ME, Hui SL and Tierney WM 1991. Validation techniques for logisticregression models. Statistics in Medicine 10, 1213-1226.

Montes C, Amat JA and Ramírez-Díaz L 1982. Ecosistemas acuáticos del bajo Guadalquivir (SW España). I. Características generales físico-químicas y biológicas de las aguas. Studia Oecologica 3, 129-158.

Montes C, Borja F, Bravo MA and Moreira JM 1998. Reconocimiento Biofísico de Espacios Naturales Protegidos. Doñana: Una Aproximación Ecosistémica. Junta de Andalucía. Consejería de Medio Ambiente.

Mooij WM, Martin J, Kitchens WM and DeAngelis DL 2007. Exploring the temporal effects of seasonal water availability on the snail kite of Florida. Temporal Dimensions of Landscape Ecology. Wildlife Responses to Variable Sources, Bissonette JA and Storch I, Eds., Springer.

Moreno CE and Halffter G 2001. Spatial and temporal analysis of alpha, beta and gamma diversities of bats in a fragmented landscape. Biodiversity and Conservation 10, 367-382.

Muñoz Reinoso JC 1996. Tipología de las descargas sobre arenas de la Reserva Biológica de Doñana. Limnetica 12, 53-63.

Mura G and Brecciaroli B 2003. The zooplankton crustacean of the temporary waterbodies of the Oasis of Palo (Rome, central Italy). Hydrobiologia 495, 93102.

Oertli B, Biggs J, Céréghino R, Grillas P, Joly P and Lachavanne J-B 2005. Conservation and monitoring of pond biodiversity: introduction. Aquatic Conservation: Marine and Freshwater Ecosystems 15, 535-540.

Oksanen J, Kindt R, Legendre P and O'Hara B 2007. vegan: Community Ecology Package. R package version 1.8-5, available at http://cran.r-project.org/.

Otto CRV, Forester DC and Snodgrass JW 2007. Influences of wetland and landscape characteristics on the distribution of carpenter frogs. Wetlands 27, 261-269.

Ovaskainen O and Hanski I 2004. From individual behavior to metapopulation dynamics: Unifying the patchy population and classic metapopulation models. American Naturalist 164, 364-377.

Ozesmi SL and Bauer ME 2002. Satellite remote sensing of wetlands. Wetlands Ecology and Management 10, 381-402.

Papastergiadou E, Retalis A, Kalliris P and Georgiadis T 2007. Land use changes and associated environmental impacts on the Mediterranean shallow Lake Stymfalia, Greece. Hydrobiologia 584, 361-372.

Parris KM 2004. Environmental and spatial variables influence the composition of frog assemblages in sub-tropical eastern Australia. Ecography 27, 392-400. 
Paton PWC and Crouch III WB 2002. Using the phenology of pond-breeding amphibians to develop conservation strategies. Conservation Biology 16, 194204.

Patterson BD and Atmar W 1986. Nested subsets and the structure of insular mammalian faunas and archipelagoes. Biological Journal of the Linnean Society $28,65-82$.

Pearce J and Ferrier S 2000. Evaluating the predictive performance of habitat models developed using logistic regression. Ecological Modelling 133, 225-245.

Pearl CA, Adams MJ, Leuthold N and Bury RB 2005. Amphibian occurrence and aquatic invaders in a changing landscape: Implications for wetland mitigation in the Willamette Valley, Oregon, USA. Wetlands 25, 76-88.

Pechmann JHK, Scott DE, Semlitsch RD, Caldwell JP, Vitt LJ and Gibbons JW 1991. Declining amphibian populations - the problem of separating human impacts from natural fluctuations. Science 253, 892-895.

Pellet J and Schmidt BR 2005. Monitoring distributions using call surveys: estimating site occupancy, detection probabilities and inferring absence. Biological Conservation 123, 27-35.

Pellet J, Schmidt BR, Fivaz F, Perrin N and Grossenbacher K 2006. Density, climate and varying return points: an analysis of long-term population fluctuations in the threatened European tree frog. Oecologia 149, 65-71.

Petranka JW, Smith CK and Scott AF 2004. Identifying the minimal demographic unit for monitoring pond-breeding amphibians. Ecological Applications 14, 1065-1078.

Petranka JW and Holbrook CT 2006. Wetland restoration for amphibians: Should local sites be designed to support metapopulations or patchy populations? Restoration Ecology 14, 404-411.

Piha H, Luoto M, Piha M and Merilä J 2007. Anuran abundance and persistence in agricultural landscapes during a climatic extreme. Global Change Biology 13, $300-311$.

Pinder AW, Storey KB and Ultsch GR 1992. Estivation and Hibernation. Environmental Physiology of the Amphibians, Feder ME and Burggren WW, Eds., University of Chicago Press.

Pleguezuelos JM, Márquez R and Lizana M 2002. Atlas y Libro Rojo de los Anfibios y Reptiles de España. Dirección General de Conservación de la Naturaleza, Ministerio de Medio Ambiente.

Pollock KH, Nichols JD, Simons TR, Farnsworth GL, Bailey LL and Sauer JR 2002. Large scale wildlife monitoring studies: statistical methods for design and analysis. Environmetrics 13, 105-119.

Pons X and Solé-Sugrañes L 1994. A simple radiometric correction model to improve automatic mapping of vegetation from multispectral satellite data. Remote Sensing of Environment 48, 191-204. 
Portheault A, Díaz-Paniagua C and Gómez-Rodríguez C 2007. Predation on amphibian eggs and larvae on temporary ponds: The case of Bufo calamita in southwestern Spain. Revue d'Ecologie: La Terre et la Vie 62, 315-322.

Porthault A. In prep. La importancia de la depredación en el éxito reproductivo de la población de anfibios de Doñana, $\mathrm{PhD}$ Thesis, University of Sevilla.

Preston FW 1960. Time and space and the variation of species. Ecology 41, 611627.

Pulliam HR 1996. Sources and Sinks: Empirical Evidence and Population Consequences. Population Dynamics in Ecological Space and Time, Rhodes OE, Chesser RK and Smith MH, Eds., University of Chicago Press, 45-74.

Ramos B 2002. Ecosistemas. Parque Nacional de Doñana, García Canseco V, Ed., Canseco Editores SL, 69-108.

Revenga C, Campbell I, Abell R, de Villiers P and Bryer M 2005. Prospects for monitoring freshwater ecosystems towards the 2010 targets. Philosophical Transactions of the Royal Society B-Biological Sciences 360, 397-413.

Reynolds-Hogland MJ and Mitchell MS 2007. Three axes of ecological studies: Matching process and time in landscape ecology. Temporal Dimensions of Landscape Ecology. Wildlife Responses to Variable Sources, Bissonette JA and Storch I, Eds., Springer.

Ricklefs RE and Schluter D, Eds., 1993. Species Diversity in Ecological Communities: Historical and Geographical Perspectives. University of Chicago.

Richards JA and Jia X 1999. Remote Sensing Digital Image Analysis. An Introduction. $3^{\text {rd }}$ ed., Springer, $363 \mathrm{pp}$.

Richter-Boix A, Llorente GA and Montori A 2006. Breeding phenology of an amphibian community in a Mediterranean area. Amphibia-Reptilia 27, 549-559.

Richter-Boix A, Llorente GA and Montori A 2007. Structure and dynamics of an amphibian metacommunity in two regions. Journal of Animal Ecology 76, 607618.

Rittenhouse TAG and Semlitsch RD 2007. Distribution of amphibians in terrestrial habitat surrounding wetlands. Wetlands 27, 153-161.

Rivas-Martínez S, Costa M, Castroviejo S and Valdés E 1980. Vegetación de Doñana (Huelva, España). Lazaroa 2, 5-189.

Rodríguez-Ramírez A and Clemente L 2002. Geomorfología. Parque Nacional de Doñana, García Canseco V, Ed., Canseco Editores SL, 19-42.

Romanuk TN and Kolasa J 2001. Simplifying the complexity of temporal diversity dynamics: a differentiation approach. Ecoscience 8, 259-263.

Rosenzweig ML 1995. Species Diversity in Space and Time. Cambridge University Press. 
Roshier DA and Rumbachs RM 2004. Broad-scale mapping of temporary wetlands in arid Australia. Journal of Arid Environments 56, 249-263.

Roshier DA and Rumbachs RM 2004. Broad-scale mapping of temporary wetlands in arid Australia. Journal of Arid Environments 56, 249-263.

Royle JA and Nichols JD 2003. Estimating abundance from repeated presenceabsence data or point counts. Ecology 84, 777-790.

Royle JA 2006. Site occupancy models with heterogeneous detection probabilities. Biometrics 62, 97-102.

Royle JA and Dorazio RM 2008. Hierarchical Modeling and Inference in Ecology. Academic Press, Elsevier, 444 pp.

Sacks LA, Herman JS, Konikow LF and Vela AL 1992. Seasonal dynamics of groundwater-lake interactions at Doñana National-Park, Spain. Journal of Hydrology 136, 123-154.

Sanderson RA, Eyre MD and Rushton SP 2005. Distribution of selected macroinvertebrates in a mosaic of temporary and permanent freshwater ponds as explained by autologistic models. Ecography 28, 355-362.

Santos X, Carretero MA, G.A. L and Montori A 1996. Inventario de las áreas importantes para los anfibios y reptiles de España. Colección Técnica. ICONA.

Saveraid EH, Debinski DM, Kindscher K and Jakubauskas ME 2001. A comparison of satellite data and landscape variables in predicting bird species occurrences in the Greater Yellowstone Ecosystem, USA. Landscape Ecology 16, 71-83.

Scribner KT, Arntzen JW, Cruddace N, Oldham RS and Burke T 2001. Environmental correlates of toad abundance and population genetic diversity. Biological Conservation 98, 201-210.

Schmidt BR 2003. Count data, detection probabilities, and the demography, dynamics, distribution, and decline of amphibians Comptes Rendus Biologies $326,119-124$

Schmidt BR 2004. Declining amphibian populations: The pitfalls of count data in the study of diversity, distributions, dynamics, and demography. Herpetological Journal 14, 167-174

Schmidt BR 2005. Monitoring the distribution of pond-breeding amphibians when species are detected imperfectly. Aquatic Conservation: Marine and Freshwater Ecosystems 15, 681-692.

Schmidt BR and Pellet J 2005. Relative importance of population processes and habitat characteristics in determining site occupancy of two anurans. Journal of Wildlife Management 69, 884-893.

Schmidt KS and Skidmore AK 2003. Spectral discrimination of vegetation types in a coastal wetland. Remote Sensing of Environment 85, 92-108.

Schwartz SS and Jenkins DG 2000. Temporary aquatic habitats: constraints and opportunities. Aquatic Ecology 34, 3-8. 
Semlitsch RD 2002. Principles for management of aquatic-breeding amphibians. Journal of Wildlife Management 64, 615-631.

Semlitsch RD and Bodie JR 1998. Are small, isolated wetlands expendable? Conservation Biology 12, 1129-1133.

Semlitsch RD, Ed. 2003. Amphibian Conservation. Smithsonian Books.

Seoane J, Bustamante J and Díaz-Delgado R 2004. Competing roles for landscape, vegetation, topography and climate in predictive models of bird distribution. Ecological Modelling 171, 209-222.

Serrano L and Toja J 1995. Limnological description of four temporary ponds in the Doñana National Park (SW, Spain). Archiv für Hydrobiologie 133, 497-516.

Serrano L and Serrano L 1996. Influence of groundwater exploitation for urban water supply on temporary ponds from the Doñana National Park (SW Spain). Journal of Environmental Management 46, 229-238.

Serrano L and Fahd K 2005. Zooplankton communities across a hydroperiod gradient of temporary ponds in the Doñana National Park (SW Spain). Wetlands $25,101-111$.

Serrano L, Reina M, Martín G, Reyes I, Arechederra A, León D and Toja J 2006. The aquatic systems of Doñana (SW Spain): watersheds and frontiers. Limnetica $25,11-32$.

Serrano L and Zunzunegui M 2008. The relevance of preserving temporary ponds during drought: hydrological and vegetation changes during a 16-year period in Doñana National Park (south-west Spain). Aquatic Conservation: Marine and Freshwater Ecosystems 18, 261-279.

Settle JJ and Drake NA 1993. Linear mixing and the estimation of ground cover proportions. International Journal of Remote Sensing 14.

Shuman CS and Ambrose RF 2003. A comparison of remote sensing and groundbased methods for monitoring wetland restoration success. Restoration Ecology 11, 325-333.

Shurin JB 2007. How is diversity related to species turnover through time? Oikos $116,957-965$.

Siljeström PA, Moreno A, García LV and Clemente LE 1994. Doñana National Park (south-west Spain): geomorphological characterization through a soil-vegetation study. Journal of Arid Environments 26, 315-323.

Skelly DK and Meir E 1997. Rule-based models for evaluating mechanisms of distributional change. Conservation Biology 11, 531 - 538.

Skelly DK, Werner EE and Cortwright SA 1999. Long-term distributional dynamics of a Michigan amphibian assemblage. Ecology 80, 2326-2337.

Skelly DK 2001. Distributions of pond-breeding anurans: An overview of mechanisms. Israel Journal of Zoology 47, 313-332. 
Skelly DK, Yurewicz KL, Werner EE and Relyea RA 2003. Estimating decline and distributional change in amphibians. Conservation Biology 17, 744-751.

Smith GR, Dingfelder HA and Vaala DA 2003. Distribution and abundance of amphibian larvae within two temporary ponds in Central Ohio, USA. Journal of Freshwater Ecology 18, 491-496.

Smith MA and Green DM 2005. Dispersal and the metapopulation paradigm in amphibian ecology and conservation: are all amphibian populations metapopulations? Ecography 28, 110-128.

Snodgrass JW, Bryan Jr AL and Burger J 2000. Development of expectations of larval amphibian assemblage structure in southeastern depression wetlands. Ecological Applications 10, 1219-1229.

Snodgrass JW, Komoroski MJ and Bryan Jr AL 2000. Relationships among isolated wetland size, hydroperiod, and amphibian species richness: Implications for wetlands regulations. Conservation Biology 14, 414-419.

Sobrino JA, Jiménez-Muñoz JC, Zarco-Tejada PJ, Sepulcre-Cantó G and de Miguel E 2006. Land surface temperature derived from airborne hyperspectral scanner thermal infrared data. Remote Sensing of Environment 102, 99-115.

Soininen J, Lennon JJ and Hillebrand H 2007. A multivariate analysis of beta diversity across organisms and environments. Ecology 88, 2830-2838.

Sousa Martín A and García Murillo P 2005. Historia ecológica y evolución de las lagunas peridunares del Parque Nacional de Doñana. Organismo Autónomo de Parques Nacionales. Ministerio de Medio Ambiente.

Spencer M, Blaustein L, Schwartz SS and Cohen JE 1999. Species richness and the proportion of predatory animal species in temporary freshwater pools: relationships with habitat size and permanence. Ecology Letters 2, 157-166.

Stiling P 1999. Ecology: Theories and Applications. $3^{\text {rd }}$ ed. Prentice Hall.

Suso J and Llamas MR 1993. Influence of groundwater development on the Doñana National Park ecosystems (Spain). Journal of Hydrology 141, 239-269.

Suso JM and Llamas M 1990. El impacto de la extracción de aguas subterráneas en el Parque Nacional de Doñana. Estudios Geológicos 46, 317-345.

Sztatecsny M, Jehle R, Schmidt BR and Arntzen JW 2004. The abundance of premetamorphic newts (Triturus cristatus, T. marmoratus) as a function of habitat determinants: An a priori model selection approach. Herpetological Journal 14, 89-97.

R Development Core Team, 2006. R: a language and environment for statistical computing. http://www.r-project.org.

Tews J, Brose U, Grimm V, Tielborger K, Wichmann MC, Schwager M and Jeltsch F 2004. Animal species diversity driven by habitat heterogeneity/diversity: the importance of keystone structures. Journal of Biogeography 31, 79-92. 
Toja Santillana J and SerranoMartín L 2006. The aquatic systems of Doñana. Doñana. Water and Biosphere, García Novo F and Marín Cabrera C, Eds., Doñana 2005 Project - Confederación Hidrográfica del Guadalquivir (Guadalquivir Hydrologic Basin Authority), Spanish Ministry of the Environment, 213-220.

Trenham PC, Koenig WD, Mossman MJ, Stark SL and Jagger LA 2003. Regional dynamics of wetland-breeding frogs and toads: turnover and synchrony. Ecological Applications 13, 1522-1532.

Trick T and Custodio E 2004. Hydrodynamic characteristics of the western Donana Region (area of El Abalario), Huelva, Spain. Hydrogeology Journal 12, 321335.

Tuomisto H and Ruokolainen K 2006. Analyzing or explaining beta diversity? Understanding the targets of different methods of analysis. Ecology 87, 26972708.

Turner W, Spector S, Gardiner N, Fladeland M, Sterling E and Steininger M 2003. Remote sensing for biodiversity science and conservation. Trends in Ecology \& Evolution 18, 306-314.

Ulrich W, Almeida M and Gotelli NJ 2009. A consumer's guide to nestedness analysis. Oikos 118, 3-17.

Urban DL 2004. Disturbance heterogeneity determines freshwater metacommunity structure. Ecology 85, 2971-2978.

Valverde JA 1958. An ecological sketch of the Coto Doñana. British Birds 51, 1-23.

Valverde JA 1960. Vertebrados de las Marismas del Guadalquivir (Introducción a su estudio ecológico). Archivos del Instituto de Aclimatación de Almería 9, 1169.

Valverde JA 1967. Estructura de una comunidad mediterránea de vertebrados terrestres. Monografías de la Estación Biológica de Doñana (CSIC).

Van Buskirk J 2005. Local and landscape influence on amphibian occurrence and abundance. Ecology 86, 1936-1947.

Vaughan IP and Ormerod SJ 2003. Improving the quality of distribution models for conservation by addressing shortcomings in the field collection of training data. Conservation Biology 17, 1601-1611.

Venier LA, Pearce J, McKee JE, McKenney DW and Niemi GJ 2004. Climate and satellite-derived land cover for predicting breeding bird distribution in the Great Lakes Basin. Journal of Biogeography 31, 315-331.

Verdin JP 1996. Remote sensing of ephemeral water bodies in western Niger. International Journal of Remote Sensing 17, 733-748.

Waterkeyn A, Grillas P, Vanschoenwinkel B and Brendonck L 2008. Invertebrate community patterns in Mediterranean temporary wetlands along hydroperiod and salinity gradients. Freshwater Biology 53, 1808-1822. 
Weiers S, Bock M, Wissen M and Rossner G 2004. Mapping and indicator approaches for the assessment of habitats at different scales using remote sensing and GIS methods. Landscape and Urban Planning 67, 43-65.

Wellborn GA, Skelly DK and Werner EE 1996. Mechanisms creating community structure across a freshwater habitat gradient. Annual Review of Ecology and Systematics 27, 337-363.

Wells KD 2007. The Ecology and Behavior of Amphibians. The University of Chicago Press, 1400 pp.

Werner EE, Skelly DK, Relyea RA and Yurewicz KL 2007. Amphibian species richness across environmental gradients. Oikos 116, 1697-1712.

Werner EE, Yurewicz KL, Skelly DK and Relyea RA 2007b. Turnover in an amphibian metacommunity: the role of local and regional factors. Oikos 116, 1713-1725.

Weyrauch SL and Grubb Jr TC. 2004. Patch and landscape characteristics associated with the distribution of woodland amphibians in an agricultural fragmented landscape: an information-theoretic approach. Biological Conservation 115, 443-450.

Whiles MR and Goldowitz BS 2005. Macroinvertebrate communities in Central Platte River wetlands: patterns across a hydrologic gradient. Wetlands 25, 462472

White EP et al. 2006. A comparison of the species-time relationship across ecosystems and taxonomic groups. Oikos 112, 185-195.

Wiest JA 1982. Anuran succession at temporary ponds in a post oak-savanna region of Texas. Herpetological communities: a symposium of the Society for the Study of Amphibians and Reptiles and the Herpetologists' League, Washington, D.C, U.S. Fish and Wildlife Service, , 239.

Williams AK and Berkson J 2004. Reducing false absences in survey data: Detection probabilities of red-backed salamanders. Journal of Wildlife Management 68, 418-428.

Williams DD 1997. Temporary ponds and their invertebrate communities. Aquatic Conservation: Marine and Freshwater Ecosystems 7, 105-117.

Williams DD 2006. The Biology of Temporary Waters. Oxford University Press, 348 pp.

Williams P, Biggs J, Fox G, Nicolet P and Whitfield M 2001. History, origins and importance of temporary ponds. Freshwater Forum 17, 7-15.

Williams P, Whitfield M, Biggs J, Bray S, Fox G, Nicolet P and Sear D 2003. Comparative biodiversity of rivers, streams, ditches and ponds in an agricultural landscape in Southern England. Biological Conservation 115, 329-341.

Yoccoz NG, Nichols JD and Boulinier T 2001. Monitoring of biological diversity in space and time. Trends in Ecology \& Evolution 16, 446-453. 
Zacharias I, Dimitrou E, Dekker A and Dorsman E 2007. Overview of temporary ponds in the Mediterranean region: Threats, management and conservation issues. Journal of Environmental Biology 28, 1-9.

Zimmermann NE, Edwards Jr TC, Moisen GG, Frescino TS and Blackard JA 2007. Remote sensing-based predictors improve distribution models of rare, early successional and broadleaf tree species in Utah. Journal of Applied Ecology 44, 1057-1067.

Zunzunegui M, Díaz Barradas MC and García Novo F 1998. Vegetation fluctuation in mediterranean dune ponds in relation to rainfall variation in water extraction. Applied Vegetation Science 1, 151-160. 
Conclusions

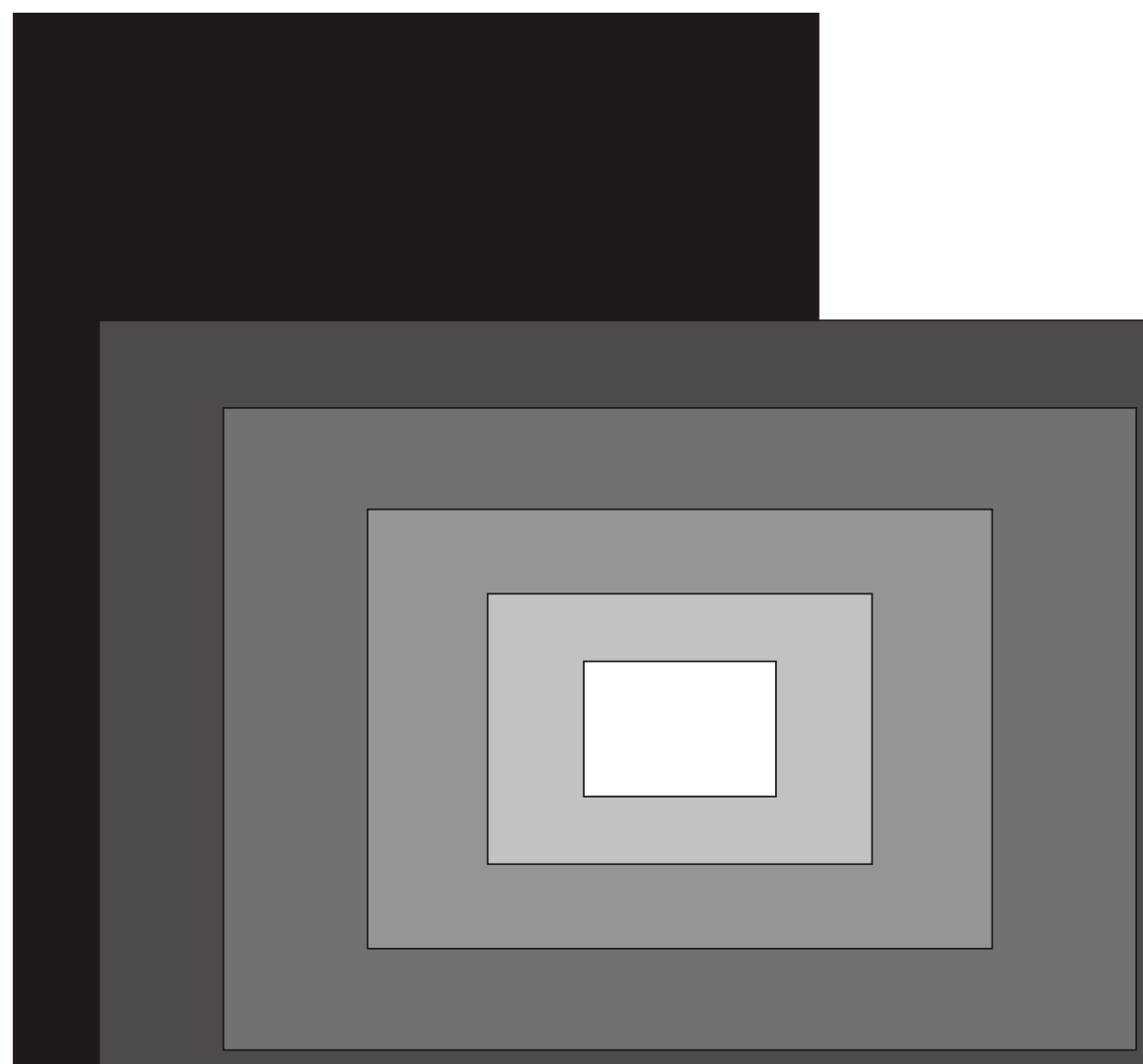


The system of temporary ponds in Doñana National Park shows a remarkable spatial and temporal variability, thus providing a heterogeneous ecosystem over space and time that favours species diversity as it provides a large number of niches for pond-breeding species.

2

High spectral and spatial resolution remote sensing data are useful for the delimitation of temporary ponds in Doñana National Park. It also enables the identification of ponds supporting a high number of species but it does not provide accurate information to identify potential breeding sites for particular species.

2 Remote sensing data of medium spatial resolution (Landsat data) can be used to understand the flooding dynamics of highly fluctuating small-sized ponds. In particular, it can be used to discriminate natural fluctuations from negative trends in habitat characteristics important for associated species. In Doñana National Park, we have identified a negative trend that may be critical for the conservation of amphibian species: the tendency to shorter annual hydroperiods.

The amphibian assemblages in Doñana National Park exhibit high interannual variability, both in species occurrence and relative abundance. However, at regional scale (entire study area), inter-annual variability was negligible during the study period since almost all species bred every year except in very dry years, when temporary ponds did not flood, like 20042005.

Inter-annual turnover at pond scale provides evidence of the inadequacy of surveys conducted only during one breeding season to characterize the species assemblage associated to a given pond.

The single-visit probability of detection is species-specific, with low values for most species, and changes among surveys and breeding seasons. For any given species, the "best month" to survey is not predictable from year-to-year, a fact that evidences the variability and uncertainty in the efficiency of surveys. Therefore, both studies of occupancy at species level and diversity assessments should be conducted on the basis of repeated surveys rather than single-surveys. 
7 In studies of species habitat requirements, we should neither assume all the non-detections as if they were real absences, nor give a similar reliability to all non-detection records. This is of special relevance when the simultaneous survey of all locations is not feasible and, mostly, when the number and timing of surveys varies among cases (ponds), turning out low for many of them, as was our case.

We require both temporally fixed and temporally variable habitat characteristics to develop a realistic understanding of amphibian diversity patterns in the study area, both when considering data collected on particular years or over several years.

Environmental attributes irrelevant for species richness gradients may be responsible for the variation in assemblage composition among ponds (beta diversity). Thereby, a multi-scale perspective of diversity is critical to avoid regarding environmental variables as irrelevant when they are contributing to the increase of species diversity.

Pond hydroperiod may be a major driver of pond-breeding assemblages in years when the duration of ponds is short and strong nested pattern occur along hydroperiod gradient. On the contrary, the role of hydroperiod in amphibian diversity is negligible in wet years, when desiccation risk is not a major stress and the pond is available for a longer time, enabling the potential breeding of most species. This would explain that, at species level, we did not observe a strong segregation pattern according to hydroperiod, since all species except Pelophylax perezi and Bufo bufo attempted to breed in ponds along the entire hydroperiod gradient during the study period.

11

Habitat model outputs, both for species occurrence and relative abundance, are species-specific. Therefore, conservation programs should focus in habitat requirements at the species level as important habitat factors maybe masked when considering solely species richness data. 
Habitat model outputs built from annual richness or species-specific abundance data change from year-to-year. This inconsistency across time compromises the utility of annual studies of amphibians for conservation purposes in Doñana, as we cannot identify with certainty the habitat requirements of species nor assemblages.

12 The occurrence of Hyla meridionalis and Triturus pygmaeus was not related to particular habitat characteristics but to a particular ecosection within the Park. Characteristics of the breeding habitat (area and hydroperiod) were of high importance for the occurrence of Pelobates cultripes and Pleurodeles waltl. Terrestrial characteristics were the most important predictors of the occurrence of Discoglossus galganoi and Lissotriton boscai, being the probability of occurrence of the latter also related to the spatial structure of the patchy population.

14

The natural dynamism of the ecosystem seems to be the most important feature for the conservation of biodiversity in the medium-term. So, a given pond would offer different breeding opportunities over time, being suitable for different species depending on its biotic and abiotic characteristics. Furthermore, the high abundance and diversity of temporary ponds would provide the spatial variability necessary for a community to persist under such high environmental variability. 
Y así acaba una tesis.

Todo lo que acabo de leer es sólo lo que he escrito y no he borrado. Mi trabajo de estos años se puede condensar en poco más de 300 páginas. Pero la tesis ha sido mucho más. Sobre todo, habéis sido muchos más. Tanto las páginas aquí condensadas, como todas las otras, son páginas de mi vida que hemos escrito juntos y no se pueden borrar. Y, sobre todo, no las quiero olvidar. Por eso, esta es una buena oportunidad para daros las gracias por haberme acompañado en este trocito de camino.

Poli, tú has compartido generosamente conmigo tu experiencia y tus inagotables conocimientos sobre ecología, los anfibios, Doñana y la complejidad del sistema que forman. Tu confianza y apoyo me han animado a aventurarme en trabajos que, de otra manera, jamás me habría planteado. Y tu amistad y cariño nunca me han faltado en los momentos críticos, cuando lo más fácil es siempre abandonar. Tú lo sabes, podría haber empezado una tesis con cualquier otra persona, pero sólo la habría acabado contigo. Porque, aunque eres muy buena jefa, tu gran virtud es ser una excelente persona... y una magnífica compañera.

Javier, a ti te agradezco enormemente que aceptaras embarcarte en este proyecto cuando el anterior no había llegado a buen puerto. Me has enseñado a disfrutar haciendo análisis estadísticos y a ser mucho más rigurosa con todo lo que hago (aunque seguro que todavía no soy todo lo autocrítica que a ti te gustaría :-D). Gracias por haberme incorporado al LAST, por haber sido siempre un guía fiable para no perderse en el difícil mundo de la estadística y por tu generoso apoyo durante estos años. 
Raquel B. Una de las mejores cosas que han tenido estos años es que tú fueras la primera persona que me encontraba por las mañanas. Eres la mejor forma de empezar un día. Es imposible resumir en cuatro líneas toda nuestra vida juntas, porque sería necesario repetir cada conversación que hemos tenido, cada palabra de cariño, cada abrazo, cada mirada... Son tan valiosos que se merecerían un sitio aquí, así que no aspiro a que estas líneas reflejen todo lo que significas para mí. Me siento muy afortunada por haber sido tu compañera y porque me invitaras a compartir tu vida. Sabes que me encantaría parecerme a ti. Y sabes que no lo conseguiré. Así que espero que sigamos juntas muchos años, como sea, para poder conservar todo lo que aportas a mi vida, que es tremendamente especial.

Matati. Cuando pienso en ti, me emociono. Han sido tantos años y has sido siempre una amiga tan increíble... Me pasa lo mismo que con Raquel, hemos compartido tantas cosas juntas, me has cuidado tanto, me has querido tanto...y yo te quiero tanto... que me parece injusto que todo se resuma en cuatro líneas. Así que no lo voy a hacer. Pero sí quiero que la gente sepa (el resto de la gente que pueda leer esto, no tú y yo) que eres una de las mejores personas que conozco. Eres bondadosa, generosa, inteligente, sensata, comprensiva, atenta, íntegra y valiente. Por todas esas virtudes, y alguna más, eres lo más valioso de toda Sevilla para mí. Renunciaría a muchas cosas, pero nunca a ti.

Margarita. Y cuando pienso en ti, me sale una sonrisa. Tienes esa capacidad de alegrar la vida a la gente que te rodea, y es genial. Y, sobre todo, tienes una magia especial que hace que sea muy fácil quererte. No se describirla. Por eso he disfrutado tanto con tu amistad estos años. Has sido una pieza clave de este último periodo de tesis, y lo sabes, pero, si tuviera que elegir un momento contigo, sería la temporada de campo que hicimos juntas. Fue sencillamente espectacular. Creo que han sido los mejores meses de mi paso por la EBD, y ha sido gracias a ti (y a "tus cosas"). A partir de ese momento, pasaste a ser una de las personas más importantes de mi vida. Y seguirás siéndolo.

Judit, tú fuiste mi otra "mami” desde el mismo día que entré en la estación. Matati y tú me acogisteis como un miembro más de vuestra familia y me habéis cuidado todos estos años. Siempre te has crecido en los momentos difíciles y has conseguido transmitirme tu fuerza. Sin duda has sido uno de los apoyos más robustos cuando los cimientos han temblado. Además, te agradezco enormemente toda la paciencia y comprensión que has tenido conmigo, que yo sé que a veces soy un poco "outlier" y no es fácil entenderme. 
Alex, mi compañero de tantos muestreos en el coto y en Gredos... i¿Qué habría sido de mí si no hubieras estado tú durante mis primeros meses en Doñana!? Te tengo que agradecer todos los buenos momentos que hemos pasado trabajando juntos y, sobre todo, que me "desurbanizaras", enseñándome cómo es "la vida en el campo".

Ivan, tú llegaste tarde al grupo (qué raro, ¿no?) pero en seguida te convertiste en una pieza importante, por lo menos para mí. Eres cabal, prudente y de pocas palabras, pero precisas. Por eso, poder hablar contigo ha sido siempre un placer. Tú y Bea habéis sido siempre capaces de transmitirme la tranquilidad necesaria para relativizar las pequeñas dificultades con las que me he ido encontrando.

Ricki y David Aragonés. Me acogisteis en vuestro grupo cuando la teledetección y los SIG eran prácticamente unos desconocidos para mí y, con mucha paciencia, fuisteis guiándome y aconsejándome para que la desorientación inicial desapareciera. Especialmente os agradezco que me hayáis regalado vuestro tiempo de una forma tan generosa y que siempre hayáis estado accesibles para mí, cualquier día y a cualquier hora. Sin vuestro apoyo técnico y científico todo esto habría sido muchísimo más complicado. Y lo digo no sólo porque siempre me habéis resuelto todas las dudas que he tenido, sino porque lo habéis hecho con mucho cariño. Me he sentido muy cuidada por vosotros en todo momento. Por cierto, Ricki, aún hoy, después de tantos años, me sigue fascinando la pasión que sientes por tu trabajo, cómo te emociona y cómo consigues transmitírmelo. Es genial.

Rocío, te he metido dentro de la gente del grupo porque para mí es como si lo fueras. Has estado muy cerca de mí todos estos años, en Doñana y en la FJI. Aunque el tiempo de Doñana es muy especial, y me has ayudado mucho con las plantas, sobre todo quiero agradecerte el trabajo y dedicación que has tenido con la FJI y Precarios-Sevilla. Sé que todo lo has hecho por convencimiento personal, y es por eso que tu forma de ser y entender la vida ha facilitado mucho la mía.

Raquel (América). iTengo tanto que agradecerte! Llevas media vida a mi lado y nunca me has fallado. Además, en estos años de la tesis, te has preocupado diariamente por mí, mostrándome que tu amistad es una de las cosas más valiosas que tengo. Siempre has estado dispuesta a corregirme el inglés, no sólo dudas puntuales, ihasta has revisado algún capítulo completo! Me has dado amistad, cariño, confianza, ánimo y seguridad (y algún que otro tirón de orejas que necesitaba...) Y me has regalado gran parte de tu tiempo. ¿Qué más puedo pedir? ¿Te apetece una vida en Santiago? 
Andrés, contigo llegó la suerte. No encuentro las palabras adecuadas para transmitirte todo mi agradecimiento. A lo mejor no existen, porque hay sentimientos que no es posible verbalizar. Podría decir que has sido mi apoyo más fiel e incondicional. Que siempre me has ayudado en todo lo que te he pedido. ¡Me has enseñado tantas cosas...! No puedo imaginarme cómo habría sido todo si tú no hubieras estado a mi lado, escuchándome, aconsejándome, cuidándome, consolándome, sonriéndome, acompañándome...Simplemente te podría decir que me has hecho feliz. Pero es que, todo lo que pueda escribir estará siempre incompleto, porque lo importante, lo especial, sigue siendo algo que sólo tú y yo compartimos. Claro.

El círculo de personas y entidades importantes para este trabajo, no termina aquí.

Miguel Delibes me abrió las puertas de la Estación Biológica de Doñana al avalar una beca de Formación del Profesorado Universitario (FPU) del Ministerio de Educación y Ciencia. Fernando Hiraldo y la Estación Biológica de Doñana me dieron una segunda oportunidad en la investigación. Xim, Pedro J., Espe y Carlos R. hicieron posible que esto ocurriera. Carlos S. solucionó todas las cuestiones admistrativas de forma eficiente y amable. El trabajo del colectivo de los becarios de la Estación Biológica de Doñana contribuyó a que existieran los mecanismos adecuados para gestionar este tipo de situaciones atípicas en la carrera investigadora.

Quiero agradecer a Cipriano V. y a Gonzalo G.-B. que me animaran y me apoyaran en esta aventura desde el principio. Además, no dudaron en venir desde Salamanca y Segovia, respectivamente, a ayudarme cuando lo necesité. Otro apoyo clave en los comienzos de esta tesis fue Loli, que desde Galicia siempre me transmitió fuerzas y ganas de trabajar en esto.

Laura Serrano no sólo ha realizado los análisis de aguas para esta tesis, sino que, de forma siempre generosa, ha compartido conmigo su excelente conocimiento sobre el funcionamiento hídrico y las características limnológicas de las charcas temporales de Doñana. Miguel Ángel F. y Jordi B. me enseñaron lo poco (o mucho) que sé sobre teoría de redes. Las conversaciones con Miguel Ángel durante esta colaboración, y a raíz de ella, han sido algunas de las más motivadoras y reconfortantes que he tenido en estos años. Javier Seoane siempre ha resuelto de forma amable y eficaz las dudas estadísticas y de programación en R (o S-Plus) con las que me he encontrado. 
Numerosas personas me han ayudado durante el trabajo de campo y han sido piezas claves de mi vida en Doñana. Obviamente, Doñana no lo puedo entender sin Alex o Marga cerca. Miguel Ángel B. y David P. consiguieron que nunca me sintiera sola en tierra de marismas. Luis siempre mostró una paciencia increíble con nuestro Patrol (Defender después) y nuestros malos hábitos de conductores de ciudad reciclados a la arena. Rosa, Fabiola, Manolo, Cecilia, Manolita, Maricarmen y Pilar convirtieron el Palacio en casa, y las horas de la comida en momentos familiares que nunca olvidaré. Y, cómo no, el resto de la familia, que siempre me han recibido con una sonrisa y me han ayudado a solucionar los pequeños problemas que me he ido encontrando allí: Margari, Olga C., Nuria, Álvaro, Jaime (padre), Jaime (hijo), Rafa L., Diego, Laíno y Chiqui. Finalmente, quiero agradecer a todas las personas que han dedicado algún periodo de su vida a enseñarme Doñana, su flora y su fauna; a capturar larvas de anfibio; a buscar huevos de sapo o a dar vueltas a charcas temporales, especialmente a Carlos M., que se pasó toda una temporada de campo con Marga y conmigo. Ellos son: Ana R. Benito, Jesús N., Lucía G., Rocío F., Bárbara L., Cipriano V., Gonzalo G.-B., Antonio B., Manuel O., M ${ }^{a}$ José F., Xabier O., Matthias, Neli, Wouter, Mónica, Xosé, Raquel, Matati, Andrés y todos aquellos que salieron algún día a muestrear con nosotros/as.

El personal de la Estación Biológica de Doñana facilita el trabajo de todos nosotros día a día. Quiero agradecer especialmente la dedicación de Maricarmen para que mis periodos "en paro" fueran lo más breves posibles; de Enrique y Héctor, la paciencia y buena voluntad para que mi ordenador "dejara de hacer cosas raras" en numerosas ocasiones; y de Raúl los numerosos pequeños trabajos pero, sobre todo, que montara un sistema de inyección de oxígeno en el coto que nunca pude rentabilizar. El trabajo diario de Olga, Concha, Maricarmen, Alicia, Franca, Mariángeles, Pepe y Antonio Páez me ha facilitado mucho la vida estos años al igual que el del resto del personal de administración, secretariado y seguridad.

Sampsa Koponen fue mi supervisor durante una estancia breve en el Laboratorio de Técnica Aeroespacial de la Universidad de Helsinki. Antoine Guisan me admitió en su Grupo de Ecología Espacial de la Universidad de Lausanne durante dos meses y, desde entonces, no ha parado de darme ánimos y reforzar mi confianza. Esa estancia en Suiza fue mucho más amena gracias a la amistad de Marie T., Carmen C., Joanna V., Wim H. y Olivier B. 
Gracias a Benito de la Morena, pude ser becaria en prácticas del Instituto de Técnica Aeroespacial (Estación del Arenosillo) durante los primeros años de la beca FPU. Allí aprendí todo lo que necesitaba sobre radiación ultravioleta y su medición.

Quiero agradecer a mis amigos, Maite Hernández; Luís Cadahía; Jaime Martí; mi tío Pepito (digo, Pepe); Alicia, José Manuel y Maritere; Oscar; Rafa y María; y Ana y Javier, que me acogieran en sus casas durante mis estancias en congresos, cursos o simplemente para proporcionarme paz y tranquilidad para poder escribir. Ana y Javier también se han asegurado de que la redacción en castellano del resumen de esta tesis sea correcta.

Andrés B. (y Escher, indirectamente) me ha ayudado en el diseño gráfico de esta tesis. No sólo ha aportado grandes ideas al diseño sino que le ha dedicado el tiempo necesario para que la portada general y las portadas interiores sean tan bonitas.

La Federación de Jóvenes Investigadores, la Asociación de Precarios-Sevilla y el colectivo de becarios de la Estación Biológica de Doñana han contribuido a mejorar las condiciones laborales del colectivo investigador y, por tanto, mis condiciones de vida. Trabajando dentro de estos colectivos he tenido la oportunidad de conocer a algunas de las personas más interesantes, comprometidas, consecuentes y generosas de toda mi vida. Muchos de los mejores momentos de estos años están asociados a mi "vida en precario" y los amigos que me ha regalado: Arquero, Pablo P, David L., Elvira, Miguel, Xosé, Nacho, Jaime M., Oriol, Rocío y Andrés.

Pero la tesis no es sólo trabajo e investigación....

En estos años he compartido piso con numerosas personas, pero los mejores recuerdos y mejores momentos los tengo asociados a mi hermana (Lucía GómezRodríguez), a Raquel, a Mónica, a Elvira y a Sofía. Ellas consiguieron que el lugar donde vivía fuera mi casa y aguantaron todos los momentos regulares que tiene una tesis y que sufren los que están más cerca.

Mis compañeros de la EBD también han vivido conmigo los momentos no vinculados directamente a la investigación. Sin duda sus conversaciones, sonrisas, risas, "Chiles" y demás cervecitas me han alegrado la vida. A algunos los he mencionado ya, el resto son: Paco C., Héctor, Roger, Hugo, Isabel A., Raphael, Ricki, Yolanda, Mónica G., María G., Alex C., Jordi F., Juanele, Lola, Miguel A., 
Alberto, Ramón S., Ainara, Alfredo V., Eva A., Begoña M. y Gema. Durante estos años también he recibido un fuerte apoyo por parte de mis amigos no vinculados directamente a la EBD. Tantos años de amistad hace que a veces no sea consciente de lo excepcional que es haberos tenido todos estos años de forma incondicional a mi lado. Picho, Eva, Sergio, Aarón, Fran B., Rafa, Maite H., Alicia, Sara y Álvaro, sois increíbles. Os quiero mucho.

También quiero agradecer de forma especial a "mis nuevos amigos", Elvira, Miguel, Ana y Javier, todo el cariño que me habéis dado en este último periodo de la tesis.

Por supuesto a mi familia, por serlo.

Y por último, a mis abuelos. Por todo y por siempre. Pepe, todavía te debo un paseo en todoterreno por Doñana. 